\begin{abstract}
UNIVERSITAT POLITÈCNICA DE VALÈNCIA
DEPARTAMENTO DE PROYECTOS DE INGENIERÍA
\end{abstract}

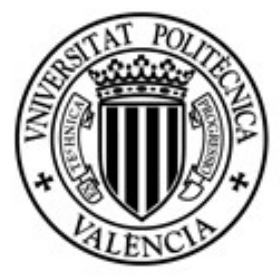

TESIS DOCTORAL

\title{
CONTRIBUCIÓN DE LA OBRA CIENTÍFICO- TÉCNICA DE LEONARDO DA VINCI A LOS PROYECTOS DE INGENIERÍA
}

PRESENTADA POR: ERNESTO CERVERÓ MELIÁ

DIRIGIDA POR:

Dr. SALVADOR CAPUZ RIZO

Dr. PABLO FERRER GISBERT 



\section{AGRADECIMIENTOS}

A mi padre por haberme enseñado a "amar la lectura y los libros", y a darme el repetido consejo de "nunca dejes de aprender".

A mi director de tesis y amigo, el catedrático Salvador Capuz Rizo, por guiarme tan adecuadamente en esta larga y ardua tarea.

A mi compañero, colaborador en varios artículos y codirector de esta tesis, el profesor Pablo Ferrer Gisbert, por aportar su granito de arena a la misma.

Y cómo no, a mi mujer (que muy a mi pesar no podrá ver esta tarea acabada) e hijas por perdonarme mi falta de atención y tiempo hacia ellas, al haberlo dedicado a llevar a cabo este trabajo. 



\section{RESUMEN}

La presente tesis persigue desarrollar una investigación teórica que identifique las principales contribuciones y aportes de la obra científico-técnica de Leonardo da Vinci (Vinci, 1452- Amboise, 1519) relacionados con el área de conocimiento de Proyectos de Ingeniería, vinculadas principalmente con dos conceptos nucleares a la misma, Diseño y Proyecto, o utilizando la nomenclatura actual, los conceptos de Diseño en Ingeniería (Engineering Desing, en la literatura en inglés) $y$ de Ingeniería de Proyectos (Project Engineering).

Para ello se realiza una revisión exhaustiva de los manuscritos y códices de Leonardo (fuentes primarias) y seguidamente se efectúa un estudio de la literatura existente sobre la obra científico-técnica del mismo (fuentes secundarias). Tras ello, se estudian diversos proyectos de Leonardo relacionándolos con los conceptos de diseño/proyecto actuales (ergonomía, ecodiseño, analogías, etc.) y se observan la coincidencia o no de sus teorías, y el grado de proximidad entre sus técnicas y herramientas, con los métodos, técnicas e instrumentos usados en la actualidad.

Finalmente se realiza una síntesis de los hallazgos y resultados presentados en los diferentes capítulos abordados en la tesis, integrando cómo las aportaciones de Leonardo en relación a las técnicas gráficas, instrumentos de diseño, morfología documental, pensamiento sistémico, racional y experimental, diseño analógico, validación experimental de las soluciones de diseño, diseño basado en la naturaleza y respetuoso con el entorno, y su capacidad para llevar a la práctica diseños funcionales y construirlos, configuran su obra científico-técnica como crucial en el desarrollo de la disciplina de los proyectos de ingeniería. 


\section{RESUM}

La present tesi persegueix desenvolupar una investigació teòrica que identifique les principals contribucions i aportacions de l'obra científicotècnica de Leonardo da Vinci (Vinci, 1452- Amboise, 1519) relacionats amb l'àrea de coneixement de Projectes d'Enginyeria, vinculades principalment amb dos conceptes nuclears a aquesta, Disseny $\mathrm{i}$ Projecte, o utilitzant la nomenclatura actual, els conceptes de Disseny en Enginyeria ("Engineering Desing", en la literatura en anglés) i d'Enginyeria de Projectes ("Project Engineering").

Per a això es realitza una revisió exhaustiva dels manuscrits i còdexs de Leonardo (fonts primàries) i seguidament s'efectua un estudi de la literatura existent sobre l'obra científico-tècnica del mateix (fonts secundàries). Després d'això, s'estudien diversos projectes de Leonardo relacionant-los amb els conceptes de disseny/projecte actuals (ergonomia, ecodisseny, analogies, etc.) i s'observen la coincidència o no de les seues teories, i el grau de proximitat entre les seues tècniques $\mathrm{i}$ eines, amb els mètodes, tècniques $\mathrm{i}$ instruments utilitzats en l'actualitat.

Finalment es realitza una síntesi de les troballes i resultats presentats en els diferents capítols abordats en la tesi, integrant com les aportacions de Leonardo en relació a les tècniques gràfiques, instruments de disseny, morfologia documental, pensament sistèmic, racional i experimental, disseny analògic, validació experimental de les solucions de disseny, disseny basat en la naturalesa i respectuós amb l'entorn, i la seua capacitat per a portar a la pràctica dissenys funcionals i construir-los, configuren la seua obra científico-tècnica com a crucial en el desenvolupament de la disciplina dels projectes d'enginyeria. 


\section{ABSTRACT}

This thesis aims to develop a theoretical investigation that identifies the main contributions of the scientific-technical work of Leonardo da Vinci (Vinci, 1452- Amboise, 1519), related to the Project Engineering area of knowledge and especially with two of its nuclear concepts Project and Design or, using the current denomination: Engineering Design and Project Engineering.

To this end, an exhaustive review of Leonardo's manuscripts and codices (primary sources) is conducted and then a study of the existing literature on his scientific-technical work (secondary sources) is carried out. Then, various Leonardo's projects are studied relating them to current design / project concepts (ergonomics, ecodesign, analogies, etc.), the coincidence or not of his theories is observed, and the degree of proximity between his methodologies, methods, techniques and tools and those used in the present is determined.

Finally, a synthesis of the findings and results presented in the different chapters addressed in the thesis is made, integrating how Leonardo's contributions in relation to graphic techniques, design instruments, document morphology, systemic, rational and experimental thinking, analogical design, experimental validation of design solutions, design based on nature and respectful of the environment, as well as his ability to put functional designs into practice and build them, configure his scientific-technical work as crucial in the development of the discipline of engineering projects. 

ÍNDICE

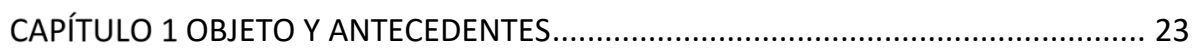

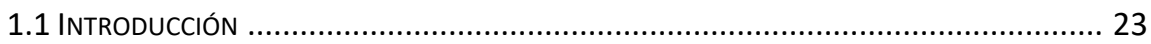

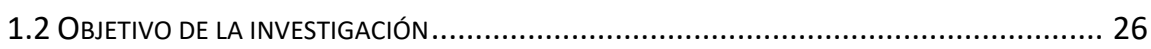

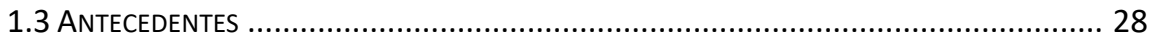

1.4 JUSTIFICACIÓN DE LA INVESTIGACIÓN. LEONARDO Y EL PROYECTO TÉCNICO ....................... 33

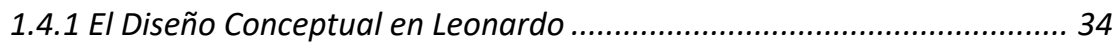

1.4.2 Las aplicaciones sistémicas y el diseño modular ................................. 38

1.4.3 La búsqueda de la automatización y la producción en serie en Leonardo

1.4 .4 las técnicas creativas en Leonardo

1.4.5 El uso de las "analogías" por Leonardo ................................................ 49

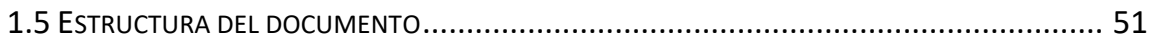

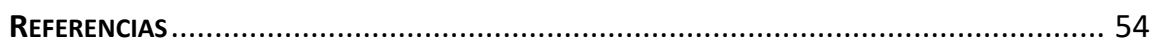

CAPÍTULO 2 ANÁLISIS TAXONÓMICO DE LA OBRA ESCRITA DE LEONARDO DA VINCI 57

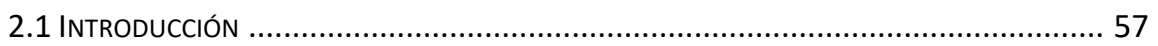

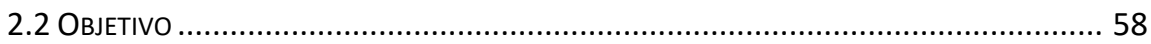

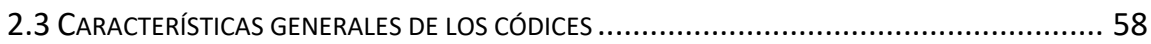

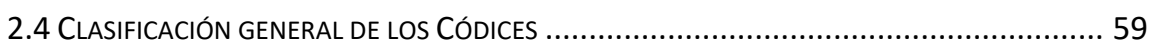

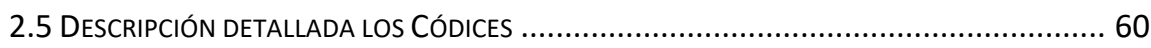

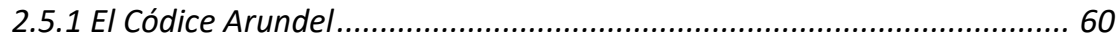

2.5.2 El Códice Atlántico.................................................................................... 61

2.5.3 El Códice o Los Folios de Windsor (Manuscritos de Anatomía y Dibujo) 64

2.5.4 Los Códices Forster $(I, I I, I I I)$................................................................ 66

2.5.5 Los Manuscritos de Francia, o de París.................................................... 66

2.5.6 El Códice del Vuelo de Los Pájaros o de Turín........................................ 68

2.5.7 El Códice Trivulziano ................................................................... 71

2.5.8 Los Códices Madrid I y Madrid II....................................................... 71

2.5.9 Códice Leicester (o Hammer) ............................................................ 73

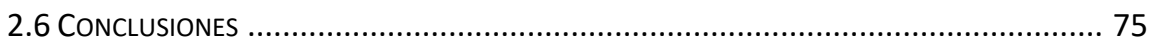

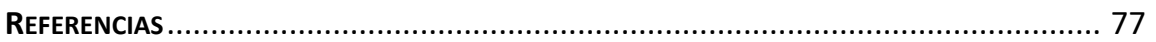

CAPÍTULO 3 ANÁLISIS DE LAS INVESTIGACIONES SOBRE LEONARDO DA VINCI ...... 81

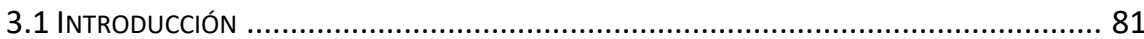

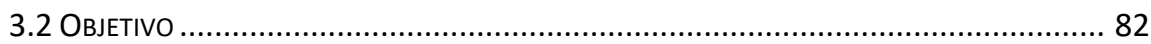

3.3 INVESTIGADORES MÁS IMPORTANTES Y SUS PUBLICACIONES...................................... 83 
3.3.1 Francesco Melzi (Milán, hacia 1493-Vaprio d'Adda, 1572/73).....

3.3.2 El Anónimo Gaddiano o Códice Magliabechiano XVII (entre1537-1541) 84

3.3.3 Paolo Giovio (Como, 1483- Florencia, 1552) ...................................... 84

3.3.4 Giorgio Vasari (Arezzo, 1511-Florencia, 1574) ..................................... 84

3.3.5 Giovanni Paolo Lomazzo (Milán, 1538-1592)....................................... 86

3.3.6 Charles Ravaisson-Mollien (1848-1919) ........................................... 87

3.3.7 Jean Paul Richter (Dresde, 1847-Lugano, 1937)................................ 88

3.3.8 Charles Harvard Gibbs-Smith (Teddington, Greater London, 1909-1981)

3.3.9 Carlo Pedretti (Casalecchio di Reno, 1928-Lamporecchio, 2018) .......... 90

3.3.10 Fritjof Capra (Viena, 1939) .............................................................. 91

3.3.11 Martin Kemp (Reino unido, 1942) ................................................. 92

3.3.12 Alessandro Vezzosi (Italia, 1950)..................................................... 93

3.3.13 Patxi Lanceros (Bilbao, 1962), y Juan Barja (La Coruña, 1954). .......... 94

3.3.14 Sara Taglialagamba (Pisa, 1977)....................................................... 95

3.3.15 Miguel Ángel Contreras López (Madrid, 1969)................................... 97

3.4 INSTITUCIONES MÁS CONOCIDAS, VINCULADAS A LA OBRA DE LEONARDO ........................98

3.4.1 Raccolta Vinciana (Colección Vinciana, 1905)........................................ 98

3.4.2 Biblioteca Leonardiana de Vinci (1928) y el Proyecto e-Leo.................. 98

3.4.3 Museo "Nazionale della Scienza e della Tecnologia Leonardo da Vinci"

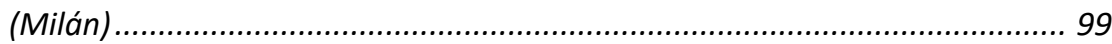

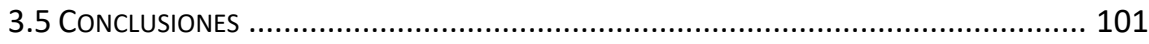

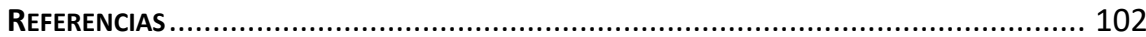

CAPÍTULO 4 TEORÍAS, MÉTODOS Y TÉCNICAS PARA EL DISEÑO DE SISTEMAS TÉCNICOS EN LA OBRA DE LEONARDO DA VINCI ................................................. 105

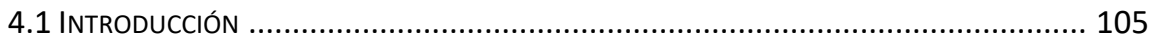

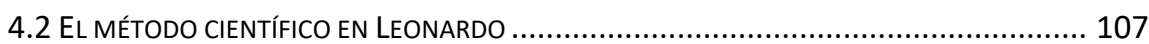

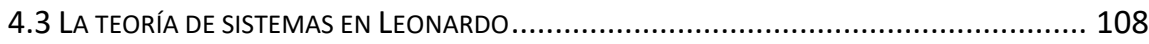

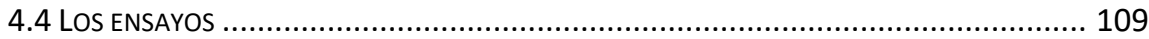

4.5 EL ESTUDIO DEL TRABAJO, LA ERGONOMÍA, Y LA SEGURIDAD Y SALUD. ....................... 113

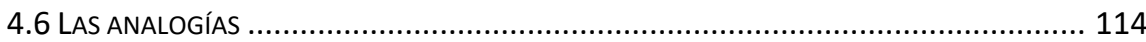

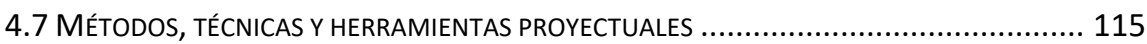

4.7.1 El Barco de Palas .................................................................................... 116

4.7.2 El proyecto de desvío del Río Arno..................................................... 118

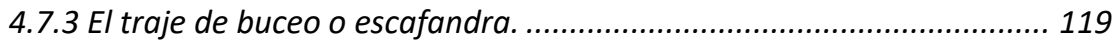

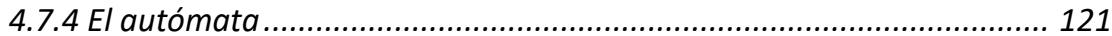

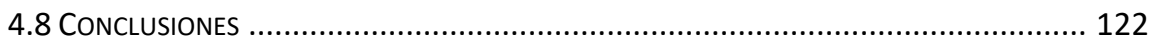

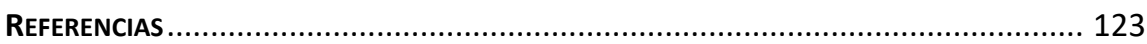

CAPÍTULO 5 LAS CARACTERÍSTICAS DEL PENSAMIENTO DE LEONARDO DA VINCI, PARADIGMA DE LA CREATIVIDAD ................................................................ 125

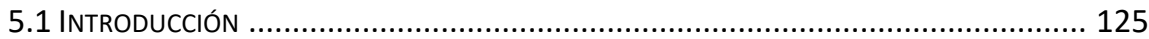

5.2 LAS REGLAS O PRINCIPIOS DE TRABAJO DE LEONARDO ........................................... 126 
5.2.1 Curiosità (despertar la curiosidad: hacerse preguntas consigue encontrar respuestas -ideas- válidas, más fácilmente)................................................ 127

5.2.2 Dimostrazione (La demostración = experimentación) .......................... 129

5.2.3 Sensazione (las sensaciones: afinar nuestros sentidos)........................ 132

5.2.4 Sfumato (la difuminación, la ambigüedad, lo matizable: aprovechar la incerteza).

5.2.5 Arte/Scienza (la unión del arte y la ciencia, símil de imaginación y lógica:

el equilibrio). 136

5.2.6 Corporalità (cultivar y equilibrar el cuerpo y la mente)....................... 137

5.2.7 Connessione (todo está conexionado con todo)................................... 138

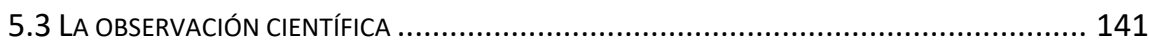

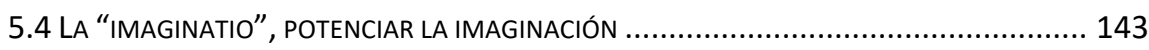

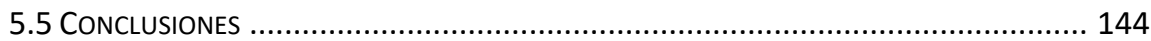

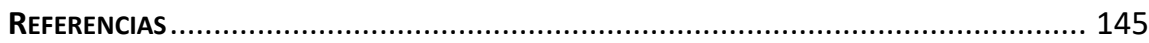

CAPÍTULO 6 ANÁLISIS DE LA DOCUMENTACIÓN TÉCNICA DE LOS DISEÑOS Y PROYECTOS DE LEONARDO DA VINCI .......................................................... 149

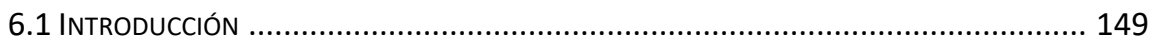

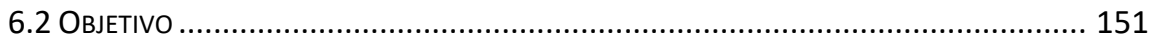

6.3 LOS DISEÑOS DE MÁQUINAS PARA LA GUERRA ..................................................... 152

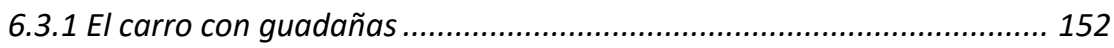

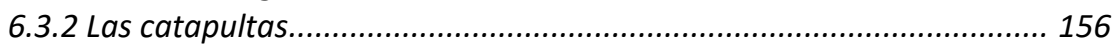

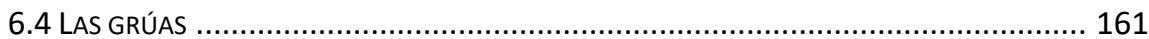

6.5 EL CONJUNTO DE DOCUMENTOS DEL PROYECTO TÉCNICO EN LEONARDO ....................... 164

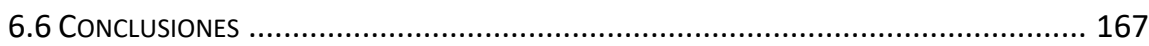

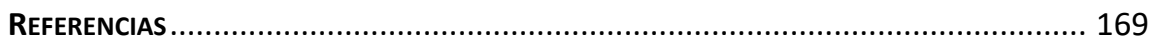

CAPÍTULO 7 CONTRIBUCIONES DE LEONARDO DA VINCI A LAS TÉCNICAS GRÁFICAS

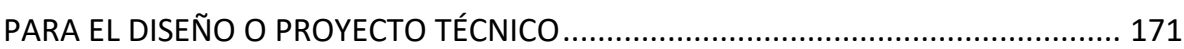

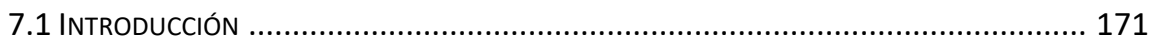

7.2 LA TÉCNICA DE LOS “DIAGRAMAS DE EXPLOSIÓN” O “EXPLOSORES” ............................. 171

7.3 LOS DIAGRAMAS O GRÁFICOS DE "FAMILIAS DE RECORRIDOS" .................................. 175

7.4 LA TÉCNICA DE ELABORAR MAPAS A “VISTA de PÁJARo" (CARTA A Volo d” UCCELLO) .... 178

7.4.1 Mapa de la Toscana, parte de la Umbria, lago Trasimeno y el Valle de

Chiana (1502) ......................................................................................... 180

7.4.2 Mapa de "Arezzo" y Valle de Chiana, con mensuración de distancias (1502)

181

7.4.3 Mapa de la ciudad de Imola (Italia) (1502) ....................................... 182

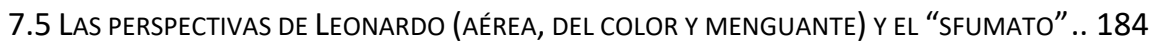
7.6 LAS tÉCNICAS DEL “ESCORZO”, DE LA “SERPENTINATA”, DE LA “SUPERPOSICIÓN” Y DE LA

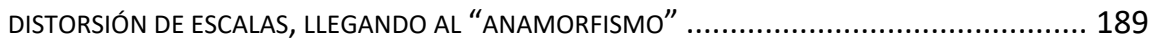

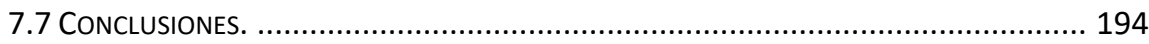

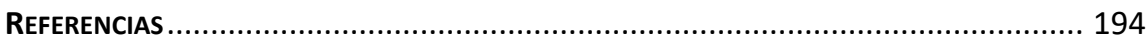


CAPÍTULO 8 ANÁLISIS DE LOS INSTRUMENTOS DE DISEÑO APORTADOS POR LEONARDO DA VINCI EN SU OBRA CIENTÍFICA Y TÉCNICA

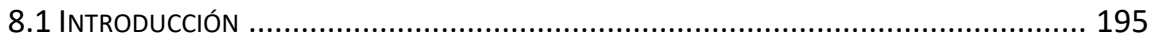

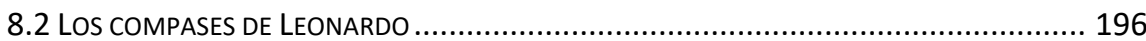

8.2.1 Los compases de varillas de apertura ajustable............................... 198

8.2.2 Los compases proporcionales.......................................................... 200

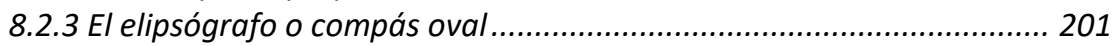

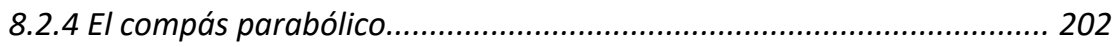

8.2.5 El compás para epicicloides............................................................. 203

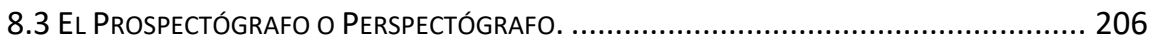

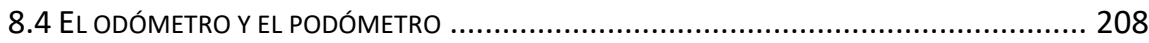

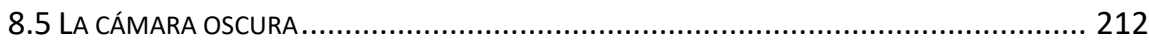

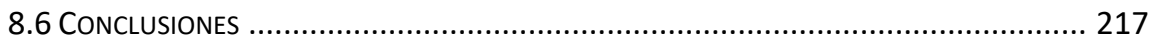

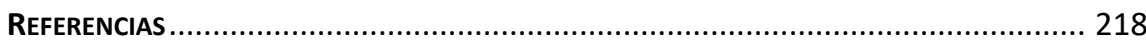

CAPÍTULO 9 EL DISEÑO BASADO EN ANALOGÍAS EN LA OBRA DE LEONARDO DA

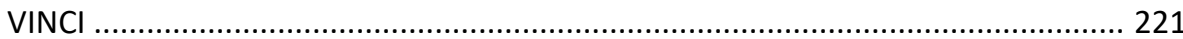

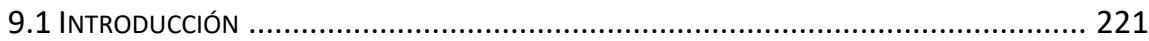

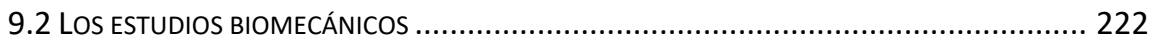

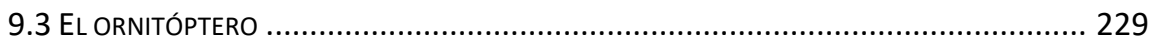

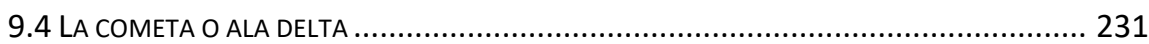

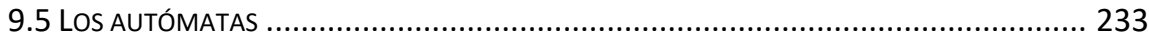

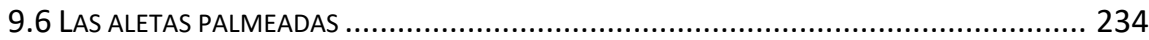

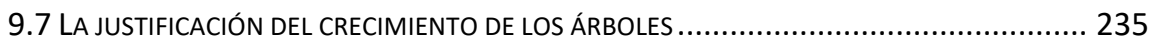

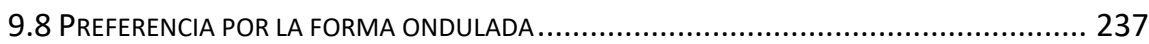

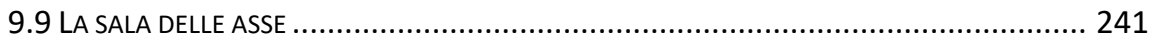

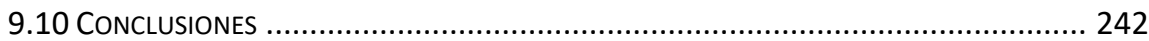

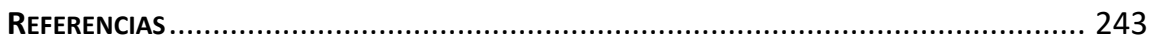

CAPÍTULO 10 LEONARDO DA VINCI PIONERO DEL ECODISEÑO ............................ 245

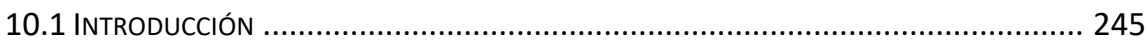

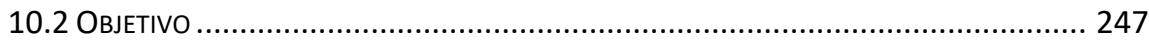

10.3 Copiando de la "MAestra naturalezA" EN SU OBRA, Filosofía y forma de VIDA. . 248

10.4 DISEÑOS URBANÍSTICOS Y CONSTRUCTIVOS CON SOLUCIONES ECOLÓGICAS .................. 251

10.4.1 El primer proyecto de Milán, las "ciudades satélite" ........................... 251

10.4.2 El segundo proyecto de Milán. La expansión geométrica .................. 256

10.4.3 La ciudad nueva de Romorantin ..................................................... 257

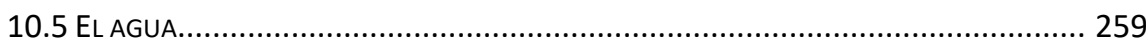

10.6 LA SALA GRANDE DELLE ASSE, Y LOS INNOVADORES FONDOS DE LAS MADONAS, UN CULTO A

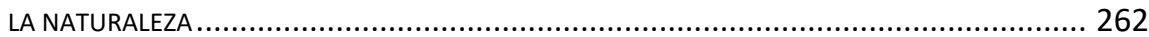

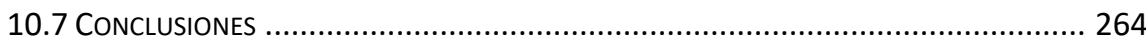

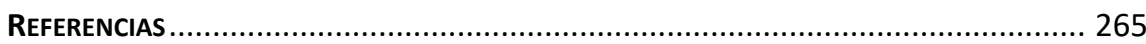


CAPÍTULO 11 REVISIÓN DE FACTIBILIDAD FUNCIONAL DE LOS SISTEMAS TÉCNICOS

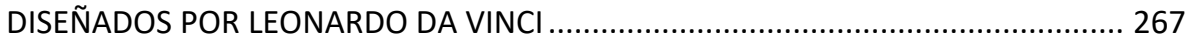

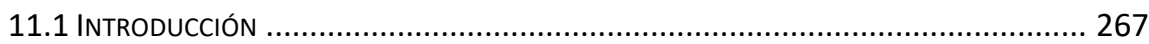

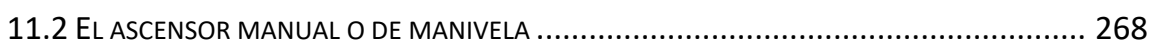

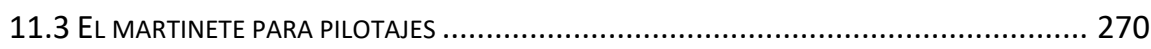

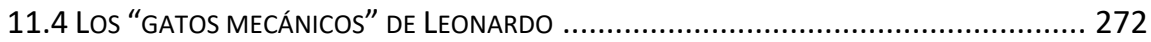

11.4.1 El gato de cremallera.......................................................................... 273

11.4.2 El Gato de husillo (tornillo-tuerca tradicional) ............................... 273

11.4.3 El gato de tornillo con rodamiento antifricción ............................... 275

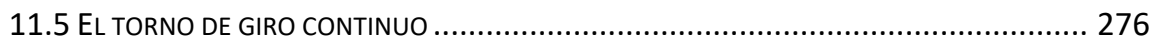

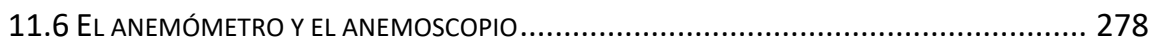

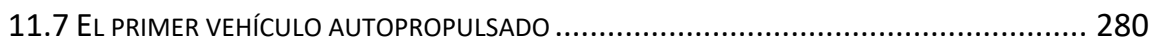

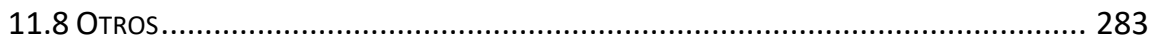

11.8.1 La escalera de doble hélice .............................................................. 284

11.8.2 El primer paracaídas de la historia ............................................... 286

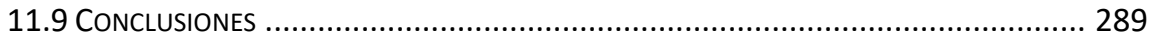

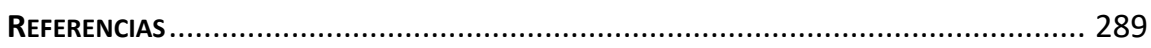

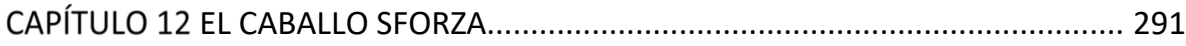

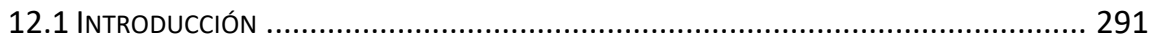

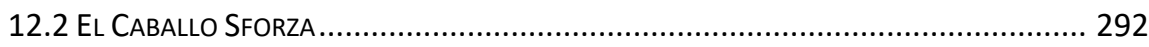

12.2.1 El contexto histórico ................................................................. 292

12.2.2 Diseño de ingeniería: estudios preliminares, los bocetos iniciales .... 296

12.2.3 Ingeniería del proyecto: el diseño de detalle o proyecto de ejecución 298

12.2.4 Ejecución del proyecto. El gran caballo hecho realidad 500 años

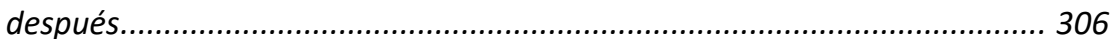

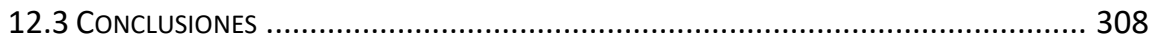

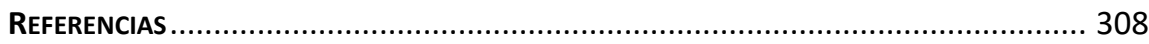

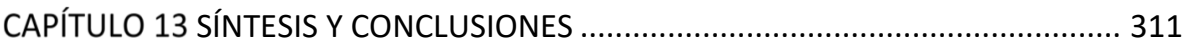

13.1 LEONARDO COMO DISEÑADOR Y PROYECTISTA MULTIDISCIPLINAR ............................ 312

13.2 EL ASPECTO MORFOLÓGICO DE LOS PROYECTOS DE LEONARDO ................................ 313

13.3 CONTRIBUCIÓN DE LEONARDO AL DESARROLLO DE LAS TÉCNICAS GRÁFICAS PARA EL DISEÑO/PROYECTO................................................................................... 315

13.4 CONTRIBUCIÓN DE LEONARDO AL DESARROLLO DE LOS INSTRUMENTOS OPERATIVOS PARA EL

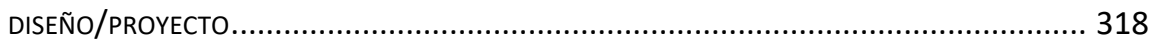

13.5 LEONARDO COMO DISEÑADOR Y PROYECTISTA SISTÉMICO. .................................. 321

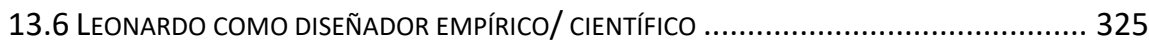

13.7 LAS ANALOGÍAS COMO FUENTE DE LA CREATIVIDAD EN EL DISEÑO DE LEONARDO ......... 327

13.8 LEONARDO COMO DISEÑADOR ECOLÓGICO/NATURALISTA. .................................... 330

13.9 LA FACTIBILIDAD DE LOS DISEÑOS Y PROYECTO DE LEONARDO................................... 331

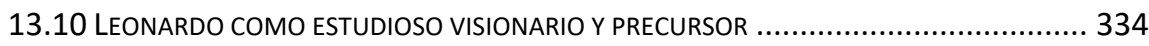

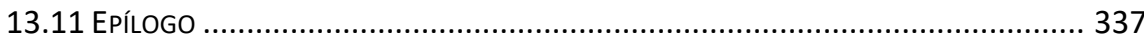




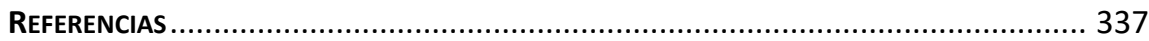

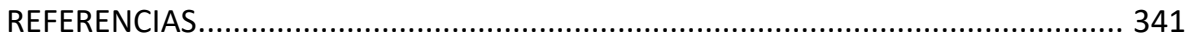

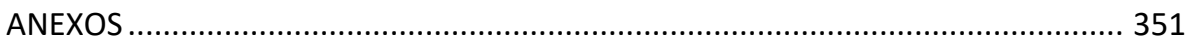

\section{ANEXO I}

TABLA RESUMEN DE LOS CÓDICES Y MANUSCRITOS DE LEONARDO CON SU UBICACIÓN, CONTENIDO Y DATACIÓN APROXIMADA

ANEXO II

TABLA RESUMEN DE LAS EDICIONES DEL CONGRESO INTERNACIONAL EN DIRECCIÓN E INGENIERÍA DE PROYECTOS EN LAS QUE SE HA PRESENTADO LOS

CAPÍTULOS 2 A 12 DE LA PRESENTE TESIS DOCTORAL. 


\section{ÍNDICE DE FIGURAS}

Figura 1.1a) Monumento a Leonardo en la Piazza della Scala de Milán (origen de la imagen: https://commons.wikimedia.org/wiki/File:2006_Milano__Da_Vinci_(2).jpg?uselang=es). b) Retrato de Leonardo realizado por su alumno Francesco Melzi (h.1493-h.1573) sobre 1517-1517; Royal Collection (RCIN 912726) Reino Unido (origen de la imagen:

https://commons.wikimedia.org/wiki/File:Francesco_Melzi_-

_Portrait_of_Leonardo.png?uselang=es .................................................. 26

Figura 1.2 a) Manuscrito F (1503-1507), de la Biblioteca del Instituto de Francia

(Paris), con la demostración euclidiana del Teorema de Pitágoras

(https://commons.wikimedia.org/wiki/File:Leonard_de_Vinci__D\%C3\%A9monstration_euclidienne_du_th\%C3\%A9or\%C3\%A8me_de_Pytha gore.jpg). b) Contratapa del Códice de Madrid I, Biblioteca Nacional de España (http://leonardo.bne.es/index.html)

Figura 1.3 a) Máquina de subir agua de II Taccola (h. 1433)

(https://commons.wikimedia.org/wiki/File:Taccola_Tartar_pump_1433.jpg?u selang=es) b) Máquinas de bombear agua de Leonardo en Códice Atlántico f. 1069r. (https://commons.wikimedia.org/wiki/File:000R-1069.jpg?uselang=es)

Figura 1.4 a) Bocetos de máquinas de elevar pesos C. Atlántico, f. 847r, (https://commons.wikimedia.org/wiki/File:Codex Atlanticus - 000R847.jpg?uselang=es). b) Boceto del Andamio para el Modelo del Caballo Sforza C. Atlántico, f. 577v, (https://commons.wikimedia.org/wiki/File:Codex Atlanticus - 000V-577.jpg).

Figura 1.5 a) Molino de cereales y herramientas para enganche y elevación de cargas C. Madrid I, f. 22r. b) Máquina de hilar con doble volante, C. Madrid. I, f. 68v. (http://leonardo.bne.es/index.html)

Figura 1.6 a) Mecanismos con engranajes helicoidales, Códice de Madrid I, f, 17v, Biblioteca Nacional de España, Madrid.

(https://commons.wikimedia.org/wiki/File:M\%C3\%A9canisme_h\%C3\%A9licoi dal-L\%C3\%A9onard.jpg?uselang=es). b) Maqueta del ajuste por engranaje helicoidal con elevación de cargas (https://commons.wikimedia.org/wiki/File:Leonardo_Engranaje_helicoidal.jp g?uselang=es)

Figura 1.7 Cojinetes de distintos tipos y transmisiones mediante ruedas, C. Madrid I, f. 101v, 102r, (Biblioteca Nacional de España. (http://leonardo.bne.es/index.html). 
Figura 1.8 Proyecto de Mecanismos de relojería: Componentes sueltos y módulo del mecanismo, C. Madrid I, f. 13v y 14r. Biblioteca Nacional de España.

(http://leonardo.bne.es/index.html).

Figura 1.9 Ganchos para bajar pesos, que se sueltan la carga al tocar el suelo, y cadenas de transmisión y rueda como mecanismo de elevar agua, C. Madrid I, f $9 v$ y $10 r$. Biblioteca Nacional de España.

(http://leonardo.bne.es/index.html).

Figura 1.10 Máquina de pulir lentes, automatizada por una corriente de agua (https://commons.wikimedia.org/wiki/File:Macchina_per_la_lavorazione_deg li_specchi_e_delle_lenti_di_Leonardo_da_Vinci_in_una_mostra_su_Leonardo _da_Vinci_al_Mulino_di_Mora_Bassa_-_Morabassa.jpg) (autor de la imagen: Capricornis crispus)

Figura 1.11 Dibujos de herramientas varias y Boceto de ventana palaciega $C$. At. $f$. 809r (origen de la imagen:

https://commons.wikimedia.org/wiki/File:Codex_Atlanticus_-_000R809.jpg?uselang=es)

Figura 1.12 a) Bocetos de La Virgen, el Niño, Santa Ana y San Juan, British Museum, Londres (https://commons.wikimedia.org/wiki/File:Leonardo_da_Vinci__1875,0612.17,_Studies_for_the_Virgin_and_Child_with_St_Anne_and_the_i nfant_Baptist,_and_some_studies_of_machinery.jpg ). b) Dibujos geométricos de Leonardo para "La Divina Proporción", "el icosaedro truncado"(https://commons.wikimedia.org/wiki/File:Leonardo_Ycocedron_A bscisus.jpg) 49

Figura 2.1 Proyecto del equipo buzo, C. Arundel, f. 24 v (h. 1502)

(https://commons.wikimedia.org/wiki/File:Codex_arundel.jpg), b) Proyecto de automóvil, C. Atlántico, f. 812r (h. 1478)

(https://commons.wikimedia.org/wiki/File:Leonardo_da_vinci,_Automobile.jp g?uselang=es). 61

Figura 2.2 Maqueta del paracaidas de Leonardo

(https://commons.wikimedia.org/wiki/File:Leonardo_da_Vinci_parachute_04 659a.jpg) y boceto de paracaídas C. Atlántico f. 1058v (h. 1485)

(https://commons.wikimedia.org/w/index.php?title=Category:Codex_Atlantic us_(codex-atlanticus.it)\&fileuntil=000V-1082.jpg\#/media/File:000V-1058.jpg).

Figura 2.3 a) Mapa de la Toscana y el valle de Chiana, RLW 12278, (h. 1502)

(hhttps://commons.wikimedia.org/wiki/File:Leonardo_da_vinci,_Map_of_Tus cany_and_the_Chiana_Valley.jpg?uselang=de), b) Proyecto de Ciudad nueva de Romorantin C. Arundel, f. 270v (1514-1518)

(http://www.bl.uk/manuscripts/Viewer.aspx?ref=arundel_ms_263_f001r). 65

Figura 2.4 a) Compás de proporción de tornillo, C. Forster I, f. 4r. (h. 1485)

(https://commons.wikimedia.org/wiki/File:Reduction_Compass_Leonardo.jpg ?uselang=), b) Proyecto de Ciudad Ideal, Man. B de Francia, f. 16 r (h. 1489) (file:///F:/ciudad\%20ideal/Quartier\%20M\%C3\%A9riadeck\%20_\%20Urbanis me\%20sur\%20dalle\%20__20Les\%20origines.html), c) Estudio de Villa de 
Carlos d' Amboise, C. Vuelo Pájaros, f. 18v (h. 1506)

(https://www.wdl.org/es/item/19477/view/1/1/).

Figura 2.5 a) Boceto de máquina de asedio, C. Trivulziano, f. 14r (1478-1493)

(https://commons.wikimedia.org/wiki/File:L19_-_Triv_2162_-

_14r_detail.jpg?uselang=es), b) Plano de la ciudad amurallada de Imola RCW

12284 (h. 1502)

(https://upload.wikimedia.org/wikipedia/commons/8/85/Leonardo_da_Vinci

_-_Plan_of_Imola_-_Google_Art_Project.jpg).

Figura 2.6 Armadura para la cabeza del Monumento Ecuestre Sforza, C. Madrid II,

f. 157r (1491-1493), (https://commons.wikimedia.org/wiki/File:Leonardo_-

_Madrid_II_-_157r.jpg).

Figura 3.1 a) Códice Forster III, Victoria \& Albert Museum, Londres

(https://commons.wikimedia.org/wiki/File:Leonardo_da_vinci,_taccuino_fors ter_III,_1490_ca._01.JPG?uselang=es), b) 1a edición impresa del Tratado de la Pintura (1651)

(https://commons.wikimedia.org/wiki/File:Trattato_Della_Pittura_(88395).jpg ?uselang=es), c) Ed. de 1913, de Vidas de los Artistas, de G. Vasari

(https://commons.wikimedia.org/wiki/File:1913-Le_vite-degli_artisti-di-

Giorgio-Vasari.jpg)..... 86

Figura 3.2 a) Publicación "Leonardo da Vinci Científico" de Vicenzo Burzagli, 1910

(https://commons.wikimedia.org/wiki/File:Leodav.jpg), b) Estudio sobre la visión de Leonardo (h. 1508), Manuscrito D, ff. 3v-4r, In. de Francia investigados por Ravaisson

(https://commons.wikimedia.org/wiki/File:Leonardo_da_Vinci,_Manuscript_

D,_1508-09.jpg?uselang=es). 90

Figura 3.3 a) Dibujos topológicos de Leonardo Cod. Atlántico f. 459r, 1478-1519 (https://commons.wikimedia.org/wiki/File:Leonardo_da_Vinci_\%E2\%80\%93_ Codex_Atlanticus_folio_459r.jpg), b) Museo Leonardiano de Vinci, sede del Museo Ideale

(https://commons.wikimedia.org/wiki/File:Vinci,_museo_leonardiano_(sede_ dell\%27ex-museo_ideale)_05..JPG).

Figura 3.4 a) Manuscrito K, Inst. de Francia, ff. 14v-15r, con demostración teorema de Pitágoras (https://commons.wikimedia.org/wiki/File:Leonard_de_Vinci__D\%C3\%A9monstration_euclidienne_du_th\%C3\%A9or\%C3\%A8me_de_Pytha gore.jpg?uselang=es), b) Prototipo de Tanque del Museo de Amboise (Diseño de Leonardo, British Museum, Pupham no 1030, Londres)

https://commons.wikimedia.org/wiki/File:DaVinciTankAtAmboise.jpeg?uselan $\mathrm{g}=\mathrm{es}$-formal) 96

Figura 3.5 a) Castello Sforcesco de Milán, sede del "Ente Raccolta Vinciana" (https://commons.wikimedia.org/wiki/File:Frontal_del_castillo_de_sforzesco, _Mil\%C3\%A1n.JPG?uselang=es-formal), b) Prototipo de Carro automotor de Leonardo, (diseñado en Cod. Atlántico, f. 812 recto, Biblioteca Ambrosiana de Milán), del Museo Leonardiano de Vinci (https://upload.wikimedia.org/wikipedia/commons/5/5c/Museo_leonardiano 
_di_vinci\%2C_modello_di_carrello_automotore\%2C_da_codice_atlantico.JPG

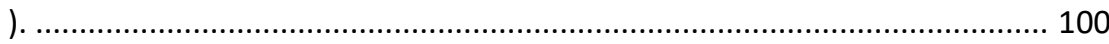

Figura 3.6 Maqueta de Cabestrante (realizada por Argan Giovenale), para elevar cañones y columnas (según diseño de Leonardo) del Museo de la Ciencia y Tecnología de Milán (http://www.museoscienza.it/dipartimenti/catalogo_collezioni/scheda_ogget to.asp?idk_in=ST070-00061\&arg=Modelli\%20leonardeschi). 100

Figura 4.1 a) Puente ideado por Leonardo y construido en Noruega por Vebjorn August Sand (https://estructurando.net/revista-estructurando-no-4-ano2015/ imagen de Sigurd Rage), b) Manuscrito L, f. 65v, del Instituto de París (https://commons.wikimedia.org/wiki/File:Leonardo_Bridge.jpg). 106

Figura 4.2 Boceto de su "ciudad nueva" (Manuscrito B, f.16r de la Biblioteca del Instituto de Francia, París)

(https://commons.wikimedia.org/wiki/File:Leonardo_da_Vinci_-_19-

553972.jpg).

Figura 4.3 a) y b)Códice Forster II, c.89v (http://www.museogalileo.it/), c) Códice de Madrid I, f 137r (http://leonardo.bne.es/index.html).

Figura 4.4 a) Códice Forster II, c.73r (http://www.museogalileo.it/), b) Códice Forster II, c.77v (http://www.museogalileo.it/), c) Manuscrito L, folio 28r de la Biblioteca del Instituto de Francia, París

(https://commons.wikimedia.org/wiki/File:Leonardo_da_Vinci_-_19-

549766.jpg).

Figura 4.5 a) Manuscrito B, folio 51v. del Instituto de Francia, París

(https://commons.wikimedia.org/wiki/File:Leonardo_da_Vinci_-_19-

554045.jpg?uselang=es), b) Códice Forster II, c. 45v

(http://www.museogalileo.it/)

Figura 4.6 Royal Collection, Windsor, f 19149 K/P 118va. Royal Collection, Windsor,

f $1264412644 r$

(https://commons.wikimedia.org/wiki/File:Leonardo_da_Vinci_-

_RCIN_912644,_Recto_Studies_of_men_in_action.jpg).

Figura 4.7 a) Manuscrito $\mathrm{H}$ folios $43 \mathrm{v}-44 \mathrm{r}$ de la Biblioteca del Intituto de Francia, París (http://www.museogalileo.it/), b) Códice de Madrid I, folio 90 v, Biblioteca Nacional de España, Madrid (http://leonardo.bne.es/index.html).

Figura 4.8 a) Códice Atlántico f. 945r

(https://commons.wikimedia.org/wiki/File:Codex_Atlanticus_-_000R-

945.jpg), b) Códice Atlántico f. 30v

(https://commons.wikimedia.org/wiki/File:Codex_Atlanticus_-_000V-30.jpg),

c) Maqueta del museo Nacional de Ciencia y Tecnología Leonardo Da Vinci,

Florencia (www.museoscienza.org).

Figura 4.9 Plano de Pisa y el río Arno (Códice Madrid II, f 52v, 53 r).

(http://leonardo.bne.es/index.html).

Figura 4.10 a) Códice Arundel folio 24v (British Museum, Londres).

(https://commons.wikimedia.org/wiki/File:Codex_arundel.jpg), b) y c) 
Maquetas pertenecientes al Museo Nacional de Ciencia y Tecnología Leonardo Da Vinci (Milán) (www.museosciencia.org).

Figura 4.11 a) Dispositivo mecánico (Códice Atlántico folio 1077v)

(https://commons.wikimedia.orgwikiFile000R-1077.jpg), b) Robot de Mario Taddei (Wikipedia), c) Robot de la Web del "Instituto e Museo di Storia della Scienza" de Florencia (http://www.museogalileo.it/).

Figura 5.1 a) Relación de libros propiedad de Leonardo que consta en su Códice de Madrid II. ff. 2v y 3r, de la Biblioteca Nacional de España, Madrid (origen de la imagen: Leonardo - Códices Madrid (bne.es)). b) Codex Forster III (h. 1490) Victoria and Albert Museum, Londres (origen de la imagen:

https://commons.wikimedia.org/wiki/File:Leonardo_da_vinci,_taccuino_forst er_III,_1490_ca._02.JPG).

Figura 5.2 a) Ensayos hidráulicos, Códice de Madrid I, f. 115r, Biblioteca Nacional de España (Madrid) (Origen de la Imagen: Leonardo - Códices Madrid (bne.es)). b) Estudio del comportamiento de los pilares cargados, Manuscrito A de la Biblioteca del Instituto de Francia (París). (Origen de la Imagen: https://commons.wikimedia.org/wiki/File:Leonardo_da_Vinci_-_19547363.jpg)

Figura 5.3 a) Diseño de Tambor militar automático, Códice Atlántico f. 837r, h. 1503 (Origen de la imagen:

https://commons.wikimedia.org/wiki/File:\%D0\%92\%D0\%BE\%D0\%B5\%D0\%BD \%D0\%BD\%D1\%8B\%D0\%B9_\%D0\%B1\%D0\%B0\%D1\%80\%D0\%B0\%D0\%B1\%D0 \%B0\%D0\%BD.jpg?brusela=es). b) Maqueta del tambor automático, exposición "Mulino di Mora Bassa" (Vigevano) (origen de la imagen:

https://commons.wikimedia.org/wiki/File:Tamburo_militare_di_Leonardo_da _Vinci_in_una_mostra_su_Leonardo_da_Vinci_al_Mulino_di_Mora_Bassa_-

_Morabassa.jpg?uselang=es-formal) 134

Figura 5.4 a) La mona Lisa o Gioconda (de 1503 a 1506) Museo del Louvre, París. (origen de la imagen:

https://commons.wikimedia.org/wiki/File:Mona_Lisa,_by_Leonardo_da_Vinci ,_from_C2RMF_retouched.jpg) b) Sistema hidráulico con válvulas de retención, Manuscrito E de la Biblioteca del Instituto de Francia (París) (origen de la imagen: File:Leonardo da Vinci - 19-547769.jpg - Wikimedia Commons).

Figura 5.5 a) El Hombre de Vitruvio o de las divinas proporciones, Galería de la Academia de Venecia, h. 1490 (origen de la imagen: File:Anatomia homem leonardo.jpg - Wikimedia Commons). b) Estudios Anatómicos: Cerebro humano, (1506-1508), Códice Windsor, Royal Library, Windsor (origen de la imagen: File:Leonardo Da Vinci's Brain Physiology.jpg - Wikimedia Commons).

Figura 5.6 a) La Virgen de la Rocas (1483), versión del Museo del Louvre, París.

(origen de la imagen:

https://commons.wikimedia.org/wiki/File:Leonardo_da_Vinci_-

_Virgin_of_the_Rocks_(Louvre).jpg). b) Dispositivos de elevar agua C. 
Atlántico f. 6r, Biblioteca Ambrosiana de Milán (origen de la imagen:

File:Codex Atlanticus - 000R-6.jpg - Wikimedia Commons).

Figura 6.1 Figura 1: a) II Taccola, Manuscrito "De Machinis", Bayerische

Staatsbibliothek (Biblioteca Nacional de Baviera), b) Di Giorgio, Manuscrito

"Opusculum de Architectura", British Museum. (origen de las imágenes a y b

Instituto y Museo de Historia de la Ciencia de Florencia o Museo Galileo,

https://brunelleschi.imss.fi.it).

Figura 6.2 a) R. Valturio Tratado de "Re Militari" (Edición de 1472) Carro con

guadañas (www.metmuseum.org , Museo Metropolitano de Arte de New York, www.metmuseum.org).

("https://play.google.com/books/reader?id=m3Q8AAAAcAAJ\&hl=es\&pg=GBS. PA231"), b) Paolo Santini, Carro incendiario "Manuscrito Latino" 7239 c. 19 r, Biblioteca Nacional de Paris. (Instituto y Museo de Historia de la Ciencia de Florencia o Museo Galileo https://brunelleschi.imss.fi.it).

Figura 6.3 a) Paolo Santini, Carro con guadañas, "Manuscrito Latino" 7239 c. 78 r,

Biblioteca Nacional de Paris (Instituto y Museo de Historia de la Ciencia de Florencia o Museo Galileo https://brunelleschi.imss.fi.it), b) Leonardo, Carro con guadañas móviles. f. 15583 r (1485) Biblioteca de Real de Turín (https://commons.wikimedia.org/wiki/File:Leonardo_da_vinci,_Assault_chari ot_with_scythes.jpg?uselang=es).

Figura 6.4 a) Maqueta del Carro de Guerra (Biblioteca Real de Turín)

(http://www.macchinedileonardo.com/index0aec.html?le-macchine), b)

Detalle del final del árbol de transmisión a las guadañas delanteras. 156

Figura 6.5 a) "Il Taccola", Catapulta de (García, 2011), b) R. Valturio, Catapulta de Tratado "Re Militari" (Edición de 1472) (Museo Metropolitano de Arte de New York, www.metmuseum.org) (https://play.google.com/books/reader?id=m3Q8AAAAcAAJ\&hl=es\&pg=GBS. PA276), c) Di Giorgio, Catapulta de "Opusculum de architectura" Ms 197.b.21 (British Museum, London) c. 37v (Instituto y Museo de Historia de la Ciencia de Florencia o Museo Galileo https://brunelleschi.imss.fi.it). 157

Figura 6.6 a) Leonardo: Proyecto de Catapulta f. 140 a r, del Códice Atlántico de la Biblioteca Ambrosiana de Milán (1485-90)

(https://commons.wikimedia.org/wiki/File:Da_Vinci_Catapult.jpg?uselang=e), b) Leonardo: Detalles de resortes y cabrestantes de sistemas para tensado de la catapulta f. 148a r del Códice Atlántico de la Biblioteca Ambrosiana de Milán (1485-90)

(https://commons.wikimedia.org/wiki/File:Codex_Atlanticus_-_000R148.jpg).

Figura 6.7 a) y b) Leonardo, Proyectos de Catapultas de un solo brazo f. 148b r; y para flechas f. 181 r, del Códice Atlántico, Biblioteca Ambrosiana de Milán (1485-90) (https://commons.wikimedia.org/wiki/File:Leonardo_Da_Vinci_Sling_Catapult .PNG?uselang=es) 160 
Figura 6.8 a) Ingeniero sienés anónimo, Grúa siglos XV-XVI, b) Di Giorgio, Grúa, "Tratado Arquitectura y Maquinas 2a versión", Biblioteca Nacional Central de Florencia (Instituto y Museo de Historia de la Ciencia de Florencia o Museo Galileo https://brunelleschi.imss.fi.it).

Figura 6.9 Bonaccorso Ghiberti, Grúa giratoria con contrapeso de Brunelleschi, Manuscrito "Zibaldone", B.R. 228, c. 107v Biblioteca Nacional Central de Florencia (sobre 1500). (Instituto y Museo de Historia de la Ciencia de Florencia o Museo Galileo https://brunelleschi.imss.fi.it).

Figura 6.10 Leonardo, gran Grúa giratoria para excavar de canales, Códice Atlántico f. 4r, 1503 Biblioteca Ambrosiana Milán.

(https://commons.wikimedia.org/wiki/File:Codex_Atlanticus_-_000R-

4.jpg?uselang=es-formal).

Figura 6.11 a) y b) Detalles de la armadura de la cabeza para la fundición del caballo Sforza, f. 157r del C.M. II, y del soporte para levantar y bajar el molde del f. 155v del Códice Madrid II (Biblioteca Nacional de España) (http://leonardo.bne.es/index.html), c) Detalle para los hornos y cuerpo de la fundición, Manuscritos de la Royal Collection, de Windsor 12349r p112r (www.museosciencia.org). 165

Figura 6.12 a) Detalle de f147r del Códice Madrid II (Biblioteca Nacional de España), b) Su traducción (http://leonardo.bne.es/index.html).... 166

Figura 6.13 a) Presupuesto del Mausoleo de Trivulzio f. 492r del Códice Atlántico (Biblioteca Ambrosiana de Milán). (https://commons.wikimedia.org/wiki/File:Codex_Atlanticus_-_000R492.jpg?uselang=es-formal), b) Traducción del mismo (Richter, 1883). (https://warburg.sas.ac.uk/pdf/cnm22b2242052v1.pdf).

Figura 7.1 Martinete actual de la marca Correggio RE (Italia) y su despiece en catálogo en forma de "explosor", de manera similar a como Leonardo lo hizo hace más de 500 años. (https://rodalsa.net/wpcontent/uploads/2020/03/martinetes.pdf).

Figura 7.2 a) Máquina de movimiento alterno para elevación de pesos (Argano),

Códice Atlántico folio 30v, (1478-1480)

(https://commons.wikimedia.org/wiki/File:Codex_Atlanticus_-_000V-30.jpg),

b) Maqueta del Museo de la Ciencia y la Tecnología de Milán

(www.museoscienza.org)

Figura 7.3 Detalle de la columna vertebral (1508-1509) RLW 19007v, K/P139v.

Royal Library de Windsor.

(https://brunelleschi.imss.fi.it/genscheda.asp?appl=LIR\&xsl=paginamanoscritt o\&chiave=100945).

Figura 7.4 a) Estudio del desarrollo del tornillo, Códice Madrid I, f. 86v.

(http://leonardo.bne.es/index.html), b) Estudio del alcance del agua a presión, Manuscrito C, c 7r, Instituto Francés de Paris (Francia), c) Diseño de Canal de irrigación de San Cristofano, Codex Atlántico f. 1097r Milán (1509). (https://commons.wikimedia.org/wiki/File:000R-1097.jpg?uselang=esformal). 
Figura 7.5 a) Detalle alcance del agua, Códice de Madrid I, f. 134v, Biblioteca Nacional de España (http://leonardo.bne.es/index.html), b) Detalle de un estudio mecánica del Codex Arundel f. 93 r (1504) British Library, Londres (https://commons.wikimedia.org/wiki/Category:Codex_Arundel_(c.14801518)_-_BL_Arundel_MS_263 ), c) Proporción geométrica de esfuerzo de bueyes tirando Codex Atlántico f. 561r (1487-1490) de la Biblioteca Ambrosiana de Milán (https://commons.wikimedia.org/wiki/File:Codex_Atlanticus_-_000R561.jpg).

Figura 7.6 Mapa del Lago "Trasimeno" de 1600, Giovanni Antonio Magini (15551617). (Fuente Wikipedia).

Figura 7.7 Carta RLW 12278, Royal Library, Windsor (Reino Unido). (https://commons.wikimedia.org/wiki/File:Leonardo_da_vinci,_Map_of_Tusc any_and_the_Chiana_Valley.jpg?uselang=de). 181

Figura 7.8 Detalle de la carta RLW 12682, Royal Library, Windsor (Reino Unido)(https://brunelleschi.imss.fi.it/itinerari/immagine/img34843.html). 182

Figura 7.9 Plano de la ciudad de Imola (1502), Royal Library, RLW 12284, Windsor (Reino Unido). (https://upload.wikimedia.org/wikipedia/commons/8/85/Leonardo_da_Vinci _-_Plan_of_Imola_-_Google_Art_Project.jpg). 183

Figura 7.10 "La Anunciación”, Galería de los Uffici, Florencia (Italia) https://commons.wikimedia.org/wiki/File:Annunciation_(Leonardo)_(cropped ).jpg?uselang=es), y detalle de su fondo. 186

Figura 7.11 a) "La Virgen de las rocas", Museo del Louvre, París.

(https://commons.wikimedia.org/wiki/File:Leonardo_Da_Vinci_-

_Vergine_delle_Rocce_(Louvre).jpg), b) Detalle del fondo del mismo cuadro,

c) "La Gioconda", Museo de Louvre, París

(https://commons.wikimedia.org/wiki/File:Mona_Lisa,_by_Leonardo_da_Vinc i,_from_C2RMF_retouched.jpg). 188

Figura 7.12 a) Estudios anatómicos de músculos, Royal Library de Windsor (Reino Unido) (https://commons.wikimedia.org/wiki/File:Leonardo_da_vinci,_Figure_studie s.jpg), b) Estudio de cabeza se apóstol para "La Ultima Cena" (1495) Royal Library (Windsor, GB) (https://commons.wikimedia.org/wiki/File:Judaskopf_(da_Vinci).jpg, c) Neptuno con los caballos marinos (alrededor 1504), RLW 12570, Royal Library (Windsor, GB).

(https://commons.wikimedia.org/wiki/File:Leonardo_da_Vinci__Neptune,_c.1504-5.jpg).... 190

Figura 7.13 a) "Martirio de San Sebastián", alrededor de 1482, colección privada. (https://elpais.com/hemeroteca/2016-12-13/), b) Copia de "Leda", del alumno de Leonardo, Francesco Melzi, 1515 Galería de los Uffizi, Florencia (Italia).

(https://commons.wikimedia.org/wiki/File:Leda_and_the_Swan_1508- 
1515.jpg), c) Estudio para "Leda arrodillada" 1503-1507. Chat-Worth

Derbyshire (Reino Unido).

(https://commons.wikimedia.org/wiki/File:Study_for_the_Kneeling_Leda.jpg)

Figura 7.14 a) y b) Estudio para caballos

(https://commons.wikimedia.org/wiki/File:Leonardo_da_vinci,_Study_of_hor ses_for_the_Battle_of_Anghiari.jpg y

https://commons.wikimedia.org/wiki/File:Leonardo_da_vinci,_Rearing_horse .jpg), c) Hombre de Vitruvio (1490) Galería de la Academia de Venecia (Italia) (https://commons.wikimedia.org/wiki/File:Da_Vinci_Vitruve_Luc_Viatour_(cr opped).jpg).

Figura 7.15 a) Imagen con anamorfismo (deformada) que, si se mira desde más a la izquierda y pegado al papel, se verá que consiste en el rostro de un niño, b) Imagen no deformada (articulo del diseñador Jesús Montes Zurita https://ihistoriarte.com/2013/04/anamorfosis-la-deformacion-reversible/).

Figura 8.1 a) El "Hombre de Vitruvio" Galería de la Academia.

(https://commons.wikimedia.org/wiki/File:Da_Vinci_Vitruve_Luc_Viatour_(cr opped).jpg), b) Manuscrito "K" f. 14v y 15r, del Inst. de Francia, París (https://commons.wikimedia.org/wiki/File:Leonard_de_Vinci__D\%C3\%A9monstration_euclidienne_du_th\%C3\%A99or\%C3\%Aㅇme_de_Pytha gore.jpg?uselang=es).

Figura 8.2 a) Estudio de instrumentos y compases. Códice Atlántico, folio 696r (https://commons.wikimedia.org/wiki/File:Codex_Atlanticus_-_000R696.jpg?uselang=es-formal), b) Detalle de compás de apertura ajustable Manuscrito $\mathrm{H}$ de Paris, f. $108 \mathrm{v}$

(https://commons.wikimedia.org/wiki/File:Leonardo_da_Vinci_-_19540164.jpg), c) Maqueta de un compás del Codex Atlanticus, Musée de I' Histoire du Fer de Jarville la Malgrange (Francia), fotografía de Caroline Léna Becker (https://commons.wikimedia.org/wiki/File:Compas_Léonard_de_Vinci.JPG).

Figura 8.3 a) Compás de proporción de tornillo, y detalle de su tuerca, Códice Forster Ms. I, c. 4 r.

(https://commons.wikimedia.org/wiki/File:Reduction_Compass_Leonardo.jpg ), b) Detalle compás proporcional de varillas, Códice Atlántico f 1046r https://commons.wikimedia.org/wiki/File:000R-1046.jpg?uselang=es-formal, c) Compases de reducción, Códice Atlántico f $672 r$ https://commons.wikimedia.org/wiki/File:Codex_Atlanticus_-_000R672.jpg?uselang=es-formal). 201

Figura 8.4 a) Elipsógrafo de Leonardo, con tres apoyos. b) Elipsógrafo de Benvenuto della Volpaia, (Florence, Istituto e Museo di Storia della Scienza.) (https://brunelleschi.imss.fi.it, Museo Galileo, Florencia). 
Figura 8.5 a) Compás Parabólico. Códice Atlántico f. 1093r

(https://commons.wikimedia.org/wiki/File:000R-1093.jpg), b) Reconstrucción en latón del Instituto y Museo de Historia de la Ciencia de Florencia

(https://brunelleschi.imss.fi.it, Museo Galileo, Florencia). 203

Figura 8.6 Formas de la Epicicloide desde $\mathrm{K}=1$ a K $=4$. (Fuente Wikipedia enciclopedia libre).

Figura 8.7 a) Compás epicicloide Códice Arundel f. 160v.

(http://www.bl.uk/manuscripts/Viewer.aspx?ref=arundel_ms_263_f001r), b) Reconstrucción en latón del Instituto y Museo de Historia de la Ciencia de Florencia (https://brunelleschi.imss.fi.it, Museo Galileo, Florencia)............ 205

Figura 8.8 Prospectógrafo de vidrio de Albert Durero, 1525 (https://commons.wikimedia.org/wiki/Albrecht_D\%C3\%BCrer\#/media/File:D \%C3\%BCrer_-_Zeichner_und_Akt.jpg). 206

Figura 8.9 a) Códice Atlántico, f. 5r.

("https://brunelleschi.imss.fi.it/genscheda.asp?appl=LIR\&xsl=paginamanoscrit to\&chiave=101361"chiave=101361), b) Detalle ampliado del prospectógrafo siendo usado por Leonardo.

(https://commons.wikimedia.org/wiki/File:Codice_Atlantico_-

_Perspectograph.jpg). 207

Figura 8.10 Maqueta según dibujo de Leonardo, de Asociación cultural Italian Art (italian_art@yahoo.com.br) de Florencia. 208

Figura 8.11 a) Maqueta del Museo Nacional de Ciencia y Tecnología de Milán. (www.museoscienza.org), b) Odómetro actual, marca Kesom mod. RR3M, c) Códice Atlánticus, folio $1 \mathrm{~b}$ r.

(https://commons.wikimedia.org/wiki/File:Odomètre-Léonard.jpg).

Figura 8.12 a) Detalles de una lámina del Códice de Madrid con contador de balanceos. (http://leonardo.bne.es/index.html), b) Maqueta asimilable al Podómetro de Leonardo construida por el artesano italiano Giorgio Mascheroni para la exposición "L`Arttigiano di Leonardo" (http://artigianodileonardo.jimdo.com).

Figura 8.13 Imágenes de cámaras oscuras transportables, conformadas por una habitación similar a las descritas por el sacerdote erudito y políglota Athanasius Kircher (1602-1680). (https://www.fotonostra.com/biografias/camaraoscura.htm).

Figura 8.14 a) Proyector de luz Códice Atlántico f. 34 r-a (1480) (https://commons.wikimedia.org/wiki/File:Codex_Atlanticus_-_000R-34.jpg), b) Maqueta del proyector realizada por el profesor italiano de enseñanzas técnicas Giralomo Covolan (http://www.macchinedileonardo.it)

Figura 8.15 Detalle de similitud de la visión del ojo y la cámara oscura, Códice Atlántico (https://commons.wikimedia.org/wiki/File:Otto_Werner_\%22Zur_physik...\%2

2, illustrations_Wellcome_L0012044.jpg fotografia de Otto Werner).

Figura 8.16 Demostración del mecanismo del ojo por medio de un modelo de vidrio (Manuscrito D, f. 3v). 
(https://commons.wikimedia.org/wiki/File:Leonardo_da_Vinci,_Manuscript_ D,_1508-09.jpg?uselang=es).

Figura 9.1 a) Estudio de los movimientos de los huesos del brazo RL 19000 v; K/P 135 r (1508-1510) Royal Library, Windsor (Reino Unido).

(https://commons.wikimedia.org/wiki/File:Studies_of_the_Arm_showing_the _Movements_made_by_the_Biceps.jpg), b) Huesos de la pierna es tres ángulos distintos y rodilla flexionada, Royal Library, Windsor RL 19008 r; K/P $140 \mathrm{r}$ (1508-1510) (Reino Unido) (https://commons.wikimedia.org/wiki/File:Leonard_de_Vinci__Anatomie_des_os_de_la_jambe.jpg).

Figura 9.2 a) Manuscrito H, f. 43v-44r del Instituto de Francia (París).

("https://brunelleschi.imss.fi.it/genscheda.asp?appl=LIR\&xsl=paginamanoscrit to\&chiave=100936"chiave=100936), b) Códice de Madrid I, f. 90 v, de la Biblioteca Nacional de España (http://leonardo.bne.es/index.html).

Figura 9.3 a) Estudio de mecanismos para ala mecánica para planeador, realizado entre 1505-1506. Códice Atlántico 934r (https://commons.wikimedia.org/wiki/File:Codex_Atlanticus_-_000R934.jpg?uselang=es-formal 934r), b) Estudio de Ala móvil (1495), Códice Atlantico 844r (https://commons.wikimedia.org/wiki/File:Codex_Atlanticus__000R-844.jpg)

Figura 9.4 a) Estudio de "Ala Batiente" movida por fuerza humana (1483-8), Manuscrito B, 88v del Instituto de Francia (Paris). (https://commons.wikimedia.org/wiki/File:Codex_on_the_Flight_of_Birds.jpg lb) Maqueta del ensayo de ala batiente del Museo de Ciencia y Tecnología de Milán (www.museoscienza.org/). 228

Figura 9.5 a) Estudio de las maniobras de equilibrio de los pájaros. Códice del Vuelo folio 8r. Turín (https://commons.wikimedia.org/wiki/File:Codice_Volo_08R_mod.jpg), b) y c) Estudios para la máquina voladora (1493-1495) Códice Atlántico folios 70b r y 846 v. Biblioteca Ambrosiana de Milán

(https://commons.wikimedia.org/wiki/File:Codex_Atlanticus_-_000R-70.jpg, y https://commons.wikimedia.org/wiki/File:Leonardo_Design_for_a_Flying_Ma chine,_c._1505.jpg). 230

Figura 9.6 a) Imagen del murciélago zorro en vuelo, b) Maqueta del Ornitóptero (www.portalplanetasedna.com.ar/davinci). 231

Figura 9.7 a) Estudios sobre cometas dirigida desde tierra mediante cables. Manuscrito I de Madrid, f. 64 r. (http://leonardo.bne.es/index.html), b) Dibujo de su Cuaderno de Notas representando el descenso suave de la cometa (Richter, 2008)

"https://commons.wikimedia.org/wiki/File:Спуск_на_землю_сухим_листко м.jpg"Спуск_на_землю_сухим_листком.jpg). 232

Figura 9.8 a) Maqueta del Robot "Caballero Mecánico" del museo de Historia de la Ciencia de Florencia (www.imss.fi.it), b) Maqueta del robot de "León 
Mecánico" realizado para el Museo "Leonardo3" de Milán (www.leonardo3.net).

Figura 9.9 a) Guante aleta para el agua nadar en el agua, Manuscrito B, folio 81 v. Instituto de Francia (https://commons.wikimedia.org/wiki/File:Leonardo_da_Vinci_-_19554103.jpg), b) Patas palmeadas de un pato doméstico, c) Aletas de buzo(www.aqua-zone.com). 235

Figura 9.10. Estudio de las igualdades de las áreas de los cortes seccionales en el ramaje de un árbol. Manuscrito $\mathrm{M} \mathrm{f} \mathrm{78v} \mathrm{del} \mathrm{Instituto} \mathrm{de} \mathrm{Francia} \mathrm{(París)}$ (https://commons.wikimedia.org/wiki/File:Paris_Manuscript_M_Fol_78v.jpg).

Figura 9.11 Estudio de flujos de agua (turbulencias), RL 12579r (1510-1513) y RL

12660r. (1509-1511) de la Royal Library, Windsor

(https://commons.wikimedia.orgwikiFileLeonardo_da_vinci,_Study_of_water. jpg, y

https://commons.wikimedia.org/wiki/File:Leonardo_da_vinci,_Studies_of_wa ter.jpg) 238

Figura 9.12 a) Detalle de mirada y cabello de Ginevra Benci (1474-76) (https://commons.wikimedia.org/wiki/File:Leonardo_da_Vinci__Ginevra_de\%27_Benci_-_Google_Art_Project.jpg), b) Cabeza de Cristo con espinas. Academia de Venecia (https://commons.wikimedia.org/wiki/File:Vinci,_Leonardo_Da__Christ_Figure_-_c._1490_-_1495.jpg)

Figura 9.13 Estudio de Diluvio, (1513-1518) RL1 2380 Royal Library, Windsor, (Reino Unido) y Estudio de tormenta, remolinos y aguacero, (1508-1511) RL 12337r Royal Library, Windsor, (Reino Unido) (https://commons.wikimedia.org/wiki/File:Leonardo_da_vinci,_Natural_disas ter.jpg y https://commons.wikimedia.org/wiki/File:Wizja_potopu.jpg). ..... 241

Figura 9.14 Decoración de Leonardo de la Sala delle Asse, del castillo Sforcesco de Milán (https://commons.wikimedia.org/wiki/File:Leonardo_Sala_delle_Asse_detail.j pg). 242

Figura 10.1 a) Cabeza de gato. The Royal Collection, Windsor, b) Frutas y verduras coloreadas (1487-89) Manuscrito B, f 2r Instituto de Francia (https://commons.wikimedia.org/wiki/File:Leonardo_da_vinci,_Fruit,_vegeta bles_and_other_studies.jpg), c) Diseño para grabado de su "Academia Leonardi Vinci" (h. 1500), Biblioteca Ambrosiana de Milán (95096B) (https://commons.wikimedia.org/wiki/File:Leonardo-da-vinci-early-16th-centbodleian-library.jpg?uselang=es-formal).

Figura 10.2 Estudios urbanísticos y de canalizaciones. Manuscrito B, f. 36r, 37r y

$37 v$, Instituto de Francia, París

(https://commons.wikimedia.org/wiki/File:Leonardo_da_Vinci_-_19-

554013.jpg), b)

(https://commons.wikimedia.org/wiki/File:Leonardo_da_Vinci_-_19- 
554015.jpg), c)

(https://commons.wikimedia.org/wiki/File:Leonardo_da_Vinci_-_19-

554016.jpg).

253

Figura 10.3 a) Original escalera de dos entradas para bloques de viviendas.

Manuscrito B f. 66v. Instituto Nacional de Francia, París

(https://commons.wikimedia.org/wiki/File:Leonardo_da_Vinci_-_19-

554079.jpg), b) Maqueta de la Ciudad ideal del Museo Nazionale della Scienza

e della Tecnologia "Leonardo da Vinci", Milán

(http://www.museoscienza.org/english/visiting/leonardo-parade/).

Figura 10.4 a) Plano esquemático de los accesos a Milán C. Atlántico f. 199v

(https://commons.wikimedia.org/wiki/File:Leonardo_Milano04.jpg), b) Nuevo

Sector de construcción tipo. Códice Atlántico f. 184v, Biblioteca Ambrosiana

de Milán. (https://commons.wikimedia.org/wiki/File:Codex_Atlanticus__000V-184.jpg?uselang=es).

Figura 10.5 a) Boceto Planta del Palacio Real de Romorantin, (h. 1517). Cod.

Atlántico f. 209r (https://commons.wikimedia.orgwikifileCodex_Atlanticus__000R-209.jpg), b) Boceto Alzado del Palacio Real de Romorantin, RCIN f.

912292v, Windsor Collection

(https://commons.wikimedia.org/wiki/File:Leonardo_da_Vinci_-

_RCIN_912292,_Verso_A_design_for_a_palace_c.1517-18.jpg?uselang=es), c)

Ciudad nueva geométrica con edificios de planta central (h. 1517). Cod.

Arundel f. 270v (1514-1518)

(http://www.bl.uk/manuscripts/Viewer.aspx?ref=arundel_ms_263_f001r).

Figura 10.6 a) Bomba hidráulica para una fuente, Códice Atlántico f. 1099r,

Biblioteca Ambrosiana de Milán, (https://www.codex-atlanticus.it/), b)

Boceto de Leonardo del primer contador hidráulico para la máquina de

Rucellai, (1510) Cod. Atlántico f. 229r Biblioteca Ambrosiana de Milán.

(https://commons.wikimedia.org/wiki/File:Codex_Atlanticus_-_000R-

229.jpg?uselang=es), c) Dibujo posterior de Benvenuto Lorenzo della Golpaia,

Códice Marciano 5363, f. 7v, Biblioteca Marciana de Venecia.

261

Figura 10.7 Techo y paredes de la Sala Delle Asse del Castillo Sforcesco de

Milán(https://commons.wikimedia.org/wiki/File:Leonardo_da_vinci,_Intrecci

_vegetali_con_frutti_e_monocromi_di_radici_e_rocce,_sala_delle_asse,_149

8,_03.JPG?uselang=es y

https://commons.wikimedia.org/wiki/File:Leonardo,_decorazione_della_sala

_delle_asse_nel_castello_sforzesco_01.jpg?uselang=e).

262

Figura 10.8 La Virgen de las rocas (1483-1486, Museo del Louvre, París) y detalle del fondo del cuadro, donde la Naturaleza sustituye a otros motivos religiosos clásicos (https://commons.wikimedia.org/wiki/File:Leonardo_Da_Vinci_-

_Vergine_delle_Rocce_(Louvre).jpg).

Figura 11.1 a) Estudio para el dispositivo de un elevador manual (1495-97), Códice

I de Madrid, f. 9r.

(https://commons.wikimedia.org/wiki/File:Ascenceur_à_manivelle- 
Léonard.jpg), b) Maqueta actual del ascensor de manivela de Leonardo, de la exposición "Leonardo da Vinci el Inventor" en el Palacio de Congresos de Salamanca en 2011, c) Elevador actual de la empresa de maquinaria industrial ALBA de Sondika (Vizcaya) https://www.alba.es/productos/elevacion/andamioscolgantes/manuales/p/andamio-manual/)

Figura 11.2 a) Códice Atlántico, f 785, Biblioteca Ambrosiana de Milán.

(https://commons.wikimedia.org/wiki/File:Sonnette-Léonard.jpg), b) Maqueta de máquina para pilotes de Leonardo, del Museo Nacional de Ciencia y Tecnología de Milán (Imagen de la Web de ese Museo www.museoscienza.org), c) Máquina actual de pilotaje, en una obra de un puente.

Figura 11.3 a) Detalle del Códice Atlántico, f. 0998 r, Biblioteca Ambrosiana de Milán. (https://commons.wikimedia.org/wiki/File:Cric-Léonard.jpg), b) y c) Gatos manuales de cremallera, modelos ZWW de tornillo sin fin, y HB-W de la compañía Columbus McKinnon Ibérica de Sevilla (www.cmiberica.com/productos/elevacion/gatos-de-cremellera-y-husillo).273

Figura 11.4 a) Detalle del Códice Atlántico f. 0138r de la Biblioteca Ambrosiana de Milán (https://commons.wikimedia.org/wiki/File:Codex_Atlanticus_-_000R138.jpg), b) Gato regulable con trípode de la empresa Chuzhou Jincheng Metalwork Co., Ltd. (www.jincheng-scaffold.com). 274

Figura 11.5 a) Detalle del Códice de Madrid I, f. 0026 r, Biblioteca Nacional de España (Madrid) (http://leonardo.bne.es/index.html) b) y c) Gato mecánico actual con rodamiento de bolas, SG12 serie MA, fabricado por la empresa COTRANSA y sección del mismo con vista de los rodamientos de bolas de apoyo (n-4) (www.cotransa.net).

Figura 11.6 a) Detalle de torno de giro por "pedal y doble pértiga, Códice Atlántico (1480) f. 47r, (https://commons.wikimedia.org/wiki/File:Codex_Atlanticus__000R-47.jpg?uselang=es), b) Detalle del Códice Atlántico, torno de giro continuo por "volante de inercia", Códice Atlántico f.1059r.

(https://commons.wikimedia.org/wiki/File:000R-1059.jpg), c) Prototipo del torno de Leonardo realizado por Stuart King en la Exposición "Wizadry in Word" en el Pewterers' Hall, London (Reino Unido) (Imagen del Blog de Stuart King www.stuartking.co.uk/index.php/how-i-built-leonardo-da-vincis-lathe/).

Figura 11.7 a) y b) Detalles del anemómetro y anemoscopio del Códice Atlántico f. 675 de la Biblioteca Ambrosiana de Milán (https://commons.wikimedia.org/wiki/File:Codex_Atlanticus_-_000R675.jpg), c) Anemómetro actual, d) Maqueta del anemómetro y anemoscopio de Leonardo, del Museo Nacional de Ciencia y Tecnología de Milán (http://www.museoscienza.org) 280

Figura 11.8 a) Manuscrito del vehículo autopropulsado, Códice Atlántico, folio 812 r (1478-80), Biblioteca Ambrosiana de Milán.

(https://commons.wikimedia.org/wiki/File:Leonardo_da_vinci,_Automobile.jp 
g?uselang=es), b) Maqueta del Museo Nacional de la Ciencia y la Tecnología de Milán de 1953, basada en el Modelo de Canestrini. (Imagen de la Web del Museo de Historia de la Ciencia de Florencia https://brunelleschi.imss.fi.it ).

Figura 11.9 a) detalle del Manuscrito B del Instituto de Francia f. 47 r, (1487) con escalera de cuatro entradas para la Ciudad Ideal.

(https://commons.wikimedia.org/wiki/File:Leonardo_da_Vinci_-_19-

554036.jpg?uselang=es), b) Detalle del Manuscrito M de Francia f. 69 r, (1490) con escalera de doble hélice, c) Escalera de doble hélice del Castillo de Chambord (www.rinconesconencantofrancia.blogspot.com.es). 285

Figura 11.10 a) Detalle del Códice Atlántico f. 1058, Biblioteca Ambrosiana de Milán

(https://commons.wikimedia.org/wiki/File:Leonardo_da_Vinci_parachute_04 659a.jpg), b) Maqueta del paracaídas de Leonardo, del Museo Nacional de Ciencia y Tecnología de Milán (Imagen de la Web del Museo: www.museoscienza.org), c) Salto de Adrián Nicholas el 20/07/2000 en República Sudafricana (Fotografía de ANSA para el Daily Telegraph londinense) www.dailymail.co.uk). 288

Figura 12.1 Área de conocimiento de "Proyectos de Ingeniería" ......................... 291

Figura 12.2 Resumen cronológico ................................................................. 295

Figura 12.3 a) Adoración de los Reyes Magos (fuente Wikipedia)

(https://commons.wikimedia.org/wiki/File:Leonardo_da_Vinci_-

_Adorazione_dei_Magi_-_Google_Art_Project.jpg), b) Folio de la Royal

Library, Windsor Castle, sobre el estudio inicial del Caballo Sforza

(https://commons.wikimedia.org/wiki/File:Leonardo_da_vinci,_Study_for_th

e_Sforza_monument_01.jpg).

Figura 12.4 Detalle de f149r y traducción (http://leonardo.bne.es/index.html).. 300

Figura 12.5 Detalle de f151v y traducción (http://leonardo.bne.es/index.html). 301

Figura 12.6 Detalle de f155v y traducción (http://leonardo.bne.es/index.html). 301

Figura 12.7 Detalle de f157r y traducción (http://leonardo.bne.es/index.html).. 302

Figura 12.8 Detalle de f157v y traducción (http://leonardo.bne.es/index.html). 303

Figura 12.9 Croquis para el transporte del modelo de arcilla (Códice Atlántico Folio

577v) (https://commons.wikimedia.org/wiki/File:Codex_Atlanticus___000V-

577.jpg). 305

Figura 12.10 Presupuesto de ejecución del Mausoleo de Trivulzio folio 492r del

Códice Atlántico (Biblioteca Ambrosiana de Milán).

(https://commons.wikimedia.org/wiki/File:Codex_Atlanticus_-_000R-

492.jpg?uselang=es-formal) y Boceto del monumento (Folio 12355 de de la

Royal Collection Trust, Windsor)

(https://commons.wikimedia.org/wiki/File:Leonardo_da_vinci,_Study_for_th

e_trivulzio_monument_02.jpg). 306

Figura 12.11 "Il Cavallo" de Milán y el "American Horse" de Grand Rapids

(Michigan) (http://www.studioequus.com/24grandrm.html). 308 
Figura 13.1 a) Ensayos hidráulicos del Códice de Madrid I, f. 150v y 151r (origen de la imagen: http://leonardo.bne.es/index.html). b) Diseño de compas y de construcción de una elipse Cod. Atlántico f. 1032r (origen de la imagen: https://commons.wikimedia.org/wiki/File:000R-1032.jpg).

Figura 13.2 a) Proyecto de máquina textil: "tundidora mecánica" (h. 1495), Cod. Atlántico f. 1105r (origen de la imagen: https://commons.wikimedia.org/wiki/File:000R-1105.jpg?uselang=es). b) Máquinas varias Cod. Madrid I, f. 104r (origen de la imagen: http://leonardo.bne.es/index.html).

Figura 13.3 a) Boceto de máquina de volar, Códice Atlántico f. 860r (origen de la imagen: https://commons.wikimedia.org/wiki/File:Leonardo_da_Vinci__Ambrosiana-Codice-Atlantico-Codex-Atlanticus-f-860-recto.jpg). b) Exclusas con compuerta tipo mitra, con inclinación, para elevación de niveles de agua en los canales, C. Atlántico 656r (h. 1497) (origen de la imagen: https://commons.wikimedia.org/wiki/File:\%C3\%89cluse-L\%C3\%A9onard-deVinci.jpg?uselang=es ). 328

Figura 13.4 a) Detalle de folio con Notas Cartográficas, con boceto de partición de media esfera en octante, C. Atlántico f. 521 r (h. 1508). (Origen de la imagen: https://es.wikipedia.org/wiki/Mapamundi_de_Leonardo) b) Proyecto de Mapamundi de Leonardo mediante octantes, Colección de la Windsor Library, RLW f. 01393 (h. 1514). (Origen de la imagen: https://commons.wikimedia.org/wiki/File:Leonardo_da_Vinci's_Mappamundi .jpg?uselang=es) 


\title{
Capítulo 1 Objeto y Antecedentes
}

\author{
"La experiencia es la madre de toda certeza..." \\ LEONARDO DA VINCI (Tratado de la Pintura de Leonardo da Vinci o \\ Códice Latinas Urbinus no 1270, de la Biblioteca Vaticana).
}

\subsection{Introducción}

La tesis pretende desarrollar una investigación teórica que defina y relacione los principales aportes de la obra científico-técnica de Leonardo da Vinci (Vinci, 1452- Amboise, 1519), amoldándola a los conceptos actuales que son base del conocimiento actual del Proyecto/Diseño, o sea: el Diseño en Ingeniería (Engineering Desing); la Ingeniería de Proyectos (Project Engineering) y la Dirección y Gestión de Proyectos (Project Management). Así como comparándola también con el actual punto de vista formal del proyecto (las fases, los documentos, etc.).

Leonardo, independientemente de sus extraordinarios conocimientos y formación en pintura manifestados a lo largo de su vida en sus distintas academias, parte de ellos expuestos en su Tratado de Pintura (hacia 1550), elaborado por su alumno preferido y heredero de sus manuscritos, Francesco Melzi (Milán, 1493-Vaprio d'Adda, 1572-73); abarcó todos los ámbitos del diseño conocidos en aquel entonces. Así, en su conjunto de Manuscritos (que alcanzan las 7000 hojas manuscritas) se pueden encontrar diseños en múltiples disciplinas:

Diseño urbanístico, como sus dos proyectos de ciudad que realizó para el Duque de Milán, Ludovico Sforza (1452, Vigevano-1508, Loches), para la expansión de la ciudad de Milán; uno mediante su solución de ciudad ideal y ecológica, y otro mediante ciudades satélite.; o como el que realizó para el Rey de Francia Francisco I (Cognac, 1494-Rambouillet, 1547) denominado Nuevo Palacio y Ciudad de Romorantin, vinculado al agua. 
Diseños arquitectónicos como el estudio de una villa y jardín para el Marqués de Mantua, o el de la Casa Guiscardi en Milán, o los de varias iglesias de planta octogonal, etc.

Diseños de ingeniería civil, como el de grúas excavadoras, el de la ampliación del puerto de Piombino, el de desecación de las bahías Pontinas, el del desvío del río Arno a su paso por Pisa, el del canal de irrigación de San Cristófono, de puentes giratorios, o de fortalezas y murallas, como la fortaleza de Verruca, etc.

Diseño industrial, como máquinas pulidoras de espejos, máquinas textiles con diferentes funciones, sierras mecánicas automáticas, máquinas tipográficas, molinos movidos por agua, el primer automóvil o automotor, o la conflictiva primera bicicleta, etc.

Diseño topográfico, como el mapa de la ciudad de Imola, el mapa de la Toscana y el Valle de Chiana, o el mapa de las bahías Pontinas a vista de pájaro, etc.

Diseño aéreo y naval, como el ala delta, el paracaídas,el tornillo volador, la draga, el barco de palas, el submarino, etc.

Diseño escultural como el proyecto del monumento ecuestre denominado el "Gran Caballo Sforza", en honor al gran duque de Milán, Francesco Sforza (San Miniato, 1401-Milán, 1466).

Diseño funerario, como el proyecto de mausoleo para el Mariscal Giacomo Trivulzio (Milán, 1440-Arpajon, 1518).

Diseño de espectáculos teatrales y de ropas, para las fiestas cortesanas de los Sforza de Milán y de la Corte del rey de Francia anteriormente citados, con máquinas y tramoyas capaces de girar un escenario como la máquina teatral de "Orfeo"; dos figuras robotizadas como el "León mecánico" que camina, se abre el pecho y ofrenda unas flores de lis al rey de Francia; o el "caballero mecánico" que movía brazos y piernas, y emitía voces, para los Sforza, etc.

Diseño de máquinas y elementos para guerra, como el carro con guadañas, el tanque o carro armado, la bombarda múltiple, la ametralladora; o como los diseñados para la república de Venecia: el buzo o escafandra, los guantes de natación, accesorios agujerea-cascos de barcos, etc.

Diseño de accesorios y herramientas, como relojes convencionales, relojes planetarios, compases, odómetros, podómetros, pedernales, cerraduras de seguridad, el primer "criptex" conocido, etc. 
Diseños anatómicos y botánicos, como los existentes en sus manuscritos de la Colección Windsor sobre los huesos, los músculos, los nervios, el corazón, el cerebro, el ojo, etc., tras haber diseccionado más de 30 cadáveres humanos y de animales).

Incluso diseños de instrumentos musicales como una viola organista, un tambor múltiple mecánico, una lira en forma de cráneo, etc.

Una buena definición de este excepcional trabajo de Leonardo, la realiza muy bien la historiadora del arte turolense y directora emérita del Departamento de Manuscritos incunables y raros de la Biblioteca Nacional, Teresa Mezquita Mesa, en el libro Los rostros del Genio (2018): <<El resultado de cuarenta años de insaciable curiosidad, dibujando y anotando ideas y observaciones. Mas su potente capacidad de razonamiento es un inmenso corpus de ingeniería, mecánica, física, hidráulica, anatomía, botánica, geometría, astronomía, música, óptica, y otros muchos asuntos, incluidos los lúdicos o "infinite pazzie">> (Mezquita, 2018).

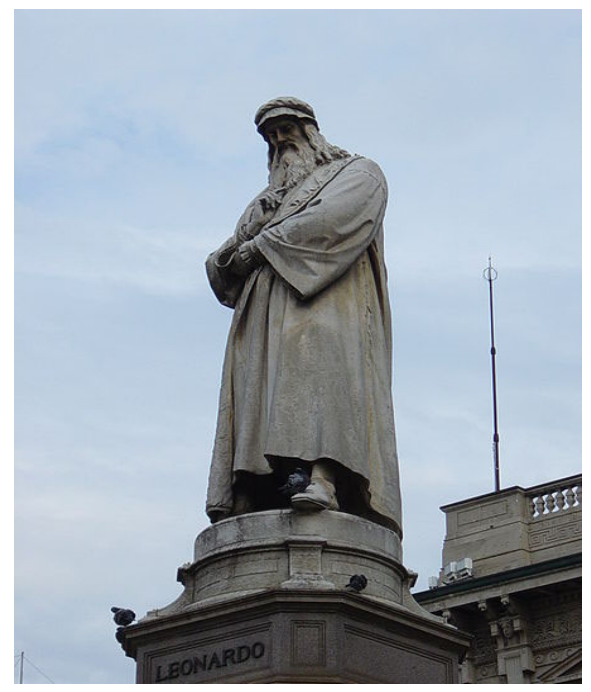

a) 


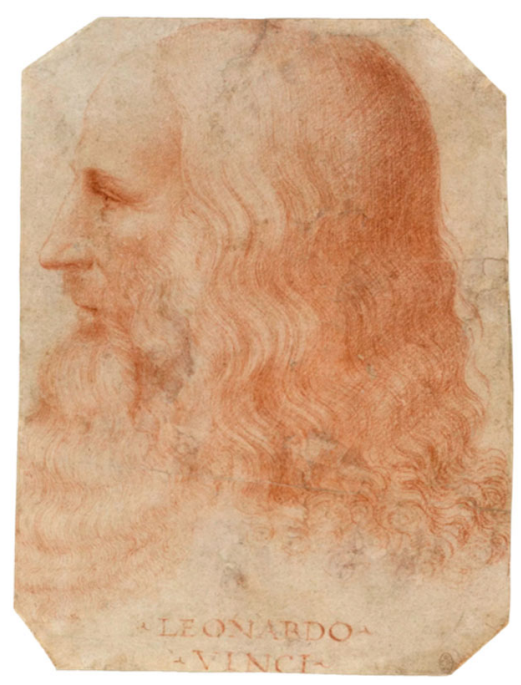

b)

Figura 1.1a) Monumento a Leonardo en la Piazza della Scala de Milán (origen de la imagen:

https://commons.wikimedia.org/wiki/File:2006_Milano_-

Da_Vinci_(2).jpg?uselang=es). b) Retrato de Leonardo realizado por su alumno Francesco Melzi (h.1493-h.1573) sobre 1517-1517; Royal Collection

(RCIN 912726) Reino Unido (origen de la imagen:

https://commons.wikimedia.org/wiki/File:Francesco_Melzi__Portrait_of_Leonardo.png?uselang=es

\subsection{Objetivo de la investigación}

Numerosos investigadores han definido a Leonardo como un excepcional diseñador, así el doctor e investigador en física subatómica de las Universidades de París, Berkeley y Stanford, y profesor en la Universidad de California, Fritjof Capra (Viena, 1939) y experto en biología y ecología, que ha estudiado el área ecológica de Leonardo y sus diseños mediante analogías, establece en su obra La Ciencia de Leonardo (2008): <<Los "buenos diseñadores" son capaces de pensar sistemáticamente y de sintetizar. Se destacan en la visualización de las cosas, en la organización de los elementos conocidos en nuevas configuraciones, en la creación de nuevas relaciones; y son capaces de transmitir esos procesos mentales en forma de dibujos casi con la misma rapidez con que se producen. Leonardo, por supuesto, tenía todas estas capacidades en altísimo grado. Además, poseía un misterioso talento natural para percibir y 
resolver problemas técnicos -otra característica clave de un buen diseñador-, a tal punto que, en su caso, era casi una segunda naturaleza >> (Capra, 2008).

Mientras que el profesor universitario, crítico de arte y director del "Museo Ideale Leonardo da Vinci", Alessandro Vezzosi (Italia, 1950), como experto generalista en la obra multidisciplinar del toscano, en su libro Leonardo, Arte y Ciencia del Universo (2011), manifiesta: $<<L a$ obra de Da Vinci es inigualable en la historia de la ilustración científica y tecnológica, no solo por su manera de exponer sus procedimientos sin demostraciones interminables y aburridas, sino también en tanto que obra de arte, "creación del diseñador">> (Vezzosi, 2011).

Al respecto de lo variado de los trabajos y profesiones de Leonardo, el historiador del arte y profesor de bellas artes en las Universidades de Oxford, Cambridge y Harvard, Ernst. H. Grombrich (Viena, 1909Londres, 2001), escribió: <<Príncipes y generales quisieron emplear a este extraordinario mago como ingeniero militar, para construir fortificaciones y canales, nuevas armas y otros descubrimientos. En tiempos de paz, Leonardo los entretenía con juguetes mecánicos de su invención e ideaba nuevas escenografías para espectáculos y procesiones. Era admirado como gran artista y buscado como músico habilísimo, pero, así y todo, pocos pudieron intuir la importancia de sus ideas y la amplitud de su conocimiento, porque Leonardo no publicó nunca sus escritos, y muy pocos pudieron conocerlos $>>$ (Grombrich,1951).

Mientras que la magnitud y calidad de la obra de Leonardo ha generado citas que llegan a asombrar: $<<$ Abarcó tanto, que muchos no creen que pudiera ser excelente en todo y haber profundizado con seriedad y rigor en tantos campos de la ciencia, la técnica y el arte. Pero el historiador del arte suizo Jacob Burckhardt (Basilea, 1818Basilea, 1897) ya en su obra "El Cicerón", Leipzig 1855 -Edición italiana, Florencia 1952-, manifestó sobre Leonardo: "No puede decirse de él que se haya dispersado, porque la actividad múltiple le era natural">> (Orlando, Cinotti, \& Rizzati, 1974).

Finalmente, cabe hacer constar lo que escribe, con referencia a los Cuadernos de Leonardo, la profesora en la Universidad de Palermo de Buenos Aires, María Cecilia Tomasini en su artículo Las máquinas de Leonardo da Vinci, en la revista Ciencia y Tecnología, $n^{0} 12$, de 2012, con relación a los contenidos de sus manuscritos de manera resumida: $<<$ En fin, la curiosidad y las inquietudes de Leonardo no tuvieron límite. Sus intereses lo llevaron a saltar, permanentemente, de un tema a 
otro, llenando sus cuadernos de bocetos y proyectos de la más amplia variedad. Así, en los Codex de Leonardo se suceden, sin solución de continuidad, estudios de facciones y expresiones, análisis de plantas y rocas, apuntes y bosquejos de sus cuadros, esquemas anatómicos y diseños de aparatos de la más diversa índole. Hoy en día sus dibujos nos siguen fascinando porque son el testimonio más claro de su inagotable e ingeniosa inventiva >> (Tomasini, 2012).

Pasados quinientos años desde la existencia del hombre considerado como el paradigma de la sabiduría universal, cabe preguntarse si sus planteamientos respecto al Diseño/Proyecto desde el punto de vista científico-técnico aún tienen validez, así como si han servido de base para el posterior desarrollo del complejo ámbito proyectual, y este es pues el objetivo principal de esta investigación.

\subsection{Antecedentes}

Los Manuscritos de Leonardo (también denominados Cuadernos), se componen de aproximadamente 7000 folios repartidos en 23 códices, los denominados: Codex Arundel (Londres, U.K.); el Códice Atlántico (Milán, Italia); los Manuscritos de Francia compuestos por 12 volúmenes (Paris, Francia); el Codex Forster compuesto por 3 volúmenes (Londres, U.K.); los Folios de la Colección "Windsor"(U.K.); el Códice del Vuelo de los Pájaros o de Turín; el Códice Trivulziano (Milán, Italia); los Códices de Madrid formados por 2 volúmenes (España) y el Codex Leicester o Hammer (Seattle, USA). Además de una cincuentena de hojas sueltas repartidas por varios museos y bibliotecas de varias ciudades de Europa y alguna de América.

En la figura siguiente, se muestran imágenes de dos de los Manuscritos de Leonardo, el Manuscrito F (1503-1507), de la Biblioteca del Instituto de Francia (París), con la demostración euclidiana del Teorema de Pitágoras y la contratapa del Códice de Madrid I, (h. 1493), de la Biblioteca Nacional de España (Madrid). 


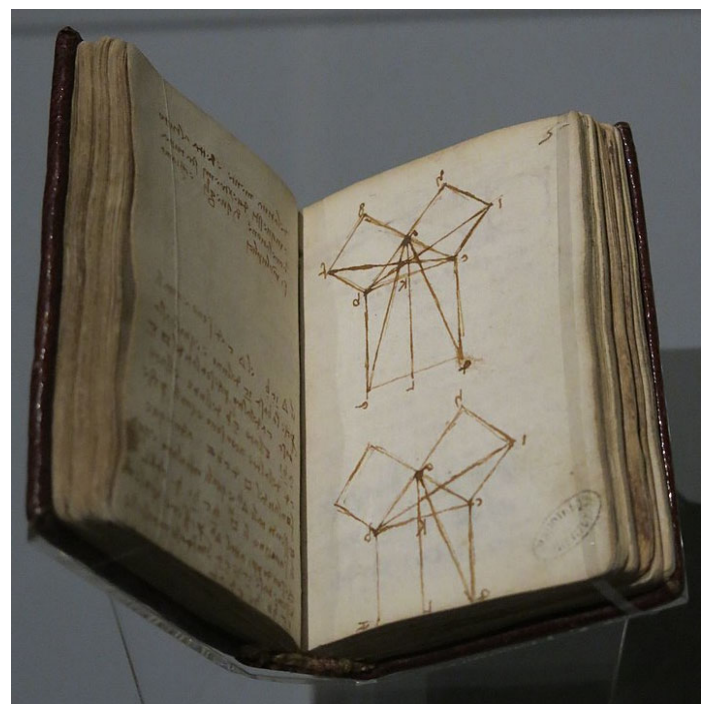

a)

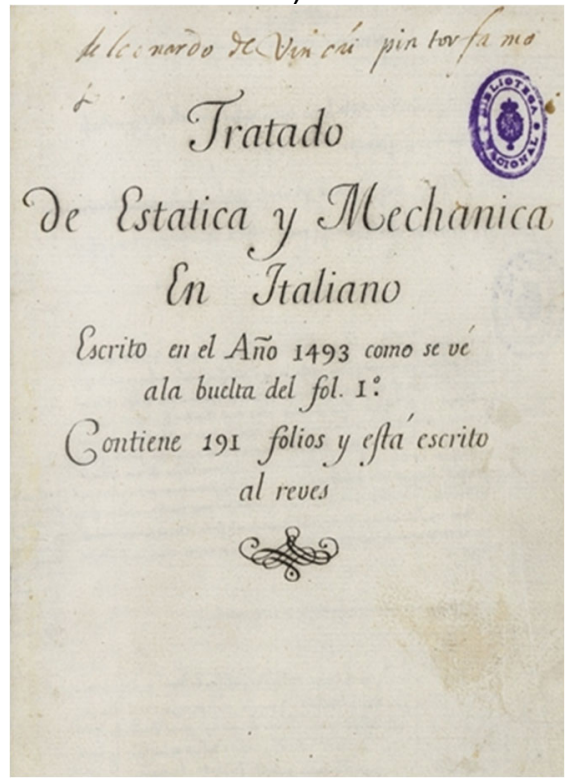

b)

Figura 1.2 a) Manuscrito F (1503-1507), de la Biblioteca del Instituto de Francia (Paris), con la demostración euclidiana del Teorema de Pitágoras (https://commons.wikimedia.org/wiki/File:Leonard_de_Vinci_D\%C3\%A9monstration_euclidienne_du_th\%C3\%A9or\%C3\%A8me_de_Pyt hagore.jpg). b) Contratapa del Códice de Madrid I, Biblioteca Nacional de España (http://leonardo.bne.es/index.html). 
Aunque a lo largo del contenido de esta tesis, sobre todo en los Capítulos 2 y 3 , se irán enumerando las investigaciones y a los investigadores e historiadores más reconocidos que han escrito sobre el dibujo, los diseños y las investigaciones de la obra técnico-científica de Leonardo, cabe adelantar unas someras matizaciones sobre el ámbito proyectual de la obra del toscano.

La escritora estadounidense y periodista especializada en medicina y ciencia, Claudia Kalb, se pronunció con respecto al conjunto de la obra manuscrita de Leonardo, en la revista National Geographic $<<$ Aunque sus pinturas son mucho más conocidas, la abundancia de manuscritos y dibujos que dejó son una ventana a los entresijos de su genialidad. Su mente fecunda -las hipótesis que testó, los viajes intelectuales, científicos y filosóficos que inauguró- queda patente en todas y cada una de las 7000 páginas conservadas en Windsor, en bibliotecas de París, Londres, Madrid, Turín y Milán, y en la colección de Bill Gates>> (Kalb, 2019).

De manera similar, el catedrático de historia del arte de la Universidad de Oxford, Martin Kemp (Reino Unido, 1942), y una de las máximas autoridades vivas sobre la ciencia y el arte de Leonardo, se expresa de esta manera en su libro "Leonardo" (2006): $<<$ Los manuscritos de Leonardo se han vuelto cada vez más comunes en los ámbitos académicos y públicos, al grado de que ahora los damos por sentados (justo como él lo hacía). No obstante, son sumamente excepcionales. Ninguno de sus predecesores o de sus contemporáneos produjo algo siquiera comparable con el vasto panorama, con el alcance, con la brillantez de la especulación y con la intensidad visual de sus cuadernos. Tampoco tenemos conocimiento de algo que realmente se pueda comparar con ellos en los siglos venideros... Un rasgo típico de su imaginación visual es que podía llevar a cabo "geometría tridimensional" mediante una forma de "modelación espacial" y escultural que operaba solo en su mente>> (Kemp, 2006).

Por otro lado y refiriéndose ya al ámbito específico del proyectodiseño, los investigadores e historiadores del arte italianos, Luca Antoccia, Andre Chastel, Marco Cianchi, Paolo Galluzzi, Domenico Laurenza, y Rodolfo Papa, en su obra "Atlas ilustrado de Leonardo da Vinci: Arte y Ciencia", se pronuncian como sigue: $<<E$ El dibujo como Proyecto: Leonardo se puede jactar de haber tenido la primacía indiscutible, que lo sitúa a la cabeza de los inicios de la ilustración científica moderna, nadie antes que él había sido capaz de exponer tan eficazmente en un dibujo un "proyecto técnico complejo">> (Antoccia y et al., 2003). 
$Y$ de similar manera se manifiesta el director técnico e investigador jefe del Centro Italiano de Estudios Leonardo 3, de Milán, Mario Taddei (1972), en su libro "Leonardo da Vinci, Autómatas y Robots", donde escribe: <<En este arte de describir las máquinas, Leonardo dejó una huella indeleble: liberó el dibujo de los vínculos que lo ataban a las artes figurativas, y lo transformó en instrumentos de estudio técnicocientífico de la gran máquina del mundo >> (Taddei, 2018).

Al respecto, ya el propio Leonardo escribió en sus Cuadernos de Notas: <<La ciencia instrumental o de las máquinas, es nobilísima, y útil más que todas las otras; por su mediación todos los cuerpos animados, capaces de movimiento, realizan operaciones>> (García, 2005).

Leonardo fue uno de los pioneros en incorporar texto a los folios de sus dibujos técnicos, como medida explicativa a sus diseños. Pero además fue el primero en añadir letras indicadoras sobre los dibujos para orientar en el diseño práctico y en las aclaraciones en las leyendas de estos (Mijksenaar \& Westendorp, 2000).

También en la línea de los proyectos/diseños de mecanismos y máquinas, el director del Instituto y Museo de Historia de la Ciencia de Florencia Paolo Galluzzi, en la introducción del libro "Las Máquinas de Leonardo" (2006) se expresa como sigue: <<El objetivo perseguido por Leonardo de proporcionar una representación precisa y absolutamente clara de la estructura y del funcionamiento de mecanismos extremadamente complejos, recurriendo a una serie de recursos gráficos (vistas en planta $y$ en alzado, vistas en transparencia, vistas de los componentes, simulación de cadenas cinemáticas, empleo del claroscuro para subrayar las superficies en contacto, esquematización de las líneas de fuerza, etc.) que nadie antes que él había concebido orgánicamente y, sobre todo, había aplicado conscientemente a un "proyecto de comunicación relativo al horizonte de la tecnología">> (Laurenza, Taddei, \& Zanon, 2006).

Y los historiadores de la ciencia, autores del último libro citado, Laurenza, Taddei y Zanon, se manifiestan en el mismo como: $<<L a$ confianza en el valor del dibujo como medio de comunicación relaciona a Leonardo con Taccola o con Francesco di Giorgio, pero Leonardo va más allá de la tradición que le había precedido no solo por la mayor calidad de sus dibujos o por las variadas e "innovadoras fórmulas visuales de presentación del proyecto" (imagen desde varios puntos de vista, representación en conjunto y de los componentes, etc.), sino también por la complejidad de los contenidos conceptuales 
expresados, a través del "lenguaje visual", por la máquina>> (Laurenza, Taddei, \& Zanon, 2006).

En la figura siguiente se pueden observar una máquina de elevar agua diseñada por el ingeniero sienés, Mariano di Jacopo, conocido como II Taccola (Siena, 1382-1453), y otras diseñadas por Leonardo en su Códice Atlántico folio $1069 \mathrm{r}^{1}$, con la diferencia de calidad, acabados, detalles, composición, etc. de manera manifiesta en favor de Leonardo.

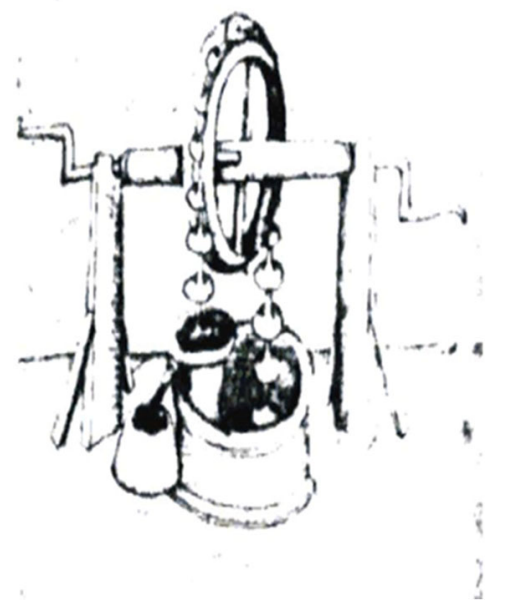

a)

${ }^{1}$ Nota: Las referencias " $r$ " $y$ " $v$ " junto a la denominación de los folios (f.) de los manuscritos o códices, se refieren a "recto" y "verso", es decir, al lado frontal y posterior de la hoja. 


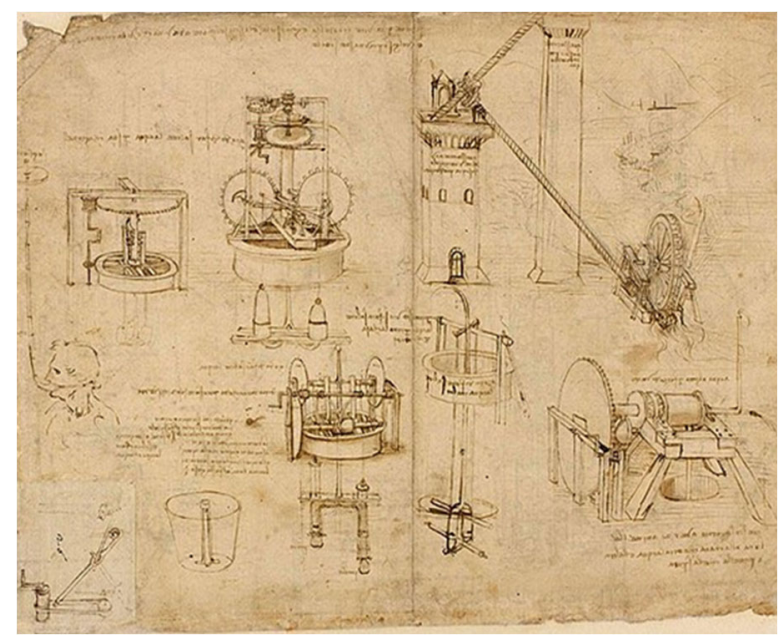

b)

Figura 1.3 a) Máquina de subir agua de II Taccola (h. 1433) (https://commons.wikimedia.org/wiki/File:Taccola_Tartar_pump_1433.jpg?us elang=es) b) Máquinas de bombear agua de Leonardo en Códice Atlántico f. 1069r. (https://commons.wikimedia.org/wiki/File:000R1069.jpg?uselang=es)

Finalmente, el ya citado Paolo Galluzzi en el apartado "Leonardo el tecnólogo" del Libro "Leonardo da Vinci" (2005), escribe: <<Si bien en realidad ha sido más oportuno destacar a grandes y originales ingenieros como Brunelleschi, Taccola o Francesco di Giorgio, por los que Leonardo sentía admiración, no hay que olvidar tampoco que éste cambió en un determinado momento radicalmente su modo de entender y ejercer la profesión de ingeniero, proponiéndose sustituir una cultura basada en la práctica y destinada a solucionar casos particulares por un "complejo de principios científicos universales" en los que basar siempre y de forma rigurosa cualquier solución técnica particular>> (Chastel, Galluzzi, \& Pedretti, 2005).

\subsection{Justificación de la investigación. Leonardo y el proyecto técnico}

Leonardo representa para el gran público el ideal del hombre renacentista, que destaca por su afán de conocerlo todo, los artefactos, el ser humano, la naturaleza, la Tierra, el universo. La gran cantidad de inventos, lo variado de sus investigaciones, la amplitud de 
su conocimiento, prueban su genialidad. La Tesis quiere incidir en realizar un recorrido principalmente por sus proyectos, sus máquinas, sus métodos, vinculados al mundo proyectual, pero también apoyándose, si puntualmente es necesario, en sus estudios anatómicos, botánicos, de óptica y perspectiva, o en sus bocetos y pinturas.

En el libro "Leonardo da Vinci, Arte y Ciencia" (2003), los historiadores italianos Luca Antoccia, Andre Chastel, Marco Cianchi, Paolo Galluzzi, Domenico Laurenza, y Rodolfo Papa escriben con referencia a una de las aportaciones de Leonardo con respecto a la representación proyectual de máquinas: <<Su originalidad consiste en la búsqueda de los "principios mecánicos generales" que rigen el funcionamiento de cualquier tipo de máquina, más que las fabulosas invenciones presentadas durante mucho tiempo como increíblemente precursoras $>>$ (Antoccia et al., 2003).

Mientras que el historiador italiano, considerado uno de los mayores expertos en los trabajos de Leonardo, y que fue titular de la Cátedra de Estudios Vincianos en la Universidad de California (UCLA), Carlo Pedretti (Casalecchio di Reno, 1928 -Lamporecchio, 2018), en su libro "Leonardo da Vinci, Las Máquinas" (2003), manifiesta: <<insiste en cómo representar la máquina en sus "elementos esenciales" y sin envoltorio, para que su funcionamiento se comprendiera rápidamente. Este se ilustra en el primer Códice de Madrid, en torno a 1497: "Y tales instrumentos se representarán en gran parte sin sus envolturas 0 cualquier otra cosa que pudiera interferir con el ojo del que los estudia">> (Pedretti, 2003).

\subsubsection{El Diseño Conceptual en Leonardo}

El diseño conceptual es la fase de análisis y síntesis del proceso de diseño en la cual se configuran las características y/o atributos teóricos y formales del producto a diseñar. Se busca encontrar los problemas esenciales, se establecen las estructuras funcionales y los principios de trabajo, hasta encontrar un principio de solución. Para ello se suelen utilizar ejercicios de abstracción.

Leonardo es visto como el primer proyectista que efectúa diseños conceptuales en la mayoría de sus diseños técnicos, así como en los bocetos iniciales de sus pinturas. Partiendo de la observación y apoyándose en la experimentación, Leonardo realiza propuestas formales de distintos diseños de productos y máquinas, que serán la 
base de estudios de detalle o incluso de prototipos posteriores, que en algunos casos llegaron a ser ejecutados (el primer automóvil conocido, el caballero-robot, el león mecánico, la ametralladora, algunos modelos de cojinetes y gatos de elevación, el diferencial, etc.). No obstante, pasados los años, con el progreso de la tecnología y los materiales, la mayoría de sus diseños innovadores, han ido adquiriendo la adecuada factibilidad (es el caso del paracaídas, el ala delta y el planeador, la estatua ecuestre denominada "el Caballo Sforza", etc.). En la figura adjunta se muestran planos de diseños conceptuales de Leonardo. El folio 847 recto del Códice Atlántico con "Bocetos de máquinas de elevar pesos" y el folio 577 verso, también del Códice Atlántico, con el "Boceto del Andamio para el Modelo del Caballo Sforza", previo para la construcción de la estatua ecuestre de gran tamaño que preparó para el Duque de Milán.

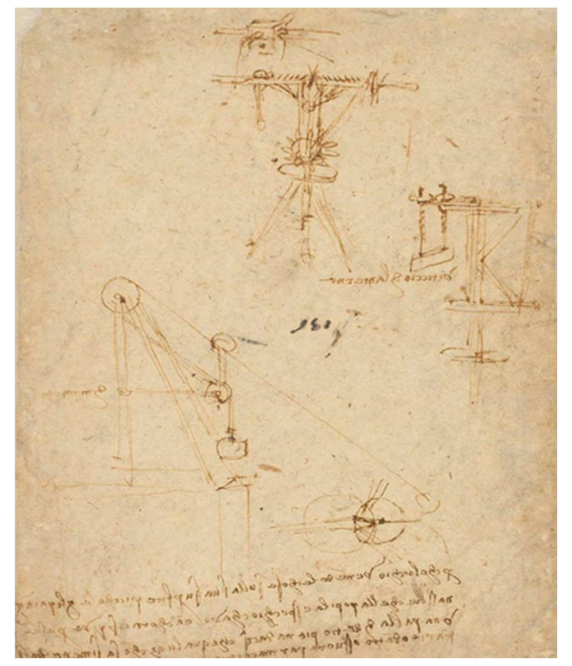

a) 


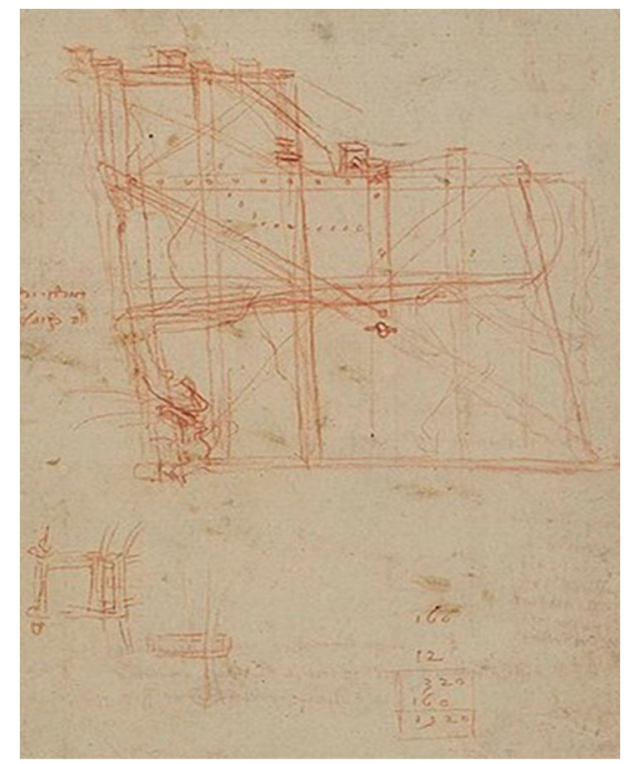

b)

Figura 1.4 a) Bocetos de máquinas de elevar pesos C. Atlántico, f. 847 r, (https://commons.wikimedia.org/wiki/File:Codex Atlanticus - 000R-

847.jpg?uselang=es). b) Boceto del Andamio para el Modelo del Caballo Sforza C. Atlántico, f. 577v, (https://commons.wikimedia.org/wiki/File:Codex Atlanticus - 000V-577.jpg).

Mientras que los diseños de detalle que realizó se cuentan a cientos. Muchos de ellos se irán mostrando a lo largo de la presente tesis, no obstante, a continuación, se muestran dos planos de diseños de detalle del Códice de Madrid I de Leonardo. El folio 22 recto muestra "el diseño de un molino de cereales y herramientas para enganche y elevación de cargas" y el folio 68 verso contiene "el proyecto de una máquina de hilar con doble volante". Es destacable el elevado nivel de definición respecto a los diseños conceptuales anteriormente expuestos. 
Objeto y Antecedentes

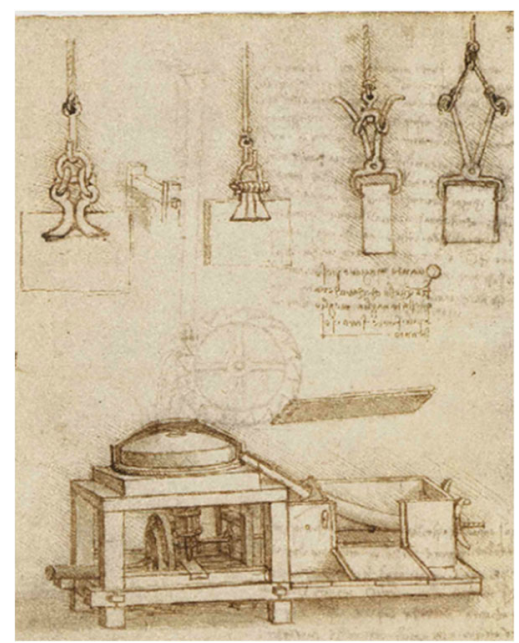

a)

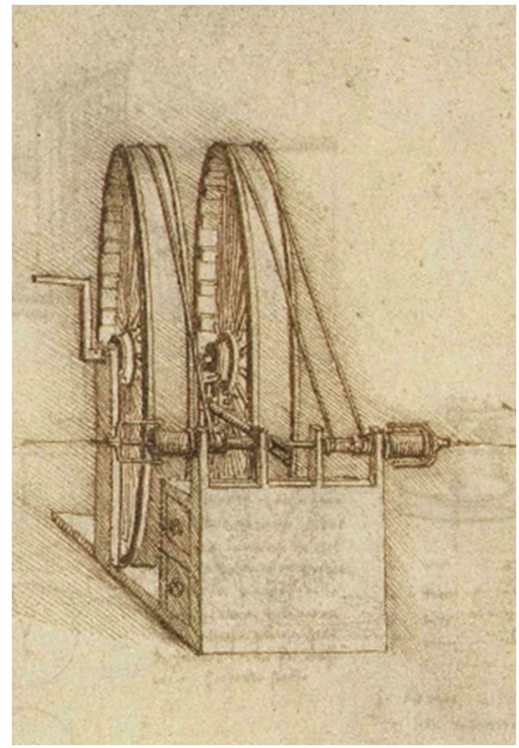

b)

Figura 1.5 a) Molino de cereales y herramientas para enganche y elevación de cargas C. Madrid I, f. 22r. b) Máquina de hilar con doble volante, C. Madrid. I, f. 68v. (http://leonardo.bne.es/index.html) 


\subsubsection{Las aplicaciones sistémicas y el diseño modular}

Otra de las facetas proyectuales en las que Leonardo se adelantó a todos fue en la capacidad de discernir los componentes sistémicos necesarios para el diseño de máquinas. Ello fue debido a compaginar sus diseños de máquinas con sus investigaciones anatómicas, mediante las cuales realizó a lo largo de su vida más de 30 disecciones de cadáveres humanos (a pesar de estar prohibido en su época) y un sinfín en varias clases de animales. A partir de ellas estableció un símil entre el cuerpo humano y sus partes y la máquina o artefacto. También se percató de las ventajas del diseño modular, cuando los técnicos predecesores y coetáneos solo entendían a la máquina en su conjunto, sin capacidad para visualizar ni discernir la potencialidad de sus componentes de carácter repetitivo para su uso en otros diseños diferentes.

Al respecto, los ya citados investigadores italianos Laurenza, Taddei y Zanon, en su libro Las Máquinas de Leonardo (2011), escriben: $<<$ Leonardo, que fue el primero en expresar la necesidad de un nuevo concepto de la "representación tecnológica entendida como diseño" de un marco cognitivo integrado, capaz de evidenciar al mismo tiempo el aspecto exterior de la máquina, los principios mecánicos que gobiernan su funcionamiento y la estructuración analítica de sus órganos. En esta concepción nueva del dibujo se identifica uno de los anticipos más pioneros, concretos y plausibles de muchas invenciones sorprendentes que han sido atribuidas a Leonardo: él fue primero en concebir el diseño de máquinas como un refinado instrumento de análisis y de investigación, incluso antes que de visualización, para finalidades puramente demostrativas >> (Laurenza, Taddei, \& Zanon, 2006).

De similar manera se expresa Alessandro Vezzosi, anteriormente citado, <<Para dibujar los aspectos más complejos de un bastidor o de un reloj, estudia sus mecanismos como si realizara una disección anatómica: descompone cada elemento e investiga de lo universal a lo particular, observa los movimientos y todos los fenómenos que se producen, de lo estático de la estructura a la dinámica de las funciones. Leonardo quiere conocer exactamente los materiales y las técnicas de construcción, las formas elementales, los datos esenciales y los principios >> (Vezzosi, 2011).

Mientras que observando de nuevo los textos de los investigadores e historiadores Laurenza, Taddei y Zanon, antes citados con relación al diseño de máquinas: <<Leonardo concibió el diseño de máquinas 
precisamente como instrumento para "analizar en sus partes componentes" los dispositivos más completos, diseccionándolos, por así decirlo, cuidadosamente, con el fin de conseguir una representación analítica y concisa al mismo tiempo>>.

Igualmente manifiestan: <<Otra "innovación" fundamental que Leonardo introduce es la de realizar un estudio que va más allá de la máquina en particular destinada a una función específica. Lleva a cabo un "estudio sistemático de los elementos básicos" que entran en la composición de cada máquina; el tornillo, la rueda, el muelle, los rodillos, las cuerdas, etc. Leonardo los llama "elementos maquinales".

La tendencia a estudiar los elementos fundamentales y comunes de cada máquina corresponde a una actitud general de la investigación de Leonardo. Por ejemplo, en anatomía, realiza también "estudios comparados", realizando comparaciones entre el ser humano y los animales o entre varias especies animales con el fin de identificar los rasgos biológicos fundamentales y comunes. >>, lo que viene hoy a conocerse como diseñar mediante analogías con la naturaleza (Laurenza, Taddei, \& Zanon, 2006).

A continuación, se muestra la imagen del folio $17 \mathrm{v}$ del Códice de Madrid I, en el que se pueden observar algunos de los "elementos maquinales" denominados así por Leonardo, para dar nombre a los componentes esenciales de una máquina. En concreto, figuran varios ajustes por engranajes helicoidales. Igualmente aparece una maqueta de uno de ellos, conformando una máquina de elevación de cargas. 


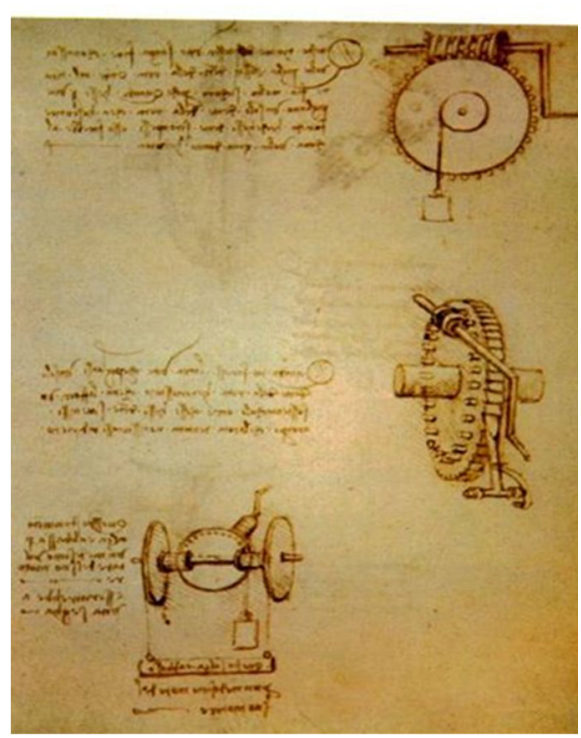

a)

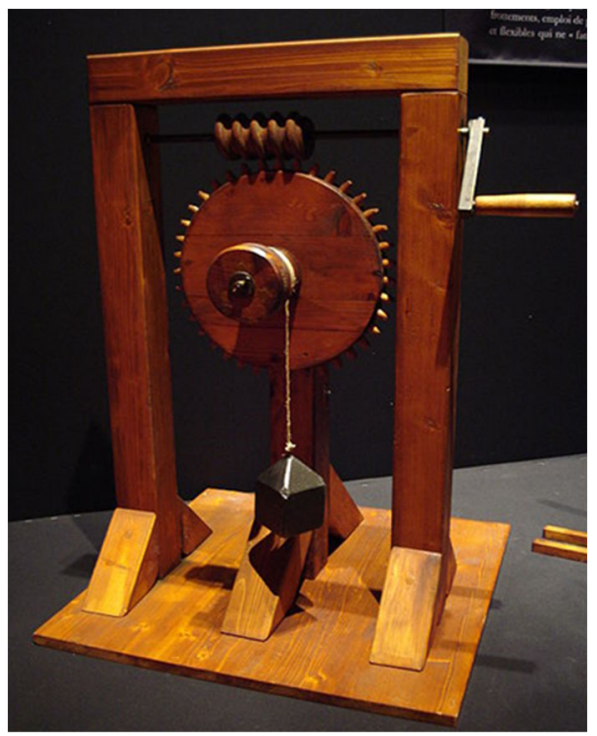

b)

Figura 1.6 a) Mecanismos con engranajes helicoidales, Códice de Madrid I, f, 17v, Biblioteca Nacional de España, Madrid.

(https://commons.wikimedia.org/wiki/File:M\%C3\%A9canisme_h\%C3\%A9lico idal-L\%C3\%A9onard.jpg?uselang=es). b) Maqueta del ajuste por engranaje helicoidal con elevación de cargas

(https://commons.wikimedia.org/wiki/File:Leonardo_Engranaje_helicoidal.jpg ?uselang=es)

De manera similar se expresa el profesor de la Facultad de Ciencias de Universidad Nacional Autónoma de México, J. Rafael Martínez Enríquez, en un artículo suyo de la Revista "Educación Matemática", manifestando claramente la búsqueda por Leonardo, de los elementos esenciales del diseño de toda máquina, y de las ventajas de su descomposición al llevar a cabo su proyecto: <<Basta con revisar el Códice Forster II y el Códice Madrid, colecciones de notas y grabados donde se ilustran los esfuerzos de Leonardo para explicar la construcción y funcionamiento de máquinas a partir de primeros principios. A partir de sus análisis, es posible deducir que Leonardo reducía las máquinas a veintiún modelos básicos que conformaban cualquier otro mecanismo>> (Martínez, 2010). 


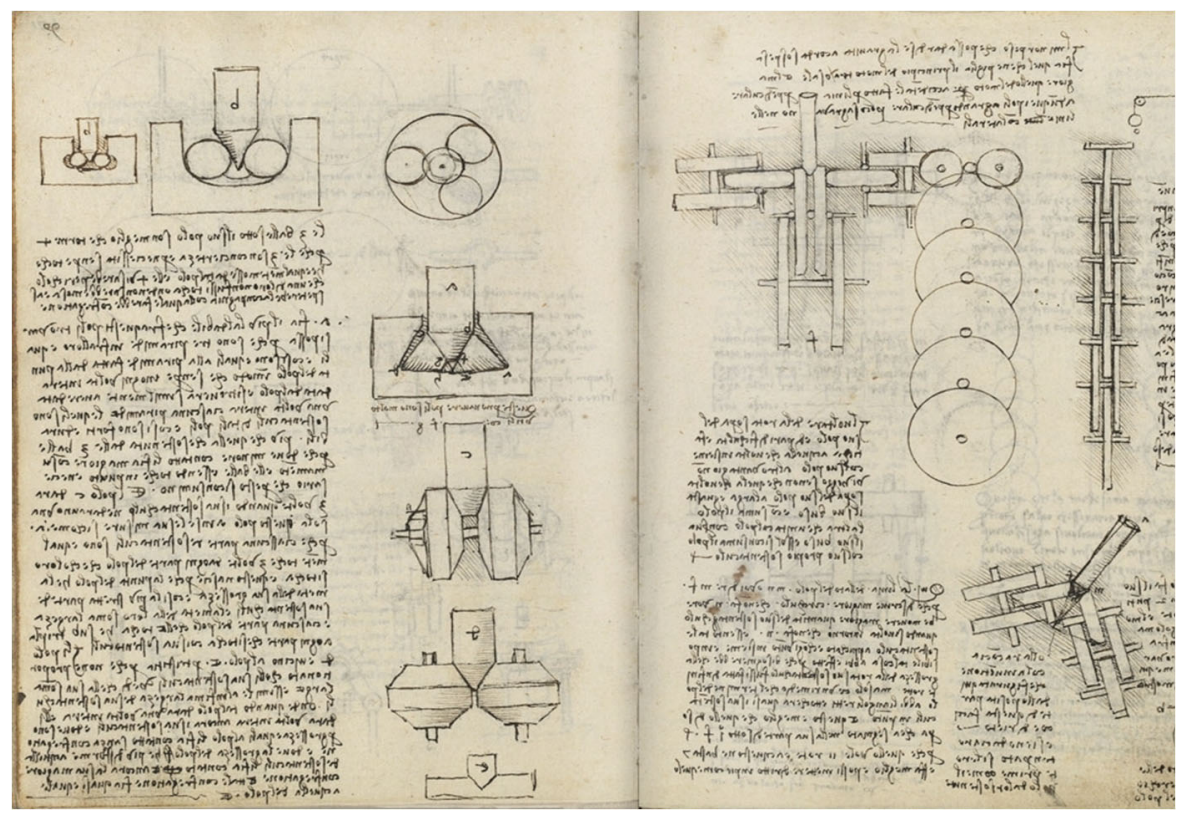

Figura 1.7 Cojinetes de distintos tipos y transmisiones mediante ruedas, C. Madrid I, f. 101v, 102r, (Biblioteca Nacional de España.

(http://leonardo.bne.es/index.html).

Y también el catedrático de Ingeniería de Fabricación de la Universidad de Zaragoza, Fernando Torres Leza, en el texto elaborado para la "presentación de la Exposición: Leonardo y las Ciencias", celebrada en Madrid en el Museo de la Ciudad, del 12 de septiembre al 15 de octubre de 2003, se manifiesta en el sentido del carácter sistémico y modular de las creaciones de Leonardo. Así se expresa: $<$ Por otra parte, Leonardo diseña diversos mecanismos predecesores de la electrónica. Interesado inicialmente por las máquinas como solución final para resolver las más variadas aplicaciones, pronto descubre que unos pocos "mecanismos elementales" son los constituyentes básicos de cualquier máquina compleja. 


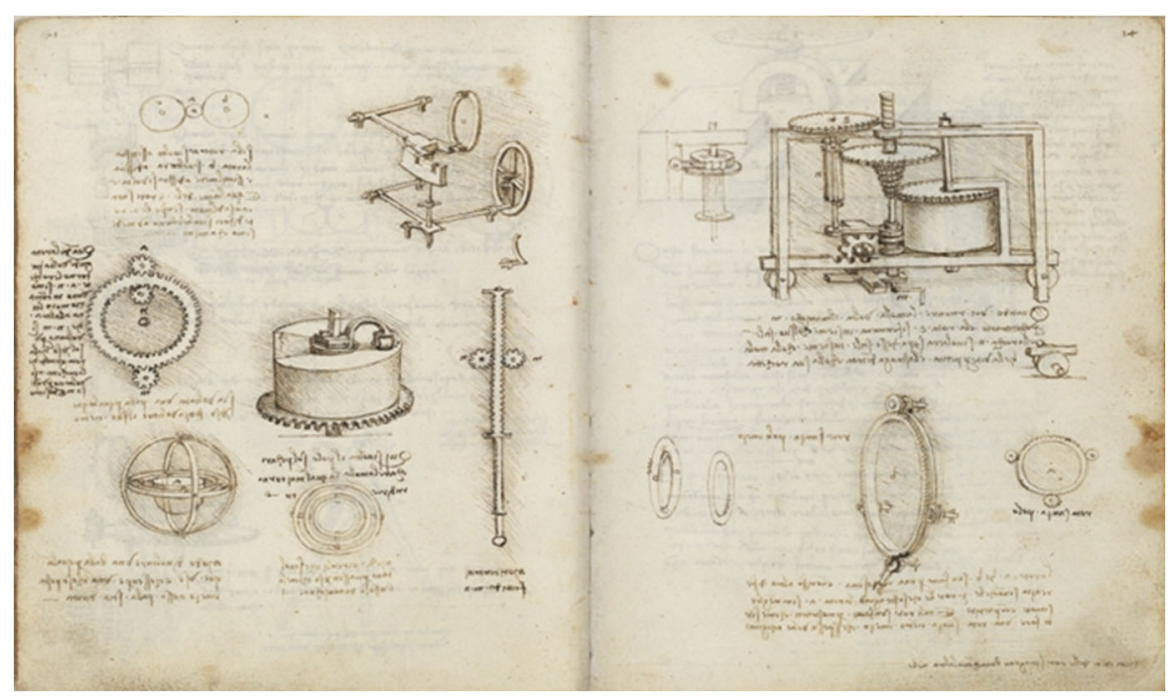

Figura 1.8 Proyecto de Mecanismos de relojería: Componentes sueltos y módulo del mecanismo, C. Madrid I, f. 13v y 14r. Biblioteca Nacional de España. (http://leonardo.bne.es/index.html).

Resulta interesante destacar que Leonardo elaboró cuadernos de notas de dos niveles y etapas científicas. Un primer tipo de cuadernos son los que reflejan a modo de diario sus observaciones en orden temporal; un segundo tipo de escritos constituyen verdaderos «libros» o síntesis monográficas sobre una materia. En este segundo grupo describe de modo sistemático los conceptos que explican claramente por qué (los principios físicos implicados) y proponen cómo (los procesos, los métodos) o con qué (los componentes tecnológicos) resolver de diversos modos el "problema analizado">> (Torres, 2003).

$<$ Para un mejor "diseño modular", reconoce las funciones de los mecanismos y los elementos capaces de llevarlos a cabo, diseñando con curiosidad y aplicación técnica todos ellos. Es un claro precedente para la versatilidad de diseño alcanzado hoy por la electrónica. Descubre nuevos elementos mecánicos, "de forma tan sistemática", que prácticamente establece un nuevo alfabeto de la mecánica. El Códice Madrid I es un excelente tratado de Mecánica, que bien podría hoy servir de introducción en nuestras universidades.>> (Torres, 2003).

En la imagen anterior puede observarse el perfecto conexionado entre piezas o partes para, una vez ensambladas, conseguir formar el adecuado conjunto o subsistema. 
Finalmente, también el escritor Charles Nicholls, en su libro "Leonardo, El Vuelo de la Mente" (2006), establece: <<El Códice de Madrid I se trata de un maravilloso manual de ingegni, un auténtico despliegue de trabajos de ingeniería a la carta: incluye telares, molinos de grano, prototipos de molinos de viento, una rueca provista de un mecanismo que devana la hebra automáticamente, varios mecanismos para elevar pesos, entre ellos una grúa cuyo gancho suelta la carga cuando esta toca el suelo, pero el tema principal del libro no son los inventos. Más que mostrar una serie de máquinas acabadas y listas para funcionar, Leonardo se centra en los "principios mecánicos y cinéticos" implícitos en ellas. Sus instrucciones tienen un marcado "carácter sistemático y práctico" enfocado hacia la situación real de una cadena de montaje. Nada se le pasa por alto: se ocupa de los tornillos y las tuercas; de las cadenas y las correas de transmisión; de las juntas universales y de las de codo; de los cojinetes de bolas y los de disco; de las roscas bidireccionales y de los engranajes epicicloidales>> (Nicholl, 2006).

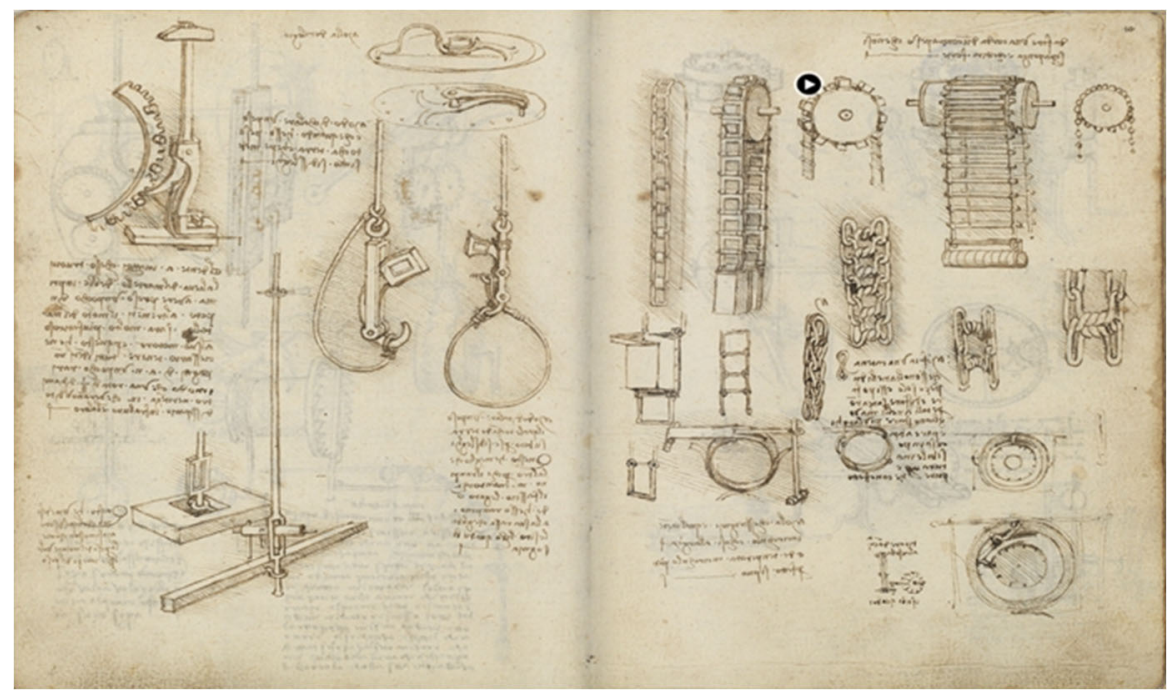

Figura 1.9 Ganchos para bajar pesos, que se sueltan la carga al tocar el suelo, y cadenas de transmisión y rueda como mecanismo de elevar agua, C. Madrid I, f $9 v$ y 10 r. Biblioteca Nacional de España. (http://leonardo.bne.es/index.html).

\subsubsection{La búsqueda de la automatización y la producción en serie en Leonardo}

Leonardo también fue precursor en el ámbito de la automatización utilizando como fuentes de energía, para sustituir las tareas del 
hombre, la gravedad y la fuerza del agua o del viento, generando máquinas y herramientas que disminuían la necesidad humana y aumentaban su producción. Así, creó ingenios para la incorporación automática del papel en la imprenta (tórculo de imprenta) a través de un mecanismo movido por la gravedad, mediante contrapesos; una sierra mecánica para madera a través de palas empujadas por la corriente da agua; un telar semiautomático, también movido por la fuerza de la gravedad mediante contrapesos y sin apenas casi intervención humana; etc.

Al respecto y siguiendo de nuevo a Vezzosi, $<<A$ propósito de la invención de la máquina de tejer mecánica, Leonardo escribe: "por importancia, va justo detrás de la imprenta, aunque no es menos útil para los hombres, puesto que es un invento más bello y sutil, portador de mejores beneficios". Esto prueba que merece su reputación de "profeta de la automatización" y de primer ingeniero del Renacimiento que se lanzó a estudios "por el progreso industrial". Se interesa en la tecnología, en particular en los "sistemas mecánicos y automáticos", ya que permiten "ganar tiempo y energía" e introducir innovaciones en los campos más diversos de la actividad humana. Anticipándose a la robótica, aplica a su proyecto de máquina de coser "principios de simultaneidad" y de serie que multiplicaban las capacidades de producción>> (Vezzosi, 2011). 


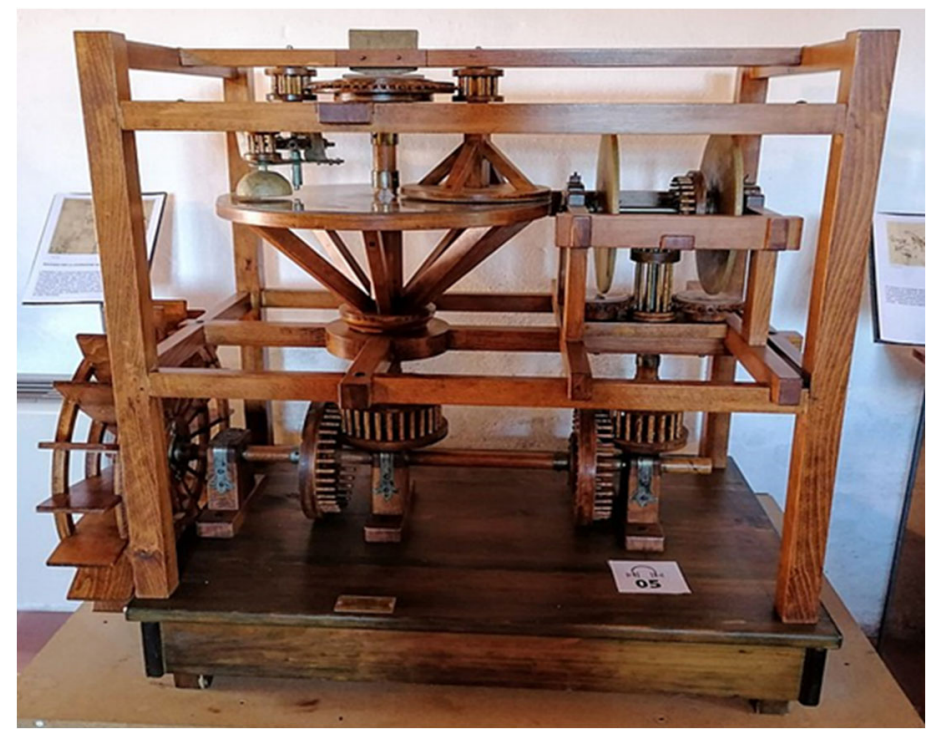

Figura 1.10 Máquina de pulir lentes, automatizada por una corriente de agua

(https://commons.wikimedia.org/wiki/File:Macchina_per_la_lavorazione_degl i_specchi_e_delle_lenti_di_Leonardo_da_Vinci_in_una_mostra_su_Leonard o_da_Vinci_al_Mulino_di_Mora_Bassa_-_Morabassa.jpg) (autor de la imagen: Capricornis crispus)

En la imagen anterior, puede verse la máquina de pulir espejos de manera automática. Las palas laterales, mediante el paso de agua, llevan a cabo el movimiento de rotación de su eje central horizontal inferior, que se solidariza con otro eje vertical engranado a él, y al que hace girar para que solidariamente también gire la mesa porta espejos. Igualmente se aprovecha dicho eje para elevar de nuevo el movimiento y, mediante una nueva rueda y engranaje de jaula, se consigue un nuevo movimiento en la parte superior del todo, con el fin de hacer también girar la muela horizontal de pulir espejos. De esta manera, la máquina realiza dos funciones de giro a la vez, el de la mesa porta espejos y el de la pieza que soporta el mismo. Así, la efectividad y rendimiento de la operación de pulido es mayor y sin necesidad de la intervención humana, ya que la energía proviene toda del movimiento de la corriente de agua. La máquina tiene en el lado derecho una solución similar pero apta para cuando la muela de pulir espejos trabaje en sentido vertical. Es pues claramente un proyecto de solución de automatización y de aumento de rendimiento y efectividad. 


\subsubsection{Las técnicas creativas en Leonardo}

Leonardo utilizaba cualquier medio a su alcance para plasmar sus ideas en el momento en que le llegaba la inspiración. Así, tal como se observa en la Figura 1.11, en un mismo folio refleja diseños de herramientas para uso en tareas agrícolas y dibujos de cómo utilizarlas, junto con un boceto de ventana palaciega de características góticas.

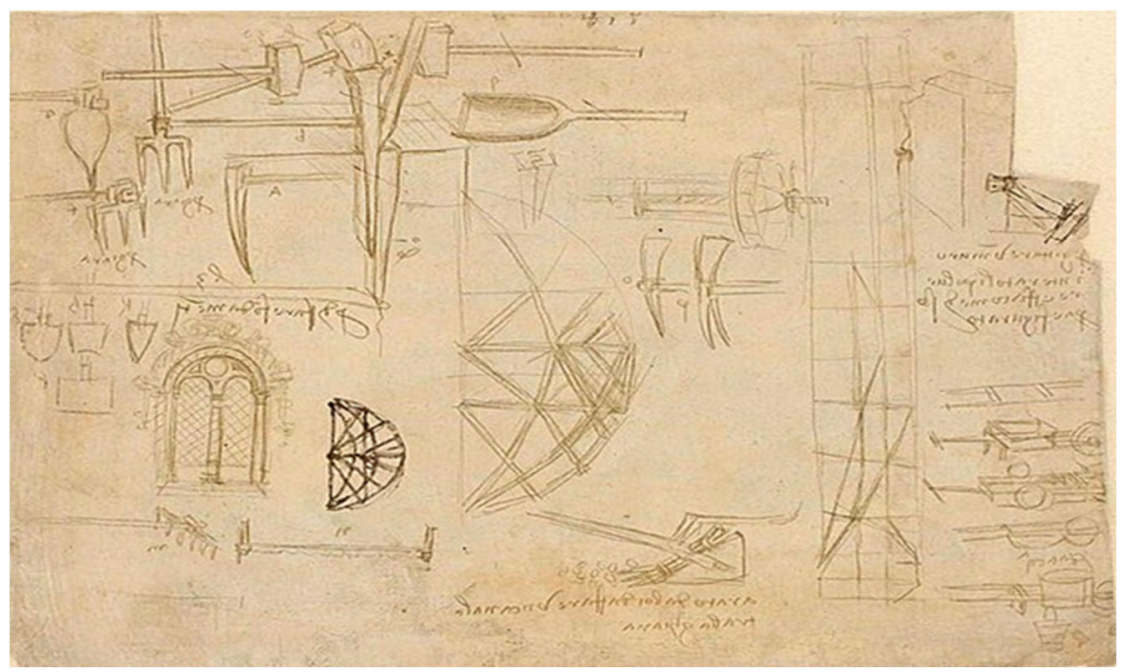

Figura 1.11 Dibujos de herramientas varias y Boceto de ventana palaciega

C. At. f. 809r (origen de la imagen:

https://commons.wikimedia.org/wiki/File:Codex_Atlanticus_-_000R809.jpg?uselang=es)

Al respecto, siguiendo al escritor y biógrafo Charles Nicholls : $<<E l$ proceso imaginativo de Leonardo, lo que él llama "el despertar de la invención", lo deja de manifiesto en el Manuscrito A de Francia (o BN 2038) folio 22v: "Contempla una pared cualquiera llena de manchas, $O$ una piedra con los más abigarrados dibujos, y encontrarás en ellas todo tipo de paisajes... batallas llenas de figuras que corren de un lado a otro, rostros de extraña a apariencia y atuendo: una infinita variedad de cosas que tú puedes convertir en representaciones precisas. Y lo mismo que ocurre con las paredes y las piedras, sucede con el sonido de las campanas, en cuyo repique descubrirás cualquier nombre que puedas imaginar >> (Nicholl, 2006).

La misma idea aparece con otras palabras en el Tratado de Pintura o Codex Urbinas Latinus 1270, folio 33v y 34 r, que redactó el pintor Francesco Melzi (Milán, h. 1493- Vaprio d' Adda, h. 1573) alumno 
preferido de Leonardo, con la recopilación de apuntes de su maestro: <<"La simple mancha que queda en una pared al arrojar contra ella una esponja empapada de colores nos permite descubrir un hermoso paisaje... Afirmo que un hombre podrá hallar en dicha mancha cabezas humanas, animales, batallas, rocas, mares, nubes, bosques y otras cosas similares". Mediante estas fantasías visuales y estos procesos de libre asociación Leonardo conseguía encauzar productivamente su faceta más soñadora y errátil: "las cosas confusas avivan la inventiva de la mente">> (Nicholl, 2006).

Y también lo corrobora el profesor universitario J. Rafael Martínez: $<<$ Un elemento central de lo que podríamos calificar como su "método de generación de conocimiento" es el acercamiento al fenómeno, la interferencia en su proceso o desarrollo y la construcción de instrumentos o estructuras que le permitieran interactuar de manera organizada con la Naturaleza. De esta práctica y de la importancia que le adjudicó, surgió la sentencia o aforismo de que "la experiencia es la madre de toda certeza..." (Leonardo 1982, Tratado de la Pintura, p.35)>> citado por (Martínez, 2010).

El que fuera escritor, economista y director de la Biblioteca Nacional de España, Luis Racionero (Seu d'Urgell, 1940-Barcelona, 2020), se pronunció en su libro "El desarrollo de Leonardo da Vinci" (1986), con respecto a su manera de generar ideas: <<Leonardo consideraba: "La sperieza, interprete fra l'artifitiosa natura e la umana spetie hombre" (la experiencia, intérprete entre la artificiosa naturaleza y el hombre). La experiencia contiene una actividad inductiva, una percepción que, como ha demostrado la teoría "Gestalt", incluye estructuras cognoscitivas previas existentes en el cerebro, que ordena el material perceptual al entrar en los sentidos. Leonardo tiene un pasaje famoso que anticipa en 400 años al test de Rorschach; dice así: "Método para fomentar la imaginación: si observas muros sucios de manchas o construidas con piedras dispares y te vas a inventar escenas, allí podrás ver la imagen de los distintos paisajes, hermoseados con montañas, ríos, arboles, llanuras, grandes valles y colinas de todas clases."

Leonardo se valió de este proceso para fomentar su creatividad..., ver en un caso cómo se mezclan los datos sensoriales con los a priori teóricos postulados por el cerebro, cuando se desea investigar; o bien abandonarse deliberadamente, en otros casos al mecanismo asociativo cuando se desea crear. Las manchas de las paredes servían de fondo nebuloso del cual emergían, en el duermevela de la imaginación, las formas de lo inventado. Fiel a este principio, Leonardo 
aconsejaba, para trazar los primeros esbozos de una obra, ser impreciso, libre y borroso. Las manchas de la pared eran sustituidas en sus apuntes por una telaraña de líneas que perfilaban y retocaban las ideas, hasta que, del garabateado boceto, emergía el perfil de la forma elegida. Es una "maniera libera de crear">> (Racionero, 1986).

En la figura siguiente se muestra como garabateaba Leonardo para conseguir la mejor forma en una pintura, en concreto un boceto inicial de La Virgen y el Niño con Santa Ana y San Juan (British Museum, Londres).

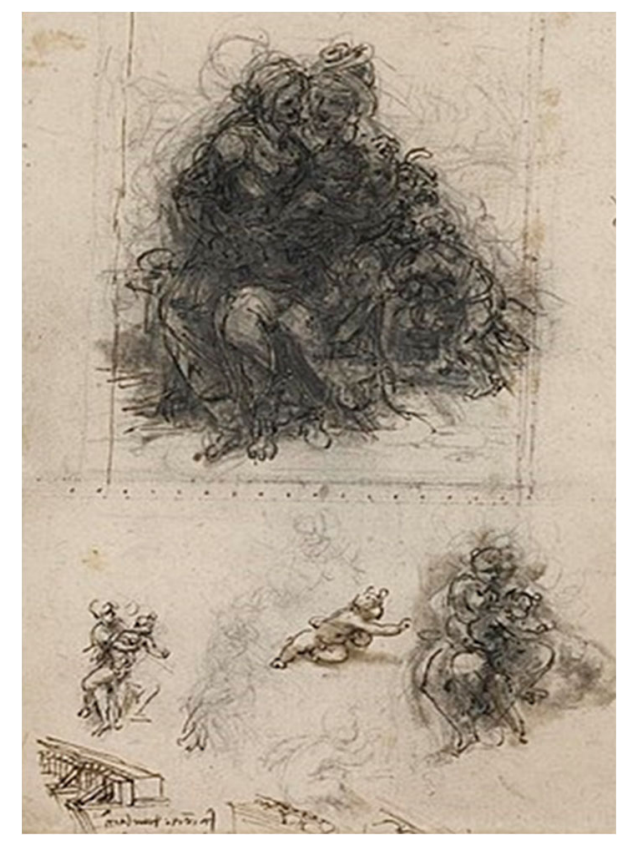

a) 


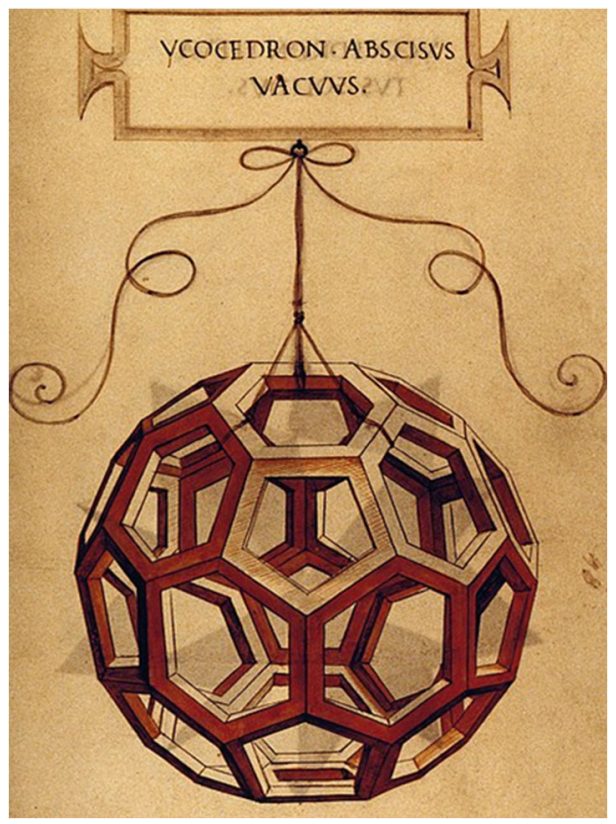

b)

Figura 1.12 a) Bocetos de La Virgen, el Niño, Santa Ana y San Juan, British Museum, Londres

(https://commons.wikimedia.org/wiki/File:Leonardo_da_Vinci__1875,0612.17,_Studies_for_the_Virgin_and_Child_with_St_Anne_and_the _infant_Baptist,_and_some_studies_of_machinery.jpg ). b) Dibujos geométricos de Leonardo para "La Divina Proporción", "el icosaedro truncado"(https://commons.wikimedia.org/wiki/File:Leonardo_Ycocedron_Ab scisus.jpg)

\subsubsection{El uso de las "analogías" por Leonardo}

Leonardo, en sus Cuadernos de Notas, escribe: $<<$ La naturaleza es la mejor maestra >>; <<La naturaleza es la fuente del conocimiento verdadero. Tiene su propia lógica, sus propias leyes, no tiene efecto sin causa ni invención sin necesidad >>, y $<<$ Nunca descubrirás invenciones más bellas, ni más simples, ni más breves que las de la naturaleza. Porque en todas las invenciones que ella lleva a cabo, nada falta ni nada sobra >> (De España, 1943). La Naturaleza fue una de sus principales causas de inspiración por lo que muchísimas veces la utilizó para buscar diseños mediante soluciones analógicas. 
En este sentido, Giselle Goicovic Madriaza, magíster en Educación docente durante años en las áreas de Diseño, Ingeniería y en la Formación de Profesores de Educación Tecnológica de la Universidad Tecnológica Metropolitana de Santiago de Chile, y autora de libros sobre pensamiento complejo, establece: $<<$ Dentro de los componentes cognitivos identificados en el proceso creativo de Leonardo (los pensamientos convergente, divergente y analógico), el tipo de pensamiento más relevante para los resultados creativos es el pensamiento analógico. Al estudiar los veinticinco códices, es posible encontrar cientos de analogías, muchas veces entre elementos distantes, lo que refuerza el poder creativo de Leonardo>> (Giocovic, 2015).

También el profesor Pedretti se pronunciaba en el mismo sentido: <<La mente analítica de Leonardo procede a base de "analogías": "Este pájaro se elevará y con el movimiento circular semejante al de un tornillo, realizará un movimiento reflejo contra el sentido del viento >> (Pedretti, 2003).

Con esta técnica, Leonardo diseñó su máquina de volar u ornitóptero, asimilada a la forma de los pájaros. Y también su planeador, asimilado a la forma de las alas de los murciélagos; y su ala delta asimilada a una pluma gigante. De todas ellas, la primera jamás funcionó por la imposibilidad de ser movido por fuerza humana, mientras que las dos siguientes, pasados los años y tras siglos de avances tecnológicos y de materiales, sí lo han conseguido. Hay un capítulo específico en esta investigación dedicado al diseño analógico en Leonardo.

Leonardo, además utilizó otras metodologías, métodos y técnicas proyectuales, que también se usan hoy en día, como la Ergonomía, la Ecología, o incluso el Método Científico 100 años antes que Galileo Galilei (Pisa, 1564-Arcetri, 1642) a quien se otorga el mérito de su invención. Y todas ellas se desarrollan a lo largo de los capítulos de la presente investigación.

Por todo lo expresado, puede concluirse el interés de profundizar en la visión del Proyecto/Diseño de esa mente privilegiada, que, aparte de su excepcionalidad como pintor y escultor, fue capaz de dominar la ingeniería militar, la arquitectura, el urbanismo, la botánica, la aerodinámica, la hidrografía, la mecánica, la música, la óptica, la astronomía, la anatomía, la zoología, la escenografía, la robótica, etc. Alessandro Vezzosi aún va más allá presentándolo como el creador de un nuevo "alfabeto tecnológico": $<<E l$ avión, el sumergible, el automóvil, el carro blindado, el ascensor e incluso la bicicleta.... A la 
luz de los trabajos recientes de los investigadores, hay que tomar distancias con el mito de un Leonardo sobrehumano, precursor, casi diabólico, autor de toda suerte de invenciones (incluidas entre ellas algunas que funcionaban desde hacía siglos). Sin embargo, no se puede negar la creación por Leonardo de un nuevo "alfabeto tecnológico">> (Vezzosi, 2011).

En conclusión, se pretende analizar la obra científico-técnica de Leonardo da Vinci desde la perspectiva del proyecto-diseño, tanto de manera directa, como a través de estudios previos realizados por autores de reconocido prestigio.

\subsection{Estructura del documento}

La presente tesis doctoral se ha estructurado en 14 capítulos y dos anexos.

En el presente capítulo se define el objetivo y justificación de la tesis así como su contenido y organización.

En el capítulo 2 se analiza las fuentes primarias de esta investigación, los manuscritos originales de Leonardo que han llegado hasta la actualidad, enumerando su datación, características físicas, localización y contenidos, destacando dentro de ellos los relacionados con el ámbito científico, técnico y proyectual. En el Anexo I se ha resumido en una única tabla la información básica de este capítulo.

Hasta finales del siglo XIX Leonardo era reconocido como un gran pintor del Renacimiento, pero tras el redescubrimiento y divulgación de su producción manuscrita, a raíz de los estudios publicados por el conservador del Museo del Louvre Charles Ravaisson-Mollien (18481919), comienza de nuevo el interés por la obra científico-técnica de Leonardo. El capítulo 3 se dedica a analizar las fuentes secundarias en las que se ha basado esta investigación doctoral, las principales publicaciones de algunos de los más reconocidos investigadores sobre la obra científico-técnica de Leonardo, incluyendo también los trabajos de otros autores que han profundizado en sus diseños más ingenieriles; y las exposiciones y museos en los que se encuentran las mejores maquetas y prototipos de los proyectos y artefactos diseñados por Leonardo.

El Capítulo 4 se ha dedicado a analizar cómo era el proceso de diseño en Leonardo, partiendo de algunos de sus proyectos principales (el desvío del Río Arno, el barco de Palas, el traje de buceo, el autómata, 
etc) y de los análisis de soluciones plasmados en sus manuscritos, para demostrar que Leonardo aplicaba un enfoque sistémico, fue un precursor del Método Científico, y empleó las analogías y otras técnicas proyectuales en sus diseños técnicos, asimilando los artefactos de creación humana al funcionamiento de los fenómenos naturales. Igualmente estableció su metodología de estudio, asimilable a la investigación experimental, fundamental para el desarrollo del método científico, y en sus inicios con el actual diseño conceptual.

El Capítulo 5 analiza el proceso intelectivo de Leonardo, las características de su pensamiento, el origen de su creatividad, curiosidad, capacidad de observación, imaginación e ingenio, disciplina y rigor, que lo convirtieron en un personaje con una inteligencia singular.

El Capítulo 6 persigue demostrar la superioridad documental de los diseños de Leonardo frente a sus coetáneos, utilizando la documentación (planos, requerimientos y especificaciones, instrucciones de construcción, montaje y operación, e incluso presupuestos) que elaboró para algunos de sus diseños técnicos, en los que realiza avances tan importantes que permiten calificarle como un precursor de la moderna documentación técnica habitual en los proyectos de ingeniería o arquitectura.

El Capítulo 7 estudia y presenta las contribuciones de Leonardo en el campo de las técnicas gráficas utilizados en los diseños técnicos y/o proyectos, incluyendo tanto las técnicas que inventó (diagramas de explosión, familias de recorridos, mapas a "vista de pájaro", perspectiva aérea etc.), como aquellas que rescató del pasado (el "escorzo", la distorsión de escalas, la "serpentinata", etc.) y las que mejoró (la perspectiva del color y la perspectiva menguante, las técnicas topológicas, etc.), explicando cómo las utilizó y mostrando ejemplos gráficos de las mismas.

El Capítulo 8 se dedica a presentar las contribuciones de Leonardo en el campo de los instrumentos de dibujo y diseño, tales como el compás de apertura ajustable, la creación de un compás parabólico o la creación de los primeros elipsógrafos, la mejora del prospectógrafo (que quedó para la posteridad como la "ventana de Leonardo"), e incluso odómetros y podómetros, profundizando en qué instrumentos gráficos son originales, cuáles suponen un desarrollo o mejora y cuáles recuperó de la antigüedad.

El Capítulo 9 analiza la técnica de creatividad y análisis y generación de soluciones en la que Leonardo alcanzó una gran maestría, el uso 
de analogías. Tras seleccionar algunos de los diseños de Leonardo más paradigmáticos, se expone cómo partiendo de la abstracción y análisis de elementos existentes, con formas parecidas o partes conocidas, y mediante la aplicación de relaciones de semejanza, Leonardo conseguía generar nuevas creaciones, tanto en objetos/artefactos, máquinas o sistemas.

El Capítulo 10 persigue demostrar que Leonardo fue un adelantado a su tiempo también en el pensamiento ecológico, introduciéndolo en lo relativo al diseño de objetos y artefactos, buscando más aprender de la Naturaleza que dominarla, no solo en sus diseños y proyectos sino en su propia forma de vida.

El Capítulo 11 se dedica a refutar la creencia generalizada de que la mayoría de los proyectos técnicos de Leonardo solo fueron plasmados en diseños conceptuales fruto de su imaginación y eran de dudosa viabilidad. En el mismo se demuestra con múltiples ejemplos (el higrómetro, el ascensor, el asador automático, su diseño de paracaídas, la escafandra de buzo, etc.) que gran parte de los diseños de máquinas y dispositivos de Leonardo, si bien no se sabe con certeza si llegaron a realizarse en su día, posteriormente se han construido y utilizado, desempeñando las funciones para las que el genio del Renacimiento los concibió.

El Capítulo 12 tiene como objetivo presentar cómo los enfoques presentes en el área de conocimiento de Proyectos de Ingeniería: el Diseño en Ingeniería, la Ingeniería de Proyectos y hasta cierto punto la Gestión de Proyectos, aparece en la obra de Leonardo, utilizando como ejemplo uno de los diseños técnicos más emblemáticos, ambiciosos y complejos de Leonardo, el monumento ecuestre denominado el "Caballo de Sforza".

El Capítulo 13 cierra el documento, realizando una síntesis de los hallazgos y resultados presentados en los anteriores capítulos, integrando cómo las aportaciones de Leonardo en relación a las técnicas gráficas, instrumentos de diseño, morfología documental, pensamiento sistémico, racional y experimental, diseño analógico, validación experimental de las soluciones de diseño, diseño analógico, diseño basado en la naturaleza y respetuoso con el entorno, y su capacidad para llevar a la práctica diseños funcionales y construirlos, etc., configuran su obra científico-técnica como crucial en el desarrollo de la disciplina de los proyectos de ingeniería.

El último capítulo es el de referencias. Si bien cada capítulo tiene sus referencias propias del capítulo, debido al origen como publicaciones 
independientes en congreso (véase Anexo 2), se ha elaborado un capítulo integrándolas todas como corresponde al documento de una Tesis doctoral.

Finalmente se incluyen dos Anexos. En el primero se hace una tabla resumen de los códices y manuscritos de Leonardo, ordenados por el país en el que actualmente se encuentran y sintetizando el contenido tratado en los mismos, de manera que presenta la información detallada en el Capítulo 2 de manera sintética y compacta, con el fin de facilitar la posible consulta a las fuentes primarias de esta investigación.

El segundo anexo se presenta otra tabla en la que se indica los datos de los congresos en los que se han publicado originalmente los capítulos 2 a 12, durante el periodo 2016-2021.

\section{Referencias}

Antoccia, L., Chastel, A., Cianchi, M., Galluzzi, P., Laurenza, D., \& Papa, R. (2003). Atlas ilustrado de Leonardo da Vinci: Arte y Ciencia. Susaeta Ediciones: Madrid. ISBN-84-305-3894-1.

Capra, F. (2008). La Ciencia de Leonardo. Editorial Círculo de Lectores/Anagrama: Barcelona. ISBN 978-84-672-3358-2.

Chastel, A., Galluzzi, P., \& Pedretti, C. (2005). Leonardo da Vinci. Ed. Planeta De Agostini: Barcelona. ISBN: 84-674-1371-9.

De España, J. (1943). Breviario de Leonardo da Vinci. Ed. El Ateneo: Buenos Aires.

Galvez, C., Mezquita, T. (2018). Leonardo da Vinci, Los rostros del Genio. Ed. Penguin Random House, Grupo Editorial: Barcelona. ISBN 978.84-03-53655-5.

García, E. (2005). Leonardo da Vinci, Aforismos, Círculo de Lectores. Ed. Espasa Calpe: Madrid. ISBN 84-672-1264-0.

Goicovic, G. (2015). Estrategias para el pensamiento complejo en estudiantes de pregrado basadas en el proceso creativo de Leonardo Da Vinci. Obtenido el 3 de marzo de 2018 desde www.ceuarkos.com/Vision_docente/index.htm)

Grombrich, E. (1951). Historia del Arte. Editorial Argos: Barcelona.

Kalb, C. (2019). Leonardo, La Eterna Genialidad. Artículo de la Revista National Geographic. 
Kemp, M. (2006). Leonardo. Ed. Fondo de Cultura Económica: México. ISBN-968-16-8010-3.

Laurenza, D., Taddei, M., \& Zanon, E. (2006). Las Máquinas de Leonardo. Susaeta Ediciones: Madrid. ISBN 84-305-5669-9.

Martínez, J. (2010). En busca de la razón del mundo: Leonardo, matemáticas y visualidad; Revista Educación matemática. vol. 22, n 1. México. ISSN 1665-5826.

Mijksenaar. P, \& Westendorp. P. (2000). Abrir aquí. El arte del diseño de instrucciones. Ed. Española: Madrid. Konemann Verlagsgesellschaft mbH; ISBN 3-8290-5433-5.

Nicholl, Ch., (2006). Leonardo, El vuelo de la mente. Círculo de Lectores S.A.: Barcelona. ISBN 84-672-1776-6.

Orlando, E., Cinotti, M., \& Rizzati, M. L. (1977). Grandes Maestros del Arte: Leonardo. Ed. Marín: Barcelona. ISBN 84-7102-125-0.

Pedretti, C. (2003). Atlas ilustrado de Leonardo da Vinci: Las Máquinas. Susaeta Ediciones: Madrid. ISBN-84-305-3894-1.

Racionero, L. (1986). El desarrollo de Leonardo da Vinci; Plaza y Janes: Barcelona. ISBN 84-01-35142-1.

Taddei, M. (2018). Leonardo da Vinci, Autómatas y Robots, Susaeta Ediciones: Madrid. ISBN-978-84-677-6361-4.

Tomasini, M. (2012). Las máquinas de Leonardo da Vinci. Ciencia y Tecnología. $\mathrm{n}^{\circ} 12$.

Torres, F. (2003). Leonardo da Vinci: Un modelo multidisciplinar abierto al mundo de hoy. Exposición "Leonardo y las Ciencias". Madrid. Museo de la Ciudad.

Vezzosi, A. (2011). Leonardo da Vinci, Arte y Ciencia del Universo. Ed. Blume: Barcelona. ISBN 978-84-8076-933-4.

White, M. (2003). Leonardo el primer científico, Random House Mondadori: México. ISBN 84-9759-578-5. 



\section{Capítulo 2 Análisis taxonómico de la obra escrita de Leonardo da Vinci}

"La mecánica es el paraíso de las ciencias matemáticas, ya que, a través de ella, uno percibe los frutos de las matemáticas". LEONARDO DA VINCI (Manuscrito E, folio $8 \mathrm{v}$, de la Biblioteca de Instituto Nacional de Francia, Paris)

\subsection{Introducción}

Aunque lo más conocido y admirado de Leonardo (Vinci, 1452Ambiose, 1519) son sus pinturas, quizás sus "manuscritos" de carácter técnico científico sean el patrimonio de Leonardo más respetado e investigado por la comunidad científica. El interés por estudiar su contenido surge a partir del siglo XIX cuando el historiador alemán Jean Paul Richter (Dresde, 1847-Lugano, 1937), en su libro The Literary Works of Leonardo da Vinci (1 ${ }^{a}$ edición 1883) (Richter, 1883), empieza a investigar con detalle el contenido de estos, encontrándose en ellos estudios matemáticos, de astronomía o perspectiva, proyectos arquitectónicos, diseños de máquinas de guerra, de apoyo a la construcción, industriales, de instrumentos musicales, estudios hidráulicos, anatómicos, entomológicos, geológicos, y botánicos, así como premoniciones, fábulas 0 estudios lingüísticos para autoaprendizaje del latín o anotaciones de su vida diaria, que aumentaron su concepción de "genio universal".

Así, la historiadora del Arte turolense y Directora emérita del Departamento de Manuscritos Incunables de la Biblioteca Nacional, Teresa Mezquita los define como $<<e l$ resultado de cuarenta años de incansable curiosidad, dibujando y anotando ideas y observaciones, más su potente capacidad de razonamiento, es un inmenso corpus de ingeniería, mecánica, física, hidráulica, anatomía, botánica, geometría, astronomía, música, óptica y otros muchos asuntos, incluso los lúdicos o "infinite pazzie">> (Gálvez et al., 2018).

Todos ellos suman 23 manuscritos autógrafos (aunque se saben varios desaparecidos) que conforman el Códice Arundel, el Códice Atlántico, los Manuscritos de París (12 códices), los Códices Forster 
(3 códices), el Códice o los Folios "Windsor", el Códice del Vuelo de los Pájaros, el Códice Trivulziano, los Códices de Madrid (2 códices) y el Códice Leicester, que suman un total de más 7000 folios reconocidos, en los que resaltan proyectos pioneros, como el primer vehículo capaz de moverse solo con motores de muelle; el de una estatua ecuestre de bronce de dimensiones colosales; el de desvío del río Arno con fines militares a su paso por Pisa; o diseños innovadores como un paracaídas, un submarino, o un traje de buzo-escafandra; o incluso un autómata en forma de león capaz de moverse y abrir su pecho mostrando un ramo de flores de lis. Además de proyectos de carácter urbanístico y constructivo como el de su "ciudad ideal" diseñado para la expansión de Milán, o el del Palacio de Romorantin, para el Rey de Francia, Francisco I (Cognac, 1494-1547, Rambouillet).

\subsection{Objetivo}

En este capítulo se pretende generar una descripción y clasificación sobre la vasta producción escrita y grafiada por Leonardo en sus manuscritos en el ámbito proyectual, y con contenido técnicocientífico, que ayuden a entender las características de sus trabajos proyectuales, posteriormente enumerando y clasificando los contenidos proyectuales de carácter técnico más importantes, existentes en cada uno de sus manuscritos. Para ello los manuscritos se encuadrarán en las siguientes Áreas Técnicas Proyectuales: Ingeniería Industrial, Ingeniería Civil, Ingeniería Naval y Aeronáutica, Ingeniería Militar y Arquitectura y Urbanismo. Finalmente se incluyen algunos ejemplos gráficos de ellos.

\subsection{Características generales de los códices}

La mayoría de la producción manuscrita por Leonardo está realizada de derecha a izquierda (letra especular), debido a que era zurdo. No obstante, cuando se dirigía por escrito a autoridades realizaba la escritura convencional, por lo que hay quien cree que Leonardo utilizaba la letra especular no solo por ser zurdo, sino para intentar esconder sus investigaciones y descubrimientos de posibles competidores. Así se manifiesta en el libro Leonardo: Arte y Ciencia; Las Máquinas: <<Esto puede ser debido tanto a que era zurdo como a cierto interés de "secretismo" $>>$ (Antoccia et al., 2003). 
Por lo general, Leonardo utiliza el italiano antiguo en la mayoría de sus textos: <<Leonardo fue el primer intelectual de su época que utilizo la lengua vernácula >> (White, 2003).

\subsection{Clasificación general de los Códices}

Los investigadores han optado por dividirlos por su "estilo" y diferenciarlos en cuatro tipos.

Los diarios de anotaciones, o "cuaderno de notas". Plasman la anotación de observaciones de su vida diaria, o acontecimientos especiales. Contienen temas variados que alternan con la aparición de dibujos o borradores sobre sus cuadros o sus diseños de máquinas, gráficos y fórmulas sobre sus investigaciones, 0 fábulas y premoniciones. <<Algunas hojas producen la impresión de haber sido elaboradas al ritmo que fluían las ideas a la mente de Leonardo, con independencia de su contenido >> (Ruiz \& Martínez, 2012).

Los tratados monográficos principalmente sobre una única materia. En algunos casos, Leonardo llegó a elaborar un verdadero tratado sistemático sobre una materia en concreto (o de algunas relacionadas), con textos y dibujos de gran calidad, lo que da a entender que Leonardo tenía voluntad de publicarlos, cosa que no se llegó a materializar. <<Estos manuscritos se caracterizan por unos cuidados dibujos que constituyen el núcleo de su pensamiento teórico y unas exposiciones complementarias que glosan la imagen con una intencionalidad pedagógica de cara al lector>> (Ruiz \& Martínez, 2012).

Los álbumes. Leonardo utilizó también hojas sueltas o fragmentos de papel para plasmar sus diseños o escribir sus pensamientos.

El escultor Pompeo Leoni, con miras a que no se extraviaran, las organizó en álbumes de gran tamaño, pegando los manuscritos sobre hojas en blanco adheridas a un soporte. Así se conformaron, por un lado, el Códice Atlántico, denominado así por su gran tamaño $(645 \mathrm{~mm}$ x $435 \mathrm{~mm}$ ), y por otro la Windsor Collection y finalmente el Códice Arundel, que no estaba formado por hojas sueltas sino por fascículos, con un tamaño medio de $220 \mathrm{~mm} \times 160 \mathrm{~mm}$.

Las hojas sueltas. Además, se conocen una cincuentena de hojas sueltas, dispersas en varios museos e instituciones de Europa (Pinacoteca de Munich, Escuela de Bellas Artes y Museo de Louvre de París, Galería de los Uffizi de Florencia, Universidad de Basilea; 
etc.); y Estados Unidos (Metropolitan Museum de New York) que plasman dibujos de máquinas, de anatomía, de armas, de arquitectura, notas sobre geometría, etc. y cuyo origen ha sido de desmembraciones de los Códices iniciales. Cabe destacar el diseño de "Carros de combate con Guadañas", f. 15583r (h. 1485) de la Biblioteca Real de Turín.

\subsection{Descripción detallada los Códices}

\subsubsection{El Códice Arundel}

Datación: Aproximadamente entre 1478 y 1518.

Ubicación actual: British Library (antigua biblioteca del British Museum) de Londres (U.K.).

Características físicas: Son 283 folios con formatos, en su mayoría de $220 \mathrm{~mm} \times 160 \mathrm{~mm}$.

Contenido general: Estudios de matemáticas, de física, de mecánica, de geometría, de pesos, de hidráulica, de óptica, de astronomía y de anatomía. Además de proyectos arquitectónicos y urbanos, diseños de máquinas voladoras, de guerra, y armas.

Contenido de ámbito técnico-proyectual destacable:

a) Ingeniería Industrial: "Estudio para montaje teatral del Orfeo de Poliziano", f. $224 r$ y $231 v$ (1506-1508). "Diseño de compás para epicicloides", f. 160v (1490-1499). "Diseño de Máquina para tallar espejos cóncavos y diferencial de ruedas de un carro", f. 17v (1478-1480).

b) Ingeniería Civil: "Estudio de pesos y rozamiento en plano inclinado", f. 40v (1493). "Estudios sobre grietas y roturas de muros", ff. 138r, 141v, 157r y 157v (h. 1506).

c) Ingeniería Naval y Aeronáutica: "Proyecto de Equipo para buzo", f. 24 v (h.1502).

d) Arquitectura y Urbanismo: "Estudio para el Palacio Real y la ciudad nueva de Romoratin", ff. 269r y 270v (1514-1518). "Estudio para su pabellón de planta central", f. 270v (1518). "Estudios de casa de tres niveles, terraza y cubierta a dos aguas", f. 126r (h. 1503). 


\subsubsection{El Códice Atlántico}

Datación: desde 1478 a 1518.

Ubicación actual: Biblioteca Ambrosiana de Milán (Italia).

Características físicas: Encuadernado por Leoni mediante 401 hojas, aunque ha sido reorganizado modernamente, para hacerlo accesible quedando formado por 1119 folios distribuidos en 12 tomos. El nombre proviene del gran tamaño de sus páginas que se utilizaban para dibujar mapas. Un pliego de papel entero y sin pliegue, se le denomina "formato atlante" (Ruiz \& Martínez, 2012), con dimensiones de $645 \mathrm{~mm}$ x $435 \mathrm{~mm}$.

Contenido en general: La mayor documentación técnico-científica; más de 1000 folios de documentos redactados durante casi toda su vida, y de variado contenido: estudios de matemáticas, geometría, mecánica, óptica, teoría de la luz, perspectiva, hidráulica, arquitectura, geografía y mapas, astronomía, botánica, zoología, anatomía y arte militar.

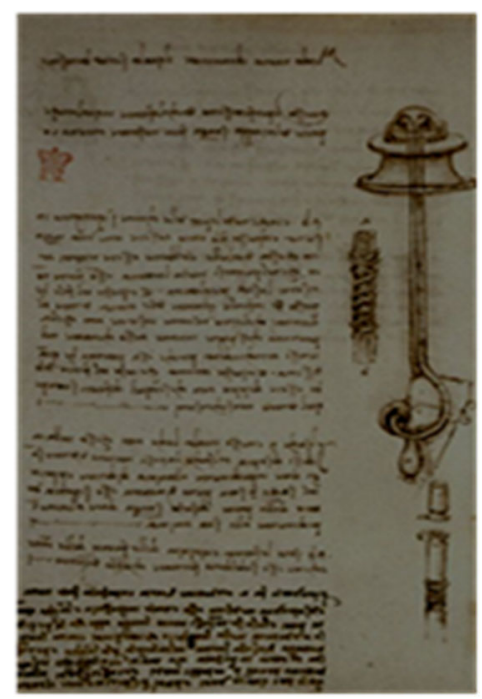

a)

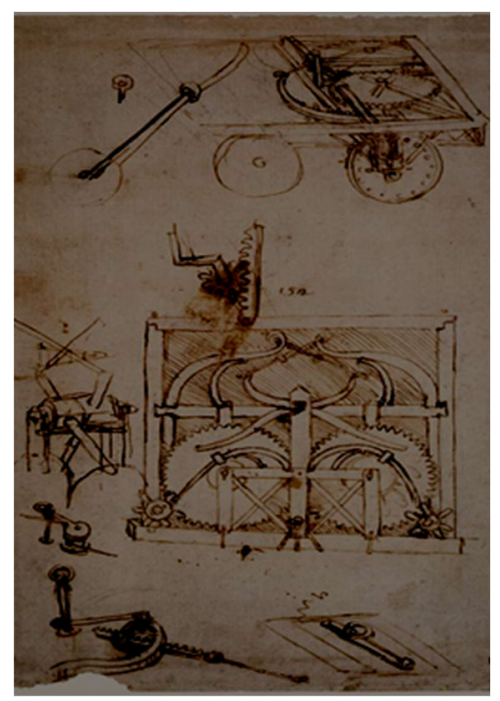

b)

Figura 2.1 Proyecto del equipo buzo, C. Arundel, f. 24 v (h. 1502) (https://commons.wikimedia.org/wiki/File:Codex_arundel.jpg), b) Proyecto de automóvil, C. Atlántico, f. 812r (h. 1478)

(https://commons.wikimedia.org/wiki/File:Leonardo_da_vinci,_Automobile.jp g?uselang=es). 

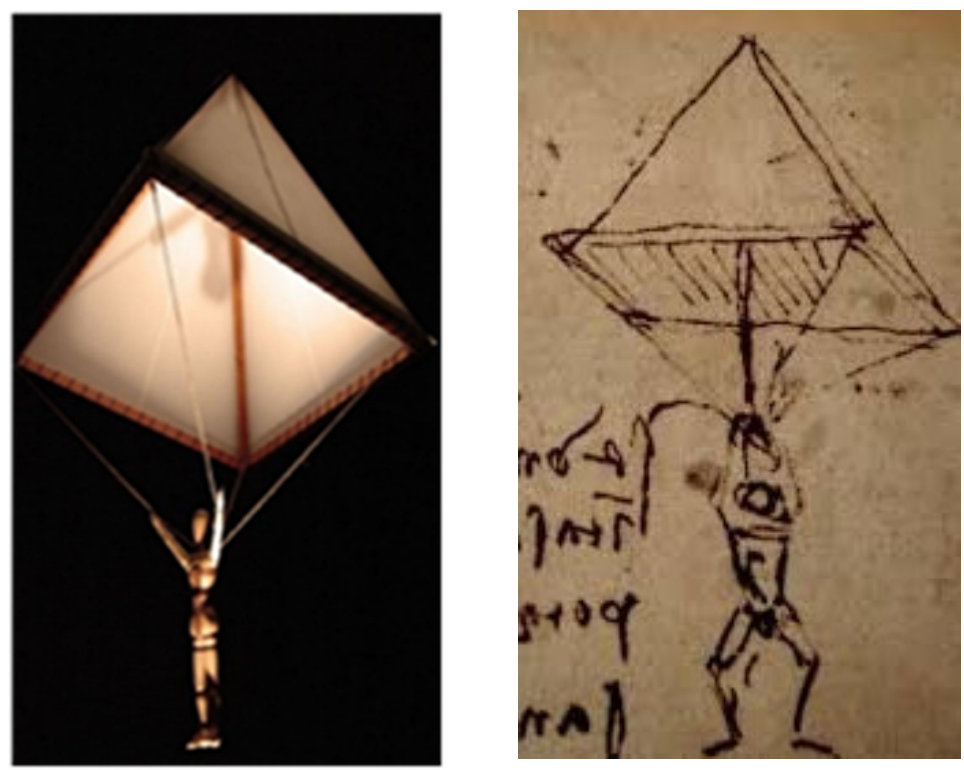

Figura 2.2 Maqueta del paracaidas de Leonardo

(https://commons.wikimedia.org/wiki/File:Leonardo_da_Vinci_parachute_04 659a.jpg) y boceto de paracaídas C. Atlántico f. $1058 \mathrm{v}$ (h. 1485)

(https://commons.wikimedia.org/w/index.php?title=Category:Codex_Atlanticu s_(codex-atlanticus.it)\&fileuntil=000V-1082.jpg\#/media/File:000V-1058.jpg).

Contenido de ámbito técnico-proyectual destacable:

a) Ingeniería Industrial: "Máquinas de elevar agua con norias y Tornillos de Arquímedes", f. 7v, (1480-1482). "Máquina con Tornillos de Arquímedes y bombas para subir agua", f. 59v (h. 1485). "Telar semiautomático", f. 106r (1490). "Proyecto de máquina tundidora mecánica f. 1105r (h. 1495). "Estudio de máquina textil", f. 356r (h. 1495). "Máquina de fabricar cuerda", f. 2v (1513-1516). "Proyecto de Tambor automático", f. 837r (15031505). "Proyecto de Piano-Viola automática", f. 93r (1493-1495). "Proyecto de Odómetro para medición de grandes distancias", f. 1 br (h. 1504). "Diseño de Compás de varillas", f. 696r (1514-1515). "Proyecto de automóvil o vehículo automotor", f. 296v (1478-1480). "Proyecto para automóvil visto en perspectiva", f. 812r (14781480). "Proyecto de Máquinas para fabricar espejos cóncavos y planos", f. 1101v (h.1500) y f. 87r (h. 1480). "Máquina de 
movimiento alterno", f. 30v (1478-1480). "Máquina de entallar limas", f. 24r (sobre 1480).

b) Ingeniería Civil: "Dibujos y estudios sobre trazados de arcos y sus cimbras para procesos constructivos", f. 535r y 200r (h. 1506). "Proyecto del Canal de irrigación de San Cristofono", f. 395r (1509). "Proyecto de Gran grúa excavadora de canales", f. 4r (1503-1504). "Estudio para una grúa de giro pivotante", f. 349r (1482). "Proyecto de Puente giratorio", f. 885r (1487-1489). "Plano hidrográfico para la Ciudad de Romorantin", f. 920r (h. 1517). "Proyecto para adoquinado de las canalizaciones a la entrada de una ciudad", $f$. 935r (h. 1510). "Estudio de sistema de exclusas para navegación fluvial", f. 90v (1480-1482). "Proyecto de galería subterránea preparada para ser inundada", f. 1000r (h.1480).

c) Ingeniería Aeronáutica y Naval: "Proyecto de Máquina de volar", f. 858r (1488-1489). "Ensayos de ala articulada", f. 844r (1508). "Proyecto de Barco de palas", f. 945r (1487-1489). "Boceto de Paracaídas", f. 1058v (1485). "Estudio de embarcación sumergible", f. 881r (1485-1487). "Proyecto del Puerto de Civitavecchia", ff. $63 v$ y $271 \mathrm{r}$ (h. 1513).

d) Ingeniería Militar: "Máquina para defensa de fortificación" f. 119r (1478-1515). "Proyectos de Catapultas", ff. 140ar y 140br (14851490). "Estudio de Ametralladora", f. 32r (h. 1482). "Diseño de Bombarda múltiple", f. 1ar (1503-1505). "Proyecto de fortaleza circular", f. 132r (1502). "Estudio para Máquina de guerra con 16 ballestas", f. 64v (1485). "Estudio de la Fortificación Campali", f. 41v (1504-1508). "Proyecto de fortaleza de planta cuadrada" en $\mathrm{f}$. $117 r$ (h. 1502). "Diseño de un mortero", f. 59v (h. 1485). "Estudios de fortificaciones", ff. 43v y 362v (h. 1490). "Diseño de Espingarda", f. $32 r$ (h. 1482).

e) Arquitectura y Urbanismo: "Proyecto segundo de expansión de la ciudad de Milán" f. 65v, 73v, 75v y 77v (h. 1493). "Estudios para fuentes", f. 80r y 293r (1487-1490). "Estudio de Planta central de una iglesia" f. 962r (h. 1488). "Proyecto arquitectónico de la Casa Guiscardi en Milán", ff. 158r y 158v (h. 1497). "Estudios para Pabellón de madera desmontable", f. 1283r (h. 1494). "Proyecto para ampliación de la Villa de los Melzi en Vaprio d'Adda", f. 395r (h. 1513). "Proyecto para los Establos de los Medici", f. 96v (15151516). "Proyecto para el Palacio de Romorantin", ff. 74v, 76v y 217v (1512-1518). 


\subsubsection{El Códice o Los Folios de Windsor (Manuscritos de Anatomía y Dibujo)}

Datación: Aproximadamente desde 1478 a 1518.

Ubicación actual: Biblioteca del Castillo Real de Windsor (Royal Collection, Reino Unido).

Características físicas: Comprenden cerca de 600 diseños que inicialmente Leoni encuadernó en 234 hojas y que en 1994 fueron desmontadas de la encuadernación original para facilitar su visión y conservación. Se convirtieron así en 604 folios de diferentes dimensiones que han quedado entre planchas de plástico acrílico, organizando por temas y cronología. La primera sección está formada por Dibujos y Temas varios de 452 folios, y la segunda por los Dibujos Anatómicos de 152 folios (Ruiz \& Martínez, 2012).

Contenido en general: La sección de Anatomía consta de alrededor de 200 dibujos de gran calidad que grafían las reflexiones científicas de Leonardo sobre el cuerpo humano, después de haber diseccionado más de 30 cadáveres humanos y varios animales. A esta sección le siguen los Paisajes. Finalmente, hay "Hojas misceláneas" que contienen material vario.

Contenido de ámbito técnico-proyectual destacable:

a) Ingeniería Industrial: "Estudios de un reloj hidráulico", RLW 12688 y 12716 (1508-1510). "Estudio de los Hornos de fundición para el monumento Sforza”, RLW 12379 (h. 1492).

b) Ingeniería Civil: "Estudio de las corrientes de agua en canales superando obstáculos y sus vórtices", RLW 12660v (1510-1513). "Estudio sobre el agua de escorrentía", RLW 12662r (1510-1513). "Estudio para desecación de pantanos", RWL 12689 (1514). "Mapa de la Toscana, Lago Trasimeno y Valle de Chiana", RLW 12278, (1502). "Mapa de Arezzo y valle de Chiana", RLW 12682 (1502). "Proyecto de desviación del rio Arno", RLW 12680 (1503). "Mapa de la costa entre Roma y Nápoles a Vista de Pájaro", RLW 12871 (h. 1515).

c) Ingeniería Naval y Aeronáutica: "Diseños de cañones para artillería naval”, RLW 12632r (1487-1490).

d) Ingeniería Militar: "Estudio para fabricación de varios tipos de cañones", RLW 12652r (1485-1490). "Estudio para carro blindado y caballero con escudo y lanza", RLW 12653r (1485-1488). "Estudio cartográfico para la roca y la Fortaleza de Imola", RLW 
12686r (h. 1502). "Diseños de fabricación de cañones en una fundición", RLW 12647 (1487-1490). "Estudio de la fortaleza estratégica de La Verruca", RLW 12683 (h. 1502). "Plano de la ciudad amurallada de Imola" RW 912284 (h. 1502). "Plano de la Ciudad amurallada de Imola”, RLW 12284 (h.1502).

e) Arquitectura y Urbanismo: "Estudios para fuentes sobre pilastras", RLW 12690r y 12691r (1511-1513). "Estudio del ábside de una iglesia", RLW 12609v (1485-1490). "Estudio de una iglesia de planta central", RLW 19134v (h. 1488). "Estudio para una Villa urbana monumental para Charles d' Amboise", RLW 12591r (h. 1508). "Estudio de la Perspectiva del Palacio de Romorantín y estudio del Monumento Trivulzio", RLW 12292v (1517-1518). "Bocetos para el monumento funerario del Mariscal Trivulzio, RLW 12353, 12355 y 12356 (1487). "Estudios para una Villa y un Jardín para el marqués de Mantua", RLW 12689 (h. 1500). "Proyecto de ampliación de la Villa de los Melzi en Vaprio d'Adda", RLW 19107 (h. 1513). "Propuesta de Plan Urbanístico para Florencia", RLW 12681 (h. 1482).

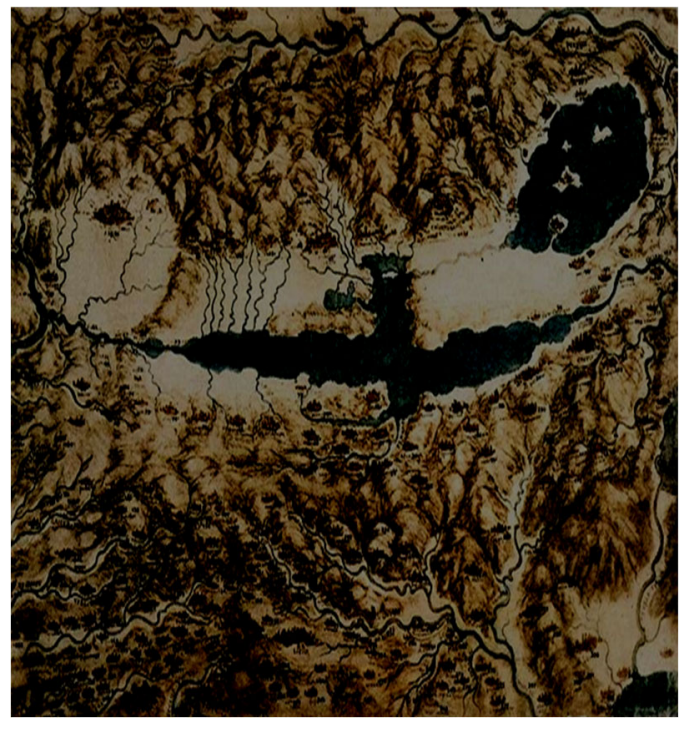

a)

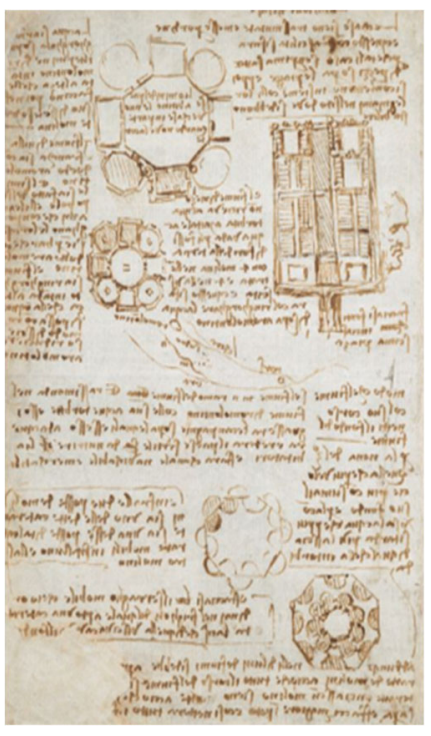

b)

Figura 2.3 a) Mapa de la Toscana y el valle de Chiana, RLW 12278, (h. 1502)

(hhttps://commons.wikimedia.org/wiki/File:Leonardo_da_vinci,_Map_of_Tus cany_and_the_Chiana_Valley.jpg?uselang=de), b) Proyecto de Ciudad nueva de Romorantin C. Arundel, f. 270v (1514-1518)

(http://www.bl.uk/manuscripts/Viewer.aspx?ref=arundel_ms_263_f001r). 


\subsubsection{Los Códices Forster (I, II, III)}

Datación: CF I de 1487-1505; CF II de 1495-1497; y CF III de 14901496.

Ubicación actual: Victoria and Albert Museum de Londres (Reino Unido).

Características físicas: Tres manuscritos, encuadernados en pergamino (sin certeza de fecha de encuadernado) y con dimensiones reducidas: el CF I, de $145 \mathrm{~mm} \times 100 \mathrm{~mm}$ y 55 folios; el CF II de 195 $\mathrm{mm}$ x $70 \mathrm{~mm}$ y 157 folios; y el CF III, de $90 \mathrm{~mm}$ x $60 \mathrm{~mm}$ y 88 folios.

Contenido en general: EI CF I versa sobre ingeniería hidráulica, y el movimiento del agua. El CF II, sobre la teoría de las proporciones, estudios sobre los pesos, sobre la tracción, tensiones y equilibrios, proyectos de mecanismos para control y paro de campanas, y de ballestas. EI CF III trata sobre geometría, estudios de pesos, máquinas hidráulicas y física.

Contenido de ámbito técnico-proyectual destacable:

a) Ingeniería Industrial: "Estudio de poleas y pesos", CF II, ff. 72v, 73r, 77v y 86v (1495-1497). "Estudio para construcción de compases de tornillo, CF I, f. 4r (1487-1505). "Diseños de cerraduras", CF III, f. 42r (1490-1493). "Estudio de soportes y mecanismos de toque de campanas", CF II, f. 10v (1495-1497). "Bocetos de bombas y rodetes de elevación de agua", CF I, f. 48r (1487-1505). "Diseño de Compás de proporción de tornillo, y detalle de su tuerca", CF I, f. $4 r$. (1485-1505).

b) Ingeniería Civil: "Estudio y ensayos de flexión en vigas", CF II, f. 89v (1495-1497). "Estudio de pesos" CF II, 47v y 48r, 88v y 89 r (1495-1497). "Estudio y ensayo de cargas en arcos", CF II, f. 92r (1495-1497).

c) Arquitectura y Urbanismo: "Estudio del relieve del perfil de Ábside de Santa María de Gracia", CF II, f. 53r y 63v (h. 1495). "Boceto de una Bóveda y sus refuerzos", CF II, f. 52v (1495-1497). "Proyecto segundo de ampliación de la ciudad de Milán", CF III, f. 23v (h. 1493). "Plano de Planta del Duomo de Milán", CF III, f. 55v (h. 1487).

\subsubsection{Los Manuscritos de Francia, o de París}

Datación: Aproximadamente de 1485 a 1516. 
Ubicación actual: Biblioteca del Instituto de Francia de París (Francia). Características físicas: Lo constituyen 12 manuscritos sobre papel, algunos encuadernados en pergamino, otros en piel y finalmente otros en cartón. Se denominan con las letras del alfabeto entre la A y la M. y en su totalidad conforman 964 folios. Son de diversas dimensiones, el más pequeño es el Manuscrito $\mathrm{M}$, de $10 \mathrm{~mm} \times 70 \mathrm{~mm}$ (tamaño de bolsillo), y el más grande es el Manuscrito C, de $315 \mathrm{~mm}$ x $220 \mathrm{~mm}$.

Contenido en general: Arte militar, óptica, geometría, vuelo de los pájaros e hidráulica.

Los Códices Ashburnham I y II (originalmente parte de los Manuscritos B y A)

Datación: Aproximadamente desde 1485 a 1492.

Ubicación actual: Biblioteca del Instituto de Francia de París, junto con Manuscritos A y B.

Características físicas: Se trata de dos manuscritos sobre papel, encuadernados en cartón que formaban parte de los antiguos Códices A (Ash 2038, II) y B (Ash 2037, I).

Contenido en general: El Códice Ash 2038 (II) trata de estudios sobre la pintura, y matemático-científicos. Y el Códice Ash 2037 (I), estudios de geometría, óptica, vuelo de los pájaros y arte militar.

Contenido de ámbito técnico-proyectual destacable (Incluye $M$. Francia y Ashburnham):

a) Ingeniería Industrial: "Estudio de tecnología y otros", M. B, f. 16v (1487- 1490). "Estudio de bombas centrifugas para vaciar zonas pantanosas", M. F, f. 15r (h. 1508 "Diseño de máquina para tallar espejos cóncavos", M. B, f. 13r (1495-1497).

b) Ingeniería Civil: "Estudio de los canales para la remodelación de Milán", M. B, f. 37v, 38v y 39r (1487-1490). "Estudio sobre estática y dinámica de arcos", M. A, ff. 49 y 53r, (h. 1492). "Diseño de un puente-doble", M. B, f. 23r (1490).

c) Ingeniería Naval y Aeronáutica: "Diseño de barca de dragado", $M$. E, f. 75v, (1513-1514). "Estudio de un salvavidas", M. B, f. 87v (1487-1490). "Proyecto de maquina voladora", M. B, f. 74v (1489). "Estudio para máquina de volar y timón", M. B, f. 75r (1487-1490). "Estudio del tornillo aéreo", M. B, f. 83v (1487-1490). "Estudio para máquina de volar accionada a mano", M. B, f. 79r (1487-1490). "Estudio y ensayos de ala batiente movida por fuerza humana", M. 
B, f. 88v (1487-1489). "Diseño de un guante para nadar", M. B, f. $81 v$ (h. 1500). "Diseño de ornitóptero vertical", M. B, f. 80r (14871490).

d) Ingeniería Militar: "Estudio de fortificación de edificios, M. B, ff. 57v y 58 r (h. 1490). "Estudio muralla con espolón y saliente", M. L, f. 63r (h. 1502). "Diseño de cañón de vapor de Arquímedes", M. B, f. 33r (1487-1490). "Estudio de fortificación en Piombino", M. L, f. 15v (1502). "Estudio sobre el Castillo de Milán", M. L, ff. 11v y 12r (1489).

e) Arquitectura y Urbanismo: "Estudio arquitectónico de edificio de planta central", M. B, f. 3v (1487-1490). "Estudio de la Iglesia S. María de la Pertica", M. B, f. 55r (1493). "Estudio de escalera de varias entradas para la ciudad de ideal de Milán”, M. B, f. 69r (h. 1490). "Estudio de escalera de hélice", M. M, f. 47r (1487-1490). "Estudio de escalera de dos entradas para la ciudad ideal de Milán", M. B, f. 66v (1487-1489). "Estudio de las relaciones de proporción de una iglesia y una cúpula", M. B, ff. $17 \mathrm{v}, 18 \mathrm{v}$ y $24 \mathrm{r}$ (1485-1490). "Estudio para cubrición del cimborrio del Duomo de Milán", M. B, f. 10v (1487-1490). "Estudios de iglesias de planta central", M. B. ff. 25v y 94r (1485-1490). "Proyecto primero de ampliación de la ciudad de Milán, la ciudad ideal”, M. B, ff. 15v, 16r, 36r, 37r, 37v, 38v, 38r (1487-1489). "Proyecto segundo de ampliación de la ciudad de Milán”, M. A, f. 114v (h. 1493).

\subsubsection{El Códice del Vuelo de Los Pájaros o de Turín}

Datación: Compilado entorno al 1505-1506.

Ubicación actual: Biblioteca Real de Turín (Italia).

Características físicas: Son 18 folios, con unas dimensiones de 210 $\mathrm{mm} \times 150 \mathrm{~mm}$.

Contenido en general: Estudios sobre el vuelo de los pájaros, mediante estudios mecánicos del funcionamiento del ala, de la resistencia del aire, y de las corrientes de viento.

Contenido de ámbito técnico-proyectual destacable: 
a) Ingeniería Industrial: "Estudios de pesos sobre planos inclinados", ff. $2 v$ y $3 r$ (h. 1505).

b) Ingeniería Civil: "Estudio para un curso de agua", f. 18v (1505).

c) Ingeniería naval y Aeronáutica: "Estudios para ensayos de un Mecanismo de Ala de Vuelo", ff. 16v y 17r (h. 1505). "Estudios de equilibrio de piloto en planeador", f. $5 r$ (h. 1505).

d) Arquitectura y Urbanismo: "Estudio de Villa de Charles d" Amboise", f. 18v (1505-1506). 


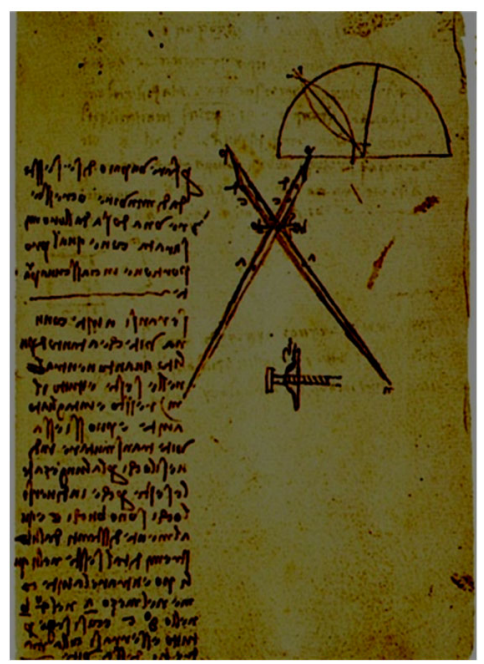

a)

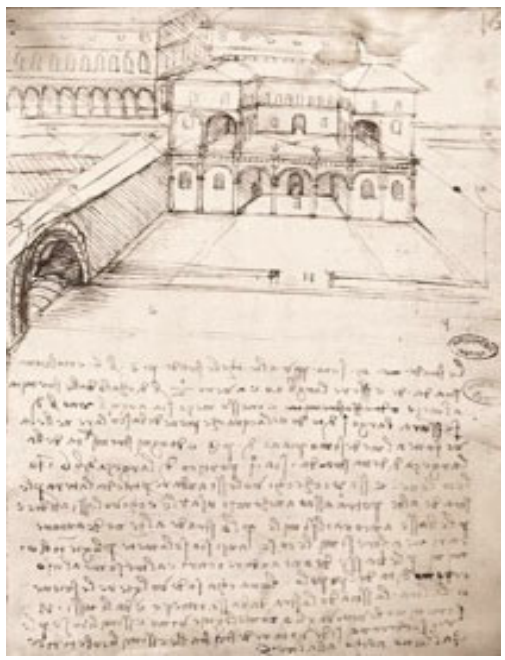

b)

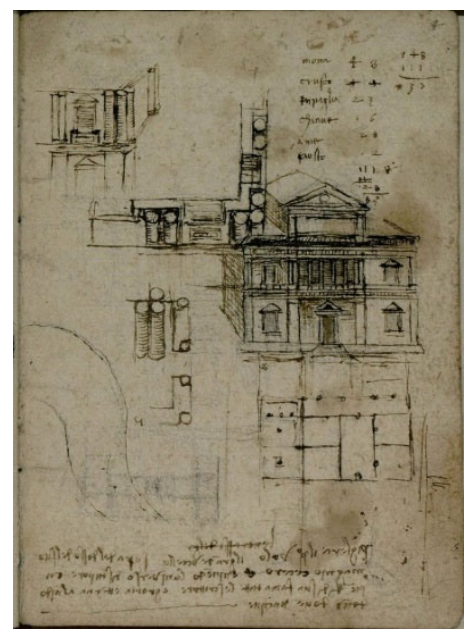

c)

Figura 2.4 a) Compás de proporción de tornillo, C. Forster I, f. 4r. (h. 1485) (https://commons.wikimedia.org/wiki/File:Reduction_Compass_Leonardo.jpg ?uselang=), b) Proyecto de Ciudad Ideal, Man. B de Francia, f. 16 r (h. 1489)

(file:///F:/ciudad\%20ideal/Quartier\%20M\%C3\%A9riadeck\%20 $\% 20$ Urbani sme $\% 20$ sur $\% 20$ dalle $\% 20$ \%20Les\%20origines.html), c) Estudio de Villa de Carlos d' Amboise, C. Vuelo Pájaros, f. 18v (h. 1506)

(https://www.wdl.org/es/item/19477/view/1/1/). 


\subsubsection{El Códice Trivulziano}

Datación: Aproximadamente desde 1478 a 1493.

Ubicación actual: Biblioteca Trivulziana del Castillo de Sforcesco de Milán (Italia).

Características físicas: Un fascículo, de 51 folios, de las 62 hojas originarias, con un formato de $205 \mathrm{~mm} \times 140 \mathrm{~mm}$.

Contenido en general: Proyectos de arquitectura militar y religiosa, y estudios autodidácticos del propio Leonardo para mejorar su formación.

Contenido de ámbito técnico-proyectual destacable:

a) Ingeniería Industrial: "Boceto de máquina con volante de giro", f. $17 r(1478-1493)$. "Estudio de pesos con la gravedad", f. 18v (14781493).

b) Ingeniería Civil: "Boceto de máquina grúa para obras", f. 32r (14781493).

c) Ingeniería Militar: "Boceto de máquina para asedio", f. 14r (14781483). "Diseño de ballesta”, f. 50r (1478-1493).

d) Arquitectura y Urbanismo: "Estudio de bóveda y su encofrado", $f$. $4 r$ (1487-1490). "Bocetos de cúpulas, secciones y pilares del Duomo de Milán", ff. 8r, 8v, 9r, 11r, 21r, 22v y 27v (1487-1488). "Fachada de edificio de 3 cuerpos y 3 alturas con arcos", f. 22r (1487).

\subsubsection{Los Códices Madrid I y Madrid II}

Datación: Del Códice I, Desde 1490 a 1496, y del Códice Madrid II, desde 1503 a 1505.

Ubicación actual: Biblioteca Nacional de España, en Madrid (España).

Características físicas: Son dos manuscritos sobre papel. El Códice de Madrid I dispone de 192 folios, de dimensiones $210 \mathrm{~mm}$ x $150 \mathrm{~mm}$. Mientras que el Códice de Madrid II tiene 157 folios, con las mismas dimensiones que el Códice Madrid I.

Contenido: El Códice de Madrid I, tiene sus textos y los dibujos con acabados de gran calidad y parece que es un refinamiento de la parte de muchas de las hojas del Códice Atlántico, aparentemente con voluntad de poder publicarlo. Se trata de un "tratado técnico" en todas 
sus consecuencias. Aborda principalmente estudios de mecánica, de hecho, el título que se le puso en su tapa interior en castellano es “Tratado de Estática y Mechánica En Italiano, Escrito en el año 1493", y se puede afirmar que es el primer tratado monográfico de estática y mecánica conocido sobre el tema.

El Códice de Madrid II, es un "cuaderno de notas", ya que sus dibujos, y escritura son mucho más bastos. "Aquí solo se persigue funcionalidad" (Ruiz \& Martínez, 2012). El título que se le otorgó en su tapa interior en castellano es "Tratados varios de Fortificación, Estática y Geometría escritos en italiano, por los años de 1491". Contiene apuntes de geometría y proyectos de arquitectura e ingeniería militar, parte del proyecto de canalización para desviar el río Arno a su paso por Pisa, el proyecto de la fortificación de la ciudad de Piombino, y diseños de instrumentos musicales. En su parte final (últimos 16 folios) los dibujos son de mejor calidad, representando en gran medida el proyecto de detalle de la fundición del "Monumento Ecuestre Sforza".

Contenido de ámbito técnico-proyectual destacable:

a) Ingeniería Industrial: "Estudios para varios tipos de muelles", CM I, f. 85r (h. 1497). "Estudio de cojinetes", CM I, f. 101r (1495-1497). "Mecanismos de engranajes helicoidales", CM I, f.17v (h. 1495). "Diseño de molino automático de grano", CM I, f. 22r (h. 1490). "Proyecto de Máquina para tallar espejos", CM I, f. 61r (14871490). "Estudio del soporte para levantar y bajar el molde del Monumento Ecuestre Sforza", CM II, f. 155v (1491-1493). "Estudio del habitáculo enterrado para molde del Monumento Ecuestre Sforza", CM II, f. 149r (1491-1493). "Detalle de la armadura de la cabeza del Caballo del Monumento Ecuestre Sforza", CM II, f. 157r (1491-1493). "Detalle de la armadura del cuerpo del Monumento Ecuestre Sforza", CM II, f. 157v (1491). "Detalle de las mazarotas para la fundición del Monumento Ecuestre Sforza", CM II, f. 151v (1491). "Estudio de dispositivo elevador manual", CM I, f. 9r (h. 1495). "Diseño de mecanismo de giro para el teatro de Curio", CM I f. 110r (h. 1495). "Diseños de engranajes de cadena", CM I, f. 10r (h. 1500).

b) Ingeniería Civil: "Detalles de la sección del Proyecto de Canal de Florencia hasta el mar", CM II, f. 10v (h. 1503). "Mapa de la zona del Proyecto de Canal de Florencia hasta el mar", CM II, ff. 22v y 23r (h. 1503). "Mapa de la zona del Proyecto de desvío del Rio Arno a su paso por de Pisa", CM II, ff. 52v y 53r (h.1503). "Estudios 
sobre la estática y la dinámica de los arcos", CM I, ff. 143R, 138v, y $139 r$ (h. 1495).

c) Ingeniería Naval y Aeronáutica: "Estudio sobre cometas dirigidos desde tierra mediante cable (símil de ala delta"), CM I, f. 64r (h. 1505).

d) Ingeniería Militar: "Vista aérea de las montañas de los alrededores de Pisa" (1502-1503). "Proyecto de fortaleza a vista de pájaro", CM II, f. 79r (h. 1504). "Plano de situación y estudio de la Fortaleza de Verruca", CM II, ff. 4r, 7v y 8r (1503). "Estudio de la fortificación", CM II, f. 37r (1502).

e) Arquitectura y Urbanismo: "Estudio de arcos de S. María de Gracia”, CM I, f. 113v (h. 1495).

\subsubsection{Códice Leicester (o Hammer)}

Datación: Aproximadamente entre 1504 y 1508.

Ubicación actual: Conservado en la colección de Bill Gates, en Seattle (Estados Unidos de América).

Características físicas: Estaba encuadernado en piel y compuesto de 36 folios (18 hojas dobles) de dimensiones medias: $290 \mathrm{~mm} \times 220 \mathrm{~mm}$. Recientemente ha sido desmontado y se presenta en hojas sueltas, como se cree que estaba en época de Leonardo. 


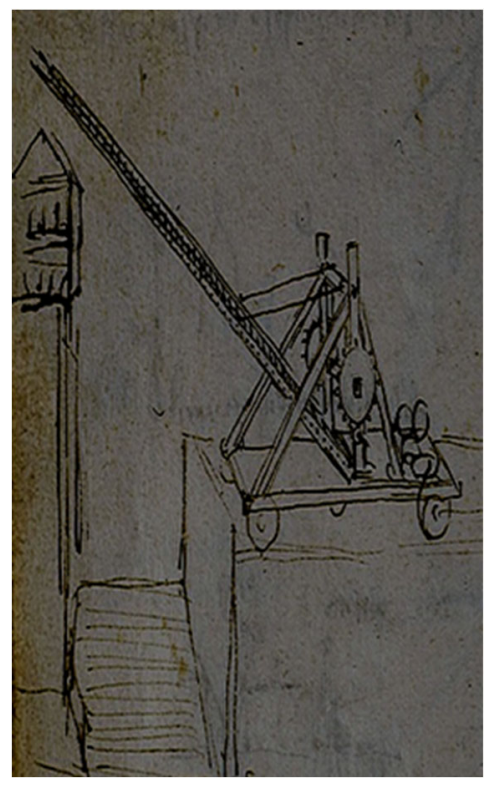

a)

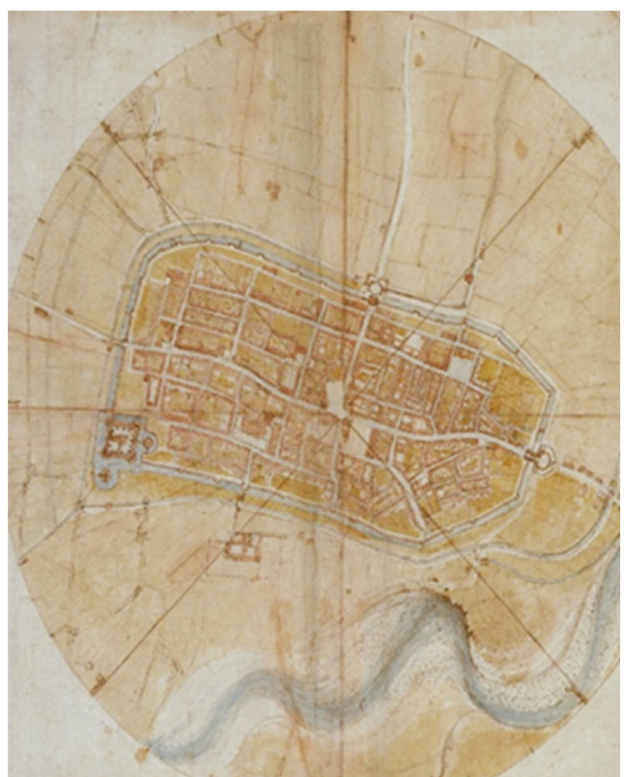

b)

Figura 2.5 a) Boceto de máquina de asedio, C. Trivulziano, f. 14r (14781493) (https://commons.wikimedia.org/wiki/File:L19_-_Triv_2162_-

_14r_detail.jpg? uselang=es), b) Plano de la ciudad amurallada de Imola RCW 12284 (h. 1502)

(https://upload.wikimedia.org/wikipedia/commons/8/85/Leonardo_da_Vinci__Plan_of_Imola_-_Google_Art_Project.jpg). 


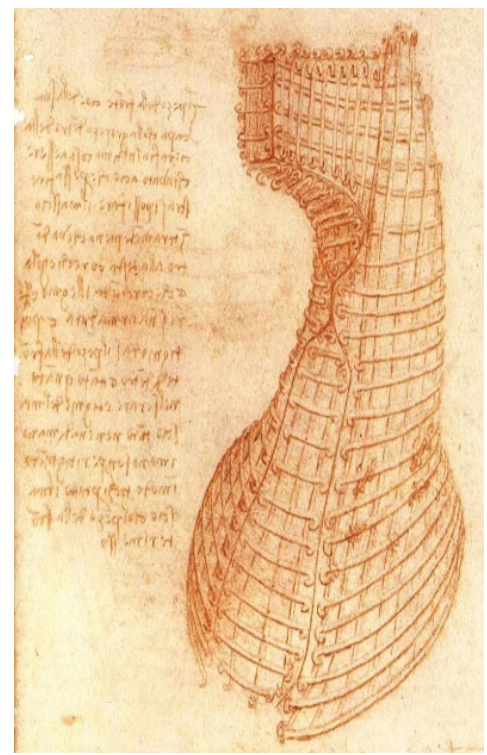

Figura 2.6 Armadura para la cabeza del Monumento Ecuestre Sforza, C. Madrid II, f. 157r (1491-1493),

(https://commons.wikimedia.org/wiki/File:Leonardo_-_Madrid_II_-_157r.jpg).

Contenido: Estudios de hidráulica y movimiento del agua. También proyectos de canales y embalses, diseños de equipos para aprovechamiento del agua y estudios de astronomía.

Contenido de ámbito técnico-proyectual destacable:

a) Ingeniería Industrial: "Estudios de vasos comunicantes y sifones", f. $34 v(1506-1508)$.

b) Ingeniería Civil: "Anotaciones sobre la Luna, dibujos y notas sobre la iluminación del Sol, de la Tierra y de la Luna", f. 36v y 1r (15061508).

c) Ingeniería naval y Aeronáutica: "Medición de las variaciones de presión del agua con la profundidad, mediante placas móviles, emplazadas en un barco flotante", f. $6 r$ (1506-1508).

\subsection{Conclusiones}

Analizados el conjunto de los manuscritos, que constituyen la mayor muestra técnico-científica del Renacimiento, los más representativos desde el punto de vista técnico-proyectual serían: 
a) Ingeniería Industrial: El Proyecto de la Fundición del Gran Caballo de más de $7 \mathrm{~m}$ de altura (1490-1493), para el Monumento Ecuestre Sforza. Se encuentra plasmado mayoritariamente en el Códice de Madrid II (16 folios últimos); la Royal Collection RLW 12379, donde dibuja los hornos para la fundición; y el Códice Atlántico, f. 577v, donde estudia hasta el soporte para trasladar el Molde de arcilla. Se ha seleccionado por la dificultad de su realización y por su magnitud, y por haber sido hecho realidad, con 7,32 m de altura en Milán, en 1999, por la escultora americana Nika Akamu (Midwest City,1955-) y la empresa de fundición de Beacon (USA), Tallix Art Foundri (Figura 2.6). (Cerveró, Ferrer, \& Capuz, 2016). Y el Proyecto de automóvil o auto carro motor (1478-1480), plasmado principalmente en el Códice Atlántico ff. 296v y 812 r. Se ha seleccionado por ser el automóvil pionero en el mundo (Figura 2.1 b)) (Laurenza, Taddei, \& Zanon, 2006) (Cerveró, Ferrer, \& Capuz, 2018)

b) Ingeniería Civil: El Proyecto de desvío del río Arno (15031505), a su paso por la ciudad de Pisa, encargado por el Gobierno de la ciudad-estado de Florencia, para someter de nuevo a los pisanos, aliados en aquel entonces con los franceses. En él elabora planos de canales, proyectos de máquinas de excavación y grúas de elevación de cargas, mapas de las zonas, y lo plasma en el Códice Atlántico f. 4r; en la Windsor Collection, RLW 12680; y en el Códice d Madrid II, ff. $10 v, 22 v, 23 r, 52 v$ y $53 r$. Se ha seleccionado por la magnitud y lo variado del proyecto (Figura 2.3 a)) (Cerveró, Ferrer, \& Capuz, 2016).

c) Ingeniería naval y Aeronáutica: En Ingeniería Naval: el proyecto de equipo buzo para respirar bajo el agua (h. 1502) plasmado en Códice Arundel, f. 24v, encargado por la República de Venecia, para defensa contra los ataques de los barcos turcos. Elegido por su novedad y complejidad (Figura 2.1 a)) (Cervero, Ferrer, \& Capuz, 2016). En Ingeniería Aeronáutica: boceto $\mathrm{e}$ instrucciones para construir un paracaídas (h. 1508), plasmado en el Códice Atlántico f. 1058v y probado con éxito dos veces por Adrián Nicholas (1962-2005) en la Rep. Sudafricana en año 2000, y por Olivier Vietti-Teppa (1971-) en Payerne (Suiza) con forma y materiales similares a los de Leonardo. Elegido por su innovación y actual factibilidad (Figura 2.2) (Cerveró, Ferrer, \& Capuz, 2018). 
d) Ingeniería Militar: los mapas y planos de fortalezas, castillos y ciudades amuralladas, realizados para Cesar Borgia (Roma, 1475-Viana, 1597) en sus campañas guerreras por la Toscana y la Romaña en 1502; plasmados en el Códice Atlántico ff. 41v, 43v, 362v, 117r, 132r; la Windsor Collection, RLW 12278, 12682 y 12683,12284 y 12286 ; el Manuscrito L de Francia, ff. 11v y 12r; y el Códice de Madrid II, f. 37r. Elegido por la magnitud del proyecto (Figura 2.5 b)) (Cerveró, Ferrer, \& Capuz, 2017).

e) Arquitectura y Urbanismo: En Arquitectura: el proyecto de Palacio de Romorantin (h. 1516) para Francisco I, Rey de Francia y su Ciudad Nueva Geometría, incluso un lago para celebrar naumaquias; con planos de perspectivas y alzados del palacio, plantas de la nueva ciudad y planos hidrográficos de la zona; plasmados en Códice Atlántico, ff. 74v, 76v y 217v; el Códice Arundel, ff. 269r y 270v; y la Royal Collection, RWL 12292v. Elegido por la complejidad y magnitud del mismo (Cerveró, Ferrer, \& Capuz, 2019) (Figura 2.3 b)). En Urbanismo: el primer proyecto urbanístico de la ampliación de la Ciudad de Milán (1487-1490) para el Duque Ludovico Sforza (Vigevano, 1451-Loches, 1508) a raíz de la peste de 1485, mostrando una ciudad ideal, de dos niveles, con detalles de escaleras de varias entradas, viviendas, establos, plazas, etc.; plasmado en el Manuscrito B de Francia, ff. 15v, 16r, 37r, 37v, $38 \mathrm{r}, 38 \mathrm{v}, 39 \mathrm{r}, 39 \mathrm{v}, 47 \mathrm{v}, 47 \mathrm{r}, 66 \mathrm{v}$ y $69 \mathrm{r}$. También el segundo proyecto de crecimiento de la Ciudad de Milán (h. 1493), mediante barrios abiertos sin amurallar, plasmado en el Cod. Atlántico, ff. 65v, 73v, 75v y 77v; el Manuscrito A de Francia, f. $114 \mathrm{v}$; y Códice Forster III, f.23v. Elegidos por su carácter innovador, novedoso y ecológico (Fig 2.4 b)) (Cerveró, Ferrer, \& Capuz, 2019).

Podemos concluir que sus manuscritos, por su elevada cantidad y lo variado de sus temas, constituyen la mayor muestra técnico-científica del Renacimiento.

\section{Referencias}

Antoccia, L., Chastel, A., Cianchi, M., Galluci, P., Laurenza, D., Papa, R., \& Pedretti, C. (2003). Atlas ilustrado de Leonardo Da Vinci. Arte y ciencia. Las máquinas. Susaeta Ediciones: Madrid. 
Cerveró, E., Ferrer, P., \& Capuz, S. (2016). El Caballo Sforza de Leonardo $\mathrm{Da}$ Vinci analizado desde la perspectiva de los Proyectos de Ingeniería. 20th International Congress on Project Management and Engineering. Cartagena. AEIPRO.

Cerveró, E., Ferrer, P., \& Capuz, S. (2016). Teorías, Métodos y Técnicas para el Diseño de Sistemas Técnicos en la Obra de Leonardo Da Vinci. 20th International Congress on Project Management and Engineering. Cartagena. AEIPRO.

Cerveró, E., Ferrer, P., \& Capuz, S. (2017). Contribuciones de Leonardo da Vinci a las Técnicas Gráficas para el Diseño o Proyecto Técnico. 21st International Congress on Project Management and Engineering. Cádiz. AEIPRO.

Cerveró, E., Ferrer, P., \& Capuz, S. (2018). Revisión de la factibilidad funcional de los Sistemas Técnicos diseñados por Leonardo da Vinci. 22nd International Congress on Project Management and Engineering. Madrid. AEIPRO.

Cerveró, E., Ferrer, P., \& Capuz, S. (2019). Leonardo da Vinci, pionero del Ecodiseño. 23rd International Congress on Project Management and Engineering. Málaga. AEIPRO.

Da Vinci, L. (1478-1518). Códice Atlántico. Milán. Biblioteca Ambrosiana. Obtenido de http://www.leonardoambrosiana.it/en/il-codice-atlantico/.

Da Vinci, L. (1478-1518). Manuscritos de la Royal Library Windsor, Royal Collection Trust. Obtenido de https://www.rct.uk/collection/themes/exhibitions/leonardo-davinci-a-life-in-drawing-0.

Da Vinci, L. (1487-1514). Conjunto de Manuscritos de París. París. Institut de France. Obtenido de https://archive.org/details/lesmanuscritsdel00leonuoft.

Da Vinci, L. (1487-1514). Códice Arundel. British Library de Londres. Obtenido de https://www.metalocus.es/es/noticias/570paginas-de-manuscritos-de-leonardo-da-vinci-estan-onlinegracias-a-la-biblioteca-britanica-y-microsoft.

Da Vinci, L. (1491-1493). Códices de Madrid. Madrid. Biblioteca Nacional de España, http://leonardo.bne.es/index.html.

Laurenza, D., Taddei, M., \& Zanon, E. (2006). Las máquinas de Leonardo. Susaeta Ediciones: Madrid. 
Richter, J. (1883). The Literary Works of Leonardo Da Vinci. S. Low, Marston, Searle \& Rivington: London.

Ruiz, E., \& Martínez, J. (2012). El Imaginario de Leonardo. Los Códices de Madrid. Ed. Minis. de Cultura: Madrid.

Ruiz-Giménez, J., King, R., Barbatelli, N., Hohenstatt, P., Garcia Querol, J., Lorente, J., Lombillo, A., \& Gálvez, Ch. (2018). Leonardo da Vinci: Los rostros del Genio. Penguin Random House, Grupo Editorial: Barcelona.

White, M. (2003). Leonardo el primer científico. Ed. De Bolsillo: Barcelona. 



\title{
Capítulo 3 Análisis de las investigaciones sobre Leonardo da Vinci
}

\author{
"Ninguna certeza hay donde no pueda aplicarse una de las \\ ciencias matemáticas". \\ LEONARDO DA VINCI (Manuscrito G, folio $96 \mathrm{v}$, de la Biblioteca del \\ Instituto de Francia, París).
}

\subsection{Introducción}

Leonardo (Vinci 1452-Amboise 1519) era y es conocido como uno de los mejores pintores de todos los tiempos, aunque a raíz del redescubrimiento y estudio con detalle de su gran producción manuscrita, que conforman 23 cuadernos, la mayoría de ellos en el siglo XIX (Códices Atlántico, Arundel, Leicester, Manuscritos de París A-M -12 tomos-, Forster -3 tomos-, Del Vuelo de los Pájaros, Trivulciano y Cuadernos de Windsor Royal Library) y otros a medianos del siglo XX (Códices de Madrid I y II), ha adquirido fama en otras disciplinas como la ingeniería, el urbanismo, la anatomía, la botánica o incluso como científico e inventor.

Es a raíz de los estudios publicados por el historiador del arte francés y conservador del museo del Louvre, Charles Ravaisson-Mollien (1848-1919), “Les Manuscrites de Léonard de Vinci” (1881-91), cuando comienza de nuevo el interés por la obra científico-técnica de Leonardo. Desde entonces un sinfín de científicos e historiadores de la ciencia han estudiado muchas de las distintas facetas de la obra científico-técnica de Leonardo y realizado publicaciones sobre ello. Cada uno de ellos ha aportado algunas ideas con relación a la faceta proyectual de Leonardo, que fue pionero en la aplicación de algunos métodos y técnicas de representación, creatividad, etc. así como en la creación y utilización de instrumentos de apoyo a la acción proyectual. Así, el investigador en física de la Universidad de Paris, Fritjof Capra (Viena, 1939) y experto en biología y ecología, que ha estudiado el 
área ecológica de Leonardo y sus diseños mediante analogías, utilizando a la "naturaleza como maestra", establece: "Los buenos diseñadores son capaces de pensar sistemáticamente y de sintetizar. Se destacan en la visualización de las cosas, en la organización de los elementos conocidos en nuevas configuraciones, en la creación de nuevas relaciones; $y$ son capaces de transmitir esos procesos mentales en forma de dibujos casi con la misma rapidez con que se producen. Leonardo, por supuesto, tenía todas estas capacidades en altísimo grado. Además, poseía un misterioso talento natural para percibir y resolver problemas técnicos - otra característica clave de un buen diseñador-, a tal punto que, en su caso, era casi una segunda naturaleza" (Capra, 2008). O el profesor universitario, crítico de arte y director del "Museo Ideale Leonardo da Vinci", Alessandro Vezzosi (Italia, 1950) como experto generalista en la obra multidisciplinar del toscano, que manifiesta: <<La obra de Da Vinci es inigualable en la historia de la ilustración científica y tecnológica, no solo por su manera de exponer sus procedimientos sin demostraciones interminables $y$ aburridas, sino también en tanto que obra de arte, creación del diseñador $>$ (Vezzosi, 2011).

\subsection{Objetivo}

Este trabajo pretende reflejar las personas o entidades que han investigado a Leonardo en su faceta científico-técnica y enumerar sus publicaciones más importantes en ese campo, junto con una somera descripción de las aportaciones mejor consideradas con la ayuda de imágenes de sus manuscritos originales (Figuras $3.1 \mathrm{a}$ ), $3.2 \mathrm{~b}$ ), $3.3 \mathrm{a}$ ) y 3.4 a)), de maquetas o prototipos de museos de la ciencia, o de las publicaciones estudiadas. La descripción se lleva a cabo tal como se ha desarrollado en el tiempo.

Conviene hacer constar al inicio de este capítulo que la desaparición de parte de los manuscritos de Leonardo y la diseminación de los restantes dificultó la investigación sobre los mismos e hizo que la parte científico-técnica no fuera estudiada hasta finales del siglo XIX, cuando se empezó a conocer con exactitud la ubicación de cada manuscrito y las entidades que los poseían se dieron cuenta de la importancia de su contenido. Por ello, en las etapas intermedias entre ese siglo y la muerte de Leonardo en 1519, solo se estudió e investigó la parte artística del mismo, sobre todo su faceta destinada a la pintura, debido a su fama como pintor y al fácil acceso a sus obras. Es a partir de finales del siglo XIX cuando se 
inicia el interés por la parte más científico-técnica de Leonardo, por lo que innumerables historiadores se adentran en el conjunto de sus obras siendo imposible recopilarlos todos en este trabajo. Por ello se ha seleccionado a aquellos de más importancia, más recientes o que tuvieran más vínculos con el enfoque tecnológico de la obra de Leonardo.

\subsection{Investigadores más importantes y sus publicaciones}

\subsubsection{Francesco Melzi (Milán, hacia 1493-Vaprio d' Adda, 1572/73)}

Pintor milanés que fue alumno de Leonardo y quedó a cargo de todo su conjunto de manuscritos, que guardó con celo hasta su muerte, mientras que sus hijos obviaron tal misión y los vendieron o regalaron a nobles y a coleccionistas de arte, comenzado la diseminación de estos, que acabó con la desaparición de varios de ellos. Melzi, es el primero que reestudió todos los manuscritos y extrajo todo lo que consideró referente a la pintura, componiendo un nuevo tratado de manera manuscrita, que ni tan siquiera se otorgó ya que lo tituló "Tratado de la Pintura de Leonardo da Vinci", y que acabó denominándose Códice Latinas Urbinus $n^{\circ} 1270$, hoy en la Biblioteca Vaticana. En realidad, los textos que traspuso son fieles a los originales de los manuscritos de Leonardo, pero reordenados según su propio criterio.

En el "Tratado de la Pintura", donde caracteriza a la pintura como el supremo arte, establece las reglas de carácter científico que debe usar el pintor: la acción principal y las secundarias y el contraste entre ambas, el decoro de las actitudes de los personajes, el arreglo de los movimientos, la contraposición de tintas y claro-oscuros, etc., manifestando la necesidad de la observación del natural, para que "las obras parezcan como hijas legitimas de la naturaleza" (Da Vinci,1784).

A partir de su publicación en imprenta en Francia en 1651 (Fiqura 3.1 b). con traducción de Rafael Trichet Du Fresne (Burc

con dibujos del pintor Nicolas Poussin (Normandía,1594Roma,1665), tuvo tan buena aceptación que se impuso en las Academias de Bellas Artes como libro de aprendizaje, al menos hasta medianos del siglo XIX. 


\subsubsection{El Anónimo Gaddiano o Códice Magliabechiano XVII (entre1537-1541)}

Es la fuente anónima más temprana que define a Leonardo. Se encuentra hoy en la Biblioteca Nacional Central de Florencia y muestra biografías y notas sobre artistas griegos de la antigüedad y de italianos, sobre todo de Florencia, desde el pintor Cimabue (Florencia, 1240-Pisa, 1302) hasta el artista Miguel Ángel Buonarroti (Caprese, 1475-Roma, 1564). Pasó a formar parte de la Biblioteca florentina por pertenecer a la colección del bibliotecario de los Medici, el erudito Antonio Magliabechi (Florencia 1633-1714), que es el núcleo principal de esta. El relato de la vida de Leonardo es detallado y fue referencia para autores posteriores (Códice Magliabechiano, 1537-1541).

El manuscrito de 128 folios perteneció a la familia Gaddi. Fue compilado en torno a 1540 por un autor desconocido que tomó parte de los datos de un "zibaldone" hoy desaparecido, que había recopilado el mercader florentino, Antonio Billi, fechado sobre 1520. El texto destinado a Leonardo son los folios 88r-91v y $121 \mathrm{v}-122 \mathrm{r}$ de ese manuscrito (Nicholl, 2006).

Define a Leonardo como: <<Era una persona de facciones finas, bien proporcionada, llena de gentileza y de un hermoso aspecto. Llevaba una túnica rosada hasta las rodillas aun cuando en ese momento la moda era llevar atuendos largos. Tenía una bien cuidada y rizada barba que le llegaba a la mitad del pecho>> (Kemp, 2006).

\subsubsection{Paolo Giovio (Como, 1483- Florencia, 1552)}

Historiador, físico y médico, fue diplomático de los Medici y obispo de Nocera, y escribió sobre las guerras de Italia y varias biografías de celebridades de su época, entre ellas un manuscrito titulado "Leonardi Vinci vita", a finales de la década de 1520. Fue publicado por primera vez en 1796. Ejerció de médico en Milán sobre 1508 y de profesor de filosofía en Roma, por lo que cabe la posibilidad de que hubiera conocido directamente a Leonardo, ya que este pasó una parte importante de su vida en Milán y tres años en Roma (Nicholl, 2006).

\subsubsection{Giorgio Vasari (Arezzo, 1511-Florencia, 1574)}

Pintor y arquitecto y artista de la corte de los Medici en Florencia, en concreto del Duque Cosme I (Florencia, 1519-1574), es considerado 
el primer historiador del arte por haber publicado en 1550 , en Florencia, la obra: "La vite de piu eccellenti pittori, scultori et architettori" y haberla revisado en 1568, conocida también como "Vidas de los artistas". En ella se enumeran las biografías de la mayoría artistas del Renacimiento italiano, desde Giotto (Colle di Vespignano, 1267-Florencia,1337) hasta Tiziano (Pieve di Cadore, ¿1490? - Venecia, 1576) (Nicholl, 2006). Ha sido reeditada muchas veces (Figura 3.1c)). El texto es una descripción bibliográfica en el tiempo, acompañada de datos artísticos y anécdotas de los biografiados. El apartado destinado a Leonardo es uno de los importantes y así lo define: $<<$ No ejercitó una sola profesión, sino todas aquellas en las que intervenía el dibujo. Y tuvo un intelecto tan divino y extraordinario que, siendo un óptimo geómetra, no se dedicó solamente a la escultura y a la arquitectura, sino que quiso que su profesión fuera la pintura>> (Antoccia, et al., 2003).

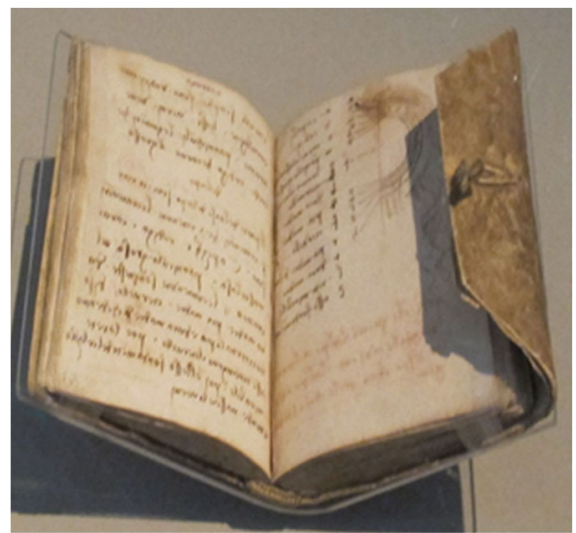

a)

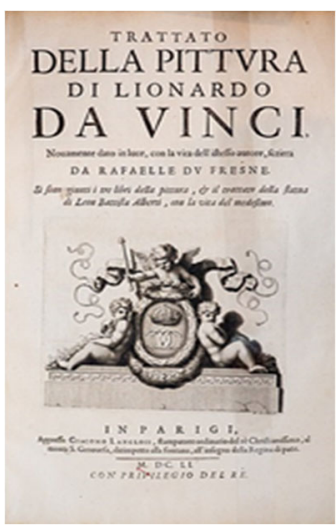

b) 


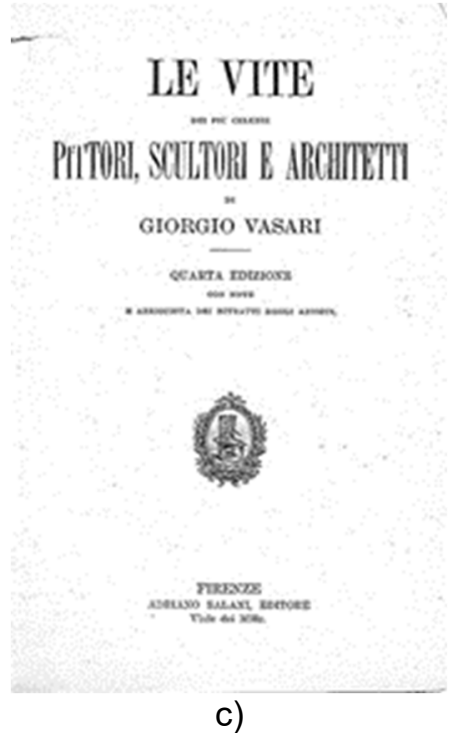

Figura 3.1 a) Códice Forster III, Victoria \& Albert Museum, Londres (https://commons.wikimedia.org/wiki/File:Leonardo_da_vinci,_taccuino_forst er_III,_1490_ca._01.JPG?uselang=es), b) $1^{\text {a }}$ edición impresa del Tratado de la Pintura (1651)

(https://commons.wikimedia.org/wiki/File:Trattato_Della_Pittura_(88395).jpg

?uselang=es), c) Ed. de 1913, de Vidas de los Artistas, de G. Vasari

(https://commons.wikimedia.org/wiki/File:1913-Le_vite-degli_artisti-di-

Giorgio-Vasari.jpg).

\subsubsection{Giovanni Paolo Lomazzo (Milán, 1538-1592)}

Pintor y crítico de arte italiano que vivió y trabajó durante el manierismo tardío. Accidentalmente quedó ciego a los 33 años dedicándose a escribir libros en los que aparecen referencias continuas a Leonardo, como en: "Sogni e raggionamenti", aún en manuscrito de comienzos de la década de 1560; "Trattato dell'arte della pittura", publicado en 1584 (Lomazzo, 1584); e "Idea del Templo della pittura", publicado en Milán en 1590. Conoció a Francisco Melzi, albacea de Leonardo, y estudió directamente de los manuscritos que este disponía y documentó algunos de los que se han perdido. Fue un especialista e incondicional de Leonardo y el primero que manifestó abiertamente que este era homosexual (Nicholl, 2006). Establece tres aspectos para la mirada crítica de una obra de arte: doctrina (o conocimiento de lo 
establecido); práctica y maneras del artista (preferencias personales); e iconografía (elemento literario del arte).

\subsubsection{Charles Ravaisson-Mollien (1848-1919)}

Historiador del arte francés que fue conservador del museo del Louvre, estudió con detalle los manuscritos de Leonardo del Instituto de Francia durante más de una década, y fue publicando sus aportaciones junto con un facsímil de cada uno de los manuscritos, en una obra de varios tomos, "Les Manuscrites de Léonard de Vinci" (1881-91). El Prefacio y el Manuscrito A, estudiado en el primer tomo, se publicó en Paris, por $A$. Quantin imprimeur-editeur, en 1881 (Ravaisson-Mollien, 1891). Es considerada la obra pionera antes de cualquier investigación de los manuscritos, más aún por haber sido realizada folio por folio, tanto en lado "recto" como en lado "verso", sobre un conjunto total de casi 1000 folios, para los 12 manuscritos de la A a la M, más los 2 "Códice Ashburnham", que hoy están anexos al A y al B.

En el "Prefacio", analiza el origen del conjunto de los manuscritos de Leonardo del Instituto de Francia (desde la A a la M), su historia y sus posibles propietarios. A continuación, analiza las características físicas del manuscrito, su origen, sus marcas físicas, etc. Después ya solo se dedica con detalle al Manuscrito A, donde coloca la hoja del manuscrito de Leonardo en facsímil y debajo su traducción al italiano (Leonardo, al escribir de izquierda a derecha, resulta inentedible, haría falta un espejo, así como conocer italiano antiguo, con variantes de la zona toscana). En la hoja siguiente dispone su traducción e interpretación en francés. En la traducción y estudio del Manuscrito A del Instituto de Francia muestra sus 64 folios tanto en recto como verso, con contenidos muy variables. Fue titulando cada folio de su traducción, según las materias tratadas en el manuscrito original, quedando títulos como: Mecánica, impacto, geometría; Balanzas; Centro de gravedad, equilibrio, fuerzas; Perspectiva; Reflexión; Óptica; Acústica, escultura, agua; Movimiento, pesos y fuerzas, unidas y separadas; Fundamentos de edificios; Construcción de edificios; Arcos y columnas; etc. De manera similar fue tratando los restantes Manuscritos de París en los años posteriores. 


\subsubsection{Jean Paul Richter (Dresde, 1847-Lugano, 1937)}

Historiador alemán que viajó por varias ciudades europeas y adquirió gran conocimiento del arte italiano, llevando a cabo varias publicaciones sobre este en Londres, siendo el más famoso el estudio realizado sobre Leonardo, en dos tomos, "The Literary Works of Leonardo da Vinci”, Londres - Nueva York (1883), publicado en inglés y en italiano (Ottino della Chiesa, 1972). De él se han hecho innumerables ediciones en varios idiomas y en 1939 fue reeditado y actualizado con la colaboración de su hija Irma Richter Schwaab (1876, Paris-1956, Roma).

La exposición de los trabajos se realiza en inglés, de todos los manuscritos conocidos en aquel momento, y no se transcribe el manuscrito tal como es en la realidad, sino que se selecciona por capítulos según los temas de más importancia, o que más investigó Leonardo. Se resume en un capítulo todo lo encontrado o interpretado sobre ese tema, así por ejmemplo, el libro segundo tiene capítulos sobre: Anatomía, zoología y sicología; Notas de topografía; Astronomía; Notas de escultura; Diseños de arquitectura; Armas navales; etc. Interpone en los textos copia de los dibujos de Leonardo.

La tarea realizada es digna de admiración ya que requería estudiar los más de 6.000 folios de Leonardo controlables en aquel entonces y aunarlos por temas. A la dificultad de su lectura se suma la desorganización de los folios, por un lado, por la improvisación y variabilidad de criterio de Leonardo, y por otro por la diseminación, reencuadernación e incluso recorte de algunos de ellos por el avatar de los propietarios que los dispusieron (por ejemplo, el escultor Pompeo Leoni (Milán, 1553-Madrid, 1608) que fue propietario tanto del Códice Atlántico como de los Folios de la Colección Windsor de la Royal Library, que recortó y ordenó a su manera).

\subsubsection{Charles Harvard Gibbs-Smith (Teddington, Greater London, 1909-1981)}

Fue historiador sobre aviación y aeronáutica y profesor de Historia Aeroespacial en el National Air and Space Museum (Smithsonian Institution, Washington EE. UU.), realizando varios libros e 
investigaciones sobre aeronáutica, entre ellos "The Inventions of Leonardo da Vinci”, publicado en 1978 (Gibbs-Smith, 1978).

El libro no se enfoca de manera biográfica, sino por áreas tecnológicas de las que Leonardo se ocupó, dedicando un capítulo para Aeronáutica, otro para Armas de Guerra, otro para Elementos de Máquinas, otro para Inventos vinculados al Agua, otro para Vehículos de tierra, y finalmente uno para Investigaciones sobre la Naturaleza y diseños para Arquitectura. Concluye con una lista de 102 invenciones de vínculo tecnológico que otorga a Leonardo.

El libro muestra a un Leonardo inventor ciñéndose solo a esta faceta de las múltiples que realizó. Así, en cada página de la obra muestra el manuscrito del diseño y su identificación y emplazamiento, junto con la máquina o el dispositivo actual construido según el mismo, o por el cual se hayan basado partes de este, observando que Leonardo era capaz de predecir la llegada de la tecnología del futuro. De esta forma muestra sus diseños de trajes de buceo, turbinas de agua, gatos de elevación, vehículo automotor y diferenciales de dirección de vehículos, tanques blindados (Figura 3.4 b)), paracaídas, etc. $Y$ manifiesta que $<<$ cada uno de sus diseños es una fuente continua de asombro y emoción, mostrando tanto la asombrosa inteligencia de Leonardo como una increíble anticipación del futuro>>.

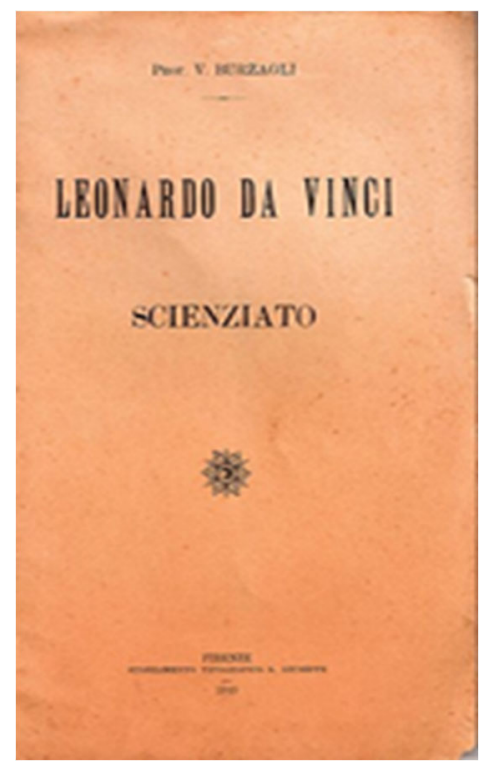

a) 


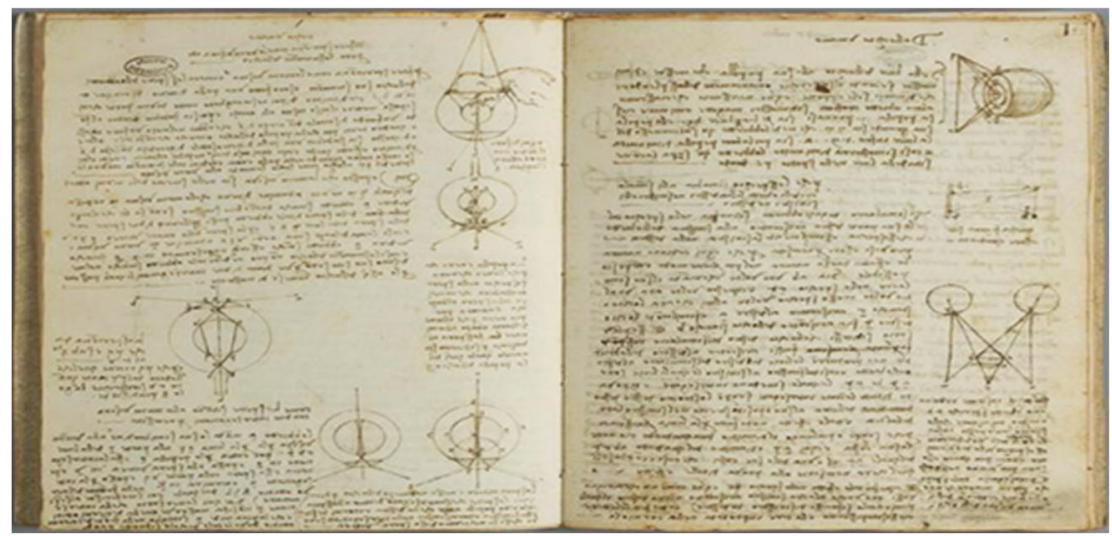

b)

Figura 3.2 a) Publicación "Leonardo da Vinci Científico" de Vicenzo Burzagli, 1910 (https://commons.wikimedia.org/wiki/File:Leodav.jpg), b) Estudio sobre la visión de Leonardo (h. 1508), Manuscrito D, ff. 3v-4r, In. de Francia investigados por Ravaisson

(https://commons.wikimedia.org/wiki/File:Leonardo_da_Vinci,_Manuscript_D ,_1508-09.jpg? uselang=es).

\subsubsection{Carlo Pedretti (Casalecchio di Reno, 1928-Lamporecchio, 2018)}

Historiador italiano, considerado uno de los mayores expertos en los trabajos de Leonardo, que titular de la Cátedra de Estudios Vincianos en la Universidad de California (Los Ángeles). En sus últimos años dirigió el Centro "Armand Hammer" de Estudios sobre Leonardo (Urbino).

Ha publicado más de 500 artículos, entre ellos varios en la "Raccolta Vinciana", en la "Achademia Leonardo da Vinci: Journal of Leonardo Studies and Bibliography of Vinciana" en su etapa americana, y en "Estudios Vincianos" en sus etapas europeas (Antoccia et al., 2003). Ha escrito más de 50 libros sobre Leonardo. Con vínculos tecnológicos cabe destacar: "Leonardo: Las Máquinas" (2002) y su posterior edición en español (Pedretti, 2007) que analiza la visión tecnológica e ingenieril de este; "Leonardo Arquitecto" (1995) (Pedretti, 1995); "Leonardo da Vinci: el Arte del Dibujo" (Pedretti, 2017); "Leonardo: Secreto de un Genio" (2015); “Leonardo: el Diseño” (2017). En un 
párrafo de "Leonardo: Las Maquinas", manifiesta: $<<A$ aproximarse a los textos del saber antiguo y medieval, Leonardo recurre al control experimental y contribuye a la renovación de la ciencia, imponiendo la justificación matemática como critica de la racionalidad>> (Antoccia et al., 2003).

El catedrático de Historia del Arte en la Universidad de Oxford, Martin Kemp (Reino Unido, 1942), escribió sobre Pedretti, <<es el que más profundo conocimiento tiene de los manuscritos de Leonardo>> (Kemp, 2006).

\subsubsection{Fritjof Capra (Viena, 1939)}

Doctor en Ciencias Físicas por la Universidad de Viena, especializado en física subatómica y profesor en varias universidades (California, Berkeley y San Francisco) es también autor de varios títulos relacionados con las implicaciones sociales y filosóficas de la Ciencia. En relación con Leonardo, sus obras más reconocidas son The Science of Leonardo (2008), y Learning from Leonardo (2013). En ellas analiza con rigor y escrúpulo científico la obra y vida de Leonardo, coordinando ambas armoniosamente.

Lo destaca como "pensador sistémico" manifestando su <<habilidad excepcional para interconectar observaciones e ideas procedentes de distintas disciplinas, anida en el corazón mismo del enfoque que Leonardo tenía del conocimiento y la investigación >> (Capra, 2008). Lo establece como precursor del método científico, y como alternativa al mecanicismo, mediante el apoyo de su ciencia en dos pilares básicos, conocidos hoy en día como la ecología y al organicismo. Así, al referirse a cómo estaba la ciencia a finales del Medioevo, manifiesta: <<Las autoridades condenaban los experimentos científicos y cualquier crítica a la ciencia de Aristóteles era para ellas un ataque a la Iglesia. Leonardo rompió con esta tradición cien años antes que Galileo y Bacon, desarrollando por sí solo un nuevo enfoque empírico de la ciencia, que implicaba: a) La observación sistemática de la naturaleza. b) El razonamiento lógico. c) Ciertas formulaciones matemáticas. Precisamente las características principales de lo que se conoce como método científico>>. Concluye con que $<<$ Leonardo es el primer científico moderno, mucho antes que Galileo, Bacon y Newton>> (Capra, 2008).

Busca la parte más ecológica de la obra de Leonardo, y sus vínculos con la Naturaleza; definiendo a Leonardo como un pensador 
sistémico, ecologista y teórico de la complejidad, científico y artista con profundo respeto por la vida y hombre con fuerte deseo de trabajar en beneficio de la humanidad. Manifiesta en sus conclusiones que la Historia de la Ciencia actual sería muy distinta si sus manuscritos, en vez de mantenerse diseminados y desconocidos durante 400 años, se hubiesen hechos públicos y estudiados adecuadamente después de su redacción.

\subsubsection{Martin Kemp (Reino unido, 1942)}

Catedrático de Historia del Arte en la Universidad de Oxford y una de las máximas autoridades vivas sobre la ciencia y el arte de Leonardo. Ha escrito varios libros y artículos sobre Leonardo, destacando desde el punto de vista tecnológico y científico, "Leonardo da Vinci: Las obras maravillosas de la Naturaleza y el Hombre" (1982, reeditado en 2006) y "Leonardo" (2006), y de manera generalista "La Ciencia del Arte" (2000).

Es el creador del Proyecto "Universal Leonardo", que se ha llevado a cabo a través de toda Europa desde 2006, en concreto en Florencia, Oxford, Londres, Múnich y Milán. En él se han realizado exposiciones científicas y recursos educacionales, con miras a publicitar los trabajos de Leonardo sobre el arte, la ciencia y la tecnología. Muestra a través del tiempo, la aparición, de los manuscritos, de sus invenciones, de sus dibujos, de sus pinturas y de su vida; con imágenes y pequeños textos explicativos. Hoy sigue estando accesible solo digitalmente a través de http://www.universalleonardo.org

Incide en que la "analogía" es la principal técnica de Leonardo, para explicar el comportamiento de las cosas. La Naturaleza despliega sus funciones, y el ingenio humano debe imitarlas, pero todo lo diseñado (dispositivos, elementos, máquinas) debe seguir su "Principio de Necesidad", como hace la Naturaleza, donde todas las formas diseñadas desempeñan alguna función. $Y$ lo establece como padre de la Topología (Figura 3.3 a)).

Destaca la relación leonardiana "Función-Forma", asimilable a la existente en la naturaleza, y que tantas veces utilizó Leonardo para diseñar o crear; aunque a veces la naturaleza no alcanza y el hombre la completa con mecanismos que ella no había creado: aunque la 
madera ya está creada, <<la naturaleza no ha creado el arco para proyectar flechas $>>$ (Kemp, 2006).

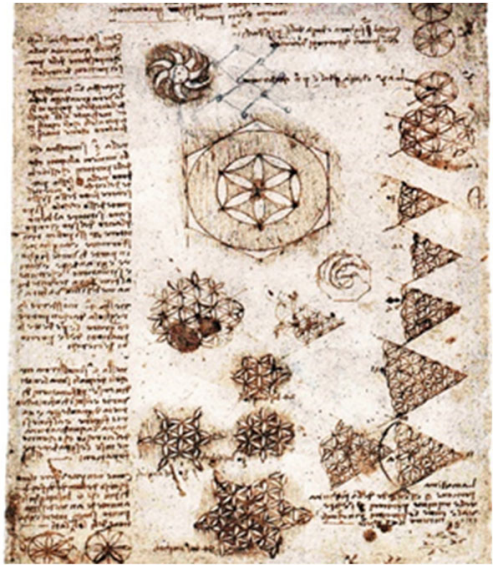

a)

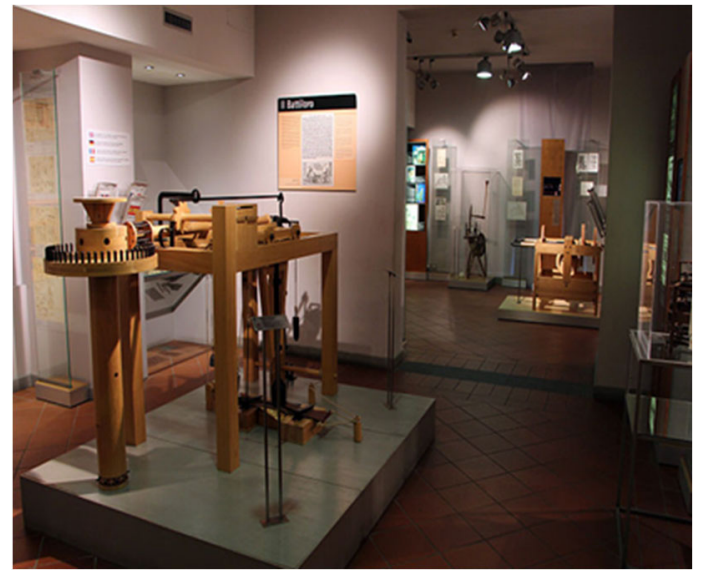

b)

Figura 3.3 a) Dibujos topológicos de Leonardo Cod. Atlántico f. 459r, 14781519

(https://commons.wikimedia.org/wiki/File:Leonardo_da_Vinci_\%E2\%80\%93 _Codex_Atlanticus_folio_459r.jpg), b) Museo Leonardiano de Vinci, sede del Museo Ideale

(https://commons.wikimedia.org/wiki/File:Vinci,_museo_leonardiano_(sede_ dell\%27ex-museo_ideale)_05..JPG).

\subsubsection{Alessandro Vezzosi (Italia, 1950)}

Crítico de arte, experto en Leonardo y en estudios interdisciplinarios y museología creativa. Fue profesor en la Universidad de Progetto en Reggio Emilia y es profesor honorario de la Academia delle Arti del Disegno de Florencia.

Es el fundador y director del "Museo Ideale Leonardo da Vinci", inaugurado en 1993 (Figura 3.3 b)) en el municipio de Vinci, que está concebido como una "máquina" museo y obra de arte viva para la investigación y el redescubrimiento del Leonardo artista, científico, inventor y diseñador. Este es accesible digitalmente en https://www.museoleonardo.it/museo-ideale/.

Ha realizado publicaciones de libros, en varios idiomas, sobre artistas italianos del Renacimiento, principalmente de Leonardo, entre los que destaca: "Leonardo da Vinci: hombre del Renacimiento", "Leonardo: utopía arte y la ciencia", "Leonardo da Vinci: arte y la ciencia del 
universo", "Leonardo da Vinci: La Mente del Renacimiento" y "Leonardo Infinito".

De todas ellas, desde el punto de vista científico técnico, cabe resaltar "Leonardo da Vinci: arte y la ciencia del universo" (2011), donde, aunque la narración del libro sigue el recorrido de la vida de Leonardo, esta se acompaña de ilustraciones de sus códices, con rigurosos datos históricos, pero resaltando la faceta científica en cada etapa, como, por ejemplo: <<El análisis de las fuerzas, del peso y del movimiento, de la inercia, del equilibrio y del principio de la balanza ofrece a Leonardo ejemplos de Mecánica del universo>>. Igualmente refleja los orígenes de sus proyectos y sus descubrimientos, y sus fuentes de información, apoyadas siempre con la experiencia o el experimento. Así, nos encontramos con manifestaciones como: <<su método que consiste en oponer su experiencia analítica de los fenómenos, a las concepciones tradicionales y dogmáticas $>>$. Finalmente destina un apartado de la publicación a la "Maquinaria de Artista", en la que enumera varios de sus diseños tecnológicos (el carro automotor (Figura 3.3 b)), las armas, los diseños marinos y aéreos, la tramoyas para teatro, la bicicleta, catalejos, etc.). También manifiesta que, aunque hay que huir del <<mito del Leonardo sobrehumano, precursor casi diabólico, autor de toda suerte de invenciones; no se puede negar la creación por Leonardo de un nuevo alfabeto tecnológico>>.

\subsubsection{Patxi Lanceros (Bilbao, 1962), y Juan Barja (La Coruña, 1954).}

Patxi Lanceros es profesor Titular de Filosofía Política en la Universidad de Deusto (Bilbao), así como autor de varios libros y colaborador habitual en diversas revistas y publicaciones periódicas. Y Juan Barja es abogado, editor, además de poeta, ensayista y colaborador en varias revistas. También fue director del Círculo de Bellas Artes de Madrid durante 15 años.

Los autores han recopilado en su libro "Leonardo da Vinci, el libro del Agua" (2017) todas las citas, estudios, dibujos y experimentos sobre "el agua" que existen en el conjunto de los más de 7000 folios que comprenden todos los manuscritos conocidos de Leonardo, intentando dar forma a un libro que él mismo había manifestado que iba a realizar pero que nunca llegó a materializar. Lo han ordenado en seis capítulos: el primero corresponde a los propios apuntes de Leonardo, indicando la cita y el origen del folio y manuscrito. En el 
segundo se plasman los procesos que unen y separan "elementos" (Agua, Tierra, Aire, Fuego) y "figuras" (Punto, Línea, Volumen). En el tercero se reúnen apuntes sobre los movimientos, fuerzas, resistencias y choques, dinámica a la que Leonardo dedicó mucho interés y tiempo. El cuarto se ciñe a plasmar las formas que puede adoptar el agua, desde la simple gota, el maligno o bondadoso río, o el magnánimo mar. El quinto muestra algunos de sus proyectos relacionados con el agua (desvío del río Arno, canales para Florencia, diques, jardines, etc.). Y finalmente en el sexto capítulo se manifiestan las consideraciones sobre el agua, tanto literarias, como físicas, etc. (el diluvio, los fósiles, etc.), así como sus premoniciones a finales inciertos.

Finalmente, defienden para la obra de Leonardo y su vida el concepto del filósofo griego Heráclito (Éfeso, 540 a. C.- 480 a. C.) de "Panta Rei”: todo está cambiando continuamente.

\subsubsection{Sara Taglialagamba (Pisa, 1977)}

Es una joven historiadora de arte e investigadora sobre los trabajos y vida de Leonardo, también especializada en el Renacimiento italiano. Ha sido Profesora Asistente del Departamento de Ingeniería del Instituto Politécnico de Milán y en Los Ángeles, University of Southern California, e investigadora en el "Istituto Nazionale di Studi sul Rinascimento" de Florencia. Colaboradora durante años de Carlo Pedretti, ha realizado muchas publicaciones y conferencias sobre Leonardo, algunas compartidas con este.

Ha publicado libros en italiano e inglés que abarcan casi todas las facetas técnicas y de Leonardo. Cabe nombrar desde ese punto de vista "Leonardo da Vinci. Automazioni \& Robótica", "Leonardo \& la Natura", "Leonardo \& la Architettura" y "Leonardo \& la Ingegneria".

En su publicación en italiano, "Leonardo \& la Ingegneria" (Taglialagamba, 2010), con presentación de C. Pedretti, empieza por un capítulo donde enumera el progreso de la ciencia, la técnica y el arte del Renacimiento, para después desglosar las Máquinas de Leonardo, dedicando un capítulo para las máquinas civiles, otro para las militares, otro para máquinas de vuelo, y otro para el "Códice del vuelo de los pájaros" o de Turín. Finalmente dedica un capítulo a la trayectoria de vida de Leonardo, de manera resumida. En cada capítulo muestra las imágenes más representativas de los dibujos de máquinas y dispositivos de los códices, junto con su identificación de 
folio y códice al que pertenece, así como acompaña su correcta explicación.

La parte de Leonardo que se dedica a la arquitectura, la trata en "Leonardo \& la Architettura" (Taglialagamba, 2010), también en italiano, pero en esta publicación los capítulos iniciales están argumentados sobre el recorrido de Leonardo por las distintas ciudades donde trabajó (Florencia, Milán, Florencia, Romaña, Milán, Roma y Cloux-Amboise). Después dedica capítulos específicos para edificios religiosos, arquitectura militar y fortificaciones, arquitectura teatral y finalmente uno para su vida de manera resumida. Al igual que la publicación anterior, muestra imágenes de los códices con referencias arquitecturales, junto con su identificación y una correcta explicación.

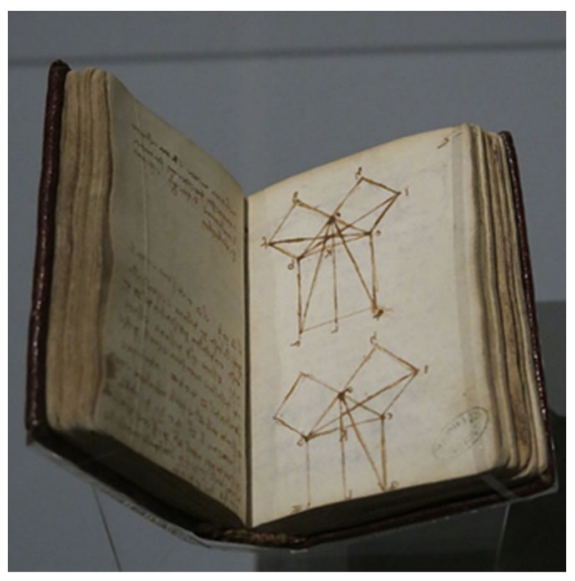

a)

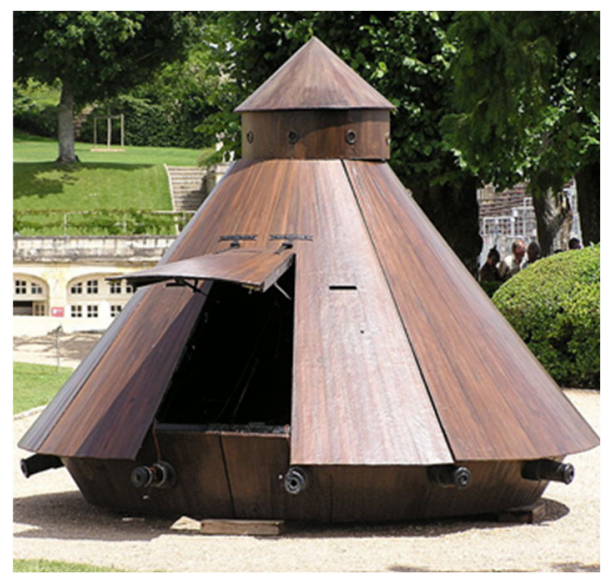

b)

Figura 3.4 a) Manuscrito K, Inst. de Francia, ff. 14v-15r, con demostración teorema de Pitágoras

(https://commons.wikimedia.org/wiki/File:Leonard_de_Vinci_D\%C3\%A9monstration_euclidienne_du_th\%C3\%A9or\%C3\%A8me_de_Pyt hagore.jpg?uselang=es), b) Prototipo de Tanque del Museo de Amboise

(Diseño de Leonardo, British Museum, Pupham no 1030, Londres) https://commons.wikimedia.org/wiki/File:DaVinciTankAtAmboise.jpeg?uselan $g=e s-f o r m a l)$. 


\subsubsection{Miguel Ángel Contreras López (Madrid, 1969)}

Es profesor titular en el Departamento de Expresión Gráfica, Diseño y Proyectos de la Universidad de Málaga, y tiene publicaciones sobre dibujo técnico, sobre utilización de herramientas multimedia en la representación gráfica y sobre arqueología industrial. Defendió su tesis doctoral titulada "Leonardo da Vinci: Ingeniero" en noviembre de 2015 (Contreras, 2015).

La tesis trata de considerar a Leonardo como uno de los ingenieros más importantes del Renacimiento e investigar cómo podría haber influido en posteriores ingenieros, y sus inventos e innovaciones en otros de épocas posteriores, con el fin de reivindicar su figura como uno de los grandes ingenieros de toda la historia. Para ello, identifica, analiza y ordena los principales temas que Leonardo escribió y dibujó sobre ingeniería militar, ingeniería mecánica, ingeniería hidráulica, ingeniería civil e ingeniería aeronáutica, dispersos por sus manuscritos, dedicando a cada una de estas especialidades de la ingeniería un capítulo de la tesis. También reflexiona sobre la figura del ingeniero hoy día, y la compara con la faceta ingenieril de Leonardo. Cabe resaltar el capítulo 5, destinado a la ingeniería mecánica en la que Leonardo fue un gran especialista, donde después de realizar un análisis y clasificación de todos los elementos básicos del movimiento de máquinas conocidos actualmente, busca y describe los mismos extrayéndolos de los dibujos y diseños dispersos en el conjunto de los manuscritos del maestro y los compara adecuadamente con la opción actual.

Finalmente, complementa su exposición con la investigación específica y la elaboración de un modelo tridimensional del famoso automóvil, o automotor de Leonardo, considerado el primero de la historia, que figura en el folio 812 r del Códice Atlántico de la Biblioteca Ambrosiana de Milán. Esta animación sirve para ayudar a comprender, y analizar los órganos complejos de los elementos que gobiernan cualquier máquina que físicamente aún no existe y tan sólo se encuentra esbozada en unos manuscritos incomprensibles para la mayoría del público. 


\subsection{Instituciones más conocidas, vinculadas a la obra de Leonardo}

\subsubsection{Raccolta Vinciana (Colección Vinciana, 1905)}

Ubicada en "Castello Sforcesco" (Figura 3.5 a)) de Milán, donde vivió largo tiempo Leonardo. Después de la restauración del Castello, entre finales del siglo XIX y principios del XX, se pensó en agregarle una colección de estudios y materiales leonardescos, que se adjuntaría al Archivo Histórico Cívico de Milán. La idea tuvo gran aceptación y se recogieron varias donaciones, creándose una biblioteca especializada sobre Leonardo, en 1905, y a la par una revista con el nombre de "Raccolta Vinciana". Desde entonces, la colección ha ido creciendo con numerosas publicaciones de todo el mundo y se han unido gran cantidad de académicos e investigadores, que bien han regalado sus publicaciones o bien han colaborado en la revista. Así se mantuvo bajo la Municipalidad de Milán hasta 1955, cuando se separó del Archivo Histórico y se constituyó como entidad dependiente del Estado italiano.

La revista es hoy una importante fuente de información para investigar la obra de Leonardo. En https://raccoltavinciana.milanocastello.it/ puede visitarse el "Ente Raccolta Vinciana".

\subsubsection{Biblioteca Leonardiana de Vinci (1928) y el Proyecto e-Leo}

Creada en 1928, en el municipio donde nació Leonardo, dispone de una una gran colección de ediciones de las obras de Leonardo a partir de 1651. Ha creado un archivo digital, el denominado Proyecto "eLeo", que, con fondos europeos, ha dado la posibilidad de hacer accesible al público en general (pero no descargable con alta resolución) prácticamente todos los manuscritos de Leonardo y por el que se puede navegar por los casi 7.000 folios conocidos hoy en día. Además, de manera automática realiza la transcripción de la escritura utilizada por Leonardo (con letra especular y variante toscana antigua) al italiano actual, siendo pues una gran herramienta para estudiosos e investigadores de la obra de Leonardo. El archivo e-Leo, puede consultarse enhttp://www.leonardodigitale.com. 


\subsubsection{Museo "Nazionale della Scienza e della Tecnologia Leonardo da Vinci" (Milán)}

Fue creado en 1953 y es gestionado por una Fundación que lleva su mismo nombre. Es el museo dedicado a la Ciencia y a la Tecnología más grande de Italia, con más de $50.000 \mathrm{~m}^{2}$ de exposición. También es líder en Italia en conservación y valoración de colecciones técnicocientíficas, de ingeniería, de matemáticas, etc.; así como ofertando acciones formativas y educativas en esos temas. Su objetivo es involucrar a la ciudadanía en temas científicos con metodologías innovadoras, implicando tanto a la comunidad científica, como a los ciudadanos.

Su catálogo de colecciones técnico-científicas es muy extenso: astronomía, equipo industrial, equipamiento técnico-científico, metales, modelos matemáticos, técnicas de sonido, telecomunicaciones, transporte ferroviario, transporte de agua, transporte aéreo, etc.

Tiene un apartado específico (salas de exposición, investigación, etc.) sobre la historia y trabajos de ingeniería de Leonardo que, en su visita on-line, se denomina "Modelos Leonardescos". Pretende que este sirva de símbolo de la unión de las culturas humanística y científica, y de ejemplo y experiencia para construir una visión basada en las conexiones del saber. La colección leonardiana on-line alberga más de un centenar de maquetas, algunas de ellas a tamaño real, de inventos, dispositivos y máquinas diseñadas por Leonardo, desde sus varios modelos de grúas, de cabestrantes (Figura 3.6), de máquinas de dragar, de cañones y bombardas, de máquinas textiles, de máquinas para hacer tornillos, de pulir espejos, de imprenta, escafandras y trajes de buzo, el tanque de guerra, el automotor o automóvil, el paracaídas, etc. Así como modelos de sus diseños arquitectónicos de iglesias, de fortalezas y maquetas de compuertas hidráulicas, de hornos, de molinos, de puentes, así como de máquinas voladoras y de planeo. También hay maquetas de sus ensayos científicos, como: el "estudio de rozamiento en plano inclinado", el de "fricción en rodillos", y de instrumentos de medida de la resistencia de un cable, destiladores, odómetros, etc. 


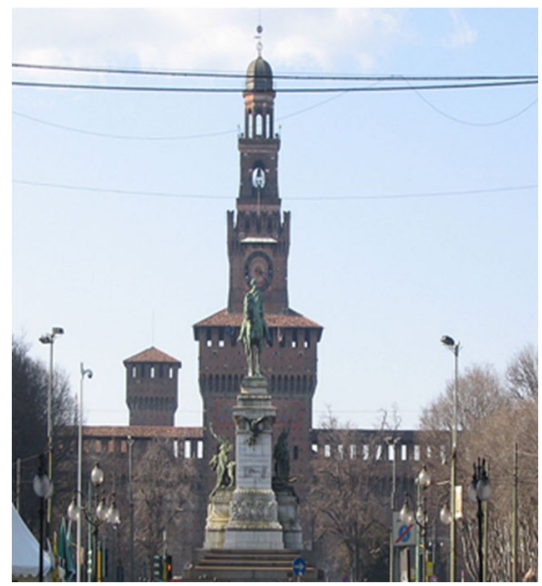

a)

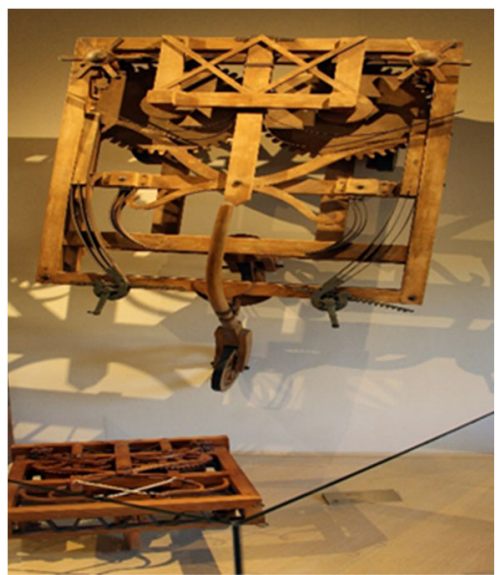

b)

Figura 3.5 a) Castello Sforcesco de Milán, sede del "Ente Raccolta Vinciana"

(https://commons.wikimedia.org/wiki/File:Frontal_del_castillo_de_sforzesco, Mil\%C3\%A1n.JPG?uselang=es-formal), b) Prototipo de Carro automotor

de Leonardo, (diseñado en Cod. Atlántico, f. 812 recto, Biblioteca Ambrosiana de Milán), del Museo Leonardiano de Vinci (https://upload.wikimedia.org/wikipedia/commons/5/5c/Museo_leonardiano di_vinci\%2C_modello_di_carrello_automotore\%2C_da_codice_atlantico.JP

G).

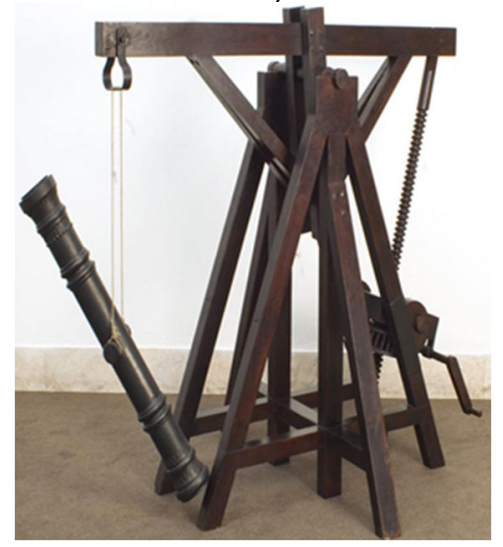

Figura 3.6 Maqueta de Cabestrante (realizada por Argan Giovenale), para elevar cañones y columnas (según diseño de Leonardo) del Museo de la Ciencia y Tecnología de Milán

(http://www.museoscienza.it/dipartimenti/catalogo_collezioni/scheda_oggett o.asp?idk_in=ST070-00061\&arg=Modelli\%20leonardeschi). 
Cada invento, ensayo, máquina o instrumento, posee después una hoja de estudio específico de esta, con las siguientes indicaciones: características físicas del modelo (dimensiones, peso, tipo de materia, etc.), persona que fabricó el modelo y fecha en que se hizo; descripción de esta; su función y uso; y finalmente referencias bibliográficas importantes sobre ello.

El idioma utilizado es el italiano, con posibilidad de cambio al inglés y el acceso digital puede hacerse a través de la web https://www.museoscienza.org.

\subsection{Conclusiones}

La relación de estudiosos e investigadores de Leonardo se ha plasmado de manera cronológica y haciendo constar lo más destacado del autor o investigador, así como la característica más importante que este ha encontrado en Leonardo en su área de estudio.

Cabe manifestar que, por falta de espacio, no han podido figurar en esta selección biógrafos puros, como el historiador británico Kenneth Clark (Londres, 1903-Hythe, 1983), o especializados a su etapa científica, como el físico y profesor militar Vicenzo Burzagli (Montevarchi, 1834-Fiesole, 1917) en su obra de 1910, "Leonardo da Vinci científico" (Figura 3.2 a)). O leonardistas de prestigio como Eugéne Muntz (Soultz sous Forêts, 1845-París, 1902). O investigadores específicos como el ingeniero Ladislao Reti (Rijeka,1901-Monza,1973) con sus estudios sobre les Códices de Madrid I y II y su publicación en facsímil. O, más actualmente, investigadores sobre las máquinas e ingenios de Leonardo como los historiadores de la ciencia Paolo Galluzzi (Florencia, 1942) y Mario Taddei (Bolonia, 1972), o el profesor de la Universidad de Granada, David Hidalgo García, con su tesis doctoral "Leonardo da Vinci: Arquitectura y urbanismo. El concepto de ciudad ideal" (2014, Universidad de Alicante). Ni biografías extravagantes, como el análisis psicológico controvertido sobre el maestro, publicado por el padre del psicoanálisis Sigmund Freud (Príbor, 1856-Londres, 1939) en 1910. Ni el poeta, ensayista y filósofo francés Paul Valery (Sète, 1871-París, 1945), con su libro "Introducción al Método de Leonardo da Vinci" (1895) por el que pretendía explicar cómo es el acto de crear de un artista, tomando a Leonardo como ejemplo, y donde escribe sobre este: <<Erase una vez un hombre que podía mirar el mismo fenómeno o el mismo objeto, ya como pintor, ya como naturalista, como físico o 
como poeta; y ninguna de estas visiones era superficial >> (Racionero, 1986).

\section{Referencias}

Antoccia, L., Chastel, A., Cianchi, M., Galluci, P., Laurenza, D., Papa, R., \& Pedretti, C. (2003). Atlas Ilustrado de Leonardo Da Vinci. Arte y ciencia. Las Máquinas. Susaeta Ediciones: Madrid.

Capra, F. (2008). La ciencia de Leonardo. Editorial Anagrama: Barcelona.

Códice Magliabechiano. (1537-1541). Copia digitalizada por Google. Obtenido

https://archive.org/details/ilcodicemagliab00freygoog/page/n7/ mode/2up.

Contreras López, M. (2015). Leonardo da Vinci Ingeniero. Tesis Doctoral Obtenido de https://riuma.uma.es/xmlui/handle/10630/11449

Da Vinci, L. (Versión traducida de Rejón De Silva, D.). (1784). Tratado de la Pintura de Leonardo da Vinci (Facsímil Lib. Paris-Valencia 1999).

Gibbs-Smith, Ch. (1978). The Inventions of Leonardo Da Vinci. Charles'Scribner's Sons, by Phaidon Press Limited: London.

Kemp. M. (2006). Leonardo. Fondo de Cultura Económica: México.

Lanceros, P., \& Barja, J. (2018). Leonardo Da Vinci: El libro del agua. Abada Editores: Madrid.

Lomazzo, P. (1584). Trattato dell' arte della pittura, scoltura et architettura. Obtenido de https://digibug.ugr.es/handle/10481/9622

Nicholl, C. (2006). Leonardo, el Vuelo de la Mente. Círculo de Lectores: Barcelona.

Ottino della Chiesa, A. (1972). La obra pictórica de Leonardo. Ed. Noguer: Barcelona.

Pedretti, C. (1995). Leonardo architetto. Ed. Electa: Milano.

Pedretti, C. (2007). Leonardo. Las máquinas. Cartoné editorial: 
Pedretti, C. (2017). Leonardo da Vinci: el arte del dibujo. Edimat: Madrid.

Racionero, L. (1986). El desarrollo de Leonardo da Vinci. Ed. Plaza y Janes: Barcelona.

Ravaisson-Mollien, C. (1881). Les Manuscrit de Léonard de Vinci. A. Quantin editeur. The Warburg Institute: Paris.

Richter, J. (1883). The Literary Works of Leonardo Da Vinci. London: Ed. S. Low, Marston, Searle \& Rivington: London.

Taglialagamba, S. (2010). Leonardo \& I'ingegneria. CB Edizioni: Poggio a Caiano.

Taglialagamba, S. (2010). Leonardo \& l'architettura. CB Edizioni: Poggio a Caiano.

Vasari, G. (1550). Las vidas de los más excelentes arquitectos, pintores y escultores italianos desde Cimabue a nuestros tiempos, descritas por Giorgio Vasari, pintor natural de Arezzo. Con una útil y necesaria introducción a las artes de aquéllos. Obtenido de http://www.historia-del-arte-erotico.com/vasari/.

Vezzosi, A. (2011). Leonardo Da Vinci, ciencia y arte del universo. Ed. Blume: Barcelona. 



\title{
Capítulo 4 Teorías, métodos y técnicas para el diseño de sistemas técnicos en la obra de Leonardo da Vinci
}

\author{
"Antes de convertir un caso aislado en regla general, se debe \\ repetir dos o tres veces el experimento, observando si cada vez los \\ mismos efectos se producen". \\ LEONARDO DA VINCI (Manuscrito L, folio 72 r, de la Biblioteca del \\ Instituto de Francia, París).
}

\subsection{Introducción}

Leonardo (Vinci 1452 - Amboise 1519), aunque más conocido como artista y pintor, fue un genio multidisciplinar capaz de destacar en la mayoría de las áreas del conocimiento; la ingeniería, la arquitectura, la zoología, la medicina, la botánica, etc. incluso la música, no escaparon a su voraz interés por dominar todo lo conocido.

En el campo de la ingeniería de producto, fue capaz de diseñar o proyectar barcos con cascos acorazados y con movimiento a palas, puentes móviles, esculturas de bronce de más de $7 \mathrm{~m}$ de altura, escafandras y submarinos, bicicletas, vehículos autopropulsados precursores del automóvil, instrumentos musicales, etc., incluso autómatas humanoides. Mientras que en el de la arquitectura e ingeniería civil diseñó fortalezas y defensas de ciudades, canales de saneamiento, desvío de ríos y hasta proyectó una "ciudad ideal".

Sólo unos pocos de esos diseños o proyectos se hicieron realidad en aquel entonces, por lo que algunos de sus contemporáneos no tomaron en serio varios de sus trabajos. Debido a ello, gran cantidad de estos se quedaron en lo que hoy denominamos Diseño Conceptual, otros alcanzaron el Diseño Preliminar, mientras que sólo unos pocos llegaron al Diseño Detallado, atendiendo como tales denominaciones 
a lo dispuesto por Martínez-Val (1993) en referencia al proceso de diseño de sistemas técnicos (Martínez-Val, 1993).

Hoy el puente que Leonardo diseñó a nivel conceptual en 1502 para el Sultán Otomano Beyazid II en el Cuerno del Oro (Estambul), es una realidad similar en la ciudad de Aas, Noruega. El Caballo Sforcesco de 7,30 m de altura, que diseñó a nivel de detalle, puede contemplarse en la plaza del hipódromo de Milán ("Il Cavallo"), y en la ciudad Grand Rapids de Michigan ("American Horse"). Mientras que su diseño de detalle del Barco de Palas fue copiado y materializado en el siglo XVIII por el Ingeniero Robert Fulton, en sus barcos a vapor.

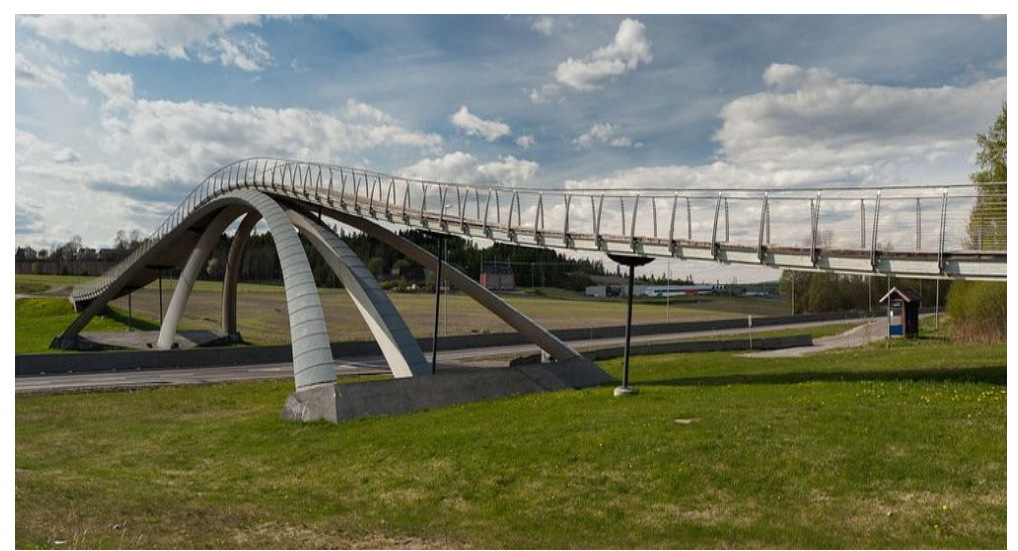

a)

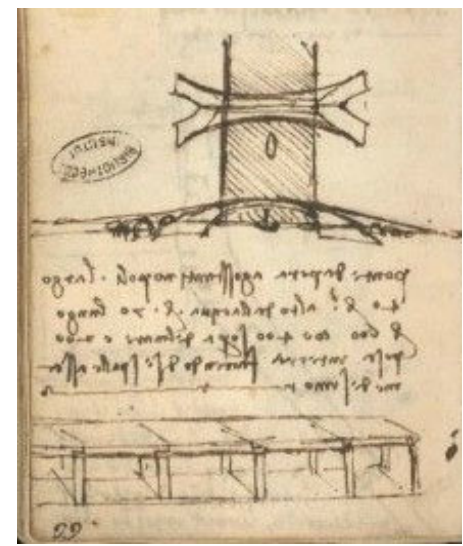

b)

Figura 4.1 a) Puente ideado por Leonardo y construido en Noruega por Vebjorn August Sand (https://estructurando.net/revista-estructurando-no-4ano-2015/ imagen de Sigurd Rage), b) Manuscrito L, f. 65v, del Instituto de

París (https://commons.wikimedia.org/wiki/File:Leonardo_Bridge.jpg). 
Teorías, métodos y técnicas para el diseño de sistemas técnicos en la obra de Leonardo da Vinci

\subsection{El método científico en Leonardo}

El método científico se basa en observar un fenómeno, elaborar unas hipótesis, llevar a cabo los experimentos correspondientes y confirmar o descartar dicha hipótesis. Si los experimentos confirman las hipótesis, se establece el vínculo de certeza (ley) y si no lo confirman, se vuelve al inicio. Leonardo, como precursor de este método, lo hacía de manera similar, optando en sus investigaciones por el sistema experimental o indagatorio de raigambre aristotélica. Así escribe <<"las Matemáticas nos brindan la certeza suprema"; "ninguna investigación humana puede llamarse verdadera ciencia si no pasa por la demostración matemática" o "ninguna certeza existe allí donde no puede aplicarse alguna de las ciencias matemáticas o de las que están unidas con ellas">> (Nicholl, 2005).

Sus investigaciones aúnan ética (poseía un carácter humanista al tiempo que inconformista) junto con estética (su gran formación en dibujo y pintura le daban una visión tanto del conjunto como de las partes). Algunas de sus propias citas sobre su manera de realizar investigación científica son (García de Zúñiga, 2005):

<"Antes de avanzar en una investigación haré alguna experiencia, pues mi intención es alegar ante todo la experiencia y demostrar luego, con el razonamiento, porque tal experiencia ha de operar de tal modo".

"Y ésta es la regla verdadera según la cual han de proceder los observadores de los efectos naturales. Por más que la naturaleza empiece por la razón y termine en la experiencia, nosotros debemos seguir la marcha contraria, es decir, empezar, como lo expresé antes, por la experiencia, y con ella investigar la razón."

"La experiencia no se equivoca jamás, solo se equivocan vuestros juicios, que se prometen resultados extraños a la experimentación personal'>> (Vezzosi, 2011).

Así, por ejemplo, se preocupó por la solidez de las vigas, y llegó a realizar formulaciones matemáticas sobre su flexión. Consiguió definir leyes, aunque imperfectas, en relación con la línea elástica en el caso de las secciones diferentes (para vigas cuadradas, horizontales y apoyadas en sus extremos) llegando a observar que la resistencia varía en relación con el cuadrado de su longitud. 


\subsection{La Teoría de Sistemas en Leonardo}

En el proyecto de sistemas técnicos (equipos, maquinas, artefactos, etc.), por ser considerados estos complejos, las partes no pueden ser diseñadas de manera individual, sin ser afectadas por las de su entorno, es decir, tienen carácter sistémico. Por ello, es necesario observar la relación de cada una de las partes con el todo u objetivo global a alcanzar (sistema objeto), así como entre ellas. De ahí la conveniencia, para el estudio del objeto, de considerar la división en subsistemas y componentes, aprovechando las zonas con menores interferencias. Es decir, deben estudiarse a la vez con una visión interdisciplinar, al menos en las etapas iniciales.

Leonardo, no sólo fue capaz de crear sistemas complejos como relojes, mecanismos, y máquinas, sino que, aprovechando los conocimientos alcanzados en todos estos campos y en el de fisonomía humana (adquirido de joven en el taller del escultor y pintor florentino Andrea Verrocchio) y en la anatomía forense (realizados con Marcantonio della Torre, profesor de anatomía de la Universidad de Pavía), los relaciona todos, y los observa desde la globalidad e interdependencia. Así, identifica al cuerpo humano como un sistema complejo (considera que así funciona la Naturaleza) y es capaz de extrapolar esos conocimientos metabólicos y orgánicos a sus diseños. Proyecta y hace funcionar incluso un autómata humanoide.

Constituye así un claro anticipo de las estrategias actuales de diseño, partiendo de la consideración de su objeto como un sistema global e interdependiente. $Y$ también de los principios del diseño sostenible o ecológico, consciente de las influencias sobre el clima, el paisaje, los seres vivos y el conjunto de la Naturaleza. En relación con esto escribe <<"Nunca se encontrará invento más bello, más sencillo o más económico que los de la naturaleza, pues en sus inventos nada falta y nada es superfluo"; "El mundo está regido, no por Dios, sino por la incesante creatividad de la naturaleza">> (García de Zúñíga, 2005).

En 1493, para el posible proyecto de expansión de Milán después de un largo periodo de peste, diseña la ciudad ideal (su "ciudad nueva") gracias a sus conocimientos de urbanismo, arquitectura e hidráulica y utilizando de manera precursora criterios de organización racional, funcional y ecológica. Dispone los cursos de agua, el alcantarillado y distintas vías de circulación interior (a ser posible una superior para las personas y otra inferior para carros y caballerías) todo ello en busca de criterios de belleza y salubridad. Incluso impone a los establos 
Teorías, métodos y técnicas para el diseño de sistemas técnicos en la obra de Leonardo da Vinci

aberturas para ventilación natural. Escribe al respecto $<<$ Los suministros como la madera, el vino y otras similares se llevarán por una puerta, mientras que los retretes, establos y otras materias fétidas deberán vaciarse subterráneamente $>>$. Unos pocos años antes de su muerte, repetirá otro diseño conceptual con dichos principios racionales y ecológicos para Francisco I rey de Francia, en la denominada ciudad geométrica de Romorantin.

Leonardo admiraba y dominaba la geometría, pero para él la complejidad de la naturaleza no podía reducirse a cifras y análisis mecánicos. Su atención especial a las cualidades, al dinamismo, y a la visión de conjunto son una parte esencial de su ciencia, presentes hoy en los actuales enfoques sistémicos y en la teoría de la complejidad (Pigem, 2013).

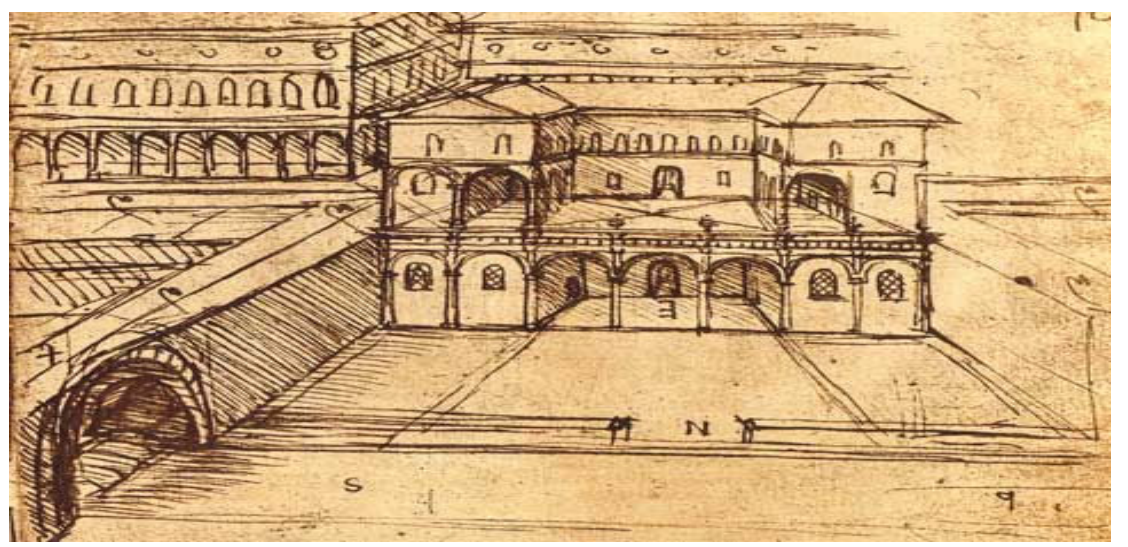

Figura 4.2 Boceto de su "ciudad nueva" (Manuscrito B, f.16r de la Biblioteca del Instituto de Francia, París)

(https://commons.wikimedia.org/wiki/File:Leonardo_da_Vinci_-_19553972.jpg).

\subsection{Los ensayos}

Para sus proyectos y diseños, Leonardo precisaba conocer los esfuerzos que podían realizar tanto los medios materiales a utilizar, como los recursos humanos empleados. Por ello realiza sus propios estudios de resistencia de materiales y sobre la naturaleza humana. Así, estudia el comportamiento a pandeo en vigas según se van aplicando cargas en su centro. Igualmente lo hace con cuerdas y cables cuando son sometidas a esfuerzos, tanto de manera directa 
como a través de poleas (Jaramillo, 2011). También hace estudios sobre el rozamiento entre distintos cuerpos y sobre elementos rodantes en distintas superficies. Todo ello para establecer posibles estimaciones trasladables con posterioridad a cada uno de sus proyectos.

Los Códices de Madrid I y II se titulan respectivamente "Tratado de estática y mecánica" y "Tratado de fortificación, estática y geometría". Los Manuscritos del Instituto Francés de París, en concreto el Manuscrito "E", es un tratado de física y mecánica, y el "M", uno de geometría. Mientras que en el Códice Forster de Londres existen temas de geometría, hidráulica y física. Finalmente, el Códice Atlántico (Biblioteca Ambrosiana de Milán), también dispone de folios con temas de mecánica, física y matemáticas.

Aunque sus estudios de mecánica adolecen de algunos errores, también se le reconocen algunos aportes a la ciencia y resistencia de materiales, como ser el primero en dibujar la catenaria y proponer su estudio mediante un modelo discreto aún hoy en uso (Truesdell, 1975). 
Teorías, métodos y técnicas para el diseño de sistemas técnicos en la obra de Leonardo da Vinci

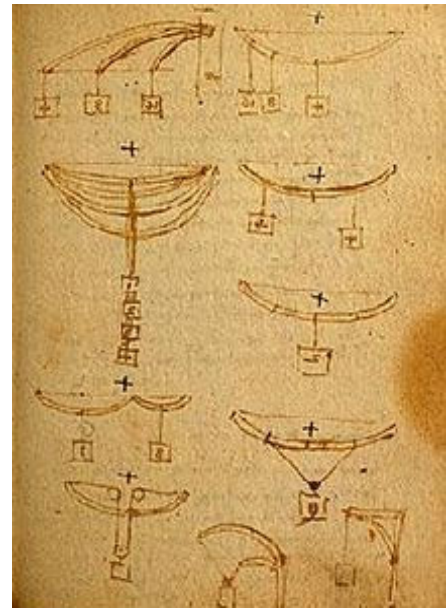

a)

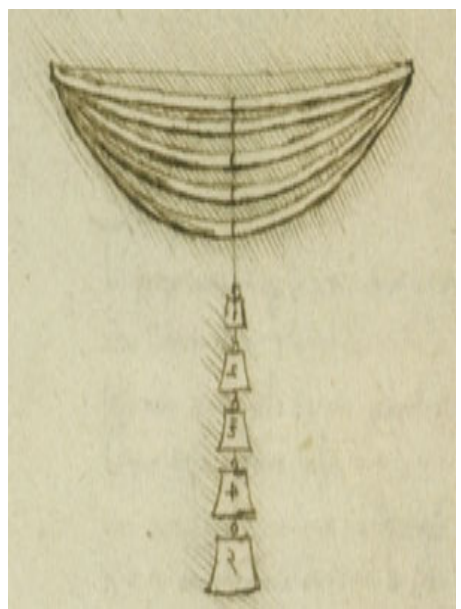

b)

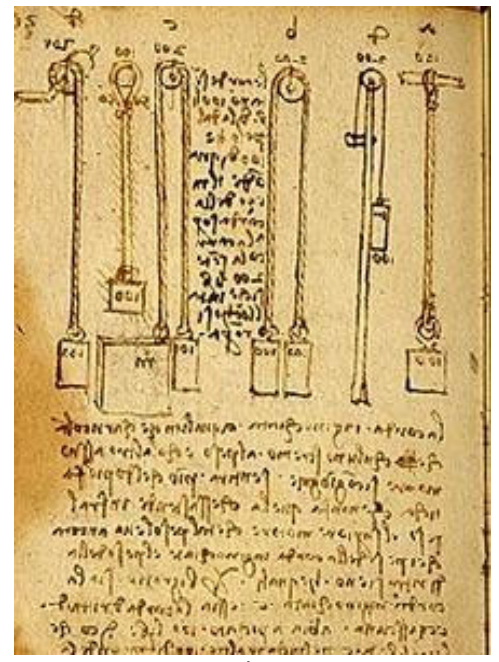

c)

Figura 4.3 a) y b)Códice Forster II, c.89v (http://www.museogalileo.it/), c) Códice de Madrid I, f 137r (http://leonardo.bne.es/index.html). 


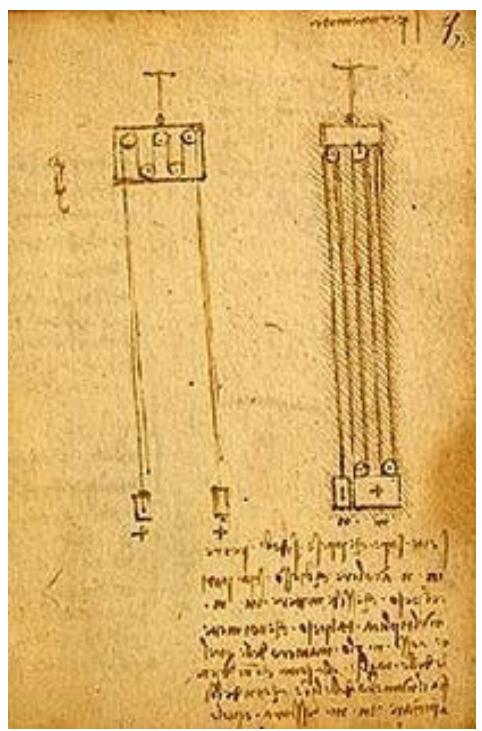

a)

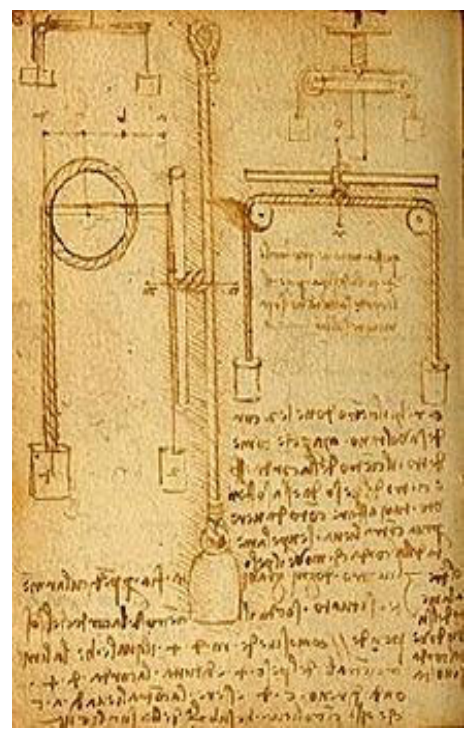

b)

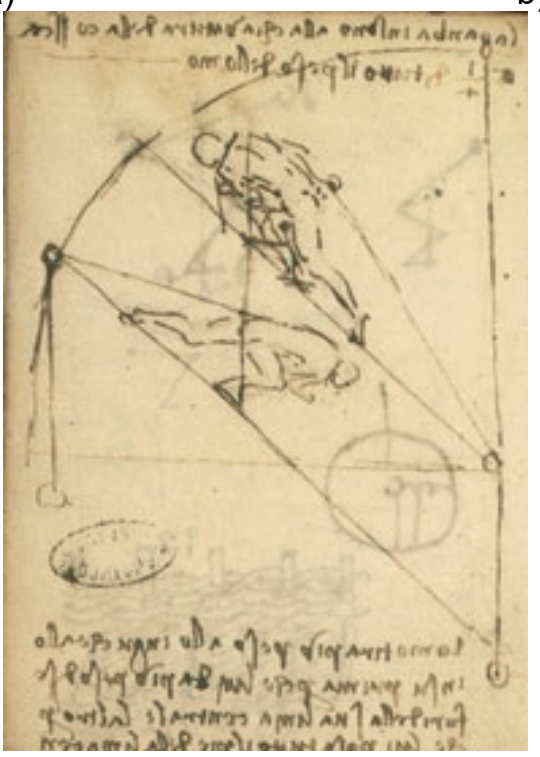

c)

Figura 4.4 a) Códice Forster II, c.73r (http://www.museogalileo.it/), b) Códice Forster II, c.77v (http://www.museogalileo.it/), c) Manuscrito L, folio $28 \mathrm{r}$ de la Biblioteca del Instituto de Francia, París

(https://commons.wikimedia.org/wiki/File:Leonardo_da_Vinci_-_19549766.jpg). 


\subsection{El estudio del trabajo, la ergonomía, y la seguridad y salud.}

Igualmente, tanto para el Proyecto de Desvío del Río Arno, como para el del Barco de Palas y otros, Leonardo establece conceptos para racionalizar el trabajo humano, observar y medir sus esfuerzos, encontrar sus rendimientos, sus mejores posturas, etc. Puede por lo tanto identificarse como un precursor en el Estudio del Trabajo, la Ergonomía y los Estudios de Seguridad y Salud.

En manuscritos del Instituto de Francia de Paris, del Códice Forster (Victoria and Albert Museum de Londres), y de la Royal Collection de Windsor, se pueden encontrar dibujos de gran calidad de los obreros trabajando o adoptando las posiciones que él creía más adecuadas, constituyendo un espléndido estudio del movimiento.

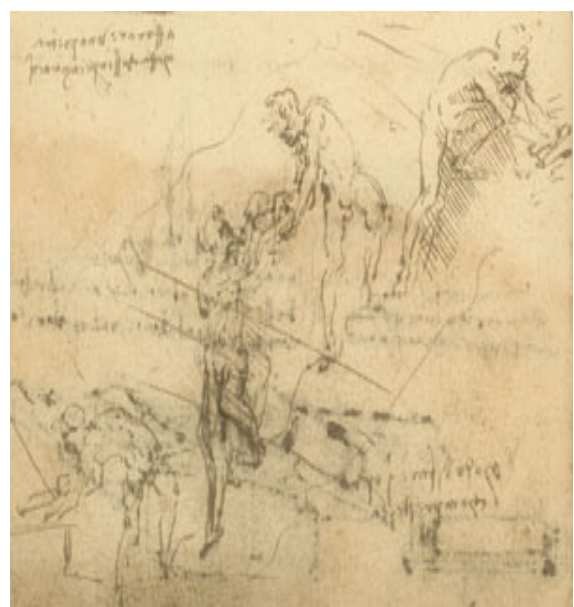

a)

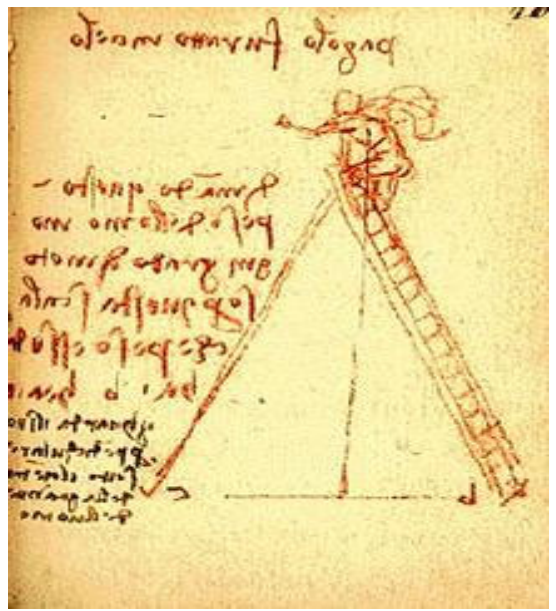

b)

Figura 4.5 a) Manuscrito B, folio 51v. del Instituto de Francia, París (https://commons.wikimedia.org/wiki/File:Leonardo_da_Vinci_-_19554045.jpg?uselang=es), b) Códice Forster II, c. 45v (http://www.museogalileo.it/). 

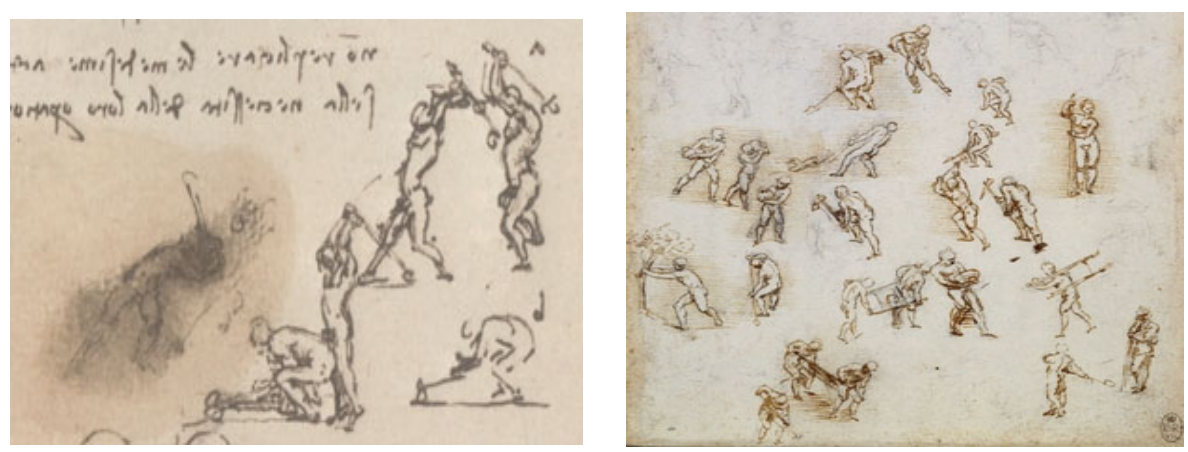

Figura 4.6 Royal Collection, Windsor, f 19149 K/P 118va. Royal Collection, Windsor, $f$ 1264412644r (https://commons.wikimedia.org/wiki/File:Leonardo_da_Vinci__RCIN_912644,_Recto_Studies_of_men_in_action.jpg).

\subsection{Las analogías}

El uso de analogías también fue un instrumento utilizado por Leonardo en muchos de sus proyectos. En los manuscritos de la Figura 4.7, analiza el movimiento de un brazo humano realizando un esfuerzo, lo dibuja y genera un mecanismo artificial que lo emula. Una analogía clara entre la Naturaleza, que era su principal fuente de inspiración, y la máquina proyectada. Se supone que este mecanismo fue utilizado en la construcción de su proyecto de "Autómata".

Igualmente realizó analogías para sus dispositivos con los que pretendía hacer volar al hombre, asimilando las alas de su prototipos a las de sus detallados "Estudios sobre el vuelo de los pájaros" existentes en el Códice de Turín, así como de los murciélagos. Las analogías son también herramientas utilizadas en los diseños de hoy en día. 


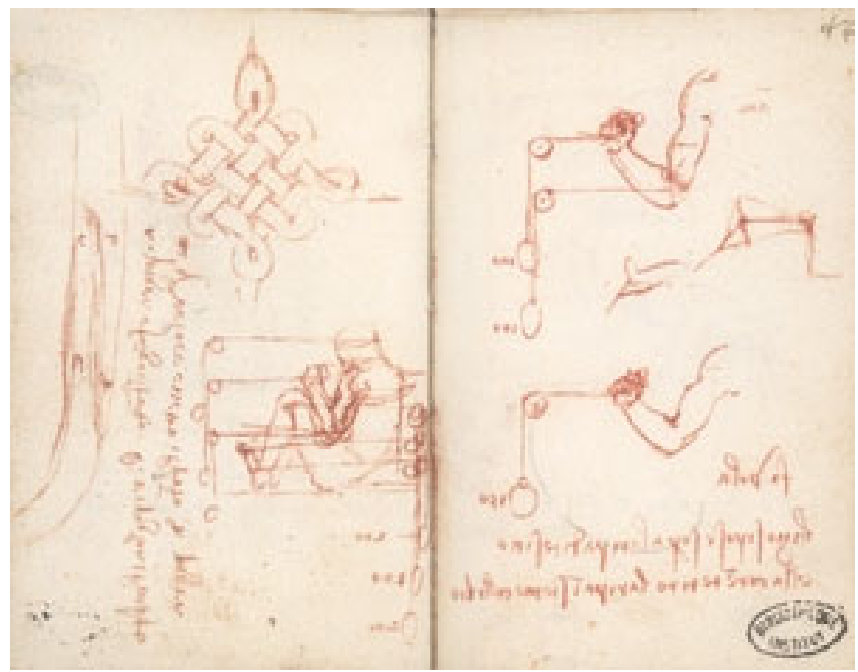

a)

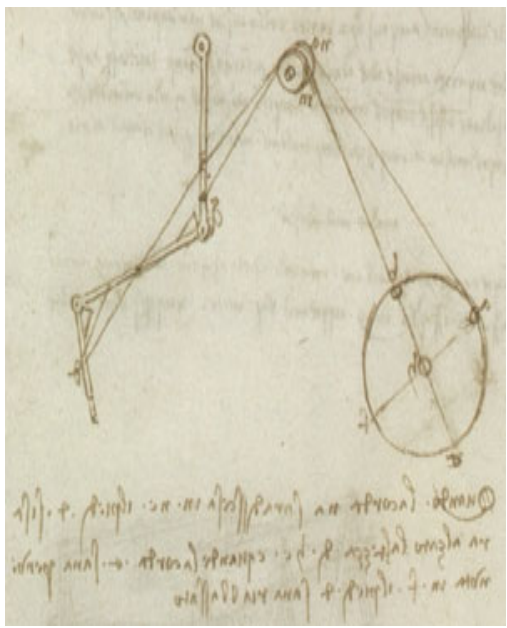

b)

Figura 4.7 a) Manuscrito $\mathrm{H}$ folios $43 \mathrm{v}-44 \mathrm{r}$ de la Biblioteca del Intituto de Francia, París (http://www.museogalileo.it/), b) Códice de Madrid I, folio $90 \mathrm{v}$, Biblioteca Nacional de España, Madrid (http://leonardo.bne.es/index.html).

\subsection{Métodos, técnicas y herramientas proyectuales}

En los proyectos del Barco de Palas, el Desvío del Río Arno, el Traje de Buceo, el Autómata, etc. Leonardo también resulta precursor en el 
empleo de muchos conceptos, métodos, técnicas y herramientas proyectuales.

\subsubsection{El Barco de Palas}

Hacia 1490, Leonardo arranca con el proyecto, y toma como base diseños de barcos preexistentes como el de Taccola o Francesco di Gorgio, que ya incorporaban la solución de las palas. Pero, junto a otras mejoras, diseña un mecanismo de engranes de ruedas dentadas, "el multiplicador", para que el barco navegue a más velocidad. Mediante la fuerza humana, moviendo unas manivelas o pedaleando, se conseguían hasta 50 vueltas/minuto alcanzando la embarcación una velocidad de 50 millas/hora.

Leonardo describe hasta el detalle los engranajes, los calcula, y los dibuja (en sección, en perspectiva y descompuestos) tal y como se realizaría en un plano de taller actual.

Descompone el sistema según sus funciones, estudiando cada subsistema con sus componentes. En el "subsistema primario" los hombres aplicarán la fuerza o energía para el movimiento. Dos "subsistemas intermedios" contienen a la "carraca". Y dos subsistemas de "coronas exteriores" y dos "conjuntos de palas", uno para cada lado de la embarcación.

También realiza estudios sobre el número de marineros que deberían aportar fuerza al sistema sin llegar a quedar exhaustos, y su posición más adecuada en la embarcación. Incluso establece protecciones para las piernas de los navegantes, aspectos relacionados con la Ergonomía y la Seguridad y Salud actuales.

En su texto, especifica la conveniencia de que la madera utilizada sea de cedro o roble, lo que verifica su experiencia en ensayos y resistencia de materiales (estanqueidad, fortaleza y duración, resistencia a la humedad, a los incendios, etc.). También establece las características de la tornillería a utilizar, lo que da una idea del nivel de detalle del proyecto.

Lleva a cabo estudios de flotabilidad, de equilibrio, de cálculo del centro de gravedad de la embarcación, de la distancia entre centroides, de la incidencia del viento, etc. lo que correspondería al documento "cálculos" de los proyectos de ingeniería.

La mayoría de los manuscritos de este proyecto se encuentran en el 
Códice Atlántico de la Biblioteca Ambrosiana de Milán, aunque existen algunos en la Royal Library de Windsor. En 1807 el ingeniero estadounidense Robert Fulton (Pensilvania, 1765 - Nueva York, 1815) utilizó esta idea con gran éxito, utilizando el vapor como fuerza.

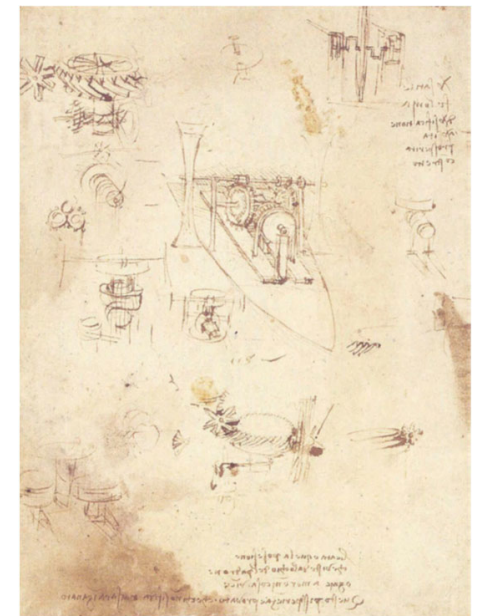

a)

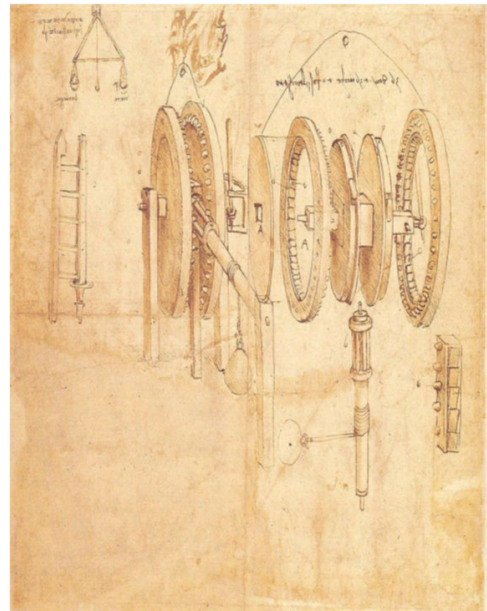

b)

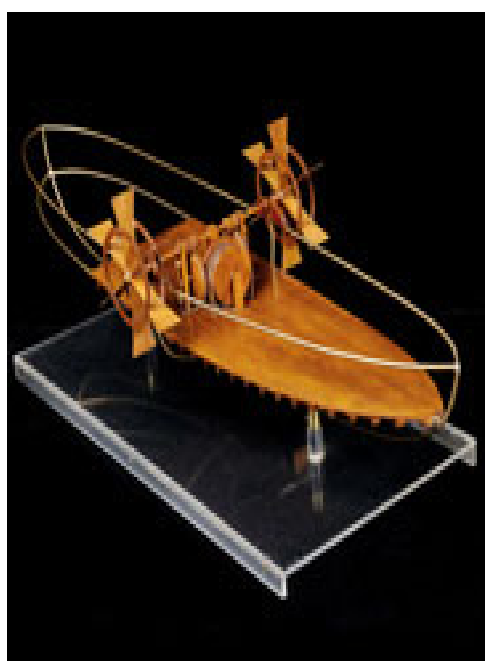

C)

Figura 4.8 a) Códice Atlántico f. 945r

(https://commons.wikimedia.org/wiki/File:Codex_Atlanticus_-_000R-945.jpg), b) Códice Atlántico f. $30 \mathrm{v}$

(https://commons.wikimedia.org/wiki/File:Codex_Atlanticus_-_000V-30.jpg), c) Maqueta del museo Nacional de Ciencia y Tecnología Leonardo Da Vinci, Florencia (www.museoscienza.org). 


\subsubsection{El proyecto de desvío del Río Arno.}

En 1494 Pisa, bajo el dominio de la Florencia de los Médicis, es cedida a los franceses, pero al año siguiente los franceses se retiran de Italia y los pisanos declaran a su ciudad independiente. Años después, Florencia, quiso forzar la rendición de Pisa para que volviera a sus dominios, y además ganar una salida al mar, lo que justificaba la decisión de alejar el Arno de Pisa. Nicolás Maquiavelo (Florencia, 1469-1527) apoderado por la ciudad, encarga a Leonardo, en 1504, el proyecto de desviarlo y hacerlo navegable.

Éste proyecta un doble canal y el cierre posterior del viejo cauce con un dique. Realiza mapas de la zona, vistas aéreas, diseña exclusas, calcula el volumen de tierra a retirar, etc. Escribe: $<<E l$ canal tendrá 20 brazos de ancho en su fondo y 30 en la parte superior, así como 2 o incluso 4 brazos de profundidad para que puedan destinarse 2 brazos de agua a los molinos... >>.

Se precisaban $19 \mathrm{~km}$ de nuevos cauces, y en una estimación inicial calculó que había que extraer cerca de 1 millón de toneladas de tierra y que se necesitarían 54.000 jornadas de trabajo. Por ello, para acelerar las obras, diseña varias máquinas, entre ellas una grúaexcavadora (Códice Atlántico folio 994r).

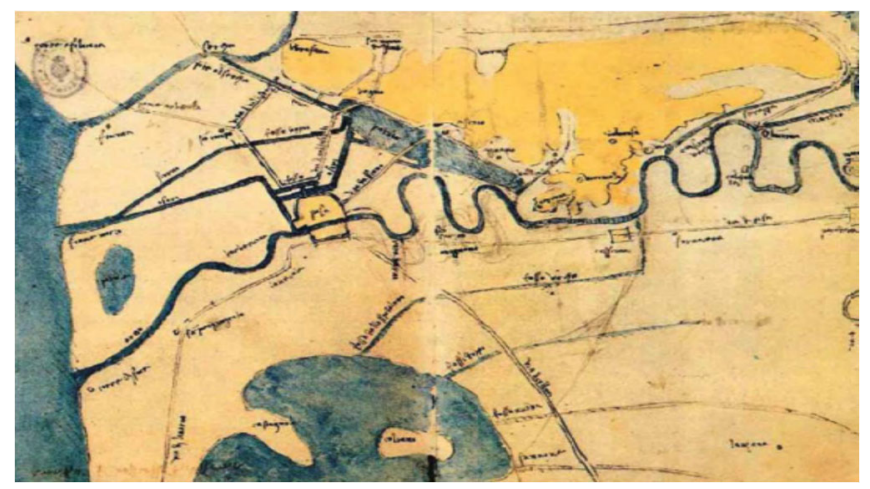

Figura 4.9 Plano de Pisa y el río Arno (Códice Madrid II, f 52v, 53 r). (http://leonardo.bne.es/index.html).

Los mapas de la zona (en planta, en perspectiva y a vuelo de pájaro), y de los montes a cruzar (en planta y alzado), están realizados al 
Teorías, métodos y técnicas para el diseño de sistemas técnicos en la obra de Leonardo da Vinci

detalle y se encuentran principalmente en el Códice II de Madrid, en el Códice Atlántico de Milán y en la Royal Collection Trust.

La ejecución del proyecto fue iniciada pero su gestión no fue otorgada a Leonardo sino a un ingeniero hidráulico llamado Colombino. Al parecer, la profundidad que éste otorgó al cauce no fue la dispuesta por Leonardo. Tras superarse las previsiones económicas iniciales con creces (nótese que se precisaba tener una parte del ejército vigilando constantemente las obras, para evitar que los pisanos las destruyeran), y habiéndose construido menos de la mitad del desvío, llegó una fuerte tempestad que destruyó gran parte de lo desarrollado. Florencia optó por abandonar el proyecto y el Arno siguió en sus viejos cauces.

\subsubsection{El traje de buceo o escafandra.}

Este proyecto le fue encargado por la República de Venecia durante su corta estancia en ella, hacia 1502. Pretendía ser una novedad en cuanto a la defensa contra barcos turcos en la bahía veneciana, para alcanzarlos de manera submarina, sin ser descubierto, así como poder ser utilizado para exploraciones acuáticas. $Y$ hoy puede afirmarse que su idea, que ha sido probada con éxito, supuso la base de las escafandras y trajes de buceo posteriores.

El proyecto, que podría considerarse un estudio preliminar, está compuesto por memorias manuscritas y dibujos, existentes en el Códice Arundel (British Museum, Londres). Describe que el traje estará hecho de cuero (piel de cerdo tratada con aceite de pescado para repeler el agua) y a él se conectarán dos mangas de aire fabricadas con cañas y muelles metálicos para que eviten ser aplastadas por la presión y mantener la flexibilidad. También una campana de madera y corcho que flotará en la superficie y mantendrá la comunicación con el aire exterior. La forma de campana aseguraba la imposibilidad de entrada de agua al interior de los tubos de respiración en su parte exterior y además minimizaba su visión exterior.

Leonardo, previsor en todo, proyecta dos tubos, uno para la entrada de aire fresco y otro tubo para la expulsión del aire ya consumido, para de esta manera no contaminar el aire entrante, y que la persona pudiera estar con seguridad más tiempo bajo las aguas. Además, proyecta una bolsa de aire intermedia, atada al pecho para garantizar una rápida flotabilidad. El buceador llevaría inicialmente dos pequeños 
sacos de arena que facilitaría su bajada y la bolsa de aire facilitaría su rápida subida. Implementó una máscara para la cabeza que llevaba incorporadas unas gafas de cristal. Además, el diseño del traje incluía otra pequeña bolsa anexa para facilitar que el submarinista pudiera orinar en ella. Todas ellas constituyen características pertenecientes a las actuales áreas de Ergonomía y de Seguridad y Salud.

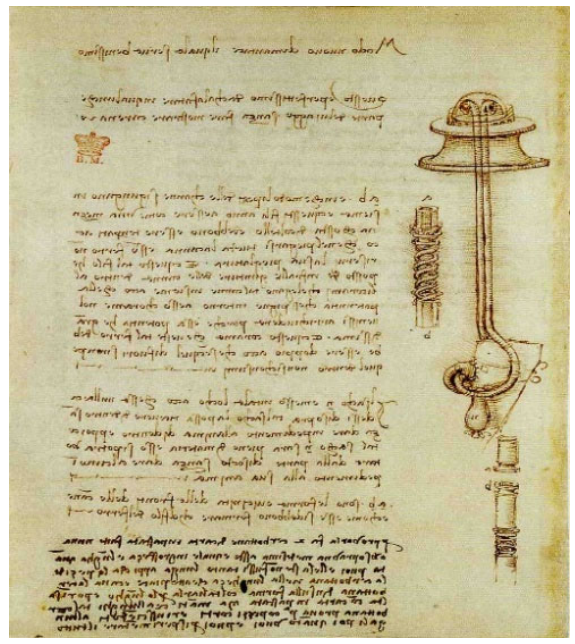

a)

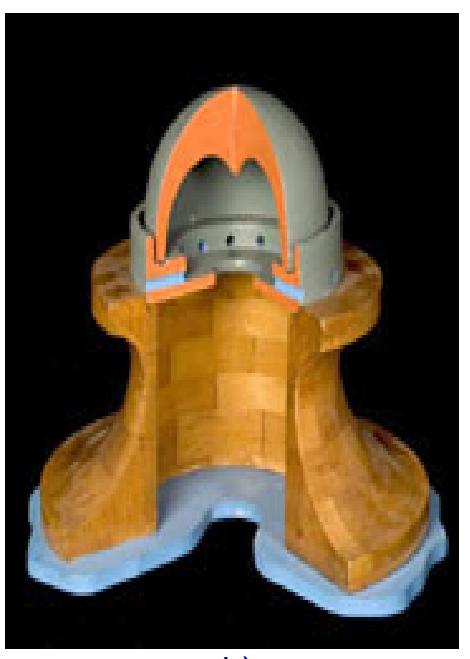

b)

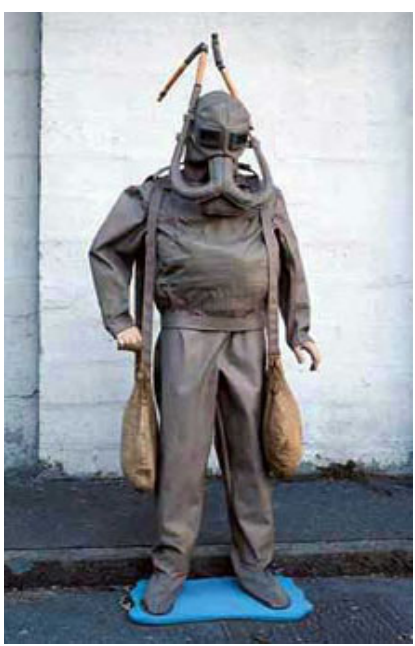

c)

Figura 4.10 a) Códice Arundel folio 24v (British Museum, Londres). (https://commons.wikimedia.org/wiki/File:Codex_arundel.jpg), b) y c) Maquetas pertenecientes al Museo Nacional de Ciencia y Tecnología Leonardo Da Vinci (Milán) (www.museosciencia.org). 


\subsubsection{El autómata}

El proyecto y realidad del "cavalieri meccanica", exhibido en Milán en 1495 para impresionar en los actos lúdicos de Ludovico Sforza (Duque de Milán), era un caballero con armadura capaz de moverse por sí solo. Podía flexionar las piernas, mover las manos y los brazos, e incluso girar el cuello. Cuando abría la boca un tambor giratorio automático en su interior le permitía simular que hablaba. Un conjunto de engranajes, muelles y árboles de levas, efectuaban el movimiento de manera previamente programada. Piezas dentadas modificables en los engranajes, así como motores accionados por un eje y compactados de una forma ingeniosa, hacían la función de mandos programables del robot. Este arquetipo mecánico causó un gran impacto en su época (Nichol, 2005) (Escrig, 2004).

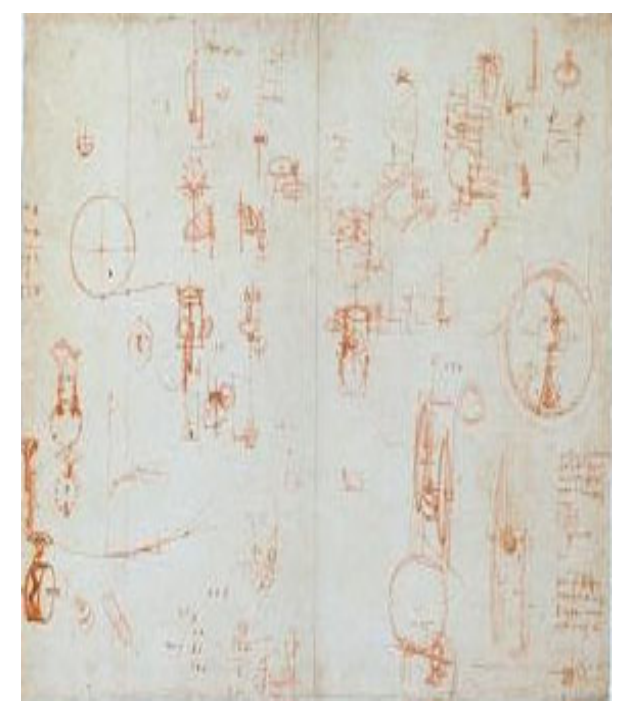

a) 


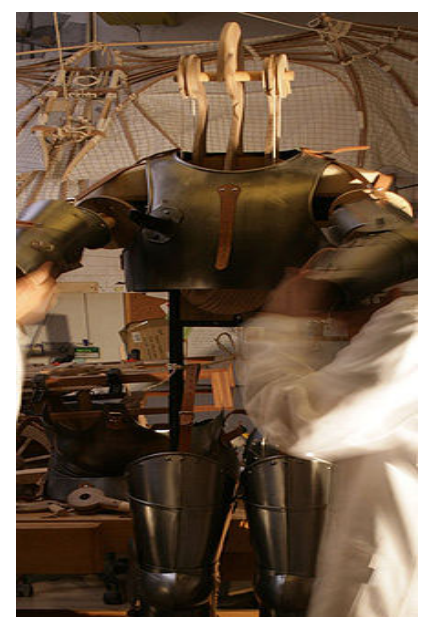

b)

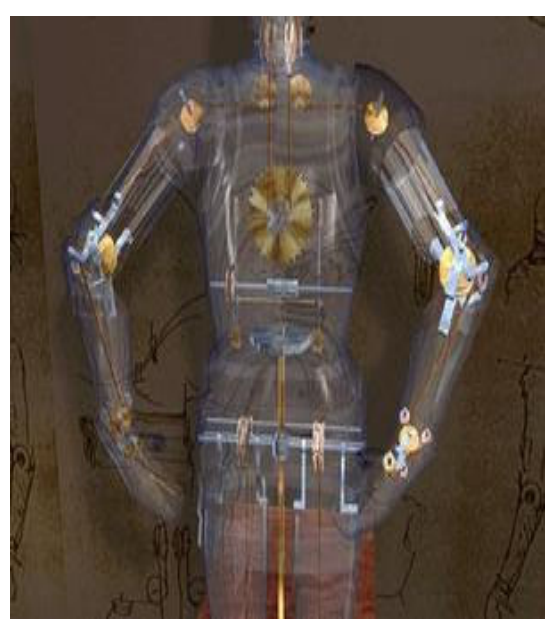

c)

Figura 4.11 a) Dispositivo mecánico (Códice Atlántico folio 1077v) (https://commons.wikimedia.orgwikiFile000R-1077.jpg), b) Robot de Mario Taddei (Wikipedia), c) Robot de la Web del "Instituto e Museo di Storia della Scienza" de Florencia (http://www.museogalileo.it/).

En los folios del Códice Forster (Victoria and Albert Museum, Londres) existen bocetos de su cabeza y cuello, y escritos aclaratorios; mientras que en el Códice de Madrid I se muestran dibujos de sus partes móviles.

El historiador italiano Carlo Pedretti (Bolonia 1928) redescubrió las notas y bocetos referentes al autómata en 1957. En 2002, Marc Rosheim, ingeniero mecánico, construyó un modelo físico completo del robot para un documental de la BBC. Finalmente, en 2007, el diseñador y profesor Mario Taddei (Bolonia 1972) reconstruyó el autómata en el Politécnico de Milán, siguiendo los planos de los códices Atlántico, de Forster y de Madrid I, y éste funcionó perfectamente para las funciones que tenía asignadas (Taddei, 2007).

\subsection{Conclusiones}

No es correcto decir que eran los proyectos y diseños de Leonardo los que tenían defectos o carencias, e impedían su construcción, sino que la tecnología del momento y la mente de los restantes actores que 
Teorías, métodos y técnicas para el diseño de sistemas técnicos en la obra de Leonardo da Vinci

participaban en sus proyectos, no estaban aún preparados para soportar la creatividad y visión de futuro del genio del Renacimiento.

Su visión y forma de trabajar en el mundo del proyecto y del diseño, sus teorías, métodos o técnicas, pueden ser útiles aun hoy en día. De hecho, si se analizan sus proyectos y sus teorías y metodologías, se puede afirmar que gran parte de lo utilizado y manifestado por Leonardo hace más de 500 años es coherente y compatible con los objetos y técnicas utilizados hoy en día en los ámbitos en los que él trabajó.

No solo fue un precursor en numerosos objetos proyectados (las propias invenciones), sino que lo fue también de la utilización de técnicas y herramientas para diseñarlos, dimensionarlos, proyectarlos, e incluso ejecutarlos.

\section{Referencias}

Escrig, A. (2004). El reloj milagroso. Grupo Almuzara, Divulgación científica: Córdoba.

García de Zuñiga, E. (2005). Leonardo da Vinci. Aforismos. Ed. Espasa Calpe: Madrid.

Jaramillo, H. (2011). Un análisis de la Resistencia de Materiales a partir de los postulados de "Consideraciones y Demostraciones Matemáticas sobre dos Nuevas Ciencias" de Galileo Galilei. Lámpsakos. No. 5, pp. 53-59.

Martínez-Val, R. (1993). Diseño industrial. Anales de Ingeniería Gráfica. Vol. 2, № 2 .

Nicholl, C. (2005). Leonardo el vuelo de la mente. Santillana Ed. Generales: Madrid.

Pigem, J. (2013). Leonardo Da Vinci El visionario de la ciencia. Revista "Historia" National Greografic, n 113.

Taddei, M. (2007). II robot di Leonardo da Vinci. Obtenido de www.leonardo3.net.

Truesdell, C. (1975). Ensayos de la Historia de la Mecánica. Editorial Tecnos: Madrid.

Vezzosi, A. (2011). Leonardo Da Vinci, ciencia y arte del universo. Ed. Blume: Barcelona. Obtenido de https://estructurando.net/revista-estructurando-no-4-ano-2015/ 



\section{Capítulo 5 Las características del pensamiento de Leonardo da Vinci, paradigma de la creatividad}

"Las cosas del espíritu que no han pasado por el juicio son vanas y solo engendran verdad aparente". LEONARDO DA VINCI (Códice Windsor, RLW 19070 v, de la Royal Collection

Library, Windsor).

\subsection{Introducción}

Leonardo (1492, Vinci-1519, Amboise), además de ser conocido como uno de los mejores pintores de todos los tiempos, está considerado como uno de los paradigmas de la creatividad tanto por su capacidad de invención, como por la de dominar un gran número de las áreas del conocimiento de su época, así como por su habilidad para generar relaciones entre ellas y conseguir nuevo conocimiento o nuevas invenciones. Así ejerció, para varias de las cortes europeas (la Ciudad estado de Florencia, el Ducado de Milán, el Reino de Francia, etc.), como ingeniero, arquitecto, urbanista, escultor, pintor, anatomista, geólogo, filosofo, etc. sin haber asistido a la universidad, y con apenas formación artesanal en pintura, escultura y orfebrería, adquirida en el taller de Andrea del Verrocchio (1435, Florencia - 1488, Venecia) ubicado en Florencia. Además fue capaz de redactar más de 7000 hojas manuscritas (y presumiblemente otras tantas desaparecidas) que conforman sus veintitrés códices y manuscritos hoy conocidos: Códice Arundel (Biblioteca del British Museun, Londres); Códice Atlántico (Biblioteca Ambrosiana de Milán); Códice Forster I, II, III (Victoria and Albert Museum, Londres); Códice Leicester-Hammer (Colección privada de Bill Gates, Seattle); Códices de Madrid I y II (Biblioteca Nacional de España, Madrid), Códice Trivulziano (Biblioteca Trivulziana de Milán); Códice del Vuelos de los Pájaros 
(Biblioteca Real de Turín); Códice Windsor (Royal Library, Windsor) y los doce Manuscritos de Francia, denominados $A$ (incluye el antiguo Códice Ashburnham II), B (incluye el antiguo Códice Ashburnham I), C, D, E, F, G, H, I, K, L y M (Biblioteca del Instituto de Francia, París); además del elaborado a partir de sus apuntes y hojas perdidas por su alumno predilecto y heredero, el pintor Francesco Melzi (1491, Milán1570, Vaprio d'Adda), denominado Códice Urbinate 1270 (Biblioteca Vaticana) en forma manuscrita, o Tratado de la Pintura de Leonardo da Vinci en publicación impresa.

Este capítulo pretende mostrar las razones por las que Leonardo, con apenas una formación artesanal y sin haber llegado a los círculos universitarios, fue capaz de ser considerado como uno de los más completos intelectuales de su tiempo, y pasar a la posteridad como uno de los mayores genios multidisciplinares de la historia.

\subsection{Las reglas o principios de trabajo de Leonardo}

El psicólogo, escritor y profesor de las universidades de Fordham y Virginia Darden, Michael J. Gelb (1952, New Jersey), que ha dedicado gran parte de sus estudios a los mecanismos del pensamiento del ser humano, su capacidad creativa y de razonamiento, etc., también se ha dedicado a investigar sobre la brillante mente de Leonardo, su manera de pensar, desarrollar sus innovaciones, proyectar, etc.

En su libro "Cómo pensar como Leonardo Da Vinci: Siete lecciones para llegar a ser un genio"; pretende dar a conocer al público en general la oportunidad de tomar como ejemplo la manera de pensar, trabajar y actuar de Leonardo, de manera que esta pueda extrapolarse al propio lector y así mejorar su capacidad creativa, su amplitud de conocimiento, su visión innovadora, etc. y para indirectamente mejorar sus relaciones con respecto al éxito en la empresa, en la familia, y en la vida en general. El autor, en su conjunto de publicaciones, manifiesta que en su opinión, Leonardo fue el hombre más brillante de su tiempo, y que su manera de pensar, proyectar, trabajar y desarrollarse en la vida puede estructurarse en las siguientes siete reglas o principios (Gelb, 2006). 


\subsubsection{Curiosità (despertar la curiosidad: hacerse preguntas consigue encontrar respuestas -ideas- válidas, más fácilmente)}

Leonardo escribió en sus Cuadernos de Notas: <<"Aprender nunca dejará exhausta a la mente", así como "Hay que observar y pensar, quien piensa poco se equivoca mucho">> (García de Zúñiga, 2005).

Aunque el ser humano de por sí es curioso, al menos en sus primeros años, esa búsqueda del aprendizaje continuo no debe perderse a lo largo de la vida, por ello Leonardo mostró una gran sed de conocimiento hasta el final de sus días. Así, el investigador, escritor y biógrafo Charles Nicholl, en su libro "Leonardo, El vuelo de la mente" manifiesta respecto a Leonardo: <<Leonardo fue como observa Kenneth Clark, el hombre más tercamente curioso de la historia>> (Nicholl, 2006).

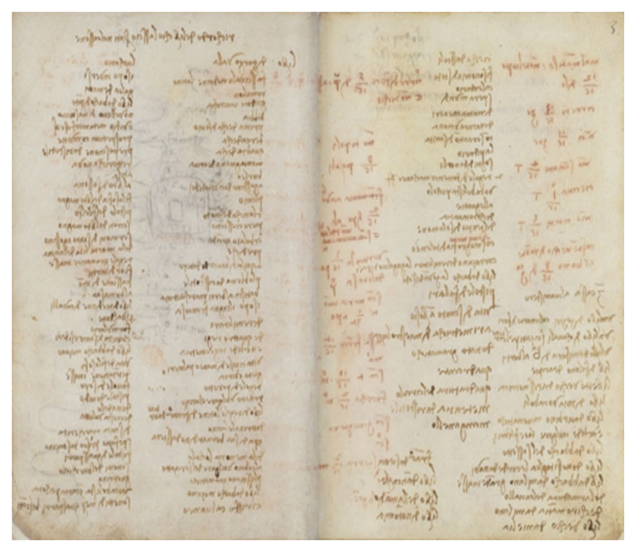

a)

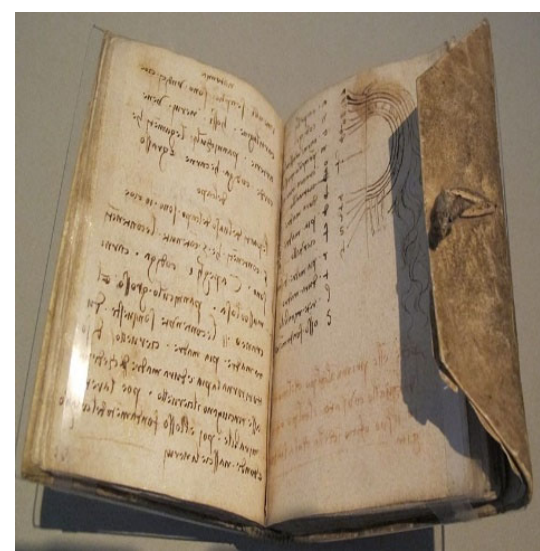

b)

Figura 5.1 a) Relación de libros propiedad de Leonardo que consta en su Códice de Madrid II. ff. 2v y 3r, de la Biblioteca Nacional de España, Madrid (origen de la imagen: Leonardo - Códices Madrid (bne.es)). b) Codex

Forster III (h. 1490) Victoria and Albert Museum, Londres (origen de la imagen:

https://commons.wikimedia.org/wiki/File:Leonardo_da_vinci,_taccuino_forste r_III,_1490_ca._02.JPG).

Su curiosidad le llevó a disponer de una importante biblioteca privada al ir adquiriendo libros y manuscritos para su autoaprendizaje durante toda su vida. Así, en su Códice de Madrid, folios 2v y 3r, ya constan la gran cantidad del libros de consulta que disponía en propiedad: el 
Libro de problemas de Aristóteles (384 a.c., Estagira-322 a.c., Calcis); los tres primeros libros de Euclides (330 a.c.-275 a.c., Alejandría) en italiano; De geometría de Euclides; Aritmética de Luca Pacioli (1445, Sansepolcro-1517, Roma); el Libro del Ábaco ilustrado; el libro De Arquitectura de León Battista Alberti (1404, Génova-1472, Roma); las Fabulas de Esopo (620 a.c., Amorio-564 a.c., Delfor); Epístolas de Ovidio (43 a.c., Sulmona-17, Constanza); Metamorfosis de Ovidio; varios libros de sonetos; Reglas de gramática latina de Perotto o Niccoló Perotti (1429-1480, Italia); Cosmografía de Ptolomeo (100170, Alejandría); la Biblia; Sermones de San Agustín (354, Tagaste430, Hipona); Vidas de Filósofos; Herbolario grande; De Chiromantia; Atila; etc. y así hasta 112 libros de todas las áreas de conocimiento conocidas por aquel entonces. Mientras que en el Códice Trivulziano de la Biblioteca Trivulziana de Milán, folio $2 r$, especifica tener 5 libros más; y finalmente en su Códice Atlántico, de la Biblioteca Ambrosiana de Milán, en el folio 210r y 559r, manifiesta haber obtenido 40 títulos más. Resultando un total de 123 títulos diferentes entre las tres fuentes vincianas recogidas (parte de los títulos de libros, extraída del texto de la traducción del Manuscrito por la Biblioteca Nacional de España, en: Leonardo - Códices Madrid (bne.es) y el libro "El imaginario de Leonardo" de 2012, de la Catedrática de Paleografía de la U. Complutense de Madrid Elisa Ruiz García (1950) y del escritor, investigador, y bibliotecario Julián Martínez Abad (1947) (Ruiz \& Martínez, 2012).

Una de las herramientas que utilizó Leonardo para recordar todo que le venía a la mente en cualquier momento era su cuaderno de notas, que llevaba siempre a mano, donde anotaba todo acontecimiento interesante que ocurriera a su alrededor, toda idea brillante que en un momento dado pasara por su cabeza, o dibujaba sus impresiones, sus pensamientos, etc.

No obstante, Leonardo cuestionaba todos los conocimientos preestablecidos, incluso los aceptados por la mayoría, y más aún aquellos que él veía que no podían demostrarse bien matemáticamente o bien con la experiencia. Incluso el profesor universitario y director del Museo Ideale Leonardo da Vinci, Alessandro Vezzosi (Italia, 1950), escribe: <<Leonardo no duda en contradecir sus afirmaciones precedentes, eso forma parte de su método, que consiste en oponer su experiencia analítica de los fenómenos a las concepciones tradicionales y dogmáticas >> (Vezzosi, 2011). Ello hizo que Leonardo consiguiera realizar diseños y proyectos 
excepcionales e innovadores como el paracaídas, el planeador, o el buzo o escafandra; y de igual manera que descubriera o innovara en técnicas de pintura como el sfumato, la perspectiva atmosférica, la perspectiva menguante y la perspectiva del color.

Los investigadores Matthias J. Gruber, Bernard D. Gelman del Centro de Neurociencia, y el también investigador de dicho centro y profesor del Departamento de Psicología, Charan Ranganath, de la Universidad de California, manifiestan que la curiosidad pone al cerebro en modo de aprendizaje y ayuda retener cualquier clase de información de interés. Tener curiosidad por algo activa el sistema de recompensa del cerebro y se moviliza la dopamina, un neuro transmisor que permite obtener objetivos, y el hipocampo, fundamental en la formación de la memoria, y también se beneficia y se activa más, cuando se muestra mayor interés. Así, escriben: $<<$ La curiosidad recluta el sistema de recompensa, y las interacciones entre el sistema de recompensa y el hipocampo parecen poner al cerebro en un estado en el que tiene más probabilidades de aprender $y$ retener información>>. (Gruber, Gelman \& Ranganath, 2014)

El aprendizaje continuo le ayudó a crecer intelectualmente y a saber encontrar respuestas. Y la mejor manera para ello es hacerse preguntas desde distintos ángulos para encontrar respuestas: ¿Qué pasaría si...?, ¿Cómo se llegaría a...?, ¿Dónde se podrá observar aquello...? Las grandes preguntas son las que consiguen posteriormente respuestas válidas para las resoluciones de problemas o el vencimiento de obstáculos. Leonardo buscó en vez de la respuesta adecuada, la pregunta correcta. Apuntaba el ¿qué quiero?; el ¿cómo conseguirlo?; las metas a perseguir y el camino para llegar a ellas. ¿Por qué el hombre no puede volar y las aves sí lo hacen? Leonardo se hacía preguntas constantemente, tenía una curiosidad insaciable y buscaba el aprendizaje continuo.

Estas premisas que fueron ya utilizadas por Leonardo hace más de 500 años, son similares a las que siglos después han acabado en los métodos aplicados al mundo proyectual, como el Brainstorming, la Lluvia de ideas, o la Lista de cuestiones de Osborn. (Osborn, 1953).

\subsubsection{Dimostrazione (La demostración = experimentación)}

El escritor Charles Nicholl, antes citado manifiesta: $<<$ Leonardo es el empirista por excelencia y firma con un florido: Leonardo Vinci 
disscepolo della sperientia, aunque también podría traducirse como discípulo del experimento>> (Nicholl, 2006).

Leonardo no tuvo la ocasión de cursar estudios universitarios, solo recibió de formación de carácter artesanal en el taller de Andrea del Verrocchio (1435, Florencia-1488, Venecia) en cuanto a dibujo, pintura, escultura, orfebrería y fundición, pero se sirvió del autoaprendizaje para alcanzar cotas de conocimiento desconocidas para su época en un variado número de áreas de la ciencia y la técnica, mediante la búsqueda de documentos, libros y manuscritos de los autores clásicos, junto con los de algunos arquitectos e ingenieros predecesores y coetáneos de su época. Además de cuestionar todo el conocimiento existente, no dando nunca algo como cierto si no había sido probado antes por la experiencia.Así escribe en su Codex Forster III: <<"La sabiduría es hija de la experiencia"; o llevando a cabo su comparación con la naturaleza, a la que siempre sostuvo como maestra, escribe en sus Cuadernos de Notas: "La naturaleza es la fuente del conocimiento verdadero. Tiene su propia lógica, sus propias leyes, no tiene efecto sin causa, ni invención sin necesidad">> (García, 2005).

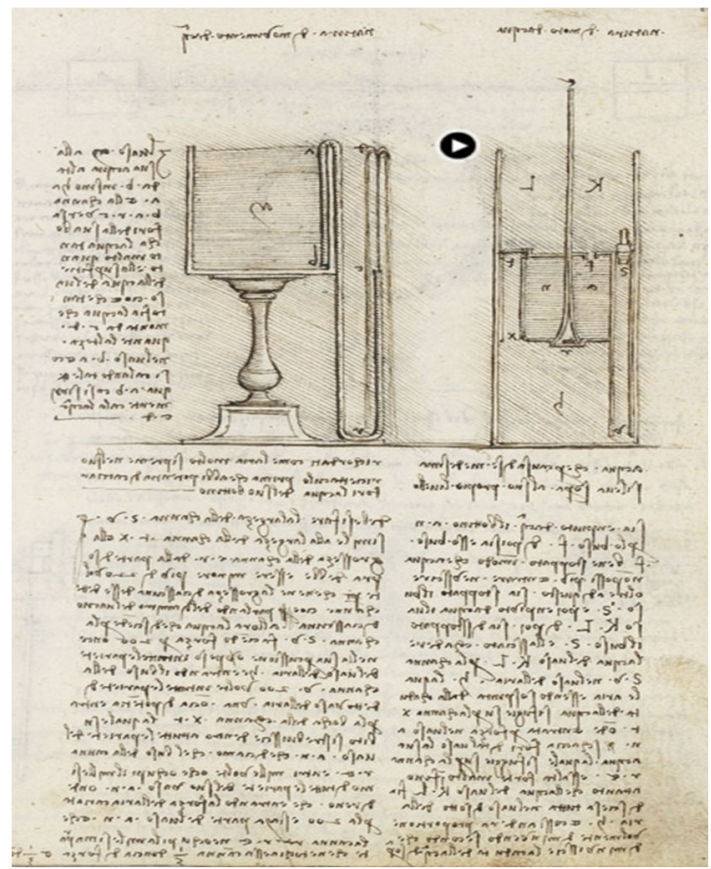

a) 


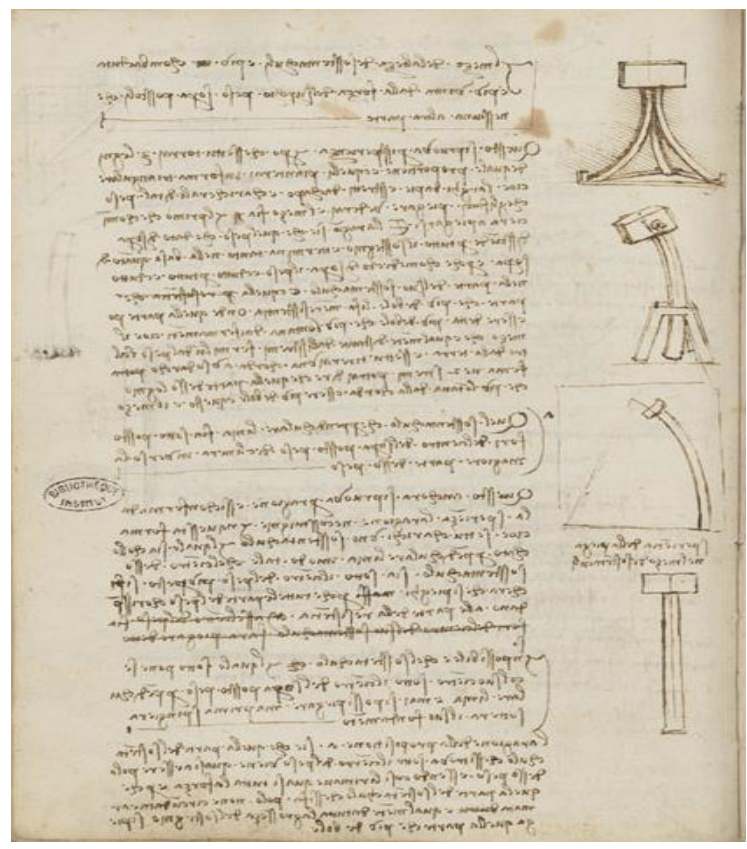

b)

Figura 5.2 a) Ensayos hidráulicos, Códice de Madrid I, f. 115r, Biblioteca Nacional de España (Madrid) (Origen de la Imagen: Leonardo - Códices Madrid (bne.es)). b) Estudio del comportamiento de los pilares cargados, Manuscrito A de la Biblioteca del Instituto de Francia (París). (Origen de la Imagen: https://commons.wikimedia.org/wiki/File:Leonardo_da_Vinci_-_19547363.jpg)

Aprender de la experiencia genera fuerza y seguridad, y hace desarrollar un mecanismo de autodefensa mental, ya no solo en situaciones de éxito, sino que también sirve para aprender de los fracasos. De nuevo Leonardo en otro de sus Cuadernos escribe: $<<L a$ experiencia es la madre de toda certidumbre>> (García de Zúñiga, 2005).

Las experiencias previas moldean para el futuro, y refuerzan respecto al pasado, dando seguridad. Desarrollar el sentido práctico ayuda a buscar soluciones y a resolver problemas y situaciones de conflicto. Las personas pragmáticas y creativas no tienen unas ideas preestablecidas, sino que se amoldan a los resultados de las experiencias, y con ello son capaces de adaptarse a las situaciones 
cambiantes, sin tener miedo a enfrentarse a los cambios. Ello debe ir unido a un comportamiento y a una formación a ser posible imparcial y a actuar siempre con independencia. Incluso los errores se toman como fuente de conocimiento y aprendizaje para no repetirlos, y no como fuente de fracaso. Toman los errores como una oportunidad y no los evitan, sino que los bordean y aprenden de ellos. Es mejor equivocarse que no intentarlo, del error también se aprende, de la inactividad no. Así, Leonardo escribe otra de sus citas en sus Cuadernos de Notas: <<He estado impresionado con la urgencia del hacer. Saber no es suficiente; debemos aplicar. Estar dispuesto no es suficiente; debemos hacer>> (Rosa, 2019).

Leonardo sabía que, al atreverse con los diseños innovadores y los proyectos novedosos, existía un alto porcentaje de riesgo al fracaso. Por ello fracasó en sus intentos de diseñar máquinas capaces de hacer volar al hombre, pero jamás rehuyó de ellos, sino todo lo contrario; los tomó como estandarte para aprender de los errores que se produjeran en los mismos y de hecho algunos de sus diseños de planeadores sí han funcionado con el tiempo.

\subsubsection{Sensazione (las sensaciones: afinar nuestros sentidos)}

Leonardo era partidario de desarrollar continuamente todo el conjunto de los sentidos del ser humano. Escribe en su Códice Trivulziano f. 20v: <<Todo nuestro conocimiento tiene su origen en nuestros sentidos >> (Nicholl, 2006); con ello venía a explicar que el origen del conocimiento humano está en relación con su capacidad sensorial, a mayor percepción de uno cualquiera de los sentidos, más conocimiento. Desarrollar el gusto con experiencias, ampliar la visión periférica, olfatear nuevos olores, tocar nuevas formas de la naturaleza, enriquecerán las experiencias para después aumentar la capacidad de dibujar, de explicar, de resolver problemas por comparación, etc. La amplitud de las sensaciones, son equivalencia al aumento de la creatividad.

La capacidad de interaccionar a la vez un sonido musical, con la visión de una pintura, puede despertar la genialidad. Hay que generar espacios de creación, con buen sonido, cómodo mobiliario, aromas agradables, temperatura idónea, etc. Con ello llegará la "iluminación o insight" tan reclamado ahora por los actuales diseñadores. Saber discernir detalles insignificantes en la naturaleza o en las cosas, ayudará a saber representarlos, o a diseñar y construir con mayor 
precisión. Leonardo era capaz de cantar, recitar, tocar la lira y el laúd, y algunos otros instrumentos. De hecho, es conocido que lo hacía habitualmente en las fiestas cortesanas de los Sforza en el Ducado de Milán.

El hacer uso de los sentidos ayudará a hacer más vivas las experiencias. Leonardo viajó incesantemente (vivió y realizó diseños en Florencia, Milán, Imola, Pavía, Mantua, Venecia, Roma, Amboise, etc.), de observar la naturaleza y los paisajes, de tocar y escuchar música, etc.; ello agudizaba sus sentidos, y le ayudaba a apreciar mejor los detalles.

La mayor intuición se obtiene al utilizar más sentidos a la vez, cuantos más sentidos se utilicen, más percepción; no obstante, para Leonardo, la vista era el principal sentido, así escribe en su Códice Atlántico f. 10r: <<"el ojo es el juez universal de todos los cuerpos", es la principal vía de información. De manera similar escribe en el f. 250r: "Tanto el ojo es más presto que el oído es su oficio como mejor conserva la semejanza de las cosas impresas en él">>.

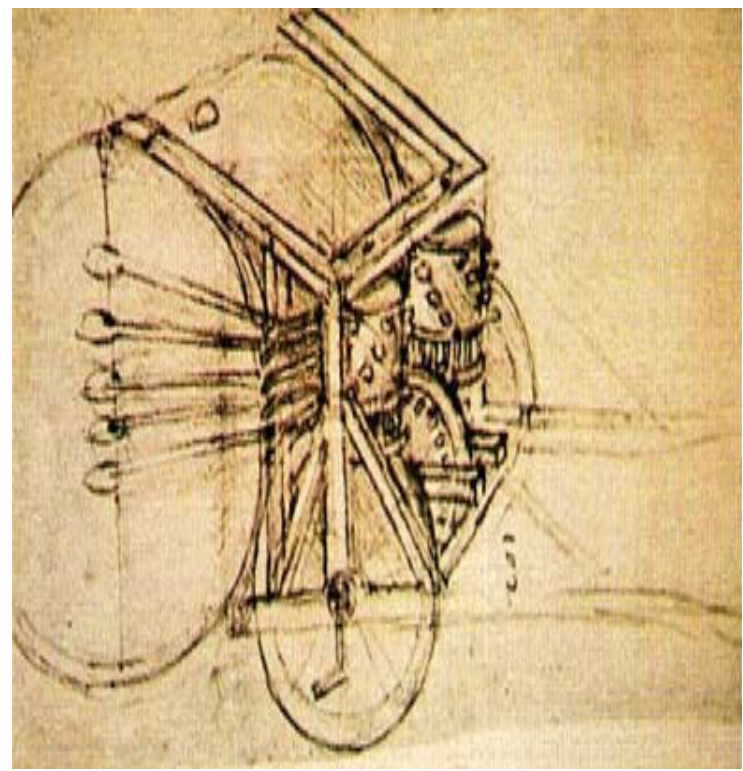

a) 


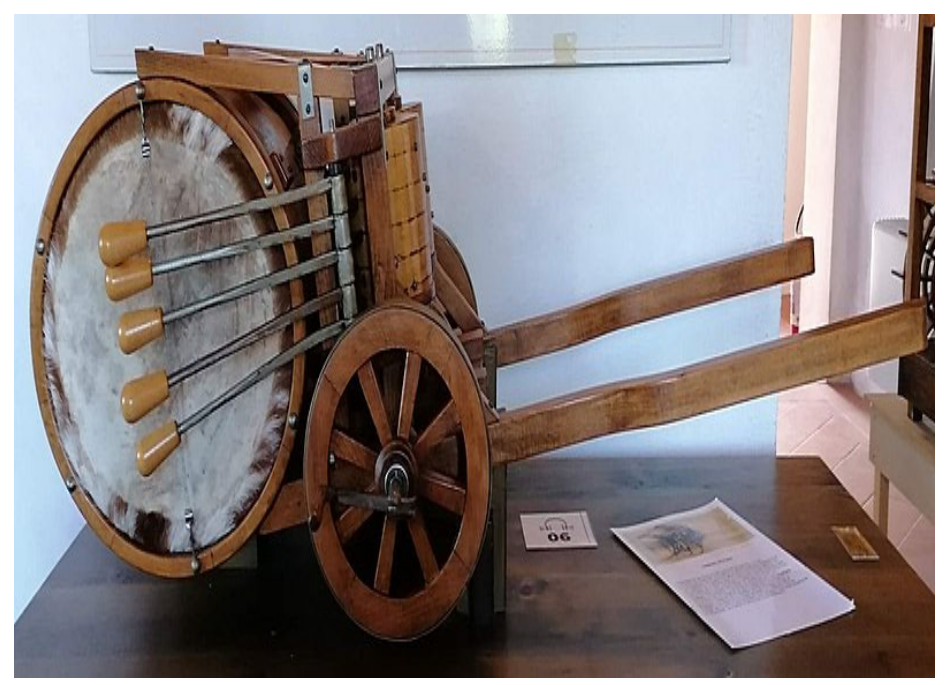

b)

Figura 5.3 a) Diseño de Tambor militar automático, Códice Atlántico f. 837r, h. 1503 (Origen de la imagen:

https://commons.wikimedia.org/wiki/File:\%D0\%92\%D0\%BE\%D0\%B5\%D0\% BD\%D0\%BD\%D1\%8B\%D0\%B9_\%D0\%B1\%D0\%B0\%D1\%80\%D0\%B0\%D

0\%B1\%D0\%B0\%D0\%BD.jpg?brusela=es). b) Maqueta del tambor automático, exposición "Mulino di Mora Bassa" (Vigevano) (origen de la imagen:

https://commons.wikimedia.org/wiki/File:Tamburo_militare_di_Leonardo_da_ Vinci_in_una_mostra_su_Leonardo_da_Vinci_al_Mulino_di_Mora_Bassa__Morabassa.jpg? ?uselang=es-formal)

Leonardo, refuerza este concepto al matizar que no todo lo que constaba en los libros era cuestión de certeza, así manifiesta en su Códice Windsor, folio RL 19070, de la Royal Library de Windsor: <<Las cosas mentales que no han pasado por los sentidos son vanas $>>$ (Méndez, 2013).

\subsubsection{Sfumato (la difuminación, la ambigüedad, lo matizable: aprovechar la incerteza)}

Aunque las situaciones seguras, las de certeza, las que se dominan fácilmente, son más cómodas y aparentemente las situaciones más deseables por las personas, la mente debe estar preparada para lo incierto, para la inseguridad, para la ambigüedad. El ser humano 
debería estar preparado para las situaciones adversas, y saber salir de ellas. Gestionar las situaciones difíciles es el objetivo de toda mente despierta e imaginativa.

Llevar a cabo un análisis de situaciones anteriores en las que hayan ocurrido resultados negativos y recordar cómo se gestionaron y cuáles fueron las acciones realizadas, ayudará a fortalecer y a saber cómo salir airoso en tales momentos, si estos se repiten.

La ambigüedad y la incertidumbre que tienden a desequilibrar las situaciones son las que harán despertar la mente más álgidamente e incrementará el uso de la imaginación y la creatividad. Leonardo aprendió de los fracasos; su diseño de máquina de volar utilizaba inicialmente pedales. Después de experimentar, probar y no conseguir su objetivo, se dio cuenta de la insuficiencia de la fuerza humana para lograrlo y cambió su estrategia hacia su planeador o símil de ala delta. Su proyecto de canalización del Arno previo a su paso por Pisa, cuya ejecución quedó incompleta entre varias razones por el hecho de que Leonardo no fue designado director de dicha obra, hizo que mejorara en sus estudios hidráulicos.

La misma mirada de la "Mona lisa" o "Gioconda", cuadro que Leonardo tardó varios años en finalizar, cuya mirada es misteriosa y ambigua, y cuyos fondos son azulados y tenebrosos, pintado mediante su técnica del sfumato, o la falta de contornos de muchas de sus pinturas, atestiguan el uso de esa técnica en Leonardo, y de lo a gusto que se encontraba en ella. 


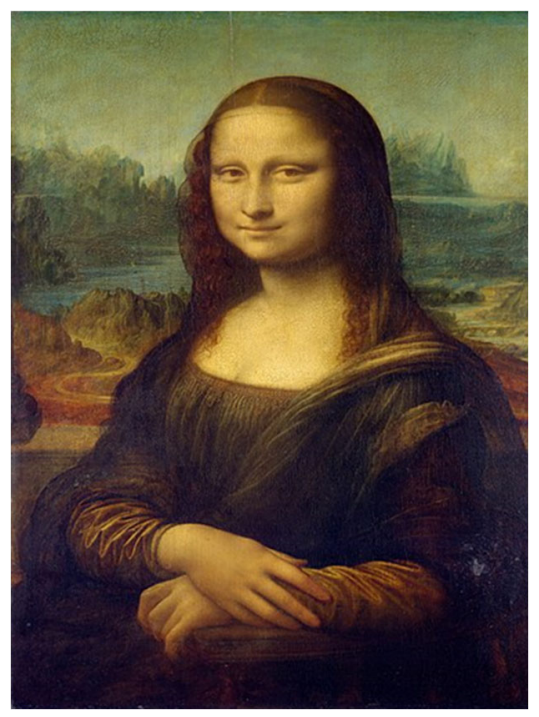

a)

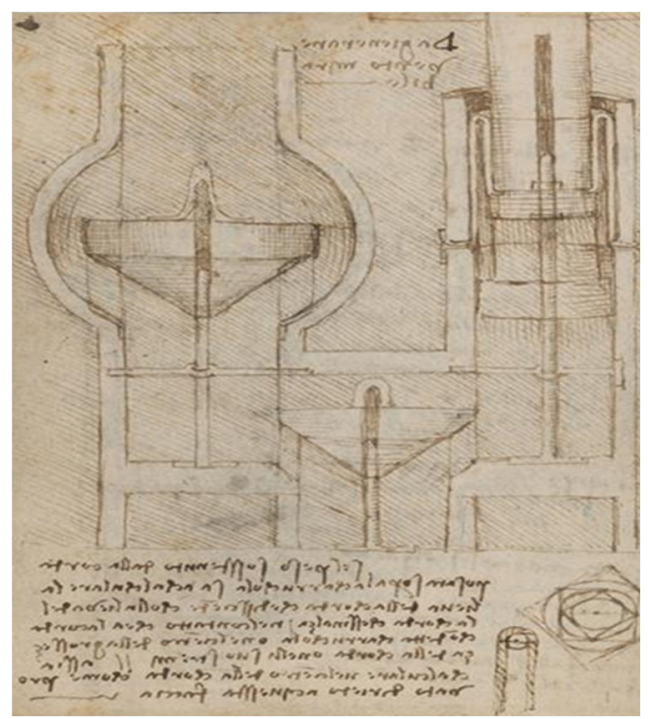

b)

Figura 5.4 a) La mona Lisa o Gioconda (de 1503 a 1506) Museo del Louvre, París. (origen de la imagen:

https://commons.wikimedia.org/wiki/File:Mona_Lisa,_by_Leonardo_da_Vinci ,_from_C2RMF_retouched.jpg) b) Sistema hidráulico con válvulas de retención, Manuscrito E de la Biblioteca del Instituto de Francia (París) (origen de la imagen: File:Leonardo da Vinci - 19-547769.jpg - Wikimedia Commons).

A veces la solución a un problema solo proviene de lo desconocido. Generalmente la idea que ocasiona el problema no lo soluciona. Si algo no se entiende no debe rechazarse, puede intentar solucionarse con situaciones de ambigüedad, incertidumbre o mediante paradojas, ello disminuirá la complejidad y facilitará la solución.

\subsubsection{Arte/Scienza (la unión del arte y la ciencia, símil de imaginación y lógica: el equilibrio)}

Ya es conocido que el cerebro del ser humano dispone de un hemisferio, el derecho, en el que se generan las actividades imaginativas, mientras que en el hemisferio izquierdo se desarrollan las actividades lógicas y las numéricas/cuantitativas. Ambos pensamientos hoy se conocen como pensamiento horizontal (el 
creador, explorador, incontrolado, provocador, sin caminos a seguir, etc.) y pensamiento vertical (el correcto, lógico, analítico, selectivo, no acorde con las desviaciones, etc.). Leonardo, aunque no era conocedor de esta característica física, era partidario del pensamiento creativo, de la mezcla y el equilibrio de ambas actividades, la lógica y la creativa, para dibujar, diseñar, y resolver problemas. Ello le sirvió para generar ideas, teorías y diseños de máquinas, instrumentos y herramientas excepcionales, adelantándose en siglos a otros científicos y técnicos posteriores.

Con la creatividad, la innovación y la imaginación se crea el "arte", pero con el conocimiento, la lógica, la razón, la demostración aparece la "ciencia". Leonardo diseñó máquinas y herramientas e hizo descubrimientos científicos excepcionales, la ciencia; y por otro lado fue capaz de realizar varias pinturas consideradas entre las mejores de todos los tiempos, el arte (La Gioconda, La Ultima Cena, La Virgen de las rocas, La Bella Ferronière, etc.). Esa mezcla de ambas disciplinas arte-ciencia, es una de las razones de su éxito.

Leonardo llevaba a cabo diseños conceptuales de sus ideas de mecanismos y máquinas, y al mismo tiempo bocetaba los inicios de sus cuadros y composiciones de manera similar a los mapas mentales de la actualidad que se dan como técnicas de diseño y proyección, así como de entendimiento y resolución de problemas. Probablemente utilizaba los dos hemisferios del cerebro de forma equilibrada entre la lógica y la imaginación. Todo ello también está resumido en una cita suya en sus Cuadernos de Notas: <<Para desarrollar una mente completa: estudia la ciencia del arte, estudia el arte de la ciencia>>.

\subsubsection{Corporalità (cultivar y equilibrar el cuerpo y la mente)}

El disponer de una mente despierta, preparada para todo, debe ir vinculada a un cuerpo sano, ya que ello evitará las preocupaciones de la primera, y dejará el camino libre para que la mente se dedique a la imaginación y a las situaciones innovadoras. Entrenar el cuerpo y entrenar la mente. Actividades deportivas, de fortalecimiento de músculos, de flexibilidad, etc. ayudará a mantener el equilibrio entre la mente y el cuerpo, a sentir la coordinación y a pensar con claridad. El ejercicio cotidiano, incluso los simples movimientos desarrollan también capacidades en el cerebro. 

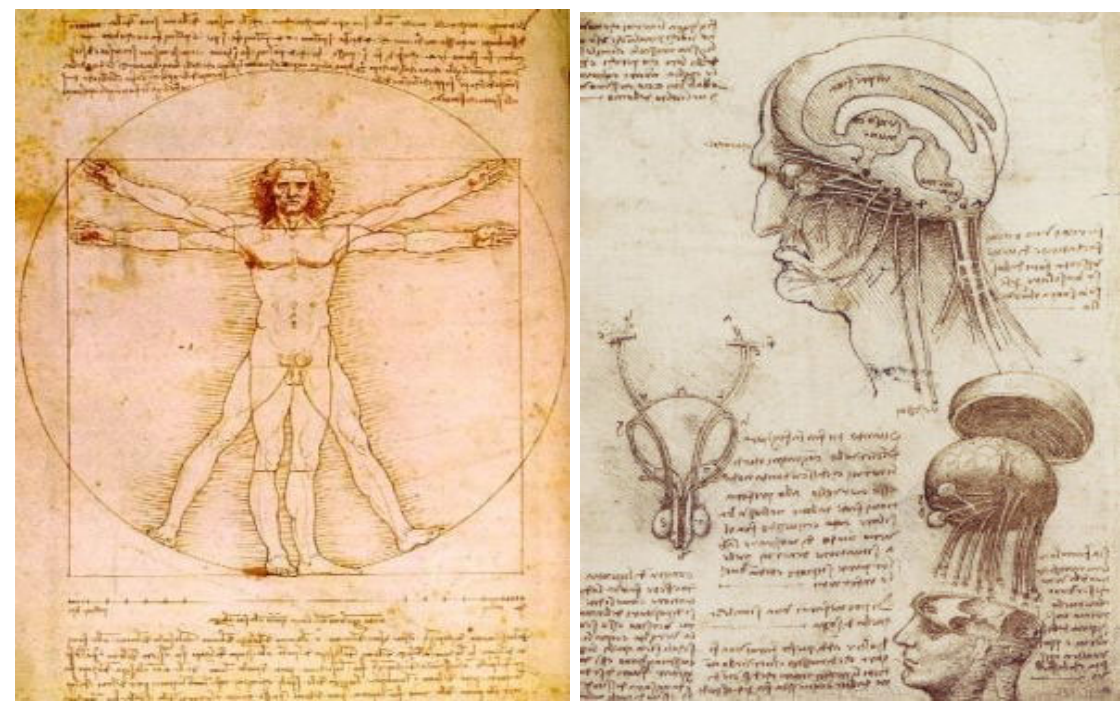

Figura 5.5 a) El Hombre de Vitruvio o de las divinas proporciones, Galería de la Academia de Venecia, h. 1490 (origen de la imagen: File:Anatomia homem leonardo.jpg - Wikimedia Commons). b) Estudios Anatómicos: Cerebro humano, (1506-1508), Códice Windsor, Royal Library, Windsor (origen de la imagen: File:Leonardo Da Vinci's Brain Physiology.jpg Wikimedia Commons).

Leonardo fue amante del ejercicio físico, de la escalada, de la equitación, de los paseos por la naturaleza, de la vida y costumbres sanas, incluso sus investigadores afirman que era vegetariano. Varios de los autores de biografías de Leonardo afirman que su famoso dibujo del cuerpo humano desnudo, "El Hombre de Vitruvio" (1490, Galería de la Academia de Venecia) que presenta una musculatura atlética y que hoy es símil del icono ideal del cuerpo perfecto, es el del propio Leonardo. En él refleja las proporciones ideales del hombre, después de haber estudiado los cánones establecidos en la obra "De Architectura" del arquitecto romano Marco Vitruvio (70 a.c.-15, Italia), y los mejora, después de realizar sus investigaciones anatómicas, reflejadas principalmente en los Folios o Códice de Windsor.

\subsubsection{Connessione (todo está conexionado con todo)}

La visión de cualquier problema debe ser, al menos inicialmente, lo más amplia posible, debe observarse con la perspectiva del "todo". Tanto los objetos como las acciones deben ser consideradas como 
parte del todo. Hay que buscar la integridad del objeto, de la situación o de la acción, el entero, el todo. Preguntarse qué sucedería en el conjunto, si apartamos una parte de ese todo, o en que cambiaría ese todo, si lo relacionamos con su entorno, etc. Así, Leonardo se expresa en sus cuadernos de notas: $<<$ Aprende a observar. Date cuenta de que todo conecta con todo>>. No se puede entender un fenómeno si no se tiene en cuenta la influencia en este, ya no solo de su conjunto, sino también de la parte exterior de mismo, a la que se le denomina "entorno".

Leonardo escribe en sus Cuadernos de Notas "¿Qué valor puede tener el que se dedica a abreviar las partes de las cosas, cuando pretende dar su conocimiento integral, y deja tras de sí la mayor parte de lo que compone el todo?" (De España, 1943).

El enfoque adoptado por Leonardo puede considerarse precursor de la Teoría de Sistemas de Ludwig von Bertalanffy (1901, Atzgersdorf1972, Búfalo), donde se establece: <<en un sistema todo está relacionado, la incidencia en una de las partes del sistema afectará al conjunto del mismo >>, muy similar a lo expuesto por Leonardo.

Al considerar que todo está interconectado, es más fácil ante un problema encontrar una solución o salida, al verlo desde una perspectiva más amplia.

Leonardo toma como ejemplo para cualquier estudio, dibujo, máquina, instrumento, etc., el cuerpo humano (de los que hizo más de 30 disecciones, y al que considera un microcosmos), y lo descompone y compara con él. Así justifica el símil de qué parte correspondería en importancia al cerebro, cuál a las manos, cuál al corazón, etc., y después lo interacciona en su conjunto. Con ello genera una búsqueda de soluciones por analogía con la naturaleza. Así, Leonardo en su Manuscrito G de Francia, f. 74 v, establece la siguiente cita: $<<$ Toda acción de la naturaleza se realiza por el camino más corto >>, por ello, repetidamente la justifica como fuente de inspiración. Muchos de los fondos de sus cuadros, como por ejemplo las dos versiones de $\mathrm{La}$ Virgen de las Rocas (versión del Louvre, Paris: 1483-1486; versión de The National Gallery, Londres: 1503-1506) también son un ejemplo de analogía con las diferentes formas de la naturaleza (su entorno son rocas, grutas, montañas, agua, etc.).

Así, Leonardo justificaba la conexión entre las cosas y los fenómenos. Cuando estuvo escalando en los Alpes y encontró fósiles de conchas marinas, se preguntó la conexión entre estos y los fondos marinos, así 
estableció la teoría hoy reconocida como cierta, de que en tiempos pretéritos las montañas actuales habían estado bajo el agua de los mares, siendo el primero en contradecir el relato bíblico del Diluvio Universal.

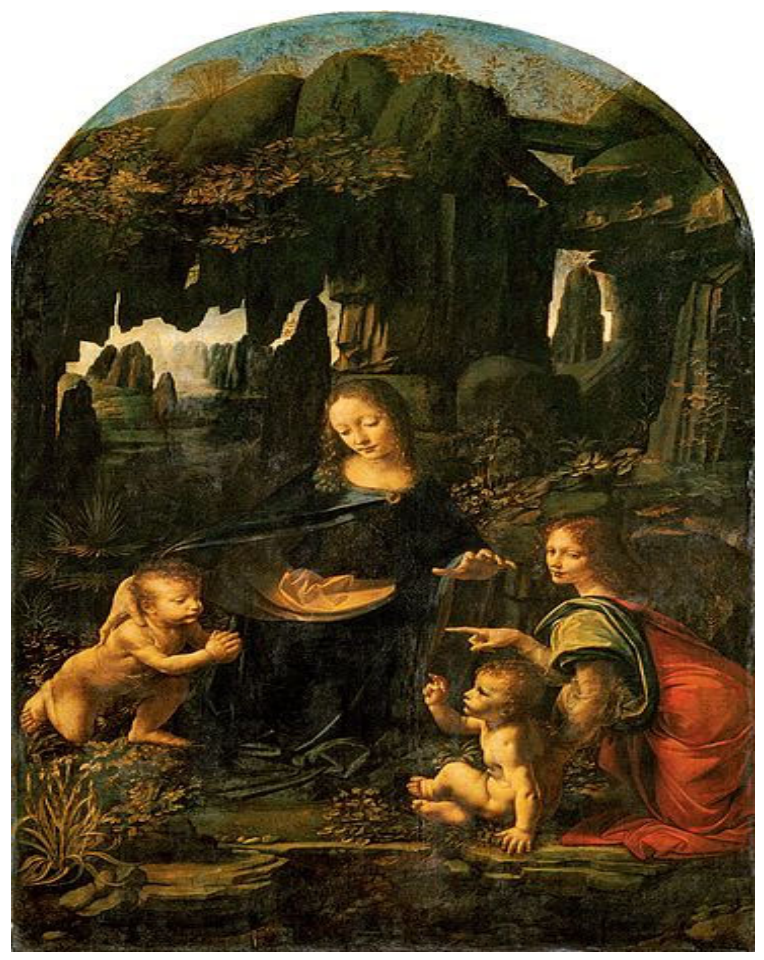

a) 


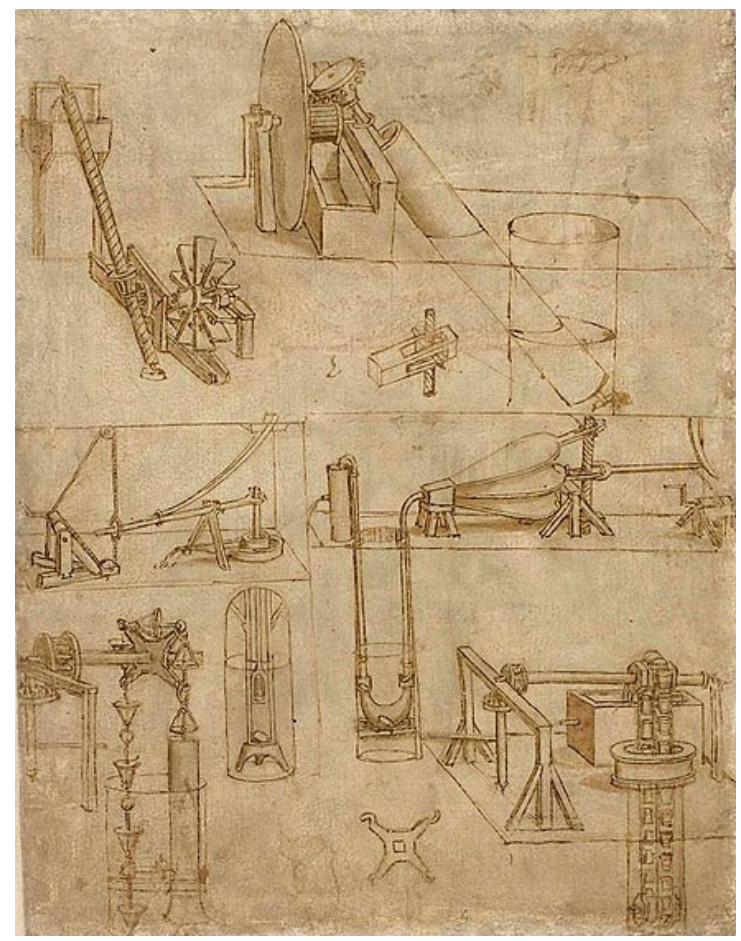

b)

Figura 5.6 a) La Virgen de la Rocas (1483), versión del Museo del Louvre,

París. (origen de la imagen:

https://commons.wikimedia.org/wiki/File:Leonardo_da_Vinci_-

_Virgin_of_the_Rocks_(Louvre).jpg). b) Dispositivos de elevar agua C. Atlántico f. $6 r$, Biblioteca Ambrosiana de Milán (origen de la imagen: File:Codex Atlanticus 000R-6.jpg - Wikimedia Commons).

\subsection{La observación científica}

Para Leonardo era muy importante el "saper vedere". Con la adecuada observación de la naturaleza, de los objetos, de los fenómenos, etc., comprobando formas y dimensiones, valorando las funciones, las necesidades, lo prescindible e imprescindible, etc., llegó a describir y diseñar nuevas máquinas, herramientas y experimentos. Apoyándose también en su gran capacidad de visualización y su dominio del dibujo y las técnicas gráficas, pasando a ser considerado, como el pionero de la ilustración científica, tal como confirma profesor y Director del 
Museo de Historia de la Ciencia de Florencia, Paolo Galluzzi: $<<$ Nadie había logrado plantear antes de manera tan eficaz el diseño de un proyecto técnico complejo>> (Chastel, Galluzzi \& Pedretti, 2005). Observar con detalle, intuir, deducir o incluso especular, y después comprobar, eran sus reglas de trabajo.

El profesor de la facultad de comunicación de la Universidad de Medellín, Óscar Jairo González Hernández, también matiza la utilización por Leonardo de esta nueva regla o principio que denomina la "observación metódica", e identifica a Leonardo con: $<<L a$ invención, la creación, la obstinación, la determinación por la apropiación de un tema, de un proyecto técnico, la observación de la naturaleza, el deseo inconmensurable por probarlo todo y por experimentarlo todo, lo hacen un hombre del renacimiento y un humanista por excelencia>>.

Leonardo opta por la observación como método de exploración y acercamiento a la naturaleza, la adapta a sus necesidades y a la dimensión y al deseo de su búsqueda. Es una observación metódica, estructurada y coherente. Manifiesta que hay que aplicar al método la perspectiva (refiriéndose a ver las cosas desde la distancia, y desde diferentes ángulos), para poder seleccionar, para poder memorizar, para poder entender lo que se observa, porque si para Leonardo las potencias son: memoria, entendimiento, apetito y concupiscencia, estas deben estar íntimamente relacionadas con la capacidad y la facultad de la observación, por la razón y por los sentidos (González, 2009).

Respecto a esa observación metódica, que más bien puede denominarse "científica", también el investigador y escritor Charles Nicholl, ya citado, manifiesta: <<La fe que tenía Leonardo en la observación de primera mano, ese elemento de reportaje visual que confiere a estos dibujos surrealistas una vivacidad y un realismo casi táctil. Un coetáneo de Leonardo, Cristoforo Giraldi, un súbdito de Ferrara que residía en la corte milanesa, viene a decirnos eso mismo: "Cuando Leonardo quería representar una determinada figura... acudía a los lugares que solía frecuentar este tipo de gente y observaba sus rostros, sus actitudes, sus ropajes y la forma en que se movían sus cuerpos. Y cuando encontraba algo que parecía ser lo que buscaba, lo dibujaba con un estilete de punta metálica en una libreta que siempre llevaba en el cinto">> (Nicholl, 2006). 
Pero Leonardo no utilizó la observación solo a efectos estéticos, él fue capaz de usarla para avanzar en sus investigaciones, e intuir lo que más tarde se denominaría la "observación científica": observar un fenómeno, hacerse preguntas sobre él, formular hipótesis, manifestar unas consecuencias o predicciones sobre esas hipótesis de manera lógica, someter a pruebas prácticas tales hipótesis, mediante experimentos 0 mediante estudios o pruebas matemáticas, y finalmente sacar conclusiones. Si estas son positivas, se avanzará en la investigación, y si no han resultado, se volverá al inicio. Así, Leonardo escribe en el Manuscrito L, c. 72, r. de la Biblioteca del Instituto de Francia (París): < <Antes de convertir un caso aislado en regla general, se debe repetir dos o tres veces el experimento, observando si cada vez los mismos efectos se producen>>. Mientras que, en el Manuscrito G, c. 96v: <<Ninguna certeza hay donde no pueda aplicarse una de las ciencias matemáticas $>>$ (Bagni \& D'Amore, 2010).

\subsection{La "imaginatio", potenciar la imaginación}

Por último, para Leonardo, tal como establece el profesor universitacio e investigador Fritjof Capra en su libro La Ciencia de Leonardo, uno de los apoyos del intelecto, junto con la habilidad técnica (arte) y el conocimiento (ciencia), era la imaginatio o phantasia, o sea la imaginación creativa (Capra, 2008), y esta debía potenciarse.

Para estimular la imaginación Leonardo ya veía como fuente de inspiración el contemplar lo variado de un cielo nuboso, o las incongruentes marcas de humo en las paredes cercanas a la salida de una chimenea. Así escribe en su Tratado de Pintura (o Codex Urbinate 1270), según la traducción de Diego Rejón de Silva en 1784: "XVI. Modo de avivar el ingenio para inventar: Quiero insertar entre los preceptos que voy dando una nueva invención de especulación, que aunque parezca de poco momento, y casi digna de risa, no por eso dexa de ser muy útil para avivar el ingenio, la invención fecunda: y es, que quando veas alguna pared manchada en muchas partes, o algunas piedras jaspeadas, podrás mirándolas con cuidado y atención advertir la invención y semejanza de algunos países, batallas, actitudes prontas de figuras, fisonomías extrañas, ropas particulares y otras infinitas cosas; porque de semejantes confusiones es de donde el ingenio saca nuevas invenciones" (Rejón de Silva, 1784). 
$<<$ La phantasia, fronteriza entre lo sensible y lo racional, muestra en la teoría de Leonardo su capacidad reproductora del mundo dado a los sentidos. Leonardo, quien al ser uno de los mayores apologistas de lo visual lo fue también de la capacidad de la mente como entidad reproductora-comprensora de la realidad natural>> (Méndez, 2013).

Mientras que para conseguir réplicas de la realidad, Leonardo establece ejercicios de prueba donde la phantasia demuestre constituirse en fidedigna de la realidad. Así escribe en el Códice Atlántico f. 104 r: <<Cuando quieras saber una cosa bien estudiada en la mente, haz de este modo: esto es cuando hayas dibujado una misma cosa tantas veces que te parezca tenerla en la mente, prueba a hacerla sin el modelo, y ten trazado a contraluz sobre un vidrio delgado y plano tu modelo y ponlo sobre la obra que ha sido hecha sin el ejemplo presente; $y$ nota bien donde el vidrio no se corresponde con tu dibujo; $y$ donde veas haber errado, retenlo allí en mente para no equivocarte más, luego retorna al modelo para reproducir tantas veces aquella parte equivocada hasta que tengas bien en la imaginativa>> (Méndez, 2013).

Enuncia otro ejercicio que debe efectuarse nel letto allo scuro. Así escribe en el Códice Atlántico folio 106v, de la Biblioteca Ambrosiana de Milán, así como en el "Libro di Pittura" f 67, 178 (h. 1492): <<He comprobado en mí mismo, ser de no poca utilidad, cuando te encuentras a oscuras en el lecho, andar con la imaginativa repitiendo las líneas superficiales de las formas antes estudiadas, $u$ otras cosas notables por sutil especulación comprendidas, y eso mismo es un acto plausible y útil para conservar las cosas en la memoria>> (Méndez, 2013).

La "ingegno" y la "phantasia" son utilizados por Leonardo explícitamente para referir a la facultad que da origen a la creación artística.

\subsection{Conclusiones}

Con todo lo descrito, Leonardo incrementaba las habilidades para el aprendizaje y la creatividad para poder desarrollar sus diseños y proyectos; igualmente se incrementaba la capacidad para imaginar, pensar y crear. Leonardo utilizó el conjunto de reglas descritas para hacer trabajar su mente, para analizar situaciones, para diseñar sus máquinas e inventos y avanzar en sus investigaciones. Su principal 
fuente de inspiración fue la naturaleza tomando, como principal interlocutor con ella, al ojo, al que estudió con detalle en sus estudios anatómicos del Códice de Windsor, y del que expresó en el Códice Atlántico folio 99r-v: <<el ojo, al que se llama ventana del alma, es la vía principal por donde el sentido común puede más copiosa y magníficamente considerar las infinitas obras de la naturaleza>> (Méndez, 2013). El citado autor lo define como: <<La universalidad de la mente está en su potencia de especular para reflejar la varieta, sin atarse a un solo canon estético... >>.

Con su insaciable curiosidad y mediante el uso de la experimentación y de las analogías con la naturaleza para buscar formas, funciones, estructuras o incluso conceptos, los cuales combinó en una interacción armoniosa, desarrolló nuevos diseños y máquinas (el vehículo automóvil, el paracaídas, el diferencial, el buzo escafandra, el ala delta, etc.) y descubrió nuevas soluciones mediante sus investigaciones (la ley de continuidad en líquidos; las dos primeras leyes básicas del rozamiento; el principio de acción y reacción; los primeros estudios del comportamiento estático de los arcos y las vigas; etc.).

Con sus métodos y reglas inició el cambio hacia la utilización de lo que hoy denominamos método científico. Como manifiesta el profesor $\mathrm{F}$. Capra, ya citado, en su libro La Ciencia de Leonardo: $<<$ No puedo sino sostener que el verdadero fundador de la ciencia moderna fue Leonardo da Vinci, y me pregunto cuál habría sido el desarrollo del pensamiento científico en caso de que los cuadernos de notas se hubiesen conocido y estudiado poco después de su muerte>> (Capra, 2008).

\section{Referencias}

Bagni, G. \& D'Amore, B. (2010). Leonardo e la Matematica, Ed. Giunti: Florencia.

Capra, F. (2008). La Ciencia de Leonardo. Círculo de LectoresEditorial Anagrama: Barcelona. (págs. 183; 206 y 217).

Chastel, A., Galluzzi, P, \& Pedretti, C. (2005). Grandes Genios de la Pintura: Leonardo da Vinci. Ed. Planeta de Agostini: Barcelona (pág. 66).

De España, J. (1943). Breviario de Leonardo da Vinci. Ed. El Ateneo: Buenos Aires. 
García de Zúñiga, E. (2005). Leonardo da Vinci, Aforismos. Ed. Espasa Calpe: Madrid.

Gelb, M. (1999). Cómo pensar como Leonardo Da Vinci: Siete lecciones para llegar a ser un genio. Ed. Planeta: Barcelona.

González, O. (2009). El Método de Leonardo Da Vinci. (25 de septiembre de 2009), Periódico El Mundo Cl. 53, 74-50, Medellín, Antioquia, Colombia. Obtenido de https://www.elmundo.com/portal/resultados/detalles/?idx=128 553).

Gruber, M., Gelman, B., \& Ranganath, C. (2014). States of Curiosity Modulate Hippocampus-Dependent Learning via the Dopaminergic Circuit, Neuron, 84, 486-496, October 22. Obtenido el 31/12/2020, de: https://www.cell.com/neuron/fulltext/S0896-6273(14)008046?_returnURL=https $\% 3 \mathrm{~A} \% 2 \mathrm{~F} \% 2 \mathrm{Flinkinghub.elsevier.com} \% 2$ Fretrieve\%2Fpii\%2FS0896627314008046\%3Fshowall\%3Dtru e\#\%20).

Da Vinci, L. (1491-1493). Códices de Madrid. Madrid. Biblioteca Nacional de España, Obtenido de http://leonardo.bne.es/index.html.

Da Vinci, L. (1478-1518). Códice Atlántico. Milán. Biblioteca Ambrosiana. Obtenido de http://www.leonardoambrosiana.it/en/il-codice-atlantico/ .

Da Vinci, L. (1478-1518). Manuscritos de la Royal Library Windsor, Royal Collection Trust. Obtenido de https://www.rct.uk/collection/themes/exhibitions/leonardo-davinci-a-life-in-drawing-0

Da Vinci, L. (1487-1514). Conjunto de Manuscritos de París. París. Institut de France. Obtenido de https://archive.org/details/lesmanuscritsdelO0leonuoft.

Da Vinci, L. (1487-1514). Codex Arundel. British Library de Londres. Obtenido de https://www.metalocus.es/es/noticias/570paginas-de-manuscritos-de-leonardo-da-vinci-estan-onlinegracias-a-la-biblioteca-britanica-y-microsoft

Méndez S. (2013). Reflexiones teóricas de Leonardo da Vinci sobre la "fantasía". Anales del Instituto de Investigaciones Estéticas, núm. 103, diciembre. Universidad Autónoma de México. 

creatividad

Obtenido el 23/12/2020 de: https://www.researchgate.net/scientific-contributions/SigmundMendez-2162794062).

Nicholl, Ch. (2006). Leonardo, El vuelo de la mente. Ed. Círculo de Lectores: Barcelona.

Osborn, A. (1953). Applied Imagination: Principles and procedures of creative thinking, Ed. Charles Scribner's Sons: New York.

Rejón de Silva, D. (1784). El tratado de Pintura por Leonardo da Vinci. 1784, Facsímil de la edición de Don Diego Rejón de Silva de 1784 de la Imprenta Real de Madrid.

Rosa, J. (2019). Leonardo da Vinci. Pensamientos: fábulas, profecías y otros. Pag 38. Ed. Verbum: Madrid.

Ruiz, E., \& Martínez, J. (2012). El imaginario de Leonardo. Editorial del Ministerio de Cultura: Madrid.

Vezzosi, A. (2011). Leonardo da Vinci, Arte y Ciencia del Universo. Pag 134. Ed. Blume: Barcelona. 



\title{
Capítulo 6 Análisis de la documentación técnica de los diseños y proyectos de Leonardo da Vinci
}

\begin{abstract}
"¿Qué valor puede tener el que se dedica a abreviar las partes de las cosas, cuando pretende dar su conocimiento integral y deja tras de si la mayor parte de lo que compone un todo?". LEONARDO DA VINCI (J. P. Richter, The Literary Works of Leonardo da Vinci, edición, Londres, Edición de 1883, pág. 1210).
\end{abstract}

\subsection{Introducción}

A finales del medievo y en los inicios del Renacimiento, Italia estaba compuesta por un sin fin de ducados (como Milán, Mantua o Ferrara), señoríos (como Rímini o Cesena) y ciudades estado (como Florencia y Venecia), que pugnaban entre ellos para incrementar el prestigio, engalanamiento y seguridad de sus respectivas cortes; lo que generó la necesidad de utilización de artistas, ingenieros y arquitectos que ayudaran a materializar tales propósitos. Ello incrementó el prestigio de dichas profesiones y facilitó el interés por el saber y la creatividad, y en concreto por el diseño de mecanismos y máquinas, tanto bélicas de defensa, como hidráulicas y de ayuda a la construcción. Muchos de ellos empezaron a plasmar sus diseños en tratados y manuscritos que son hoy objeto de estudio y admiración.

Leonardo da Vinci (1452 Vinci-1519 Amboise) es el más conocido de los ingenieros que ejercieron en todas estas disciplinas y que, dotado de una notable curiosidad y de una gran capacidad inventiva, hicieron que, aparte de su trabajo artístico, ejerciera como ingeniero civil y militar, a lo largo de su vida, para varios mandatarios como los Duques de Milán, las Repúblicas de Venecia y de Florencia, varios pontífices, incluso reyes de Francia. Todo ello lo plasmó junto con apuntes de pintura, escultura, etc. en un sinfín de hojas manuscritas, de las que hoy se conservan unas 7000 , distribuidas en varios códices y manuscritos como el Códice Atlántico (Biblioteca Ambrosiana de 
Milán), el Códice de Madrid I y II (Biblioteca Nacional de España), el Códice Arundel (British Library, Londres), el Códice Forster (Victoria and Albert Museum, Londres), el Códice Hammer o Leicester (propiedad de Bill Gates, Seatlle), el Códice del vuelo de los pájaros (Biblioteca Real, Turín), el Códice Trivulzio (Biblioteca Trivulziana, Castello Sforcesco de Milán), los manuscritos de Anatomía y otros (Royal Library del Castillo de Windsor) y los Manuscritos A a M (Biblioteca del Instituto de Francia, París).

A continuación, se mencionan algunos de los ingenieros destacados de aquel entonces que, junto con Leonardo, plasmaron sus diseños técnicos.

Mariano di Jacobo, conocido como "Il Taccola" (1382-1458 Siena). Es autor de dos tratados manuscritos, uno conocido como "De ingeneis" (compuesto por el libro I-II, emplazado en la Biblioteca Estatal de Baviera, Munich, denominado Codex Latinus Monacensis 197 II; y por el libro III-IV ubicado en la Biblioteca Nacional de Florencia y denominado Manuscrito Palatino 766); y otro conocido como "De machinis" (un solo libro ubicado en la Biblioteca Estatal de Baviera, Munich, denominado Codex Latinus Monacensis 28800). En ambos representa dibujos y diseños de ingenios, mecanismos y máquinas hidráulicas, de molienda, de ayuda a la construcción y de guerra. Era poco conocedor del conjunto de elementos que conforman la perspectiva, por lo que sus métodos de representación tienen todavía mucho de medieval. No obstante, sus dispositivos son del todo ingeniosos y sirvieron de base a otros ingenieros posteriores.

Roberto Valturio (1405-1475 Rímini). Fue el autor del tratado militar "De Re militari" conformado por una historia de la guerra, con dibujos propios de maquinaria y defensa militar y alusiones a libros clásicos sobre ello, así como una dedicación al Señor de Rímini, Pandolfo Malatesta (1417 Brescia - 1468 Rímini). La primera edición es de 1446, escrita en latín, y fue objeto de varias ediciones posteriores.

Francesco di Giorgio Martini, (1439-1501 Siena). Persona polifacética que actuó como ingeniero, arquitecto, pintor y escultor. Fue conocedor de los escritos de "II Taccola", y amigo de Leonardo, con el que coincidía en inquietudes, y con el que colaboró para el asesoramiento en la reconstrucción de la catedral de Pavía. No obstante, tuvo menor amplitud de campo y de análisis reflexivo que este último. Su manuscrito el "Codicceto" (1465-70), existente en la Biblioteca Apostólica Vaticana de Ciudad del Vaticano y denominado 
Manuscrito Latino Urbinate 1757, contiene diseños de mecanismos y máquinas hidráulicas, de molinos, carros de combate, etc., algunos de ellos copiados y mejorados de los de "II Taccola". El "Opusculum de Architectura" (1475-78) tiene un contenido similar al anterior, pero con mejores detalles y explicaciones y que se denomina Manuscrito 197.b.21, ubicado en el British Museum de Londres. Y el "Tratado de Arquitectura y Máquinas", del que hizo dos versiones; la primera de 1480, denominada Manuscrito Ashburham 361, ubicado en la Biblioteca Medicea Laurenziana de Florencia, y en el que Leonardo también realizó algunas anotaciones; y la segunda versión de 1490, mucho más extensa, denominado Manuscrito II.I.141, ubicado en la Biblioteca Nacional Central de Florencia. Ambos se estructuran con una primera parte dedicada a dibujos y reflexiones sobre arquitectura, y una segunda dedicada a mecanismos y máquinas.

Paolo Santini (de Lucca). Es autor del denominado Manuscrito Latino 7239 , de medianos del siglo XV, existente en la Biblioteca Nacional de París, aunque algunos historiadores lo creen más antiguo, de finales del siglo XIV, identificando al autor como Pauli Sanctini Ducensis (Catalogue des manuscrits de la Biblioteca Nacional de Francia), y que viene a ser casi una copia fiel de los tratados de "II Taccola" pero debidamente adornados y coloreados. (Lucchesini, 1825).

Bonaccorso Ghiberti (1451-1516 Florencia). Ingeniero florentino, que escribió un manuscrito sobre artillería, armas y tecnología varia toscana, denominado "Zibaldone", existente en la Biblioteca Nacional Central de Florencia. En él dibujó grúas, entre ellas la "grúa giratoria con contrapeso" que el arquitecto Filippo Brunelleschi (1377-1446 Florencia) inventó y utilizó en la construcción de la cúpula de Santa María de Fiore, para ir subiendo el material apoyándose en la propia construcción.

\subsection{Objetivo}

El objetivo de este capítulo es demostrar la superioridad documental de los diseños de Leonardo frente a sus coetáneos y predecesores, mostrando además ejemplos de ello y de que la documentación por él elaborada en algunos de sus diseños técnicos puede calificarse como precursora de la moderna documentación técnica que conforman hoy los Proyectos Técnicos.

Martin Kemp (1942 Reino Unido) profesor de Historia del Arte en la Universidad de Oxford y uno de los mejores expertos en la obra de 
Leonardo, a raíz de la muestra "Los ingenios de Leonardo", realizada en Londres en 2016, manifestó: <<Lo más asombroso de Leonardo, y lo que de verdad le distingue de sus coetáneos, es la calidad de sus dibujos...; su capacidad de observación y su habilidad para visualizarlo todo le desmarcan del resto >> (Fresneda, 2016).

$\mathrm{Y}$ el investigador italiano y doctor en Historia, Domenico Laurenza, opina: <<La confianza en el valor del dibujo como medio de comunicación relaciona a Leonardo con Taccola o con Francesco di Giorgio, pero Leonardo va más allá de la tradición que le había precedido no solo por la mayor calidad de sus dibujos o por las variadas e innovadoras fórmulas visuales de presentación del Proyecto (imagen desde varios puntos de vista, representación en conjunto y de los componentes, etc.), sino también por la complejidad de los contenidos contextuales expresados, a través del lenguaje visual, por la máquina>> (Laurenza, Taddei \& Zanon, 2006).

No solo Leonardo fue más prolífico que sus coetáneos y predecesores, en cuanto a cantidad de diseños de mecanismos y máquinas, sino que al comparar sus diseños técnicos y los del resto de ingenieros, observando los dibujos de los códices y manuscritos de varios de ellos, pueden comprobarse los adelantos y mejoras en los diseños de Leonardo. Así pues, el presente capítulo pretende poner de manifiesto que los primeros diseños técnicos a los que puede otorgárseles la denominación de verdaderos Proyectos Técnicos, similares a como se conciben hoy en día, fueron los de da Vinci.

\subsection{Los diseños de máquinas para la guerra}

La defensa de ciudades y castillos fue fundamental en el final de la Edad Media, por lo que los ingenieros al servicio de los mandatarios tuvieron que diseñar o proyectar máquinas bélicas que iban desde un simple carro de guadañas a una catapulta.

\subsubsection{El carro con guadañas}

Consistía en un carro, tirado por caballos o bueyes, al que se le incorporaban hoces de grandes dimensiones o guadañas, tanto a las ruedas laterales como en la parte delantera de las guías de las bestias, 
con el fin de que, simplemente embistiendo al enemigo, las guadañas hicieran su función mortal.

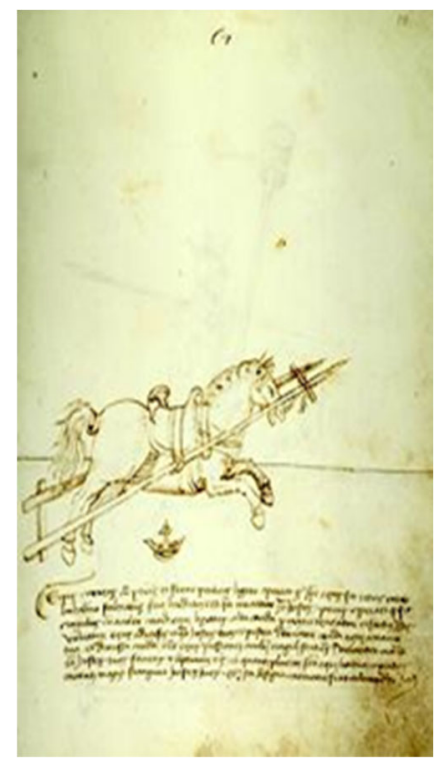

a)

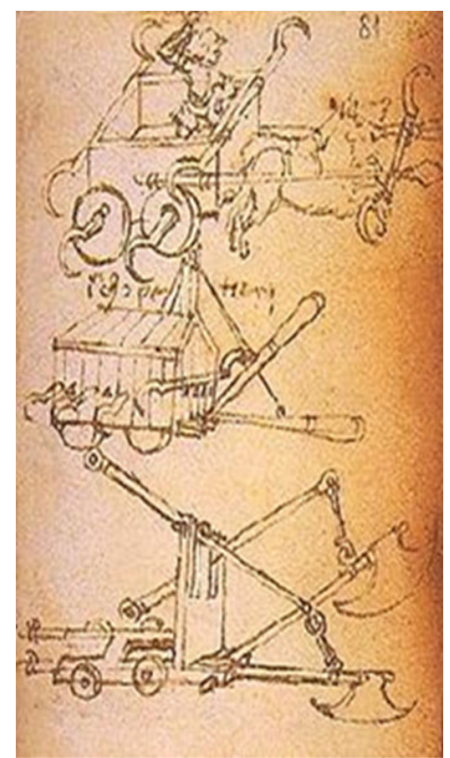

b)

Figura 6.1 a) II Taccola, Manuscrito "De Machinis", Bayerische Staatsbibliothek (Biblioteca Nacional de Baviera), b) Di Giorgio, Manuscrito "Opusculum de Architectura", British Museum. (origen de las imágenes a y b Instituto y Museo de Historia de la Ciencia de Florencia o Museo Galileo, https://brunelleschi.imss.fi.it). 


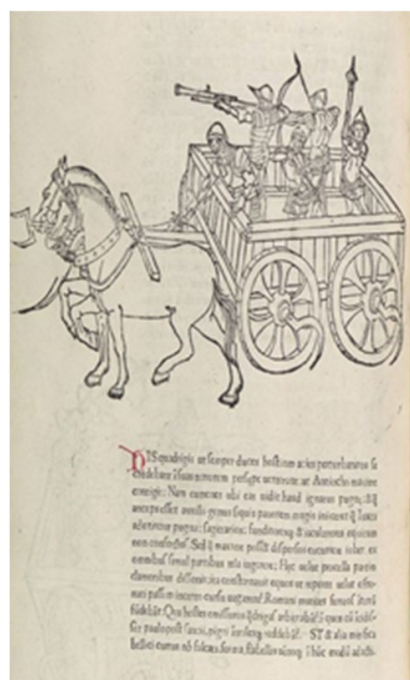

a)

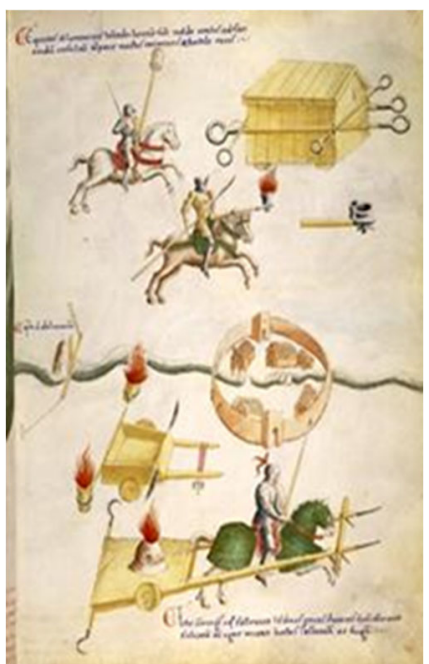

b)

Figura 6.2 a) R. Valturio Tratado de "Re Militari" (Edición de 1472) Carro con guadañas (www.metmuseum.org , Museo Metropolitano de Arte de New York, www.metmuseum.org).

("https://play.google.com/books/reader?id=m3Q8AAAAcAAJ\&hl=es\&pg=GB S.PA231"), b) Paolo Santini, Carro incendiario "Manuscrito Latino" 7239 c. 19 r, Biblioteca Nacional de Paris. (Instituto y Museo de Historia de la

Ciencia de Florencia o Museo Galileo https://brunelleschi.imss.fi.it).

Los diseños de "II Taccola" (Figura 6.1 a)) y Di Giorgio (Figura 6.1 b)) apenas son dibujos coherentes, que parecen de aprendices. La visión y perspectiva elegidas son inadecuadas e incluso el tamaño o relación entre las distintas partes del dibujo son a veces erróneas. R. Valturio (Figura 6.2 a)) mejora en los acabados del dibujo, pero no es ilustrativo en cuanto al funcionamiento de la máquina, solo la explica en el texto. Mientras que P. Santini (Figura 6.2 b) y 6.3 a)) elabora figuras deficientes, que son similares al Manuscrito "De Machinis" de II Taccola, pero debidamente coloreadas; de hecho, hay expertos que establecen que son copia de las de "II Taccola". En definitiva, puede apreciarse en los dibujos y bocetos de los carros de guerra o con guadañas del resto de ingenieros predecesores y coetáneos de Leonardo que, aunque precisos desde el punto de vista descriptivo, son solo ilustrativos y con una deficiente perspectiva, tamaño de ruedas desproporcionado, sin visión o referencia clara a los mecanismos de funcionamiento, etc. Leonardo los supera a todos con 
los dos diseños del manuscrito de 1485 de la Biblioteca Real de Turín f.15583 r (Figura 6.3 b) (existiendo otro similar en el British Museum de Londres).

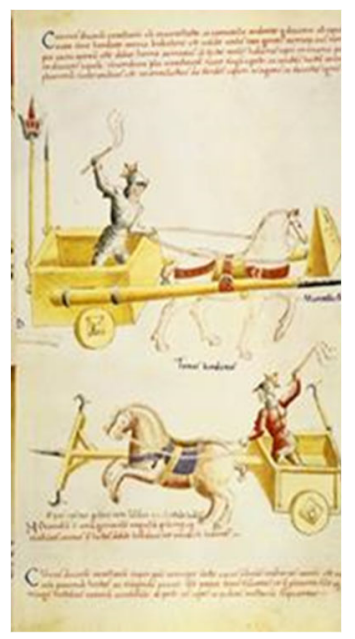

a)

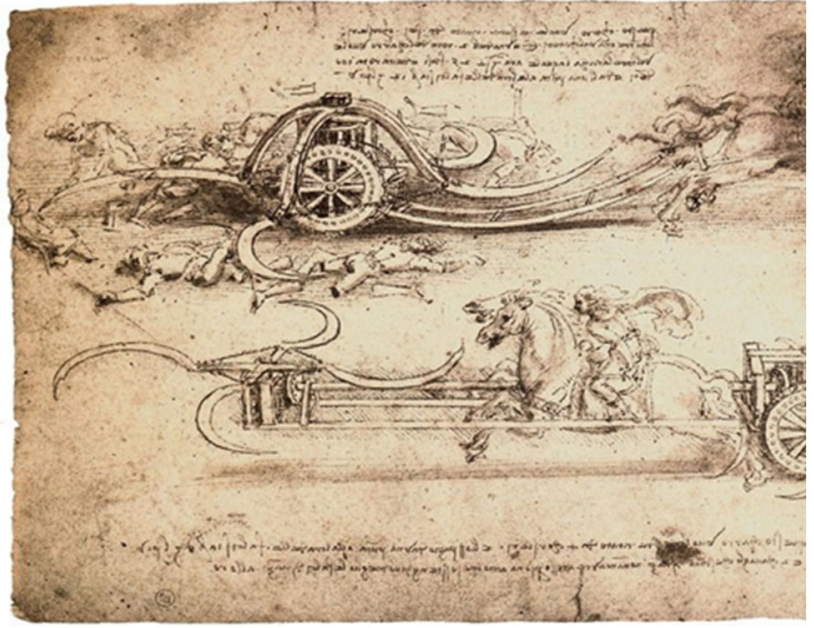

b)

Figura 6.3 a) Paolo Santini, Carro con guadañas, "Manuscrito Latino" 7239 c. 78 r, Biblioteca Nacional de Paris (Instituto y Museo de Historia de la Ciencia de Florencia o Museo Galileo https://brunelleschi.imss.fi.it), b) Leonardo, Carro con guadañas móviles. f. 15583 r (1485) Biblioteca de Real de Turín

(https://commons.wikimedia.org/wiki/File:Leonardo_da_vinci,_Assault_chari ot_with_scythes.jpg?uselang=es).

Los dos diseños plasmados por Leonardo en el manuscrito no son solo superiores en dibujo, sino que este no se conforma con la solución estática y convencional de sus predecesores y coetáneos (donde las guadañas delanteras no se mueven y las de las ruedas solo recorren el movimiento de estas) y, además de añadir unas guadañas traseras, aprovecha el movimiento de las ruedas para hacer que las guadañas tanto traseras como delanteras (Figura 6.4 b)) sean más eficaces. Para ello, mediante dos engranajes principales de tipo jaula 0 linternas, y un árbol de unión central, también provisto de engranajes en su inicio y fin, traslada el movimiento de las ruedas por un lado a las guadañas traseras y por otro a las de la parte delantera del carro y hace que todas las guadañas giren a mayor velocidad, en función del árbol multiplicador, siendo estas mucho más efectivas. Lo que supone ya no solo un boceto de solución como los del resto de ingenieros, sino 
un diseño o proyecto complejo, con necesidad de conocimientos de mecánica para su correcto diseño y construcción.

Además, ambas soluciones comunican movimiento y expresan dinamismo, incluyendo incluso figuras humanas con sus extremidades recién cortadas que muestran el dramatismo y la eficacia en el uso de la máquina.

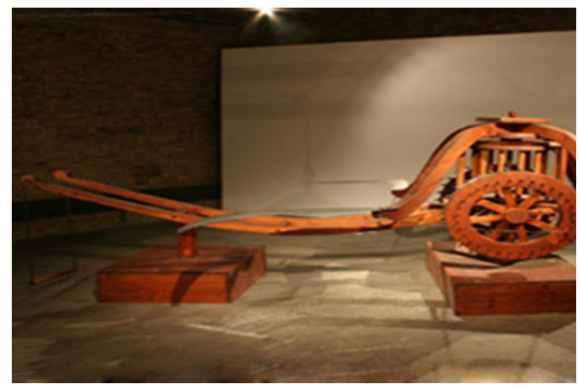

a)

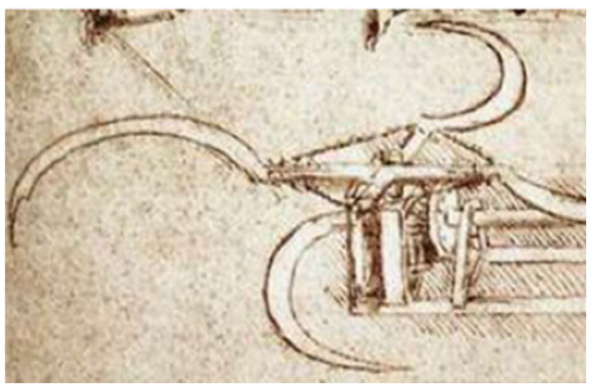

b)

Figura 6.4 a) Maqueta del Carro de Guerra (Biblioteca Real de Turín) (http://www.macchinedileonardo.com/index0aec.html?le-macchine), b) Detalle del final del árbol de transmisión a las guadañas delanteras.

\subsubsection{Las catapultas}

Fueron la solución de ataque y defensa más eficaces, hasta la aparición de armas que aprovechaban el uso de la pólvora. Su función era lanzar un proyectil de elevado peso (piedra o bola de hierro) o flecha punzante, a la mayor distancia posible gracias a la energía almacenada en un elemento elástico, generalmente un mecanismo, que actuaba al estar en tensión, adquirida bien por torsión, tracción o contrapeso. 


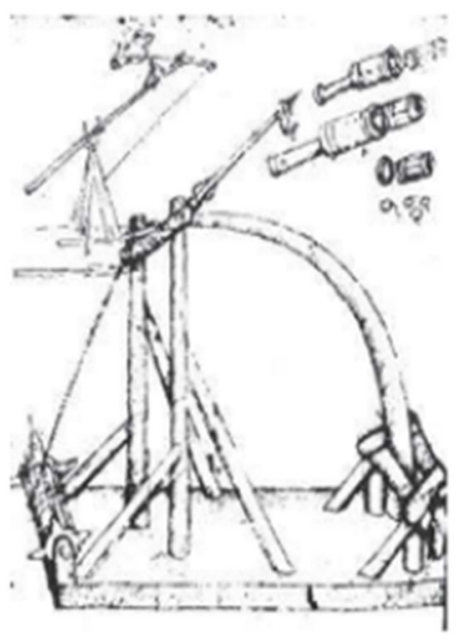

a)

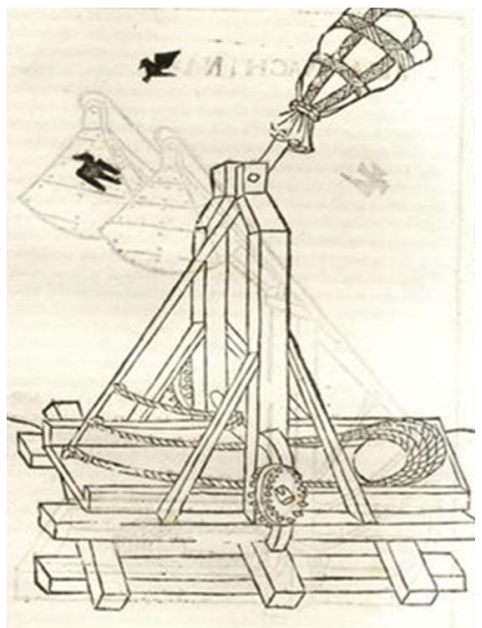

b)

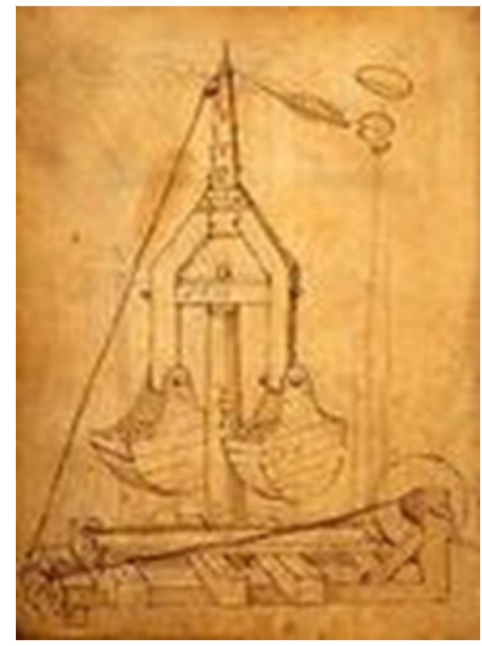

c)

Figura 6.5 a) "Il Taccola", Catapulta de (García, 2011), b) R. Valturio, Catapulta de Tratado "Re Militari" (Edición de 1472) (Museo Metropolitano de Arte de New York, www.metmuseum.org)

(https://play.google.com/books/reader?id=m3Q8AAAAcAAJ\&hl=es\&pg=GBS

.PA276), c) Di Giorgio, Catapulta de "Opusculum de architectura" Ms 197.b.21 (British Museum, London) c. 37v (Instituto y Museo de Historia de la Ciencia de Florencia o Museo Galileo https://brunelleschi.imss.fi.it). 
Los diseños de los ingenieros predecesores (Figura 6.5 a), b) y c)) y coetáneos de Leonardo tienen una representación gráfica muy elemental, están carentes de una perspectiva correcta, e incluso sin coherencia en cuanto a la relación entre los tamaños de los elementos que conforman la máquina.

Leonardo (Figura 6.6) de nuevo mejora la solución convencional de catapulta de un brazo, añadiendo, junto con un dibujo perfecto, una perspectiva correcta y un adecuado número de vistas, una novedosa solución tecnológica, con la opción de utilizar dos brazos o ballestas de madera combada para garantizar un impulso más fuerte. Un arrollamiento de cuerda sobre el eje central asegura el tensado cómodo de los brazos o ballestas que, mediante un trinquete, frena la posibilidad de soltarse. Muestra en otra vista (Figura 6.6 a)) el tornillo sin fin (que será el que mueve la rueda de gran tamaño que fuerza el arrollamiento de la cuerda) movido por una manivela que sirve para tensar las ballestas de una manera cómoda. Mientras que en otra vista muestra un martillo que sirve para liberar el mecanismo o resorte y producir el disparo mediante un golpe. Las aclaraciones a los posibles mecanismos de funcionamiento las detalla en otro plano también con varias vistas y texto adjunto aclaratorio (Figura 6.6 b)).

La visión en perfecta perspectiva, así como la colocación del propio proyectil en la cuchara, dan una perfecta expresión gráfica del proyecto.

También diseñó otras grúas de un solo brazo (Figura 6.7 a)) o incluso más complejas para lanzamiento de flechas de gran tamaño, como la del folio $181 \mathrm{r}$ del Códice Atlántico de la Biblioteca Ambrosiana de Milán, (Figura 6.7 b) (Da Vinci, 1478-1518), con cuya sola visualización en perspectiva se clarifica su funcionamiento. 


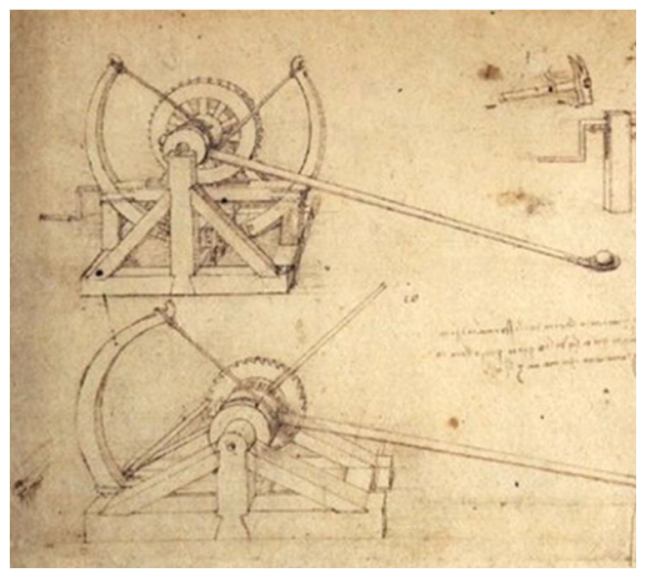

a)

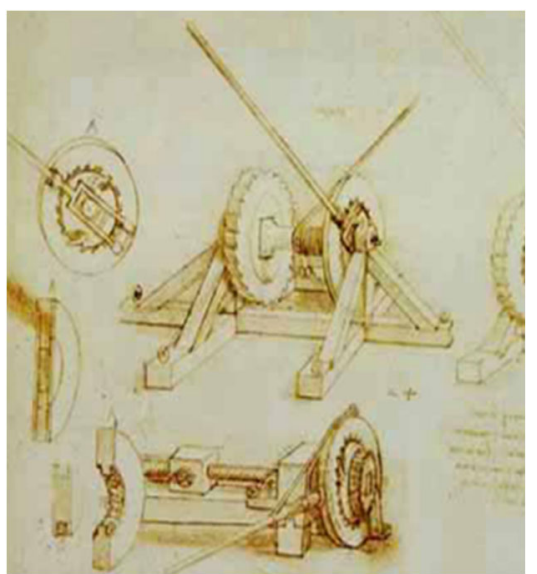

b)

Figura 6.6 a) Leonardo: Proyecto de Catapulta f. 140 a r, del Códice Atlántico de la Biblioteca Ambrosiana de Milán (1485-90) (https://commons.wikimedia.org/wiki/File:Da_Vinci_Catapult.jpg?uselang=e), b) Leonardo: Detalles de resortes y cabrestantes de sistemas para tensado de la catapulta f. 148a r del Códice Atlántico de la Biblioteca Ambrosiana de Milán (1485-90)

(https://commons.wikimedia.org/wiki/File:Codex_Atlanticus_-_000R-148.jpg). 


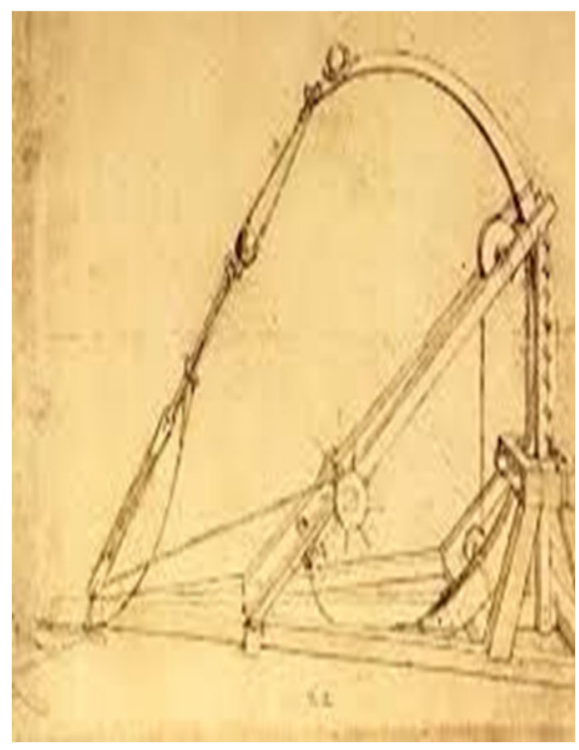

a)

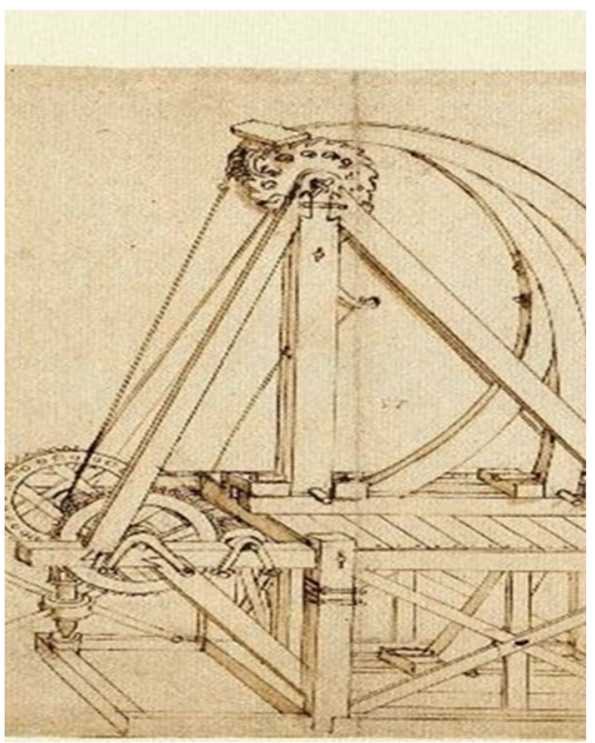

b)

Figura 6.7 a) y b) Leonardo, Proyectos de Catapultas de un solo brazo f. $148 \mathrm{~b}$ r; y para flechas f. 181 r, del Códice Atlántico, Biblioteca Ambrosiana de Milán (1485-90)

(https://commons.wikimedia.org/wiki/File:Leonardo_Da_Vinci_Sling_Catapul t.PNG? uselang=es).

Colocando dos flechas de gran tamaño en la plataforma de la parte alta de la pilastra delantera, al liberar la catapulta, estas serán empujadas a larga distancia. Una manivela horizontal sirve para el tensado que, mediante engranajes, transmite el movimiento al cabestrante. En este caso diseña el trinquete de frenado en la parte superior de la pilastra trasera y el mecanismo de liberación en el centro de esta.

En el conjunto de diseños de catapultas, las de Leonardo son superiores en calidad, más completas, muestran diferentes vistas de un mismo proyecto, e incluso detalles de los mecanismos de funcionamiento, y se apoyan muchas veces en varios planos compuestos de las vistas necesarias. Demuestran un dominio excepcional de los elementos mecánicos, muy por encima del resto de 
ingenieros predecesores y de su época, que solo observan dibujos generalistas de la máquina.

\subsection{Las grúas}

Las grúas son elementos mecánicos que se precisan para un sinfín de tareas, por ejemplo, la elevación de cargas en trabajos de desvío de ríos, de piezas de artillería, o de columnas en construcción. Todos los ingenieros anteriormente citados, junto con Leonardo, las diseñaron o dibujaron a su manera, con más o menos corrección y detalle.

Como en puntos anteriores, se aprecia en los diseños del resto de ingenieros (Figura 6.8 a), b) y Figura 6.9) una menor precisión en los dibujos, así como una falta de la perspectiva adecuada. Igualmente, sus dibujos no manifiestan de manera clara el funcionamiento de los elementos mecánicos base para el accionamiento de las grúas.

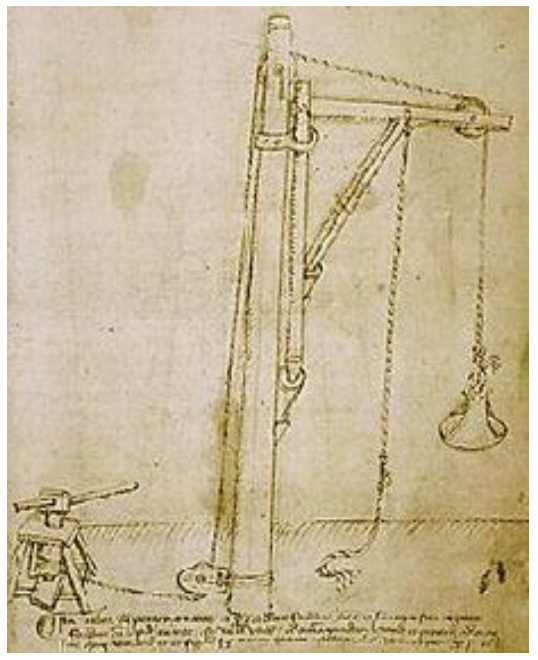

a)

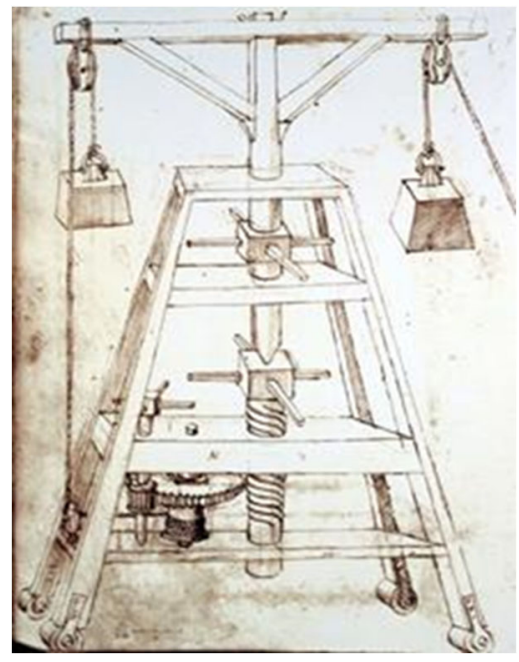

b)

Figura 6.8 a) Ingeniero sienés anónimo, Grúa siglos XV-XVI, b) Di Giorgio, Grúa, "Tratado Arquitectura y Maquinas $2^{\mathrm{a}}$ versión", Biblioteca Nacional Central de Florencia (Instituto y Museo de Historia de la Ciencia de Florencia o Museo Galileo https://brunelleschi.imss.fi.it). 


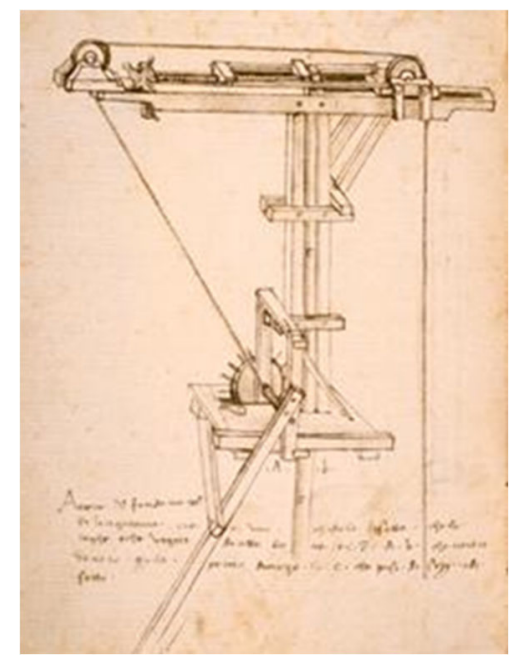

Figura 6.9 Bonaccorso Ghiberti, Grúa giratoria con contrapeso de Brunelleschi, Manuscrito "Zibaldone", B.R. 228, c. 107v Biblioteca Nacional Central de Florencia (sobre 1500). (Instituto y Museo de Historia de la Ciencia de Florencia o Museo Galileo https://brunelleschi.imss.fi.it).

Leonardo también tiene diseños similares a los de todos ellos (por ejemplo, Códice de Madrid, folio 96r (Da Vinci, 1490-1505) y en el Códice Atlántico, folios 905 y 944v) pero la República de Florencia le encargó en 1503 el proyecto de desvío del río Arno, con el fin de dejar a la ciudad de Pisa sin control del mismo y hacerlo navegable hasta Florencia. Para ello tuvo que estudiar soluciones de máquinas que hicieran las funciones de excavación de tierras de manera rápida y en grandes cantidades, con lo que diseñó varias soluciones de grúas, destacando una gran grúa giratoria y móvil, con doble brazo de actuación y a dos niveles de acción, que supera gráficamente y en características tecnológicas a todas las existentes hasta entonces.

La dibuja (Figura 6.10) en el Códice Atlántico con tiza, pluma y tinta sobre papel. La grúa es de grandes dimensiones, con un radio de giro de la mitad del tamaño del canal proyectado para solo tener que tocar el material una vez. En el recorrido de la grúa, girando a un lado o a otro, haría que el material central extraído se depositara en cada lateral $y$, con una sola operación, iría conformando un dique en cada lateral o extremo. En su parte baja diseña unos raíles que, a medida que avanzase la excavación, se irían prolongando, retirando los traseros y facilitando el desplazamiento de la grúa. Un cabestrante ubicado en la 
parte baja de la pata central delantera de la grúa facilitaría el desplazamiento de esta a través de los tres raíles. El elevado número y la distribución de los cajones de carga de tierra dan una idea de la magnitud de la obra, de las dimensiones de la grúa y de la necesidad de mano de obra.

La ratificación de que se trataba de un Proyecto completo, la reafirma el ya citado Domenico Laurenza: <<Este estudio es probablemente un proyecto para un contratista. Lo revela el carácter perfeccionista: Leonardo ha trazado primero con lápiz negro las líneas generales (los signos son todavía visibles), y después ha delineado con pluma el dibujo final, completado con acuarela. Por tanto, no se trata de un estudio hecho de manera improvisada, sino una copia en limpio. La necesidad de crear modelos antes de realizar la obra definitiva era común entre ingenieros, escultores y arquitectos. El contratista de la obra observando el modelo, podía pedir modificaciones o aceptar la propuesta y dar vía libre a su realización... El artífice podía crear modelos tridimensionales a escala o hacer dibujos, cuidados en los detalles y en la forma, casi siempre acabados con acuarela... Los contratistas eran probablemente los representantes de la República Florentina, que habian pedido a Leonardo que hiciera navegable el río Arno >> (Laurenza, Taddei \& Zanon, 2006).

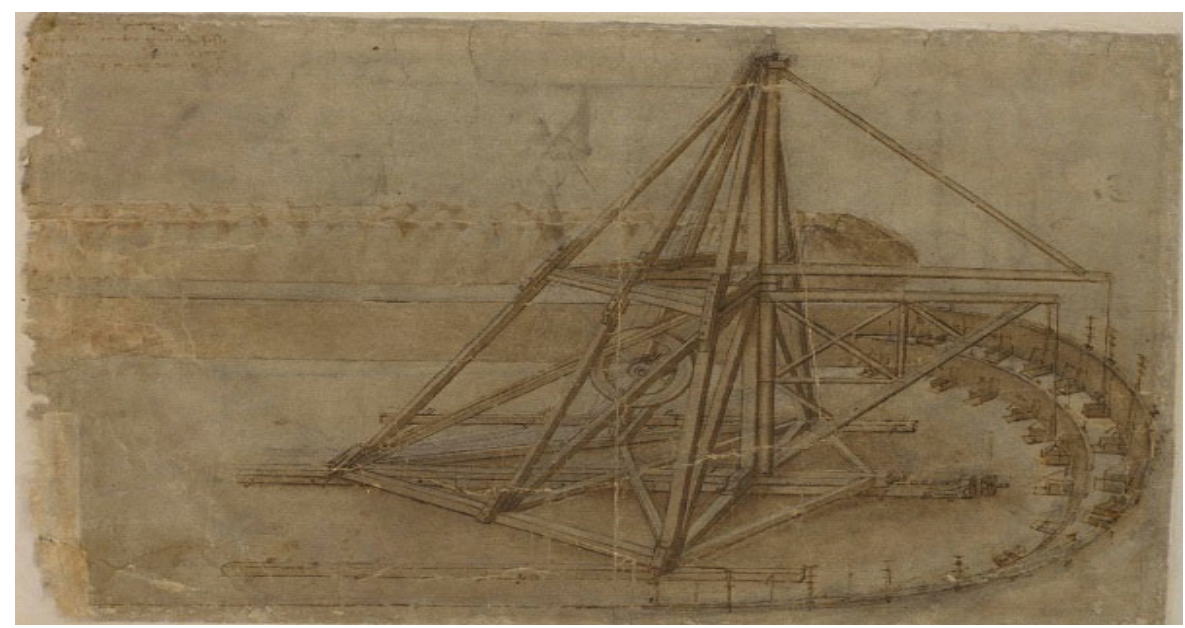

Figura 6.10 Leonardo, gran Grúa giratoria para excavar de canales, Códice Atlántico f. 4r, 1503 Biblioteca Ambrosiana Milán.

(https://commons.wikimedia.org/wiki/File:Codex_Atlanticus_-_000R-

4.jpg?uselang=es-formal). 


\subsection{El conjunto de documentos del proyecto técnico en Leonardo}

Los manuscritos de Leonardo estudiados documentan con claridad lo que es la visión gráfica actual de un proyecto técnico, o sea el conjunto de planos es abordado con detalle por Leonardo. Además, lo considerado como memoria aparece también claramente en las descripciones escritas junto a sus dibujos o planos.

Pero además podemos encontrar más partes del concepto actual de Proyecto en otros trabajos de Leonardo, como por ejemplo en su Proyecto del Caballo Sforcesco (Cerveró, Ferrer \& Capuz, 2016), que pretendía crear una estatua de fundición de más de $7 \mathrm{~m}$ de altura en honor del Duque de Milán, desarrollado principalmente en los manuscritos del Códice de Madrid II, en su parte final, a partir del folio 144v, hasta el folio 157v. Existen 27 hojas manuscritas con los dibujos, planos, croquis, y memorias de construcción mediante escritos de manera especular, con datos, cálculos, estimaciones, mediciones, etc. (algunas de ellas se detallan en las Figuras 6.11, a) y b), y 6.12 a)).

Previsor en cuanto a detallar el proyecto, Leonardo redacta también planos, información y referencias de cómo construir los habitáculos para los hornos y cuerpo de la propia fundición del caballo (folio 1103 $r$ del Códice Atlántico y en los folios manuscritos 12349r-p112r; 12348p112r; y 12348r-p108r de la Royal Collection, de Windsor) (Da Vinci, (1478-1518)). Esto último, como ejemplifica la Figura 6.12 a) y b), constituye un auténtico pliego de condiciones técnicas de ejecución del proyecto. Además, lo diseña enterrado, para ganar en estabilidad térmica, y con varios hornos en los laterales para, mediante canales, aportar la gran cantidad de metal líquido fundido en el menor tiempo posible. 


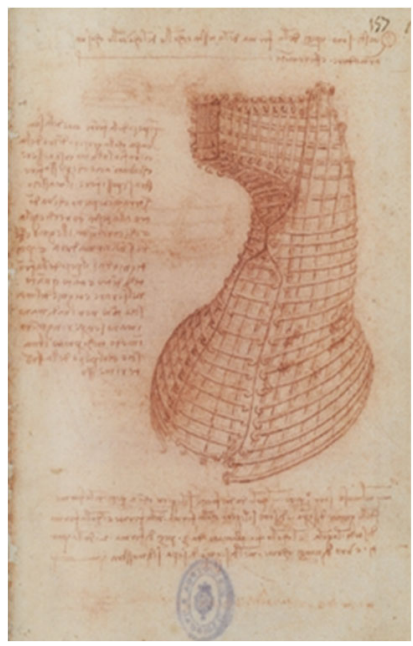

a)

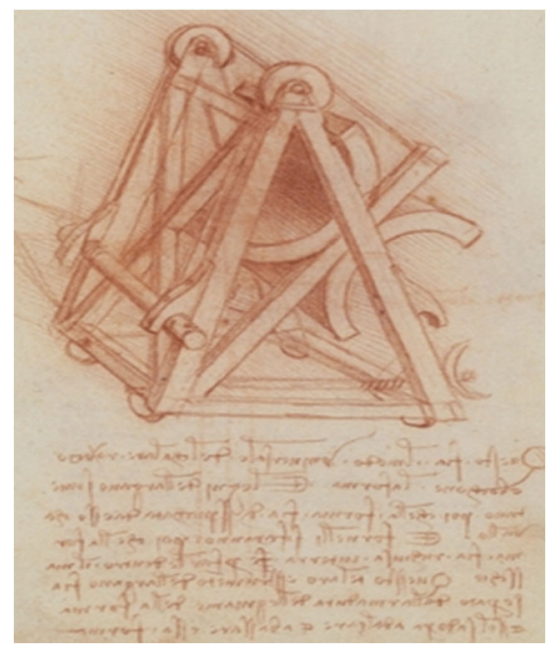

b)

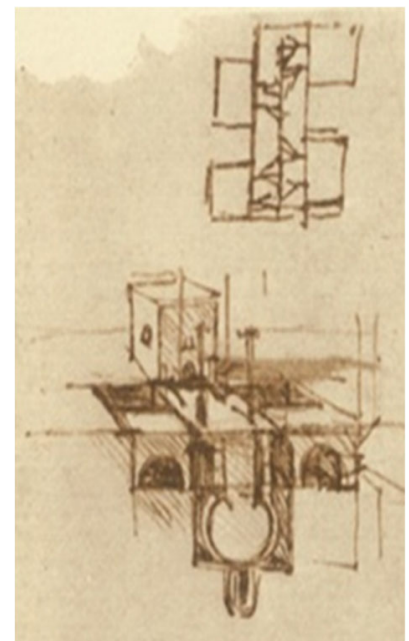

c)

Figura 6.11 a) y b) Detalles de la armadura de la cabeza para la fundición del caballo Sforza, f. 157 r del C.M. II, y del soporte para levantar y bajar el molde del f. 155v del Códice Madrid II (Biblioteca Nacional de España) (http://leonardo.bne.es/index.html), c) Detalle para los hornos y cuerpo de la fundición, Manuscritos de la Royal Collection, de Windsor 12349r p112r

(www.museosciencia.org).

En el folio f157v del Códice de Madrid II manifiesta "Aquí quedan registradas todas aquellas cosas que están relacionadas con el proyecto del caballo de bronce en el que estoy trabajando en la 
actualidad (17-5-1491)..."; pareciendo que Leonardo daba así por completada la documentación técnica del Proyecto.

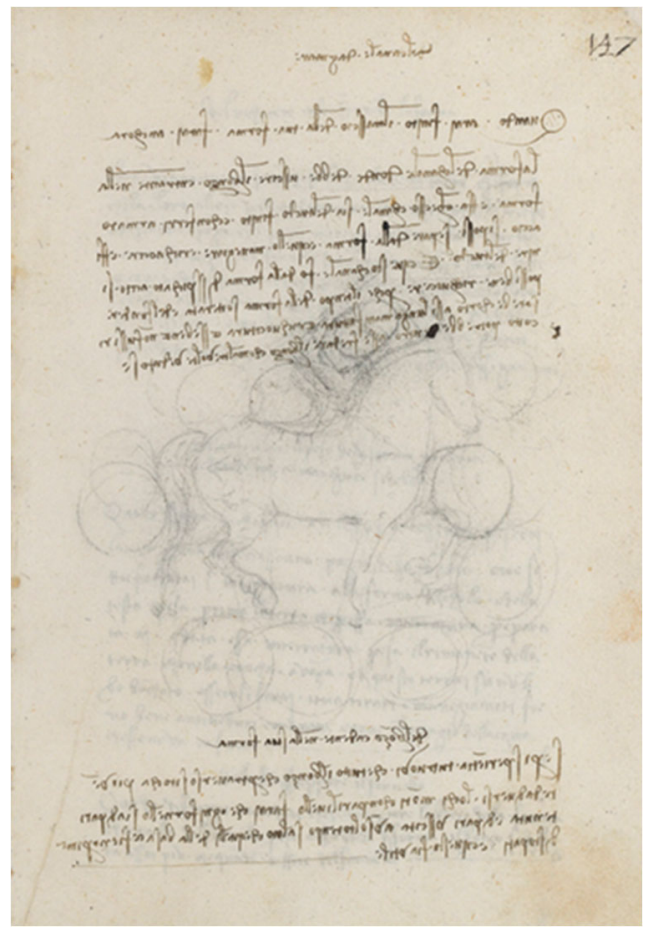

a)

\section{Acerca del condudo de fundición}

Cuando hayas acabado el macho de tu molde, prepararas también el molde del conducto por donde debe circular el bronce que entrara en el molde. Y procura que este conducto quede bien acabado y $\infty n$ los hierros de la armadura, $\infty n$ el fin de que se pueda separar del molde y manejar, recocer y ultimar por completo. Haré este conducto separado del molde para que se pueda recocer bien, porque la duración del tiempo que debe estar el molde bajo tierra y que necesita la fundición resultania escasa respedo al tiempo necesario para la manufactura y recocido del conducto, que es más largo. $Y$ si el conducto no estuviese bien recocido, el bronce se podria entriar en su interior, como se ha podido comprobar en algunas ocasiones.

\section{[Figura]}

Sobre la caida del bronce en el molde

Si has comprobado experimentalmente que todo el bronce se comunica de manera transversal, procedente de diferentes lugares, y alcanza un mismo nivel, procurarás que cada hornillo tenga idéntica capacidad yla salida se efecué al mismo tiempo, excepto los hornillos del pedestal que deben ser abiertos antes, ya que esto resulta útil.

Figura 6.12 a) Detalle de f147r del Códice Madrid II (Biblioteca Nacional de España), b) Su traducción (http://leonardo.bne.es/index.html).

Si quisiera observarse otro Proyecto con presupuesto incluido, basta consultar su Proyecto del Mausoleo para el Mariscal Gian Giacomo Trivulzio (existente parte en el folio 179 del Códice Atlántico de la Biblioteca Ambrosiana de Milán, (Figura 6.13 a)) y en los manuscritos de la Royal Collection de Windsor). En este proyecto, además de la memoria y los planos, se incluye un presupuesto con precios detallados por partidas, casi equivalente a los que se realizan en la actualidad. Leonardo divide el presupuesto en distintos conceptos coherentes de la obra que puedan considerarse y ejecutarse por separado, y le asigna costos a cada uno de ellos. En definitiva, crea lo que hoy en día conocemos como "partidas", y le asigna precios a cada uno de ellos, o lo que conocemos como "precios unitarios" y "asignación de precios". Asignándole al proyecto un presupuesto total de 3046 ducados de la época. La traducción del citado Presupuesto 
por el historiador de arte alemán Jean Paul Richter (Dresde 1847Lugano 1837) y primer compilador de los escritos de Leonardo, se adjunta en la Figura 6.13 b).

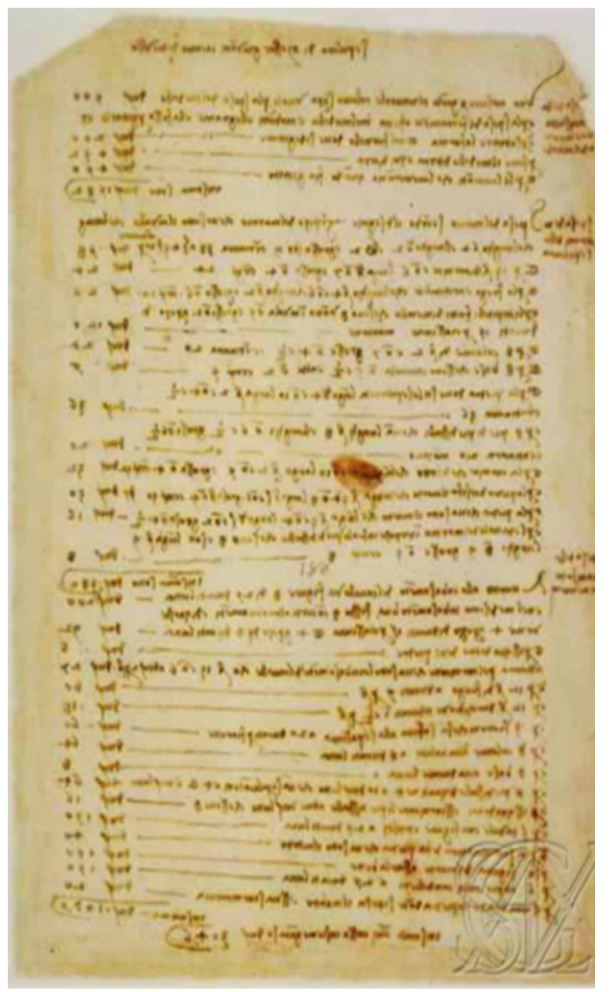

a)

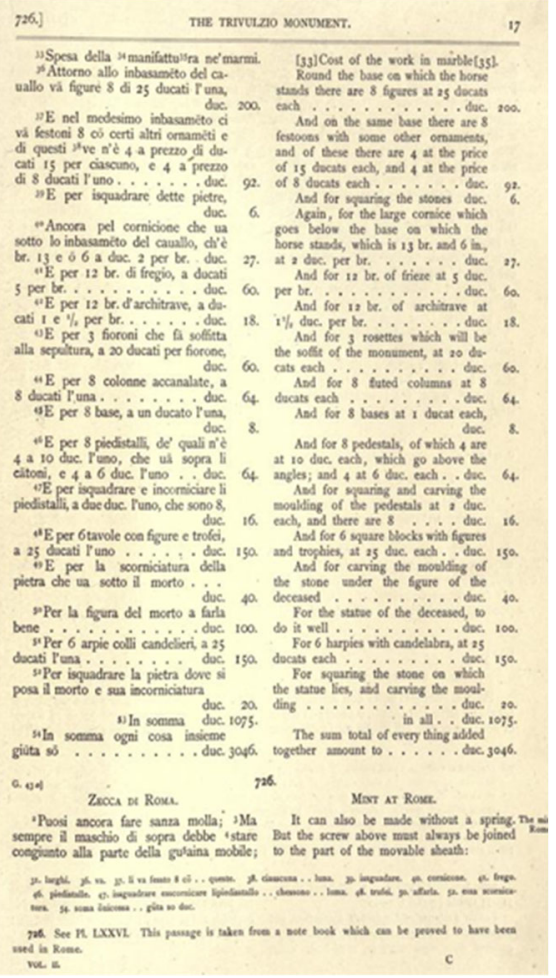

b)

Figura 6.13 a) Presupuesto del Mausoleo de Trivulzio f. 492r del Códice Atlántico (Biblioteca Ambrosiana de Milán).

(https://commons.wikimedia.org/wiki/File:Codex_Atlanticus_-_000R492.jpg?uselang=es-formal), b) Traducción del mismo (Richter, 1883). (https://warburg.sas.ac.uk/pdf/cnm22b2242052v1.pdf).

\subsection{Conclusiones}

Se ha identificado perfectamente que Leonardo en sus folios manuscritos sobre diseños técnicos de hace más de 500 años ya conformó las clásicas partes o documentos que desde de la visión actual contemplan lo que es un Proyecto Técnico.

También se ha mostrado cómo fue innovador, con referencia a sus predecesores y coetáneos, no solo por la fuerza intelectual de sus 
dibujos y de una correcta perspectiva, sino por ser además pionero en la utilización de algunos recursos gráficos: utilización de mayor número de vistas en los planos, mayor descomposición en el diseño de componentes, utilización de vistas en transparencia para dibujar las partes opuestas o no visibles, utilización de zonas de sombreado para dar profundidad a las vistas en perspectiva o grafiar zonas de colisión o rozamiento, e incluso simulación de momentos gráficos seguidos, utilizando vistas casi solapadas del dibujo para dar sensación de movimientos seriados, lo que hoy equivaldría a las cadenas cinemáticas.

Todo ello viene confirmado por Soledad Álvarez, Catedrática de Historia del Arte de la Universidad de Oviedo, en la introducción del libro "Once máquinas e ingenios de Leonardo Da Vinci interpretados por Carlos Gancedo": <<La polifacética y magistral actividad creativa de Leonardo son el origen de la ilustración científica en las que la imagen supera con minuciosidad y exactitud descriptiva a la reflexión teórica>> (Gancedo, 2011).

Pero Leonardo va aun más lejos y no solo se adelanta en la concepción de la morfología del Proyecto Técnico, sino que alcanza la filosofía actual del mismo. De acuerdo con la "Teoría de sistemas" de Karl Ludwing von Bertenlanffy (Viena 1901-Búfalo 1972), todas las partes del proyecto y su objeto están interrelacionadas entre sí y con el entorno. Y Leonardo ya alude a esta visión en su siguiente manifestación: <<¿Qué valor puede tener el que se dedica a abreviar las partes de las cosas, cuando pretende dar su conocimiento integral y deja tras de sí la mayor parte de lo que compone el todo? >> (Richter, 1883).

En el mismo sentido opina que para diseñar no basta conocer solo lo referente del pasado, sino que hay que pensar en la necesidad de la propia experimentación y comprobación para adelantar en el conocimiento, manifestando en su Cuaderno de Notas (Da Vinci, 1982): <<Aquellos que se dedican a resumir obras perjudican al conocimiento y el deseo, ya que el deseo de algo es la fuente de conocimiento, y el deseo es tanto más ferviente cuando más cierto es el conocimiento. Esta seguridad nace del conocimiento profundo de todas las partes que componen el conjunto de una cosa>>. 


\section{Referencias}

Biblioteca Real de Turín. (n.d.). Obtenido el 24/02/2019 de https://www.museireali.beniculturali.it/biblioteca-reale/.

Cerveró, E., Ferrer, P., \& Capuz, S. (2016). El Caballo Sforza de Leonardo Da Vinci analizado desde la perspectiva de los proyectos de ingeniería. 20th International Congress on Project Management and Engineering. Cartagena. AEIPRO.

Da Vinci, L. (1478-1518). Códice Atlántico. Milán. Biblioteca Ambrosiana. Obtenido de http://www.leonardoambrosiana.it/en/il-codice-atlantico/.

Da Vinci, L. (1478-1518). Manuscritos de la Royal Library Windsor, Royal Collection Trust. Obtenido de https://www.rct.uk/collection/themes/exhibitions/leonardo-davinci-a-life-in-drawing-0.

Da Vinci, L. (1490-1505). Códices de Madrid. Madrid. Biblioteca Nacional de España. Obtenido de http://leonardo.bne.es/index.html.

Da Vinci, L. (1982). Cuaderno de Notas. Editorial Busma: Madrid.

Fresneda, C. (2016, septiembre, 2). Los "ingenios" de Leonardo. El Mundo. Obtenido el 08/03/2019 de www.elmundo.es/ciencia/2016/02/09/56b9f0b1268e3e2f108b4 735.html.

Galería de la Academia de Venecia. (n.d.). Obtenido el 20/02/2019 de http://www.gallerieaccademia.it/leonardo-da-vinci-universalman-gallerie-dellaccademia-venice.

Gancedo, C. (2011). Once Máquinas e Ingenios de Leonardo Da Vinci interpretados por Carlos Gancedo. Editorial Fundación Museo Evaristo Valle: Gijón.

García Fitz, F. (2011). Tecnología, literatura técnica y diseño de máquinas de guerra durante la Baja Edad Media occidental. Anuario de Estudios Medievales 41/2.

Instituto y Museo de Historia de la Ciencia de Florencia o Museo Galileo. (n.d.). Obtenido el 04/03/2019 de https://brunelleschi.imss.fi.it.

Laurenza, D., Taddei, M., \& Zanon, E. (2006). Las máquinas de Leonardo. Susaeta Ediciones: Madrid. 
Les macchine di Leonardo da Vinci. (n.d.). Obtenido el 15/02/2019 de http://www.macchinedileonardo.com/index.php?machineswar\#5.

Lucchesini, C. (1825). Memorie e Documenti per servire alla storia del Ducato di Lucca. Francesco Bertini, tipografo ducale.

Museo Metropolitano de Arte de Nueva York. (n.d.). Obtenido el 06/03/2019 de www.metmuseum.org

Museo de la Ciencia y la Tecnología de Milán. (n.d.). Obtenido el $27 / 02 / 2019$ de http://www.museoscienza.org/english/visiting/leonardoparade/.

Richter, J. (1883). The Literary Works of Leonardo Da Vinci. Edición de J.P. Richter: Londres. Obtenido de https://warburg.sas.ac.uk/pdf/cnm22b2242052v1.pdf. 


\section{Capítulo 7 Contribuciones de Leonardo da Vinci a las técnicas gráficas para el diseño o proyecto técnico}

"Huye de los preceptos de esos especuladores, cuyas razones no están confirmadas por la experiencia". LEONARDO DA VINCI (Manuscrito B, folio 11v de la Biblioteca del Instituto de Francia, París).

\subsection{Introducción}

Es en el Renacimiento cuando empieza a aparecer la ilustración científica moderna con muchas innovaciones gráficas y como una manera de colocar al hombre y a la naturaleza en el centro del universo, dando seguimiento a la corriente humanística aparecida entonces. Leonardo no fue ajeno a ello, y con su capacidad creativa, formación y conocimiento, es el creador de un conjunto de técnicas gráficas innovadoras para el diseño, que revolucionaron el dibujo técnico y la pintura, y que aún hoy se siguen utilizando.

Abandonó las técnicas de representación preconcebidas utilizadas en el Quattrocento, y con sus detallados conocimientos de la luz y las sombras, de la mecánica, de la geometría, de la botánica, de la anatomía, de la geología, etc. generó sus propias técnicas en busca de la perfección estética de manera constante.

\subsection{La técnica de los "diagramas de explosión" o "explosores"}

Esta técnica de representación de objetos ha sido muy útil para la comprensión de la conformación y funcionamiento de máquinas y productos. Pero no es hasta mediados del siglo XX, cuando surge el término como una ilustración de tres dimensiones (isométrica) que muestra la relación de acoplamiento de las piezas, subconjuntos y 
conjuntos mayores. También puede mostrar la secuencia de montaje o desmontaje de las piezas de detalle. Aún es muy utilizada hoy para plasmar las vistas conjuntas de interiores de los dibujos de mecanismos, elementos mecánicos o eléctricos, etc. Las vistas en tres dimensiones y la animación son las nuevas herederas de esta técnica.
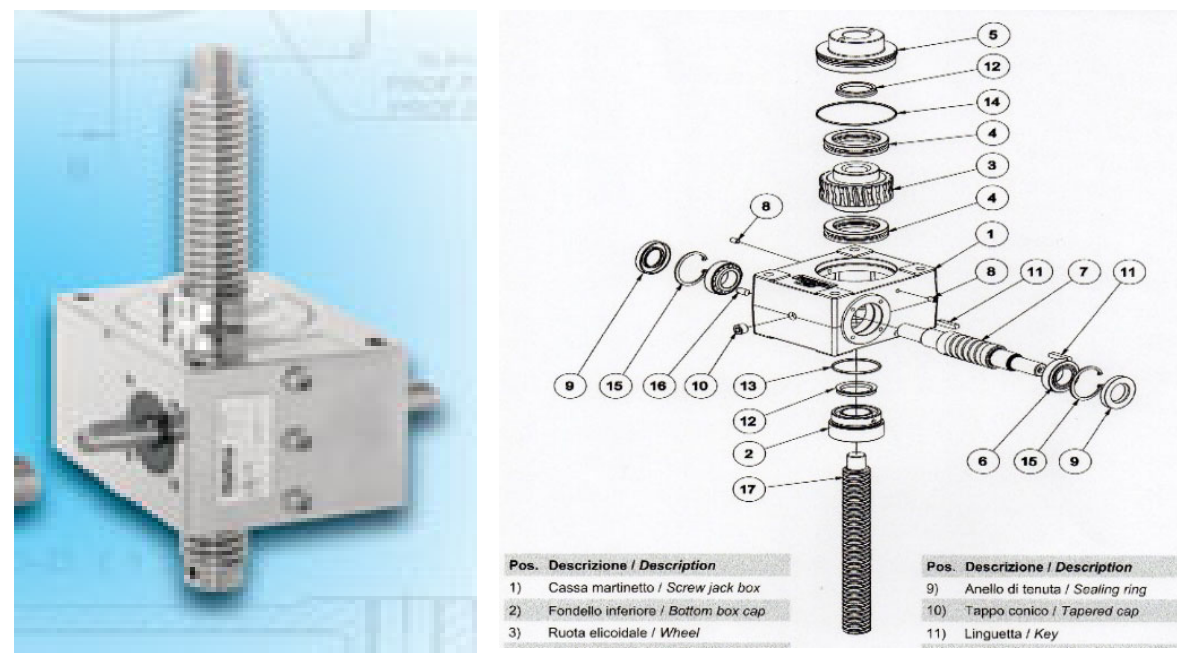

Figura 7.1 Martinete actual de la marca Correggio RE (Italia) y su despiece en catálogo en forma de "explosor", de manera similar a como Leonardo lo hizo hace más de 500 años. (https://rodalsa.net/wpcontent/uploads/2020/03/martinetes.pdf).

Leonardo, que diseccionó en partes individuales, tanto cuerpos humanos (en su faceta de anatomista), como máquinas y artefactos (en su faceta ingenieril), precisaba representarlos mediante partes separadas, pero sin perder la visión del conjunto. Utilizó para ello esta técnica, junto con la identificación y relación de las partes mediante letras y textos cortos cercanos a las vistas, por lo que puede considerarse el precursor de "los diagramas de explosión" en el uso de estudios anatómicos y junto con el ingeniero italiano Mariano di Jacopo (1382-1453), conocido como "Il Taccola", para las máquinas y artefactos.

Leonardo, en el Códice Atlántico, folio $30 \mathrm{v}$ de la Biblioteca Ambrosiana de Milán, dibuja su máquina (árgano) ensamblada en perspectiva, y a su derecha la descompone con detalle, también en una vista en perspectiva, como si hubiera "explosionado", pero de manera que, aunque los mecanismos ya están separados, conservan su visión de conjunto. De esta manera no precisa de 

proyecto técnico

explicación alguna para su construcción o para entender su funcionamiento.

Se trata de una máquina para elevar pesos (árgano), compuesta por un mecanismo para movimiento alterno desde una manivela, producido por un ser humano, que es pasado a un movimiento continuo, de manera que eleve un peso de manera constante. La máquina inventada por Leonardo tiene como mecanismo de accionamiento principal lo que en la actualidad se denominarían martinetes mecánicos.

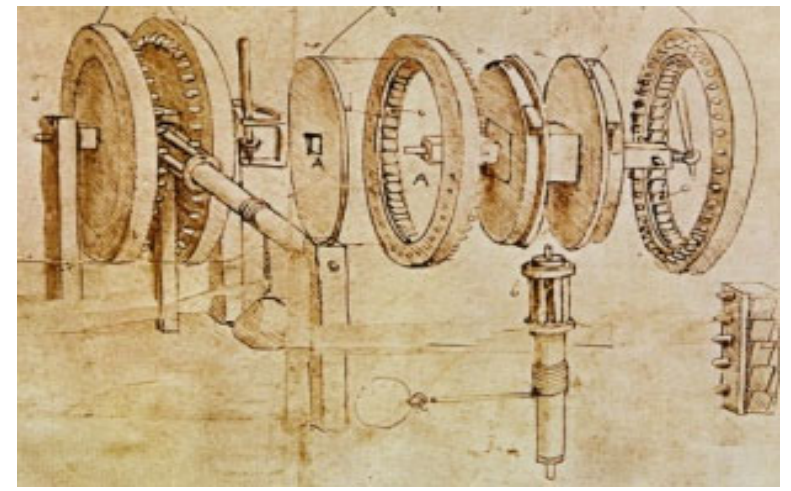

a)

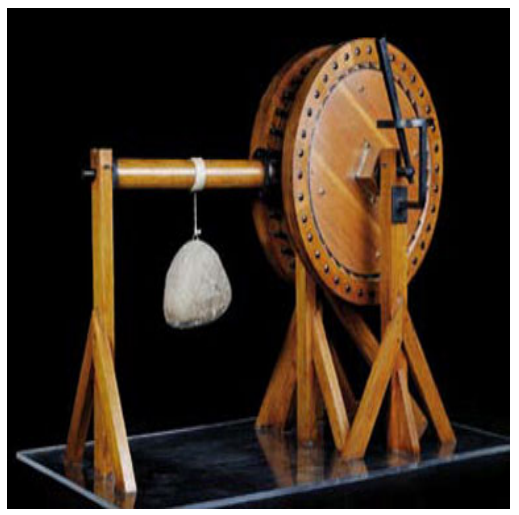

b)

Figura 7.2 a) Máquina de movimiento alterno para elevación de pesos (Árgano), Códice Atlántico folio 30v, (1478-1480)

(https://commons.wikimedia.org/wiki/File:Codex_Atlanticus_-_000V30.jpg), b) Maqueta del Museo de la Ciencia y la Tecnología de Milán (www.museoscienza.org). 
El martinete es un accionador mecánico para levantar o desplazar cargas. Transforma un movimiento rotativo de entrada, generalmente mediante un tornillo sinfín, en desplazamiento axial del husillo. De esta manera, el martinete es capaz de levantar cargas. Hoy los martinetes pueden ser accionados bien manualmente o mediante motores de c.c., c.a., o de manera neumática o hidráulica.

Esta técnica también la utilizó en sus estudios anatómicos, ya que Leonardo, a pesar de la prohibición de la Iglesia de aquel entonces, diseccionó y dibujó al detalle a lo largo de su vida unos 30 cadáveres humanos y de cientos de animales. Todo ello para atajar su curiosidad por conocer cómo era el hombre, al que consideraba la máquina más perfecta de la naturaleza. La mayor parte de sus estudios anatómicos están en la Royal Library de Windsor (Reino Unido).

Leonardo dibuja longitudinalmente toda la columna en el lado derecho de la figura, indica en ella mediante las letras "A-d" un posible detalle de su parte inicial superior, y ese detalle lo grafía en perspectiva en el centro del dibujo. Finalmente, "explosiona" las 3 primeras vértebras de su dibujo central y las representa en una perspectiva forzada, para que pueda verse su interior claramente. Al mismo tiempo redacta sus anotaciones aclaratorias en escritura de espejo, junto a las figuras. Tal es la calidad y detalle de tales dibujos anatómicos que, hasta el siglo XIX, copias de algunos de ellos fueron usados en clases de estudiantes de medicina.

Según frase del historiador y teórico del arte francés Daniel Arasse (Paris, 1944-2003) Leonardo representaba objetos mediante sus incisivos esquemas, de manera que constituían verdaderos "modelos conceptuales". 


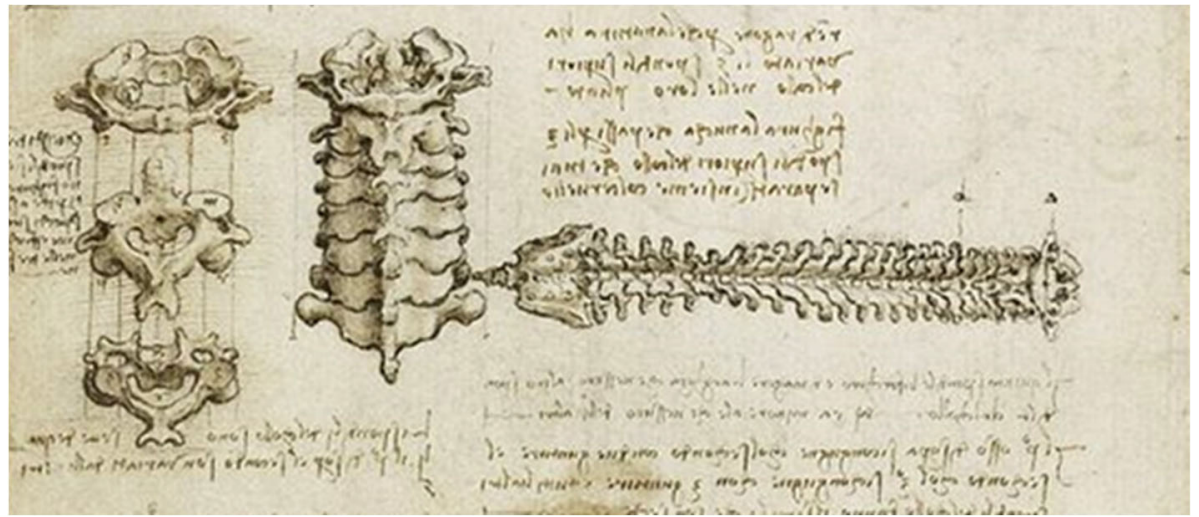

Figura 7.3 Detalle de la columna vertebral (1508-1509) RLW 19007v, K/P139v. Royal Library de Windsor.

(https://brunelleschi.imss.fi.it/genscheda.asp?appl=LIR\&xsl=paginamanoscri tto\&chiave=100945).

\subsection{Los diagramas o gráficos de "Familias de recorridos"}

También es pionero en hacer uso de lo que hoy se denominan gráficos de "familias de recorridos", válidos para representar un parámetro o una variable que va variando únicamente en función de otra única variable.

Leonardo estimaba que el incremento o disminución de la fuerza o "potenze" natural sigue una ley piramidal, o sea una proporción aritmética (su Ley Piramidal de la Óptica la extendía a los esfuerzos, que asimilaba al plano inclinado o triángulo en forma de cuña, así como a la presión en sus estudios hidráulicos). Manifestaba que la fuerza aumenta con la velocidad y disminuye con la distancia, mientras que el peso y la percusión crecen proporcionalmente con la velocidad. Para él su Ley Piramidal representaba una constante universal.

En sus estudios del tornillo, para justificar su desarrollo, lo asimila también a un plano inclinado, y la relación entre el desarrollo helicoidal y éste, la justifica en un diagrama existente en el Códice Madrid I, folio $86 \mathrm{v}$ de la Biblioteca Nacional de Madrid.

También estudia el fenómeno de la presión en diferentes casos. En los cursos de agua abiertos, como en su diseño de canal de irrigación a San Cristofano existente en el Códice Atlántico folio $1097 \mathrm{r}$, de la Biblioteca Ambrosiana de Milán (1509). En el alcance de chorros de agua, como puede observarse en el detalle del Códice de Madrid I, 
folio $134 \mathrm{v}$, de la Biblioteca Nacional de Madrid, donde se observa de nuevo la consideración "piramidal" del fenómeno (la distancia o alcance del chorro disminuye al aumentar la altura del mismo). $\mathrm{O}$ en recipientes cerrados a presión, en su estudio del alcance del agua a presión del Manuscrito $\mathrm{C}$, carta $7 \mathrm{r}$, del Instituto Francés de París (Francia).

Así mismo, puede considerarse pionero en la utilización de diagramas en disposición circular, utilizando un símil de los "diagramas de cuerdas" con el fin de mostrar relaciones funcionales entre distintas partes del dibujo, como por ejemplo líneas de fuerza. Así, por ejemplo, Leonardo estimaba que la fuerza para vencer los planos inclinados seguía una proporción aritmética, por lo que en uno de sus estudios de las tracciones, para interpretar la fuerza de tracción necesaria en un carro de bueyes con relación al diámetro de las ruedas del carro, expresa mediante un dibujo circular concéntrico el crecimiento de la rueda y la relaciona con la pirámide lateral del esfuerzo que deben realizar los bueyes (Códice Atlántico folio 561v, de la Biblioteca Ambrosiana de Milán). Igualmente utiliza diagramas circulares similares para sus estudios de mecánica y óptica del Códice Arundel, folio $93 r$ de la British Library de Londres, que registra una ratio entre un grado de ímpetu y su correspondiente grado de percusión en unidades de medida florentinas.

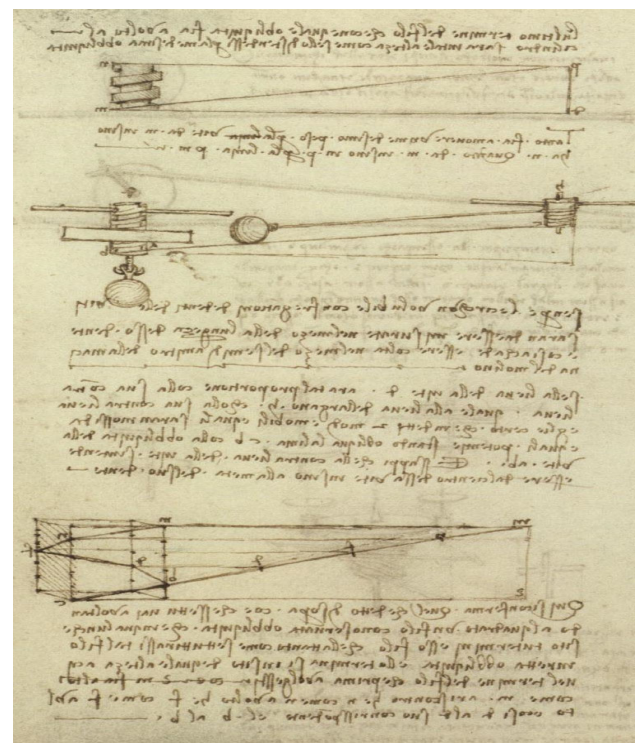

a) 


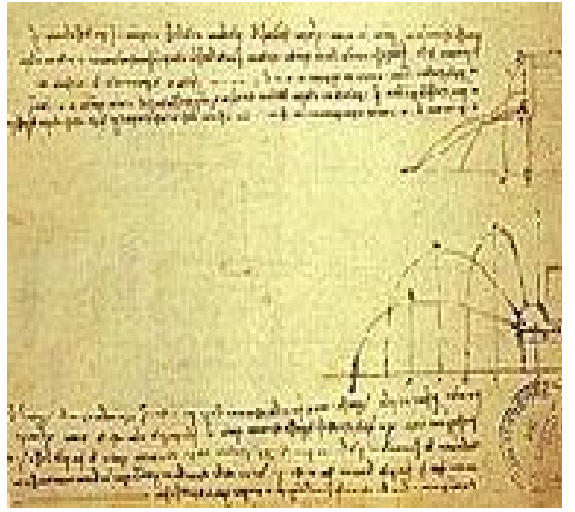

b)

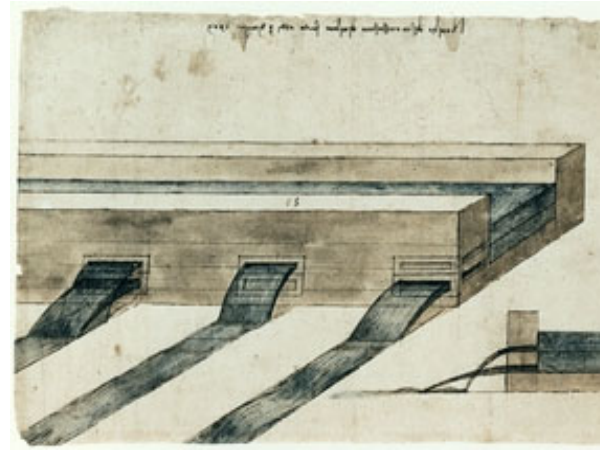

c)

Figura 7.4 a) Estudio del desarrollo del tornillo, Códice Madrid I, f. 86v. (http://leonardo.bne.es/index.html), b) Estudio del alcance del agua a presión, Manuscrito C, c 7r, Instituto Francés de Paris (Francia), c) Diseño de Canal de irrigación de San Cristofano, Codex Atlántico f. 1097r Milán (1509). (https://commons.wikimedia.org/wiki/File:000R1097.jpg? uselang=es-formal).

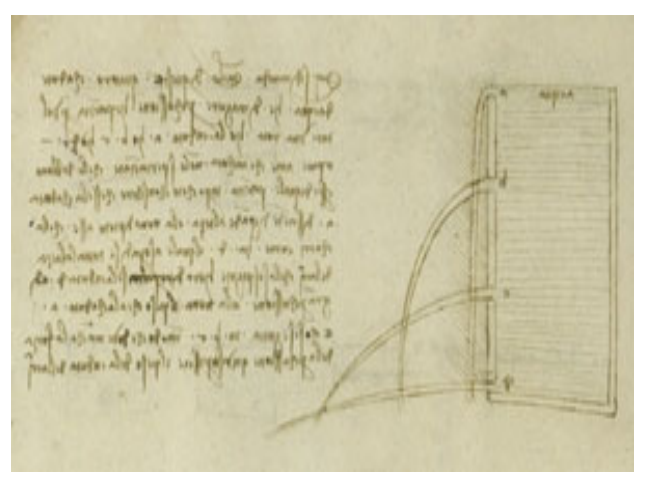

a)

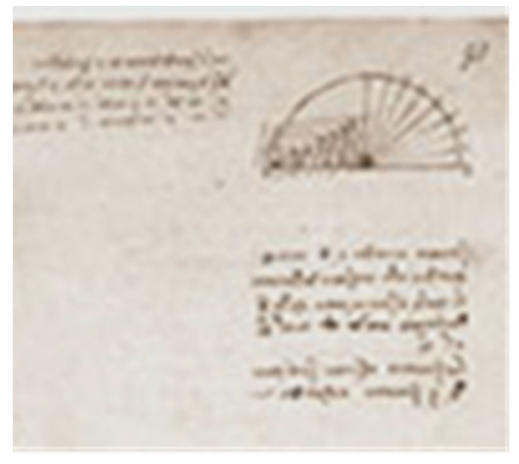

b) 


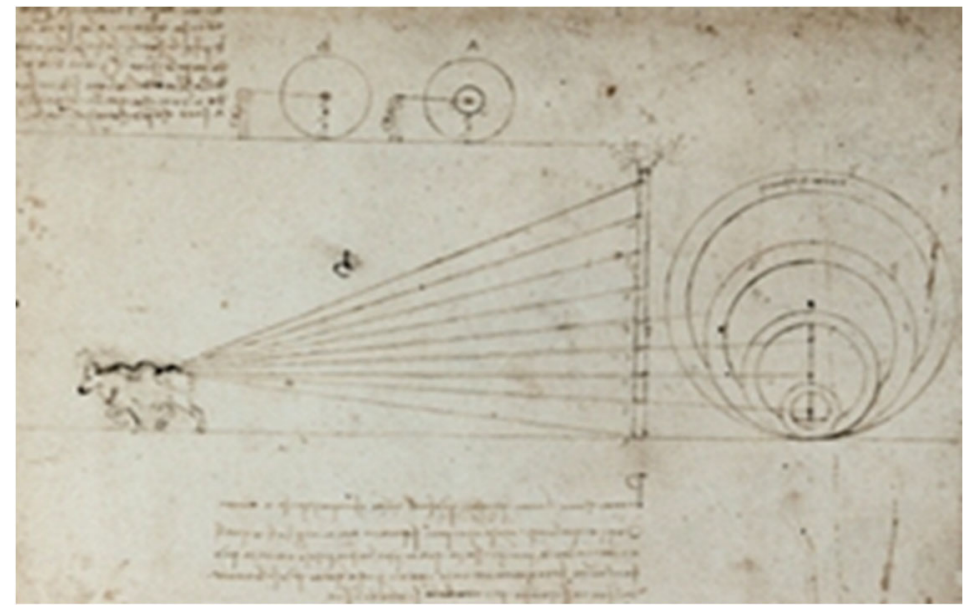

C)

Figura 7.5 a) Detalle alcance del agua, Códice de Madrid I, f. 134v, Biblioteca Nacional de España (http://leonardo.bne.es/index.html), b) Detalle de un estudio mecánica del Codex Arundel f. 93 r (1504) British Library, Londres

(https://commons.wikimedia.org/wiki/Category:Codex_Arundel_(c.14801518)_-_BL_Arundel_MS_263 ), c) Proporción geométrica de esfuerzo de bueyes tirando Codex Atlántico f. 561r (1487-1490) de la Biblioteca Ambrosiana de Milán

(https://commons.wikimedia.org/wiki/File:Codex_Atlanticus_-_000R-561.jpg).

\subsection{La Técnica de elaborar Mapas a "vista de pájaro" (Carta a volo d'uccello)}

Leonardo también es autor de varios planos y mapas, sobre todo de ciudades y terrenos vinculados a la Toscana y, en menor cuantía, a los estados pontificios de aquel entonces. Fue en su segunda etapa florentina (1500-1506), época al inicio de la cual (entre 1502 y 1503) estuvo al servicio de César Borgia (Roma 1475-Viana 1507), conocido como "Il Valentino", que lo nombró arquitecto e ingeniero general de los dominios pontificios. <<Ordenamos y mandamos que al portador del mismo, nuestro bien amado y muy excelso arquitecto e ingeniero general Leonardo da Vinci, al que hemos encargado la inspección de las plazas y fortalezas de nuestros estados, se le preste la ayuda que se requiera en cada caso o que a su juicio estime necesaria >> (Nicholl, 2005). A su servicio realizó estudios de fortificaciones y ciudades y le acompañó en sus campañas militares por la Romagna. Durante el 
gobierno (Signorina) de la ciudad de Florencia, Leonardo fue elegido para redactar el proyecto del desvío del Río Arno para que Florencia tuviera salida directa al mar, sin pasar por Pisa su ciudad enemiga. El impulsor de la idea había sido Nicolás Maquiavelo (Florencia 14691527 ) en 1503, como secretario de la Chancillería florentina. Fue en este proyecto en el que más tiempo actuó Leonardo como un cartógrafo/topógrafo, elaborando magníficos planos y mapas con un detalle y precisión como nadie lo había hecho antes. En la Royal Library de Windsor (Inglaterra), en el Gabinete de Diseño y Estampas de la Galería Uffizi de Florencia y en el Museo de Leonardo, en Vinci, se encuentran la mayoría de ellos.

También estudió y mejoró la técnica de la perspectiva, por lo que junto con su dominio del dibujo y el color, fue capaz de generar vistas desde el cielo de las zonas y resaltar lo que el pretendía en cada momento de manera excepcional. Hasta el "Quattroccento", e incluso mucho después, los desniveles se representaban como unas simples "toperas" (p. ej. el Mapa del Lago "Trasimeno" o "di Perugia" de 1600, del cartógrafo y matemático italiano Giovanni Antonio Magini (15551617), posterior en casi 100 años a los de Leonardo).

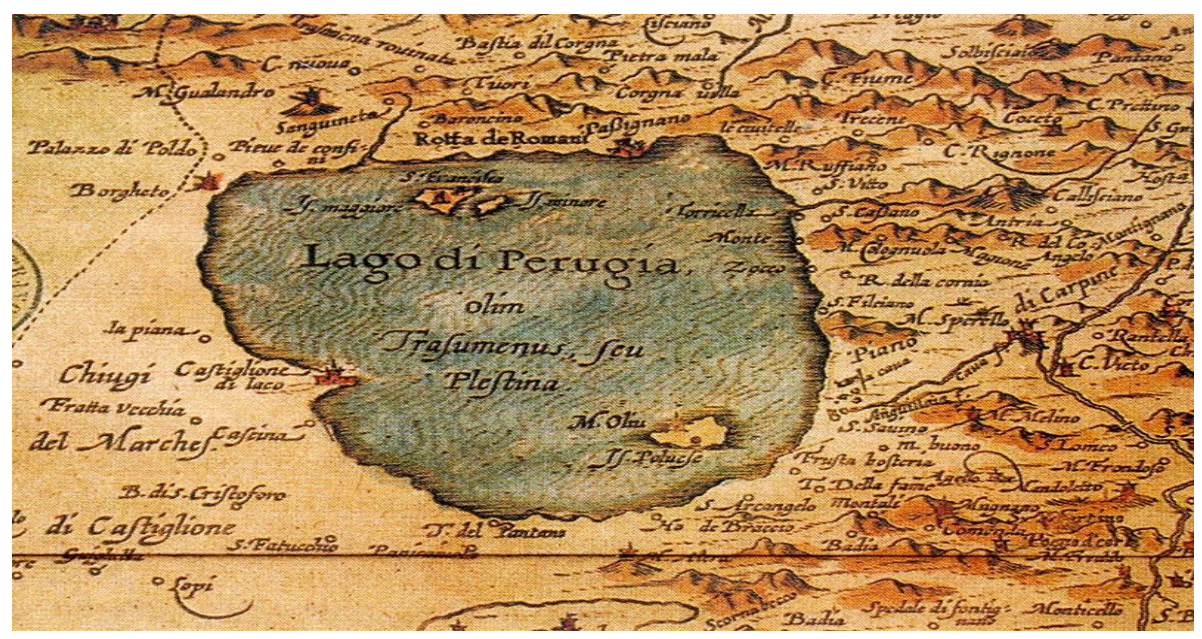

Figura 7.6 Mapa del Lago "Trasimeno" de 1600, Giovanni Antonio Magini (1555-1617). (Fuente Wikipedia).

Leonardo supera todo ello y recurre a los sombreados de contornos y a su técnica del "claroscuro" para lograr una mayor objetividad en la representación del territorio. 
Además, utilizó la técnica de la distorsión de escalas en las zonas oportunas para remarcar lo que estimaba necesario (cursos de agua, ciudades, montañas y valles, etc.). El conjunto unido de todas estas técnicas muestra unos mapas con un acabado excepcional para el que los visualiza, con una adecuada sensación de profundidad, tamaño o distancia comparativa con relación al resto de lo dibujado; estableciéndose como el precursor de los planos y mapas "a vista de pájaro", cuando aun no se podía ver desde el aire. Algunos ejemplos se muestran a continuación.

\subsubsection{Mapa de la Toscana, parte de la Umbria, lago Trasimeno y el Valle de Chiana (1502)}

Fue realizado al servicio de César Borgia al que accedió por recomendación del gobierno de la ciudad de Florencia. Las poblaciones están resaltadas con su nombre y ubicación, así como los castillos, el río y los valles, que han sido grafiados de manera excepcional, lo que presupone que se trataba un mapa estratégico para el uso informativo y decisional de César en sus campañas de apoderamiento de las ciudades-estado que iba captando para que quedaran bajo los dominios papales. Aunque otra suposición es que se tratara de un plano para estudiar el régimen hidrográfico de la zona y de posibles mejoras de irrigación. De hecho el lago alargado denominado "di Chiana" fue disecado con posterioridad.

Los colores utilizados de manera acertada dan sensación de volumen. La escritura del mismo no es especular, lo que da a entender que el trabajo de Leonardo era para hacerse público y no para sí mismo, como hizo en otros muchos manuscritos con carácter de trabajo o de investigación propia. Se encuentra hoy en la Royal Library de Windsor. 

proyecto técnico

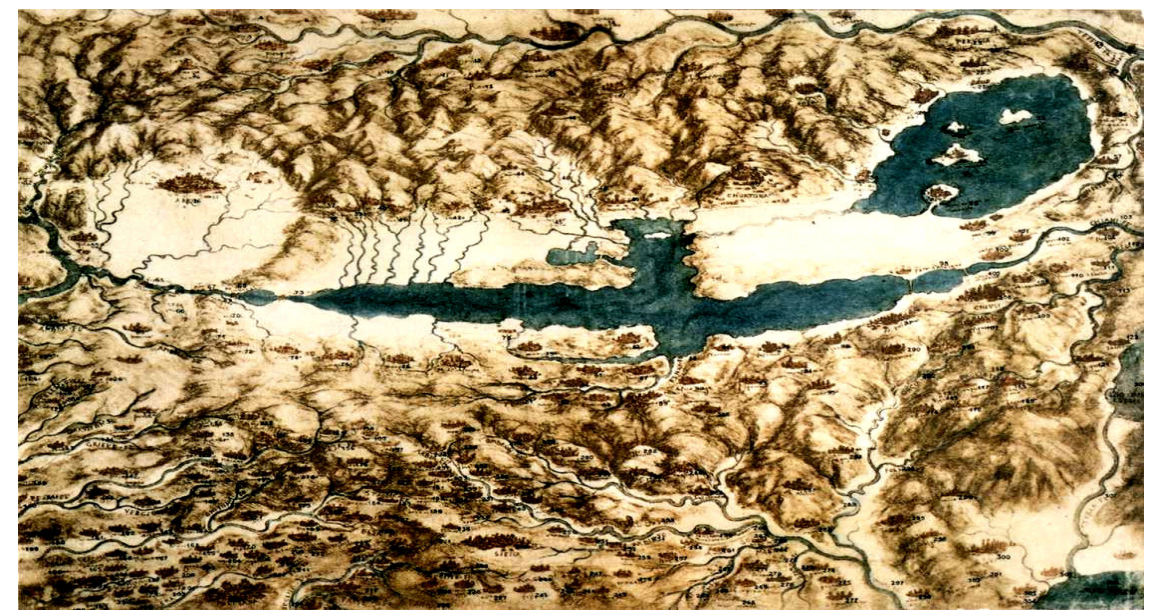

Figura 7.7 Carta RLW 12278, Royal Library, Windsor (Reino Unido). (https://commons.wikimedia.org/wiki/File:Leonardo_da_vinci,_Map_of_Tusc any_and_the_Chiana_Valley.jpg?uselang=de).

\subsubsection{Mapa de "Arezzo" y Valle de Chiana, con mensuración de distancias (1502)}

Usa la perspectiva, junto con la técnica del claroscuro generando el efecto visual de volumen. El plano aparentemente es un detalle sacado del anterior y pretendía dar a conocer con mayor seguridad a César Borgia el conocimiento de la zona, ya que la ciudad de Arezzo estaba en rebelión por el condotiero italiano Vitellozzo Vitelli (14581502), que acabaría estrangulado a finales de ese año presuntamente por orden de César. 


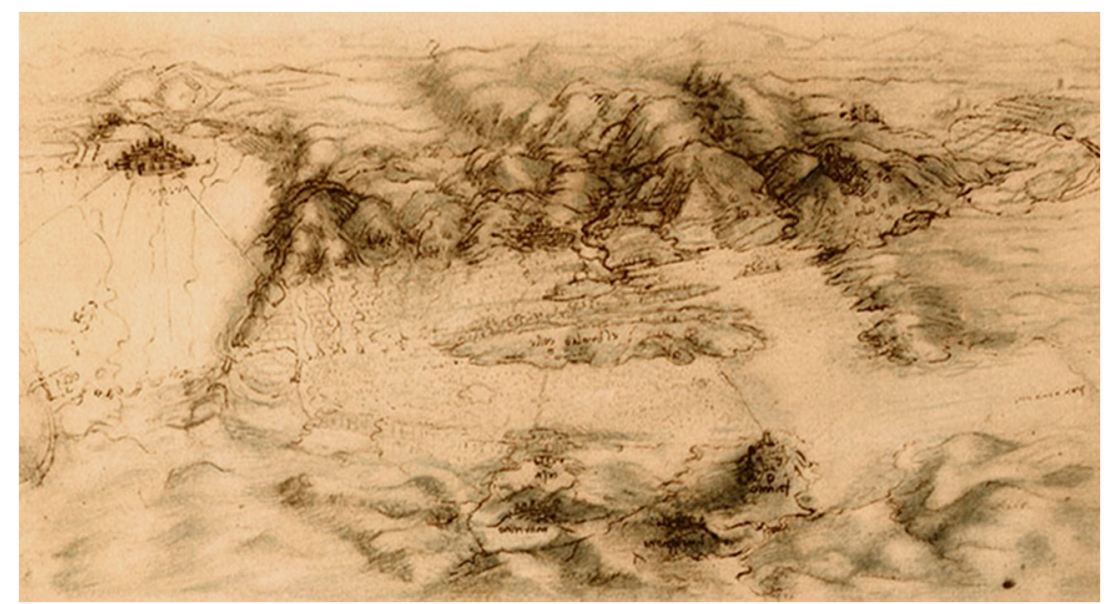

Figura 7.8 Detalle de la carta RLW 12682, Royal Library, Windsor (Reino Unido)(https://brunelleschi.imss.fi.it/itinerari/immagine/img34843.html).

En este mapa sí que utiliza en sus anotaciones la escritura especular, quizás porque era un mapa de trabajo aclaratorio. Se encuentra hoy en la Royal Library de Windsor (Reino Unido).

\subsubsection{Mapa de la ciudad de Imola (Italia) (1502)}

Este plano de la por aquel entonces pequeña ciudad de Imola, fue realizado por Leonardo cuando estaba al servicio de César Borgia y se encuentra en el Códice Windsor, folio RLW 12284, de la Royal Library de Windsor (Reino Unido).

II Valentino, que llegó a disponer del título de Duque de la Romaña, en su campaña por dominar parte de los terrenos de Italia, y apoyado por su padre el Papa Alejandro VI (Roderic de Borja, Játiva 1431-Roma 1503), aprovechó esta ciudad amurallada como su cuartel de invierno, y en ella montó su pequeña corte durante el corto pero intenso tiempo que mantuvo el poder.

Leonardo, a su servicio en 1502, dibuja el río Reno y la ciudad amurallada con muros de 4,5 m de grosor, incluso puede verse su foso perimetral de defensa de la misma, que en algunos puntos tiene $12 \mathrm{~m}$ de profundidad. Igualmente puede distinguirse perfectamente la trama urbana con los diferentes anchos de calles, plazas, caminos de llegada a la ciudad y sus puertas de acceso a través de las murallas, etc. Utiliza diferentes colores para distinguir entre plazas en amarillo, calles públicas en blanco, edificios con un tono marrón más oscuro y los 
extrarradios con marrón claro. Finalmente, para el río y el foso protector de las murallas usa el azul, como referente del agua. Las medidas aproximadas del plano son $44 \times 60 \mathrm{~cm}$.

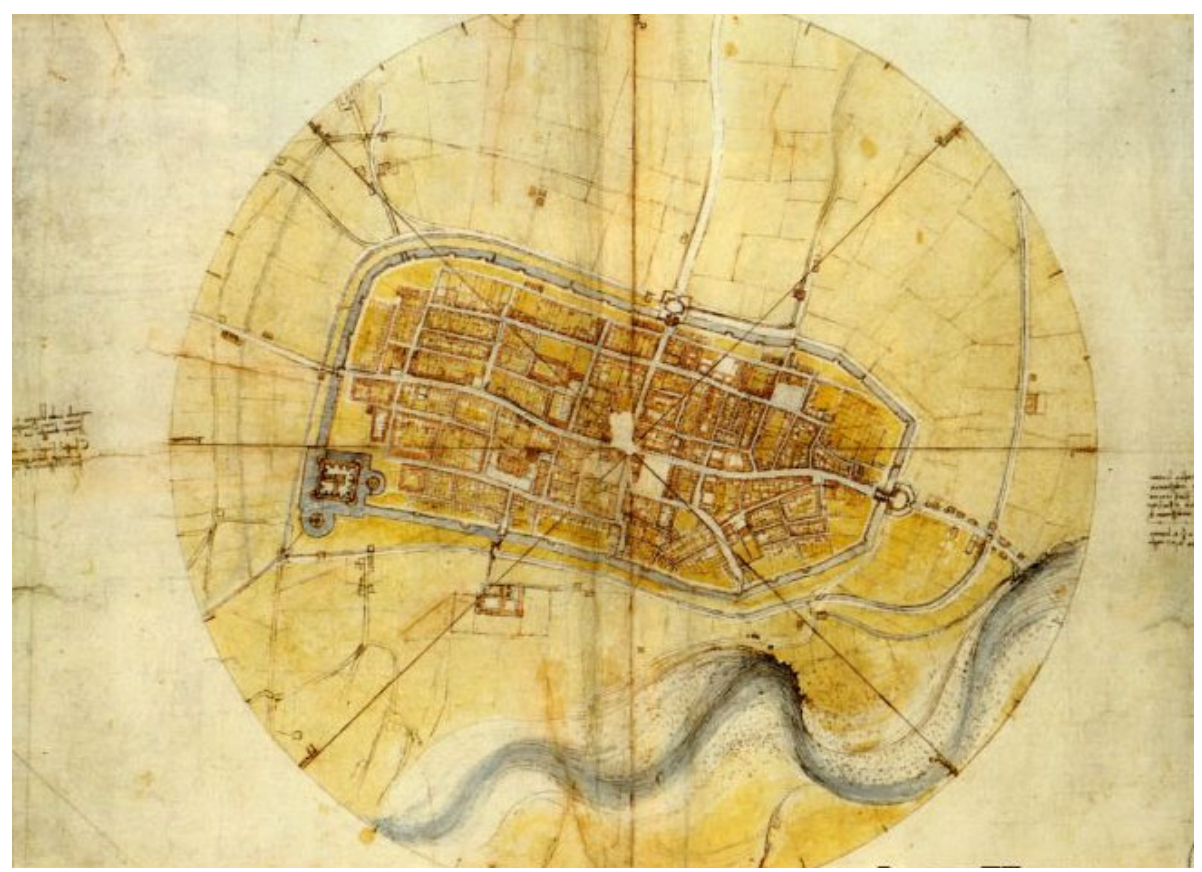

Figura 7.9 Plano de la ciudad de Imola (1502), Royal Library, RLW 12284, Windsor (Reino Unido).

(https://upload.wikimedia.org/wikipedia/commons/8/85/Leonardo_da_Vinci__Plan_of_Imola_-_Google_Art_Project.jpg).

El acceso a la ciudad del lado suroeste es el más impresionante, ya que se accede a través de una fortaleza independiente del resto de la ciudad ( $\mathrm{y}$ que el plano de Leonardo también refleja perfectamente); es la denominada Rocca Sforcesca, realizada bajo el dominio de la familia Sforza que regentó durante bastante tiempo el Ducado de Milán.

Leonardo estuvo solo aproximadamente un año al servicio de César. Después de ver la brutalidad de sus acciones, hizo constar su opinión sobre la guerra, en su Códice Urbinus Latinus 59v, McM 2666, de la Biblioteca Vaticana de Roma: <<es el tipo de locura más brutal que existe >> (Nicholl, 2005). 


\subsection{Las perspectivas de Leonardo (aérea, del color y menguante) y el "sfumato"}

El paso de la realidad tridimensional a la bidimensionalidad del papel planteó desde antiguo una importante dificultad. Esta limitación se superó con el sistema de representación en perspectiva lineal, geométrica o euclidiana, que se ajusta bastante a la visión del ojo humano.

Leonardo estudió todo lo conocido por aquel entonces de la perspectiva lineal, desde lo dispuesto por el matemático y astrónomo árabe Alhazen (Irak 968- Egipto 1040), a lo que se denomina la Teoría Intelectual (los objetos parecen más pequeños cuando más lejos estén) establecida por el arquitecto florentino Filippo Brunelleschi (Florencia 1377- 1446), y ampliada y divulgada al poco tiempo por el artista genovés León Battista Alberti (Génova 1404-Roma 1472) en su libro de 1436 "De Pictura". Pero Leonardo se da cuenta de que la visión geométrica, que encuadra al objeto en un haz de líneas (denominado pirámide visual), que convergen en un punto de fuga, tienen la limitación de que la visión ocular es esférica y binocular, y que no tiene en cuenta la pérdida de nitidez con la lejanía. Establece: $<<$ Cuando pintes del natural, refleja en el lienzo todo lo que veas, Pero debes esforzarte por asimilar los elementos invisibles. He ahí el secreto de la profundidad y el realismo >> (Galland, 2014).

Para superar las limitaciones de la Teoría Intelectual, establece su técnica, que contempla la Perspectiva cromática o del color y la Perspectiva menguante o de la desaparición, que tiene en cuenta los efectos propios de la atmósfera y de la distancia sobre la visión de los colores y su percepción. Hace constar en su Tratado de Pintura, realizado de manera póstuma (sobre 1550) por su alumno y secretario personal, el pintor Francesco Melzi (Milán, 1493- Vaprio d'Adda 1572/73) con la recopilación de notas del maestro: $<<$ La ciencia de la pintura comprende todos los colores de la superficie y las figuras de los cuerpos que con ellos se revisten, y su proximidad y lejanía, según proporción entre diversas disminuciones y las diversas distancias. Esta ciencia es madre de la perspectiva, esto es, de la ciencia de las líneas de la visión, ciencia que se divide en tres partes; de éstas, la primera solo comprende la construcción lineal de los cuerpos (perspectiva lineal); la segunda, la difuminación de los colores en relación con las diversas distancias (perspectiva de color), y la tercera, la pérdida de determinación de los cuerpos en relación a las diversas distancias (perspectiva menguante) >> (Sarnago, 2002). 

proyecto técnico

Su obra temprana La Anunciación (óleo sobre tabla de 98x217 cm, 1472-1475), existente en la Galería de los Uffici de Florencia y realizada cuando aún trabajaba en el Taller del maestro escultor Andrea del Verrocchio (Florencia 1435-Venecia 1485) ya da muestras claras de su conocimiento de la perspectiva y de la incorporación de sus propias técnicas en el fondo del cuadro.

En el detalle de la derecha de la figura, puede verse que el fondo del cuadro, donde converge la perspectiva, podría ser por sí solo, un cuadro excepcional por el nivel de detalle y perfección de las figuras (barcos, ciudad, puerto, etc.) y del paisaje (lago, montañas y nubes). Ello es prueba de la gran importancia que Leonardo dio a lo existente detrás de la vista principal.

Para demostrar la veracidad de su perspectiva de color establece el siguiente ensayo: <<Ponte frente a un árbol con un cristal muy fino, y copia el árbol exactamente como lo ves sobre él, haciendo que los perfiles del árbol real limiten con el dibujado, y dale el color más semejante al original. Así recomiendo ir haciendo un segundo y un tercero a cada distancia, y comprobar luego como se ha ido perdiendo el color $>$. 

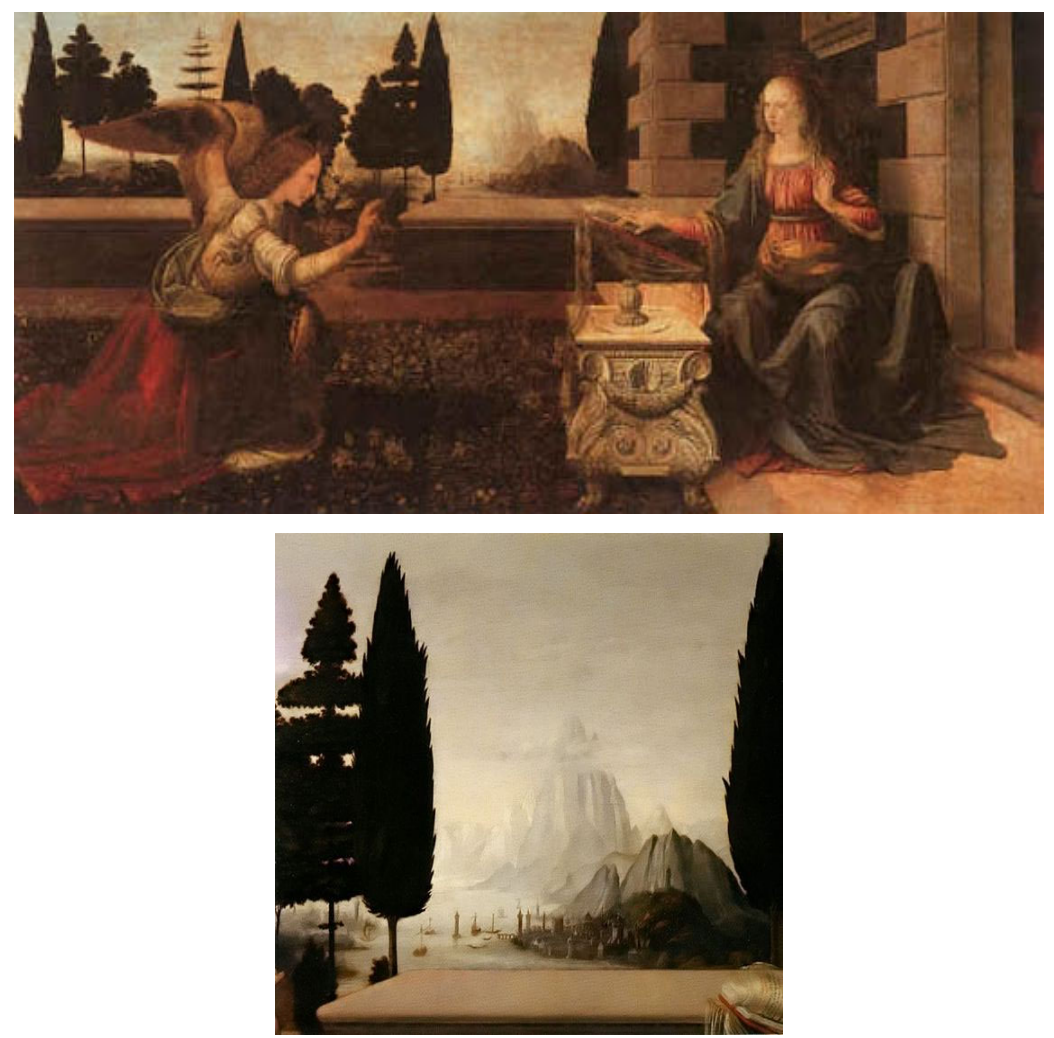

Figura 7.10 “La Anunciación”, Galería de los Uffici, Florencia (Italia) https://commons.wikimedia.org/wiki/File:Annunciation_(Leonardo)_(cropped) .jpg?uselang=es), y detalle de su fondo.

Al conjunto de todas estas novedades acabará añadiéndole su Perspectiva aérea o atmosférica (debido a la presencia del aire atmosférico que tiene vapor de agua, las figuras más lejanas pierden nitidez y se vuelven más azules), con la que Leonardo difumina sus figuras y los contornos del paisaje de fondo, utilizando tonalidades de color más apagadas en los objetos más lejanos, consiguiendo así una mejor sensación de profundidad. Los colores cálidos deben incorporarse en la cercanía, mientras que los tonos fríos deben quedar para los planos alejados.

Leonardo, en su Tratado de Pintura, establece: $<<. . . s i ~ a c a b a s ~ m u c h o$ y con gran detalle los objetos lejanos, parecerá que están cerca en 
lugar de distanciados. Procura imitar con discernimiento, atendiéndote a la distancia de cada objeto y allí donde estén confusos y con rebordes poco definidos, represéntalos tal cual son y no los acabes demasiado >.

Otro ejemplo de la aplicación de sus técnicas es "La Virgen de las rocas" (óleo sobre tabla de 198×123 cm, de 1483-1486), existente en el Museo del Louvre de París. En él puede apreciarse, aparte de su coherente composición, la existencia de un paisaje de fondo con plantas, una gruta rocosa, una montaña entre brumas, y un cielo de color azul grisáceo con cierta luminosidad que, en conjunto, dan una perfecta sensación de profundidad y al mismo tiempo generan intriga y dramatismo. En la Figura 7.11 b) siguiente puede apreciarse el fenomenal paisaje de fondo del cuadro, que sigue todas las características de las técnicas de Leonardo.

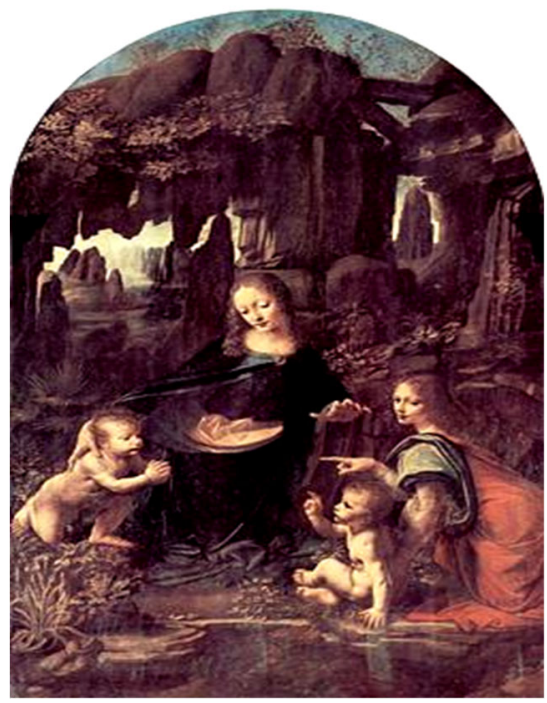

a)

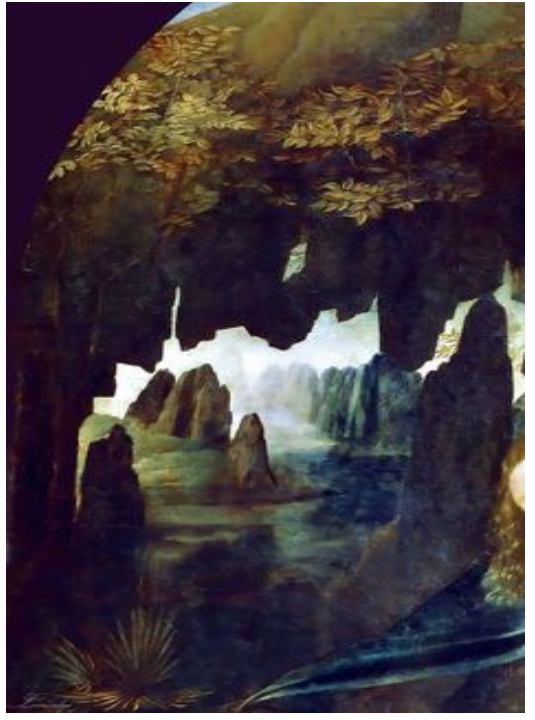

b) 


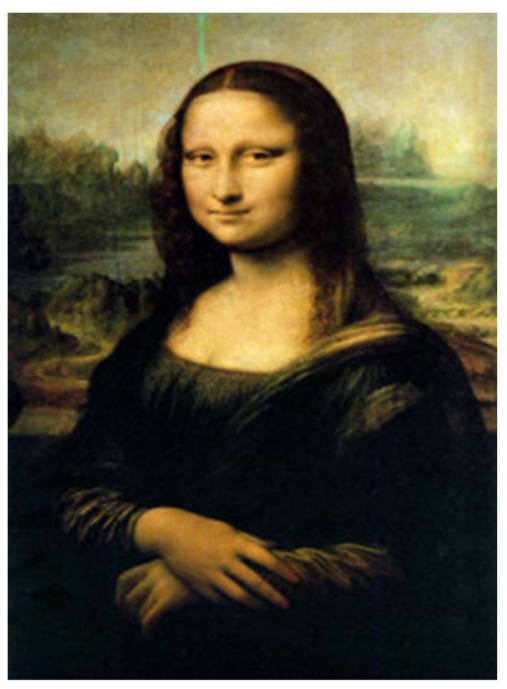

c)

Figura 7.11 a) "La Virgen de las rocas", Museo del Louvre, París.

(https://commons.wikimedia.org/wiki/File:Leonardo_Da_Vinci_-

_Vergine_delle_Rocce_(Louvre).jpg), b) Detalle del fondo del mismo cuadro, c) "La Gioconda", Museo de Louvre, París

(https://commons.wikimedia.org/wiki/File:Mona_Lisa,_by_Leonardo_da_Vinc i,_from_C2RMF_retouchèd.jpg).

El conjunto de todas estas técnicas acabará completándose con su especial técnica del "sfumato" o esfumado, consistente en un sutil sombreado por todo el cuadro (para Leonardo las sombras son tan importantes como la luz ya que de ellas depende el efecto relieve), pero más resaltado en la cara y en las manos, que confieren al cuadro una inquietante latencia de vida. La obra cumbre, que refleja el conjunto de todo lo descrito por Leonardo (fondos azules verdosos, con paisajes de fondo apenas contorneados, etc.), es quizás el cuadro más famoso del mundo, La Gioconda o Mona Lisa (óleo sobre tabla de 77x53 cm, de 1503-1506) existente en el Museo del Louvre de París. Por su importancia, características y complejidad, precisaría por sí solo de un artículo aparte. Como dijo el crítico de arte y profesor universitario inglés Walter Pater (Stepney, Londres 1839-Oxford 1894) $<<$ Con la Gioconda, Leonardo define de un modo totalizador su concepción del arte y de su propia vida>> (Ricart, 2006). 
7.6 Las técnicas del "escorzo", de la "serpentinata", de la "superposición" y de la distorsión de escalas, llegando al "anamorfismo"

También recuperó la técnica del "escorzo", utilizada para dar profundidad al dibujo en la época helenística, y abandonada en la Edad Media. Consiste en el modo de representar lo que en la realidad está dispuesto perpendicular $u$ oblicuamente al plano donde es representado. La perspectiva de lo representado debe ser más exagerada de lo habitual, para ser considerada "escorzo", es decir, debe existir deformación de sus proporciones reales al ser trasladadas sus dimensiones de su forma tridimensional al plano bidimensional. Generalmente habrá una contracción proyectiva, pero no debe haber partes ocultas que eliminen la continuidad de lo visto. En algunos de sus estudios anatómicos de los músculos humanos y en los bocetos de "cabezas de apóstoles" para La Última Cena, ambos existentes en la Royal Library de Windsor (Reino Unido), utiliza esta técnica.

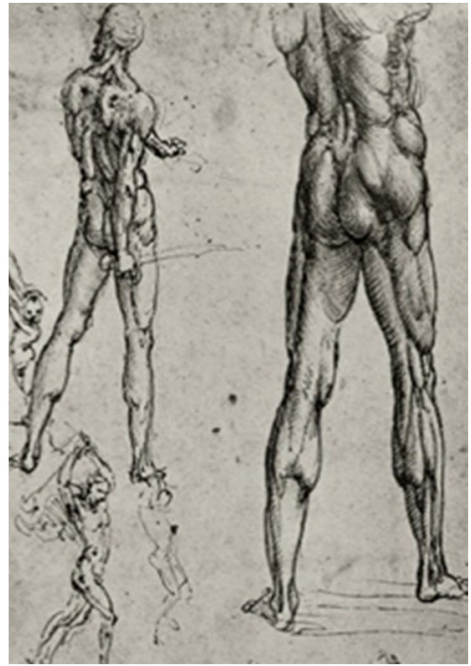

a)

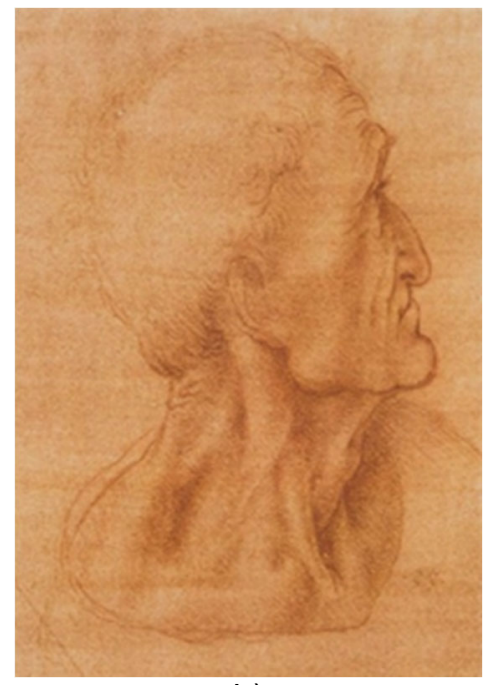

b) 


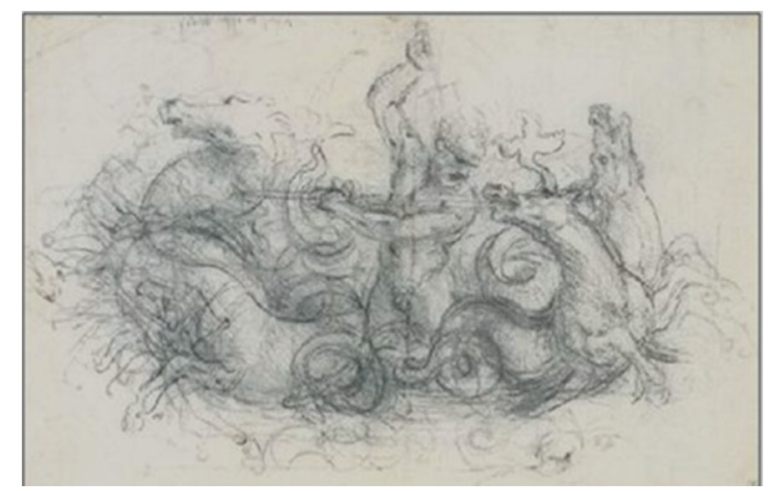

c)

Figura 7.12 a) Estudios anatómicos de músculos, Royal Library de Windsor (Reino Unido)

(https://commons.wikimedia.org/wiki/File:Leonardo_da_vinci,_Figure_studie s.jpg), b) Estudio de cabeza se apóstol para "La Ultima Cena" (1495) Royal Library (Windsor, GB)

(https://commons.wikimedia.org/wiki/File:Judaskopf_(da_Vinci).jpg, c) Neptuno con los caballos marinos (alrededor 1504), RLW 12570, Royal Library (Windsor, GB).

(https://commons.wikimedia.org/wiki/File:Leonardo_da_Vinci__Neptune,_c.1504-5.jpg).

Otra técnica que recupera de la antigua Grecia para conseguir sensación de movimiento es la "serpentinata" (usada en la escultura helenística Venus, de la isla griega Milo, existente en el museo de Louvre), y que consiste en disponer las figuras en forma helicoidal ascendente (forma de "serpentina"), o sea girando sobre sí mismas, lo que da la sensación de un movimiento giratorio contorsionado. Un ejemplo claro es su dibujo a lápiz negro sobre papel existente en la Biblioteca Real del Castillo de Windsor (Inglaterra), donde tanto la postura del dios como de los caballos muestran un claro giro sobre sí mismas para conseguir una sensación de movimiento y furia. Estas soluciones las repite en El Martirio de San Sebastián, hoy en colección privada.

Es también frecuente en varios estudios para cuadros (p. ej. "Leda", símbolo de las fuerzas generadoras de la naturaleza, en sus versiones "arrodillada" y "de pie", esta última, hoy desaparecida aunque existen varias copias de sus alumnos) y dibujos del <<"movimiento activo" que la figura realiza en sí misma sin desplazarse y con insinuación implícita de una marcha en espiral, es la base para la figura "serpentina" 
característica que posteriormente utilizó Miguel Ángel y los manieristas >> (Antoccia et al., 2003).

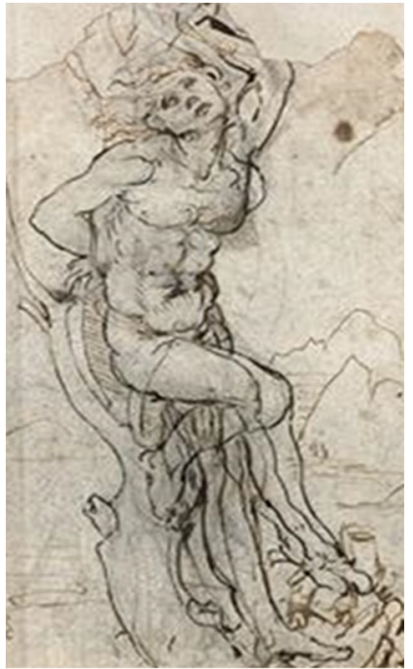

a)

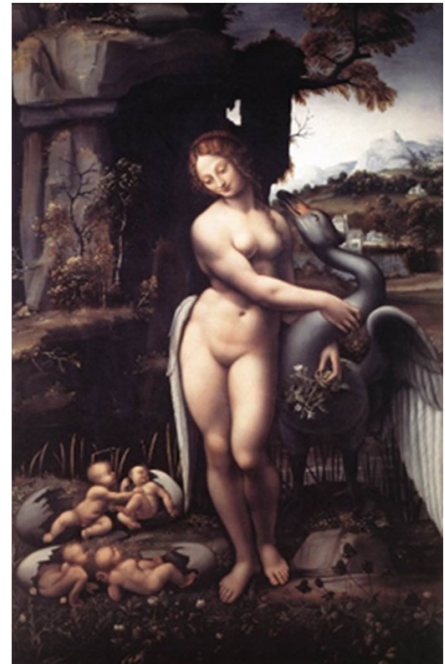

b)

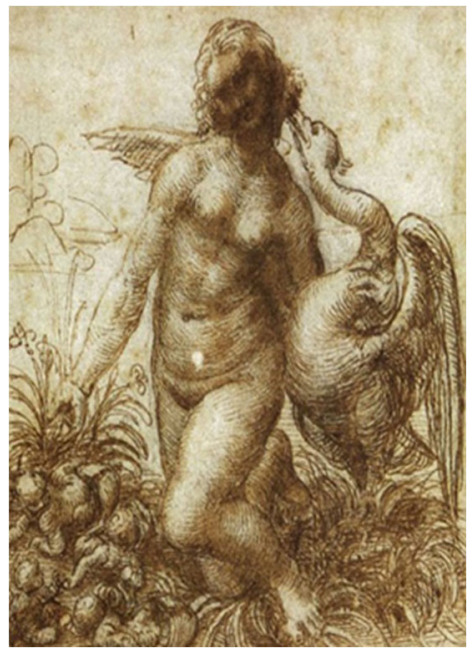

c)

Figura 7.13 a) "Martirio de San Sebastián", alrededor de 1482, colección privada. (https://elpais.com/hemeroteca/2016-12-13/), b) Copia de "Leda", del alumno de Leonardo, Francesco Melzi, 1515 Galería de los Uffizi, Florencia (Italia).

(https://commons.wikimedia.org/wiki/File:Leda and the Swan 15081515.jpg), c) Estudio para "Leda arrodillada" $\overline{1503-1507 .}$. Chat-Worth Derbyshire (Reino Unido).

(https://commons.wikimedia.org/wiki/File:Study_for_the_Kneeling_Leda.jpg). 


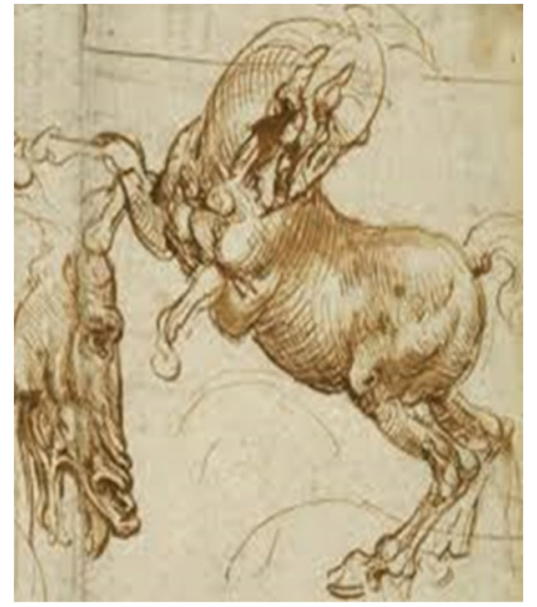

a)

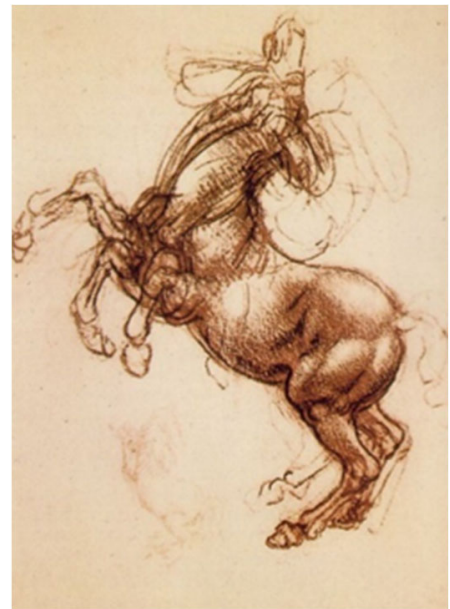

b)

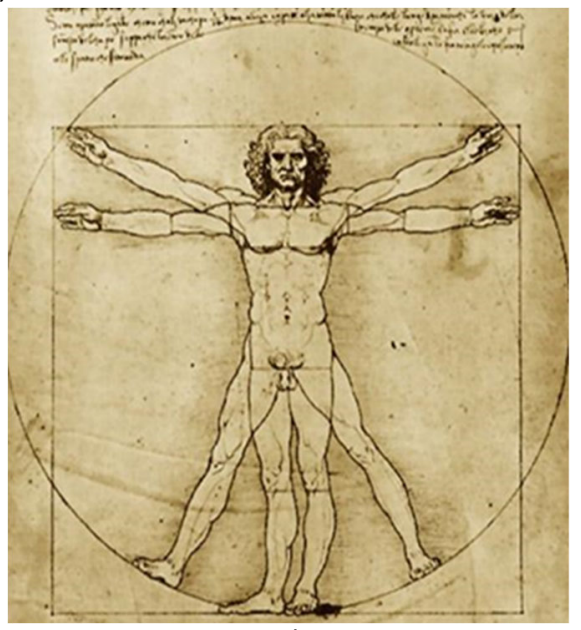

c)

Figura 7.14 a) y b) Estudio para caballos

(https://commons.wikimedia.org/wiki/File:Leonardo_da_vinci,_Study_of_hors es_for_the_Battle_of_Anghiari.jpg y

https://commons.wikimedia.org/wiki/File:Leonardo_da_vinci,_Rearing_horse. jpg), c) Hombre de Vitruvio (1490) Galería de la Academia de Venecia (Italia)

(https://commons.wikimedia.org/wiki/File:Da_Vinci_Vitruve_Luc_Viatour_(cro pped).jpg).

Huyendo de las pinturas de carácter estático del Quattrocento, Leonardo solapa varias posiciones de una figura superpuestas en una misma vista, con lo que consigue dar movilidad y movimiento a la 
figura representada. Es lo que se denomina técnica de superposición, así en varios de sus "Estudios de caballos" vemos esa solución. Igualmente, en el Hombre de Vitruvio (1490), que en realidad es el estudio de las proporciones humanas ideales para Leonardo según sus estudios de los cánones de belleza de la antigüedad (Galería de la Academia de Venecia), consigue una sensación de movimiento al simultanear dos imágenes superpuestas del hombre desnudo, pero variando la posición de sus piernas y brazos (y de su miembro viril) e inmiscuirlas en un círculo y un cuadrado al mismo tiempo.

Finalmente, cuando la referida distorsión de escalas es llevada a un grado exagerado, acaba convirtiéndose en la anamorfosis o anamorfismo, consistente en deformar el dibujo o la imagen, siendo necesario que, para observarlos de la manera más natural, se precise situarse desde un punto de vista diferente de lo habitual, generalmente habría que colocarse en los laterales y en postura muy forzada. El primer ejemplo conocido de la historia es también el de Leonardo, aproximadamente del año 1485, y que se muestra a continuación.

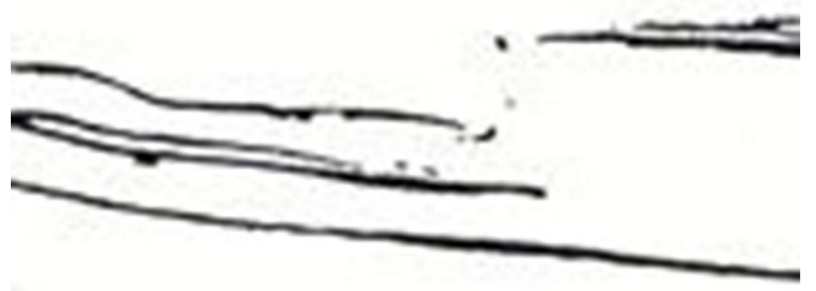

a)

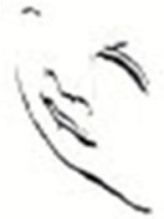

b)

Figura 7.15 a) Imagen con anamorfismo (deformada) que, si se mira desde más a la izquierda y pegado al papel, se verá que consiste en el rostro de un niño, b) Imagen no deformada (articulo del diseñador Jesús Montes Zurita https://ihistoriarte.com/2013/04/anamorfosis-la-deformacionreversible/).

Esta técnica se ha seguido utilizando hasta hoy, siendo uno de sus más famosos seguidores el artista y impresor alemán Hans Holbein, el Joven (1497?-1543) con el cuadro "Los Embajadores", donde aparece o desaparece una calavera a los pies de los personajes dibujados en el cuadro, en función del ángulo de visión que se adopte al mirarlo. 


\subsection{Conclusiones.}

Leonardo, en cuanto a representaciones gráficas, aunó a su experiencia y conocimiento, su excepcional creatividad en busca de una mejora constante. Por ello trató de dar carácter científico a la producción artística, utilizando el dibujo como base de esa producción artística y como ayuda al conocimiento, no solo en la pintura, sino también al plasmar mapas, planos constructivos, de máquinas o de mecanismos, o incluso en sus dibujos anatómicos. Para ello se ayudó de innumerables técnicas gráficas, algunas recuperadas de la antigüedad, y otras muchas creadas por él, debido a su deseo constante deseo de experimentar.

Todas estas técnicas las dejó plasmadas tanto en sus manuscritos y códices, como en su Tratado de Pintura, y algunas de ellas siguen siendo válidas en la actualidad.

En frase del profesor y crítico de arte italiano Allesandro Vezzosi, uno de sus mejores biógrafos de la actualidad, Leonardo utilizó "un método de representación que otorga toda su fuerza a las formas y a los caracteres" (Vezzosi, 2011).

\section{Referencias}

Antoccia, L., Chastel, A., Cianchi, M., Galluci, P., Laurenza, D., Papa, R., \& Pedretti, C. (2003). Atlas ilustrado de Leonardo Da Vinci. Arte y ciencia. Las máquinas. Susaeta Ediciones: Madrid.

Galland, R. (2014). Libro de los enigmas del Leonardo da Vinci. Círculo de Lectores.

Nicholl, C. (2005). Leonardo el vuelo de la mente. Santillana Ed. Generales: Madrid.

Ricart, J. (2006). Leonardo. Grandes maestros de la pintura. Editorial Sol 90: Barcelona.

Sarnago, E. (2002). La perspectiva en la pintura italiana del Quattrocento. La Teoría Intelectual. Obtenido el 01 de enero de 2017, del Portal de Historia-Proyecto Clio: http://clio.rediris.es/arte/400_pa5.htm

Vezzosi, A. (2011). Leonardo Da Vinci, arte y ciencia del universo. Ed. Blume: Barcelona. 


\title{
Capítulo 8 Análisis de los instrumentos de diseño aportados por Leonardo da Vinci en su obra científica y técnica
}

\author{
"La experiencia no engaña jamás; sino vuestros juicios que se \\ prometen efectos cuyas causas no pueden residir en la \\ experiencia". \\ LEONARDO DA VINCI (Códice Atlántico, folio 154 r, de la Biblioteca \\ Ambrosiana de Milán).
}

\subsection{Introducción}

Los instrumentos aplicables al proyecto-diseño son un componente fundamental tanto para poder plasmarlo en papel ("los documentos del proyecto"), o incluso a veces para poder llevarlo a la realidad física ("el objeto del proyecto") (Gomez-Senent, 1997). Así hace falta el compás como herramienta de precisión en el trazo de elementos geométricos, o en la realización de mapas y planos topográficos; igualmente se precisan instrumentos de medida de distancias en los procesos de construcción, de desarrollo de cursos de agua, etc.

Leonardo (Vinci 1452 - Amboise 1519), realizó a lo largo de su vida multitud de diseños y proyectos, desde el desvío de ríos, el diseño de puentes, de barcos, de máquinas y mecanismos de fabricación y vuelo, de dispositivos de guerra, hasta incluso estudios anatómicos.

Para ello precisó de instrumentos de diseño, muchos de ellos de invención propia, y con los que llevó a cabo sus estudios de óptica, de perspectiva, de hidráulica, de tribología, etc. 


\subsection{Los compases de Leonardo}

Desde la antigüedad el compás ha sido un importante instrumento de diseño tanto para la generación de circunferencias, como para obtener las bisectrices de los ángulos, la traza de rectas perpendiculares y paralelas, la comparación entre medidas e incluso para ser usado en el cálculo proporcional.

Ya los griegos lo consideraban como la herramienta de construcción más elegante y de extremada sencillez. No solo su ámbito de aplicación es el diseño, sino las matemáticas, la astronomía, la navegación, la topografía, el uso militar, etc. También ha sido ampliamente utilizado como elemento de representación indicativo de la ciencia y el arte.

En el Renacimiento se generan gran cantidad de compases especiales y con funciones específicas como por ejemplo la generación de elipses, parábolas, etc. Y Leonardo no es ajeno a ello: diseña varios modelos de compases tanto para el uso convencional, como con apertura ajustable, así como otros más complejos aptos para la ejecución de curvas cónicas como las elipses (el denominado elipsógrafo), o las parábolas (compás parabólico). También diseña compases de reducción de centro móvil e incluso crea un compás para curvas epicicloides.

Ejemplo renacentista y humanista, asimila al hombre como centro del universo, y como gran amante de la naturaleza estudia sus proporciones y establece el ideal de las mismas, generando en un dibujo (hacia 1492, existente en Galería de la Academia, Venecia) dentro de un círculo y de un cuadrado, un hombre desnudo en dos imágenes superpuestas, resultando el icono más famoso y representado de todos los tiempos, al que denominó el "Hombre de Vitruvio" (en honor al genial arquitecto romano) o de las "Divinas proporciones".

Y en su texto adjunto escribe: $<<\ldots$ si un hombre se echa sobre la espalda, con las manos y los pies extendidos, y coloca la punta de un compás en su ombligo, los dedos de las manos y los de los pies tocarán la circunferencia del círculo que así trazamos>> (Ricart, 2006).

Sus modelos de compases están reflejados en varios de sus códices y manuscritos, algunos con un detalle excepcional, y que aún hoy podrían ser construidos y usados. 


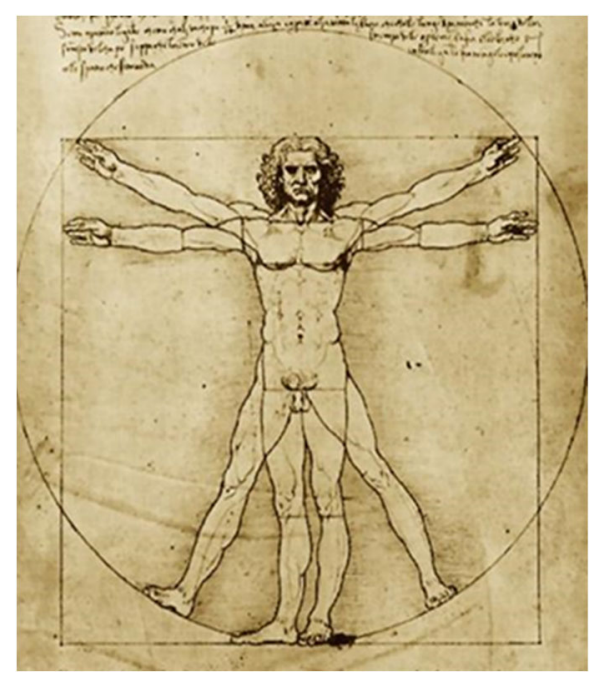

a)

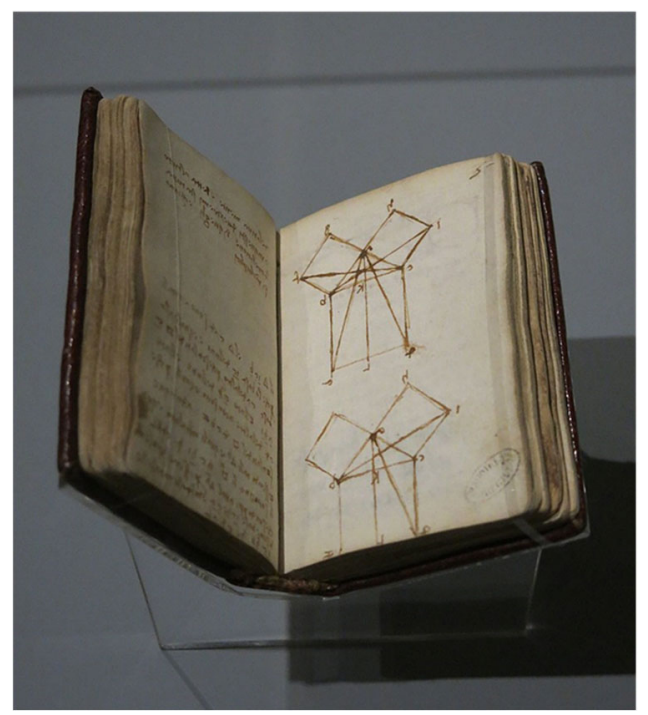

b)

Figura 8.1 a) El "Hombre de Vitruvio" Galería de la Academia. (https://commons.wikimedia.org/wiki/File:Da_Vinci_Vitruve_Luc_Viatour_(cro pped).jpg), b) Manuscrito "K" f. 14v y $1 \overline{5 r}$, del Inst. de Francia, París

(https://commons.wikimedia.org/wiki/File:Leonard_de_Vinci__D\%C3\%A9monstration_euclidienne_du_th\%C3\%A9or\%C3\%A8me_de_Pyt hagore.jpg? uselang=es). 


\subsubsection{Los compases de varillas de apertura ajustable.}

En el Códice Atlántico existente en la biblioteca Ambrosiana de Milán, existen varios diseños de Leonardo de este tipo de compases. Así, en el folio 48r, hay unos estudios de cabezas de compases diseñadas para aumentar el rozamiento entre las mismas y así asegurar la estabilidad de su apertura. Mientras que en el folio 696r (1514-15), dibuja un precioso compás ribeteado y decorado, con cabeza circular de grandes dimensiones, pensando en aumentar y asegurar el roce de sus charnelas.

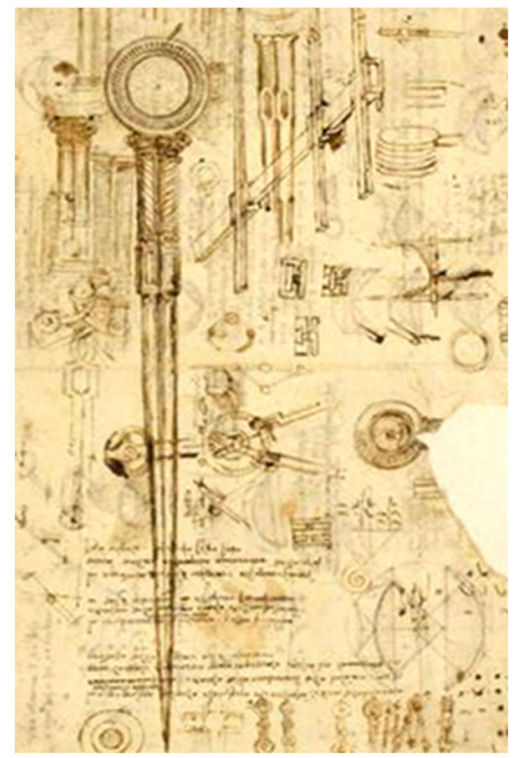

a)

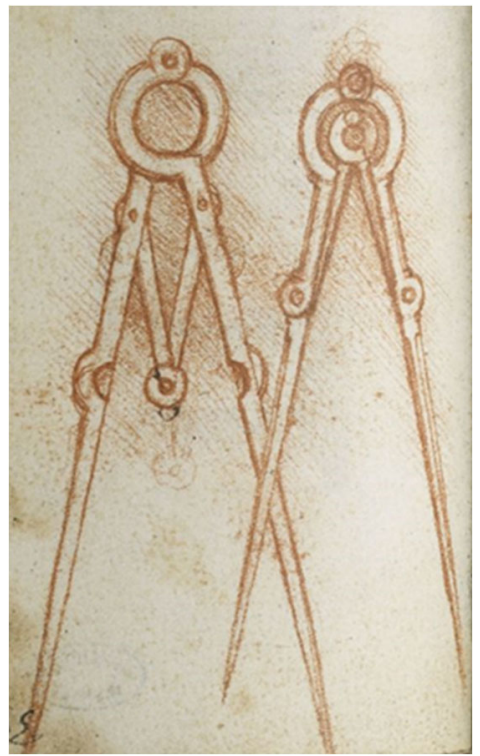

b) 


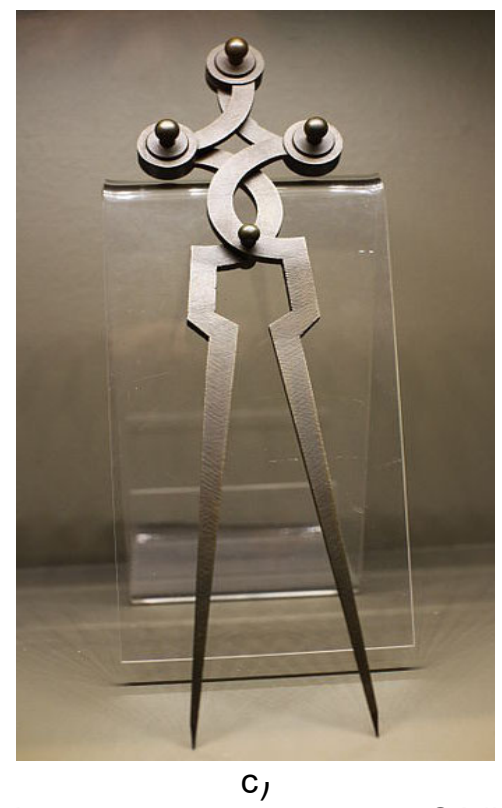

Figura 8.2 a) Estudio de instrumentos y compases. Códice Atlántico, folio 696r (https://commons.wikimedia.org/wiki/File:Codex_Atlanticus_-_000R696.jpg?uselang=es-formal), b) Detalle de compás de apertura ajustable Manuscrito $\mathrm{H}$ de Paris, f. $108 \mathrm{v}$

(https://commons.wikimedia.org/wiki/File:Leonardo_da_Vinci_-_19540164.jpg), c) Maqueta de un compás del Codex Atlanticus, Musée de I' Histoire du Fer de Jarville la Malgrange (Francia), fotografía de Caroline Léna Becker

(https://commons.wikimedia.org/wiki/File:Compas_Léonard_de_Vinci.JPG).

Existen más diseños de compases de varillas a lo largo de este códice. Igualmente, en el folio $108 \mathrm{v}$ (1493-94) del manuscrito $\mathrm{H}$ del Instituto de Francia de París, existen dos compases similares a los anteriores, aunque sin tanta belleza, pero dotados de ejes intermedios que rotulan y dan más estabilidad a los mismos durante su funcionamiento.

$<$ en su diseño y construcción Leonardo conjuga la investigación tecnológica con la estética. Uno de los resultados deseados para el diseño de un compás era su estabilidad una vez abierto. Para obtenerla, se debía aumentar la fricción entre los dos vástagos del compás y un modo de hacerlo era aumentando el numero de charnelas. En varias de las hojas del Códice Atlántico, Leonardo no solo alcanza este objetivo, sino que se aprovecha de él para conferir a la cabeza del compás una forma variada y original. La eficacia 
funcional del instrumento se convierte en motivo de elaboración estética, casi según el espíritu del diseño industrial>> (Laurenza, Taddei \& Zanon, 2006).

\subsubsection{Los compases proporcionales}

Son instrumentos de cálculo, ya que por la propiedad de semejanza de triángulos de sus varillas (entre una parte y otra del compás) con ellos se pueden realizar operaciones aritméticas, geométricas 0 trigonométricas. Pueden usarse tanto para ampliar como para reducir formas. Leonardo es el primero que los documenta e ilustra técnicamente y explica sus propiedades (p. ej. en el folio 1046r y $672 r$ del Códice Atlántico de la Biblioteca Ambrosiana de Milán y en el folio $4 r$ del Manuscrito I del Códice Forster del Victoria Albert Museum de Londres). Así diseña varias versiones, unos con perno central fijo, otros de reducción con perno central móvil, y finalmente unos con perno fijo, pero con posibilidad de incorporar puntas intercambiables de diferentes longitudes.

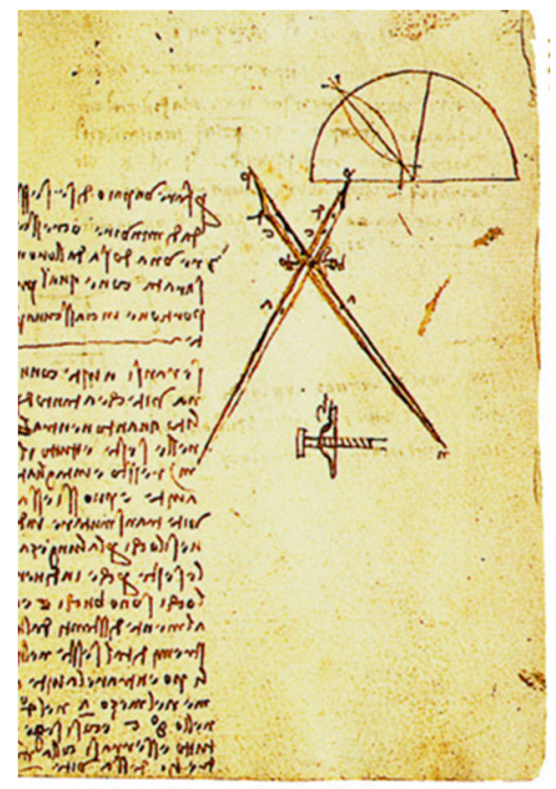

a)

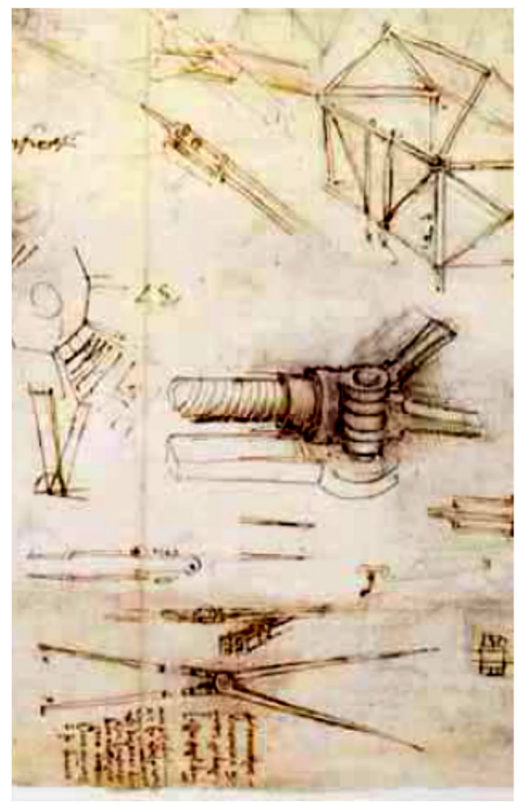

b) 


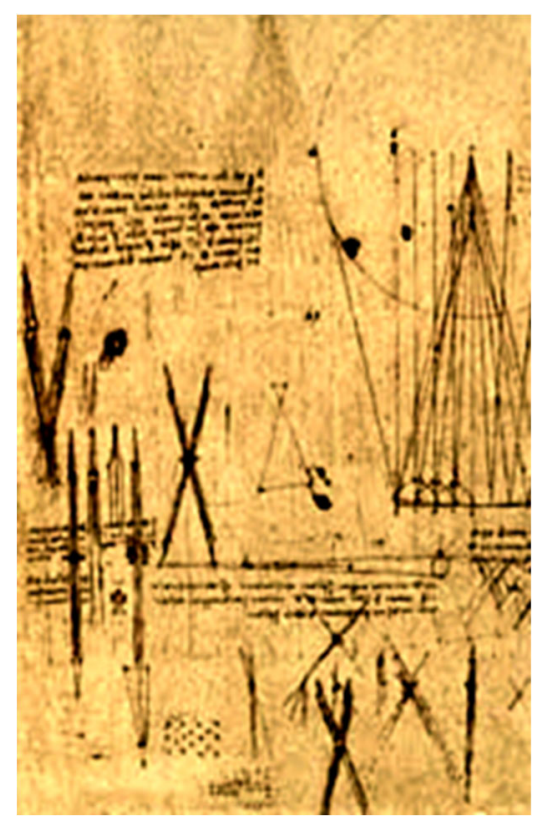

c)

Figura 8.3 a) Compás de proporción de tornillo, y detalle de su tuerca, Códice Forster Ms. I, c. 4r.

(https://commons.wikimedia.org/wiki/File:Reduction_Compass_Leonardo.jpg

), b) Detalle compás proporcional de varillas, Códice Atlántico f 1046r https://commons.wikimedia.org/wiki/File:000R-1046.jpg?uselang=es-formal,

c) Compases de reducción, Códice Atlántico f $672 \mathrm{r}$

https://commons.wikimedia.org/wiki/File:Codex_Atlanticus_-_000R-

672.jpg?uselang=es-formal).

\subsubsection{El elipsógrafo o compás oval}

Aunque hay documentación al respecto de que los matemáticos árabes ya lo conocían, no se reconoce su invención a ninguno de ellos, siendo Leonardo el primero en plasmarlo gráficamente, así como en aplicar y explicar su funcionamiento. Con ellos creó las ruedas ovales para sus relojes planetarios.

Posteriormente, contemporáneos tardíos de Leonardo, como el relojero y mecánico Benvenuto della Volpia (1462-1532), que sí reconoce la autoría de este modelo a Leonardo, y el pintor Albert Durero (1471-1528), asimilaron esta solución y este último la difundió por Alemania (Antoccia et al., 2003). 
El compás precisa de tres apoyos y una varilla ajustable; el apoyo más largo representa el eje de un cono, mientras que la varilla ajustable sobre el arco graduado, y que puede deslizarse sobre dicho apoyo, representa la generatriz de dicho cono. Bastará girar dicha varilla ajustable alrededor del eje de tal manera que la aguja o carboncillo de su extremo, se deslice (con respecto al eje del cono) y pueda marcar sobre una superficie una elipse.

Para la exposición de Bolonia de 1953, (Florence, Istituto e Museo di Storia della Scienza.) fue reconstruido en latón un modelo posterior y muy similar al de Leonardo, en concreto el de Benvenuto della Volpaia, Libro o códice di macchine diverse (sobre 1524) de la Biblioteca Nacional Marciana It. 5363, c. $18 \mathrm{r}$ de Venecia.

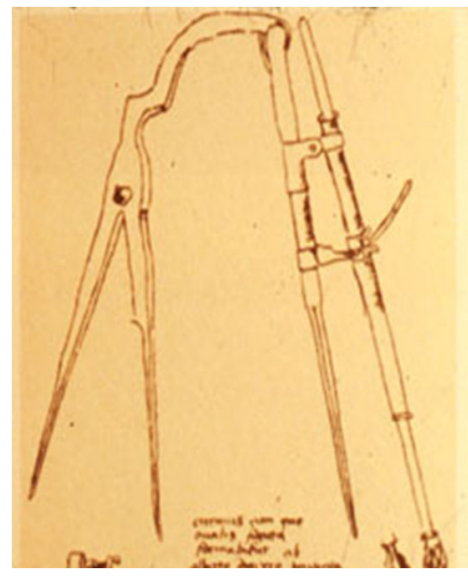

a)

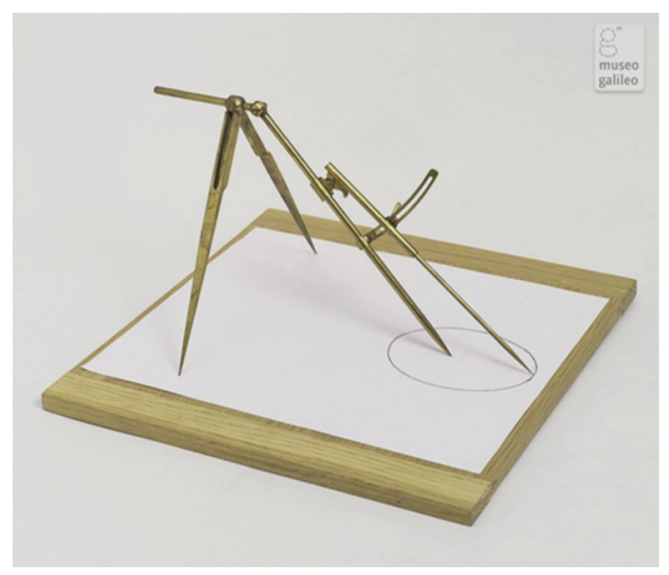

b)

Figura 8.4 a) Elipsógrafo de Leonardo, con tres apoyos. b) Elipsógrafo de Benvenuto della Volpaia, (Florence, Istituto e Museo di Storia della Scienza.) (https://brunelleschi.imss.fi.it, Museo Galileo, Florencia).

\subsubsection{El compás parabólico}

Su invención es atribuida a Leonardo, y está diseñado en el folio 1093r del Códice Atlántico de la Biblioteca ambrosiana de Milán (1513-14). 


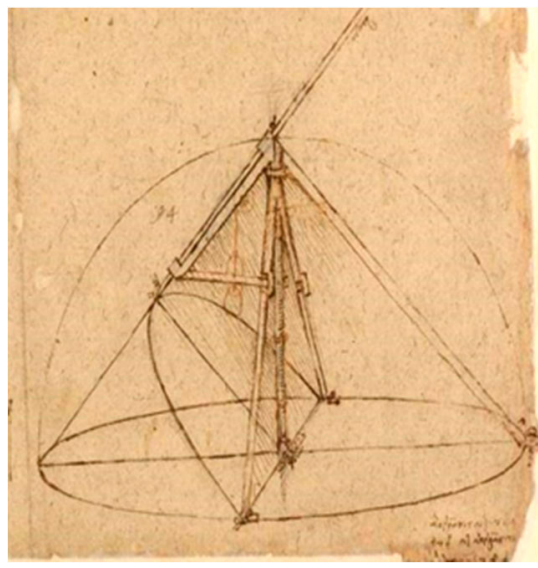

a)

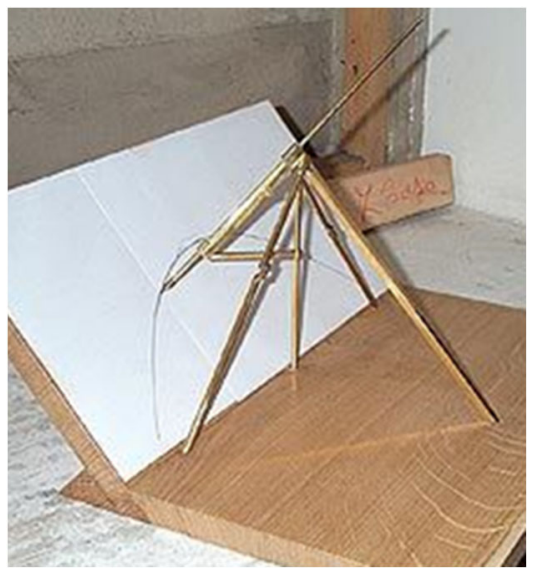

b)

Figura 8.5 a) Compás Parabólico. Códice Atlántico f. 1093r (https://commons.wikimedia.org/wiki/File:000R-1093.jpg), b) Reconstrucción en latón del Instituto y Museo de Historia de la Ciencia de Florencia (https://brunelleschi.imss.fi.it, Museo Galileo, Florencia).

Consiste en reproducir la estructura de un cono rectangular de manera estable, con un brazo móvil y retráctil a $45^{\circ}$, que simula la generatriz del cono. Bastará colocar un plano inclinado que corte tal generatriz, y sobre él, apoyar el papel, donde poder marcar con el trazo del compás la parábola.

\subsubsection{El compás para epicicloides.}

La epicicloide es la curva que se genera por la trayectoria del punto de contacto perteneciente a una circunferencia generatriz que rueda, sin deslizamiento por el exterior de otra circunferencia directriz . Es un tipo de ruleta cicloidal.

Según va cambiando la relación $\mathrm{K}$ de los radios directriz y generatriz, va cambiando la forma de la curva. 

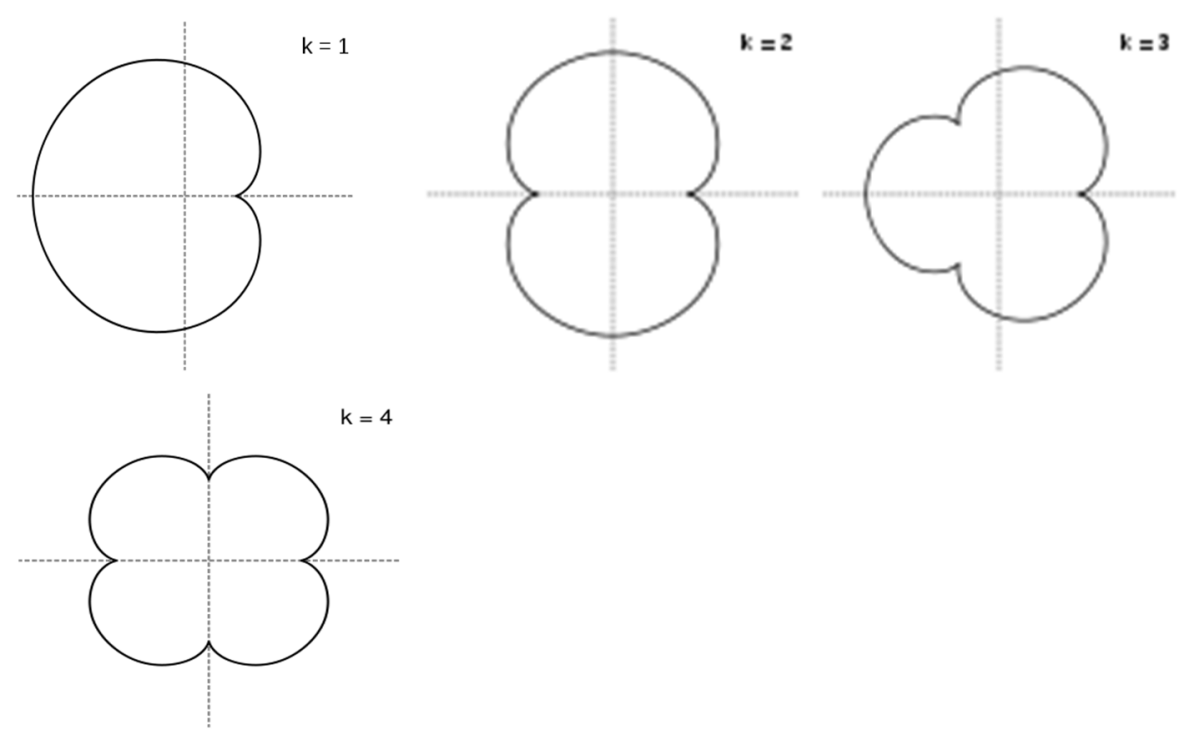

Figura 8.6 Formas de la Epicicloide desde $\mathrm{K}=1 \mathrm{a} \mathrm{K}=4$. (Fuente Wikipedia enciclopedia libre).

Leonardo estudia las curvas epicicloides para establecer las trayectorias de sus relojes planetarios, donde un planeta aparte de girar alrededor de sí mismo, orbita alrededor de otro; este doble movimiento es el que replica en su invento de compás o brújula epicicloide de Leonardo, existente en el Códice Arundel folio 160v de la British Library de Londres. 


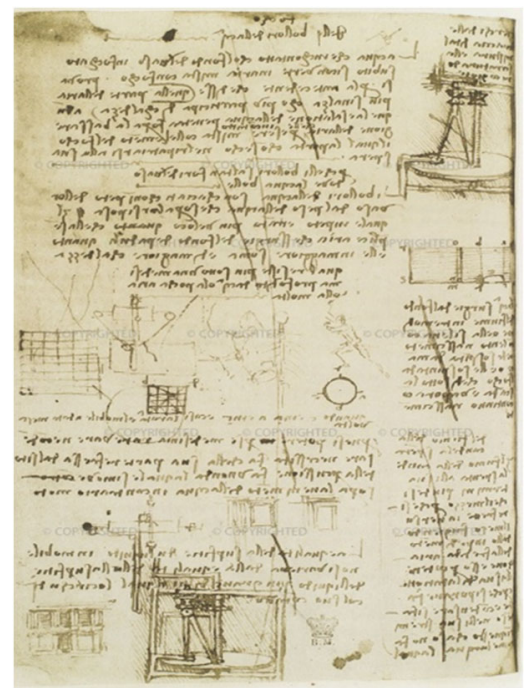

a)

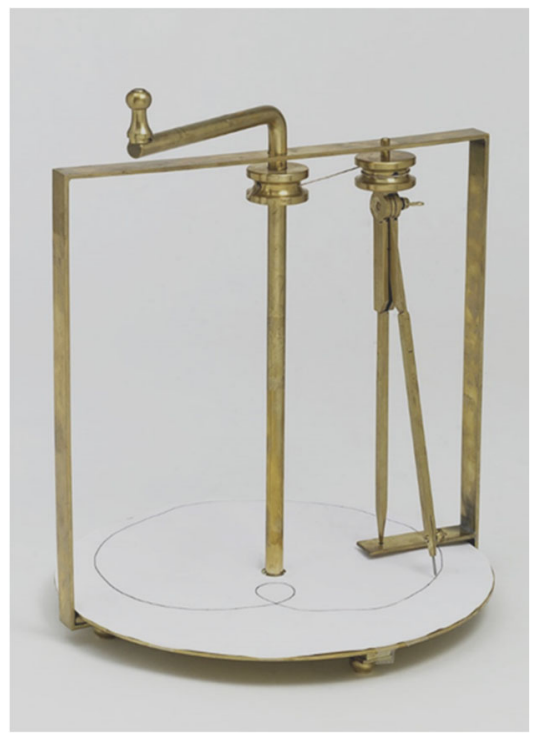

b)

Figura 8.7 a) Compás epicicloide Códice Arundel f. 160v.

(http://www.bl.uk/manuscripts/Viewer.aspx?ref=arundel_ms_263_f001r), b) Reconstrucción en latón del Instituto y Museo de Historia de la Ciencia de Florencia (https://brunelleschi.imss.fi.it, Museo Galileo, Florencia). 


\subsection{El Prospectógrafo o Perspectógrafo.}

El arquitecto italiano León Battista Alberti (1404-1472), ya mencionó en alguna de sus obras el uso de este instrumento (Taglialagamba, Pedretti, 2010), pero es Leonardo el primero en dibujarlo con detalle en su Códice Atlántico en el folio $5 r$ (1480-1482) y describir su utilización. Incluso aparece dibujado el propio Leonardo utilizando su prospectógrafo de velo, dibujando una esfera armilar.

Leonardo distingue y utiliza dos clases de prospectógrafo: el de velo y el de vidrio. El de velo, nombrado ya por Alberti, sobre el que se dibuja la imagen observada directamente con algún elemento que manche (p. ej. betún) y posteriormente esta se traslada al papel.

El otro, el de vidrio, está basado en la representación sobre el vidrio de la realidad exterior manteniendo un punto de vista fijo; es el que utiliza una ventana llena de cuadrículas (también conocida como la Ventana de Leonardo) por donde el diseñador observa el objeto a través de la mirilla del prospectógrafo y las traslada a su papel, donde también existen unas cuadrículas similares a las de la ventana (este modelo es el que más tarde popularizó en Alemania Albert Durero (1471-1528)).

Del estudio y análisis de los dibujos así realizados, posteriormente se establecieron los principios que rigen la representación en perspectiva cónica.

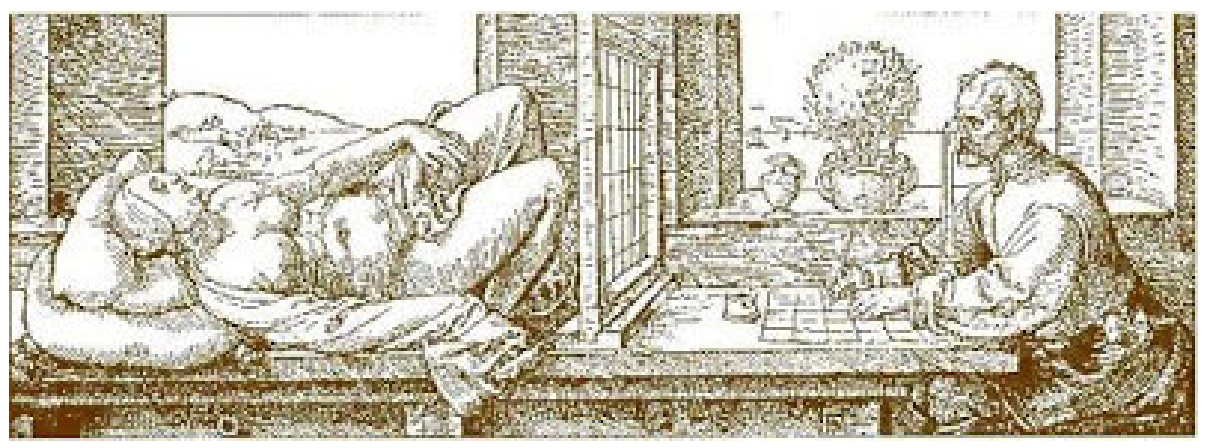

Figura 8.8 Prospectógrafo de vidrio de Albert Durero, 1525

(https://commons.wikimedia.org/wiki/Albrecht_D\%C3\%BCrer\#/media/File:D $\%$ C3\%BCrer_-_Zeichner_und_Akt.jpg). 


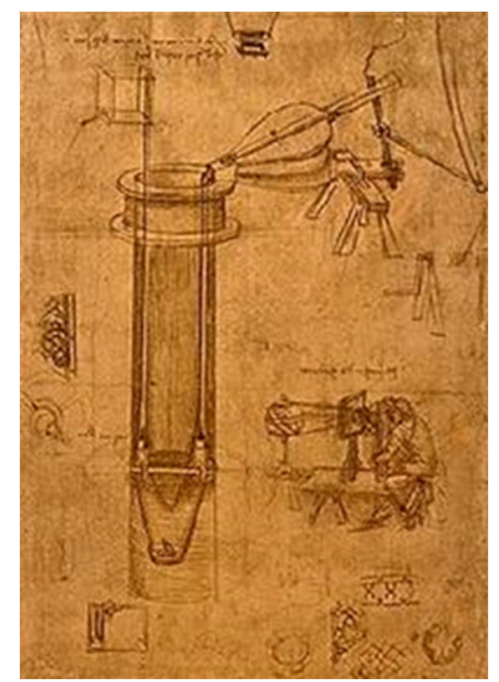

a)

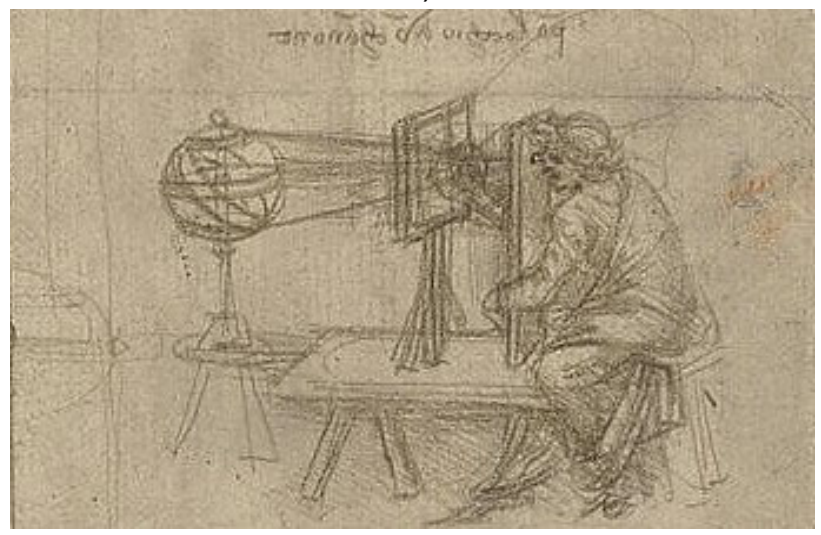

b)

Figura 8.9 a) Códice Atlántico, f. 5r.

("https://brunelleschi.imss.fi.it/genscheda.asp?appl=LIR\&xsI=paginamanoscr itto\&chiave=101361"chiave=101361), b) Detalle ampliado del prospectógrafo siendo usado por Leonardo.

(https://commons.wikimedia.org/wiki/File:Codice_Atlantico__Perspectograph.jpg). 


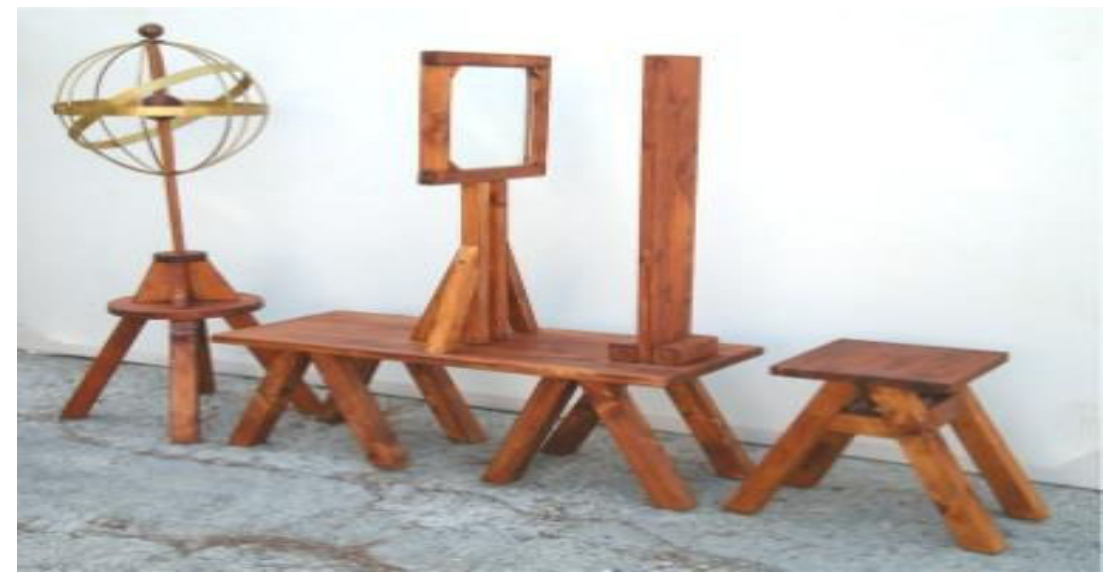

Figura 8.10 Maqueta según dibujo de Leonardo, de Asociación cultural Italian Art (italian_art@yahoo.com.br) de Florencia.

\subsection{El odómetro y el podómetro}

Un odómetro es un dispositivo que indica la distancia recorrida por la persona, o por el vehículo que lo lleva incorporado (del griego "hodo" = camino y "metron" = medida). $\mathrm{Y}$ es el precursor de los "cuentakilómetros" y tacógrafos de los vehículos actuales. Inicialmente eran de constitución mecánica y hoy, estos instrumentos de campo son de carácter electrónico.

Se atribuye al matemático, ingeniero y astrónomo griego Arquímedes de Siracusa (287 a.C.-212 a.C.), la posible invención de este instrumento. Posteriormente el arquitecto e ingeniero romano Vitrubio (80 70 a.C.- 15 a.C.) vuelve nombrarlo en su tratado "De Architectura".

Parece ser que la primera aplicación de este la hizo el ingeniero y matemático Herón de Alejandría (siglo I - 75), al incorporar engranajes a las ruedas de los carruajes con el fin de conocer la distancia recorrida por estos.

No obstante, no es hasta el Renacimiento cuando Leonardo describe su construcción y características, siendo el primero en dibujarlo hasta el detalle.

Leonardo, en 1502 (primera etapa romana), tuvo los encargos César Borgia (hijo del Papa Alejandro VI), al ser nombrado "arquitecto e ingeniero general de los dominios Papales", de establecer defensas y mejoras en las fortificaciones de los dominios del Papa "Borgia" y para 
lo cual precisaba de efectuar grandes medidas longitudinales. Para ello ideó varias máquinas de medida automatizada de longitudes, en concreto el folio $1 \mathrm{~b}$ r (hacia 1504) del Códice Atlántico de la Biblioteca Ambrosiana de Milán, existen dibujadas al detalle dos odómetros y un podómetro.

El odómetro, en forma de carretilla, medía longitudes con las unidades establecidas por aquel entonces ("braccias"), mientras que el podómetro lo media con la equivalencia a "pasos" de la persona que lo llevaba.

En el Odómetro de Leonardo, la rueda dentada, $<<$ diseñada para avanzar un diente cada 10 braccias recorridas (alrededor de 6 metros), hasta que, al llegar a los mil seiscientos metros (una milla), un guijarro caía de un modo audible en un recipiente de metal>>. (Capra, 2008).

Por cada vuelta de la rueda grande central se adelantaba un diente de la rueda dentada lateral en vertical; agotada la vuelta total de esta última, ya se accionaba otra rueda horizontal superior, que llevaba incorporadas unas pequeñas bolas o piedras redondas en su parte alta, y se efectuaba la caída de una de ellas a una caja ubicada en la parte baja de la carretilla. Bastaba contar el número de bolas que habían caído para saber la longitud recorrida.

Leonardo diseña dos modelos en el manuscrito, uno más robusto y pesado, con dos ruedas de apoyo, y otro más liviano de una rueda. Ambos muestran solidez suficiente para ser utilizados ajustándose al estado irregular de los caminos y terrenos de entonces, con el menor error posible.

El Podómetro o cuenta pasos (tercer dibujo del manuscrito antes citado) servía para saber la distancia recorrida por las tropas (o por un caminante entre ciudades) en cualquier momento. El balanceo de la cuerda con un peso en su extremo inferior, incorporada al muslo de una persona, se movía hacia adelante y atrás en cada paso, y hacía accionar el diente del primer engranaje, asimilándose al balanceo del péndulo de los relojes. Después, en función del número de dientes de engrane de cada una de las tres coronas posteriores ensambladas, se podría saber en cada instante la distancia recorrida sin tener que contar los pasos constantemente. 
CAPÍTULO 8

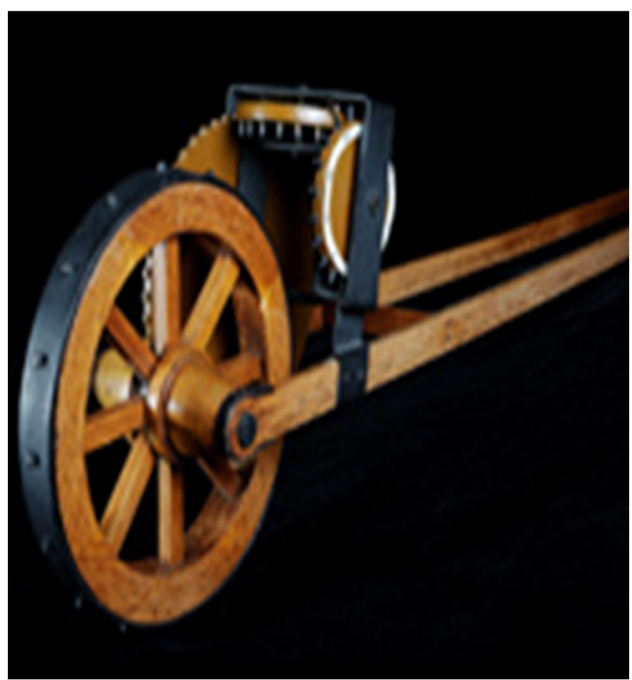

a)

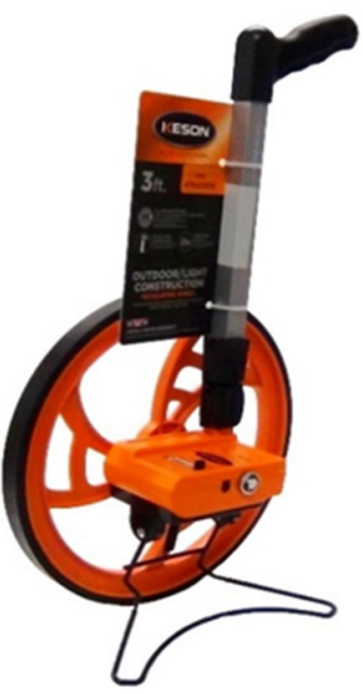

b) 


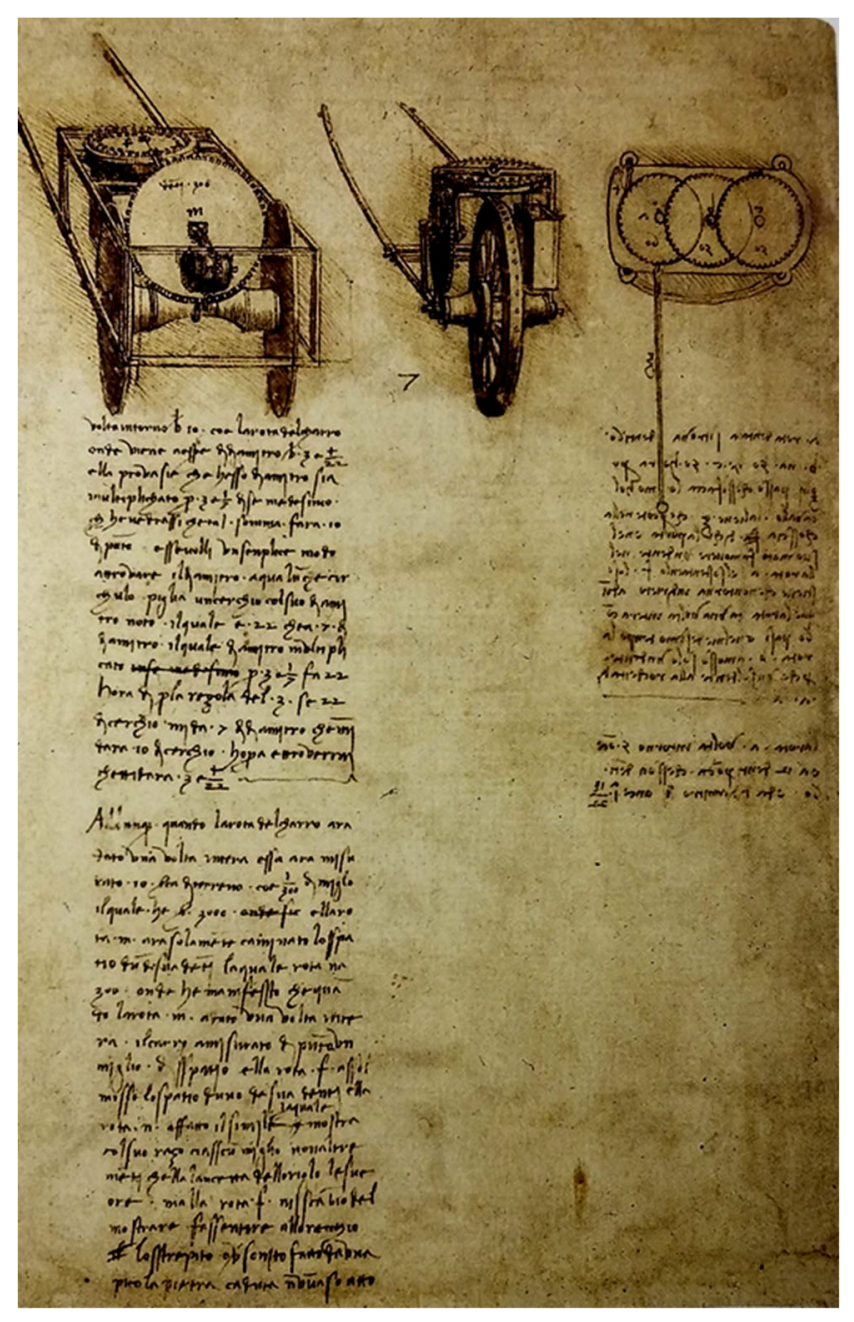

c)

Figura 8.11 a) Maqueta del Museo Nacional de Ciencia y Tecnología de Milán. (www.museoscienza.org), b) Odómetro actual, marca Kesom mod. RR3M, c) Códice Atlánticus, folio $1 \mathrm{~b}$ r. (https://commons.wikimedia.org/wiki/File:Odomètre-Léonard.jpg). 


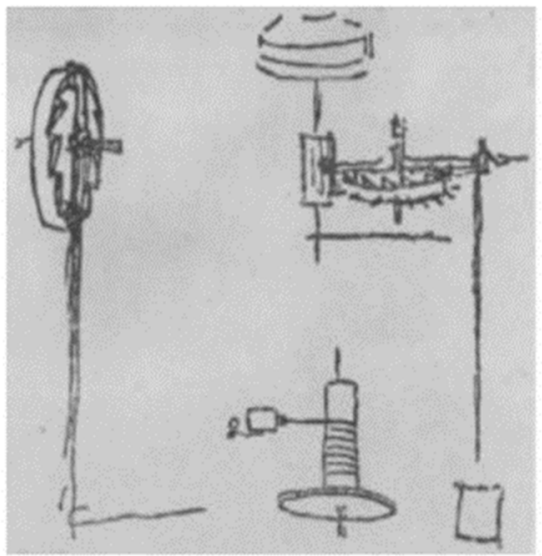

a)

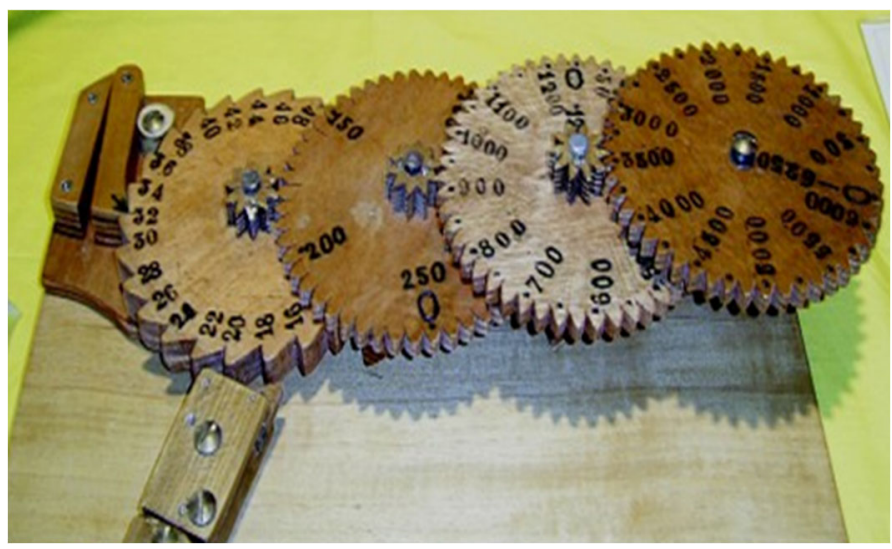

b)

Figura 8.12 a) Detalles de una lámina del Códice de Madrid con contador de balanceos. (http://leonardo.bne.es/index.html), b) Maqueta asimilable al

Podómetro de Leonardo construida por el artesano italiano Giorgio Mascheroni para la exposición "L`Arttigiano di Leonardo" (http://artigianodileonardo.jimdo.com).

\subsection{La cámara oscura}

Este instrumento óptico permite obtener una proyección plana de una imagen externa sobre una zona interior. O sea, es posible dibujar con la luz, colocando un papel traslúcido en la parte posterior, justo 
enfrente del orificio por donde pasa la luz. El orificio debe ser muy pequeño para que la calidad de la imagen sea nítida y clara.

Habitualmente se realiza con una caja cerrada y un pequeño agujero, por el que entra una cantidad de luz que proyecta en la pared opuesta de la caja la imagen del exterior, pero en sentido contrario.

Inicialmente se realizaba en una sala cerrada (para que pudiera introducirse en ella el artista y dibujar desde su interior), practicando en uno de sus muros un pequeño orificio para la entrada de los rayos luminosos, que reflejaban los objetos exteriores en una de sus paredes.
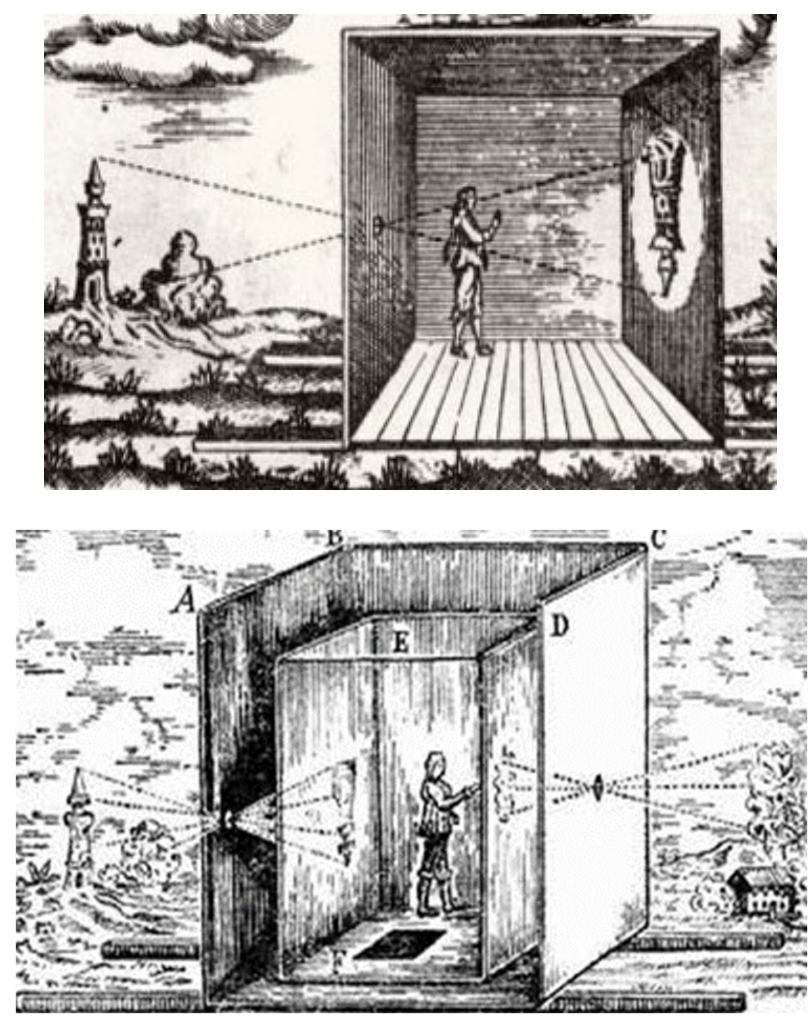

Figura 8.13 Imágenes de cámaras oscuras transportables, conformadas por una habitación similar a las descritas por el sacerdote erudito y políglota Athanasius Kircher (1602-1680).

(https://www.fotonostra.com/biografias/camaraoscura.htm). 
Los primeros conocimientos escritos sobre el fenómeno son del griego Aristóteles (384-322 a.c.). El matemático árabe conocido como Alhacen (Abu Ali ibn al-Hasan, 965-1038) estudioso de la óptica, es el primero que utiliza este fenómeno para explicar el funcionamiento de la imagen visual en el ojo humano, y que refuta las teorías griegas sobre los rayos luminosos (estableciendo que los rayos luminosos van de los objetos al ojo que los observa, y no al revés como decían los griegos) y es el que le otorga la denominación de "cámara" en óptica.

Pero es Leonardo, que profundizó en los conocimientos de óptica de Alhacen, sobre todo para sus propios estudios sobre la perspectiva, el que hace en sus manuscritos la primera descripción completa e ilustrada sobre su funcionamiento. Además de redescubrir su funcionamiento y darle utilidad práctica, es el primero en incorporarle una lente para perfeccionar (o incluso acercar) la imagen que se proyectaba en el interior desde fuera (Contreras, 2015).

Describe varias veces sus experiencias con la cámara oscura. Dice en su "Tratado de la Pintura": <<Un experimento que muestra cómo los objetos transmiten imágenes o simulacros que se intersectan dentro del ojo en el humor cristalino. Esto queda demostrado cuando por un pequeño orificio circular penetran en una habitación muy obscura imágenes de objetos muy iluminados. Si tú recibes esas imágenes en un papel blanco situado dentro de la tal habitación y muy cerca del tal orificio, verás en el papel esos objetos con sus cabales formas y colores, aunque, por culpa de la intersección, a menor tamaño y cabeza abajo. Si dichas imágenes proceden de un lugar iluminado por el sol, parecerán como pintadas en el papel que habrá de ser sutilísimo y visto del revés. El orificio se abrirá en una placa de hierro muy delgada. (...) ¡Así ocurre dentro de la pupila!>>

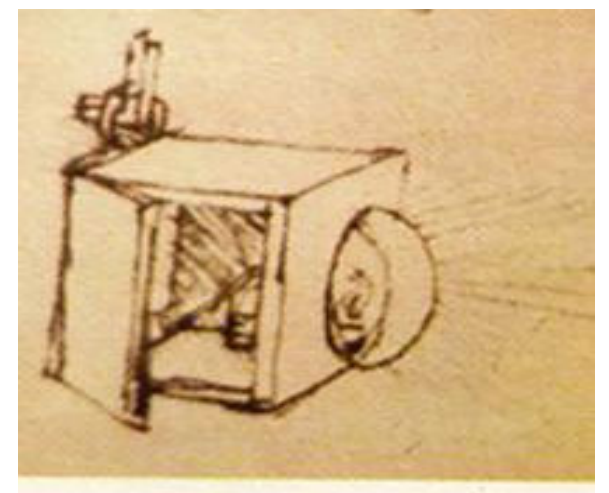


a)

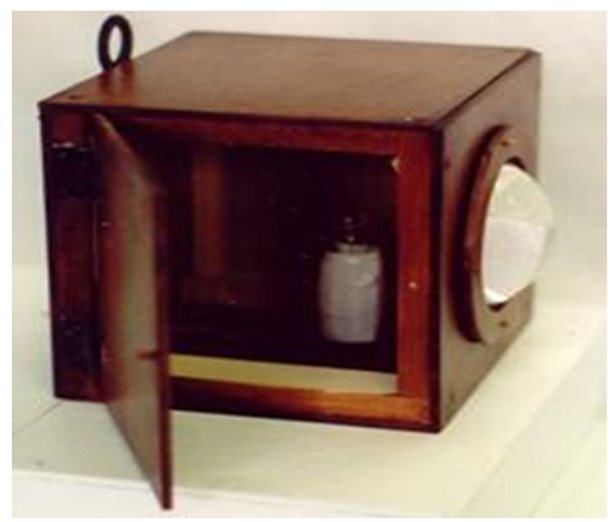

b)

Figura 8.14 a) Proyector de luz Códice Atlántico f. 34 r-a (1480) (https://commons.wikimedia.org/wiki/File:Codex_Atlanticus_-_000R-34.jpg), b) Maqueta del proyector realizada por el profesor italiano de enseñanzas técnicas Giralomo Covolan (http://www.macchinedileonardo.it).

En otro de sus textos, para demostrar la similitud entre el funcionamiento del ojo humano y la cámara oscura, matiza: $<<D e$ cómo las imágenes de los objetos percibidos por el ojo se entrecortan en el humor cristalino >>, también en ello, es el pionero en hacerlo constar.
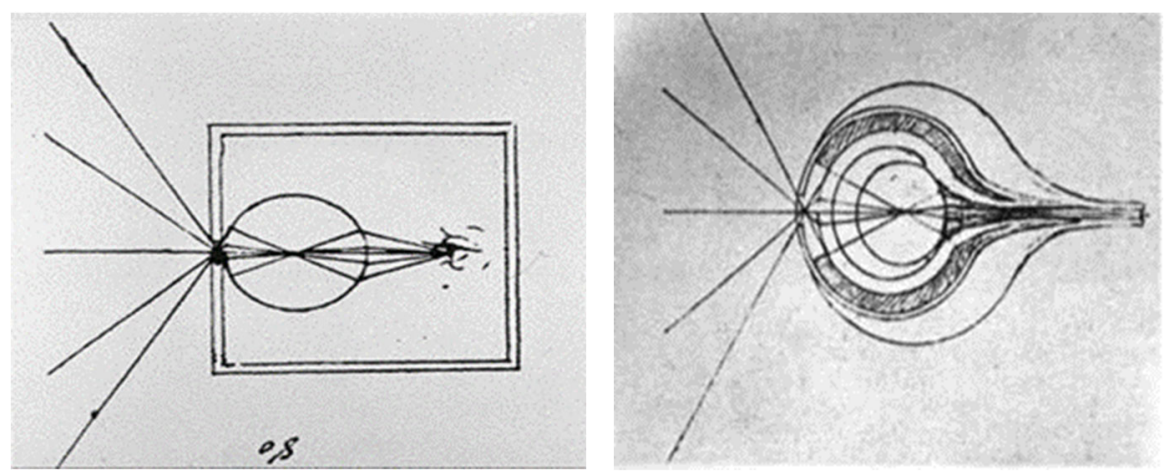

Figura 8.15 Detalle de similitud de la visión del ojo y la cámara oscura, Códice Atlántico

(https://commons.wikimedia.org/wiki/File:Otto_Werner_\%22Zur_physik...\%2

2, illustrations_Wellcome_L0012044.jpg fotografia de Otto Werner). 
En el folio 3v (hacia 1508) del Manuscrito D del Instituto de París intenta demostrar el funcionamiento del ojo humano con un experimento. $<<H a$ llenado de agua un globo transparente, que representa el globo ocular, y en su parte delantera ha colocado una placa con un pequeño agujero en el centro, que representa a la pupila. En el centro del globo hay suspendida una bola de cristal delgado que representa al cristalino >>, detrás de la cual Leonardo sitúa su propio ojo debajo del agua, en la posición del nervio óptico. $<<$ Tal instrumento enviará imágenes [...] al ojo de la misma manera que el ojo las envía a la facultad visual>> (Capra, 2008).
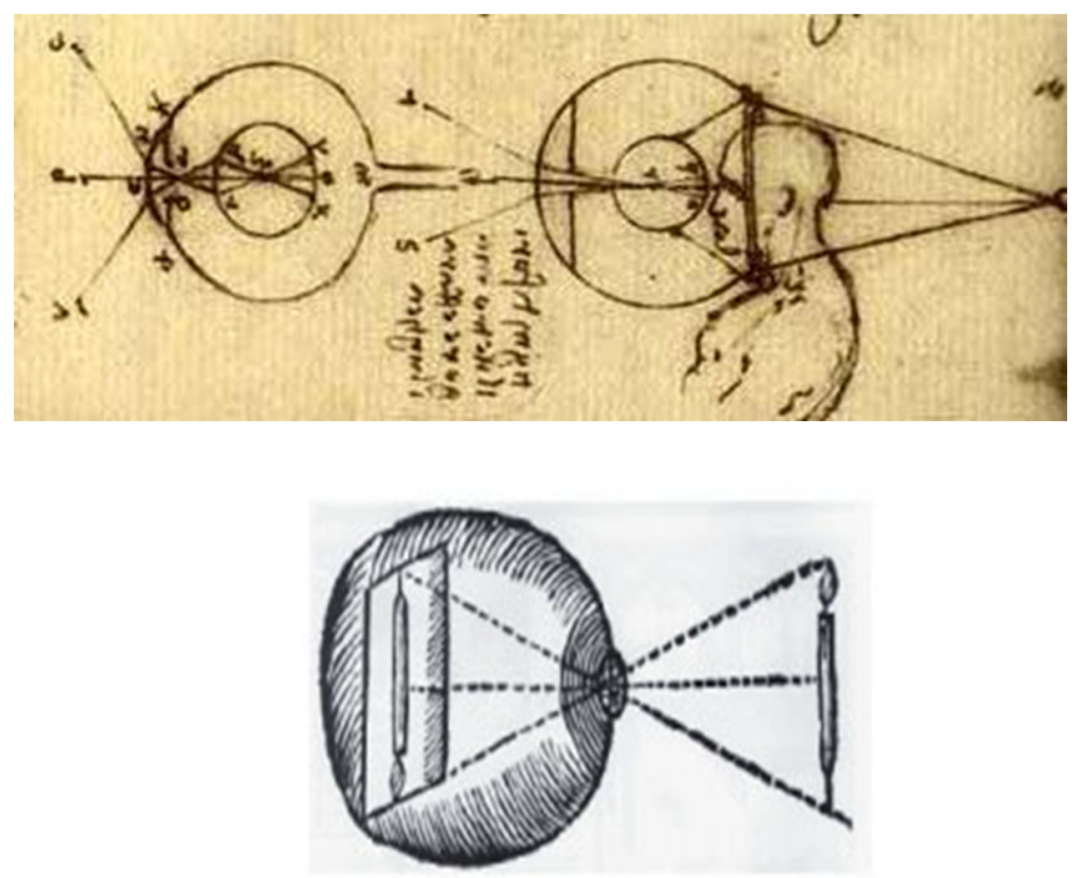

Figura 8.16 Demostración del mecanismo del ojo por medio de un modelo de vidrio (Manuscrito D, f. 3v).

(https://commons.wikimedia.org/wiki/File:Leonardo_da_Vinci,_Manuscript_D ,_1508-09.jpg?uselang=es).

Para Leonardo, la cámara fue un medio en potencia para calcar las imágenes con un lápiz. A partir de entonces se popularizó como herramienta auxiliar para el dibujo y la pintura.

Algunas de estas ideas, así como la incorporación por Leonardo de espejos parabólicos para realizar observaciones astronómicas ("Para 
ver la naturaleza de los planetas abre el techo y muestra en la base, de la pirámide de reflexión, un solo planeta y el movimiento reflejado de dicha base determinará la complexión de tal planeta, pero haz que en la base no se refleje más que un planeta por vez") fueron fundamento para el desarrollo posterior del telescopio reflector de Isaac Newton (1642-1727). (Nicholl, 2005).

Este principio también derivó mucho más tarde en la creación de la cámara fotográfica (manteniéndose el concepto de "cámara") por Nicéphore Niepce (1765-1833) a partir de de una cámara oscura con lente de menisco en 1827. Conseguía fijar la imagen sobre una plancha de peltre plateado, cubierta de betún de Judea que, al exponerla a la luz, las partes afectadas por esta hacían solubles el betún; y al ser bañada posteriormente en un disolvente (aceite esencial de lavanda y petróleo blanco), se marcaban claros y sombras en la placa plateada, en distintos tonos, según fuera más o menos soluble el betún.

Hasta la utilización masiva de la fotografía, las cámaras oscuras tuvieron mucha importancia siendo objeto de una asignatura en los estudios oficiales de Bellas Artes (Historia de las cámaras oscuras, $n$. d.).

\subsection{Conclusiones}

Leonardo, quizás el mayor polímata de todos los tiempos, en sus Cuadernos de Notas conformados hoy en varios manuscritos y códices que superan las 7.000 hojas, dejó constancia de la creación o mejora de varios instrumentos y herramientas relacionados con el mundo del diseño/proyecto.

No aceptó nunca la ciencia y los dogmas transmitidos de tiempos anteriores, si no habían sido validados por su propia comprobación o experimentación. Lo que le llevó a innovar y comprobar de manera constante en cualquier campo del conocimiento y el mundo del diseño no fue para él una excepción.

Entre sus invenciones y mejoras de instrumentos al servicio del diseño, cabe destacar que mejoró tanto los compases de apertura ajustable como los proporcionales y que inventó un compás parabólico, un elipsógrafo o compás oval, así como uno para trazar epicicloides. Igualmente mejoró el prospectógrafo o máquina de 
perspectiva, que popularmente se conocería como la "ventana de Leonardo".

También mejoró el odómetro para medir largas distancias, e inventó el podómetro o instrumento de medida de pasos. Finalmente estudió y amplió el conocimiento de las "cámaras oscuras", estableciendo mejoras técnicas y su uso como herramienta auxiliar del dibujo y la pintura.

Su excelente formación estética y técnica, su gran creatividad y perfeccionismo, hacen que todas estas invenciones aúnen precisión, estética y seguridad, propiedades que muchos años después caracterizarían el espíritu del diseño industrial.

\section{Referencias}

Antoccia, L., Chastel, A., Cianchi, M., Galluci, P., Laurenza, D., Papa, R., \& Pedretti, C. (2003). Atlas ilustrado de Leonardo Da Vinci. Arte y ciencia. Las máquinas. Susaeta Ediciones: Madrid.

Capra, F. (2008). La ciencia de Leonardo. Editorial Anagrama: Barcelona.

Contreras, M. (2015). Leonardo da Vinci: Ingeniero. Tesis doctoral. Universidad de Málaga.

Epicicloide (2015, 8 noviembre). Obtenido 13 de marzo de 2017 de Wikipedia, la enciclopedia libre: http://es.wikipedia.org/wiki/Epicicloide

Furor Mechanicus (n. d.). Obtenido el 12 de marzo de 2017 de http://redi.imss.fi.it/invenzioni/index.php/Categoria:Strumenti_d a_disegno

Girolamo C. (n.d.). Macchine Di Leonardo.it. Obtenido el 10 de marzo de 2017, de http://www.macchinedileonardo.it/lemacchine/didattiche

Gómez-Senent Martínez, E. (1997). El proyecto. Diseño en ingeniería. Universidad Politécnica de Valencia.

Historia de las cámaras oscuras (n. d.). Obtenido el 12 de marzo de 2017 de http://www.camaraoscuraworld.com/es/historia/

Laurenza, D., Taddei, M., \& Zanon, E. (2006). Las máquinas de Leonardo. Susaeta Ediciones: Madrid. 
Análisis de los instrumentos de diseño aportados por Leonardo da Vinci en su obra científica y técnica

Mascheroni, G. (n.d.). Artigiano di Leonardo. Obtenido el 13 de marzo de 2017 de http://artigianodileonardo.jimdo.com

Nicholl, C. (2005). Leonardo el vuelo de la mente. Santillana Ed. Generales: Madrid. Edición en italiano.

Ricart, J. (2006). Grandes maestros de la pintura. Editorial Sol 90: Barcelona.

Taglialagamba, S., \& Pedretti, C. (2010). Leonardo: La Arquitectura. CB Edizione: Poggio a Caiano. 



\title{
Capítulo 9 El diseño basado en analogías en la obra de Leonardo da Vinci
}

\author{
"La adquisición de cualquier conocimiento es siempre útil al \\ intelecto, puesto que siempre se puede desechar lo inútil y retener \\ lo bueno".
} LEONARDO DA VINCI (Códice Atlántico, folio 233 r, de la Biblioteca Ambrosiana de Milán).

\subsection{Introducción}

Según el investigador del CNRS (Centro nacional de investigación científica francés), filósofo y sociólogo francés Edgar Morín (París, 1921), dentro de los distintos tipos de pensamiento, uno de los que proporciona mejores resultados creativos es el denominado pensamiento analógico.

Partiendo de la abstracción y análisis de elementos existentes, con formas parecidas o partes conocidas, y mediante la aplicación de una relación de semejanza, se generan nuevas creaciones (máquinas, artefactos o productos artificiales). Se suele trabajar identificando un objeto que sirva de inspiración, observándolo detenidamente, descomponiendo sus sistemas en elementos básicos; interpretando tanto en el conjunto como las partes bajo nuevas situaciones, y finalmente intentando obtener una nueva solución, así como el desarrollo y diseño de esta.

Nadie mejor que Leonardo (Vinci 1452- Amboise 1519), paradigma de la creatividad que escribe en su Cuaderno de Notas: $<<$ La naturaleza es la mejor maestra>>, para buscar diseños con soluciones analógicas. 
Giselle Goicovic, Magíster en Educación para la docencia universitaria de la Universidad de Ciencia de Informática chilena, y autora de libros sobre pensamiento complejo, establece: <<Dentro de los componentes cognitivos identificados en el proceso creativo de Leonardo (los pensamientos convergente, divergente y analógico), el tipo de pensamiento más relevante para los resultados creativos es el pensamiento analógico. Al estudiar los veinticinco códices, es posible encontrar cientos de analogías, muchas veces entre elementos distantes, lo que refuerza el poder creativo de Leonardo>> (Giocovic, 2015).

En el "Tratado de la Pintura" de Leonardo, que reconstruyó su alumno el pintor Francesco Melzi (Milán 1491-Vaprio d'Adda 1570) con sus apuntes, Leonardo ya sugiere a sus discípulos una técnica de creatividad: La Alucinación: <<Partiendo de la observación de una mancha en la pared y concentrando en ella las capacidades visuales $y$ emotivas de uno mismo, puede reconocerse en ese muro los contornos de paisajes fantásticos, con montañas, ríos, rocas, árboles

$y$ valles, $y$ a veces escenas de batalles, o rostros extraños o trajes todavía más extraños, lo que se podía traducir en formas y colores. También utiliza esta técnica en el terreno de la acústica, en el Tratado de Pintura, compara las extrañas sugestiones que nacen de una mancha en las paredes por aquella provocada por el sonido de las campanas, en cuyo repicar nos parece oír toda clase de sonidos y palabras>> (Orlando, Cinotti, \& Rizatti, 1974).

Mientras que el catedrático de historia del arte de la Universidad de Oxford, Martin Kemp (1942 Reino Unido-), especifica al respecto del uso de analogías por Leonardo, que este <<Comprueba que las formas diseñadas desempeñaran sus funciones, pero las invenciones humanas deben ir más allá de la imitación de la naturaleza con la idea de crear mecanismos que ella no había creado. Como ejemplo explica que en la naturaleza no había un arco para proyectar flechas>> (Kemp, 2006).

\subsection{Los estudios biomecánicos}

Las investigaciones anatómicas que había realizado Leonardo, tanto sobre seres humanos como sobre animales, le habían dado un especial conocimiento del funcionamiento de las articulaciones. Leonardo pretendía conformar un tratado ilustrado de anatomía humana, con una precisión jamás vista, ya que la ilustración anatómica 
de entonces tenía un carácter elemental. Pero su muerte impidió su publicación.

Leonardo refirió prácticamente todos los huesos del cuerpo y muchos los principales músculos. Utilizo su capacidad para la perspectiva para grafiar huesos (la espina dorsal y su despiece son una verdadera obra de arte) y músculos del hombro, del brazo, etc., de manera que algunos de ellos disponen de hasta ocho vistas y varias perspectivas que aclaran con todo detalle la fidelidad de su visión.

La mayoría de estos dibujos e investigaciones fueron adquiridos en 1590 a los familiares de Francesco Melzi, pintor, alumno y heredero de la mayoría de cuadernos y manuscritos de Leonardo, por el escultor italiano Pompeo Leoni (Milán, aprox.1533-Madrid, 1608), al servicio de la corte española de Carlos V y Felipe II. Este procedió a encuadernarlos según criterios temáticos, y grabó su nombre, junto al de Leonardo, con el siguiente texto "Dibujos de Leonardo da Vinci, preservados por Pompeo Leoni". Hacia 1680, el cuaderno destinado a anatomía fue adquirida para la Colección Real de Inglaterra, por lo que unas 150 páginas de sus estudios de anatomía se han conservado en la Royal Library del Castillo de Windsor.

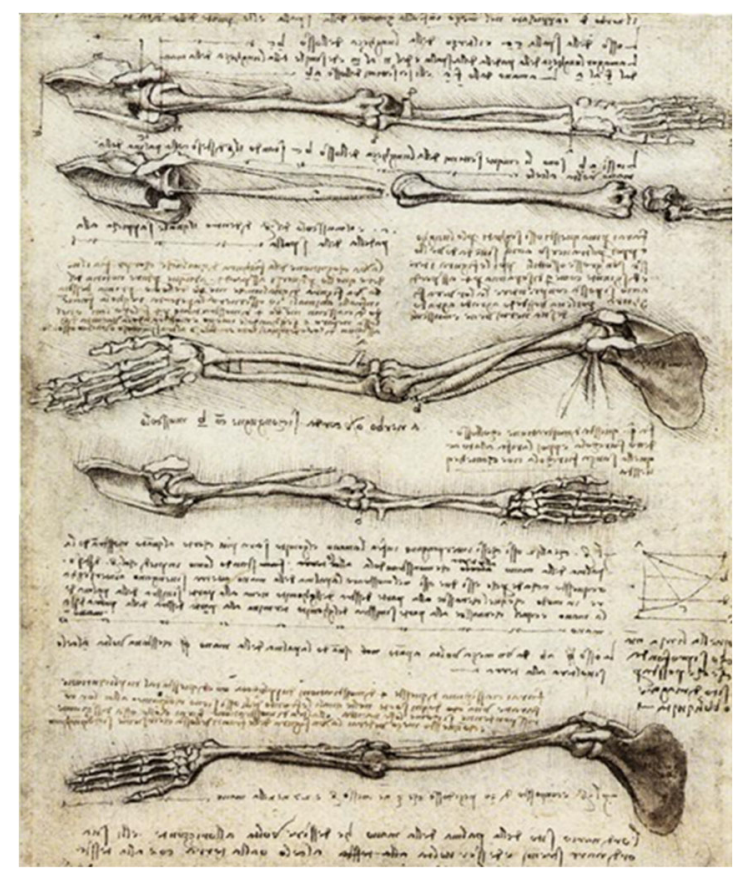

a) 


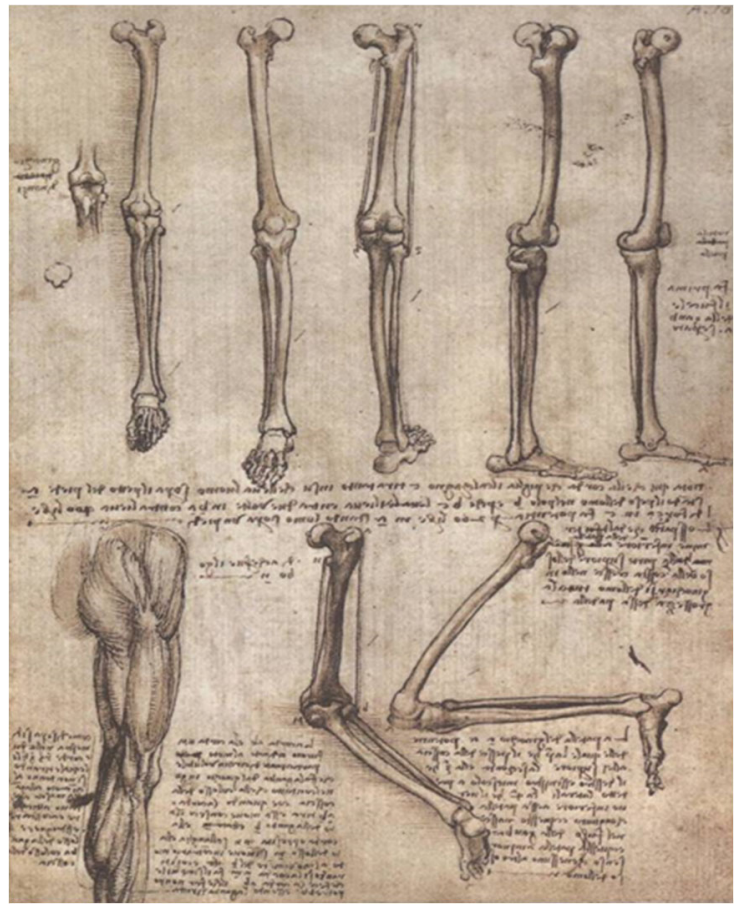

b)

Figura 9.1 a) Estudio de los movimientos de los huesos del brazo RL 19000 v; K/P 135 r (1508-1510) Royal Library, Windsor (Reino Unido).

(https://commons.wikimedia.org/wiki/File:Studies_of_the_Arm_showing_the Movements_made_by_the_Biceps.jpg), b) Huesos de la pierna es tres ángulos distintos y rodilla flexionada, Royal Library, Windsor RL 19008 r; K/P 140 r (1508-1510) (Reino Unido)

(https://commons.wikimedia.org/wiki/File:Leonard_de_Vinci__Anatomie_des_os_de_la_jambe.jpg).

La analogía es representada mediante la sustitución de la función del músculo por una cuerda, tal como se ve en los huesos de la pierna oblicua de la parte baja central del manuscrito anterior, es decir, utiliza una estructura de hilos para mostrar la acción de los músculos y tendones. En los manuscritos que se detallan a continuación, Leonardo analiza los movimientos del brazo humano y el esfuerzo que este requiere, lo dibuja y genera su analogía mediante un mecanismo artificial que haga el mismo movimiento.

Tanto el mecanismo del Códice de Madrid I, f. 90 v, de la Biblioteca Nacional de España (Da Vinci, 1490-1505), donde asimila su analogía 
de un brazo humano y el Manuscrito $\mathrm{H}$ f. 43v-44r del Instituto de Francia (Paris) (Da Vinci, 1487-1492), donde grafía como conseguir el movimiento mecánicamente, representados en la Figura 9.1, se supone que fueron utilizados en la construcción de su proyecto del "Autómata" o "Caballero Mecánico" (véase apartado 9.5). Aunque también hay otros manuscritos sobre el mismo en el Códice Atlántico de la Biblioteca Ambrosiana de Milán, folios 519 r; 1077 r; 1021 r y 1021 v (Da Vinci, 1478-1518), donde hay detalles de engranajes, esqueleto o estructura, y articulaciones.

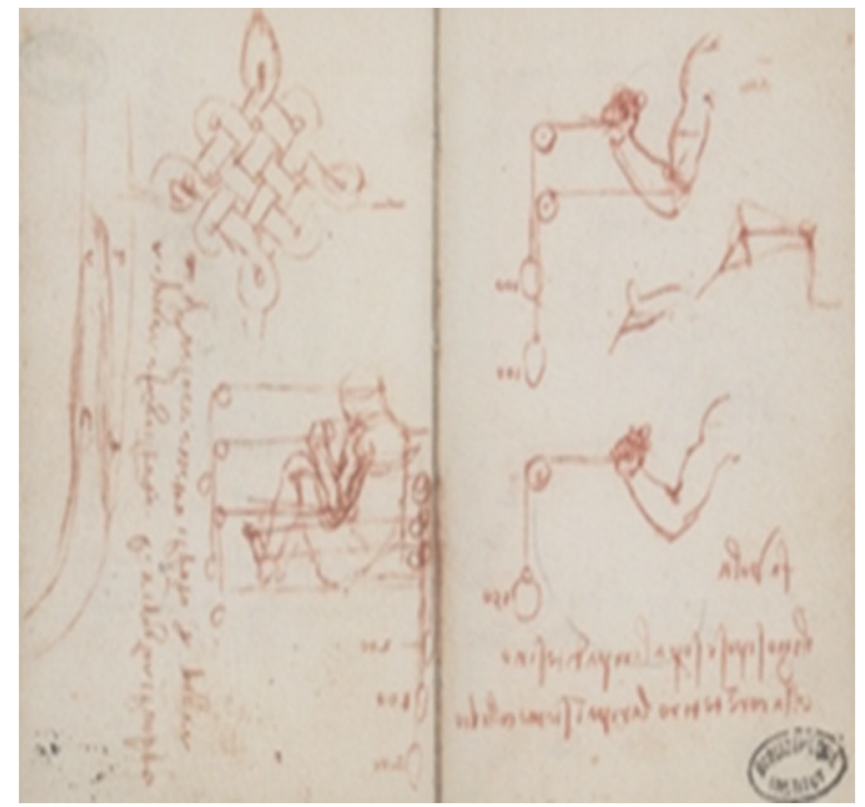

a) 


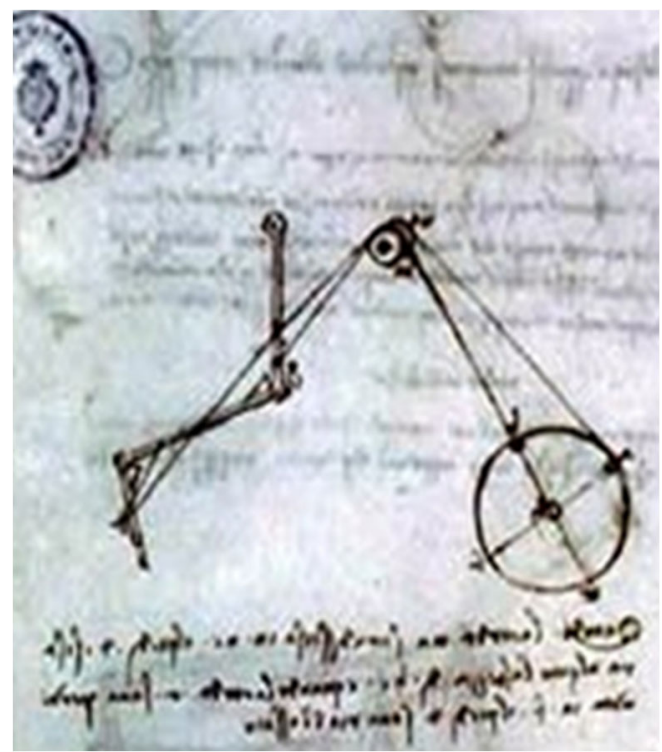

b)

Figura 9.2 a) Manuscrito H, f. 43v-44r del Instituto de Francia (París). ("https://brunelleschi.imss.fi.it/genscheda.asp?appl=LIR\&xsl=paginamanoscr itto\&chiave=100936"chiave=100936), b) Códice de Madrid I, f. 90 v, de la Biblioteca Nacional de España (http://leonardo.bne.es/index.html).

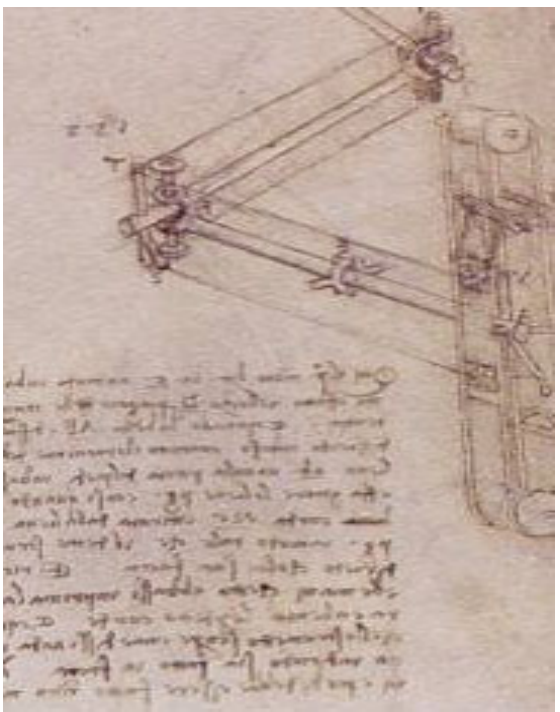

a) 


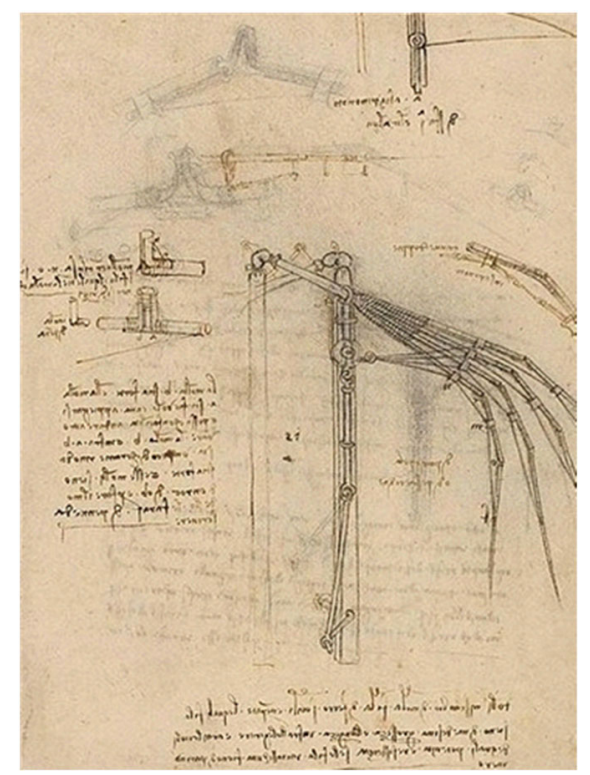

b)

Figura 9.3 a) Estudio de mecanismos para ala mecánica para planeador, realizado entre 1505-1506. Códice Atlántico 934r

(https://commons.wikimedia.org/wiki/File:Codex_Atlanticus_-_000R-

934.jpg?uselang=es-formal 934r), b) Estudio de Ala móvil (1495), Códice Atlantico 844r (https://commons.wikimedia.org/wiki/File:Codex_Atlanticus__000R-844.jpg).

Para comprobar el funcionamiento de su diseño, Leonardo proyecta experimentar un "ala batiente" construida mediante telas tupidas y nervios, con forma análoga a la de un ala de murciélago. Esta debería ensamblarse en el límite de un precipicio, conectada a un contrapeso en su parte baja con una carga equivalente al peso de un hombre, y este sistema estructural estaría unido a una palanca accionada por un ser humano, con el fin de ver que el movimiento de la palanca accionaría hacia abajo al ala artificial, permitiendo observar si este esfuerzo sería capaz de elevar el contrapeso que simulaba el peso de la persona conductora.

Esto lo plasma hacia 1483-84 en el Manuscrito B, folio $88 \mathrm{v}$ del Instituto de Francia (París), existiendo una maqueta del citado experimento en el Museo de la Ciencia y Tecnología de Milán (http://www.museoscienza.org/). 


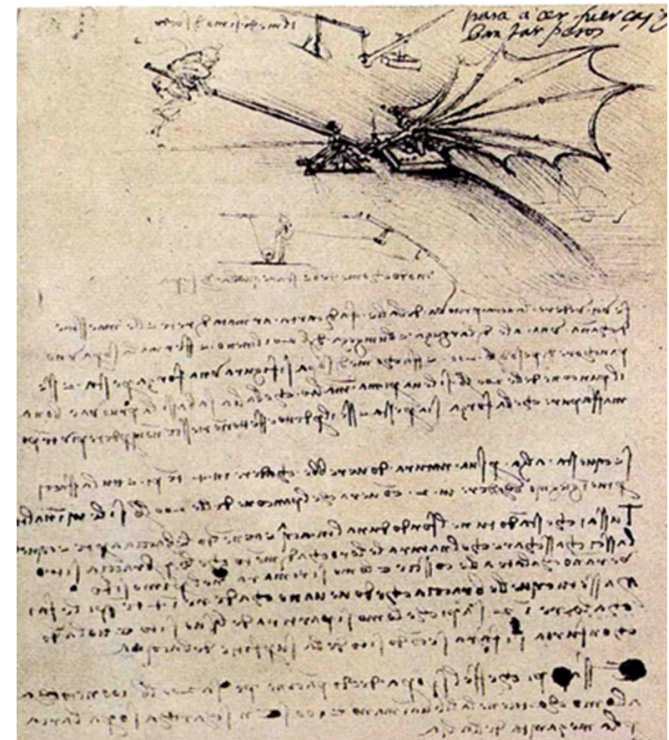

a)

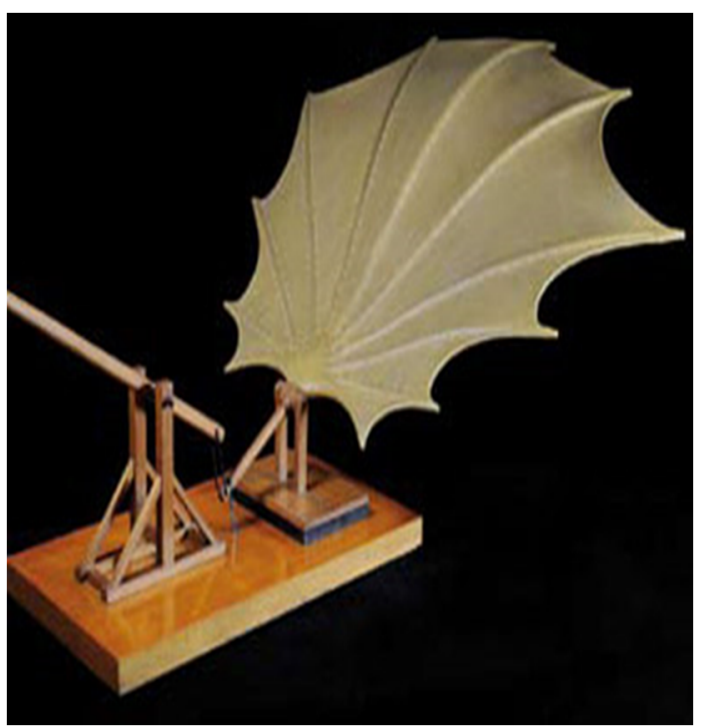

b)

Figura 9.4 a) Estudio de "Ala Batiente" movida por fuerza humana (1483-8), Manuscrito B, $88 \mathrm{v}$ del Instituto de Francia (Paris).

(https://commons.wikimedia.org/wiki/File:Codex_on_the_Flight_of_Birds.jpg) b) Maqueta del ensayo de ala batiente del Museo de Ciencia y Tecnología de Milán (www.museoscienza.org/). 


\subsection{El ornitóptero}

Leonardo pretendía hacer volar al hombre, y realizó estudios y prototipos de máquinas (batientes, planeadoras, de hélice, etc.) casi hasta el final de sus días; y para ello utilizó varias analogías asimilando las alas de sus prototipos a las de sus detallados "estudios sobre el vuelo de los pájaros" existentes en el Códice de Turín, así como a la de los murciélagos. Parte de sus "estudios para la máquina voladora" (1493-1495) están en el Códice Atlántico en los folios 70 b r y 846 v, de la Biblioteca Ambrosiana de Milán.

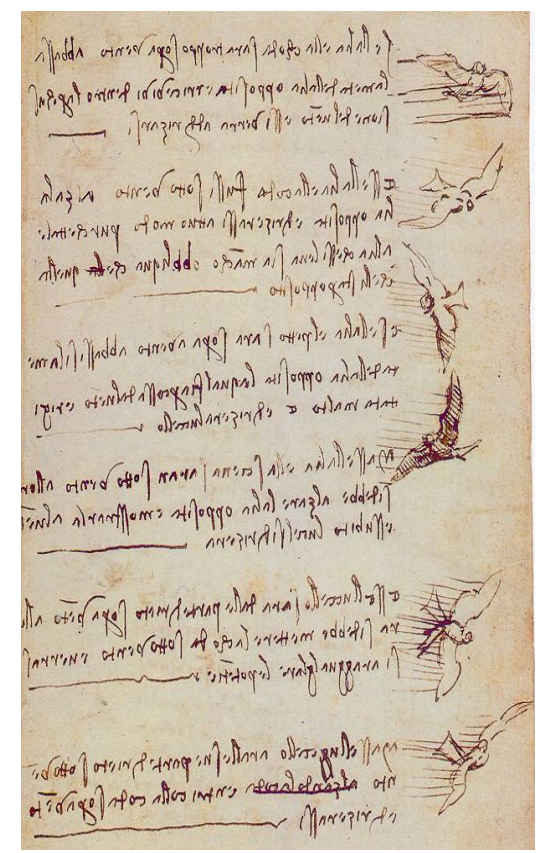

a)

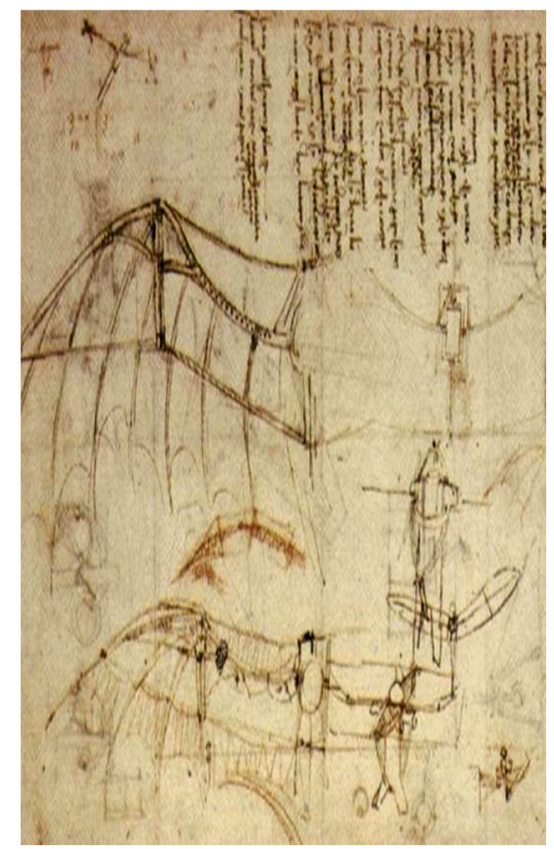

b) 


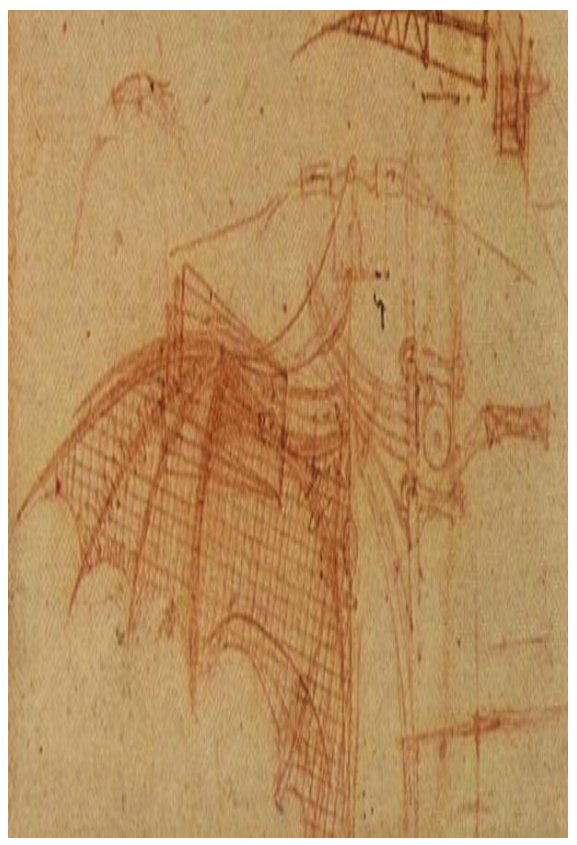

c)

Figura 9.5 a) Estudio de las maniobras de equilibrio de los pájaros. Códice del Vuelo folio 8r. Turín

(https://commons.wikimedia.org/wiki/File:Codice_Volo_08R_mod.jpg), b) y

c) Estudios para la máquina voladora (1493-1495) Códice Átlántico folios

$70 b$ r y 846 v. Biblioteca Ambrosiana de Milán

(https://commons.wikimedia.org/wiki/File:Codex_Atlanticus_-_000R-70.jpg, y https://commons.wikimedia.org/wiki/File:Leonardo_Design_for_a_Flying_Ma chine,_C._1505.jpg).

La analogía con estos últimos animales es coincidente con el diseño de su "ornitóptero" como se aprecia en una de las maquetas de la Exposición sobre Leonardo del Palacio de Congresos y Exposiciones de Castilla y León, emplazado en Salamanca en julio de 2011. 


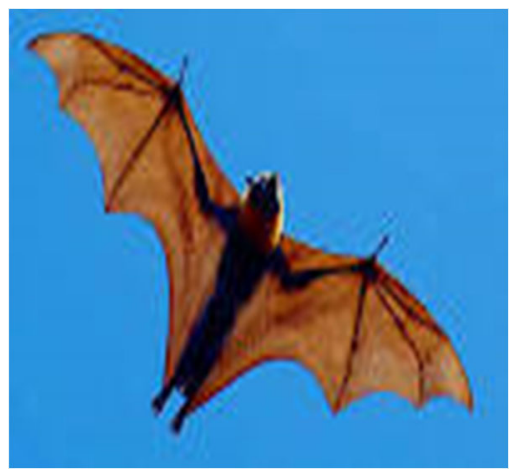

a)

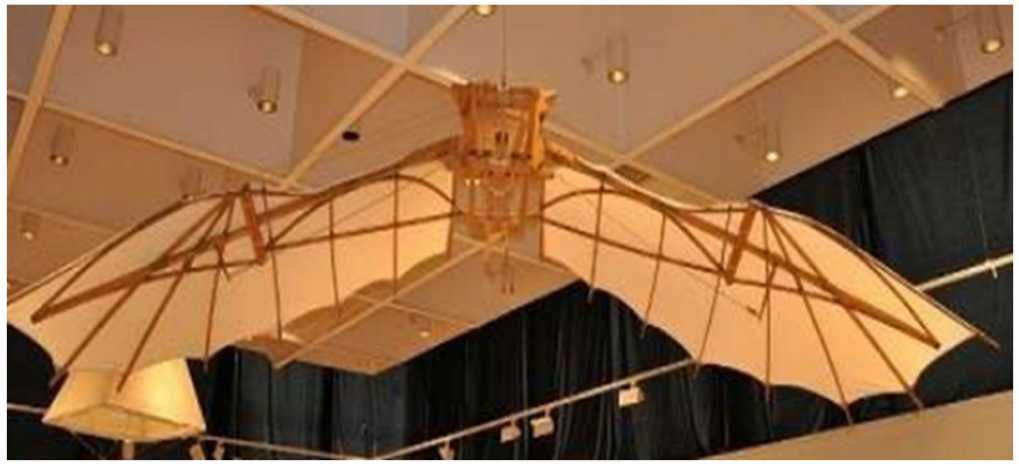

b)

Figura 9.6 a) Imagen del murciélago zorro en vuelo, b) Maqueta del Ornitóptero (www.portalplanetasedna.com.ar/davinci).

En Inglaterra, en 16 de diciembre de 2003, se hizo una reconstrucción del planeador de Leonardo por los constructores de aviones y aeromodelistas Steve Robert y Martim Kim, utilizando los planos de Leonardo y materiales similares a los por él especificados. Añadiéndole un arnés de cintura, la experimentada piloto de planeadores Judi Leden, voló a una altura de $15 \mathrm{~m}$, una distancia de $91 \mathrm{~m}$, lo que supone una distancia mucho mayor que la que hicieron los hermanos Wright en su primer intento. (Kemp, 2006).

\subsection{La cometa o ala delta}

También estudió el vuelo de las cometas para realizar un posible vuelo a vela (especie de ala delta actual). Sería una estructura para planear, capaz de ser dirigida modificando el centro de gravedad del cuerpo. 
Utiliza la analogía de la forma con una pluma de ave, que permanece en el aire con facilidad, y lo plasma en el Códice I de Madrid.

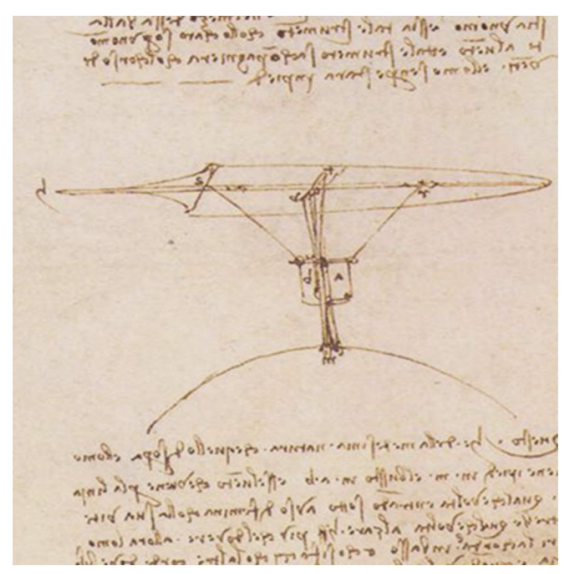

a)

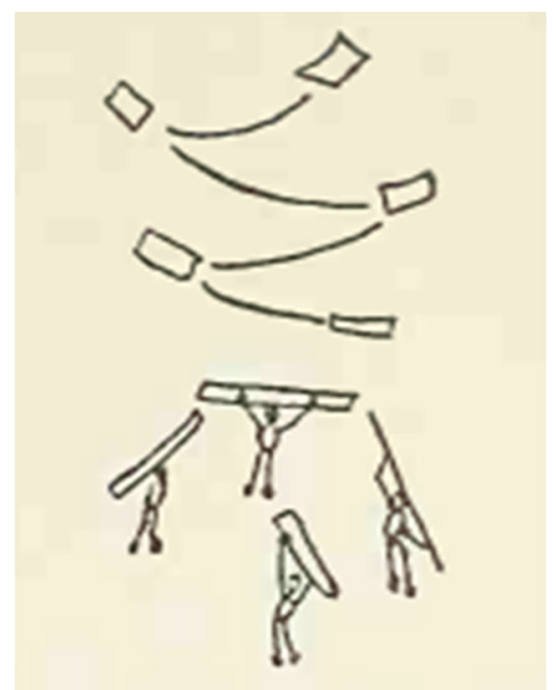

b)

Figura 9.7 a) Estudios sobre cometas dirigida desde tierra mediante cables. Manuscrito I de Madrid, f. 64 r. (http://leonardo.bne.es/index.html), b) Dibujo de su Cuaderno de Notas representando el descenso suave de la cometa (Richter, 2008)

"https://commons.wikimedia.org/wiki/File:Спуск_на_землю_сухим_листком .jpg"Спуск_на_землю_сухим_листком.jpg). 
En su Cuaderno de Notas dibuja la manera adecuada de moverse por el posible piloto, balanceándose para bajar con suavidad. La modernidad de la idea es asombrosa. En Inglaterra, se llevó a cabo una primera reconstrucción de esta cometa o ala delta en 1993, con la que se realizaron algunos intentos de vuelo afortunados. (Antoccia et al., 2003).

\subsection{Los autómatas}

El uso de analogías también fue un arma utilizada por Leonardo en sus proyectos de robotización. Es conocido que, al menos, generó un robot de "León mecánico" (1515-16), para el rey de Francia Francisco I (Cognac, 1494 - Rambouillet, 1547), que era capaz de moverse unos pasos, levantarse y abrir su pecho saliendo del mismo una "flor de lis" (símbolo de la casa real francesa), así como un "caballero mecánico" (1495) para el Duque de Milán, capaz de mover los brazos y piernas, así como emitir sonidos similares al habla humana.

Para la construcción de estos dispositivos resultaron fundamentales los estudios sobre biomecánica mencionados en anteriores apartados. Junto al conocimiento de los músculos y las articulaciones (Figuras 9.1 y 9.2), sus especiales conocimientos de mecánica y su formación polivalente facilitó la capacidad de diseñar los robots antes citados, en una época en la que ello era desconocido. Ambos robots funcionaban accionados por muelles resortes, que se cargaban previamente, como se hacía con el mecanismo de un reloj de cuerda.

En el Instituto y Museo de Historia de la Ciencia de Florencia existe un prototipo del "Caballero Mecánico", y en el Museo Leonardo 3 de Milán existe otro prototipo del "León Mecánico", que fue creado bajo la dirección del académico e investigador italiano, Mario Taddei (Bolonia 1972), director de este último museo. 


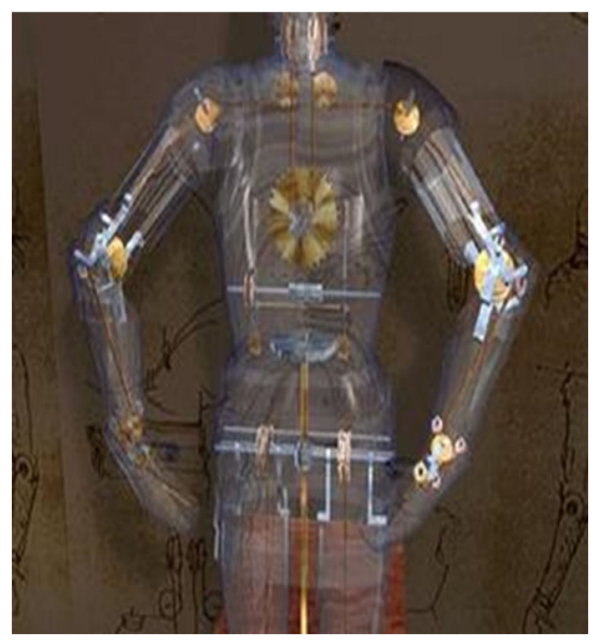

a)

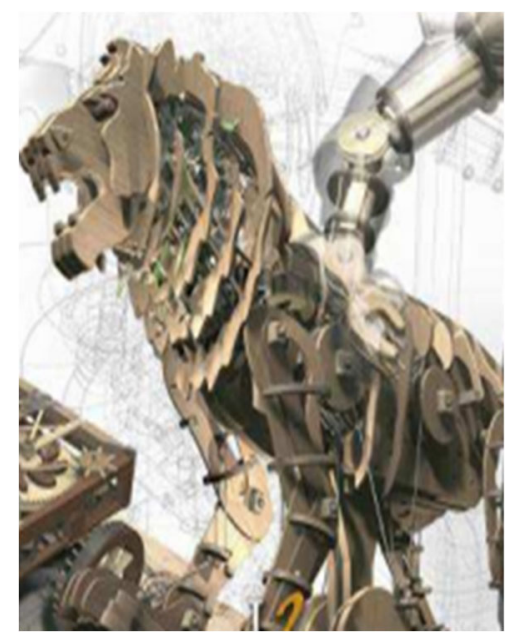

b)

Figura 9.8 a) Maqueta del Robot "Caballero Mecánico" del museo de Historia de la Ciencia de Florencia (www.imss.fi.it), b) Maqueta del robot de "León Mecánico" realizado para el Museo "Leonardo3" de Milán (www.leonardo3.net).

\subsection{Las aletas palmeadas}

En el año 1500 Leonardo se pone al servicio de la Serenísima República de Venecia para diseñarles defensas de carácter naval contra una posible invasión turca. Así diseña la primera escafandra conocida, un buzo, un salvavidas, aletas palmeadas para incrementar el rendimiento en la natación, un sumergible, y hasta una curiosa manera de caminar sobre las aguas.

En concreto las aletas palmeadas son una clara analogía con la naturaleza, asimilables a las patas de una rana o de un pato. Las dibuja para colocarlas como un guante en el Manuscrito B folio $81 \mathrm{v}$, del Instituto de Francia (París). 


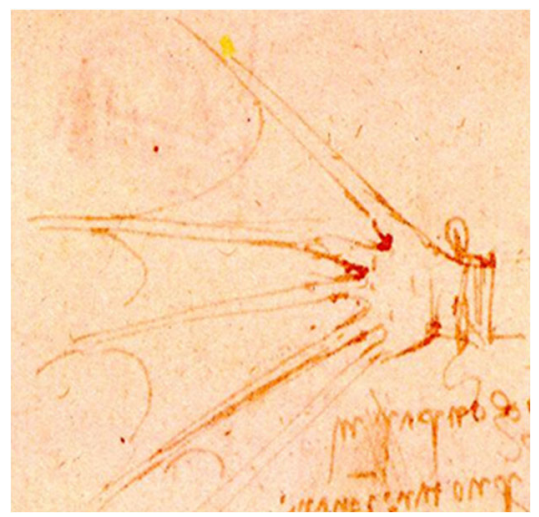

a)

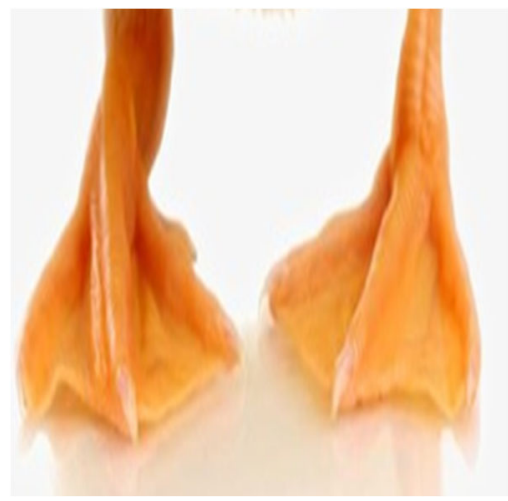

b)

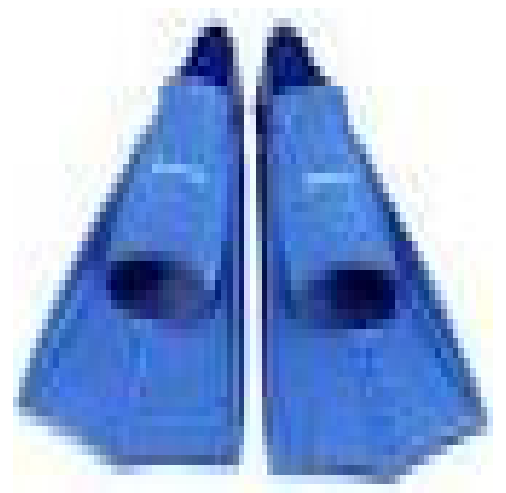

c)

Figura 9.9 a) Guante aleta para el agua nadar en el agua, Manuscrito B, folio $81 \mathrm{v}$. Instituto de Francia

(https://commons.wikimedia.org/wiki/File:Leonardo_da_Vinci_-_19-

554103.jpg), b) Patas palmeadas de un pato doméstico, c) Aletas de buzo(www.aqua-zone.com).

\subsection{La justificación del crecimiento de los árboles}

Leonardo, qué diseccionó más de 30 cadáveres humanos a lo largo de su vida, estudió la ramificación de los canales arteriales, y ello lo asemeja (analógicamente) a los tallos de las plantas. Si el volumen de fluido que atraviesa un canal principal para llegar a su destino debe hacerlo cruzando los múltiples ramales en los que se divide el canal original, según él, el total de la suma de las secciones transversales en cada nivel o etapa de la ramificación debe ser la misma, y esta 
obviamente debe coincidir con el área del canal principal del que se derivan los demás.

$<<$ El área total de todas las secciones transversales de los ramales de cada nivel, definidos como los arcos sucesivos de un arco centrado en algún punto del tronco principal, debe ser igual a la sección del árbol que atraviesa el centro horizontalmente. Esta ley era un caso particular, medible, de una ley de continuidad más general que Leonardo suponía válida en la Naturaleza: el volumen de un flujo en un tubo durante cierto tiempo es proporcional a la sección transversal del tubo >> (Martínez, 2010).

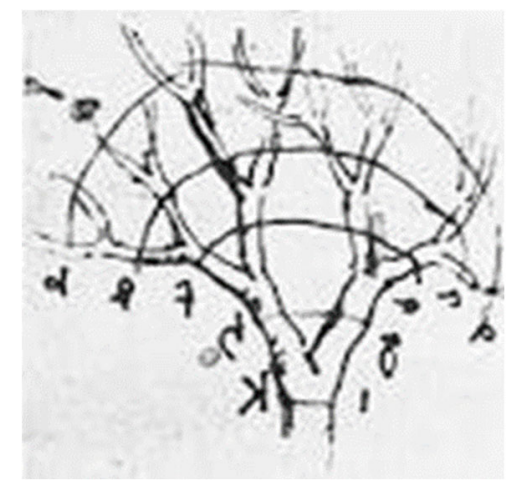

Figura 9.10. Estudio de las igualdades de las áreas de los cortes seccionales en el ramaje de un árbol. Manuscrito $\mathrm{M} \mathrm{f} 78 \mathrm{v}$ del Instituto de Francia (París)

(https://commons.wikimedia.org/wiki/File:Paris_Manuscript_M_Fol_78v.jpg).

En el Manuscrito $\mathrm{M} f 78 \mathrm{v}$ del Instituto de Francia (Paris) y en el Codex Urbina $346 r$ de la Biblioteca Vaticana hay estudios de las igualdades de las áreas de los cortes seccionales en el ramaje de un árbol, mostrando la manera y lugar del árbol, para medir y constatar la validez de su principio.

También descubrió que era posible determinar la edad de un árbol por la cantidad de anillos de la sección transversal del tronco, e investigó los patrones de disposición de las hojas y las ramas del tallo (los que actualmente se denomina estudio de la filotaxis) (Capra, 2008). 


\subsection{Preferencia por la forma ondulada}

En su Tratado de Pintura, así como en Manuscrito A folio $9 \mathrm{~b}$, del Instituto Francés de París, Leonardo, para explicar el desplazamiento del sonido utiliza argumentos de carácter analógico: $<<A$ igual que una piedra arrojada al agua se convierte en el centro desde donde se producen varios círculos, el sonido producido en el aire, se desplaza en círculos y llena las partes que lo rodean con un número infinito de imágenes de sí mismo, y todo aparece en todas y cada una de las partes $>$.

Y para explicar cómo transcurre el flujo del agua por un canal de sección transversal variable, utiliza la analogía mediante un modelo de fila de hombres que camina por una calle de ancho variable (Capra, 2008).

Era su voluntad llevar a cabo un Tratado del Agua que no pudo ver la luz, pero sí realizó numerosos estudios hidráulicos que están diseminados por varios de sus Códices. Para dibujar las corrientes de agua, los vórtices, etc., utilizó constantemente la línea ondulada como analogía representativa. En los Códices de la Royal Library de Windsor (Reino Unido) hay varios estudios hidráulicos.

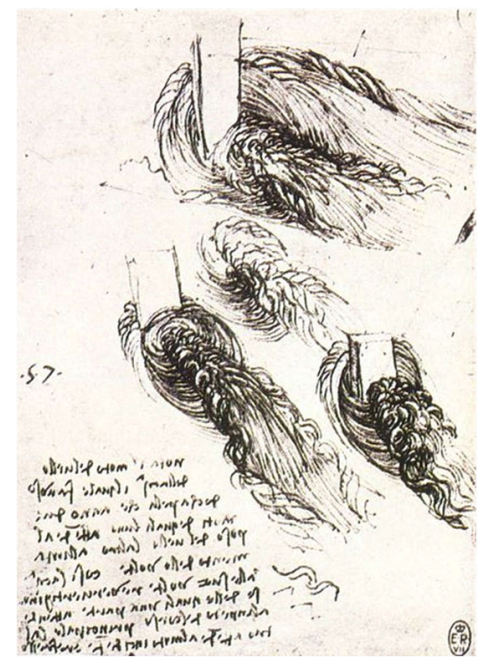




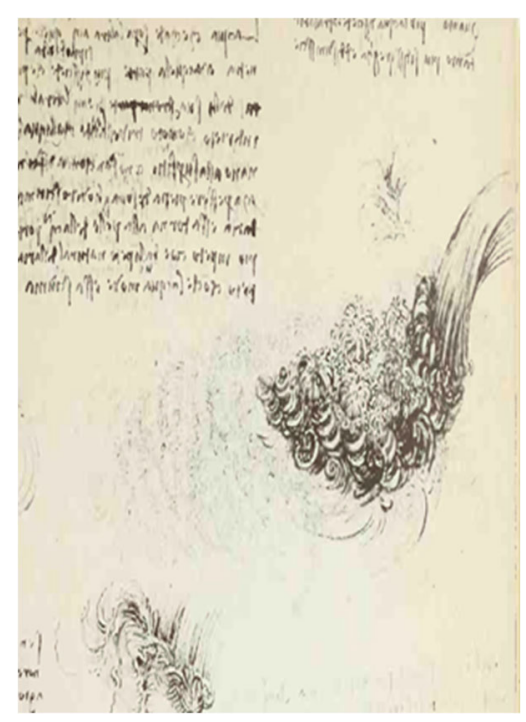

Figura 9.11 Estudio de flujos de agua (turbulencias), RL 12579r (15101513) y RL 12660r. (1509-1511) de la Royal Library, Windsor (https://commons.wikimedia.orgwikiFileLeonardo_da_vinci,_Study_of_water. jpg, y

https://commons.wikimedia.org/wiki/File:Leonardo_da_vinci,_Studies_of_wat er.jpg).

Su dominio de la forma ondulada, y su obsesión por esta forma natural, lo llevan a usar esta ondulación en sus pinturas constantemente, siendo famoso por su facilidad para expresar los rizos de los cabellos, como una analogía a las formas hidráulicas. El Retrato de Ginevra Benci y la cabeza de Cristo con espinas son ejemplos claros de ello. 


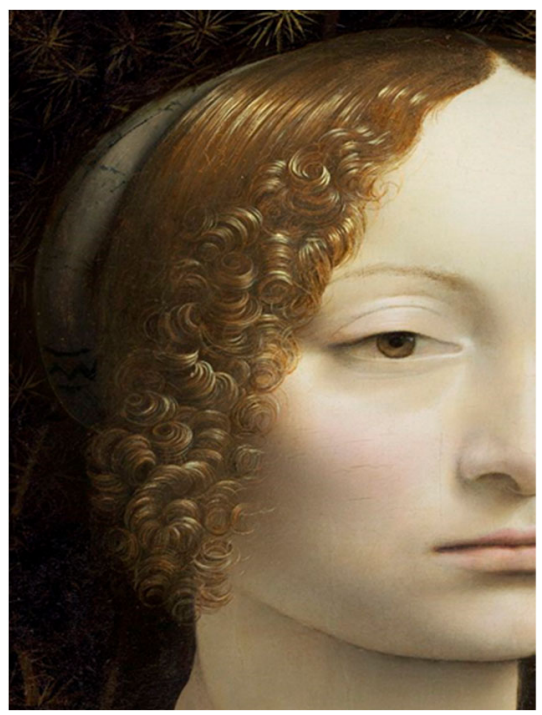

a)

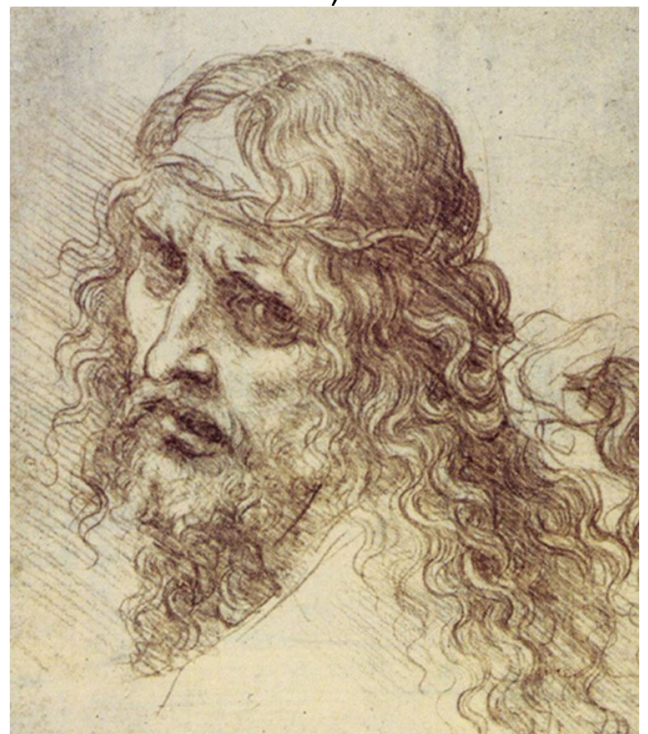

b)

Figura 9.12 a) Detalle de mirada y cabello de Ginevra Benci (1474-76) (https://commons.wikimedia.org/wiki/File:Leonardo_da_Vinci__Ginevra_de\%27_Benci_-_Google_Art_Project.jpg), b) Cabezza de Cristo con espinas. Academia de Venecia

(https://commons.wikimedia.org/wiki/File:Vinci,_Leonardo_Da_-

_Christ_Figure_-_C._1490_-_1495.jpg). 
En la Colección Windsor (1513-1515) en el Reino Unido se conservan diez dibujos en los que Leonardo intenta plasmar la visión y las consecuencias catastróficas del Diluvio. Es conocido que, en 1513 en los Alpes, cerca de la ciudad suiza de Bellinzona muy próxima a la frontera italiana, se produjeron unas intensas lluvias durante muchos días que produjeron grandes derrumbamientos y destruyeron varias poblaciones. Para manifestarlo, Leonardo recurre de nuevo a otra analogía natural a la forma ondulada que tanto le gustaba, asimilándolo a "olas de gran fiereza", con miras a causar fascinación y plasmar el poder destructivo de las aguas.

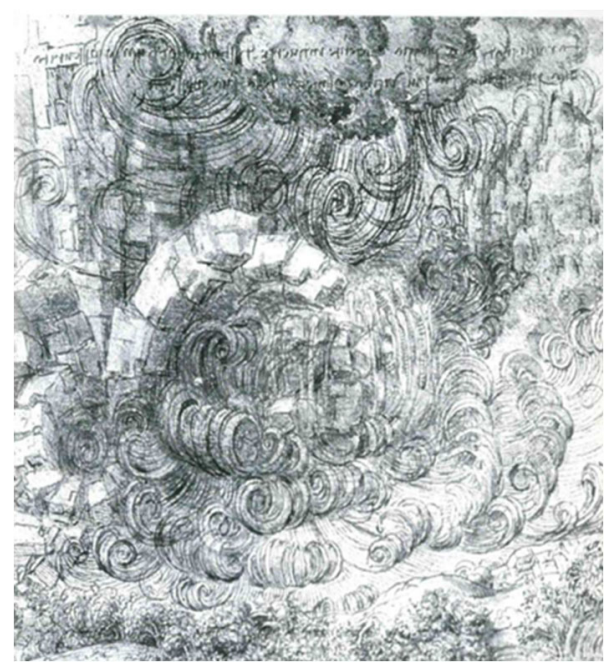




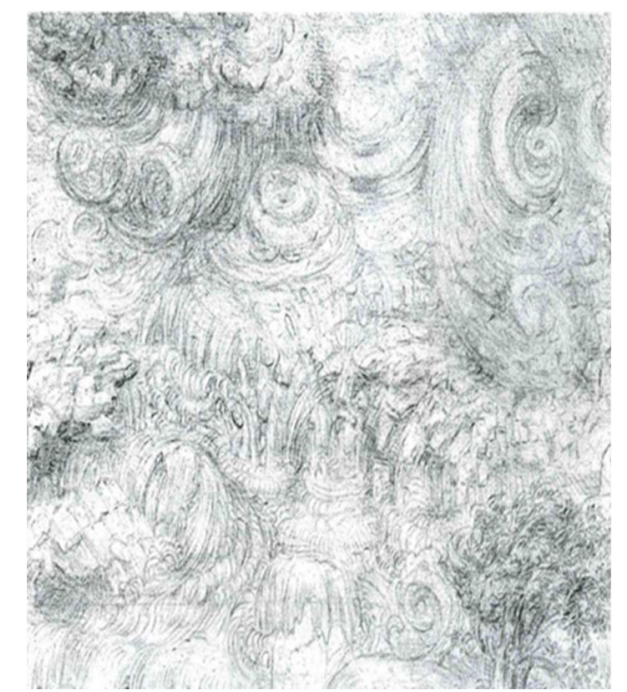

Figura 9.13 Estudio de Diluvio, (1513-1518) RL1 2380 Royal Library, Windsor, (Reino Unido) y Estudio de tormenta, remolinos y aguacero, (15081511) RL 12337r Royal Library, Windsor, (Reino Unido) (https://commons.wikimedia.org/wiki/File:Leonardo_da_vinci,_Natural_disast er.jpg y https://commons.wikimedia.org/wiki/File:Wizja_potopu.jpg).

\subsection{La sala delle asse}

Leonardo, en su primera y más larga estancia en Milán (1481-1499), estuvo al servicio de Ludovico Sforza, "el Moro", (Vigevano 1452Loches 1508) Duque de Milán, con multitud de funciones tanto artísticas como técnicas, y sobre 1498 realizó la decoración de varias salas del Castillo de los Sforza, entre ellas y la Sala delle Asse, uno de los salones principales del castillo, destinado a bailes, fiestas, etc.

Leonardo no va a utilizar ni ángeles, ni dioses, ni cielos, tan utilizados en la decoración de salas de palacios y castillos entonces. Asimila las columnas laterales a los troncos del árbol, mientras que el techo es un sinfín de hojas y ramas entrecruzadas con una hábil analogía hacia la Naturaleza, que tanto le gusta, pero al mismo tiempo una alegoría hacia la familia de su mentor Ludovico, colocando en el techo los emblemas de la familia.

$<<$ Leonardo, conocedor de que la morera hacía alusión al conocido apelativo del príncipe "il Moro" (en italiano significa tanto "Moro" como "morera"), y que además tiene fama de ser un árbol sabio y prudente, 
pues florece lentamente y su fruto madura con rapidez, lo que era conocido como símbolo de buen gobierno>> (Capra, 2008).

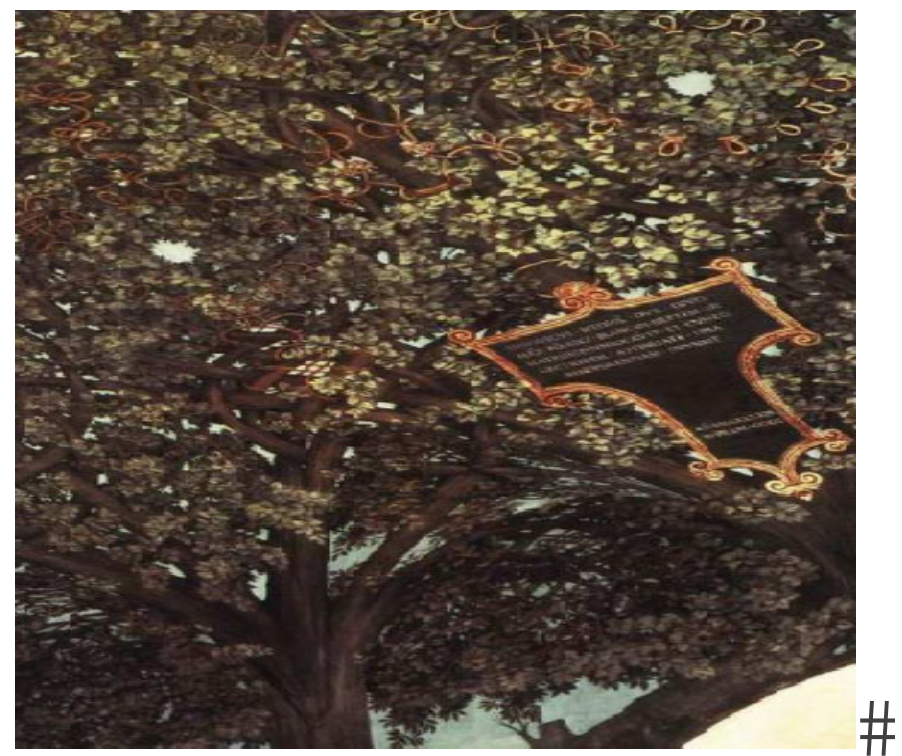

Figura 9.14 Decoración de Leonardo de la Sala delle Asse, del castillo Sforcesco de Milán (https://commons.wikimedia.org/wiki/File:Leonardo_Sala_delle_Asse_detail.j $\mathrm{pg})$.

\subsection{Conclusiones}

Una buena manera de generar soluciones o creaciones nuevas es utilizar las "analogías" mediante el análisis y abstracción de elementos existentes, como animales, objetos, etc. y aplicarlo a los productos o elementos buscados. Generalmente se encontrarán formas o funciones parecidas que podrán ayudar en el adelanto creativo.

$<<$ Con un enfoque globalizador en que la analogía y las matemáticas permitían transitar entre el funcionamiento de máquinas, organismos vivos y las razones de los fenómenos naturales, Leonardo hizo de la geometría y de la visión sus herramientas principales para explicar el mundo >> (Martínez, 2010).

$<<$ Para Leonardo, la analogía no era sencillamente una herramienta estratégica en la argumentación, sino también una expresión de la fundamental naturaleza común tras la organización de todas las cosas. 
Así pues, si se contaba con una explicación satisfactoria para algún fenómeno y podía observarse que otro fenómeno compartía sus patrones esenciales de comportamiento, podría estarse lo bastante seguro sobre las causas ("ragioni") que operaban en el segundo caso. Con base en esto podía concebirse la meta (de otro modo absurda) del entendimiento universal>> (Kemp, 2006).

En resumen, Leonardo, con formación multidisciplinar y pionero en casi todo, aprovecha su pensamiento analógico y su gran conocimiento de la naturaleza y de sus formas como uso creativo. Así, entrelaza conceptos, formas y estructuras existentes, y desde la complejidad, establece otros nuevos vínculos para crear soluciones que hasta entonces no existían. Maestro en las analogías, especificó en su Cuaderno de Notas: $<<$ La naturaleza benigna provee de manera que en cualquier parte halles algo que aprender>>.

\section{Referencias}

Antoccia, L., Chastel, A., Cianchi, M., Galluci, P., Laurenza, D., Papa, R., \& Pedretti, C. (2003). Atlas ilustrado de Leonardo Da Vinci. Arte y ciencia. Las máquinas. Susaeta Ediciones: Madrid.

Capra, F. (2008). La ciencia de Leonardo. Editorial Anagrama: Barcelona.

Da Vinci, L. (1478-1518). Códice de Atlántico. Milán. Biblioteca Ambrosiana. Obtenido de http://www.leonardoambrosiana.it/en/il-codice-atlantico/.

Da Vinci, L. (1478-1518). Códice de Windsor. Windsor. Royal Library of Windsor. Obtenido de https://www.royalcollection.org.uk/collection.

Da Vinci, L. (1487-1492). Códice de París. París. Institut de France. Obtenido de https://archive.org/details/lesmanuscritsdel00leonuoft.

Da Vinci, L. (1490-1505). Códice de Madrid. Biblioteca Nacional de España: Madrid. Obtenido de http://leonardo.bne.es/index.html.

Goicovic, G. (2015). Estrategias para el pensamiento complejo en estudiantes de pregrado basadas en el proceso creativo de Leonardo Da Vinci. Obtenido el 3 de marzo de 2018 de www.ceuarkos.com/Vision_docente/index.htm). 
Kemp, M. (2006). Leonardo. Fondo de Cultura Económica: México.

Martínez, E. (2010). En busca de la razón del mundo: Leonardo matemáticas y visualidad. Educación Matemática. vol 2, nº 1.

Orlando, E., Cinotti, M., \& Rizzati, M. (1974). Leonardo - Colección de Grandes Maestros del Arte. Editorial Marín: Barcelona.

Richter, I. A. (2008). Leonardo da Vinci notebooks. Oxford University Press. Obtenido el 2 de febrero de 2018 de www.aquazone.com.

www.imss.fi-it, obtenido el 10 de febrero de 2018.

www.leonardo3.net, obtenido el 3 de febrero de 2018.

www.museoscienza.org, obtenido el 2 de febrero de 2018

www.portalplanetasedna.com.ar/davinci, obtenido el 10 de febrero de 2018

http://www.museoscienza.org/, obtenido el 10 de febrero de 2018 


\title{
Capítulo 10 Leonardo da Vinci pionero del Ecodiseño
}

\author{
"Quien pueda acudir a la fuente (la naturaleza), no va al cántaro
}

(los textos de libros antiguos o clásicos)".

LEONARDO DA VINCI (Códice Atlántico f. 534v, Biblioteca

Ambrosiana de Milán).

\subsection{Introducción}

El "antropocentrismo tecnológico", dominante en el siglo XX y derivado de la antigua concepción cristiana según la cual Dios dio la Tierra al hombre para su sustento, y del "pienso luego existo" de los pensadores de la llustración, suponía que el ser humano estaba por encima del resto de seres vivos y preconizaba el "crecimiento ilimitado como única vía de bienestar", colocando a la Tierra al servicio del mismo, y considerando la Naturaleza como obstáculo al progreso.

Leonardo (1452 Vinci - 1519 Amboise), además de pintor y escultor, es conocido por sus investigaciones en un sinfín de campos, aunando naturalismo, botánica, anatomía, zoología, astronomía, filosofía, música, física, ingeniería, urbanismo y arquitectura; que fueron plasmadas en casi 7000 hojas repartidas en varios códices y manuscritos. Habiendo sido precursor en muchísimas disciplinas, no podía quedarse atrás en el respeto a la Naturaleza. Con ese espíritu escribe en uno de sus cuadernos de notas: <<nunca se producirá una invención más bella, ni más simple, ni más apropiada que las que hace la Naturaleza, porque en sus invenciones nada falta, ni nada es superfluo > (Richter, 1883). Mientras que en otro manifiesta $<<$ Llegará un día en que los hombres serán juzgados por la muerte de un animal como hoy se juzga el asesinato de un hombre>>, pensamiento que se adelanta a lo que hoy se conoce como "ecología profunda" que no sitúa a los seres humanos, ni a ninguna cosa, por encima del medio ambiente, y que ha sido liderada desde 1973 por el filósofo noruego Arne Nees (1912 Slemdal - 2009 Oslo) que creía que 
nuestro destino está unido al de la biosfera ya que somos parte de ella, y que defendía:

- La armonía del ser humano con el medio, nunca por encima o fuera de este.

- Una igualdad biocéntrica donde todos los ecosistemas tienen derecho a existir, independientemente de su grado de autodeterminación.

- Dando valor por igual a cada paisaje, a cada ser o a cada ecosistema, con una visión holística o de interconexión global, por la afección totalitaria entre ellos.

Leonardo fue hijo ilegitimo de Piero di Antonio da Vinci (Vinci 1426 Florencia 1504), notario de Florencia (que rápidamente se desinteresó de él, con miras a seguir su promoción laboral y social en Florencia) y de su criada Caterina di Meo Lippi (1427-1495 Cerreto Guido). Fue educado en Vinci, tanto en su niñez como adolescencia, por su abuelo paterno Antonio (1372-1468 Vinci), hombre culto y de hacienda acomodada, y por su tío Francesco (1436-1507 Vinci) que fue quien más le apreció a lo largo de su vida, y de hecho el único de la familia que, al no tener descendencia, le testó todos sus bienes. La pequeña ciudad de Vinci era entonces una comunidad rural, con riachuelos y el castillo conocido como Castello Guidi, cercana al río Arno, Todo ello facilitó que su formación inicial fuera del todo libre, abierta y vinculada a la naturaleza, sin ningún tipo de sesgo ni encorsetamiento. Su abuela paterna Lucía Zosi da Bacchareto (1392 Toia di Bacchereto 1470 Vinci) disponía de un apreciable patrimonio, que incluía un horno de cocción de cerámica artística, lo que facilitó su participación desde niño, tanto en dibujos, como en otras actividades artísticas, en las que empezó a destacar de manera precoz.

$<<$ Leonardo, de joven también intervenía personalmente en el proceso de obtención de aceite de nogal y en el entretejido de mimbres para hacer cestos >> (Nicholl, 2006). Su familia paterna lo envía a Florencia, con 17 años, como aprendiz a uno de los talleres artísticos más importantes, el de Andrea del Verrocchio (1435 Florencia - 1488 Venecia), donde aprende escultura, pintura y orfebrería. Allí, su apasionada preocupación por expresar la movilidad vital de la figura humana, le hace estudiar anatomía humana y de animales, pasión que no abandonará hasta el fin de sus días. A lo largo de su vida participó en la disección de más de 30 cadáveres, unas veces de manera legal en la Universidad de Pavía, y otras alegal en distintos hospitales y 
morgues de Milán y Roma. La fácil descomposición de los cuerpos obligaba a que trabajara velozmente, realizando observaciones anatómicas, generando dibujos y apuntes de músculos, nervios, venas, etc. como nadie antes. Movido por su gran curiosidad llevó a cabo descubrimientos como el número exacto de vértebras de la columna humana y su inclinación; o el "mesenterio", repliegue del peritoneo que mantiene en su posición los intestinos, uniéndolos a la pared posterior de la cavidad abdominal. Dejó plasmados sus resultados en los más de 600 dibujos de los Manuscritos de Anatomía de la Royal Collection Library de Windsor.

$<<$ A los 20 años ya aparece registrado en el Gremio San Lucas de Artistas de Florencia como pintor independiente. Su formación posterior ya fue en su mayoría autodidacta, apoyándose en lecturas de obras y discursos de eruditos de su época, como el profesor de la Universidad de Florencia y erudito humanista Giovanni Argirópulo (1415 Constantinopla-1487 Florencia) que influyó en sus ideas en cuanto a ética y física, así como en el aspecto científico y analítico de su filosofía y en su predilección por las ideas aristotélicas y su afición al empirismo >> (Nicholl, 2006).

También aprendió matemáticas con Paolo dal Pozzo Toscanelli (1397-1482 Florencia) matemático, astrónomo y cosmógrafo italiano, y profundizó en los libros de aritmética del matemático Piero Borgi (1424-1484 Venecia). Ello derivó en que solo admitiría como verdaderos métodos científicos la observación de la naturaleza y la experimentación. Pensaba que el conocimiento de los escritores antiguos tenía su utilidad como base, pero nunca como objetivo final; había que cuestionarlo todo y después pasarlo por la observación y experimentación.

\subsection{Objetivo}

El capítulo pretende demostrar mediante la descripción de facetas de la obra técnico-artística, y de la filosofía y forma de vida de Leonardo, que este ya pensaba con el mismo espíritu de lo que hoy se conoce como el Ecodiseño y el Desarrollo Sostenible. Añadiendo como ejemplos sus soluciones novedosas para diseños de nuevas ciudades, y su importante concepto sobre el agua como vehículo de la naturaleza. Así, ya el investigador en biología y ecología, profesor en varias universidades americanas y europeas, Fritjof Capra (1939 Viena), manifiesta en su libro "La Ciencia de Leonardo" que este <<trabajó con una 
actitud de aprecio y respeto por la naturaleza y en ello subyace una posición filosófica que no concibe a los seres humanos separados del resto del mundo vivo, sino más bien como fundamentalmente insertos en la comunidad total de la vida de la biosfera y en dependencia de ella>> (Capra, 2008).

\subsection{Copiando de la "maestra naturaleza" en su obra, filosofía y forma de vida.}

Leonardo siempre consideró que es en la naturaleza donde debe buscarse toda fuente de saber y conocimiento, y así lo hizo tanto para su quehacer diario como para su filosofía. Así, escribe en el Manuscrito H f.3v, existente en la Biblioteca del Instituto de Francia, Paris: $<<L a$ bondadosa naturaleza procede siempre de tal manera que en todo el universo siempre encontrarás cosas dignas de imitar". Mientras que en otro de sus cuadernos de notas manifiesta: "Verdaderamente el hombre es el rey de los animales, pues su brutalidad supera a la de estos > (Catalogue des manuscrits de la BnF, n.d.).

Es conocido como anécdota que al llegar a los mercados solía comprar los pájaros enjaulados a la venta y que, en el mismo momento de adquirirlos, procedía a liberarlos. (Kalb, 2019).

Leonardo también redactó fábulas, leyendas, alegorías y profecías, donde los protagonistas son elementos o fenómenos de la naturaleza, con intención educativa y ecológica. La mayoría de ellas están en el Códice Atlántico de la Biblioteca Ambrosiana de Milán (Da Vinci, 14781518) y en el Manuscrito H del Instituto de Francia de Paris (Da Vinci, 1478-1518). Así ocurre en su "Fábula de la piedra" escrita en el Cod. Atlántico f. 175 v,a: <<Una piedra puesta al descubierto por las aguas, de hermosa grandeza se elevaba por encima de un cierto lugar en el que había un delicioso bosquecillo, atravesado por un caminito pedregoso, en compañía de pequeñas hierbas y variadas flores. Viendo la gran cantidad de piedras que había en el camino le vino el deseo de dejarse hacer abajo diciendo: “¿Qué hago aquí con estar hierbas? Quiero vivir en compañía de mis hermanas que están alli". Se dejó caer entre las deseadas compañías y puso término a su recorrido. Al cabo de cierto tiempo empezó a percibir las ruedas de los carros, las pisadas de los caballos que le causaban un tormento continuo. Algunos la removían, otros la resquebrajaban, a veces estaba recubierta de lodo. Inútilmente recordaba el lugar en el que había gozado de la paz. Así ocurre a los que, de la vida solitaria y 
contemplativa, quieren pasar a vivir en las ciudades llenas de infinidad de males $>$.

Fruto de esa constante observación y experimentación de los fenómenos de la naturaleza, Leonardo realizó varios hallazgos y descubrimientos:

a) Al realizar estudios geológicos en los valles lombardos, con la aparición de fósiles en lo alto de las montañas, cuestionó la apreciación religiosa asentada en tales años de que el Diluvio Universal facilitó la llegada de especies de animales marinos a lo alto de las montañas, y preconizó que la Tierra es más antigua que las Sagradas Escrituras, y que eran las montañas las que se habían levantado sobre el mar al producirse cambios en la corteza de la Tierra.

b) Confirmó que los círculos existentes en los troncos cortados indican el número de sus años siendo pionero en reconocer que su espesor indica si el año correspondiente fue húmedo o seco (Capra, 2008), lo que más tarde se denominó "dendrocronología".

c) Llegó a entender, dibujar y explicar correctamente la manera en que las plantas despliegan sus formas en respuesta a la gravedad terrestre (crecimientos positivos hacia arriba o negativos) y que posteriormente se llamó "geotropismo".

d) También estudió el modo en que las plantas cambian su orientación en función de la luz del sol, que se denominó "fototropismo" (Pigem, n.d.).

e) Fue el primero en observar la disposición regular de las hojas sobre el tallo y justificarlo y describirlo, lo que posteriormente se denominó "filotaxis". Así escribe en su Tratado de la Pintura: $<<L a$ naturaleza ha dispuesto las hojas de las últimas ramas de muchas plantas de manera que la sexta hoja esté debajo de la primera, y así sucesivamente siempre que nada venga a oponerse a esta regla. Esto ha sido en procura de una doble utilidad: en primer lugar la rama y el fruto del año siguiente que nacen de la yema que está debajo en contacto con la inserción de una hoja, puede recibir el agua que baña esa rama y que desciende por ella para alimentar esa yema deteniendo sus gotas en la concavidad que forma la hoja; la segunda ventaja consiste en que naciendo de tal manera, las ramas del año siguiente no se cubren la una a la otra, puesto que nacen orientadas hacia cinco distintas direcciones, naciendo la sexta debajo de la primera, separadas por una gran distancia >>. 
Así lo confirma Carlo Pedretti al comentar la afición de Leonardo por el movimiento espiral, que le sirve para <<identificar la disposición de la ramas, fenómeno que le anima a descubrir la ley de la filotaxis, que en la Botánica moderna lleva su nombre>> (Antoccia et al., 2003). Igualmente, Capra hace constar con relación a ello: <<Investigó los patrones de disposición de las hojas y las ramas en torno al tallo, que es lo que los botánicos en la actualidad conocen como estudio de la filotaxis; y relacionó los modelos de ramificación con la actividad del humor de un árbol, extraordinaria intuición de los efectos de la actividad hormonal que solo llegó a conocerse en el siglo XX. Lo mismo que en tantos otros campos, el pensamiento científico de Leonardo transcendió ampliamente el de sus contemporáneos, al punto de constituirse en el primer gran teórico de la botánica >> (Capra, 2008).

La afición hacia la naturaleza le llevó a realizar dibujos excepcionales de animales y plantas (Figura 10.1 a) y b)) o incluso a diseñar como grabado para una de las opciones del emblema de su Academia la inscripción "Academia Leonardi Vinci" (hacia 1500), apoyándose en una asimilación de nudos o flores como alusión a la naturaleza (Figura 10.1 c)), y que existe en Biblioteca Ambrosiana de Milán (ref. 95096B).

Fue también, debido a su amor por los animales, de costumbres vegetarianas a lo largo de toda su vida.

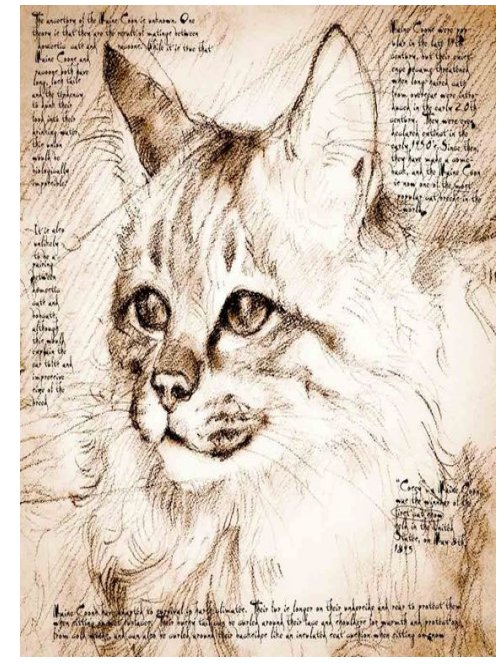

a)

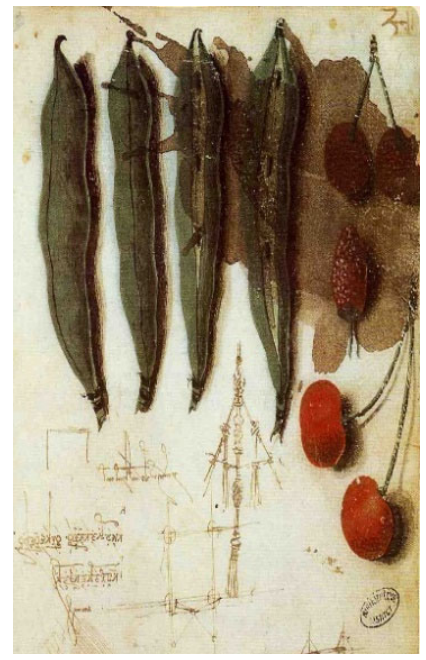

b) 


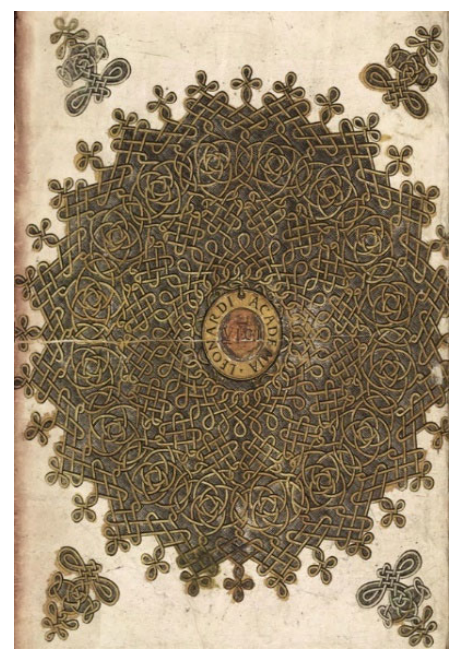

c)

Figura 10.1 a) Cabeza de gato. The Royal Collection, Windsor, b) Frutas y verduras coloreadas (1487-89) Manuscrito B, f $2 r$ Instituto de Francia (https://commons.wikimedia.org/wiki/File:Leonardo_da_vinci,_Fruit,_vegetab les_and_other_studies.jpg), c) Diseño para grabado de su "Academia Leonardi Vinci" (h. 1500), Biblioteca Ambrosiana de Milán (95096B) (https://commons.wikimedia.org/wiki/File:Leonardo-da-vinci-early-16th-centbodleian-library.jpg?uselang=es-formal).

\subsection{Diseños urbanísticos y constructivos con soluciones ecológicas}

\subsubsection{El primer proyecto de Milán, las "ciudades satélite"}

Leonardo estuvo al servicio del Duque de Milán Ludovico Sforza (1451 Vigevano - 1508 Loches) desde 1482 hasta 1499, actuando como ingeniero civil y militar. En 1484-1485 la ciudad sufrió una epidemia de peste que acabó con casi un tercio de su población. Ello provoca que el Duque piense en una ciudad nueva y Leonardo le proponga su "ciudad ideal", con unos criterios de organización racional, dinámica, funcional y ecológica, no solo a nivel urbanístico, sino también a nivel de estancia o dependencia.

En lugar de una clásica ampliación anexa a la vieja ciudad, proyecta 10 ciudades satélite separadas del Milán existente, para disminuir así el hacinamiento y la masificación del interior de las murallas. La 
morfología de toda ellas es semejante, con manzanas cuadradas, una gran plaza central y capacidad para unas 5.000 casas y 30.000 habitantes.

Propone, con sus conocimientos de arquitectura, urbanismo e hidráulica, soluciones nuevas de sanidad y salubridad, generando nuevos caminos y cursos de agua por dentro de cada nueva ciudad, que sirvieran de red de alcantarillado para evacuación de los sobrantes, y de vías de transporte. No distingue entre clases sociales sino entre las distintas infraestructuras a realizar. Las nuevas ciudades serían abiertas, sin amurallar, con disposición en retícula, manifestando que deben escogerse emplazamientos cerca de un gran río que facilite el agua a los canales (Figura 10.2 b) y c)) que discurrirían por ellas.

En cuanto a criterios urbanísticos, proyecta calles con dos niveles de circulación que recorrerían la ciudad (Figura 10.2 a)). La superior solo sería peatonal, abierta y soleada; y la inferior apta para personas, vehículos de carga de mercancías y animales, cerrada bajo arcos, que también accedería a los canales de tránsito. En este nivel inferior existirán agujeros para evacuación de agua a los canales, lo que equivale a la primera solución existente que se asimile a las redes de alcantarillado actuales. $Y$ en el nivel subterráneo establece los establos y lugares pestilentes, que tendrán ventilación natural; y también proyecta aseos públicos.

Establece una fórmula para la anchura mínima de una calle: Ancho calle $=\sum$ altura de casas del mayor edificio de la calle $/ \mathrm{n}^{\circ}$ casas del edificio. Lo que viene a resultar que, en cualquier caso, el ancho de la calle será igual o mayor que el del edificio medio de ella. Medida innovadora que no reaparecerá hasta los "higienistas" de finales del siglo XIX y principios del XX, y que resulta del todo saludable para la vida humana y el desarrollo sostenible. 


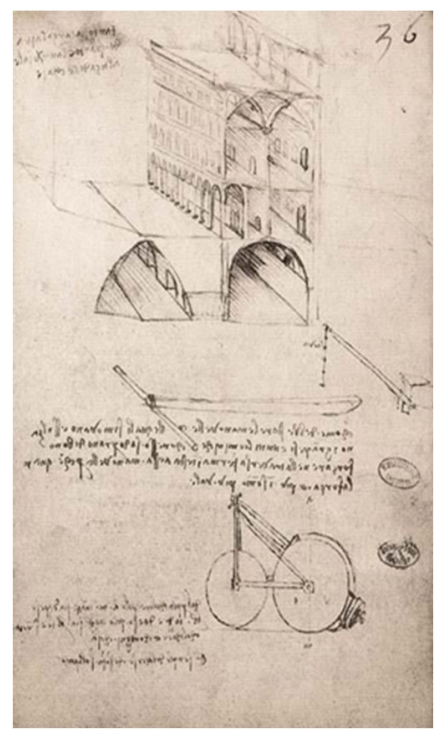

a)

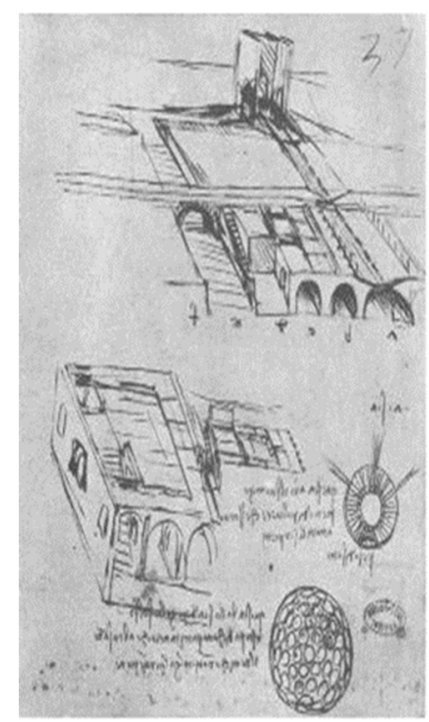

b)

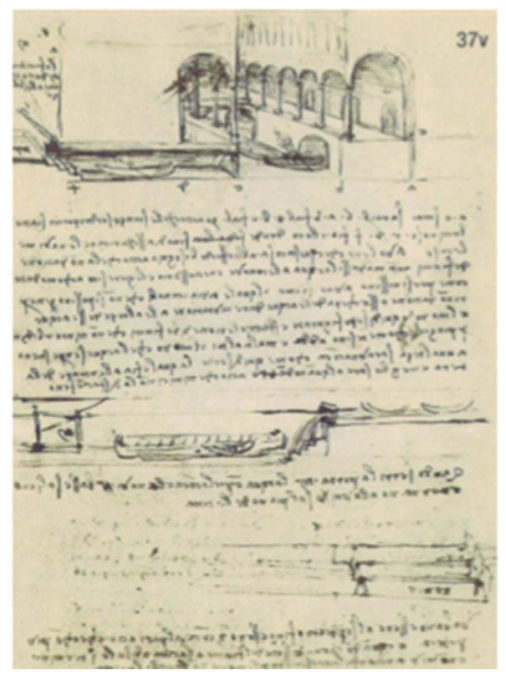

c)

Figura 10.2 Estudios urbanísticos y de canalizaciones. Manuscrito B, f. 36r, $37 r$ y $37 v$, Instituto de Francia, París

(https://commons.wikimedia.org/wiki/File:Leonardo_da_Vinci_-_19554013.jpg), b)

(https://commons.wikimedia.org/wiki/File:Leonardo_da_Vinci_-_19554015.jpg), c)

(https://commons.wikimedia.org/wiki/File:Leonardo_da_Vinci_-_19554016.jpg). 
También proyecta los canales en retícula y con dársenas y aliviaderos en los límites de la ciudad, como defensa ante las posibles crecidas del agua de los canales, y para regular el nivel de los mismos.

En cuanto a las construcciones o edificios, estarán separados en su contorno; las viviendas se darán la espalda entre sí y tendrán la parte trasera con puerta accesible desde la calle inferior para la entrada de provisiones. Para las viviendas unifamiliares proyecta una sola puerta de acceso para el control de entrada y dependencias independientes para el amo, la esposa (con vestíbulo propio), la familia, los sirvientes, la cocina, la despensa, y un vestíbulo general. Un jardín comunicado con la dependencia de la esposa y con acceso a los establos. La cocina estará en contacto con la mantequería y limpieza de vajillas. Criterios de características ecológicas y de salubridad que se asemejan incluso a las soluciones constructivas de hoy en día, denominadas adosados y unifamiliares de edificación abierta.

Para los bloques de viviendas proyecta escaleras dobles en la parte central, con acceso independiente desde cada planta (Figura 10.3 a)) y que llegan hasta el sótano. Los pórticos de las viviendas tendrán también salida a los canales.

El proyecto de su "ciudad nueva" para Milán se encuentra en el Manuscrito B del Instituto de Francia, Paris. Y una simulación de la misma en una maqueta del Museo Nacional de Ciencia y Tecnología de Milán (http://www.museoscienza.org/english/ visiting/leonardo-parade/) (Figura 10.3 b)). Quizás el elevado coste de la inversión hizo que el Duque de Milán no llevara adelante el proyecto y este no fuera ejecutado. 


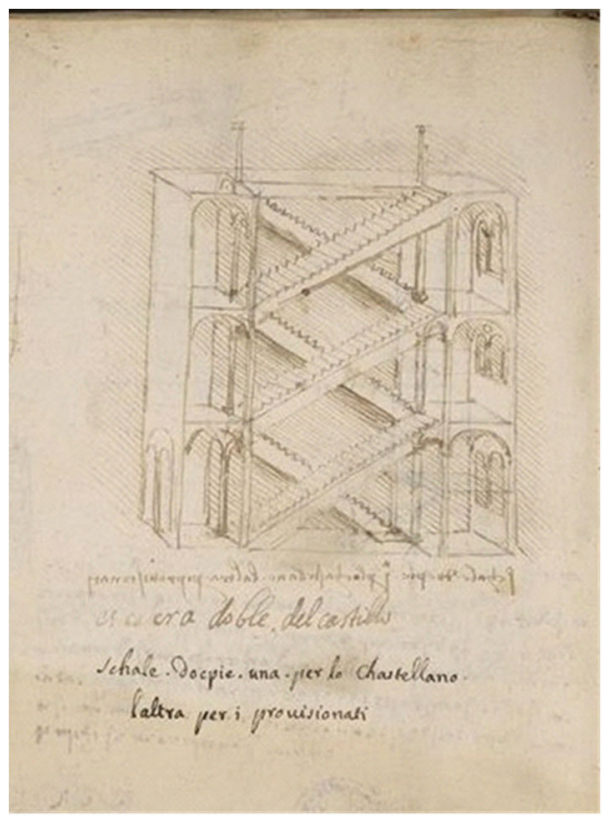

a)

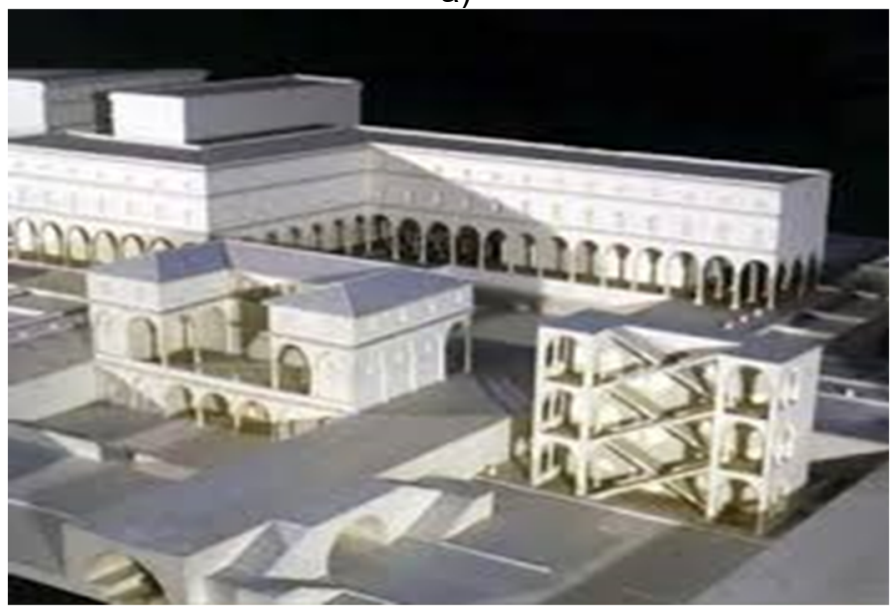

b)

Figura 10.3 a) Original escalera de dos entradas para bloques de viviendas. Manuscrito B f. 66v. Instituto Nacional de Francia, París (https://commons.wikimedia.org/wiki/File:Leonardo_da_Vinci_-_19554079.jpg), b) Maqueta de la Ciudad ideal del Museo Nazionale della

Scienza e della Tecnologia "Leonardo da Vinci", Milán (http://www.museoscienza.org/english/visiting/leonardo-parade/). 
Los criterios de diseño de Leonardo, tanto urbanísticos como edificatorios y de dotación de infraestructuras, ya tienen visos ecológicos, proyectando ciudades pequeñas, anchas plazas y calles, edificios de poca altura que no superan el ancho de sus calles, redes de saneamiento, etc.

\subsubsection{El segundo proyecto de Milán. La expansión geométrica}

Sobre 1493, Leonardo acomete la redacción de un segundo proyecto, menos ambicioso que el anterior, para expansión y reconstrucción de la propia ciudad de Milán (Figura 10.4). Basado en un anillo de crecimiento radial a partir de las murallas medievales, tomando como ejes los caminos de acceso a la ciudad (Figura 10.4 a)). Los nuevos barrios o sectores son de nuevo abiertos, sin amurallar, emplazados en las cercanías de los accesos iniciales a las antiguas murallas. Para ello elaboró planos o dibujos precisos de los caminos de entrada a la ciudad.

En cuanto a criterios urbanísticos, diseña sectores geométricos alrededor de una gran plaza central porticada, donde ubicará un mercado (Figura 10.4 b)). El resto del sector será con calles, canales y manzanas geométricas; la distribución de todo ello será simétrica a ambos lados de la plaza central, con las adecuadas condiciones de salubridad e higiene.

También proyecta una red de canales navegables dentro de la propia ciudad, que sirvan de vía de abastecimiento, evacuación y comunicación. Establece que al menos una de las fachadas de los nuevos edificios, lindarán con algún canal para conseguir una vía fácil de evacuación.

En cuanto a la edificación proyecta viviendas en bloque, con caja de escalera en el centro de cada edificio y desde ellas un pasillo distribuidor a las viviendas. Las viviendas son de pequeñas dimensiones y todas tienen fachada a los canales, para facilitar la evacuación. De nuevo los criterios impuestos por Leonardo para su nueva ciudad, manifiestan carácter ecológico y de minimización de impacto ambiental con referencia a lo preexistente. 


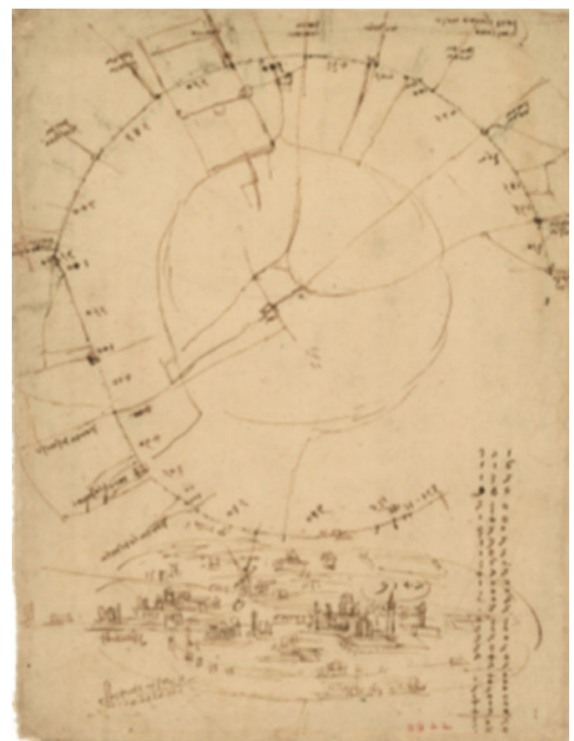

a)

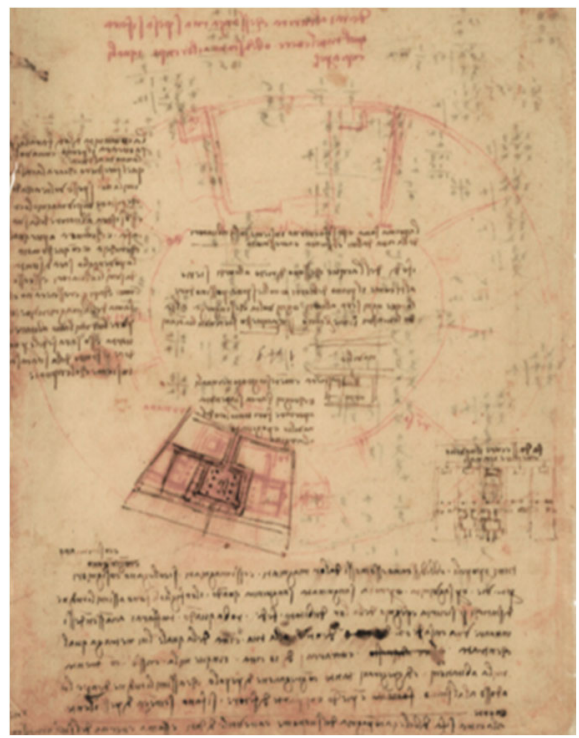

b)

Figura 10.4 a) Plano esquemático de los accesos a Milán C. Atlántico f. 199v (https://commons.wikimedia.org/wiki/File:Leonardo_Milano04.jpg), b)

Nuevo Sector de construcción tipo. Códice Atlántico f. $184 \mathrm{v}$, Biblioteca Ambrosiana de Milán.

(https://commons.wikimedia.org/wiki/File:Codex_Atlanticus_-_000V184.jpg?uselang=es).

Los manuscritos del proyecto se encuentran distribuidos entre el Códice Atlántico de la Biblioteca Ambrosiana de Milán, el Códice Windsor RL de la Royal Library del Castillo de Windsor y el Códice Forster III del Victoria and Albert Museum de Londres.

\subsubsection{La ciudad nueva de Romorantin}

En 1516 pasa al servicio del Rey de Francia, Francisco I (1494 Cognac - 1547 Ramboullet), como "premier peintre, architecte et méchanicien du roi" y este le encarga el proyecto arquitectónico del palacio o castillo de la reina madre en Romorantin, existiendo bocetos en planta y alzado (Figura 10.5 a) y b)) del mismo. Situado en el centro de Francia para un posible traslado de la corte, es donde Leonardo retoma sus ideas naturalistas y ecológicas establecidas en Milán, junto con un estudio de canalizaciones y saneamiento a gran escala de la zona del Loira, entre Romorantin y Amboise y la región de Sologne, 
$<<$ proyectando hacer navegable el rio Adda, acontecimiento que ya se produjo a finales del siglo XVI>> (Vezzosi, 2011).

A la par del palacio, proyecta una nueva ciudad con principios racionales, ecológicos y geométricos para Romorantín, que asimila a un "castrum" romano, diseñando un canal en el centro, y repartiendo calle y edificios también en dos niveles, con carreteras, puentes, edificios y plazas (Figura $10.5 \mathrm{c}$ )). Dibuja varios edificios de planta central, solución que gustaba de utilizar. Indica las cocinas y caballerizas, así como las fuentes. Leonardo pretendía que los habitantes de la ciudad cercana de Villefranche se trasladaran a Romorantin, así como desviar el curso del rió Sauldre (afluente del Loira) para crear un canal navegable y comercial, semejante a las ideas que un día preconcibió para Milán. Describe también la utilización de compuertas hidráulicas móviles para controlar caudales y aportaciones de agua a los molinos, e incluso apunta la posibilidad de desplazar casas de la ciudad cercana, que en su mayoría eran de madera, transportándolas a piezas. Por ello algunos autores, también lo citan como pionero en la construcción de casas prefabricadas. Pretendía generar, además, junto al palacio y el canal navegable, un estanque de grandes dimensiones para celebrar "naumaquias" o justas navales (Figura 10.5 a)).

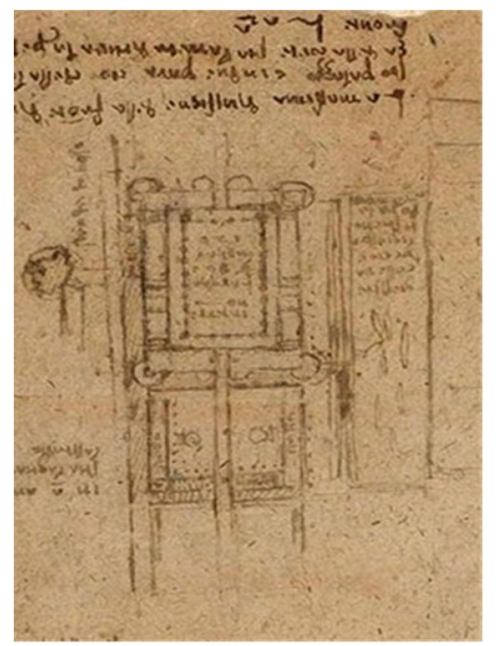

a)

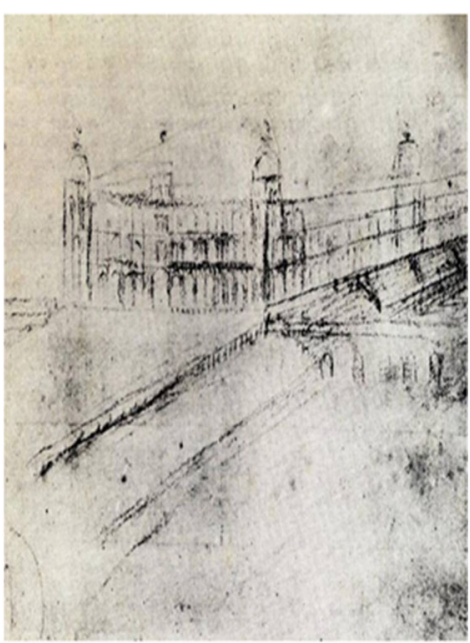

b) 


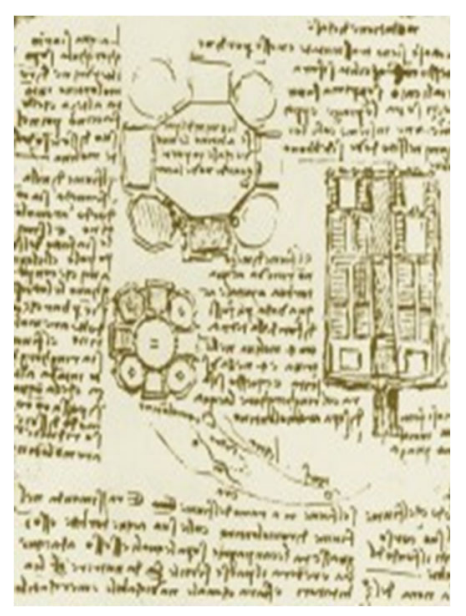

c)

Figura 10.5 a) Boceto Planta del Palacio Real de Romorantin, (h. 1517). Cod. Atlántico f. 209r

(https://commons.wikimedia.orgwikiFileCodex_Atlanticus_-_000R-209.jpg),

b) Boceto Alzado del Palacio Real de Romorantin, RCIN f. 912292v, Windsor Collection

(https://commons.wikimedia.org/wiki/File:Leonardo_da_Vinci__RCIN_912292,_Verso_A_design_for_a_palace_c.1517-

18.jpg? uselang=es), c) Ciudad nueva geométrica con edificios de planta central (h. 1517). Cod. Arundel f. 270v (1514-1518)

(http://www.bl.uk/manuscripts/Viewer.aspx?ref=arundel_ms_263_f001r).

De nuevo los criterios de Leonardo para diseñar el nuevo palacio y ciudad, se manifiestan con soluciones ecológicas que inciden en la Naturaleza lo menos posible.

Las obras llegaron a iniciarse, pero Leonardo ya estaba enfermo y además, la zona fue en aquel entonces objeto de una epidemia, por lo que el rey Francisco I paralizó el proyecto y optó por trasladar sus voluntades al nuevo Palacio de Chambord, donde Leonardo ya en sus últimos días, solo llegó a influir en algunos de los diseños interiores del palacio (escaleras de doble entrada, salas en forma de cruz, etc.).

\subsection{El agua}

Por sus conocimientos de hidráulica, que dejó plasmados en varios de sus códices, obtuvo el encargo de numerosos proyectos hidráulicos 
como: el desvío del Río Arno a su paso por Pisa, para el gobierno de Florencia (1504); la desecación de las bahías pontinas y el Puerto de Civitavecchia, para los Estados pontificios (1514), en su etapa al servicio de la República de Venecia (1500) para generar defensas de la ciudad y sus canales frente a los ataques turcos; o el diseño del Canal de irrigación de San Cristofano (h. 1509). Ello le llevó a intentar dominarla y usarla como generación de fuerza diseñando líneas de fabricación accionadas por agua; esclusas y compuertas hidráulicas abatibles y plegables, donde en algunos modelos resultó innovador; y bombas de elevación de agua para fuentes (Figura 10.6 a)) para sus proyectos de jardines como el que diseñó en 1500 para la Villa del Marques de Mantua, Francesco II Gonzaga (1466-1519 Mantua). Llegó a proyectar, para el escritor y humanista italiano Bernardo Rucellai (1448 -1514 Florencia), el primer contador hidráulico conocido (Figura 10.6 b)), capaz de medir y controlar el agua servida. Este data de 1510 y se encuentra en el Códice Atlántico f. 229r, aunque los dibujos con mayor detalle que hoy se conocen (Figura $10.6 \mathrm{c}$ )) son un poco posteriores y corresponden al relojero y constructor de máquinas Benvenuto Lorenzo della Golpaia (o Volpaia) (1486 Florencia - 1532 Roma), existentes en el Códice Marciano 53 f. 7v, de la Biblioteca Marciana de Venecia.

Todo ello le hizo comprender la importancia del agua, no solo para la economía, sino para la vida de cualquier ser vivo y del planeta Tierra. Así escribe en el Manuscrito K, f. $2 r$ del Instituto de Francia, París: "El agua es el vehículo de la naturaleza". Llegando a augurar con esa visión ecológica del agua, en una de sus "Profecías" escritas en el Códice Arundel (1504-1516) del Museo Británico de Londres (Códice Arundel, n.d.): "Y los ríos perderán sus aguas, y la fructuosa tierra no podrá impulsar desde sí ningún renuevo, y no crecerá sobre los campos la inclinada belleza de la espiga; y así morirán los animales, no pudiendo nutrirse con el fresco herbazal de los prados; (...) y los hombres, tras múltiples intentos, de igual manera perderán la vida, falleciendo por fin la especie humana. Y la tierra fértil, rica en frutos, quedará convertida en un desierto" (Lanceros y Barja, 2018). Alusión clara a lo que hoy se preconiza como las consecuencias del cambio climático, si no se actúa con severidad contra las inadecuadas acciones del hombre y se toma el camino correcto hacia el desarrollo sostenible. 


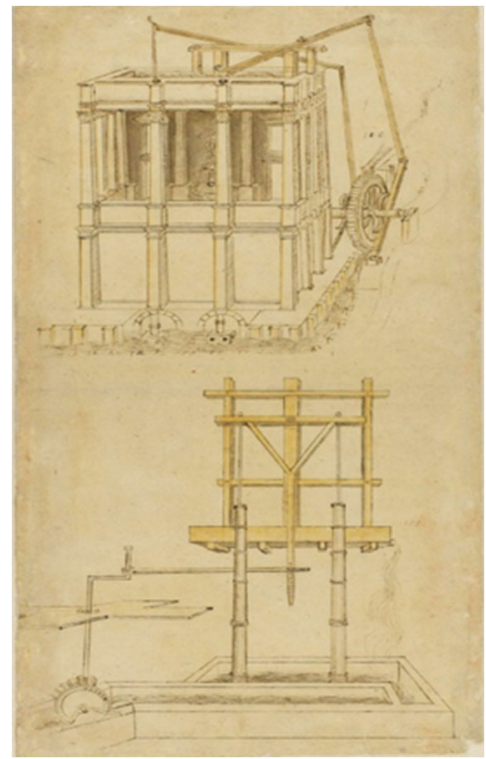

a)

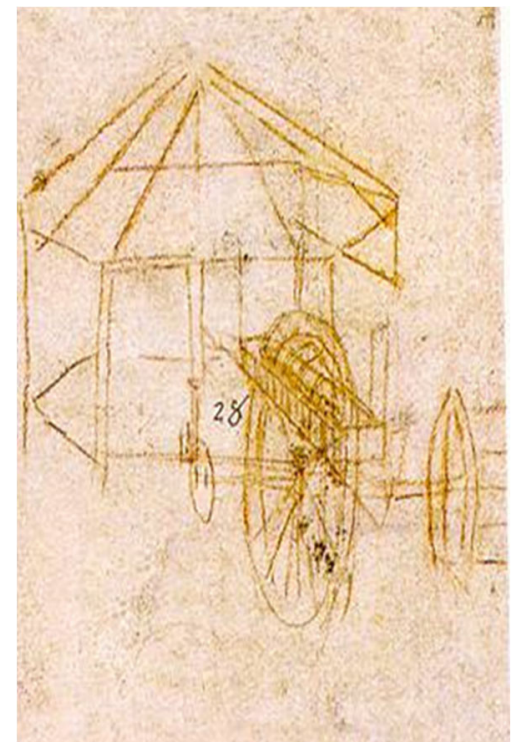

b)

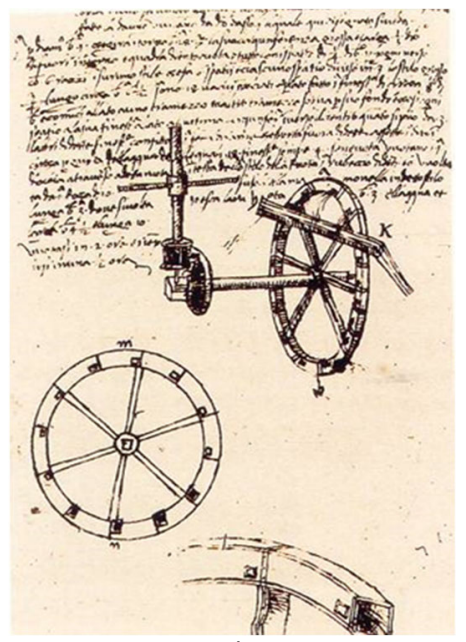

c)

Figura 10.6 a) Bomba hidráulica para una fuente, Códice Atlántico f. 1099r, Biblioteca Ambrosiana de Milán, (https://www.codex-atlanticus.it/), b) Boceto de Leonardo del primer contador hidráulico para la máquina de Rucellai, (1510) Cod. Atlántico f. 229r Biblioteca Ambrosiana de Milán. (https://commons.wikimedia.org/wiki/File:Codex_Atlanticus_-_000R229.jpg?uselang=es), c) Dibujo posterior de Benvenuto Lorenzo della Golpaia, Códice Marciano 5363, f. 7v, Biblioteca Marciana de Venecia. 


\subsection{La Sala Grande delle Asse, y los innovadores fondos de las madonas, un culto a la naturaleza}

Durante los años 1498 y 1499, Leonardo cumple el encargo del Duque de Milán de decorar la Gran Sala de la esquina norte del Castillo Sforcesco (Figura 10.7). Para ello, olvida las visiones religiosas tan en boga en esos momentos, y diseña mediante pintura al fresco, un entrelazado de ramas de un conjunto de árboles que se elevan para dar apariencia de una bóveda o pérgola vegetal. Los troncos llegan hasta el suelo, dando apariencia que se clavan en el mismo como si de un bosque se tratara, generando una perfecta analogía con la naturaleza. Los clásicos cielos azules, con vírgenes, santos, o ángeles de los techos de los palacios, son sustituidos por su amada naturaleza.

Algunos autores califican esta cúpula arbórea como de "ritmo leonardesco" por la alegría que proporciona la decoración de la sala a la celebración de fiestas de la corte. $<<$ No existe nada más ingenioso, ni siquiera acreditado, que esta traducción vegetal del arabesco a escala monumental; siempre se ha captado en ella una hábil segunda finalidad, conforme al "naturalismo" y unida al geometrismo, que cruzan continuamente las reflexiones del artista. ... Esta puede acoger las formas y las gracias de la naturaleza tan solo haciendo notar el rigor matemático de una organización que las supera>> (Chastel, Galluzzi, \& Pedretti, 2004).
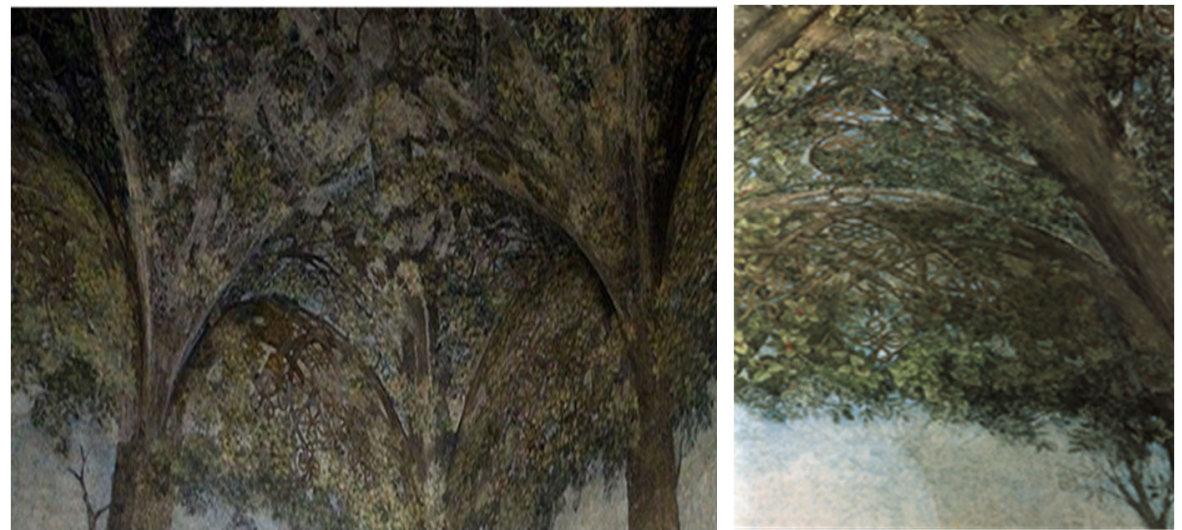

Figura 10.7 Techo y paredes de la Sala Delle Asse del Castillo Sforcesco de

Milán(https://commons.wikimedia.org/wiki/File:Leonardo_da_vinci,_Intrecci_ vegetali_con_frutti_e_monocromi_di_radici_e_rocce,_sala_delle_asse, $14 \overline{9}$ 8,_03.JPG? uselang=es y

https://commons.wikimedia.org/wiki/File:Leonardo,_decorazione_della_sala_ delle_asse_nel_castello_sforzesco_01.jpg?uselang=e). 

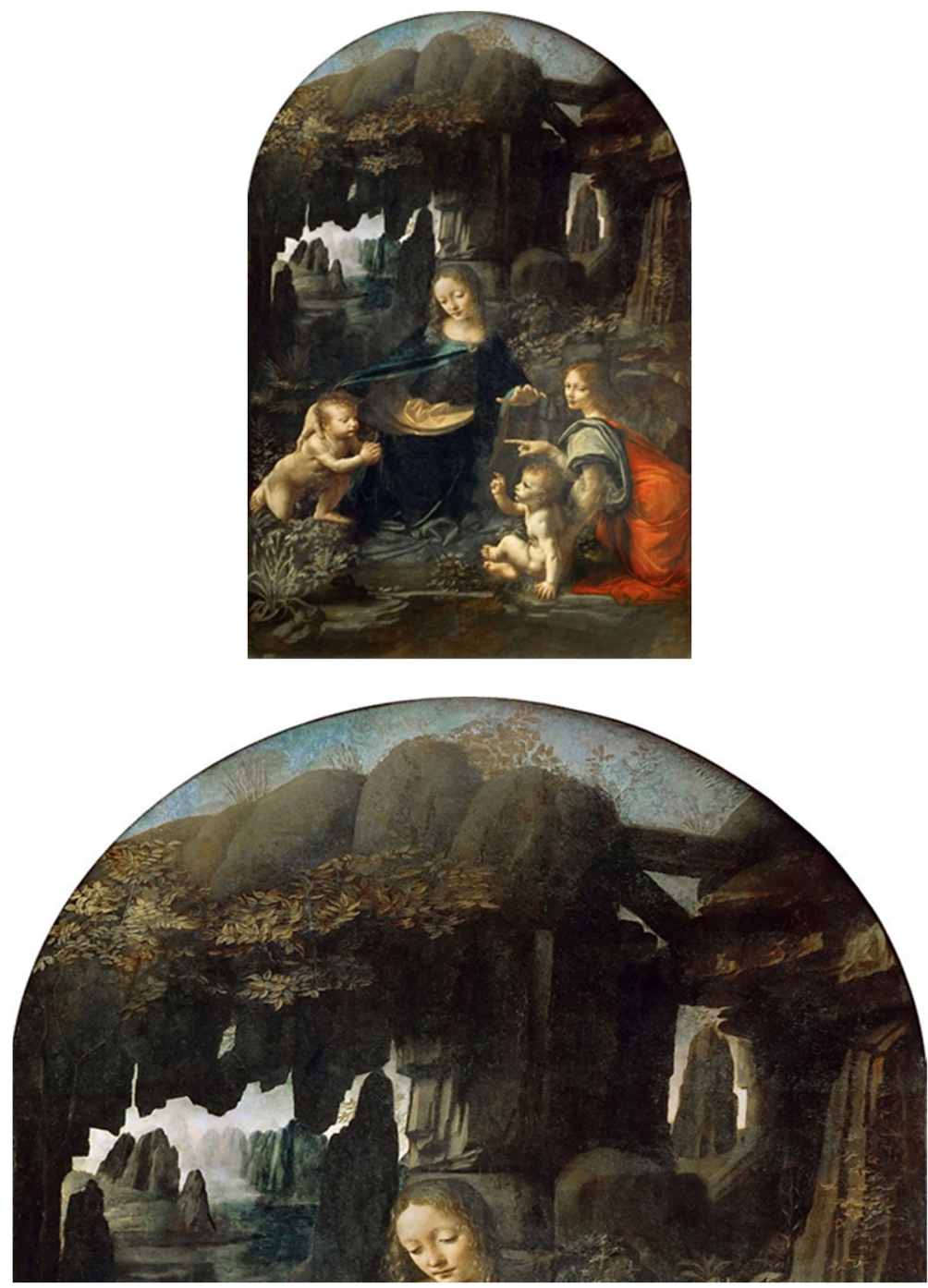

Figura 10.8 La Virgen de las rocas (1483-1486, Museo del Louvre, París) y detalle del fondo del cuadro, donde la Naturaleza sustituye a otros motivos religiosos clásicos

(https://commons.wikimedia.org/wiki/File:Leonardo_Da_Vinci__Vergine_delle_Rocce_(Louvre).jpg). 
Con referencia a sus Adoraciones y Madonas, también resulta innovador y naturalista, ya que sus fondos cambian por completo con referencia a los artistas anteriores, abandonando las idealizaciones y mostrando en ellos una visión mucho más humana, que no había aparecido antes en cuadros de índole religiosa. Así lo confirma la frase siguiente: <<muestra aquí que parte experimentalmente "de la naturaleza", y no de la iconología tradicional>> (Vezzosi, 2011). Así puede observarse en su versión de la Virgen de la Rocas, existente en el Museo el Louvre de Paris (Figura 10.8).

En vez de representar a la Virgen escoltada con ángeles y cielos, la representa con un fondo con una extraña gruta de rocas, plantas y agua, donde los elementos paisajísticos, la "naturaleza", predomina sobre la simbología religiosa de presencia indispensable en las pinturas de los antecesores de Leonardo, que resulta innovador en generar una interpretación tan naturalista de un tema sagrado. Así, refiriéndose al cuadro, el profesor titular de Historia del Arte de la Universidad de Barcelona, Juan Ramon Triado Tur, y la doctora en Historia del Arte, Laura García Sánchez, manifiestan: <<con una iconografia totalmente nueva, en cierta manera un poco al margen de los términos establecidos en el contrato, Leonardo presentó en esta obra una Virgen sin la clásica escolta de ángeles, representada en el marco de un prodigioso escenario geológico y cuidando con ternura a los dos niños desnudos, asistidos por el ángel>> (Triado \& Garcia, 2001).

\subsection{Conclusiones}

La búsqueda del progreso y crecimiento tecnológico y económico sin límites han derivado en daños irreparables sobre el medio ambiente, cuya consecuencia ha sido la aparición de algunos de los principales problemas de nuestro tiempo. Ello ha hecho reflexionar a la sociedad y pasar a una visión global más ecológica y holística, con una concepción del mundo compleja e interconectada para cualquier innovación.

Por ello, como dice el investigador y doctor en Física Fritjof Capra: $<<$ Necesitamos con urgencia una ciencia que haga honor a la unidad de vida y la respete, que reconozca la fundamental interdependencia de todos los fenómenos naturales y vuelva a conectarnos con la tierra viva $>>$. Mientras que refiriéndose a Leonardo matiza: $<<A$ pesar de 
ser un brillante inventor y proyectista, siempre pensó que el ingenio de la naturaleza era enormemente superior al propósito humano. Estaba convencido de lo prudente era respetar la naturaleza y aprender de ella, actitud que hoy ha vuelto a presentarse en la práctica del proyecto ecológico>> (Capra, 2008).

En resumen, puede afirmarse que lo largo de su extensa obra y de variada temática, Leonardo intentó enseñar al hombre a vivir en armonía con la naturaleza y a mostrarle el respeto hacia la misma, con el fin de que existiera para la humanidad un futuro adecuado, con principios ecológicos, que solo se han asentado en nuestra sociedad desde hace pocos años. Leonardo se adelantaba casi en 500 años a la primera Declaración de las Naciones Unidas sobre el Medio Ambiente (United Nations, 1972).

\section{Referencias}

Biblioteca Leonardiana de Vinci. (n.d.). Obtenido el 10/03/2019 de http://www.leonardodigitale.com.

Biblioteca Real de Turín. (n.d.). Obtenido el 24/02/2019 de https://www.museireali.beniculturali.it/biblioteca-reale/.

Capra, F. (2008). La ciencia de Leonardo. Editorial Anagrama: Barcelona.

Catalogue des manuscrits de la BnF. Biblioteca Nacional de Francia. (n.d.). Obtenido el 10/03/2019 de http://archivesetmanuscrits.bnf.fr/ark/12148/cc66429v.

Códice Arundel, British Library de Londres (antigua Biblioteca del British Museum). (n.d.). Obtenido el 10/03/2019 de https://www.metalocus.es/es/noticias/570-paginas-demanuscritos-de-leonardo-da-vinci-estan-online-gracias-a-labiblioteca-britanica-y-microsoft.

Chastel, A., Galluzzi, P., \& Pedretti, C. (2004). Grandes Artistas y Genios de la Pintura. Planeta De Agostini: Barcelona.

Da Vinci, L. (1478-1518). Códice de Atlántico. Milán. Biblioteca Ambrosiana. Obtenido de http://www.leonardoambrosiana.it/en/il-codice-atlantico/.

Da Vinci, L. (1478-1518). Manuscritos de la Royal Library Windsor, Royal Collection Trust. Obtenido de 
https://www.rct.uk/collection/themes/exhibitions/leonardo-davinci-a-life-in-drawing-0.

Da Vinci, L. (1487-1514). Conjunto de Manuscritos de París. París. Institut de France. Obtenido de https://archive.org/details/lesmanuscritsdel00leonuoft.

García de Zuñiga, E. (2005). Leonardo da Vinci. Aforismos. Espasa Calpe: Madrid.

Kalb, C. (2019). Leonardo la eterna Genialidad. National Geographic, mayo, p. 15.

Lanceros, P., \& Barja, J. (2018) Leonardo Da Vinci: El libro del agua. Abada Editores: Madrid.

Museo de la Ciencia y la Tecnología de Milán. (n.d.). Obtenido el 13/03/2019 de http://www.museoscienza.org/english/visiting/leonardoparade/

Nicholl, C. (2006). Leonardo, el Vuelo de la Mente. Círculo de Lectores: Barcelona.

Pedretti C., \& Antoccia, L. (2003). Atlas de Leonardo Da Vinci: Las Máquinas. Susaeta Ediciones: Madrid.

Pigem, J. (n.d.). Leonardo da Vinci, un hombre adelantado a su tiempo National Goegraphic. Obtenido el 1/05/2019 de https://www.nationalgeographic.com.es/historia/grandesreportajes/leonardo-da-vinci_7277/2.

Richter, J. (1883). The Literary Works of Leonardo Da Vinci. Edición de J. P. Richter: Londres.

Triado, J., \& García, L. (2001). Leonardo, pintores de siempre. Susaeta Ediciones: Madrid.

United Nations (1972). Declaration of the United Nations Conference on the Human Environment. Stockholm. Obtenido el 1/04/2109 de https://digitallibrary.un.org/record/523249? In=es

Vezzosi, A. (2011). Leonardo Da Vinci, ciencia y arte del universo. Ed. Blume: Barcelona. 


\section{Capítulo 11 Revisión de factibilidad funcional de los sistemas técnicos diseñados por Leonardo da Vinci}

"El que discute alegando autoridades, no da prueba de genio, sino más bien de memoria". LEONARDO DA VINCI (Manuscrito A, folio76 r, de la Biblioteca del Instituto de Francia, París).

\subsection{Introducción}

Existe la creencia de que la mayoría de los proyectos científicotécnicos de Leonardo (Vinci 1452 - Amboise 1519), sólo fueron plasmados en diseños conceptuales fruto de su imaginación, y de difícil realización, en base a que prácticamente ninguna máquina, mecanismo o dispositivo diseñado en sus casi 7000 folios manuscritos han llegado a nuestros días. Abarcó tanto, que muchos no creen que pudiera ser excelente en todo y haber profundizado con seriedad y rigor en tantos campos de la ciencia, la técnica y el arte. Pero el historiador del arte suizo Jacob Burckhardt (Basilea 1818-Basilea 1897) ya en su obra "El Cicerón", Leipzig 1855 -Edición italiana, Florencia 1952-, manifestó sobre Leonardo: <<No puede decirse de él que se haya dispersado, porque la actividad múltiple le era natural >> (Orlando, Cinotti, \& Rizzati, 1974).

Aunque el siglo XIX fue el del redescubrimiento del Leonardo pintor, filósofo, imaginativo, andrógino, etc., durante el siglo XX y los inicios del presente, se ha reestudiado su obra científico-técnica, e intentado demostrar que los proyectos técnicos de Leonardo pueden ser llevados a la realidad, y podrían desempeñar adecuadamente las prestaciones para los que el hombre universal los había diseñado.

Así podemos afirmar, que su diseño pionero de "paracaídas", plasmado en 1485 en el folio 1058v del Códice Atlántico, ha sido 
probado con éxito por paracaidistas en la República Sudafricana el año 2000 y en Payerne (Suiza) en el 2005. Igualmente, su "vehículo móvil o primer automóvil", pionero al menos en planos, fue por fin montado y llevado a la práctica en 2004 en el Museo de la Historia de la Ciencia de Florencia, funcionando de manera autónoma y programada, con motores de muelles, tal como lo había diseñado Leonardo en el Códice Atlántico folio 812 r en el año 1478.

El capítulo pretende demostrar, con algunos ejemplos, que gran parte de los diseños de máquinas y dispositivos de Leonardo, si bien en su día no se sabe con certeza si llegaron a materializarse, a través de los años han sido realizables y aptos para las funciones para las que el genio del Renacimiento los había diseñado y no se trataba por tanto de meras entelequias imaginativas.

\subsection{El ascensor manual o de manivela}

Leonardo proyectó obras importantes. Algunas de ellas se iniciaron, como el desvío de $19 \mathrm{~km}$ del Río Arno para la ciudad de Florencia, y otras quedaron solo en planos, como la desecación de las Lagunas Pontinas para el pontífice León X (Juan de Médeci, Florencia 14751521) en Roma. Ello requería realizar grandes movimientos de tierra y elevación de cargas, por lo que diseñó varias máquinas y herramientas que facilitaran esas tareas.

En el Códice I de Madrid, folio 9 r, de la Biblioteca Nacional de España (Da Vinci, 1490-1505) (que en castellano lleva por título Tratado de Estática y de Mecánica, de 1493 y que el historiador Carlo Pedretti sostiene que Leonardo lo nombró como "Tratatto sugli elementi macchinali") (Laurenza, D., Taddei, M., Zanon, E., 2006), Leonardo diseña un dispositivo apto para actuar como un ascensor o elevador manual de cargas. El dispositivo actúa mediante una manivela, que mueve un tornillo sin fin que gira las coronas dentadas y tuercas interiores, por las que se desliza el cable o cuerda de "tiro". Al impedir el giro el tornillo elevador, en un sentido o en otro, permite que éste suba o baje con seguridad, y con una adecuada multiplicación, consigue el movimiento con muy poco esfuerzo.

Su dominio en elevación de pesos hizo que el pintor e historiador milanés Giovanni Paolo Lomazzo (Milán 1538-1600) en 1590 estableciera, al ver los libros de Leonardo en poder de su discípulo y heredero principal, el pintor Francesco Melzi, (Milán 1493-Vaprio 
d'Adda 1570): $<<Y$ mostró el arte de sacar pesos con facilidad [con sus libros] de los cuales toda Europa está llena y son tenidos en mucha estima entre los entendidos, porque consideran que no se puede hacer más de lo que él ha hecho>> (Orlando, Cinotti, \& Rizzati, 1974).

En el mismo sentido se pronunció, el pintor e historiador de arte italiano Giorgio Vasari (Arezzo 1511- Florencia 1574): <<Demostró cómo levantar y arrastrar grandes pesos por medio de palancas, cabrias $y$ tornos>> (Nicholl, 2005).

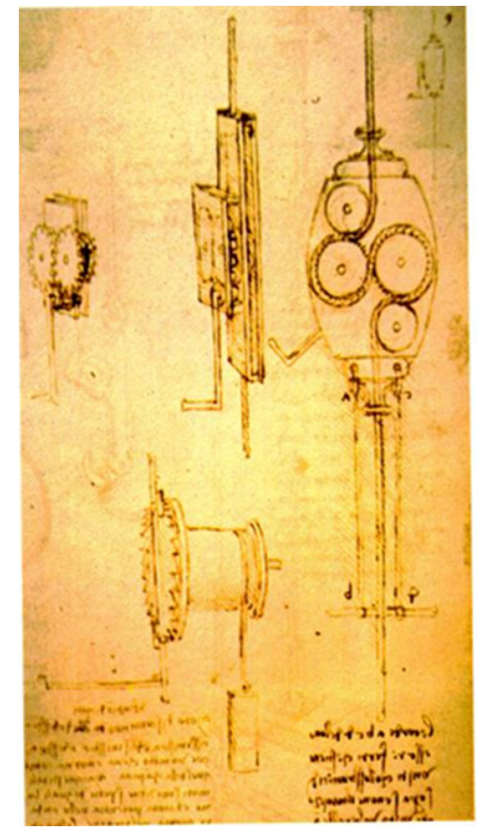

a)

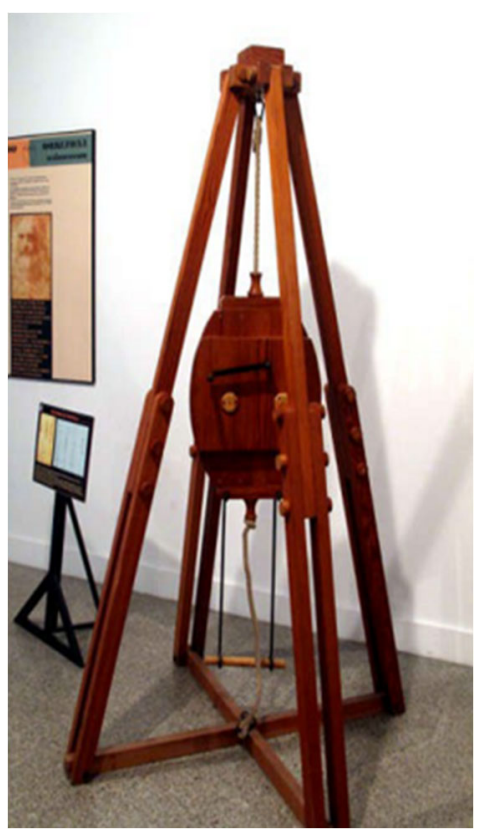

b) 


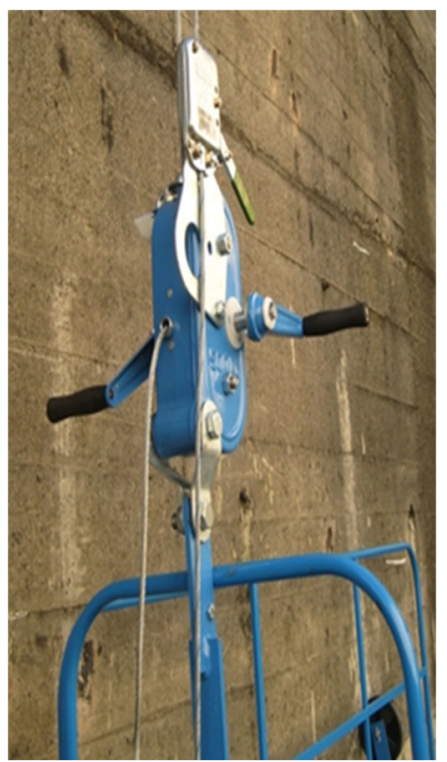

c)

Figura 11.1 a) Estudio para el dispositivo de un elevador manual (1495-97), Códice I de Madrid, f. 9r.

(https://commons.wikimedia.org/wiki/File:Ascenceur_à_manivelleLéonard.jpg), b) Maqueta actual del ascensor de manivela de Leonardo, de la exposición "Leonardo da Vinci el Inventor" en el Palacio de Congresos de

Salamanca en 2011, c) Elevador actual de la empresa de maquinaria industrial ALBA de Sondika (Vizcaya) https://www.alba.es/productos/elevacion/andamioscolgantes/manuales/p/andamio-manual/).

El adecuado uso de esta máquina para elevar cargas o incluso personas de manera segura y cómoda ha hecho que este diseño sea factible y se continúe utilizando hoy en día de manera muy similar en obras de la construcción para el ascenso de cargas o incluso de andamios porta personas en trabajos por fachadas.

\subsection{El martinete para pilotajes}

Las máquinas piloteadoras sirven para introducir elementos prefabricados en el suelo, en forma de poste o columna, bien de madera, hormigón o metálicos. Su función es permitir la realización de cimentaciones en terrenos poco aptos para ello. Dichos elementos, denominados "pilotes", suelen ser "hincados" en el suelo a base de golpes de "martinete", esto hace que el elemento descienda, 
penetrando el terreno, tarea que se prolonga hasta que se alcanza la profundidad de diseño.

En el Códice Atlántico, folio 785 (sobre 1500) (Da Vinci, 1478-1518), Leonardo dibuja su máquina para hincar troncos en la profundidad del terreno. Pretendía usarlos en su proyecto de desvío del río Arno en Florencia y estaba compuesto de un órgano que elevaba el peso a través de poleas y manivelas, siendo guiado el peso en el interior para controlar la precisión de su caída, que al impactar sobre el tronco proporcionase la mayor fuerza posible. Con la relación polea manivela se facilitaba la repetición de la operación.

La forma de trabajo no ha cambiado a día de hoy con referencia al diseño de Leonardo, solamente la manera de introducir en la máquina la energía para la elevación de peso del pilote se ha modificado con los adelantos tecnológicos. La idea o diseño inicial sigue siendo factible.

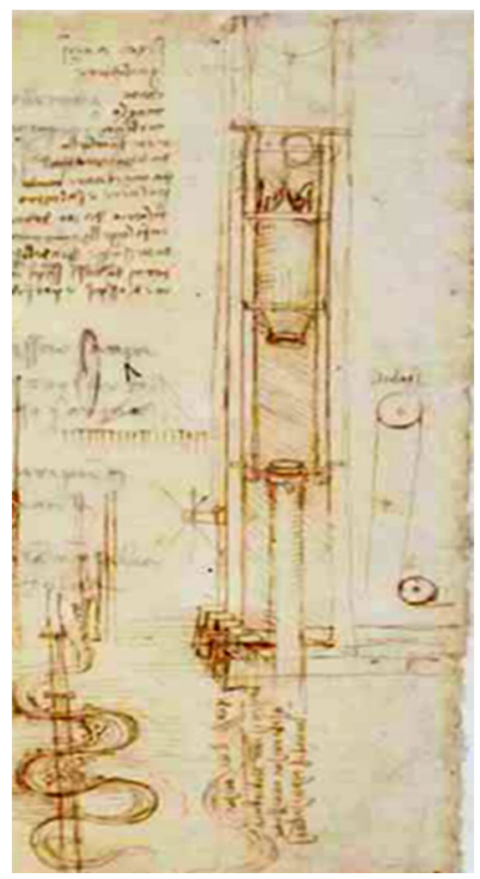

a)

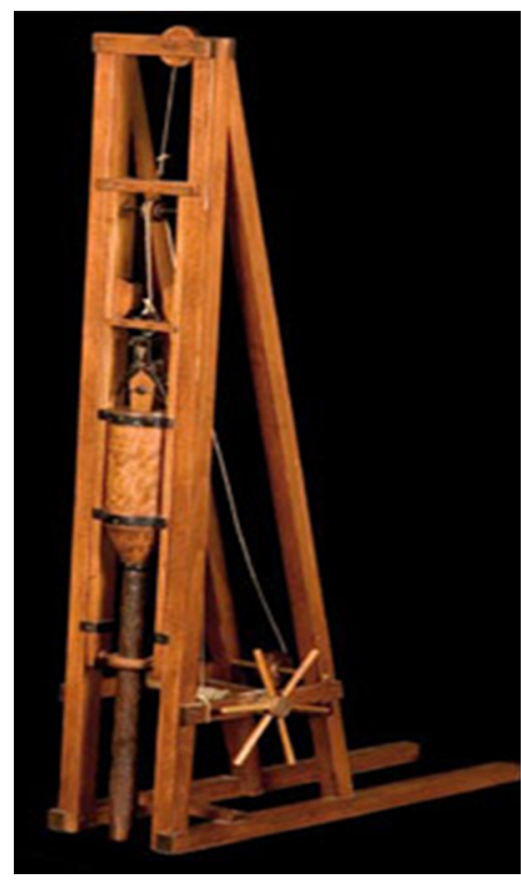

b) 


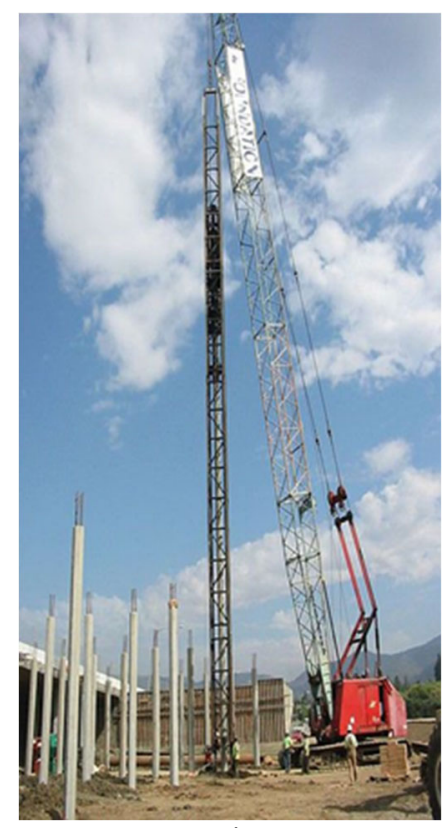

c)

Figura 11.2 a) Códice Atlántico, f 785, Biblioteca Ambrosiana de Milán. (https://commons.wikimedia.org/wiki/File:Sonnette-Léonard.jpg), b) Maqueta de máquina para pilotes de Leonardo, del Museo Nacional de Ciencia y Tecnología de Milán (Imagen de la Web de ese Museo www.museoscienza.org), c) Máquina actual de pilotaje, en una obra de un puente.

\subsection{Los "gatos mecánicos" de Leonardo}

Leonardo establece en sus Cuadernos de Notas: "La mecánica es el paraíso de las ciencias matemáticas, porque con ella se alcanza el fruto matemático".

Gran conocedor de la física, de la mecánica, de metalurgia, etc. de su tiempo y de los principios de funcionamiento de los elementos de máquinas, aprovecha este conocimiento para desarrollar varias máquinas que más tarde se conocerán como máquinas-herramienta. Entre ellas diseña, en varios de sus Códices, al menos tres gatos mecánicos con diferentes sistemas de funcionamiento. 


\subsubsection{El gato de cremallera}

Su funcionamiento consiste en mantener fija la cremallera vertical ( $p$. ej. apoyada en el suelo) y haciendo girar la manivela, se consigue que el sistema de engranajes suba o baje, con el peso o pieza que éste sujeta al mismo. La adecuada relación de reducción entre rueda y piñón hará disminuir el esfuerzo necesario para elevar pesos.

Leonardo lo diseña en su Códice Atlántico, f. 0998 r, de la Biblioteca Ambrosiana de Milán.

Tanto en talleres electromecánicos actuales, para elevar cargas, como en el cambio habitual de las ruedas pinchadas de un vehículo, hoy en día se sigue utilizando el mecanismo dibujado por Leonardo a finales del siglo XV.

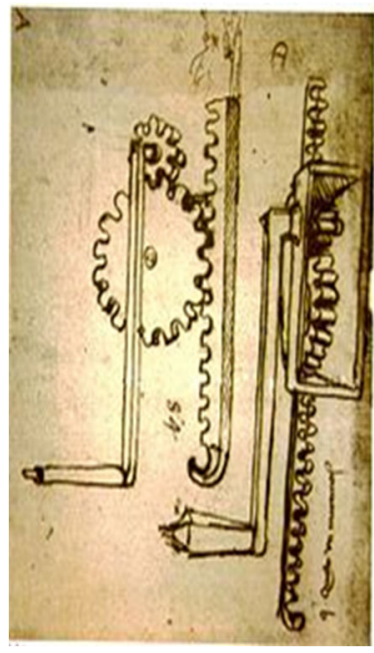

a)

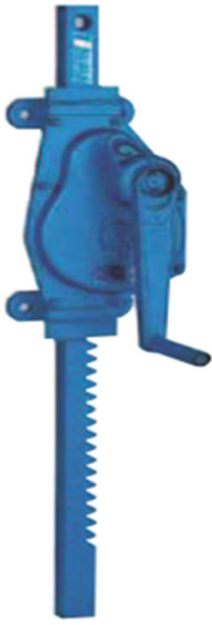

b)

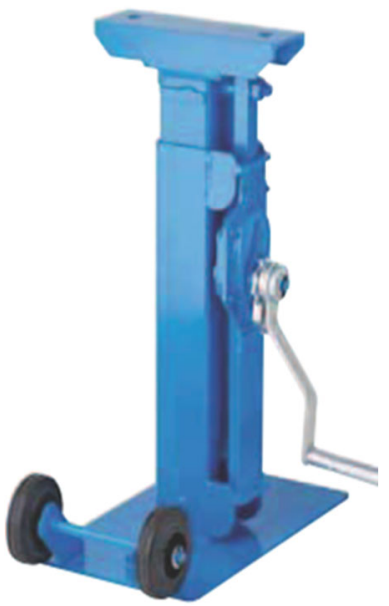

c)

Figura 11.3 a) Detalle del Códice Atlántico, f. 0998 r, Biblioteca Ambrosiana de Milán. (https://commons.wikimedia.org/wiki/File:Cric-Léonard.jpg), b) y c) Gatos manuales de cremallera, modelos ZWW de tornillo sin fin, y HB-W de la compañía Columbus McKinnon Ibérica de Sevilla (www.cmiberica.com/productos/elevacion/gatos-de-cremellera-y-husillo).

\subsubsection{El Gato de husillo (tornillo-tuerca tradicional)}

El mecanismo constituido por el tornillo-tuerca permite, al efectuar un movimiento giratorio sobre el tornillo y mantener fija la tuerca, que el primero se desplace. De manera similar si fijamos el tornillo, el que se 
desplazará al girar será la tuerca. De esta manera se trasforma un movimiento circular en uno rectilíneo. Es un sistema para levantar y arrastrar cargas sencillo y seguro, pero de accionamiento lento, ya que en una vuelta de tornillo solo se adelanta el "paso" del mismo. En el Códice Atlántico folio $0138 \mathrm{r}$, de la Biblioteca Ambrosiana de Milán, establece el diseño de un "gato mecánico" para levantar o arrastrar cañones, así como otro dispositivo similar para arrastre fijo de cargas, ambos mediante el sistema de "Husillo".

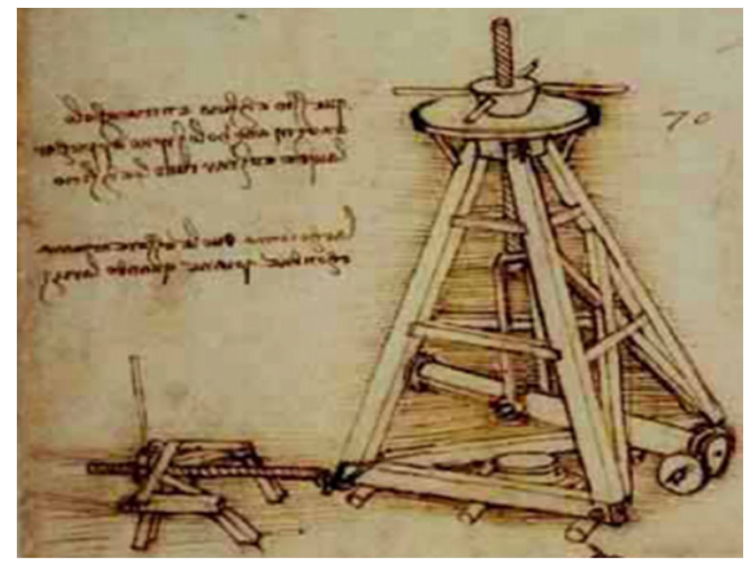

a)

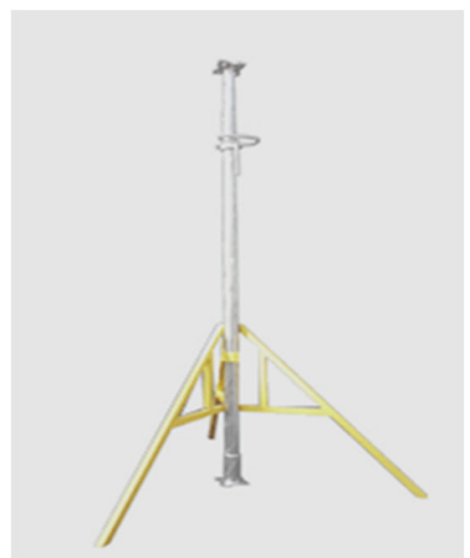

b)

Figura 11.4 a) Detalle del Códice Atlántico f. 0138r de la Biblioteca Ambrosiana de Milán

(https://commons.wikimedia.org/wiki/File:Codex_Atlanticus_-_000R-138.jpg), b) Gato regulable con trípode de la empresa Chuzhou Jincheng Metalwork Co., Ltd. (www.jincheng-scaffold.com). 
Tanto el sector metalmecánico, como el de la construcción siguen utilizando hoy en día este sistema de sostén y elevación de cargas plasmado por Leonardo.

\subsubsection{El gato de tornillo con rodamiento antifricción}

Leonardo, innovador como siempre, va más allá de un simple gato de fuerza, y con el fin de disminuir el rozamiento y alargar la vida de la máquina, incorpora una especie de rodamiento dentado giratorio apoyado en bolas, entre la plataforma de apoyo fija y el disco superior dentado giratorio. Además, le incorpora la manivela en sentido lateral para producir el giro de manera más fácil. Gracias al rodamiento de bolas y a un engrane de dientes en su parte superior, el dispositivo funciona de manera más sencilla y con menos esfuerzo. Ello lo diseña en el Códice de Madrid I f. 0026 r de la Biblioteca Nacional de España (Madrid). Esta solución de Leonardo se sigue utilizando hoy en día por las empresas de fabricación de utillaje para talleres mecánicos.

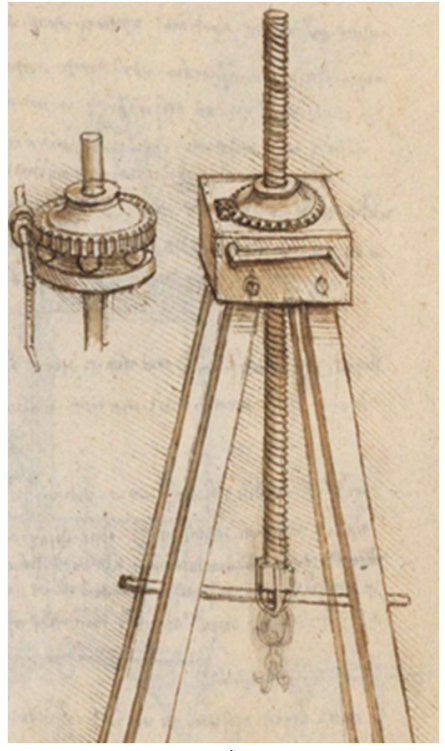

a)

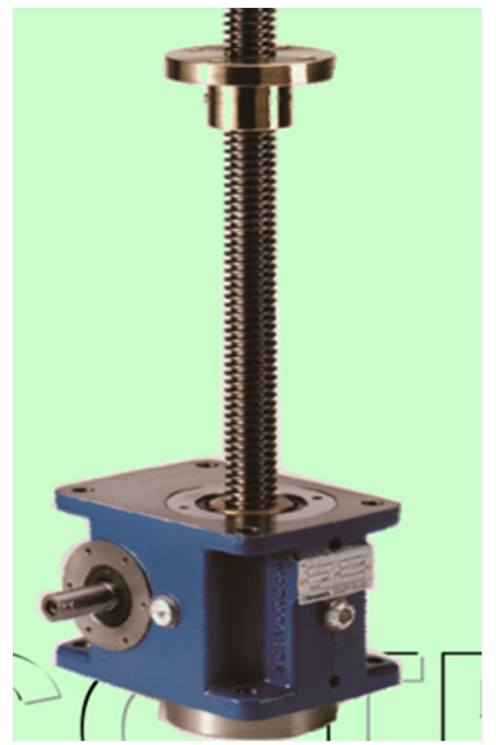

b) 


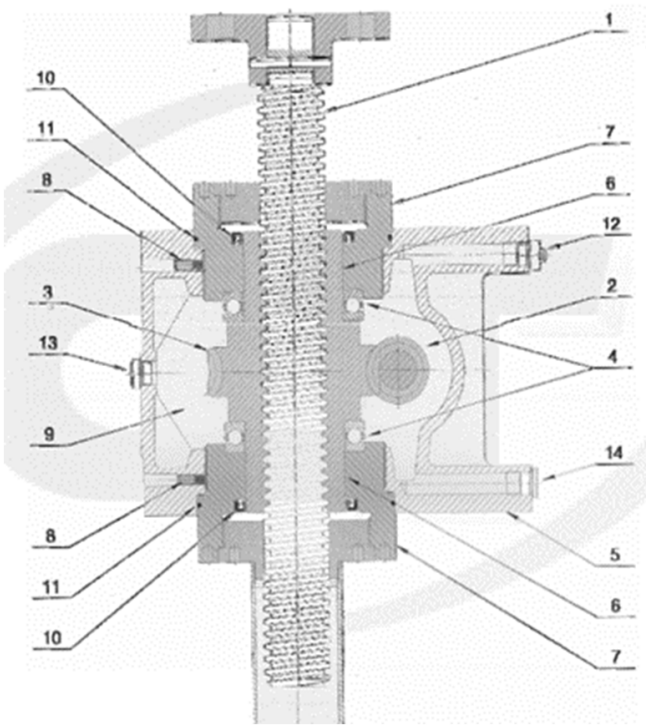

c)

Figura 11.5 a) Detalle del Códice de Madrid I, f. 0026 r, Biblioteca Nacional de España (Madrid) (http://leonardo.bne.es/index.html) b) y c) Gato mecánico actual con rodamiento de bolas, SG12 serie MA, fabricado por la empresa COTRANSA y sección del mismo con vista de los rodamientos de bolas de apoyo $\left(n^{\circ} 4\right)$ (www.cotransa.net).

\subsection{El torno de giro continuo}

El torneado precisa de la acción rotatoria continua. Inicialmente, si una persona soportaba y guiaba la herramienta, otra debía hacer girar el eje soporte de la pieza a tornear ya que a finales del siglo XV no había una fuente de energía continua para hacerlo.

El instrumento de accionamiento giratorio alternativo más antiguo era el que utilizaba el denominado "pedal y pértiga elástica", consistente en colocar en la parte superior del torno una pértiga elástica y una cuerda, que servía para que el operario accionara el giro de la pieza actuando sobre ella con un pedal y una cuerda atada y enrollada a la misma, que recuperaba el movimiento contrario al del pedal por la elasticidad de la pértiga, atada y arrollada al otro extremo de la pieza, actuando de resorte. Así, la misma persona que soportaba la herramienta conseguía el giro del eje del torno. Con esta solución, la 
pieza solo era trabajada cuando el movimiento alternativo era hacia el filo de la herramienta. Leonardo, lo plasma en el Códice Atlántico de la Biblioteca Ambrosiana de Milán, hacia 1480.

Pero él va más allá, realizando el primer diseño de un nuevo torno, el de "giro continuo de rueda y pedal", con velocidad constante y de mayor rendimiento (la pieza ya era trabajada de manera continuada). Para ello combina un pedal con un vástago y una biela (conjunto bielamanivela), con un volante de inercia o rueda de balanceo, que permitía superar los puntos muertos del giro en su parte más alta y más baja. Un cabezal ajustable mediante roscado fijaría a la máquina la pieza a tornear. También se encuentra dibujado en el Códice Atlántico.

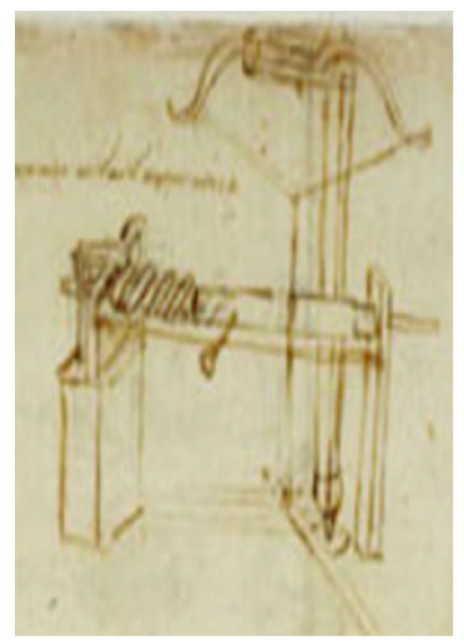

a)

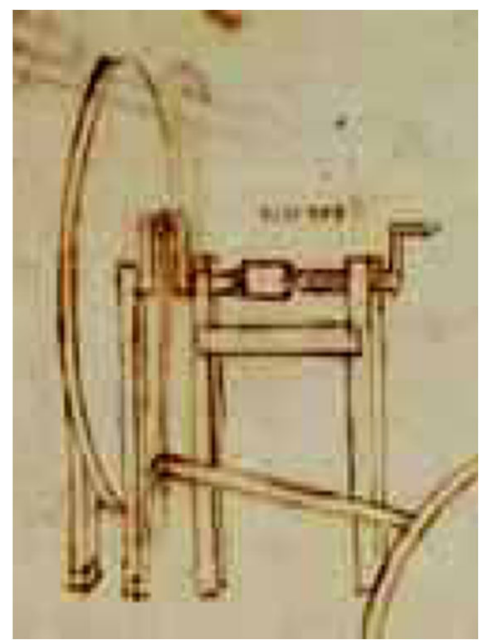

b) 


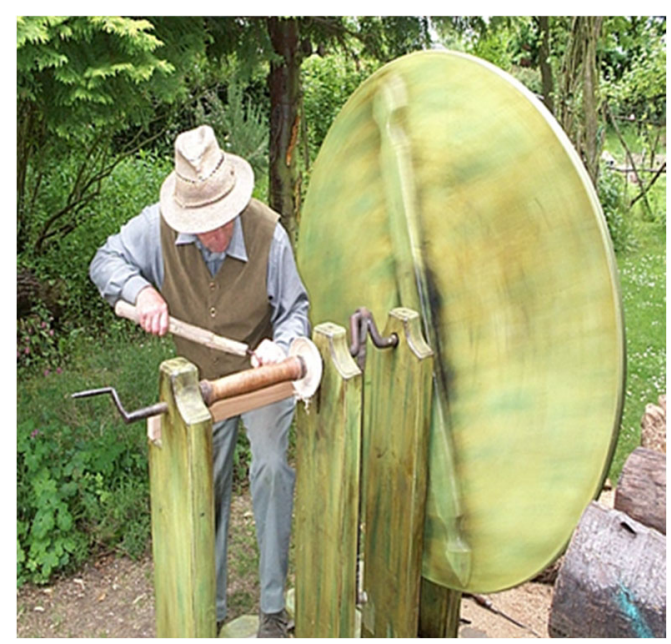

c)

Figura 11.6 a) Detalle de torno de giro por "pedal y doble pértiga, Códice Atlántico (1480) f. 47r,

(https://commons.wikimedia.org/wiki/File:Codex_Atlanticus_-_000R-

47.jpg?uselang=es), b) Detalle del Códice Atlántico, torno de giro continuo por "volante de inercia", Códice Atlántico f.1059r.

(https://commons.wikimedia.org/wiki/File:000R-1059.jpg), c) Prototipo del torno de Leonardo realizado por Stuart King en la Exposición "Wizadry in Word" en el Pewterers' Hall, London (Reino Unido) (Imagen del Blog de Stuart King www.stuartking.co.uk/index.php/how-i-built-leonardo-da-vincislathe/).

En 2004, el artista plástico portugués José Aurelio (Alcobaça 1938-) realizó un prototipo metálico de este torno en honor a Leonardo, para la Fundación cultural Armazén das Artes de Alcobaça (Portugal). También en 2004, se realizó una exposición sobre "Magia en Madera" en el Pewterers' Hall de Londres, y el artesano inglés Stuart King construyó el prototipo de torno por pedal y volante, diseñado por Leonardo y lo puso a funcionar con un resultado de funcionamiento satisfactorio y sorprendente, probando la funcionalidad y factibilidad del mismo.

\subsection{El anemómetro y el anemoscopio}

Para medir la velocidad del viento se utiliza un instrumento denominado anemómetro (del griego "anemo" = viento y "metro" = medida), mientras que para establecer su dirección se utiliza el 
anemoscopio, comunmente denominado "veleta". Leonardo para sus "estudios sobre el vuelo" precisaba de datos sobre los fenómenos atmosféricos y por ello diseñó varios instrumentos de medida relacionados con ellos (anemómetros, anemoscopios, higrómetros, etc.), con el fin de establecer más seguridad a sus ensayos.

Aunque se conoce que el arquitecto italiano León Battista Alberti (Génova 1404 - Roma 1472) en 1450 ya generó un instrumento para medir la velocidad del viento mediante una placa que gira sobre un péndulo, y que con casi toda seguridad lo conoció Leonardo, este diseña su propio anemómetro, utilizando una fina lámina unida mediante una bisagra a la parte superior de un semicírculo que dispone de una escala graduada.

Si el viento incide en la lámina, esta se alzará de su parte baja y, dependiendo de la altura de la escala graduada a la que llegue en su desplazamiento, podrá tenerse una idea de la velocidad del viento. Sobre 1480, en el folio 675 del Códice Atlántico existente en la Biblioteca Ambrosiana de Milán, lo dibuja, y en otro detalle del mismo diseña la veleta o anemoscopio para completar el conocimiento de la dirección del viento y de esta manera orientar el instrumento en esa dirección. Este último indicará también los cambios de dirección.

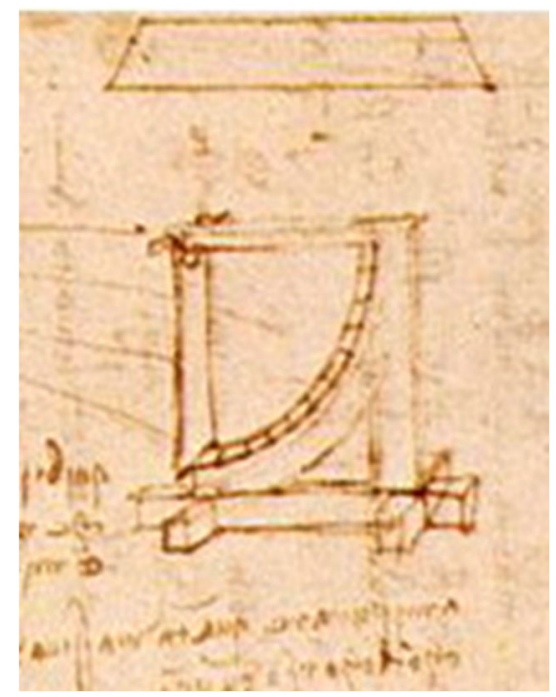

a)

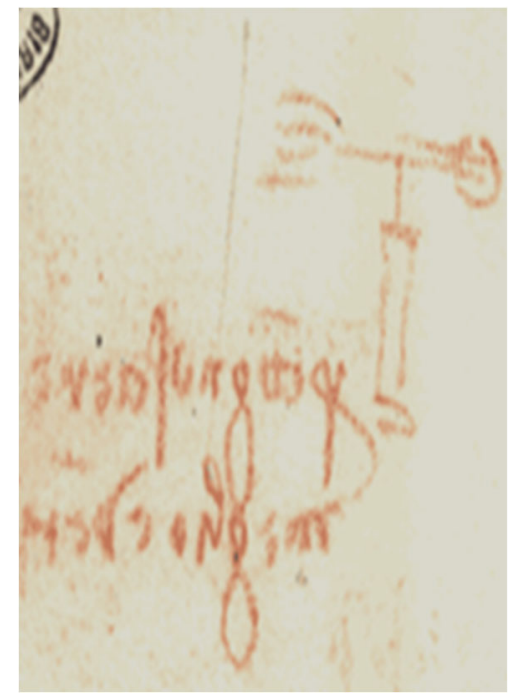

b) 


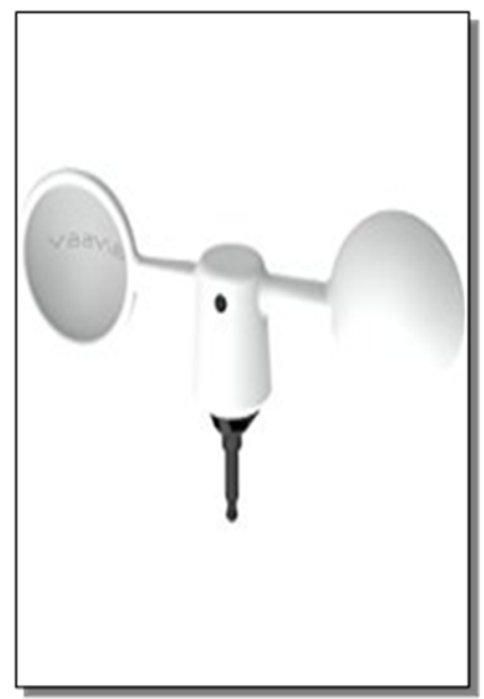

c)

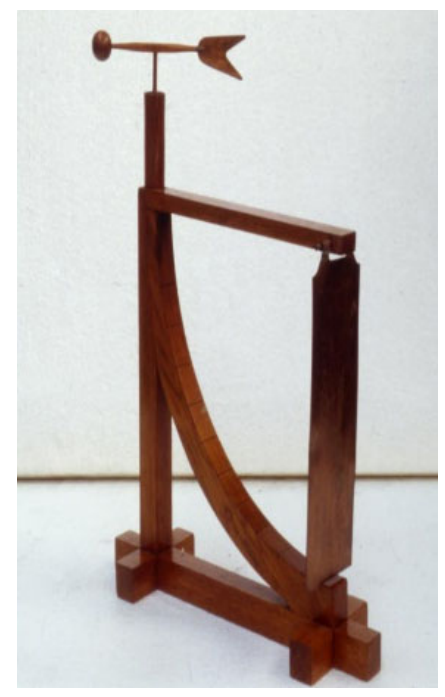

d)

Figura 11.7 a) y b) Detalles del anemómetro y anemoscopio del Códice Atlántico f. 675 de la Biblioteca Ambrosiana de Milán (https://commons.wikimedia.org/wiki/File:Codex_Atlanticus_-_000R-675.jpg),

c) Anemómetro actual, d) Maqueta del anemómetro y anemoscopio de Leonardo, del Museo Nacional de Ciencia y Tecnología de Milán (http://www.museoscienza.org).

\subsection{El primer vehículo autopropulsado}

Leonardo es el primero que diseña una máquina capaz de moverse por sí sola, sin aplicación de la fuerza humana o animal, que se va a convertir en el primer vehículo autopropulsado conocido de la historia. Conocedor a fondo de los elementos de máquinas (su Códice de Madrid I, titulado Tratado de Estática y de Mecánica, de 1493, puede considerarse como el más completo tratado de Mecánica del Renacimiento) piensa en aprovechar la fuerza de dos muelles de arrollamiento en espiral, encerrados en unos habitáculos en forma de tambor, que de manera similar a como se carga la cuerda de un reloj, serían previamente cargados, y al soltar a través de una anilla un resorte que los frena, trasladarían su potencia a dos ruedas.

En el Códice Atlántico, folio 812 r (1478-80) de la Biblioteca Ambrosiana de Milán, establece su proyecto con dos vistas, una en planta, grafiando muelles, engranajes, ballestas, etc., y otra en perspectiva donde añade la idea de un posible sistema de dirección. 
Formado por una pequeña rueda complementaria acoplada a su parte trasera y un vástago accesible desde arriba del vehículo, actuaría de volante para poder ser direccionado a conveniencia, o bien mediante una programación previa. Para esto último utilizaba "excéntricas" de distintas formas, incorporadas a los ejes rotatorios. En función de la forma de las "excéntricas" introducidas inicialmente cambiará la dirección del vehículo.

Incorpora además dos ballestas frontales, regulables, que pueden actuar de control de los engranajes que interrelacionan los muelles de potencia con las ruedas, ya que los muelles motores no tienen un impulso constante en todo el tiempo de su descarga y de esta manera se puede controlar la velocidad del vehículo.

Finalmente incorpora un vástago de madera que actúa como freno general por control remoto, actuando sobre los dientes de los engranajes o ruedas horizontales impidiendo el movimiento hacia las ruedas verticales traseras, consiguiendo que no se transmita potencia a las ruedas aún en el caso de que los muelles estén cargados. Una anilla actuando sobre el vástago, y a través de una cuerda, lo retiraba a distancia y entraba en movimiento el vehículo. En la parte baja del manuscrito grafía la pieza complementaria que servía como freno inicial accionado desde la distancia mediante una cuerda.

Usado como máquina teatral que se movía por sí sola, tanto en dirección recta como curva, fue capaz de impresionar a todo ser humano que lo viera en las fiestas cortesanas del Duque de Milán Ludovico Sforza (Vigevano 1452 - Loches 1508), y más tarde de la corte francesa del Rey Francisco I (Coñac, 1494 - Rambouillet, 1547), para los que trabajó Leonardo. 


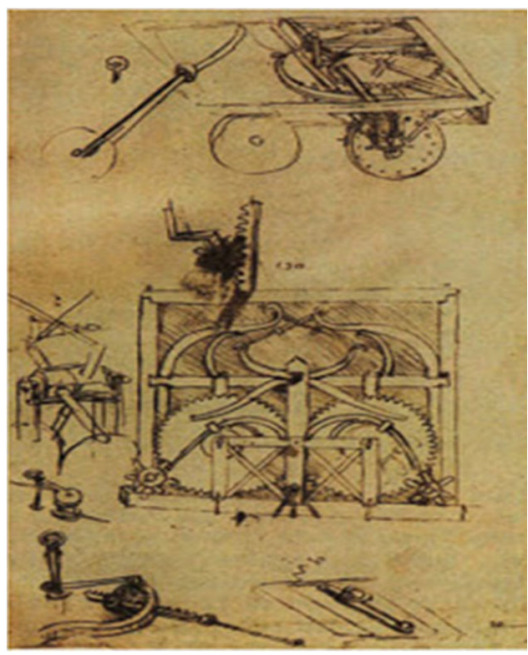

a)

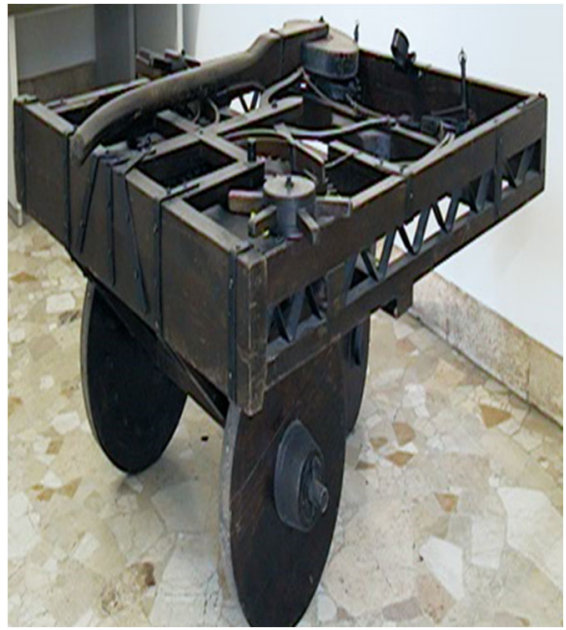

b)

Figura 11.8 a) Manuscrito del vehículo autopropulsado, Códice Atlántico, folio 812 r (1478-80), Biblioteca Ambrosiana de Milán.

(https://commons.wikimedia.org/wiki/File:Leonardo_da_vinci,_Automobile.jp g?uselang=es), b) Maqueta del Museo Nacional de la Ciencia y la Tecnología de Milán de 1953, basada en el Modelo de Canestrini. (Imagen de la Web del Museo de Historia de la Ciencia de Florencia https://brunelleschi.imss.fi.it ). 
Los dibujos no están acotados, pero como las funciones del vehículo eran para aparecer en espectáculos teatrales, se deduce que no debería tener dimensiones excesivamente grandes. Los prototipos realizados por el Museo de Historia de la Ciencia de Florencia a partir del 2004, fecha en la que por primera vez fue puesto en funcionamiento, oscilan entre unas dimensiones aproximadas de 1,70 $\mathrm{m} \times 1,50 \mathrm{~m}$ el mayor, y otro de menor tamaño de alrededor de $0,60 \mathrm{~m}$ $\times 0,50 \mathrm{~m}$.

La escasez de documentación técnica sobre el diseño generó durante siglos confusiones en su construcción, como por ejemplo que las ballestas podían ser la fuente de energía, e hizo que no se consiguiera hacer funcionar esta máquina. De hecho, el ingeniero e historiador italiano Giovanni Canestrini (Coredo 1893 - Milán 1975), publicó en 1939 el estudio "Leonardo costructtore di macchine e di veicoli" y fabricó el modelo hoy perdido, similar a los existentes Museo Nacional de la Ciencia y la Tecnología de Milán, que no llegó a moverse, manifestando que la máquina de Leonardo no podría funcionar.

La reaparición en 1967 de los Códices de Madrid I y II de la Biblioteca Nacional de España, con extensa información de los conocimientos de Leonardo sobre muelles, cadenas, engranajes, y elementos de máquinas en general, facilitó información sobre el vehículo complementaria a la que inicialmente existía en el Códice Atlántico, y pudo ser construido con éxito en 2004. En ese año, tras varios estudios realizados en el Museo de Historia de la Ciencia de Florencia, dirigidos por los historiadores e investigadores italianos Paolo Galluzzi (Florencia 1942-) y Carlo Pedretti (Bolonia 1928 - Lamporecchio 2018), junto con las aportaciones aclaratorias del profesor estadounidense de robótica Mark Elling Rosheim, que digitalizó todo el conjunto de piezas necesarias, se consiguió poner de nuevo en funcionamiento el automóvil, dando factibilidad real a la solución que Leonardo proyectó hace más de 500 años.

\subsection{Otros}

Los ejemplos hasta aquí descritos están relacionados con el diseño de máquinas y mecanismos, pero la inventiva de Leonardo se extendió a otros campos. 


\subsubsection{La escalera de doble hélice}

Los estudios de arquitectura de Leonardo no son tan prolíferos como los de ingeniería, pero también los hubo y en cantidad, ya que prácticamente no existían áreas de conocimiento científico y técnico de su época en las que no se atreviera a investigar.

Los tres últimos años de su vida (1516-1519), Leonardo los pasó en Francia, en la mansión de Cloux, cerca de Amboise, al servicio del Rey de Francia Francisco I que lo nombró << "pintor y arquitecto del rey"... "con una asignación anual de 1000 escudos">> (Nicholl, 2005).

El rey, que pasaba gran parte de su tiempo en el castillo de Amboise, le encargó entre otros proyectos, el de la Ciudad Geométrica de Romorantin, que incluía un Palacio Real y una nueva ciudad enlazada con canales fluviales desde el río Loira: <<El Proyecto de Leonardo es muy conceptual, el canal en el centro, en dos niveles, constituye el eje a cuyos lados se reparten las carreteras, los puentes, los edificios y las plazas. La perspectiva urbana culmina con el Palacio del Príncipe. Están también indicadas las fuentes, las cocinas y las caballerizas >> (Vezzosi, 2011). Realizó varios planos con posibles soluciones, aunque su repentina muerte, en 1519, dejó en el aire ese proyecto.

Para este proyecto Leonardo recuperó ideas y bocetos que años antes utilizó para realizar su Proyecto de Ciudad Ideal (1487-1490), en la corte milanesa de los Sforza, ciudad que por aquel entonces había sufrido un importante número de muertes por la peste. Es conocido que entre sus diseños había varios dibujos sobre escaleras, una de ellas de doble hélice, capaz de hacer bajar personas desde una planta a otra sin cruzarse. Ello consta en el Manuscrito M folio f. 69 r, (1490) del Instituto Francés de París (Da Vinci, 1487-1492). También existen en el manuscrito $B$, en el folio $47 r$ (1487), dibujos más detallados de una escalera de cuatro entradas de soluciones parecidas, que da posibilidad para cuatro recorridos independientes entre plantas. 


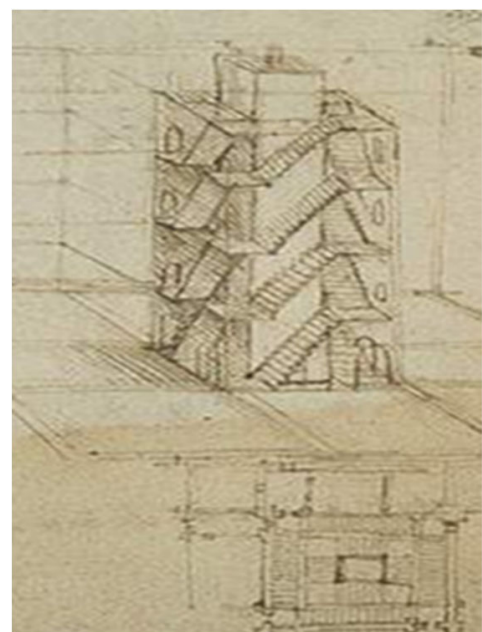

a)

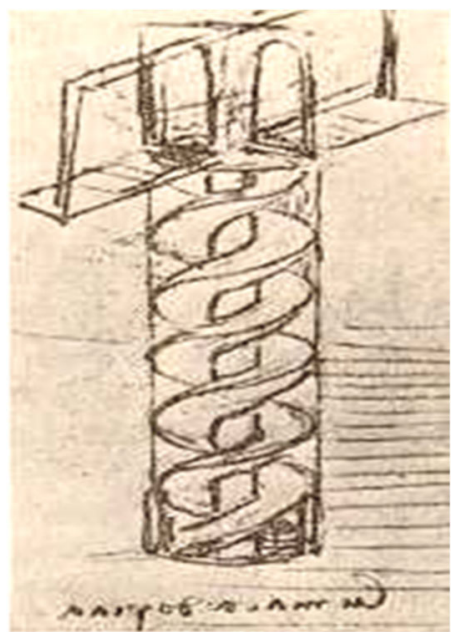

b)

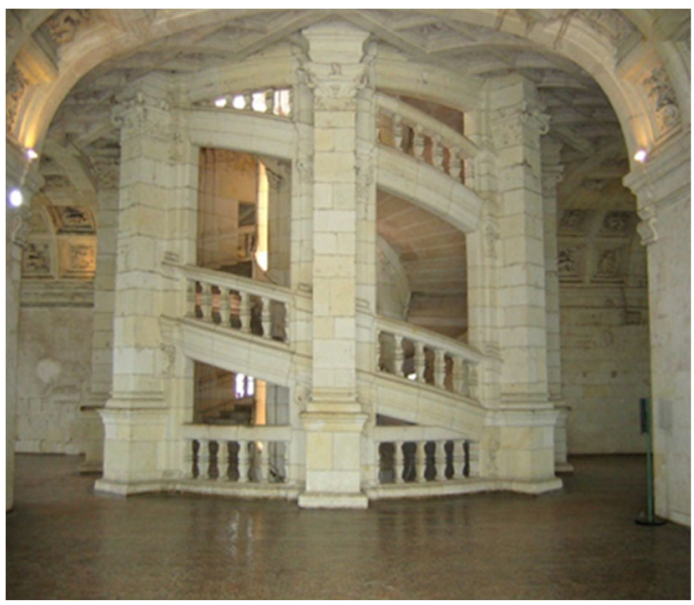

c)

Figura 11.9 a) detalle del Manuscrito B del Instituto de Francia f. 47 r,

(1487) con escalera de cuatro entradas para la Ciudad Ideal.

(https://commons.wikimedia.org/wiki/File:Leonardo_da_Vinci_-_19554036.jpg? uselang=es), b) Detalle del Manuscrito M de Francia f. $69 \mathrm{r}$, (1490) con escalera de doble hélice, c) Escalera de doble hélice del Castillo de Chambord (www.rinconesconencantofrancia.blogspot.com.es).

Con Leonardo en vida nada de ello llego a realizarse, pero en una zona cercana a la de su proyecto y el mismo año de su muerte, Francisco I encarga el proyecto de la construcción del Palacio de Chambord al 
arquitecto italiano Domenico Bernabel da Cortona (Cortona 1465 Paris 1549). El castillo hoy tiene una longitud de $156 \mathrm{~m}$ y una altura de $56 \mathrm{~m}$, y curiosamente en el centro del castillo aparece por primera vez una impresionante escalera interior de doble hélice de $9 \mathrm{~m}$ de diámetro, que con casi toda seguridad se hizo en honor a Leonardo (al que el rey tenía en gran estima), o al menos se inspiraron en los bocetos de este.

La escalera está dispuesta en el medio de una cruz griega, por donde se conectan los vestíbulos del castillo con la entrada y salida de las escaleras a cada nivel del edificio. Comunica los tres niveles del castillo, desde la planta baja hasta las terrazas superiores. Los soportes centrales consisten en la unión de ocho grandes columnas donde apoyan dos rampas escalonadas que giran en forma de hélice alrededor de un pequeño patio o linterna.

Todo lo relacionado con la escalera mantiene unas exactas simetrías y proporciones, como tanto le gustaba a Leonardo. La ubicación y el tamaño de las ventanas, las dimensiones de la escalera, la forma de la cruz, etc. así lo hacen. Con este diseño se aseguraba que el rey no se cruzara con la servidumbre en sus desplazamientos internos. No obstante, las ventanas intermedias que dan al pequeño patio central de la escalera, en los puntos de coincidencia, hacen que puedan verse las personas, y parezca que se está en una misma escalera.

\subsubsection{El primer paracaídas de la historia}

Es conocido el interés de Leonardo por hacer volar al hombre. De hecho, durante años llevó a cabo estudios sobre el vuelo de los pájaros con el fin de conseguir diseñar una máquina que lo consiguiera. Por ello, sobre el 1485, en el Códice Atlántico, folio 1058 v, de la Biblioteca Ambrosiana de Milán (Italia), junto con otros dibujos sobre estudios para el vuelo de humanos, Leonardo establece su boceto de paracaídas como un instrumento para lanzarse desde grandes alturas. Y junto a él anota esta afirmación: <<Con una tienda del lino de forma piramidal, de tejidos tupidos y cuya base fuese tenida rígidamente abierta, con 12 braccias de lado y 12 de altura (un brazo toscano $=58$ $\mathrm{cm}$ ), un hombre puede lanzarse desde cualquier altura considerable sin ningún riesgo >>.

No existe constancia de que entonces se llegara a experimentar con este diseño de manera real, pero sí que después de 500 años, su 
diseño ha sido puesto en práctica con resultados adecuados, pudiendo considerarse este como pionero del "paracaídas", ya que fue probado por el saltador e investigador británico Adrián Nicholas (1962-2005) en la Republica Sudafricana en el año 2000, y por el paracaidista suizo Olivier Vietti-Teppa (1971-), en el Aeropuerto militar de Payerne (Suiza) en el 2008, ambos con éxito.

Fue el 26 de junio de 2.000, cuando Adrian Nicholas, un paracaidista inglés, lo probó desde una altura de 3.000 metros, en el Parque Kruger de Sudáfrica. El paracaídas respondía casi exactamente a la descripción de Leonardo, excepto que utilizó lona de algodón en lugar de lino. El casquete, amarrado a unos palos de madera de pino, pesaba casi 100 kilos, unas 40 veces más que un paracaídas moderno, pero aun así funcionó perfectamente. Nicholas descendió 2000 metros en cinco minutos: una caída lenta. Para la última parte del descenso utilizó un paracaídas normal: el fallo del modelo de Leonardo estaba en que no se plegaba, de forma que existía el peligro de que todo el artilugio aterrizara sobre él. <<Experimenté una sensación de júbilo -dijo Nicholas-. No pude resistirme a decir: Sr. Da Vinci, ha cumplido usted su promesa. Muchas gracias >> (Nicholl, 2005). De manera similar también lo anunció el diario londinense Daily Telegraph en su edición de 27 de junio de 2000 (www.dailymail.co.uk).

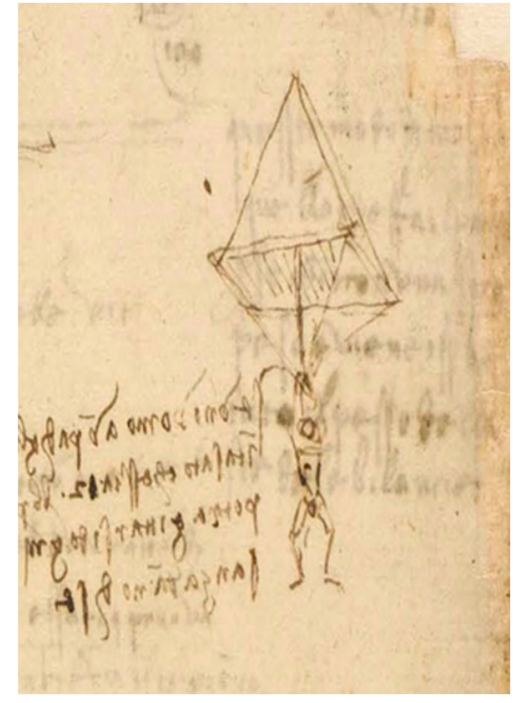

a)

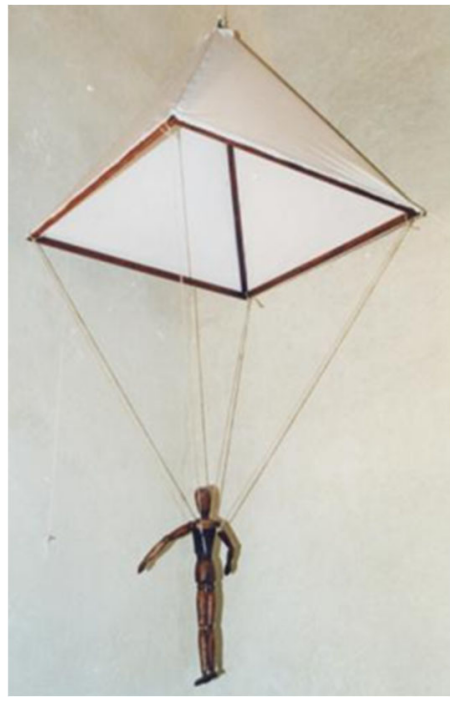

b) 


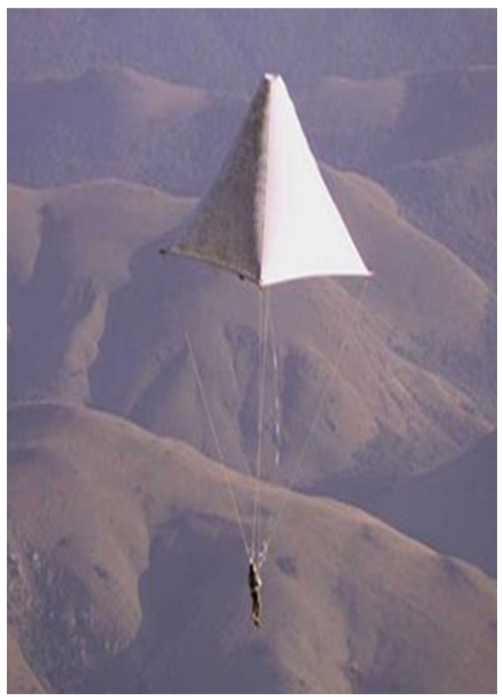

c)

Figura 11.10 a) Detalle del Códice Atlántico f. 1058, Biblioteca Ambrosiana de Milán

(https://commons.wikimedia.org/wiki/File:Leonardo_da_Vinci_parachute_04 659a.jpg), b) Maqueta del paracaídas de Leonardo, del Museo Nacional de Ciencia y Tecnología de Milán (Imagen de la Web del Museo: www.museoscienza.org), c) Salto de Adrián Nicholas el 20/07/2000 en República Sudafricana (Fotografía de ANSA para el Daily Telegraph londinense) www.dailymail.co.uk).

Mientras que el domingo 27 de abril de 2008, el suizo Oliver ViettiTeppa con un paracaídas de las mismas medidas y forma que lo indicado por Leonardo pero con materiales más actuales, a base de tela mosquitera, para facilitar su desplegado. Se lanzó desde un helicóptero en Suiza, en el aeropuerto militar de la ciudad de Payerne, desde $650 \mathrm{~m}$ de altura, y aterrizó en el suelo de manera correcta, como los paracaídas actuales. $<<H e$ aterrizado a las $18 H 58$ (16H58 GMT) en pleno centro de la pista del aeropuerto militar de Payerne. Ha sido impecable>>, manifestó el saltador a la Agencia France Presse ese día. Sin haber podido realizar la prueba previa veraz de que amortiguara la caída, Oliver consiguió hacer que funcionase adecuadamente y que el diseño de Leonardo resultara factible 500 años después de haber sido ideado. El único inconveniente encontrado por el paracaidista fue la falta de control frente al viento, y por ello se realizaron previamente ensayos con una maqueta a escala desde un helicóptero teledirigido. 


\subsection{Conclusiones}

Al igual que los distintos proyectos de Leonardo aquí relacionados, en los que se ha justificado su factibilidad posterior, existen muchos otros como su diseño de escafandra, su salvavidas, su higrómetro, el sistema diferencial mecánico, el contador hidráulico, el asador automático, el barco de palas, el gran caballo "Sforza", etc., en los que también puede considerársele como el pionero, o al menos el que primero los plasmó gráficamente, y que con posterioridad han sido construidos y se ha comprobado su factibilidad real.

El estudio en mayor profundidad de sus códices y manuscritos, la mejora de los materiales con el paso del tiempo, la aparición de nuevas fuentes energéticas, etc. han ido dando la razón a Leonardo, y sus bocetos, dibujos o proyectos, que se creían irrealizables, han podido convertirse en artefactos y ser aptos para las funciones para las que él pensaba que podrían utilizarse.

Nótese que Leonardo manifestó en sus Cuadernos de Notas citas como: <<"la sabiduría es hija de la experiencia", o "son vanas y están plagadas de errores las ciencias que no han nacido del experimento, madre de toda certidumbre">>, lo que le llevó a no confiar en los escritos del pasado y a comprobar por sí mismo todo aquello que quería utilizar o diseñar. De hecho, muchos de sus manuscritos de índole técnica los firma como "Leonardo Vinci disscepolo della sperientia". Ello ayuda a ratificar que buscaba la factibilidad de aquello que diseñaba.

El catedrático de Historia del Arte de la Universidad de Oxford, Martín Kemp (1942- ) manifestó <<La inventiva práctica, los precedentes de la antigüedad y la inverosimilitud imaginativa se funden en él, en una mezcla sin fisuras >> (Nicholl, 2005).

\section{Referencias}

Da Vinci, L. (1478-1518). Códice de Atlántico. Milán. Biblioteca Ambrosiana. Obtenido de http://www.leonardoambrosiana.it/en/il-codice-atlantico/. 
Da Vinci, L. (1478-1518). Códice de Windsor. Windsor. Royal Library of Windsor. Obtenido de https://www.royalcollection.org.uk/collection

Da Vinci, L. (1487-1492). Códice de París. París. Institut de France. Obtenido de https://archive.org/details/lesmanuscritsdel00leonuoft.

Da Vinci, L. (1490-1505). Códice de Madrid. Madrid. Biblioteca Nacional de España. Obtenido de http://leonardo.bne.es/index.html.

Laurenza, D., Taddei, M., \& Zanon, E. (2006). Las máquinas de Leonardo. Susaeta Ediciones: Madrid.

Nicholl, C. (2005). Leonardo el vuelo de la mente. Santillana Ed. Generales: Madrid. Págs. 168, 216, 229; 546 y 547.

Orlando, E., Cinotti, M., \& Rizzati, M. (1974). Leonardo. Colección de Grandes Maestros del Arte. Ed. Marín: Barcelona.

Vezzosi, A. (2011). Leonardo Da Vinci, arte y ciencia del universo. Ed. Blume: Barcelona.

www.cmiberica.com/productos/elevacion/gatos-de-cremallera-yhusillo, obtenido el 13/03/18

www.cotransa.net, obtenido el 5/02/18

www.dailymail.co.uk, obtenido el 13/03/18

www.brunelleschi.imss.fi.it/automobile/html/digitale_00.htm

(imágenes de prototipos de vehículos), obtenido el 9/03/18

www.jincheng-scaffold.com, obtenido el 8/03/18

http://www.museoscienza.org, obtenido el 5/02/18

www.rinconesconencantofrancia.blogspot.com.es/2013/06/castillode-chambord.html, obtenido el 9/03/18

www.stuartking.co.uk/index.php/how-i-built-leonardo-da-vincis-lathe/, obtenido el 09/03/18 


\title{
Capítulo 12 El Caballo Sforza
}

\author{
"He estado impresionado con la urgencia del hacer. Saber no es \\ suficiente; debemos aplicar. Estar dispuesto no es suficiente, \\ debemos hacer". \\ LEONARDO DA VINCI (Juana Rosa Pita, "Leonardo da Vinci. \\ Pensamientos: fabulas, profecías y otros". 2019. Ed. Verbum; \\ ISBN: 9788413370934. Pag 38).
}

\subsection{Introducción}

Este capítulo tiene como objetivo relacionar los tres enfoques presentes en el área de conocimiento de "Proyectos de Ingeniería" el Diseño en Ingeniería, la Ingeniería de Proyectos y la Gestión de Proyectos- con algunos de los aportes de la obra científico-técnica de Leonardo Da Vinci.

Los enfoques del Proyecto mencionados se podrían resumir como se indica en la Figura 11.1.

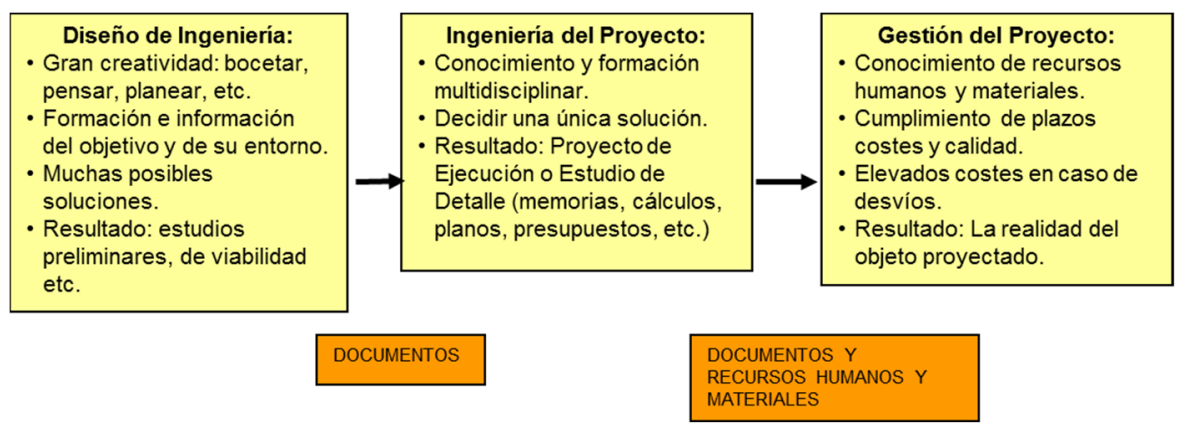

Figura 12.1 Área de conocimiento de "Proyectos de Ingeniería" 
Se pretende analizar si algunas de las obras científico-técnicas de Leonardo, con más de 500 años de antigüedad, siguieron en alguna medida este enfoque actual del proyecto, mostrando la documentación asimilable que en su día elaboró el toscano. El estudio se centrará principalmente en el Proyecto del Caballo de Sforza, completándose con alguna referencia al del Mausoleo del Mariscal Trivulzio.

\subsection{El Caballo Sforza}

\subsubsection{El contexto histórico}

Leonardo Da Vinci (Vinci 1452 - Amboise 1519) en 1482, con 30 años, sabedor de la competencia entre artistas destacados en la Ciudad de Florencia y conocedor de la pujanza económica, social y cultural del Ducado de Milán, buscó congratularse con sus mandatarios y escribió al Duque de Milán, Ludovico Sforza (Vigevano 1451- Loches 1508), destacando sus aptitudes, habilidades y competencias. Constituirá uno de los más famosos currículos de la historia (Da Vinci, 2005).

$<<$ A Ludovico Sforza, regente de Milán.

Ilustrísimo Señor mío, después de ver y considerar suficientemente las pruebas de todos aquellos que se llaman maestros y compositores de instrumentos bélicos, y toda vez que la invención y operación con dichos instrumentos no están fuera del uso corriente, me esforzaré, sin menoscabo de otras, en hacerme entender por su excelencia, le abriré mis secretos y me pongo a disposición de su excelencia para llevar a efecto y demostrar cuando lo estime oportuno aquellas cosas que en parte brevemente se anotan a continuación:

1. Tengo proyectos de puentes ligerísimos y fuertes, que se pueden transportar con mucha facilidad.

2. Sé cómo hacer el asedio de un terreno para sacar el agua de los fosos y hacer un número infinito de puentes, escaleras de cuerda y otros instrumentos.

3. Si por la altura del terreno o por la fuerza del lugar y del sitio no se pudiese usar un asedio, sé hacer bombas, conozco maneras de acabar con ciudadelas y fortalezas, aún cuando estén construidas con roca.

4. Asimismo, tengo ideas para hacer cañones comodísimos y muy fáciles de trasladar, con los que tirar piedras pequeñas como una lluvia de granizo. 
5. Y si sucediera algo en el mar, tengo planos de numerosos instrumentos utilísimos para atacar y defenderse, incluyendo barcos que resistirían el fuego de los mayores cañones, polvo y humo.

6. También conozco modos de llegar sigilosamente a un determinado lugar por cuevas y pasajes secretos, aunque para ello fuera necesario pasar bajo un río.

7. Puedo construir carros cubiertos (tanques), seguros e inofensivos con los que entrar dentro de las líneas enemigas con artillería, y no habrá compañía de hombres con armas tan grande como para que los carros no la deshagan. Y tras ellos la infantería llegará y los encontrará prácticamente desarmados y sin ninguna oposición.

8. Del mismo modo, si fuera preciso, haré cañones, morteros y artillería de formas bellísimas y útiles, fuera del uso común.

9. Donde no sea posible usar cañones, diseñaré diferentes tipos de catapultas y otros instrumentos de inmejorable eficacia muy diferentes de los comúnmente usados, en resumen, dependiendo de lo que las variadas circunstancias dicten, diseñaré infinitos artefactos de ataque y defensa.

10. En tiempos de paz, creo que puedo darle tanta satisfacción como cualquier otro en arquitectura, con la construcción de edificios públicos y privados, así como en la conducción de agua de un sitio a otro.

11. Puedo realizar esculturas en mármol, bronce o barro, así como pinturas, y mi trabajo puede compararse al de cualquier otro, quien quiera que sea.

12. Además, yo podría asumir la obra del caballo de bronce que sería una gloria inmortal y honor eterno de la memoria feliz de su señor padre y de la ilustre casa de los Sforza.

13. Y si alguna de las cosas mencionadas le pareciesen a alguien imposibles o no factibles, me declaro dispuesto a hacerle una demostración en su parque o el lugar que prefiera. Vuestra Excelencia, a quien me encomiendo con toda humildad>>.

Leonardo es aceptado en la corte del Duque de Milán, quien durante años será su mecenas, y aparte de nombrarle "ingeniarius ducalis" y pintor, decorador y amenizador de los actos festivos de la corte milanesa, le encomienda crear la escultura con la que resaltar la figura 
de su padre. Comienza así el primer periodo milanés del artista (14821500).

En 20 de diciembre de 1493, con motivo de la boda de la sobrina del Duque, Bianca Maria Sforza, con Maximiliano I (Emperador del Sacro Imperio Romano), se exhibió el modelo de arcilla que estaba terminando, en el patio del Castillo Sforzesco de Milán. Tenía más de $7 \mathrm{~m}$ de altura y se dijo que <<En verdad, aquellos que han visto el gran modelo en barro hecho por Lionardo, aseguran que jamás contemplaron nada más bello y soberbio >> (Vasari, 1550).

Otra prueba de que aquello fue cierto y que el modelo de arcilla llego a ejecutarse, nos llega a través de matemático Luca Pacioli, autor del libro "la Divina Proporción", que indica: $<<L a$ admirable y estupenda estatua ecuestre, de la cerviz a la tierra plana, tiene 12 brazas, y toda su masa asciende a unas 200.000 libras>> (De España, 1943). 
Conceptos y Documentos vinculados: Planteamiento, Estudios previos, de viabilidad, bocetos, croquis, etc.I Formación multidisciplinar e información vinculada al proyecto y su entorno

(1469-1479) Leonardo aprende y colabora en el taller de A. Verrocchio, y ayuda en el modelo de la estatua ecuestre del Condotiero "Coleoni" para la ciudad de Venecia

(1481) Leonardo estudia con detalle los caballos para hacer el fondo del su cuadro la Adoración de los Reyes Magos del convento de San Donato de Scopeto (Florencia)

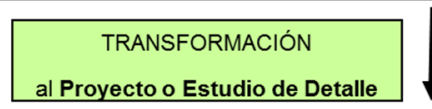

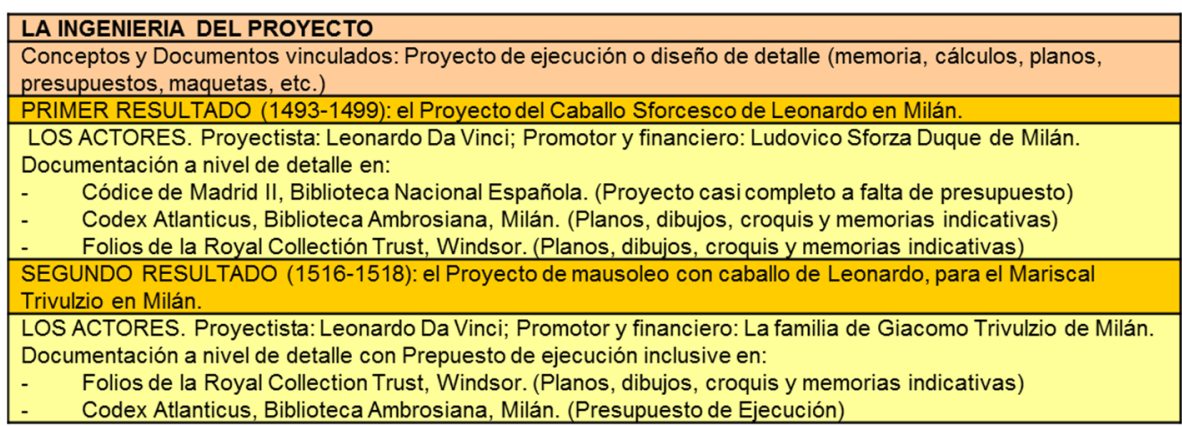

TRANSFORMACIÓN

a la Ejecución

\begin{tabular}{|l|}
\hline EL PROJECT MANAGEMENT \\
\hline Conceptos y Documentos vinculados: Realización, Gestión y dirección de proyectos \\
\hline RESULTADO (1996-1999): La ejecución real de cuatro caballos Sforcescos o Leonardinos: \\
- $\quad$ "Il Cavallo" de 24 pies de altura ( $7,3 \mathrm{~m}$ ), para Milán, ciudad donde se hizo su diseño y pretendia ejecutarse \\
el proyecto de Leonardo (Italia). \\
- $\quad$ "American Horse" de 24 pies de altura, en City of Grands Rapids (Michigan, USA). \\
- $\quad$ Uno de 12 pies de altura ( $3,68 \mathrm{~m}$ ) en City of Allentown, ciudad natal de Charles Dent (Pensilvania, USA). \\
\hline Uno de 7,4 pies de altura ( $2,27 \mathrm{~m}$ ) en la Ciudad de Vinci, ciudad natal de Leonardo (Italia). \\
\hline LOS ACTORES. Dirección-Ejecución: Nina Akamu. Escultora estadounidense; y Taller de fundición: Tallix Art \\
Foundri de Beacon, Nueva York, \\
Financiación: Charles Dent, expiloto estadounidense y su Fundación. \\
\hline
\end{tabular}

Figura 12.2 Resumen cronológico

Posteriormente comienza la recopilación de gran cantidad de metal para su proceso de fundición y los planos de detalle para la colada y los hornos necesarios. Pero al iniciarse la guerra entre el Ducado milanés y la Francia de Luís XII, se tuvo que utilizar la materia prima acumulada hasta entonces (más de 60 t de bronce) en la construcción de cañones y otras armas de defensa.

Finalmente, en septiembre de 1499, los soldados franceses invaden Milán y sus ballesteros destruyen el modelo de arcilla de gran tamaño utilizándolo de blanco (Capra, 2008). El Duque al perder Milán, huyó a Alemania y volvió con mercenarios suizos para intentar reconquistarlo, pero fue hecho prisionero por los franceses y trasladado a Loches (Francia) donde permaneció encarcelado hasta su muerte. 


\subsubsection{Diseño de ingeniería: estudios preliminares, los bocetos iniciales}

El conjunto del Proyecto del Caballo Sforza se encuentra principalmente en el Códice de Madrid II (el Códice de Madrid I es un tratado de Mecánica), en la Biblioteca Nacional. No obstante, hay documentación en los folios manuscritos de la Royal Collection de Windsor (British Royal Library) y el Códice Atlántico de la Biblioteca Ambrosiana de Milán. El conjunto de manuscritos de Leonardo fue testado por este a su discípulo y pintor Francesco Melzi (Milán, 1493 - Vaprio d'Adda, 1572/73?), quien los custodió adecuadamente hasta su muerte. Pero sus herederos los vendieron o donaron; de aquí su diseminación en diferentes códices, y por diferentes bibliotecas, fundaciones y casas reales que por su valor ambicionaban su propiedad o pertenencia.

Conocidos los objetivos del proyecto, se recopilan en este apartado los esfuerzos invertidos en su formación y en la consideración de soluciones alternativas, estudiando sus ventajas e inconvenientes.

Leonardo, conocidas por su padre las habilidades excepcionales para el dibujo y el aprendizaje artístico, es presentado en 1469 en el taller de Andrea Verrocchio (1436-1488) donde es aceptado inmediatamente. Aprende de su maestro pintura, escultura, grabado, arquitectura, ingeniería y música. Es conocida la anécdota de que colaboró con este en la pintura del Bautismo de Cristo, ejecutando los ángeles de su parte inferior. Al parecer, Verrocchio, al ver la perfección y belleza de sus caras y vestidos, que superaban con creces a las de la imagen principal de Cristo y el Bautista, decidió no volver a pintar jamás. Tras casi diez años desde su admisión, Leonardo se independizará.

En 1479 Verrocchio, por encargo de la ciudad de Venecia, arranca la estatua ecuestre en bronce sobre el Condottiero (mercenario) Bartolomeo Colleoni, pero muere antes de acabarla, atribuyéndose su finalización y fundición (sobre 1493) al orfebre Alessandro Leopardi (Venecia 1465-1523).

La estatua está instalada hoy en el Campo di San Zanipolo de Venecia y se da por cierto que Leonardo, aún colaborador del taller donde aprendió todas las técnicas de la fundición, fue partícipe en la elaboración de la obra por los estupendos acabados, el dinamismo, la postura del jinete mostrando movimiento, etc. Por ello se estima que al menos el modelo de arcilla salió de las finas manos del mismo. 


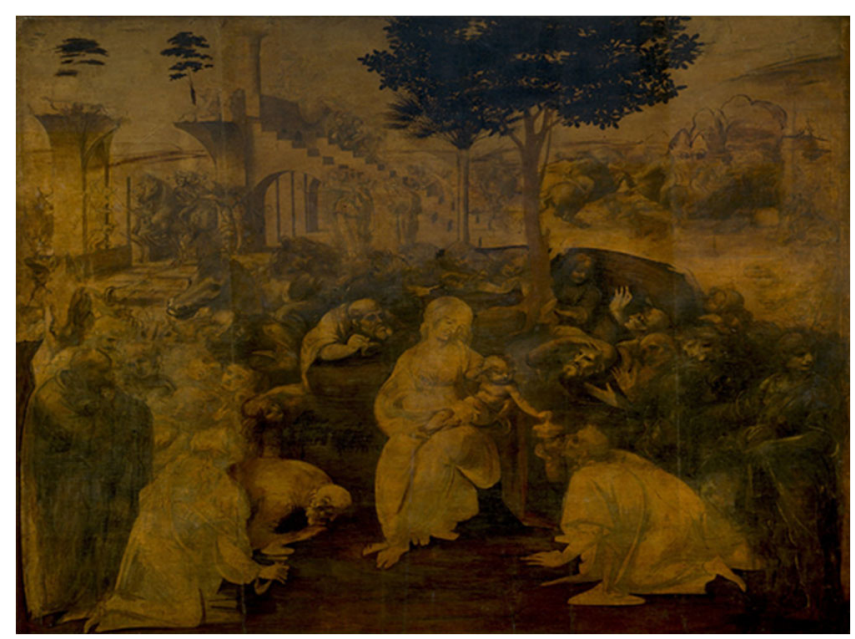

a)

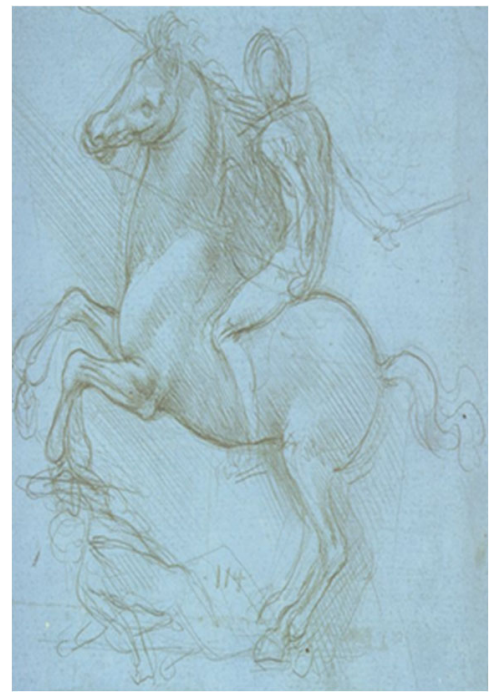

b)

Figura 12.3 a) Adoración de los Reyes Magos (fuente Wikipedia) (https://commons.wikimedia.org/wiki/File:Leonardo_da_Vinci_Adorazione_dei_Magi___Google_Art_Project.jpg), b) Folio de la Royal Library, Windsor Castle, sobre el estudio inicial del Caballo Sforza (https://commons.wikimedia.org/wiki/File:Leonardo_da_vinci,_Study_for_the _Sforza_monument_01.jpg).

Esta estatua junto con la estatua ecuestre de otro Condottiere, el general Erasmo da Narni, conocido como "Gattamelata" (sobre 1453, en bronce, 3,40 x, 3,90 m) realizada por Donato Di Betto Bardia ("Donatello", 1386-1466) y ubicada en la plaza de la basílica de San 
Antonio de Padua, eran las dos estatuas ecuestres en bronce más famosas y conocidas en la época.

Hasta aquel entonces todas las estatuas ecuestres de gran tamaño estaban en posición de apoyo en 3 de las 4 patas del caballo. Algunas de ellas, incluso colocaban motivos en la cuarta pata (a un enemigo caído, a un animal, una ola, etc.), para que sirviera de cuarto punto de apoyo.

En 1481, un Leonardo ya emancipado recibe el encargo de los mojes del Convento de San Donato en Scopeto (Florencia) para pintar el retablo del altar de su capilla con "La Adoración de los Reyes Magos", sobre tabla y al óleo. Decide llenar la perspectiva y fondo del cuadro de caballos en distintas y variadas posiciones, con jinete y sin jinete, lo que le otorga cierta originalidad al cuadro. Se conserva en la Galería de los Uffizi de Florencia.

Para llevarlo a cabo, Leonardo boceta y dibuja intensamente. Realiza numerosos dibujos y estudios preparatorios sobre caballos, incluyendo además una perspectiva lineal de una arquitectura clásica en ruinas que forma parte del fondo de la escena. Dejó inacabada esta obra por haber partido hacia Milán al año siguiente.

Para distinguirse de todo lo existente hasta el momento, concibe la idea de llevar a cabo el caballo en posición de encabritamiento, y así aparecen los primeros dibujos y bocetos para el Caballo Sforcesco. Pero debido a las dificultades físicas de ese diseño y de su estabilidad, acabará optando por la solución del "caballo al trote" pero con solo dos patas apoyadas en el suelo (Minués, 2009).

\subsubsection{Ingeniería del proyecto: el diseño de detalle o proyecto de ejecución}

En esta fase se precisa de formación específica y conocimientos técnicos para desarrollar con detalle y documentar una única solución, hacia la que se habrán hecho converger las estudiadas en la fase anterior. Esta solución definitiva debe quedar definida a nivel de subsistemas, componentes y partes, con el suficiente detalle para considerarse adecuada, con el fin de que otra persona con formación similar, sea capaz de entender los documentos redactados y dirigir por sí misma la construcción del objeto del proyecto de una manera adecuada, cumpliendo con los objetivos iniciales marcados en las fases anteriores. 
Leonardo utilizó, además de sus conocimientos artísticos, los de ingeniería y arquitectura (construcción, mecánica, metalurgia, ciencia y tecnología de materiales, mecánica de fluidos, etc.) que había ido adquiriendo a través de su paso por el Taller de Andrea Verrocchio y su propia experiencia y autoformación. Como fuente de información adicional, Leonardo poseía una excepcional biblioteca para la época (más de 150 libros de todas las materias del saber). Además, era amigo del matemático Luca Pacioli, con el que colaboró con dibujos, planos y figuras en el libro del matemático "La Divina Proporción".

La parte principal del Proyecto del Caballo Sforcesco se desarrolla en los manuscritos del códice de Madrid II, y se encuentra principalmente en su parte final. Existen 27 hojas manuscritas con dibujos, planos, croquis; y escritos (de manera especular) con datos, cálculos, estimaciones, mediciones, etc. Hay también alguna otra información y referencias en el Códice Atlántico y en los folios Códice Windsor.

A continuación, se muestra por su especial interés, parte la documentación disponible en la Biblioteca Nacional de España, relacionada con el "Proyecto Sforza" con el que Leonardo pretendía resolver las incidencias e inconvenientes para la creación de la estatua (http://leonardo.bne.es/index.html).

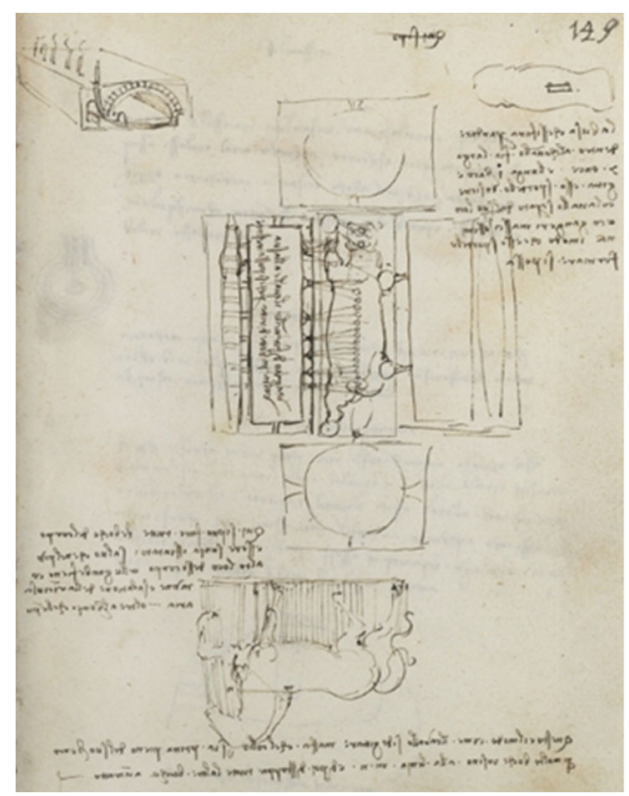


[Figura] [1348] [Figura]

La abertura que se practicara para acceder al interior del caballo será de 7 pulgadas [1349] de ancho y 1 codo de largo. Fundirás un portillon, junto con el caballo, separado de su stio y con pernos, macho y hembra, de tal manera que el portillon se pueda cerrar.

[Figura 1]

Interior de un homillo, el cual tiene una bóveda de cañón recta para facilitarlas mezclas [1350]

[Figura 2]

Aqui resulta posible hacer todas las bocas del cuerpo sin respiraderos, salvo en la parte mas ata del cuerpo. Y las patas tengan un respiradero común del aire encerrado, además del bronce que las rellena.

[Figura]

De esta manera se tiene que fundir el cabalo, pero procura que el cuello se rellene antes de bronce a través de muchas bocas hasta la línea $m \mathrm{n}, \mathrm{y}$ luego abre todas las otras bocas de una vez.

Figura 12.4 Detalle de f149r y traducción (http://leonardo.bne.es/index.html).

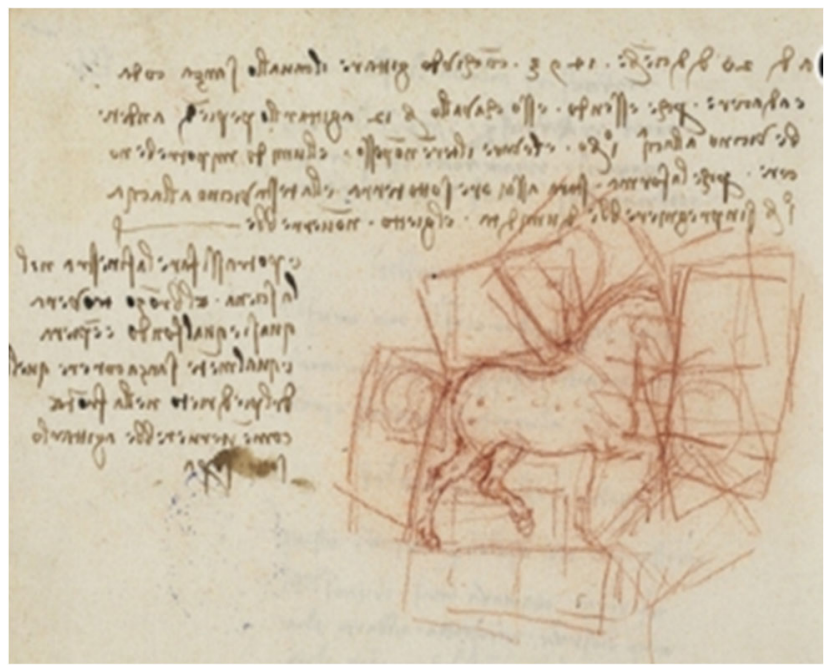


El dia 20 de diciembre de 1493 decidi finalmente fundir el caballo sin la cola y en posición tumbada porque, midiendo el caballo 12 codos, si lo fundiera por los pies, quedaria tan solo a un codo del agua, y como no puedo quitar mas tierra, la humedad la podria perjudicar ya que el molde deberá pemanecr bastantes horas bajo tierra, y la cabeza estando a un codo del agua, se impregnaria de humedad. Y la fundición fracasaria.

[Figura]

Y se podria practicar una abertura en el lomo. El bronce encontrara el fondo de igual manera y rellenara por igual, sin tener ir desde la pata de atrás hasta la frente, como sucederia si lo fundiésemos con las patas hacia arriba.

Figura 12.5 Detalle de f151v y traducción

(http://leonardo.bne.es/index.html).

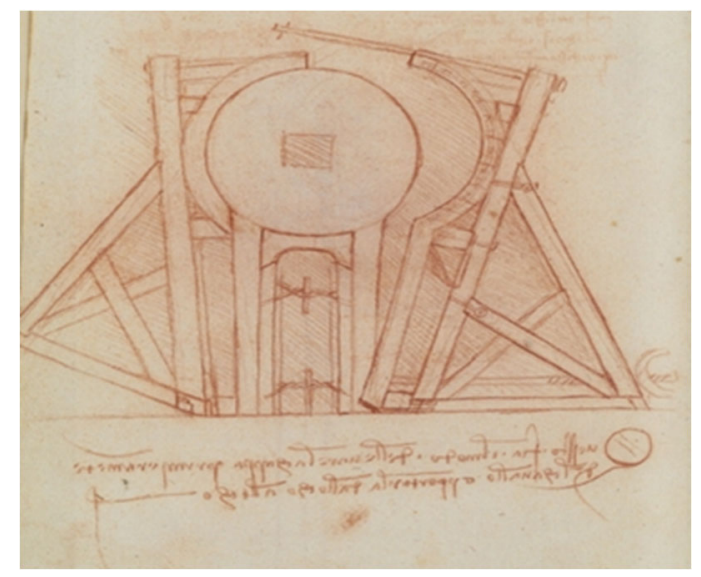

[Figura]

Esta es la manera de quitar, en primer lugar, el recubrimiento del caballo y de llevarlo de un sitio a otro

Figura 12.6 Detalle de f155v y traducción (http://leonardo.bne.es/index.html). 


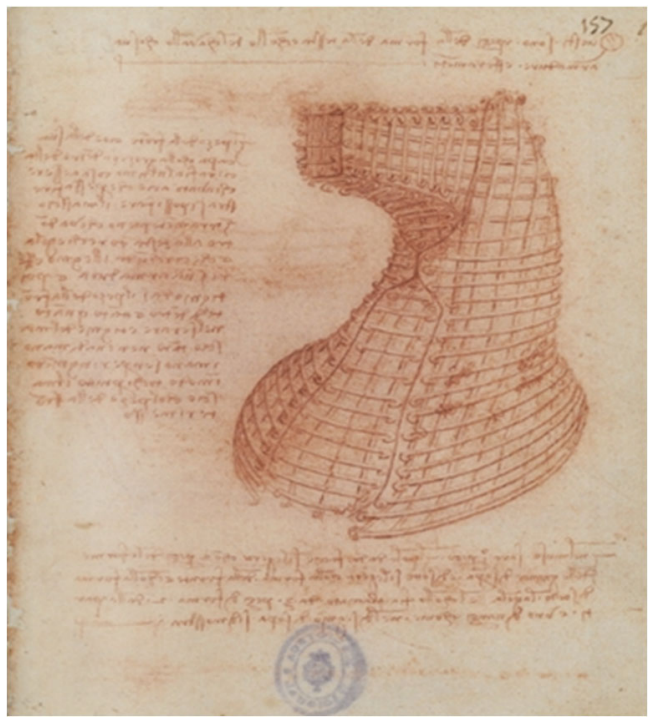

Estas son las piezas del molde de la cabeza y cuello del caballo con sus armaduras y herrajes.

\section{[Figura ]}

La pieza frontal, mejor dicho, el recubrimiento con el engrosamiento de la cera en su interior, ser la última cosa que se clave, con elf in de que por esa abertura se pueda rellenar por completo el macho, que va en el interior de la cabeza, orejasy cuello, y que está rodeado exteriormente por la maderay herraje de la armadura. Luego, retocarás la pieza de la frente por dentro y en la misma medida retocarás el macho, antes decerrar, e iras rebajando poco a poco mientras que retocas, de manera que el macho quede ajustado por completo con la piez a frontal, 7 una vez colocada.

En la parte del morro del caballo habrá una pieza que por dos de sus lados se unirá con las dos piezas correspondientes a las carriladas, y se unirá con la pieza de la frente, en cuanto a la parte de arriba, y con la de la garganta, por la parte de abajo. El cuello estará formado por tres trozos del molde, dos de las partes laterales y uno de la del antera, como está representado en el dibujo

Figura 12.7 Detalle de f157r y traducción

(http://leonardo.bne.es/index.html). 


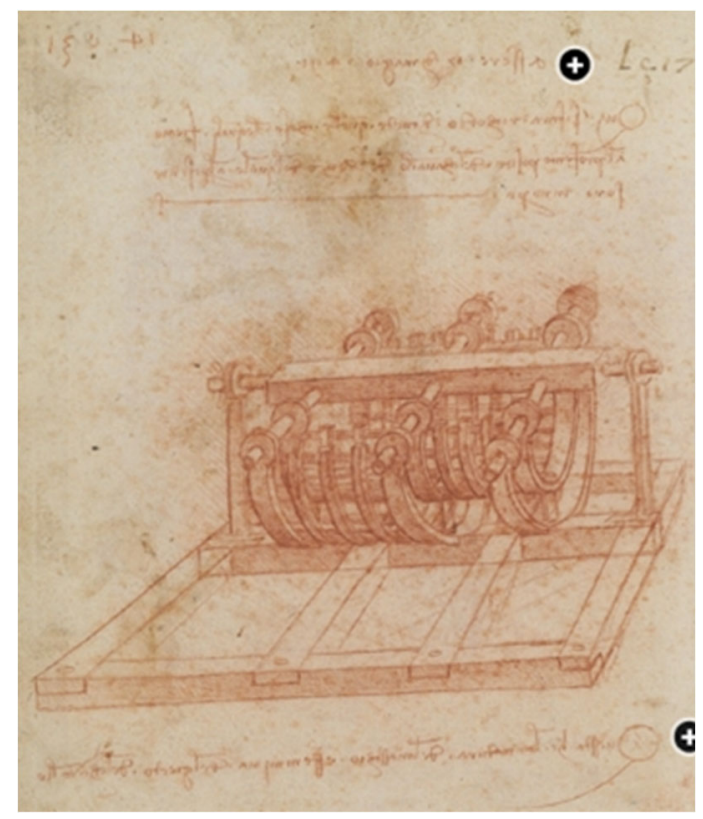

Le $17^{1384}$

14 y 31

17 de May o de 1491, por la tarde.

Aqui quedan registradas todas aquellas cosas que están relacionadas con el proyecto del caballo de bronce en el que estoy trabajando en la actualidad.

\section{[Figura ]}

Esta es la armadura del macho y de la hembra para la fundición del caballo.

Figura 12.8 Detalle de f157v y traducción (http://leonardo.bne.es/index.html).

También proyecta un habitáculo enterrado para la fundición y varios hornos en los laterales para, mediante canales, aportar a ésta la mayor cantidad de metal fundido en el menor tiempo posible.

En estos folios manuscritos pueden identificarse los documentos clásicos del proyecto. 
En lo que sería la Memoria, Leonardo identifica con detalle cada uno de los elementos constructivos necesarios para poner en marcha el objetivo del proyecto. Identifica perfectamente el sistema (el propio caballo), los subsistemas (el habitáculo y los canales para la fundición, los hornillos, etc.), los componentes (molde, modelo, etc.) y las partes (vigas para levantamiento y transporte del monumento, herrajes, etc.).

El lenguaje que emplea es directo y las instrucciones claras. Nótese que sobre todo el Códice II de Madrid es un "cuaderno" y a Leonardo le gusta dirigirse a un "lector imaginario" como si de un alumno suyo se tratará.

A partir de este momento se encuentran epígrafes que hacen referencia a los diferentes aspectos que deben tenerse en cuenta durante la ejecución de los trabajos. Estos epígrafes (“...cómo preparar la sal que se debe emplear en los moldes", "...sobre el macho, de la forma del horno", "... modo de aplicar la ceniza") permiten ordenar la ejecución de la obra cronológicamente y por partidas.

Durante el desarrollo de esta asimilación a memoria se encuentran epígrafes en los que las referencias a las magnitudes y proporciones son el objeto de atención del proyectista (“...cómo mantener el bronce en estado líquido.", "...cuánto metal corresponde por cada onza de cera", "...cálculo del peso del molde para averiguar la fuerza necesaria para su manejo...”.). Por lo que los cálculos también están definidos en el proyecto de una manera intrínseca. Especialmente interesante es el folio $\mathrm{f} 150 \mathrm{v}$, donde se indican proporciones relativas de bronce. Así en el texto traducido se indica, por ejemplo:

$<$

- $\quad$ Cuánto bronce corresponde para cada libra de tierra seca: A 100 libras de metal corresponden 16 libras de tierra seca.

- Cuánto bronce corresponde por cada libra de tierra mojada: 20 libras de tierra convenientemente mojada se corresponden de forma equivalente con 100 libras de metal porque, aunque la tierra contenga 4 libras de agua, dicha agua solo representa la porosidad de la tierra. Y cuando el líquido se evapora, la tierra no disminuye de tamaño, antes bien los poros que estaban ocupados por el agua, al perderla, se llenan de aire.>>

Su representación (Planos) se realiza "acompañando" a la descripción de tareas planteada en la memoria. En cualquier caso, se muestran 
perfectamente identificados los elementos constructivos y detallado el funcionamiento esperado de los mecanismos considerados.

Las ilustraciones son ricas y cuidadosas en los detalles. Más que un croquis técnico son propias de apuntes de un pintor. Cuando aparecen magnitudes, cotas, referencias o notas, se justifican en la literatura de la que se acompaña junto al dibujo. Leonardo está considerado como uno de los precursores del dibujo técnico.

El nivel de detalle de los dibujos es excepcional. El folio $149 \mathrm{r}$ del Códice de Madrid II, por ejemplo, dibuja los dos posibles hornos circulares de donde deberá salir el bronce hacia el habitáculo central destinado al molde. Igualmente aparece el negativo del caballo, que debería ser en un principio fundido cabeza hacia abajo. Mientras que en el folio157r, se observa los herrajes para el negativo del molde de la cabeza y cuello, con el fin de reforzar esa parte que recibirá mayores esfuerzos y facilitar su retirada posterior.

Realizó incluso un plano de alzado del modelo de arcilla del caballo, con toda la aparamenta, andamiaje y ataduras necesarias para su transporte, sin riego de caída, rotura, accidente, etc.

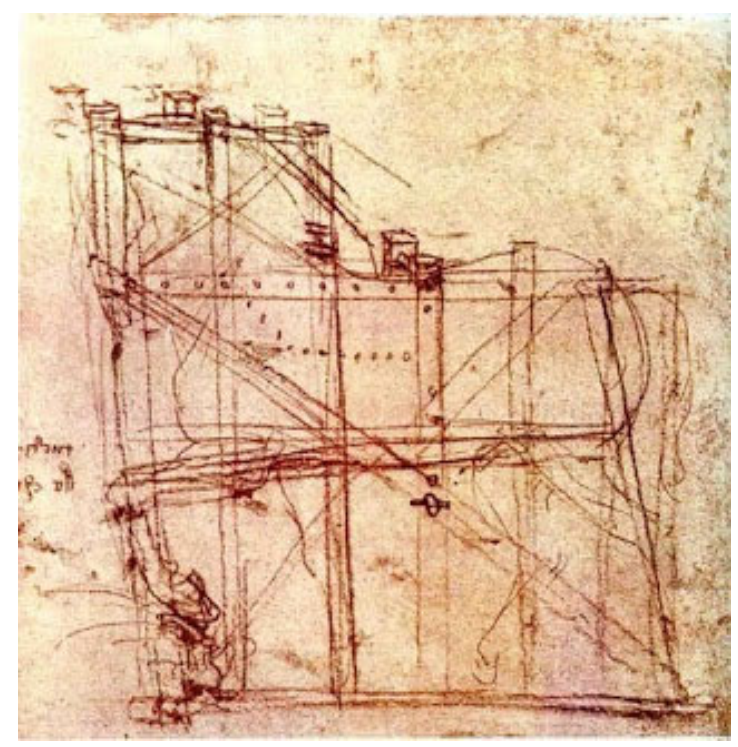

Figura 12.9 Croquis para el transporte del modelo de arcilla (Códice Atlántico Folio 577v)

(https://commons.wikimedia.org/wiki/File:Codex_Atlanticus_-_000V-577.jpg). 
En este proyecto, quizás porque era una necesidad o deseo Ducal (máxima autoridad de Milán) o por su novedad y magnitud, no se encuentran referencias claras a presupuestos o costes de materiales. Podría decirse que el encargo se realizó por "administración". En cambio, sí que existen referencias a la economía de materiales y su gestión óptima (evitando derrochar materiales, recursos $u$ operaciones) o a la justificación (y aval) de los trabajos de un artista artesano frente a otras tareas que podrían compararse pero cuya complejidad resulta menor (p. ej. fabricación de campanas en el torno).

En un proyecto posterior de menor envergadura, el mausoleo del Mariscal Trivulzio, Leonardo sí desarrolla un presupuesto de ejecución detallado de los costes del mismo (Vezzosi, 2011) (Figura 12.10).
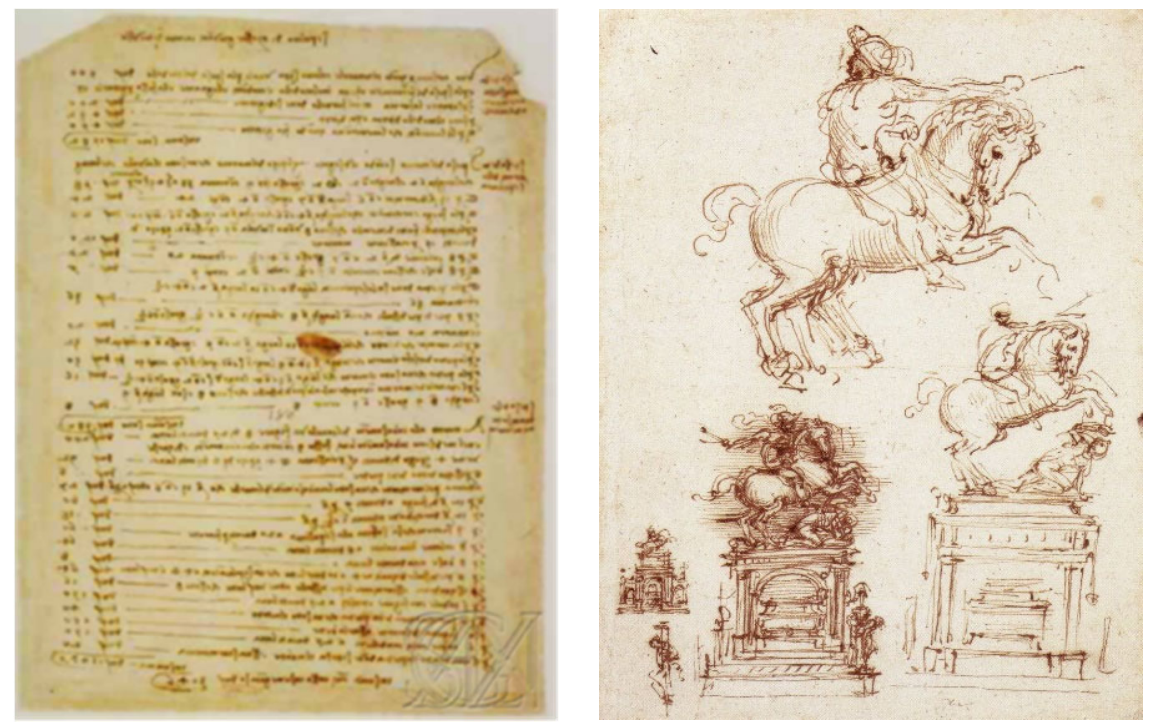

Figura 12.10 Presupuesto de ejecución del Mausoleo de Trivulzio folio 492r del Códice Atlántico (Biblioteca Ambrosiana de Milán).

(https://commons.wikimedia.org/wiki/File:Codex_Atlanticus_-_000R492.jpg? uselang=es-formal) y Boceto del monumento (Folio $123 \overline{5} 5$ de de la Royal Collection Trust, Windsor)

(https://commons.wikimedia.org/wiki/File:Leonardo_da_vinci,_Study_for_the _trivulzio_monument_02.jpg).

\subsubsection{Ejecución del proyecto. El gran caballo hecho realidad 500 años después}

Leonardo no pudo ver ejecutado su colosal caballo por los avatares de la historia. Pero en 1977, el piloto de aviación norteamericano Charles 
Dent se interesó en su realización. Utilizando los planos y escritos de Leonardo, modeló uno a pequeña escala, y promovió una fundación (www.leonardoshorse.org) para que financiara su construcción. Inició los pasos para realizar el de 24 pies $(7,32 \mathrm{~m})$ de altura, pero las distorsiones en el modelo de arcilla al agrandarlo y su repentina muerte en 1994, impidieron de nuevo su ejecución.

No obstante, las personas donantes de los fondos iniciales contrataron en 1996 a la prestigiosa escultora norteamericana Nina Akamu quien, con la empresa de fundición Tallix Art Foundri de Beacon (Nueva York), previos ajustes del proceso, consiguió realizarlo con las medidas proyectadas por Leonardo. Aunque en realidad, el conjunto de mayor tamaño (24 pies o 7,35 metros de altura) no ha sido realizado en una sola pieza, sino que es un ensamble de varias.

Curiosamente los donantes que lo financiaban decidieron regalar a la ciudad de Milán el primero de ellos, llamado "Il Cavallo", que se instala el 30 de septiembre de 1999 en Milán, en el Parque del Hipódromo San Siro, como tributo a Leonardo (500 años después de la destrucción del modelo de gran tamaño en arcilla de Leonardo, por los arqueros franceses que invadieron Milán).

Un mes más tarde se inaugura otro "el American Horse", de iguales características, también supervisado la escultora Nina Akamu, en concreto en el Parque Jardín de Esculturas Fedrick Meijer, en la ciudad de Grand Rapids (Michigan) (la Figura 12.11 fue extraída del blog de Nina Akamu).

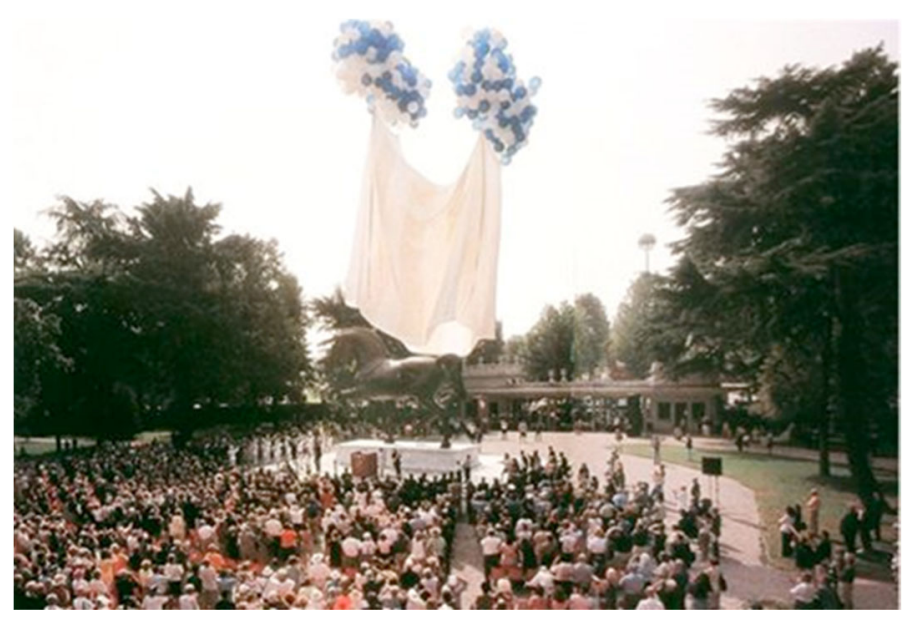




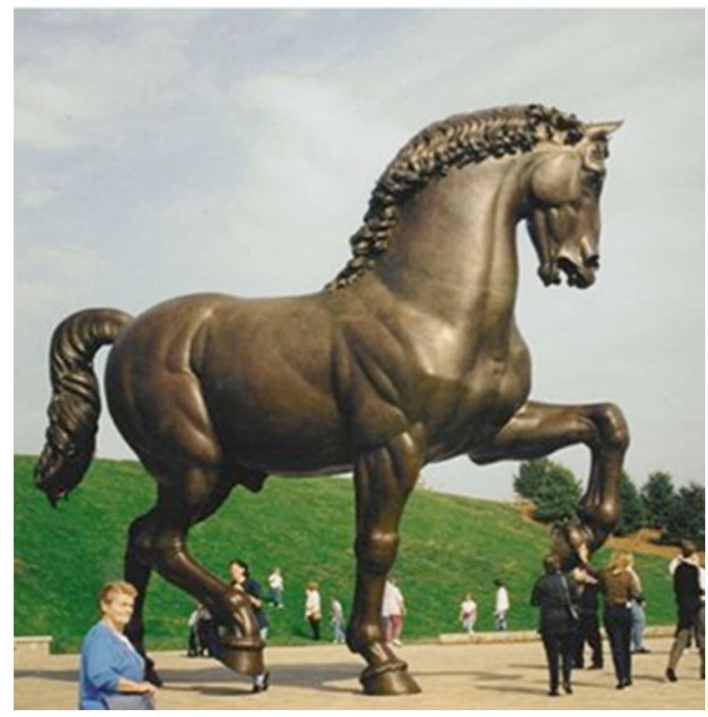

Figura 12.11 "Il Cavallo" de Milán y el "American Horse" de Grand Rapids (Michigan) (http://www.studioequus.com/24grandrm.html).

\subsection{Conclusiones}

A lo largo de este capítulo sobre el Proyecto del Caballo Sforza se han identificado claramente las diferentes fases en que se subdividen los Proyectos de Ingeniería en la actualidad y con los que la técnica y la ciencia están familiarizadas: el Diseño en Ingeniería, la Ingeniería del Proyecto y La Gestión del Proyecto.

Se puede concluir que Leonardo dibujó, redactó, y proyectó sus diseños técnicos, con metodologías muy similares a las actualmente promulgadas por la Ciencia del Proyecto. Aún hoy resulta admirable la imaginación, creatividad, y saber hacer del genio toscano en temas tremendamente multidisciplinares, así como el cuidado y orden con el que el genio de Vinci documentó los trabajos técnicos en los que participó.

\section{Referencias}

Capra, F. (2008). La ciencia de Leonardo. Editorial Anagrama: Barcelona.

Da Vinci, L. (2005). Aforismos. Traducción de E. García de Zuñiga. Círculo de Lectores. 
De España, J. (1943). Breviario de Leonardo da Vinci. Editorial El Ateneo: Buenos Aires.

Minués, V. (2009). Cuando el poder cabalga. Repositori UJIUniversitat Jaume I. Revista Memoria y civilización, $\mathrm{n}^{\circ}$ 12, $71-$ 108.

Vasari, G. (1550). Las vidas de los más excelentes arquitectos, pintores y escultores italianos desde Cimabue a nuestros tiempos, descritas por Giorgio Vasari, pintor natural de Arezzo. Con una útil y necesaria introducción a las artes de aquéllos. Obtenido de http://www.historia-del-arte-erotico.com/vasari/.

Vezzosi, A. (2011). Leonardo Da Vinci, ciencia y arte del universo. Ed. Blume: Barcelona. 



\title{
Capítulo 13 Síntesis y Conclusiones
}

\author{
"El buen juicio nace de la buena inteligencia y la buena \\ inteligencia de la razón, originada ella misma en las buenas \\ reglas, hijas de la buena experiencia, madre de todas las ciencias y \\ de todas las artes". \\ LEONARDO DA VINCI (Códice Atlántico, folio 216 v, de la Biblioteca \\ Ambrosiana de Milán).
}

\begin{abstract}
A lo largo de esta investigación se ha analizado la obra de Leonardo plasmada en sus manuscritos o códices de contenido técnicocientíficos conocidos actualmente, con el fin de identificar los principios y técnicas de diseño que Leonardo ideó, introdujo y/o mejoró y sobre los que se apoyan las metodologías, métodos y técnicas de diseño disponibles en la actualidad.
\end{abstract}

Así mismo se ha podido constatar cómo su formación autodidacta y multidisciplinar (con conocimientos en ingeniería, arquitectura, botánica, geología, física, química, música, etc.) le llevó a las más altas cotas del saber de su tiempo, en un sinfín de disciplinas, y a atreverse a realizar diseños y proyectos en numerosas áreas de conocimiento.

Para ello, se ha estudiado y analizado en el Capítulo 2, el conjunto de los manuscritos conocidos de Leonardo, que pueden considerarse la mayor muestra técnico-científica del Renacimiento, y que se organizan en los siguientes códices: el Codex Arundel (Londres, U.K.); el Códice Atlántico (Milán, Italia); los Manuscritos de Francia compuestos por 12 volúmenes, que hoy también incluyen los reabsorbidos Códices Ashburnham (París, Francia); el Codex Forster compuesto por 3 volúmenes (Londres, U.K.); los Folios de la Colección "Windsor"(U.K.); el Códice del Vuelo de los Pájaros o de Turín; el Códice Trivulziano (Milán, Italia); los Códices de Madrid formados por 2 volúmenes (España) y el Codex Leicester o Hammer (Seattle, USA), además de 
una cincuentena de hojas sueltas repartidas por varios museos y bibliotecas de varias ciudades de Europa y alguna de América.

El análisis se ha realizado desde el punto de vista técnico-proyectual, y después se ha establecido una división de los proyectos y diseños allí expuestos según las áreas de conocimiento técnico más representativas de hoy en día. O sea, los que corresponderían a la Ingeniería Industrial, los de Ingeniería Civil, los de Ingeniería Naval y Aeronáutica, los de Arquitectura y Urbanismo, y los de Ingeniería Militar, enumerando finalmente los más importantes según el área correspondiente. Complementariamente también se ha estudiado, en lo que se ha considerado dentro del alcance de la presente investigación, el Tratado de Pintura de Leonardo da Vinci, también denominado Códice Ubinate 1270 (h. 1550) (Ciudad del Vaticano), que aun no saliendo de sus manos, lo fue de su discípulo preferido Francesco Melzi (Milán, h. 1491-Vaprio de Adda, h. 1570), quien de manera coherente lo tituló bajo el nombre de su maestro, ya que todo el texto allí presente es copia recopilatoria de las enseñanzas del mismo y de extractos de otros de sus códices, algunos de ellos dados por desaparecidos en la actualidad.

Para completar la enumeración de las fuentes empleadas en la presente tesis, en el Capítulo 3 se relacionan los principales estudiosos e investigadores sobre Leonardo y su obra, siguiendo un criterio cronológico, exponiendo los aportes más significativos de cada investigador.

\subsection{Leonardo como diseñador y proyectista multidisciplinar}

Un aspecto sorprendente de Leonardo es la gran cantidad de áreas y campos en los que desarrolló su obra. La profesora titular del departamento de Diseño de la Universidad Tecnológica Metropolitana de Santiago de Chile, Giselle Goicovic, investigadora en los ámbitos de creatividad y psicología del pensamiento, aduce que esa formación transdisciplinar de Leonardo y su ansia de saber y aprender, fueron la clave de su éxito. El "mix" entre los conocimientos sobre el arte y la ciencia que llegó a alcanzar, junto con su espectacular imaginación (o "fantasía", como él la nombraba), le llevaron a producir algunas de las famosas pinturas más famosas de todos los tiempos, a generar proyectos de máquinas y artefactos no conocidos hasta entonces, así como a llevar a cabo descubrimientos científicos que fueron reafirmados más de 100 años después. Para la profesora Goicovic, 
Leonardo ejemplariza el modelo ideal del pensamiento creativo $y$ complejo, destacando que su estrategia principal para el diseño era aprender a través de la experiencia, mientras que para avanzar en ella y aumentar la formación y el conocimiento, es muy adecuado trabajar mediante la metodología de aprendizaje por proyectos (Goicovic, 2019).

Su facilidad de pasar de la ciencia al arte y viceversa, o de un área de conocimiento a otra, le llevaba a emprender todo tipo de proyectos o diseños. Al respecto, el escritor Christian Gálvez (Móstoles 1980) en su artículo "Aproximación a la mente de Leonardo da Vinci" escribe: $<<$ También conocemos ahora la mente de Leonardo, esa "inteligencia expansiva" a la que nos referimos al principio. Ya lo define Martin Kemp (2007, p. 91): nunca observó algo sin pensar en otra cosa: para él todo existía en una continuidad causa efecto. Leonardo da Vinci fue un pintor, científico, matemático, ingeniero, inventor, anatomista, escultor, arquitecto, urbanista, botánico, músico, poeta, filósofo y escritor. Pero lejos de permanecer impávido en cada una de las ramas del saber, Leonardo siempre buscó la sincronía entre los conocimientos para llegar a un objetivo común. Como ejemplo tenemos sus estudios de hidráulica. El Leonardo científico analizaba los movimientos del agua mientras que el Leonardo artista utilizaba esos experimentos para poder aplicarlos a sus bocetos y crear las ondas de los mechones de pelo de los retratos. Aplicaba el movimiento del fluido a la oscilación de los cabellos>> (Galvez, 2018).

La capacidad multidisciplinar de proyectar de Leonardo ya fue destacada por el poeta, ensayista y filósofo francés Paul Valery (Sète, 1871-París, 1945), en su libro “Introducción al Método de Leonardo da Vinci" (1895) en el que intentaba explicar cómo ocurre el acto creativo de un artista, tomando a Leonardo como ejemplo. Así escribió sobre este: <<Érase una vez un hombre que podía mirar el mismo fenómeno o el mismo objeto, ya como pintor, ya como naturalista, como físico o como poeta; y ninguna de estas visiones era superficial>> (Racionero, 1986).

\subsection{El aspecto morfológico de los proyectos de Leonardo}

Una cuestión que se consideró básica desde el principio de la investigación fue analizar la estructura documental utilizada por Leonardo para diseñar y plasmar sus proyectos. A lo largo de la tesis se encuentran suficientes ejemplos para poder afirmar que el aspecto 
formal de los proyectos de Leonardo presenta características similares a la estructura documental clásica utilizada habitualmente en la actualidad. Así, encontramos que sus proyectos más representativos, como el Proyecto del Monumento del Gran Caballo Sforcesco que le encargó el Duque de Milán Ludovico el Moro (Vigevano, 1452 Loches, 1508) en honor a su padre Francesco Sforza (San Miniato, 1401- Milán, 1466), y el Proyecto del desvío del Río Arno a su paso por Pisa, a petición de la ciudad de Florencia, ya disponen de los documentos clásicos del proyecto: la Memoria, los Planos y el Presupuesto, si bien al documento que hoy conocemos como Pliego de Prescripciones Técnicas, Leonardo no le otorga la categoría de documento independiente sino que lo muestra como un texto complementario acompañando al propio dibujo o plano como solución aclaratoria, en el que suele incluir las características, composición, etc. de lo representado, y la manera de llevar a cabo su ejecución; y suele dirigir esas prescripciones de ejecución como una indicación al posible lector o al futuro ejecutor del proyecto o diseño hacia la futura realidad, con frases como "deberás...", tendrás....", "harás....", "comprobarás....", etc.

La investigadora y directora del Departamento de Patrimonio Bibliográfico de la Biblioteca Nacional, Teresa Mezquita, en su artículo "Hallazgo en Madrid" refiriéndose al redescubrimiento de los Códices de Madrid I y II, en el año 1965, escribe respecto a Leonardo y sus códices: <<Su obsesivo afán de perfección, el "Ostinato rigore" de su divisa, le hacía volver una y otra vez sobre los mismos temas en diferentes cuadernos y no dar nunca algo por terminado. Plasmaba su pensamiento en un dibujo, numero de página, y añadía después textos explicativos>> (BNE, Códice Madrid II, f. 112r) (Mezquita, 2018).

También fue el primero que añadió letras indicadoras sobre los dibujos para orientar en el diseño práctico y en las aclaraciones en las leyendas de estos. Así se expresa Paul Mijksenaar (1944, Amsterdam), profesor de la University of Technology de Delft, en el libro "Abrir aquí. El Arte de diseño de Instrucciones": <<Leonardo da Vinci fue el primero que añadió letras a los dibujos científicos. Su método derivaba de las demostraciones geométricas en la tradición de Euclides. El sistema de referencia de da Vinci se adoptó rápidamente >> (Mijksenaar, \& Westendorp, 2000).

En el Capítulo 11 se amplían estos conceptos con detalle, al analizar minuciosamente el Proyecto del Gran Caballo Sforcesco, que aunque Leonardo solo llegó a proyectarlo y a realizar una maqueta o modelo 
de tamaño natural del mismo (7,35 metros) en arcilla (destruida por los soldados franceses que invadieron Milán en 1499), fue construido finalmente en 1999 por la escultora americana Nina Akamu, (1955, Midwest City, Oklahoma), llegando a producir cuatro unidades del mismo en la Fundición artística Tallix, sita en Beacon, New York. Las dos del tamaño proyectado por Leonardo se encuentran, una en Milán (ciudad donde mayoritariamente vivió Leonardo) denominado "II Cavallo", y otra en Michigan, denominado el "American Horse". La tercera, de la mitad de altura $(3,68 \mathrm{~m})$, se ubica en Allentown (Pensilvania), ciudad de nacimiento del piloto de aviación norteamericano Charles Dent (1917 -1994), iniciador de la fundación "Leonardo da Vinci's Horse, Inc." (LDVHI) que financió la construcción de los monumentos. Y finalmente una cuarta, más pequeña (de 2,27 $m$ de altura) se encuentra en Vinci, ciudad de nacimiento de Leonardo.

En cuanto a otros documentos complementarios que hoy en día son imprescindibles en todo proyecto técnico, como los Estudios de Seguridad y Salud y la Ergonomía, cabe hacer constar que Leonardo ya los tuvo en cuenta en muchos de sus diseños. Igualmente, Leonardo también tiene en cuenta y estudia las capacidades humanas, las de algunas de sus máquinas, y las de otras ya existentes, y establece rendimientos conjuntos en algunos de sus proyectos, adelantándose a lo que hoy en día en el ámbito proyectual se conoce como "Estudio del Trabajo". Estos temas se han tratado en detalle en los correspondientes apartados del capítulo 4.

\subsection{Contribución de Leonardo al desarrollo de las técnicas gráficas para el diseño/proyecto}

Leonardo utilizó innumerables técnicas gráficas, algunas recuperadas de la antigüedad, y otras muchas creadas por él, debido a su deseo constante deseo de experimentar y mejorar las herramientas y medios existentes. Por ello trató de otorgar carácter científico a la producción artística, utilizando el dibujo como base de esa producción artística y como ayuda al conocimiento; no solo en la pintura, sino también a la generación de mapas, planos constructivos de máquinas o de mecanismos, o incluso en sus dibujos anatómicos. Todas estas técnicas las plasmó tanto en sus manuscritos y códices, como en su Tratado de Pintura, y algunas de ellas siguen siendo válidas en la actualidad. 
Así, puede considerarse el precursor de los actualmente denominados "diagramas de explosión" que utilizó tanto en la representación de sus proyectos de máquinas y artefactos como en las de sus estudios anatómicos. También es pionero en el uso de lo que hoy se denomina gráficos de "familias de recorridos", válidos para representar un parámetro o una variable que varía en función de otra. Las utilizó en sus investigaciones para expresar los alcances de la salida del agua en función de la altura tanto en canales abiertos como en depósitos cerrados, o para ilustrar, como él creía, la proporción geométrica del esfuerzo de las bestias de tiro en función de la carga de los carros, etc. El historiador y teórico del arte francés Daniel Arasse (París, 19442003) estableció al respecto: <<Leonardo representaba objetos mediante sus incisivos esquemas, de manera que constituían verdaderos "modelos conceptuales" >>.

También es autor de varios planos y mapas, sobre todo de ciudades y terrenos vinculados a las regiones Toscana y Romaña, realizados "a vista de pájaro", con una perfección inusual cuando aún no era posible tener medios para elevarse y realizar el dibujo desde el aire. Algunos ejemplos serían: el mapa de la Umbria y del lago Trasimeno (1502) RLW 12278, (Royal Library, Windsor); el mapa de "Arezzo" y Valle de Chiana (1502) RLW 12682, (Royal Library, Windsor); o el mapa de la ciudad amurallada de Imola (1502) RLW 12284, (Royal Library, Windsor). La mayoría de estos mapas fueron realizados cuando estuvo al servicio de César Borgia (Roma 1475-Viana 1507), hijo del Papa Alejandro VI, Roderic de Borja, (Játiva 1431-Roma 1503), durante sus campañas guerreras, siendo nombrado arquitecto e ingeniero general del papado.

Además, mejoró la perspectiva, cuyas bases conocía perfectamente al haber estudiado a Alhazen (Irak, 968- Egipto, 1040). Era también conocedor de la Teoría Intelectual (los objetos parecen más pequeños cuando más lejos estén), establecida por el arquitecto florentino Filippo Brunelleschi (Florencia, 1377- 1446), y su ampliación por el artista genovés León Battista Alberti (Génova, 1404-Roma, 1472), en su libro de 1436 "De Pictura". Leonardo se percató de que la visión geométrica, que encuadra al objeto en un haz de líneas (denominado pirámide visual) que convergen en un punto de fuga, tienen la limitación de que la visión ocular es esférica y binocular, y que no tiene en cuenta la pérdida de nitidez con la lejanía. Así, establece: <<Cuando pintes del natural, refleja en el lienzo todo lo que veas, pero debes esforzarte por asimilar los elementos invisibles. He ahí el secreto de la profundidad y el realismo >> (Galland, 2014). 
De esta manera, las innovaciones en perspectiva que propuso fueron la perspectiva cromática o del color (la difuminación de los colores en relación con las diversas distancias) y la perspectiva menguante o de la desaparición, que tiene en cuenta los efectos propios de la atmósfera y de la distancia sobre la visión de los colores y su percepción (pérdida de determinación de los cuerpos en relación con las diversas distancias). El conjunto de todas estas técnicas acabará completándose con su especial técnica del "sfumato", consistente en un sutil sombreado por todo el cuadro (para Leonardo las sombras son tan importantes como la luz, ya que de ellas depende el efecto relieve), pero más resaltado en la cara y en las manos, que confieren al cuadro una inquietante latencia de vida. Estas técnicas fue aplicándolas a cada una de sus obras pictóricas, siendo el ejemplo más preclaro de su utilización el de la Gioconda o Mona Lisa del Museo del Louvre (París).

La escritora y catedrática de Ciencias y Técnicas Historiográficas de la Universidad Complutense de Madrid, Elisa Ruiz García, lo establece además como pionero de otra técnica, descrita en el Códice de Madrid II, consistente en un efecto óptico nominado por el propio Leonardo con el término "lustro o riverberazione": <<"La reverberación participa bastante más del color de la luz que ilumina el cuerpo representado que el color del propio cuerpo. Y este efecto se produce en superficies opacas" (Leonardo da Vinci, Códice de Madrid II, BNE, mss. 8936, f. 26r>> (Ruiz, 2018).

Por otro lado, Leonardo, huyendo de las pinturas de carácter estático del Quattrocento, descubre que solapando varias posiciones de una figura, superpuestas en una misma vista, se consigue dar movilidad y movimiento a la figura representada. Es lo que se denomina técnica de superposición que utiliza en varios de sus Estudios de caballos. Igualmente la usa en su diseño del hombre perfecto o de las divinas proporciones, conocido como el Hombre de Vitruvio (1490), de la Galería de la Academia de Venecia.

Finalmente, también recupera soluciones de la época helenística como el escorzo, consistente en el modo de representar la realidad como dispuesta perpendicular $u$ oblicuamente al plano donde es representada. La perspectiva de lo representado debe ser más exagerada de lo habitual, así la utiliza en algunos de sus estudios anatómicos de los músculos humanos y en los bocetos de "cabezas de apóstoles" para La Última Cena. Y también utiliza la "serpentinata", que consiste en disponer las figuras en forma 
helicoidal ascendente (forma de "serpentina"), o sea girando sobre sí mismas, lo que da la sensación de un movimiento giratorio contorsionado; ejemplos de ello son sus estudios sobre Leda, el Martirio de San Sebastián y el Neptuno con los caballos marinos. Finalmente utilizó la anamorfosis, cuando la referida distorsión de escalas es llevada a un grado exagerado y acaba convirtiéndose en un anamorfismo, consistente en deformar el dibujo o la imagen, y siendo necesario que, para observarlos de manera más natural, se precise situarse desde un punto de vista diferente al habitual.

En frase del profesor universitario, crítico de arte italiano y director del "Museo Ideale Leonardo da Vinci", Alessandro Vezzosi (Italia, 1950), uno de sus mejores biógrafos en la actualidad, Leonardo utilizó <<un método de representación que otorga toda su fuerza a las formas y a los caracteres $>$ (Vezzosi, 2011).

Todo lo concerniente a las técnicas gráficas en las que Leonardo fue pionero e introdujo en sus proyectos y diseños, así como lógicamente en sus pinturas, se ha desarrollado en el Capítulo 7 del presente documento.

\subsection{Contribución de Leonardo al desarrollo de los instrumentos operativos para el diseño/proyecto}

Leonardo también dejó constancia de la creación o mejora de varios instrumentos y herramientas relacionados con el mundo del diseño/proyecto en varios de sus Códices. Su genialidad y creatividad le llevó a innovar de manera constante en cualquier campo del conocimiento, y el ámbito del dibujo y el diseño no fue una excepción. Entre sus invenciones y mejoras de instrumentos al servicio del dibujo, cabe destacar que mejoró tanto los compases de apertura ajustable (folios 48r y 696r del Códice Atlántico de la Biblioteca Ambrosiana de Milán, y folio $108 \mathrm{v}$ del Manuscrito $\mathrm{H}$ de Paris) como los proporcionales (folios 1046r y 672r del Códice Atlántico y folio $4 r$ del Manuscrito I del Códice Forster del Victoria Albert Museum de Londres); y que inventó un compás parabólico (Códice Atlántico f. 1093r), un elipsógrafo o compás oval, así como uno para trazar epicicloides (Códice Arundel folio 160v de la British Library de Londres).

Igualmente mejoró el prospectógrafo o máquina de perspectiva, que popularmente se conocería como la "ventana de Leonardo", mostrando un diseño de este en el folio $5 r$ del Códice Atlántico. 


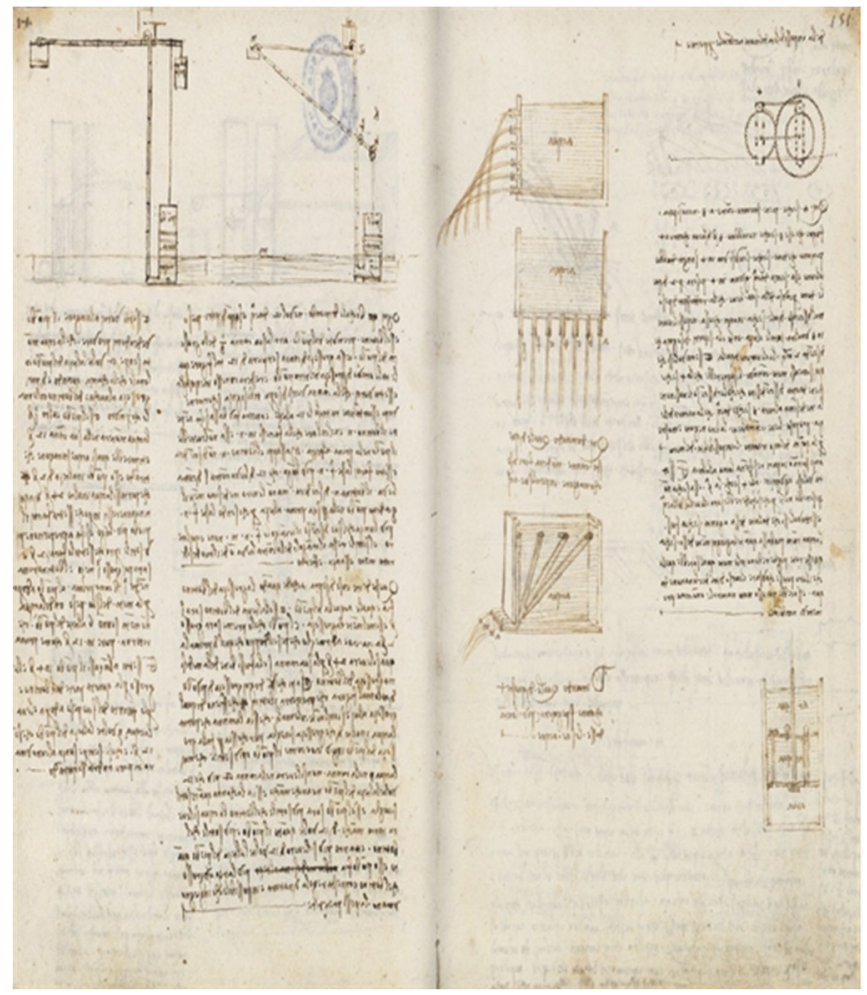

a) 


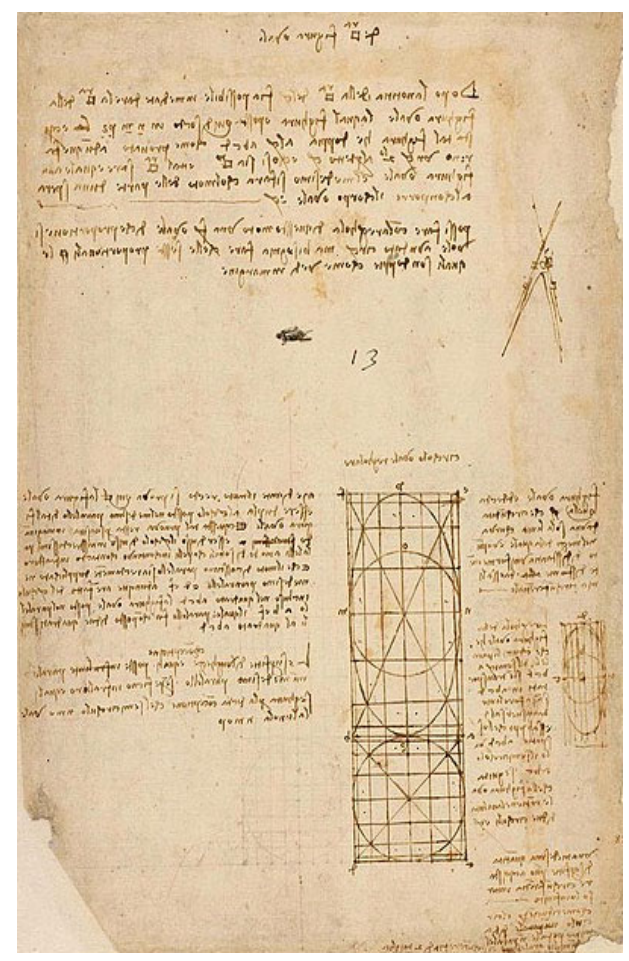

b)

Figura 13.1 a) Ensayos hidráulicos del Códice de Madrid I, f. 150v y 151r (origen de la imagen: http://leonardo.bne.es/index.html). b) Diseño de compas y de construcción de una elipse Cod. Atlántico f. 1032r (origen de la imagen: https://commons.wikimedia.org/wiki/File:000R-1032.jpg)

El odómetro, instrumento que permite medir largas distancias, atribuido al matemático, ingeniero y astrónomo griego Arquímedes de Siracusa (287 a.C.- 212 a.C.), también fue mejorado por Leonardo, quien diseñó dos modelos, uno en forma de carro con dos ruedas de apoyo delanteras, y otro, más pequeño, en forma de carretilla (Códice Atlántico f. 1r), apto para medir longitudes con las unidades establecidas por aquel entonces ("braccias"). A este incorpora una mejora mediante dos ruedas dentadas, una vertical solidaria a la rueda que recorre el camino, y otra horizontal, con una relación de transformación adecuada entre las dos. Esta última lleva incorporada unas bolas que caen a un recipiente inferior por cada milla recorrida, de manera que bastaba contar las bolas para saber la distancia. $<<$ Diseñada para avanzar un diente cada 10 braccias recorridas 
(alrededor de 6 metros), hasta que, al llegar a los mil seiscientos metros (una milla), un guijarro caía de un modo audible en un recipiente de metal >> (Capra, 2008). En el mismo folio muestra un podómetro o instrumento de medida de pasos, de la persona que lo llevaba.

Finalmente estudió y amplió el conocimiento de las "cámaras oscuras", estableciendo mejoras técnicas y su uso como herramienta auxiliar del dibujo y la pintura. Al respecto, en el Códice Atlántico f. 10 $r$, diseña un proyector de luz, mientras que en folio 337r, muestra detalles de similitud de la visión del ojo y de la cámara oscura. Por otro lado, en el Manuscrito D, f. $3 \mathrm{v}$ de la Biblioteca del Instituto Nacional de Francia, establece cómo realizar un ensayo para la demostración del mecanismo de funcionamiento del ojo humano por medio de un modelo de vidrio; <<"Ha llenado de agua un globo transparente, que representa el globo ocular, y en su parte delantera ha colocado una placa con un pequeño agujero en el centro, que representa a la pupila. En el centro del globo hay suspendida una bola de cristal delgado que representa al cristalino", detrás de la cual Leonardo sitúa su propio ojo debajo del agua, en la posición del nervio óptico. "Tal instrumento enviará imágenes [...] al ojo de la misma manera que el ojo las envía a la facultad visual">> (Capra, 2008).

En el Capítulo 8 del presente documento se ha analizado las aportaciones de Leonardo a los instrumentos operativos relacionados con el mundo del diseño.

\subsection{Leonardo como diseñador y proyectista sistémico.}

Leonardo estudió el cuerpo humano con minuciosidad, realizando más de 30 disecciones, junto con otras tantas de animales, y lo plasmó en los dibujos (el esqueleto y sus huesos, el sistema nervioso, los músculos, etc.) existentes en la Colección Windsor, no superados en detalle, rigor y perfección hasta el siglo XIX. Ello le llevó a entender al cuerpo humano como sistema, y como necesidad de estudio conjunto, considerándolo como un microcosmos.

Al respecto, el catedrático de Historia del arte de la Universidad de Oxford, Martin Kemp (Reino Unido, 1942), escribe: <<...que pudiéramos alcanzar un entendimiento veraz de las maravillosas formas y funciones del cuerpo como un todo y de cada una de sus partes. Con tal propósito muestra los componentes del cuerpo no solo en su forma sólida (a menudo bajo perfiles transparentes del 
cuerpo) sino también seccionados de modos diversos y dibujados uno separado del otro en diagramas "proyectados" -a veces incluso en versiones que funcionan como si viéramos a través de ellas- $y$, luego, transformados en diagramas lineales que explican las acciones de cada órgano. Absolutamente todas las técnicas de ilustración anatómica que habrían de emplearse en los distintos manuales de medicina y anatomía hasta el siglo XIX fueron cultivadas precozmente por Leonardo >> (Kemp, 2006).

Al mismo tiempo entendió que la Tierra, a la que denominó macrocosmos, precisaba de ser analizada también de manera conjunta, ya que creía que existía interrelación entre todos los fenómenos que ocurren en ella. En base a ellos, extrapoló ese concepto sistémico a todos sus proyectos/diseños. Descompuso los diseños de máquinas existentes, examinó el conjunto de componentes necesarios, e ideó y plasmó conjuntos modulares de componentes para su utilización en los proyectos de nuevas máquinas y artefactos.

Leonardo escribe al respecto en sus cuadernos de notas: $<<$ ¿Qué valor puede tener el que se dedica a abreviar las partes de las cosas, cuando pretende dar su conocimiento integral y deja tras de sí la mayor parte de lo que compone el todo?>> (García, 2005).

De similar manera, el profesor universitario e investigador Fritjoff Capra, escribe refiriéndose a Leonardo: <<Para él, comprender un fenómeno significaba ponerlo en conexión con otros fenómenos mediante una semejanza de modelos. Cuando estudió las proporciones del cuerpo humano, las comparó con las proporciones de los edificios de arquitectura renacentista. Sus investigaciones sobre músculos y huesos lo condujeron a estudiar y dibujar engranajes y palancas, interrelacionando así la fisiología animal y la ingeniería. Los modelos de turbulencia en el agua lo llevaron a observar modelos similares en la corriente del aire; y de allí pasó a explorar la naturaleza del sonido, la teoría de la música y el diseño de instrumentos musicales. Esta habilidad excepcional para interconectar observaciones e ideas procedentes de distintas disciplinas anida en el corazón mismo del enfoque de Leonardo tenía del conocimiento y la investigación >> (Capra, 2008). 


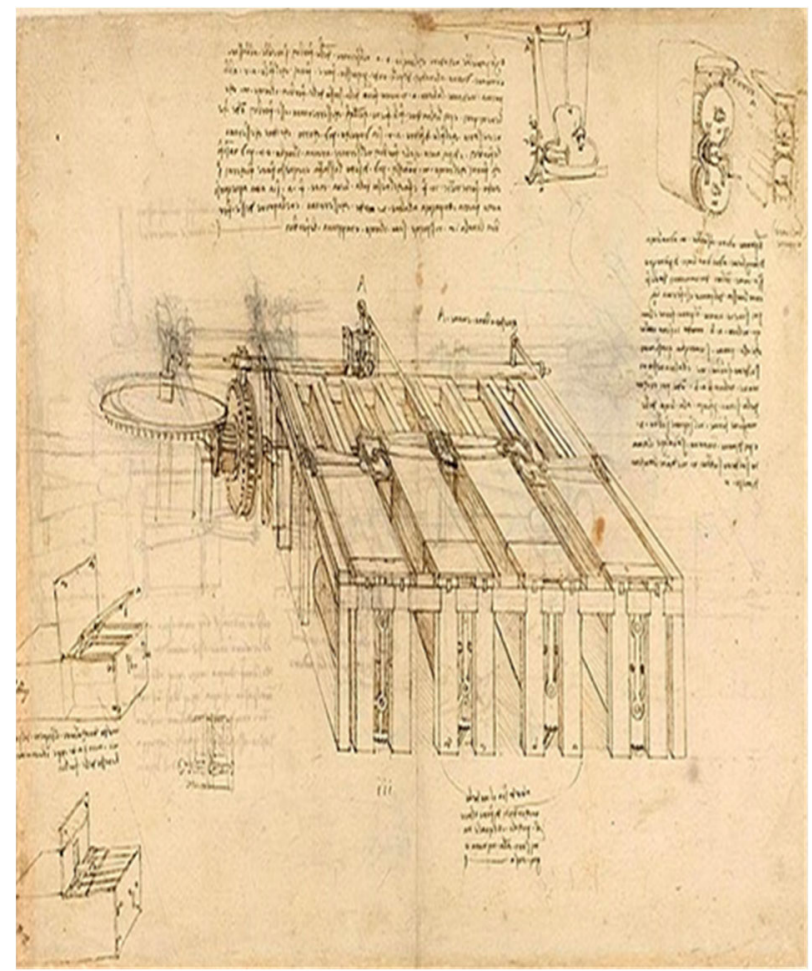

a) 


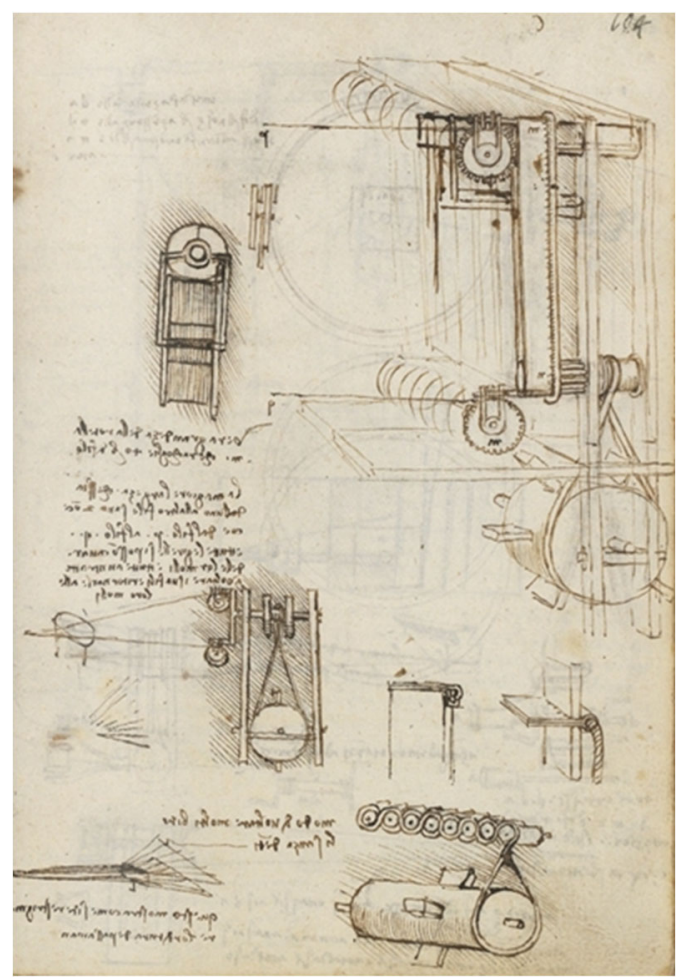

b)

Figura 13.2 a) Proyecto de máquina textil: "tundidora mecánica" (h. 1495), Cod. Atlántico f. 1105r (origen de la imagen:

https://commons.wikimedia.org/wiki/File:000R-1105.jpg?uselang=es). b)

Máquinas varias Cod. Madrid I, f. 104r (origen de la imagen: http://leonardo.bne.es/index.html).

Y citando de nuevo al catedrático de historia del arte $\mathrm{M}$. Kemp, con referencia al diseño de conjunto de componentes maquinales: $<<D a d a$ su insistencia en la anatomía racional de las máquinas, resultaba natural que Leonardo intentara diseñar un conjunto de componentes dados que, al combinarse, pudieran crear cualquier variedad de "nuevo" cuerpo. Los ingenieros anteriores se habian dedicado a construir máquinas complejas, pero Leonardo dirigía su atención a los "elementos" de las máquinas, es decir, componentes que potencialmente eran útiles más allá de un solo contexto: un componente diseñado adecuadamente, uno cuyas matemáticas fueran correctas, debería tener una explicación universal. Así pues, nos encontramos con dibujos maravillosamente sucintos de 
rodamientos de rodillos, ejes, goznes, engranes, trinquetes, levas, empalmes, resortes, etc. Cualquier tipo de cuerpo nuevo, podría ensamblarse potencialmente a partir de éstos para llevar a cabo cualquier función designada. En los mejores ejemplos, estos diseños cuentan con ese aire de compacta inevitabilidad que nos lleva a preguntarnos por qué a nadie se le había ocurrido antes >> (Kemp, 2006).

También el catedrático de Ingeniería de Fabricación de la Universidad de Zaragoza, Fernando Torres Leza, en la presentación que hizo de la exposición "Leonardo y las Ciencias" en el Museo de la Ciudad de Madrid, en 2003, establece: <<En el siglo XIX el alemán Franz Reuleaux editó un manual con la totalidad de los elementos constructivos de los mecanismos conocidos hasta la fecha, y la mayor parte de ellos habian sido ya dibujados por Leonardo, excepto uno de los tipos: los remaches. El diseño de los más avanzados ingenios le lleva a dibujar tanto las máquinas conocidas en su época como otras mejoradas >> (Torres, 2003).

Al carácter sistémico de los proyectos y diseños de Leonardo, que impregna toda su obra y pensamiento, se le ha dedicado el apartado 3 del Capítulo 4 de este documento.

\subsection{Leonardo como diseñador empírico/ científico}

Como se ha presentado, una de las fuentes principales de conocimiento de Leonardo fue la propia experimentación. Ensayó, modelizó y construyó maquetas de un sinfín de sus diseños, bien para probar sus posibles resultados antes de su realización posterior, bien como método de investigación.

Al respecto, Capra escribe: <<Las autoridades condenaban los experimentos científicos y cualquier crítica a la ciencia de Aristóteles era para ellas un ataque a la Iglesia. Leonardo rompió con esta tradición cien años antes que Galileo y Bacon, desarrollando por sí solo un nuevo enfoque empírico de la ciencia, que implicaba:

- La observación sistemática de la naturaleza.

- El razonamiento lógico.

- Ciertas formulaciones matemáticas.

Precisamente las características principales de lo que se conoce como método científico>> (Capra, 2008). 
Leonardo ya hace constar en su Manuscrito A, f. 47r de la Biblioteca del Instituto Nacional de Francia: <<Antes de establecer una regla general para este caso, ponla a prueba dos o tres veces y observa si las repeticiones producen los mismos efectos $>>$, mientras que, en el Manuscrito M, f. $57 \mathrm{r}$ de la misma Biblioteca, escribe: $<<E s t e$ experimento debería realizarse varias veces; a fin de que ningún accidente entorpezca o falsee la prueba >>.

$Y$ con referencia a complementar matemáticamente lo probado, escribe en su Manuscrito G, f. 96v también de la Biblioteca citada: $<<$ No existe ninguna certeza en aquello a lo que no pueda ser aplicada alguna de las ciencias matemáticas, o bien alguna de las que están relacionadas con ellas >>.

Lo que confirma a Leonardo como un precursor de lo que hoy denominamos método científico, si bien lo habitual es encontrar atribuida dicha paternidad al tándem Galileo - Descartes, más de cien años posteriores a los pronunciamientos de Leonardo.

Así lo confirma el profesor Capra: $<<$ Quinientos años antes de que el método científico fuera reconocido y formalmente descrito por filósofos y científicos, Leonardo da Vinci desarrolló y practicó en solitario sus características esenciales: el estudio de la literatura disponible, las observaciones sistemáticas, la experimentación, las mediciones cuidadosas y reducidas, la formulación de modelos teóricos y los frecuentes intentos de generalizaciones matemáticas. $>>$. Y también: $<<$ La concepción orgánica de la vida, propia de Leonardo, siguió durante siglos su curso como una corriente subterránea de la biología, con breves períodos en los que emergía y dominaba el pensamiento científico. No obstante, ninguno de los científicos de este linaje reparó en que el gran genio del Renacimiento ya había anticipado muchas de las ideas que ellos exploraban. Mientras los manuscritos de Leonardo acumulaban polvo en antiguas bibliotecas europeas, Galileo Galilei era celebrado como el "padre de la ciencia moderna". No puedo sino sostener que el verdadero fundador de la ciencia moderna fue Leonardo da Vinci, y me pregunto cuál habría sido el desarrollo del pensamiento científico en caso de que los cuadernos de notas se hubiesen conocido y estudiado poco después de su muerte>> (Capra, 2008). 


\subsection{Las analogías como fuente de la creatividad en el diseño de Leonardo}

Una buena manera de generar soluciones o nuevas creaciones es utilizar las "analogías" mediante el análisis y abstracción de elementos existentes, como animales, objetos, etc. y aplicarlo por asimilación a los nuevos productos o elementos que pretenden diseñarse. Generalmente se encontrarán formas o funciones parecidas que podrán ayudar en el proceso creativo.

El Catedrático de Historia del Arte de la Universidad de Oxford, Martin Kemp, se pronuncia sobre ello: $<<$ Para Leonardo, la analogía no era sencillamente una herramienta estratégica en la argumentación, sino también una expresión de la fundamental naturaleza común tras la organización de todas las cosas. Así pues, si se contaba con una explicación satisfactoria para algún fenómeno y podía observarse que otro fenómeno compartía sus patrones esenciales de comportamiento, podría estarse lo bastante seguro sobre las causas ("ragioni") que operaban en el segundo caso. Con base en esto podía concebirse la meta (de otro modo absurda) del entendimiento universal >> (Kemp, 2006).

Leonardo tomó siempre como maestra a la Naturaleza; de hecho, escribe en el Códice Atlántico f. 534v $<<$ Quien pueda acudir a la fuente (referida a la naturaleza), no va al cántaro (referido a los textos de libros antiguos o clásicos)>>. Por ello, la establece como principal fuente de inspiración en sus diseños y proyectos, así como en sus investigaciones. Igual utiliza una analogía respecto a las "formas" (las alas del murciélago o las del pez volador, le valieron para dar forma a sus diseños de máquinas voladoras), que hace uso de esta con respecto a la "función". Por ejemplo, el funcionamiento de las válvulas del corazón que descubrió en sus investigaciones anatómicas mediante disecciones de cadáveres, lo utilizó como inspiración para sus innovaciones en el sistema de apertura de compuertas de exclusas tipo "mitra" que diseñó en el Códice Atlántico, y posteriormente fueron implantadas de manera generalizada, siendo utilizadas aún en día. 


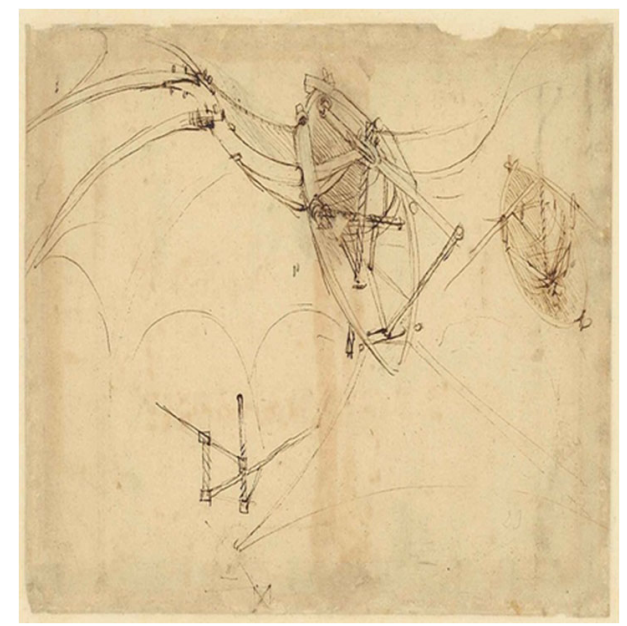

a)

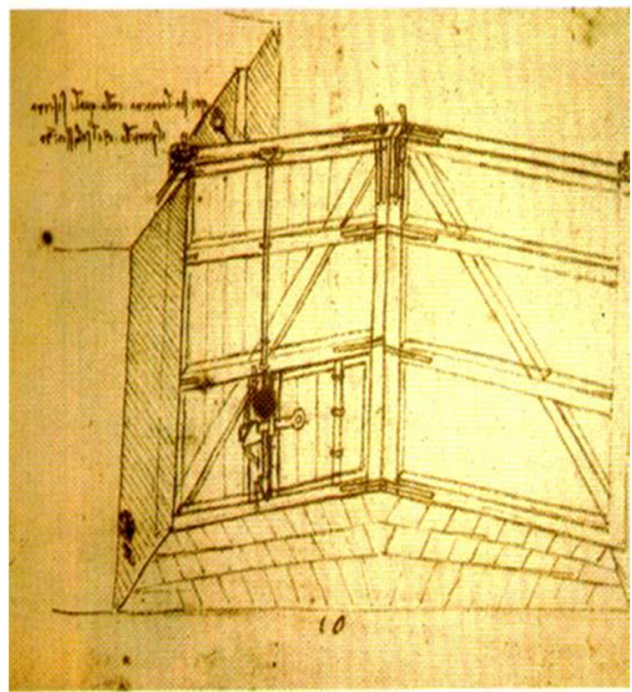

b)

Figura 13.3 a) Boceto de máquina de volar, Códice Atlántico f. 860r (origen de la imagen: https://commons.wikimedia.org/wiki/File:Leonardo_da_Vinci_Ambrosiana-Codice-Atlantico-Codex-Atlanticus-f-860-recto.jpg). b) Exclusas con compuerta tipo mitra, con inclinación, para elevación de niveles de agua en los canales, C. Atlántico 656r (h. 1497) (origen de la imagen: https://commons.wikimedia.org/wiki/File:\%C3\%89cluse-

L\%C3\%A9onard-de-Vinci.jpg?uselang=es ).

En este sentido el profesor e investigador Capra, escribe: $<<$ Sin embargo Leonardo va más allá de las analogías comunes cuando 
compara, por ejemplo, la cúpula de una iglesia con el cráneo humano, o los arcos de su bóveda con la caja torácica $>>Y<<$ Leonardo prestó atención a las semejanzas de formas orgánicas en diferentes especies y a las semejanzas de modelos en distintos fenómenos naturales. Los cuadernos de notas contienen gran número de dibujos de esos modelos: semejanzas anatómicas entre la pierna de un hombre y las patas de un caballo, entre vórtices en espiral y follajes espiralados de ciertas plantas, entre la corriente de agua y la fluidez del movimiento del cabello >> (Capra, 2008).

De similar manera, el profesor de la Facultad de Ciencias de la Universidad Nacional Autónoma de México, J. Rafael Martínez Enríquez, en su artículo "En busca de la razón del mundo: Leonardo, matemáticas y visualidad", de la Revista "Educación Matemática", escribe sobre el uso de las analogías por el toscano: $<<A$ la analogía como estrategia para ampliar el conocimiento, Leonardo contribuyó fortaleciendo el nivel de convicción que podría aportar lo visual. Así, al trazar los mapas de los valles vecinos a Milán, las "venas de agua" mostraban, bajo la pluma de Leonardo, un carácter que las equiparaba a los conductos de un elemento vital, a la manera de "el árbol de vasos [capilares]", que en su tiempo era imaginado como el medio de transporte de los "espíritus" animales o vitales para los sitios más recónditos del cuerpo humano. En este caso, la analogía no respondía tanto a lo visual como a lo fisiológico, descansando en un principio o ley dinámica enunciada por Leonardo y que tal vez, por ello, debería llevar su nombre. Sin embargo, y añadiendo una entrada más al catálogo de injusticias, no ocurrió así>> (Martínez, 2010).

Leonardo, con su formación multidisciplinar y pionero en numerosos ámbitos, aprovechó su pensamiento analógico y su gran conocimiento de la naturaleza y de sus formas como cimientos de su proceso creativo. Así, entrelazó conceptos, formas y estructuras existentes, y desde la complejidad, estableció otros nuevos vínculos para crear soluciones que hasta entonces no existían.

El Capítulo 9 del presente documento se ha dedicado a la utilización de la analogía por Leonardo como principio y técnica para el diseño y proyecto. No obstante, Leonardo utilizó muchas más técnicas del pensamiento para proyectar/diseñar. 


\subsection{Leonardo como diseñador ecológico/naturalista.}

Siguiendo con su predilección y respeto por la naturaleza, Leonardo pintó, dibujó y estudió un sinfín de clases de animales, de plantas, de formaciones geológicas, etc., a veces para fondos de sus pinturas, a veces para sus diseños técnicos y sus procesos investigadores, y de esta manera avanzar en sus estudios y descubrimientos. Así, escribe en su Manuscrito H, f. 3v, de la Biblioteca del Instituto Nacional de Francia: $<<$ La bondadosa naturaleza procede siempre de tal manera que en todo el universo siempre encontrarás cosas dignas de imitar>> (De España, 1943).

Al respecto, el profesor universitario e investigador Fritjof Capra manifiesta: <<En la mayoría de sus proyectos de villas y palacios, concebía el jardín como parte de la casa misma. Estos proyectos reflejan sus continuos esfuerzos por integrar arquitectura $y$ naturaleza >> (Capra, 2008).

Mientras que el profesor Rafael Martínez, también citado con anterioridad, especifica: $<<Y$ esto era a lo que Leonardo aspiraba: a través del entendimiento de los modos de actuar de la Naturaleza fueran fuerzas, ímpetus, resistencias, colisiones y demás elementos identificados como provocadores del cambio y responsables de la constancia en el mundo natural- construir obras y objetos que, además de satisfacer un propósito práctico, reflejaran la belleza que les confería la fantasía (fantasía en el siglo XVI, era un término retórico que se refería a la capacidad imaginativa del artista de crear cosas que, posiblemente, no existían en la naturaleza, es decir, aquello que no había sido creado por Dios. En los escritos previos al año 1500, Leonardo destaca el poder del artista para generar "lo che la natura mai le creò" y lo llamaba fantasía o "imaginatione") de un artesano>> (Martínez, 2010).

Puede afirmarse que a lo largo de su extensa obra y de variada temática, Leonardo intentó enseñar al hombre a vivir en armonía con la naturaleza y a mostrarle el respeto hacia la misma, con el fin de que existiera para la humanidad un futuro adecuado, con principios ecológicos, que solo han cobrado relevancia en nuestra sociedad desde el final del pasado siglo. Puede afirmarse que los principios expuestos por Leonardo en sus escritos se adelantaron casi 500 años a la primera Declaración de las Naciones Unidas sobre el Medio Ambiente (1972). 
En relación con ello, Capra establece: $<<N e c e s i t a m o s$ con urgencia una ciencia que haga honor a la unidad de vida y la respete, que reconozca la fundamental interdependencia de todos los fenómenos naturales y vuelva a conectarnos con la tierra viva >>. Mientras que refiriéndose a Leonardo matiza: $<<A$ pesar de ser un brillante inventor y proyectista, siempre pensó que el ingenio de la naturaleza era enormemente superior al propósito humano. Estaba convencido de que lo prudente era respetar la naturaleza y aprender de ella, actitud que hoy ha vuelto a presentarse en la práctica del proyecto ecológico >> (Capra, 2008).

En el Capítulo 10 del presente documento se han analizado los conceptos que justifican el valor que dio Leonardo a la ecología y su iniciativa hacia lo que hoy denominamos ecodiseño. Así, entre otros, se muestra su diseño naturalista de la Sala delle Asse del Castillo Sforcesco de Milán, sus dos proyectos innovadores para ampliar la ciudad de Milán de manera ecológica y saludable, y el que realizó para el rey de Francia Francisco I (Cognac, 1494-Rambouillet, 1547), para el palacio y la nueva ciudad de Romorantin.

\subsection{La factibilidad de los diseños y proyecto de Leonardo}

Muchos de los dispositivos, máquinas y mecanismos diseñados por Leonardo, y representados en sus manuscritos, sólo alcanzaron el nivel de diseño conceptual. Mientras que algunos de los proyectos científico-técnicos de Leonardo, debido a la carencia en su época de tecnología, procedimientos y materiales adecuados a sus diseños, nunca llegaron a tener aplicación real.

Por ello, existe una controversia sobre si podrían ser llevados a la práctica con los instrumentos y materiales adecuados, es decir, sobre si Leonardo, como ya se ha apuntado, debe ser considerado un ingeniero adelantado a su tiempo o un pensador visionario.

A lo largo de esta investigación se ha demostrado lo incierto de esa controversia, ya que la mayoría de sus proyectos y diseños se han llevado a la práctica siguiendo la esencia los mismos, y otros serían perfectamente ejecutables.

Así, su diseño pionero de "paracaídas", plasmado en el folio $1058 \mathrm{v}$ (1485) del Códice Atlántico, y donde anota esta afirmación: <<Con una tienda del lino de forma piramidal, de tejidos tupidos y cuya base fuese tenida rígidamente abierta, con 12 braccias de lado y 12 de altura (un 
brazo toscano $=58 \mathrm{~cm}$ ), un hombre puede lanzarse desde cualquier altura considerable sin ningún riesgo >>, ha sido probado con éxito por paracaidistas en la República Sudafricana el año 2000, y en Payerne (Suiza) en el 2005, mientras que todos los bocetos de inventores anteriores y coetáneos (Abbās ibn Firnās (Ronda, 810-Córdoba, 887); ingenieros sieneses del siglo XV y XIV, etc.) son manifiestamente afuncionales.

Igualmente, su "vehículo automóvil" considerado el primero de la historia, aunque fuentes secundarias ya habían manifestado que había funcionado en las fiestas cortesanas del Duque de Milán, fracasó en varios intentos de ejecución a lo largo del siglo XX, debido a que solo se disponía de parte de sus planos. Pero finalmente fue montado y llevado a la práctica en 2004 en el Museo de la Historia de la Ciencia de Florencia, funcionando de manera autónoma y programada, con motores de muelles, tal como lo había diseñado Leonardo en el Códice Atlántico folio 812 r en el año 1478.

De igual manera, la mayoría de sus diseños existentes en el Códice I de Madrid, de la Biblioteca Nacional de España, cuyo título es el de Tratado de Estática y de Mecánica (1493) son realizables y se han probado con éxito. Incluso muchos de ellos han sido incorporados a la "técnica" desde hace mucho tiempo. Así, tenemos el ascensor manual o de manivela, en el folio $9 \mathrm{r}$ de dicho Códice, que se sigue utilizando en la construcción y rehabilitación de fachadas en la actualidad.

De manera similar, ocurre con su diseño de martinete para pilotajes, grafiado en el Códice Atlántico, folio 785r (h. 1500), que Leonardo utilizó para realizar obras en canales hidráulicos, y que de manera similar se sigue utilizando hoy en día para llevar a cabo determinadas cimentaciones.

También dispone de diseños innovadores de "gatos mecánicos" en varios de sus códices: el gato de cremallera ya lo dibuja en su Códice Atlántico, f. 0998 r, de la Biblioteca Ambrosiana de Milán, prácticamente igual a como se construyen en la actualidad. El gato de husillo (tornillo-tuerca tradicional), lo diseña con miras a levantar cañones y columnas, en Códice Atlántico folio $0138 \mathrm{r}$. Y finalmente, el gato de tornillo, que diseña con un rodamiento antifricción. Innovador como siempre, va más allá de un simple gato de fuerza y, con el fin de disminuir el rozamiento y alargar la vida de la máquina, incorpora una especie de rodamiento dentado giratorio apoyado en bolas, entre la plataforma de apoyo fija y el disco superior dentado giratorio. Además, le incorpora la manivela en sentido lateral para producir el giro de 
manera más fácil. Todo ello lo plasma en el Códice de Madrid I f. 0026 $r$ de la Biblioteca Nacional de España.

Igualmente, muestra en el Códice Atlántico el diseño de un "torno de giro continuo de rueda, pedal y volante de inercia", que mejoraba a los antiguos de pedal y pértiga elástica, ya que el de Leonardo trabaja con velocidad constante y mayor rendimiento. Para ello, combina un pedal con un vástago y una biela (conjunto biela-manivela), con un volante de inercia o rueda de balanceo, que permitía superar los puntos muertos del giro. La solución de Leonardo fue probada con éxito, y también fue incorporada a la técnica en su día, en talleres artesanos.

También sus diseños de aparatos de ensayo y medida han funcionado adecuadamente. Así, su anemómetro y anemoscopio, del folio $675 \mathrm{del}$ Códice Atlántico existente en la Biblioteca Ambrosiana de Milán, han sido probados para medir la velocidad y la dirección del viento de manera adecuada.

Aparte de sus diseños ingenieriles, también realizó innovaciones y mejoras arquitectónicas, como su escalera de cuatro entradas del Manuscrito M de Francia f. 47 r, (1487) que da posibilidad para cuatro recorridos independientes entre plantas, que utilizó en el proyecto de renovación y ampliación de la Ciudad de Milán, después de un periodo de peste. O la escalera de doble hélice, del Manuscrito M de Francia f. 69 r (1490), similar a la que más tarde se construyó en el Castillo de Chambord en Francia.

Finalmente, es conocido su diseño y posterior construcción de al menos dos autómatas, un León Mecánico, capaz de andar y abrir su pecho y ofrendar una flor de lis al rey de Francia; y un Caballero Mecánico capaz de mover brazos y piernas y emitir ruidos similares a la voz humana, para las fiestas cortesanas de los Sforza en Milán. Al respecto de asegurar su factibilidad, se plasman las palabras del académico italiano, director técnico e investigador jefe del centro de estudios italiano Leonardo3 en Milán, Mario Taddei (Bolonia, 1972), en su libro "Leonardo da Vinci, autómatas y robots": <<Leonardo realizó y dibujó con certeza algunos robots, entendidos como dispositivos automáticos capaces de realizar un trabajo y de imitar los movimientos del cuerpo humano sin asistencia humana, pero tenemos sus dibujos, sus notas y algunos escritos de terceras personas. Así no se trata de mitos sino de la realidad de los hechos>> (Taddei, 2018).

En el Capítulo 11 de esta investigación se ha ampliado e ilustrado con detalle la justificación de la factibilidad de los proyectos de Leonardo. 


\subsection{Leonardo como estudioso visionario y precursor}

Finalmente, cabe hacer constar que Leonardo fue un visionario y precursor, no solo en cuanto a su faceta pictórica, sino también en su faceta técnico-científica. Fue capaz de imaginar técnicas y métodos para el dibujo y la pintura ("sfumato", mejoras en perspectiva y óptica, etc.), realizar descubrimientos en anatomía (fue el pionero en describir al corazón como un músculo y centro del sistema sanguíneo, y en dibujar y entender las funciones y la forma de la válvula aórtica, también creó la primera representación de la glándula tiroides pasando a ser reconocida por primera vez como un órgano anatómico y no como una patología), en botánica (entendió, dibujó y explicó correctamente la manera en que las plantas despliegan sus formas en respuesta a la gravedad terrestre: el geotropismo; también manifestó que los círculos existentes en los troncos cortados indican el número de sus años, mientras que su espesor indica si el año correspondiente fue húmedo o seco: la dendrocronología; estudió el modo en que las plantas cambian su orientación en función de la luz del sol: el fototropismo; observó la disposición regular de las hojas sobre el tallo y lo justificó y describió: la filotaxis; y estableció el principio aproximado de que si en un árbol se midiera el grosor de todas sus ramas, excluyendo el tronco central, y se sumaran estos grosores, el valor final sería igual al valor del grosor del tronco mismo) y en geología (estableció que los fósiles marinos de las montañas no provenían del Diluvio Universal, sino del crecimiento de las montañas desde el fondo de los mares al producirse cambios en la corteza de la Tierra, etc.).

También fue capaz de predecir principios (el de acción y reacción; el de la constancia del producto de la sección por velocidad en fluidos; los de rozamiento; el que el agua es incompresible y que su masa permanece constante, etc.) y proyectar máquinas y artefactos novedosos (el paracaídas, el planeador y ala delta, el automóvil, el elevador mediante manivela, el diferencial, la máquina de sumar, la bicicleta, autómatas, etc.) que fueron reafirmados siglos después. Todo ello ha sido confirmado por los investigadores, tanto por sus biógrafos como por los autores especialistas de sus obras pictóricas o técnico-científicas. Incluso algunos de ellos se atreven a establecerlo como el iniciador de la ciencia de nuestro tiempo.

Así por ejemplo, fue el primero en establecer una visión novedosa del globo terráqueo, a través de su proyecto de "mapamundi", mediante partición en octantes (donde ya se muestra una pequeña porción de América, sin haber sido navegante, ni viajado más allá de Europa), 
una solución que mejora la visualización de los mapas y representaciones geográficas conocidos en su tiempo, y que ha dado origen a los posteriores "mapamundi".
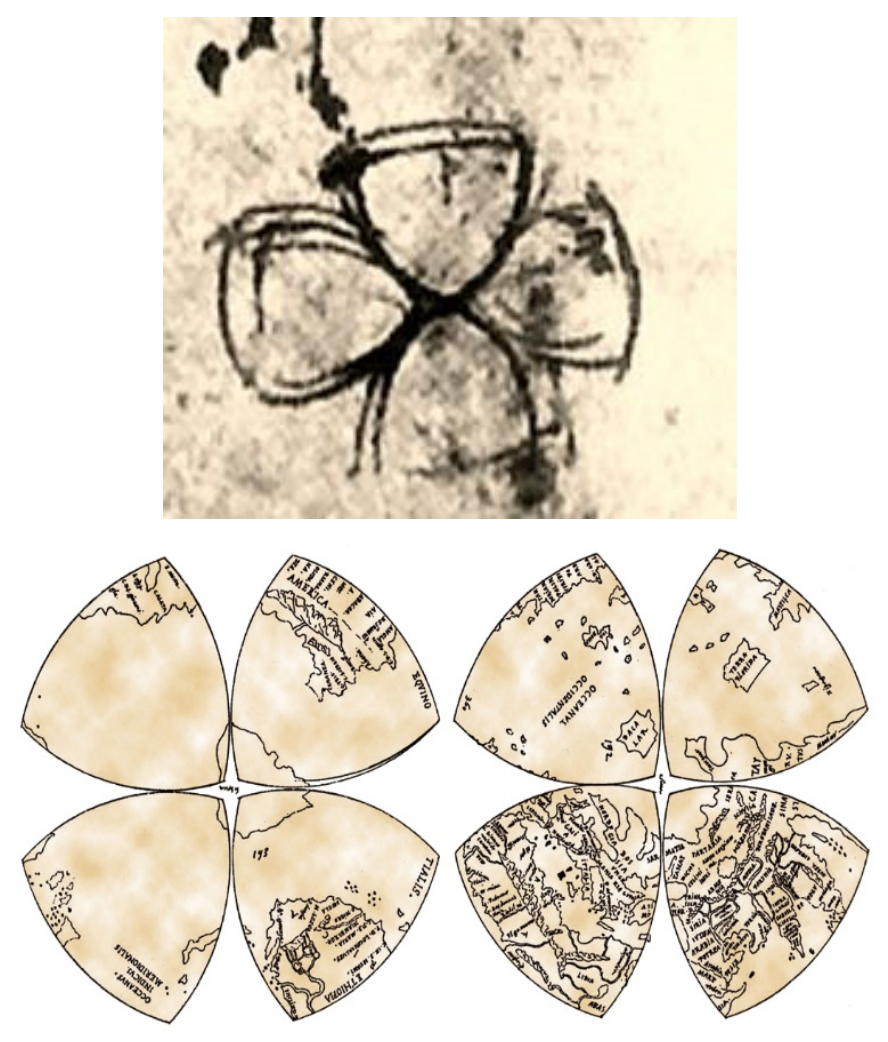

Figura 13.4 a) Detalle de folio con Notas Cartográficas, con boceto de partición de media esfera en octante, C. Atlántico f. $521 \mathrm{r}$ (h. 1508). (Origen de la imagen: https://es.wikipedia.org/wiki/Mapamundi_de_Leonardo) b) Proyecto de Mapamundi de Leonardo mediante octantes, Colección de la Windsor Library, RLW f. 01393 (h. 1514). (Origen de la imagen: https://commons.wikimedia.org/wiki/File:Leonardo_da_Vinci's_Mappamundi. jpg?uselang=es)

En relación a ello, los profesores e investigadores André Chastel, Paolo Galluzzi y Carlo Pedretti, en su libro "Leonardo da Vinci", escriben: <<Si bien el interés por Leonardo técnico e ingeniero perdura intenso, sin pausas ni atenuaciones significativas, los dos siglos transcurridos desde el "redescubrimiento" de los manuscritos del artista, se registran en cambio, variaciones significativas en la valoración que los estudiosos han ido haciendo con el tiempo acerca 
del carácter y las investigaciones de Leonardo en ese campo. Considerado durante muchas décadas la más alta manifestación de la genialidad humana e invocado como prueba elocuente de la "ahistoricidad" de la razón humana, capaz de superar con intrépidos vuelos los límites característicos del tiempo en el que se vio obligado a actuar, Leonardo continúa siendo hoy para un amplio público un sensacional "precursor", un hombre que intuyó y siguió con siglos de adelanto las direcciones del desarrollo posterior de la ciencia y de la técnica>> (Chastel, Galluzzi, \& Pedretti, 2005).

En ese sentido también se pronuncia el ya citado Martin Kemp, con las siguientes palabras: <<..., es también "moderno" en el sentido específico de este periodo; su ciencia y su tecnología, en particular se ha incorporado a la red de supuestos que alimentan nuestra edad moderna. Se ha convertido en un hombre "adelantado a su tiempo", el pionero del vuelo, del carruaje sin caballos, del submarino, de la bicicleta, de las armas de destrucción masiva, de la dinámica de fluidos $y$, seguramente en algún lugar, también del refrigerador >> (Kemp, 2006).

De similar manera, los profesores e investigadores Luca Antoccia, Andre Chastel, Marco Cianchi, Paolo Galluzzi, Domenico Laurenza, y Rodolfo Papa, en su libro "Leonardo da Vinci: Arte y Ciencia", escriben: $<<$ Celebrado durante décadas como la más alta manifestación de la genialidad humana e invocado como prueba elocuente de la "avidez" de la razón humana, capaz de superar mediante sus audaces vuelos los límites propios del tiempo en el que le tocó trabajar, Leonardo continua siendo, para la mayoría de la gente, un sensacional "adelantado", un hombre que intuyó y siguió, con siglos de anticipación, las sucesivas directrices que marcaban el desarrollo de la ciencia y de la técnica >> (Antoccia et al., 2003).

Y finalmente, el profesor Martínez, antes mencionado, manifiesta: $<$ De sus exploraciones e intentos por teorizar a partir de lo observado, nos quedan imágenes memorables, extraídas de sus experiencias y de los esfuerzos de su mente para establecer patrones que apuntaran a la presencia de regularidades geométricas o numéricas. Así, parecía asomarse al futuro. Y este afán por descubrir las leyes que explicaran el orden de la Naturaleza fue lo que, en gran medida y como consecuencia de una empresa colectiva, dio lugar a la ciencia de nuestro tiempo>> (Martínez, 2010). 


\subsection{Epílogo}

Finamente, habiendo observado las características tanto generales como particulares de los proyectos y diseños de los manuscritos y códices de Leonardo, queremos citar las palabras del investigador Mario Taddei que dan una visión conjunta y general de todo el ámbito del diseño de Leonardo: <<El fin supremo de Leonardo fue alcanzar la máxima claridad con la mayor concisión. La sencillez y la intensidad expresiva fueron su norma tanto en la pintura como en las demostraciones científicas, proyectos y escritos. La precisión de su lenguaje es fruto de la precisión de su pensamiento, que siempre fue enemigo de lo indeterminado>> (Taddei, 2018).

$Y$ como cierre de este documento cabe referir las opiniones sobre Leonardo de dos de los estudiosos contemporáneos más importantes que ha habido sobre él.

Martin Kemp, catedrático de Historia de Arte de la Universidad de Oxford afirmó $<<$ Nosotros, como en cualquier otra época anterior, inventamos el Leonardo que queremos. Eso es particularmente cierto cuando los científicos visitan su vida y sus obras. Lo que Leonardo nos dejó es tan rico, diverso, sugerente, insinuante e indefinido que ofrece múltiples oportunidades para cualquiera que quiera introducirse en los intersticios de la historiografía >> (Kemp, 2006).

$Y$ el que fuera profesor emérito de Historia del Arte de la Universidad de California, Carlo Pedretti, (Bolonia, 1928-Lamporecchio, 2018): $<$ Murió ya una primera vez en Francia el 2 de mayo de 1519, y muchas veces en los escritos de las siguientes generaciones, paradójicamente aquellas que proclaman su inmortalidad $>>$ (Pedretti, 2003).

Y cómo no, con una de las tantas frases del propio Leonardo, la que escribe en su Códice Trivulziano, folio $2 r$, de la Biblioteca Trivulziana de Milán: <<El sumo bien es la sabiduría>>.

\section{Referencias}

Antoccia, L., Chastel, A., Cianchi, M., Galluzzi, P., Laurenza, D., \& Papa, R. (2003). Atlas ilustrado de Leonardo da Vinci: Arte y Ciencia, Susaeta Ediciones: Madrid. ISBN-84-305-3894-1.

Capra, F. (2008). La Ciencia de Leonardo. Editorial Círculo de Lectores/Anagrama: Barcelona. ISBN 978-84-672-3358-2. 
Chastel, A., Galluzzi, P., \& Pedretti, C. (2005). Leonardo da Vinci. Planeta De Agostini: Barcelona. ISBN: 84-674-1371-9.

De España, J. (1943). Breviario de Leonardo da Vinci. Ed. El Ateneo: Buenos Aires.

Galland, R. (2014). Libro de los enigmas de Leonardo da Vinci. Círculo de Lectores.

Galvez, Ch. (2018). Aproximación a la mente de Leonardo da Vinci. incluido en el libro: "Leonardo da Vinci, Los rostros del Genio", Penguin Random House, Grupo Editorial: Barcelona. ISBN 978.84-03-53655-5.

García, E. (2005). Leonardo da Vinci, Aforismos. Círculo de Lectores/ Espasa Calpe: Madrid. ISBN 84-672-1264-0.

Goicovic, G. (2015) Estrategias para el pensamiento complejo en estudiantes de pregrado basadas en el proceso creativo de Leonardo Da Vinci. Obtenido el 3 de marzo de 2020 de www.ceuarkos.com/Vision_docente/index.htm)

Kemp, M. (2006). Leonardo. Ed. Fondo de Cultura Económica: México. ISBN-968-16-8010-3.

Martínez, J. (2010). En busca de la razón del mundo: Leonardo, matemáticas y visualidad. Revista Educación matemática, vol. 22, no 1. México. ISSN 1665-5826.

Mezquita, T. (2018). Hallazgo en Madrid. Incluido en el libro: "Leonardo da Vinci, Los rostros del Genio", Penguin Random House, Grupo Editorial: Barcelona. ISBN 978.84-03-53655-5.

Mijksenaar. P, \& Westendorp. P. (2000). Abrir aquí. El arte del diseño de instrucciones. Ed. Española: Madrid. Konemann Verlagsgesellschaft GmbH; ISBN 3-8290-5433-5.

Pedretti, C. (2003). Atlas ilustrado de Leonardo da Vinci: Las Máquinas. Susaeta Ediciones: Madrid. ISBN-84-305-3894-1.

Racionero, L. (1986). El desarrollo de Leonardo da Vinci. Plaza y Janes: Barcelona. ISBN 84-01-35142-1.

Ruiz, E. (2018). Leonardo da Vinci. Itinerario de una mente creativa. Incluido en el libro: "Leonardo da Vinci, Los rostros del Genio", Penguin Random House, Grupo Editorial: Barcelona. ISBN 978.84-03-53655-5. 
Taddei, M. (2018). Leonardo da Vinci, Autómatas y Robots. Susaeta Ediciones: Madrid. ISBN-978-84-677-6361-4.

Torres, F. (2003). Leonardo da Vinci: Un modelo multidisciplinar abierto al mundo de hoy. Exposición: "Leonardo y las Ciencias" celebrada en Madrid. Museo de la Ciudad.

Vezzosi, A. (2011). Leonardo da Vinci, Arte y Ciencia del Universo. Ed. Blume: Barcelona. ISBN 978-84-8076-933-4. 



\section{REFERENCIAS}

Antoccia, L., Chastel, A., Cianchi, M., Galluci, P., Laurenza, D., Papa, R., \& Pedretti, C. (2003). Atlas ilustrado de Leonardo Da Vinci. Arte y ciencia. Las máquinas. Susaeta Ediciones: Madrid. ISBN-84-305-3894-1.

Bagni, G. \& D'Amore, B. Leonardo e la Matematica, (2010). Ed. Giunti: Florencia.

Biblioteca Leonardiana de Vinci. (n.d.). Obtenido el 10/03/2019 de http://www.leonardodigitale.com.

Biblioteca Real de Turín. (n.d.). Obtenido el 24/02/2019 de https://www.museireali.beniculturali.it/biblioteca-reale/.

Capra, F. (2008). La ciencia de Leonardo. Editorial Anagrama: Barcelona.

Catalogue des manuscrits de la BnF. Biblioteca Nacional de Francia. (n.d.). Obtenido el 10/03/2019 de http://archivesetmanuscrits.bnf.fr/ark/12148/cc66429v.

Cerveró, E., Ferrer, P., \& Capuz, S. (2016). El Caballo Sforza de Leonardo da Vinci analizado desde la perspectiva de los proyectos de ingeniería. Actas del XX Congreso Internacional de Dirección e Ingeniería de Proyectos. Cartagena. AEIPRO.

Cerveró, E., Ferrer, P., \& Capuz-Rizo, S. (2016). Teorías, métodos y técnicas para el diseño de sistemas técnicos en la obra de Leonardo da Vinci. Actas del XX Congreso Internacional de Dirección e Ingeniería de Proyectos. Cartagena. AEIPRO.

Cerveró, E., Ferrer, P., \& Capuz, S. (2017). Análisis de los instrumentos de diseño aportados por Leonardo da Vinci en su obra científica y técnica. Actas del XXI Congreso Internacional de Dirección e Ingeniería de Proyectos. Cádiz. AEIPRO.

Cerveró, E., Ferrer, P., \& Capuz, S. (2017). Contribuciones de Leonardo da Vinci a las Técnicas Gráficas para el Diseño o Proyecto Técnico. Actas del XXI Congreso Internacional de 
Dirección e Ingeniería de Proyectos. Cádiz. AEIPRO.

Cerveró, E., Ferrer, P., Capuz, S. (2018). El diseño basado en analogías en la obra de Leonardo da Vinci. Actas del XXII Congreso Internacional de Dirección e Ingeniería de Proyectos. Madrid. AEIPRO.

Cerveró, E., Ferrer, P., \& Capuz, S. (2018). Revisión de la factibilidad funcional de los sistemas técnicos diseñados por Leonardo da Vinci. Actas del XXII Congreso Internacional de Dirección e Ingeniería de Proyectos. Madrid. AEIPRO.

Cerveró, E., Ferrer, P., \& Capuz, S. (2019). Leonardo da Vinci, pionero del Ecodiseño. Actas del XXIII Congreso Internacional de Dirección e Ingeniería de Proyectos. Málaga. AEIPRO.

Cerveró, E., Ferrer, P., \& Capuz, S. (2019). Análisis de la documentación técnica de los diseños y proyectos de Leonardo da Vinci. Actas del XXIII Congreso Internacional de Dirección e Ingeniería de Proyectos. Málaga. AEIPRO.

Cerveró, E., Ferrer, P., \& Capuz, S. (2020). Análisis de las investigaciones realizadas sobre la obra de Leonardo da Vinci. Actas del XXIV Congreso Internacional de Dirección e Ingeniería de Proyectos. Alcoi. AEIPRO.

Cerveró, E., Ferrer, P., \& Capuz, S. (2020). Análisis taxonómico de la obra escrita por Leonardo da Vinci. Actas del XXIV Congreso Internacional de Dirección e Ingeniería de Proyectos. Alcoi. AEIPRO.

Cerveró-Meliá, E., Capuz-Rizo S.F., \& Ferrer-Gisbert P. (2020). Leonardo da Vinci's Contributions from a Design Perspective. Designs. Vol. 4 No. 3:38.

Chastel, A., Galluzzi, P., \& Pedretti, C. (2004). Grandes Artistas y Genios de la Pintura. Planeta De Agostini: Barcelona.

Códice Arundel. (n.d.). British Library de Londres (antigua Biblioteca del British Museum). Obtenido el 10/03/2019 de https://www.metalocus.es/es/noticias/570-paginas-demanuscritos-de-leonardo-da-vinci-estan-online-gracias-a-labiblioteca-britanica-y-microsoft.

Códice Magliabechiano. (n.d.). Copia digitalizada por Google. Obtenido https://archive.org/details/ilcodicemagliab00freygoog/page/n7/ 
mode/2up.

Contreras, M. (2015). Leonardo da Vinci: Ingeniero. Tesis doctoral. Universidad de Málaga.

Da Vinci, L. (1478-1518). Códice Atlántico. Milán. Biblioteca Ambrosiana. Obtenido de http://www.leonardoambrosiana.it/en/il-codice-atlantico/.

Da Vinci, L. (1478-1518). Manuscritos de la Royal Library Windsor, Royal Collection Trust. Obtenido de https://www.rct.uk/collection/themes/exhibitions/leonardo-davinci-a-life-in-drawing-0.

Da Vinci, L. (1478-1518). Códice de Windsor. Windsor. Royal Library of Windsor. Obtenido de https://www.royalcollection.org.uk/collection.

Da Vinci, L. (1487-1514). Conjunto de Manuscritos de París. Institut de France. Obtenido de https://archive.org/details/lesmanuscritsdel00leonuoft.

Da Vinci, L. (1487-1514). Codex Arundel. British Library de Londres. Obtenido de https://www.metalocus.es/es/noticias/570paginas-de-manuscritos-de-leonardo-da-vinci-estan-onlinegracias-a-la-biblioteca-britanica-y-microsoft

Da Vinci, L. (1478-1518). Códice Atlántico. Milán. Biblioteca Ambrosiana. Obtenido de http://www.leonardoambrosiana.it/en/il-codice-atlantico/ .

Da Vinci, L. (1490-1505). Códices de Madrid. Madrid. Biblioteca Nacional de España. Obtenido de http://leonardo.bne.es/index.html.

Da Vinci, L. (Versión traducida de Rejón De Silva, D. (1784)). Tratado de la Pintura de Leonardo da Vinci (Facsímil Lib. Paris-Valencia 1999).

Da Vinci, L. (1982). Cuaderno de Notas. Madrid: Editorial Busma.

Da Vinci, L. (2005). Aforismos. Traducción de E. García Zúñiga. Círculo de Lectores.

Da Vinci, L. (1487-1514). Conjunto de Manuscritos de París. París. Institut de France. Obtenido de https://archive.org/details/lesmanuscritsdel00leonuoft.

De España, J. (1943). Breviario de Leonardo da Vinci. El Ateneo: 
Buenos Aires.

Epicicloide (2015). Obtenido 13/03/2017 de Wikipedia, la enciclopedia libre de http://es.wikipedia.org/wiki/Epicicloide.

Escrig, A. (2004). El reloj milagroso. Grupo Almuzara, Divulgación científica: Córdoba.

Fresneda, C. (2016). Los "ingenios" de Leonardo. El Mundo. Obtenido el 08/03/2019 de www.elmundo.es/ciencia/2016/02/09/56b9f0b1268e3e2f108b4 735.html.

Furor Mechanicus. (n. d.). Obtenido el 12/03/2017 de http://redi.imss.fi.it/invenzioni/index.php/Categoria:Strumenti_d a_disegno.

Galería de la Academia de Venecia. (n.d.). Obtenido el 20/02/2019 de http://www.gallerieaccademia.it/leonardo-da-vinci-universalman-gallerie-dellaccademia-venice.

Galland, R. (2014). Libro de los enigmas del Leonardo da Vinci. Círculo de Lectores.

Galvez, Ch. (2018). Aproximación a la mente de Leonardo da Vinci. Incluido en el libro: "Leonardo da Vinci, Los rostros del Genio", Penguin Random House, Grupo Editorial: Barcelona. ISBN 978.84-03-53655-5.

Gancedo, C. (2011). Once Maquinas e Ingenios de Leonardo Da Vinci interpretados por Carlos Gancedo. Editorial Fundación Museo Evaristo Valle: Gijón.

García de Zuñiga, E. (2005). Leonardo da Vinci. Aforismos. Espasa Calpe: Madrid.

García Fitz, F. (2011). Tecnología, literatura técnica y diseño de máquinas de guerra durante la Baja Edad Media occidental. Anuario de Estudios Medievales, 41/2.

Gelb, M. (1999). Cómo pensar como Leonardo Da Vinci: Siete lecciones para llegar a ser un genio. Ed. Planeta: Barcelona.

Gibbs-Smith, C. (1978). The Inventions of Leonardo Da Vinci. Charles'Scribner's Sons, by Phaidon Press Limited: London.

Girolamo C. (n.d.). Macchine Di Leonardo. Obtenido el 10/03/2017 de http://www.macchinedileonardo.it/le-macchine/didattiche. 
Goicovic Madriaza, G. (2015). Estrategias para el pensamiento complejo en estudiantes de pregrado basadas en el proceso creativo de Leonardo Da Vinci. Obtenido el 3/03/2018 de www.ceuarkos.com/Vision_docente/index.htm).

Gómez-Senent Martínez, E. (1997). El proyecto. Diseño en ingeniería. Universidad Politécnica de Valencia.

González, O. "El Método de Leonardo Da Vinci”; (25 de septiembre de 2009), Periódico El Mundo Cl. 53, 74-50, Medellín, Antioquia, Colombia. Obtenido el 20/11/2020 de https://www.elmundo.com/portal/resultados/detalles/?idx=128 553).

Gruber, M. Gelman, B. D., Ranganath, C. States of Curiosity Modulate Hippocampus-Dependent Learning via the Dopaminergic Circuit, Neuron, 84, 486-496, October 22, 2014. Obtenido el $31 / 12 / 2020$ de https://www.cell.com/neuron/fulltext/S08966273(14)00804-

6?_returnURL=https $\% 3 \mathrm{~A} \% 2 \mathrm{~F} \% 2 \mathrm{Flinkinghub.elsevier.com} \% 2$ Fretrieve\%2Fpii\%2FS0896627314008046\%3Fshowall\%3Dtru e\#\%20).

Historia de las cámaras oscuras (n. d.). Obtenido el 12/03/2017 de http://www.camaraoscuraworld.com/es/historia/.

Instituto y Museo de Historia de la Ciencia de Florencia o Museo Galileo. (n.d.). Obtenido el 04/03/2019 de https://brunelleschi.imss.fi.it.

Jaramillo, H. (2011). Un análisis de la Resistencia de Materiales a partir de los postulados de "Consideraciones y Demostraciones Matemáticas sobre dos Nuevas Ciencias" de Galileo Galilei. Lámpsakos. No. 5, pp. 53-59.

Kalb, C. (2019, mayo). Leonardo la eterna Genialidad. National Geographic, p. 15.

Kemp, M. (2006). Leonardo. Fondo de Cultura Económica: México.

Lanceros, P., \& Barja, J. (2018). Leonardo Da Vinci: El libro del agua. Abada Editores: Madrid.

Laurenza, D., Taddei, M., \& Zanon, E. (2006). Las máquinas de Leonardo. Susaeta Ediciones: Madrid.

Le macchine di Leonardo da Vinci. (n.d.). Obtenido el 15/02/2019 de http://www.macchinedileonardo.com/index.php?machines- 
war\#5.

Lomazzo, P. (1584). Trattato dell' arte della pittura, scoltura et architettura. Obtenido de https://digibug.ugr.es/handle/10481/9622.

Lucchesini, C. (1825). Memorie e Documenti per servire alla storia del Ducato di Lucca. Francesco Bertini, tipografo ducale.

Martínez, E. (2010). En busca de la razón del mundo: Leonardo matemáticas y visualidad. Educación Matemática, vol 2, nº 1.

Martínez-Val, R. (1993). Diseño industrial. Anales de Ingeniería Gráfica. Vol. 2, № 2.

Mascheroni, G. (n.d.). Artigiano di Leonardo. Obtenido el 13/03/2017 de http://artigianodileonardo.jimdo.com.

Méndez S. (2013). Reflexiones teóricas de Leonardo da Vinci sobre la "fantasía". Anales del Instituto de Investigaciones Estéticas, núm. 103, diciembre. Universidad Autónoma de México. Obtenido el 23/12/2020 de https://www.researchgate.net/scientific-contributions/SigmundMendez-2162794062).

Mezquita, T. (2018). Hallazgo en Madrid. Incluido en el libro: "Leonardo da Vinci, Los rostros del Genio", Penguin Random House, Grupo Editorial: Barcelona. ISBN 978.84-03-53655-5.

Mijksenaar. P, y Westendorp. P. (2000). Abrir aquí. El arte del diseño de instrucciones. Ed. Española: Madrid. Konemann Verlagsgesellschaft GmbH; ISBN 3-8290-5433-5.

Minués, V. (2009). Cuando el poder cabalga. Repositori UJIUniversitat Jaume I. Revista Memoria y civilización, $\mathrm{n}^{\circ}$ 12, 71108.

Museo de la Ciencia y la Tecnología de Milán. (n.d.). Obtenido el 13/03/2019 de http://www.museoscienza.org/english/visiting/leonardoparade/.

Museo Metropolitano de Arte de Nueva York (n.d.). Obtenido el 06/03/19 de www.metmuseum.org.

Nicholl, C. (2005). Leonardo el vuelo de la mente. Santillana Ed. Generales: Madrid. Págs. 168, 216, 229; 546 y 547.

Orlando, E., Cinotti, M., \& Rizzati, M. (1974). Leonardo - Colección de 
Grandes Maestros del Arte. Editorial Marín: Barcelona.

Osborn, A. (1953). Applied Imagination: Principles and procedures of creative thinking, Ed. Charles Scribner's Sons: New York.

Ottino della Chiesa, A. (1972). La obra pictórica de Leonardo. Ed. Noguer: Barcelona.

Pedretti, C. (1995). Leonardo architetto. Electa Edizioni: Milano.

Pedretti C., \& Antoccia, L. (2003). Atlas de Leonardo Da Vinci: Las Máquinas. Susaeta Ediciones: Madrid.

Pedretti C. (2007). Leonardo. Las máquinas. Cartoné Editorial.

Pedretti, C. (2017). Leonardo da Vinci: el arte del dibujo. Edimat: Madrid.

Pigem, J. (n.d.) Leonardo da Vinci, un hombre adelantado a su tiempo National Geographic. Obtenido el 01/05/2019 de https://www.nationalgeographic.com.es/historia/grandesreportajes/leonardo-da-vinci_7277/2.

Pigem, J. (2013). Leonardo Da Vinci. El visionario de la ciencia. Revista Historia National Greografic, $\mathrm{n}^{\circ} 113$.

Racionero, L. (1986). El desarrollo de Leonardo da Vinci. Ed. Plaza y Janes: Barcelona.

Ravaisson-Mollien, C. (1881). Les Manuscrit de Léonard de Vinci. A. Quantin editeur.

Rejón de Silva, D. (1784). El tratado de Pintura por Leonardo da Vinci. Facsímil de la edición de Don Diego Rejón de Silva de 1784 de la Imprenta Real de Madrid.

Ricart J. (2006). Leonardo. Grandes maestros de la pintura. Editorial Sol 90: Barcelona.

Richter, I. (2008). Leonardo da Vinci notebooks. Oxford University Press: Oxford.

Richter, J. (1883). The Literary Works of Leonardo Da Vinci. Ed. S. Low, Marston, Searle \& Rivington: London.

Rosa, J. (2019). Leonardo da Vinci. Pensamientos: fabulas, profecías y otros. Ed. Verbum. Madrid.

Ruiz E., \& Martínez, J. (2012). El Imaginario de Leonardo. Los Códices de Madrid. Ed. Minis. de Cultura: Madrid. 
Ruiz-Gimenez, J., King, R., Barbatelli, N., Hohenstatt, P., Garcia, J., Gonzalez, J., Pedretti, C., Mezquita, T., Ruiz, E., Querol, J., Lorente, J., Lombillo, A., \& Gálvez, C. (2018). Leonardo da Vinci: Los rostros del Genio. Penguin Random House, Grupo Editorial: Barcelona.

Sarnago, E. (2002). La perspectiva en la pintura italiana del Quattrocento. La Teoría Intelectual. Obtenido el 01/01/2017, del Portal de Historia-Proyecto Clio: http://clio.rediris.es/arte/400_pa5.htm.

Taddei, M. (2007). II robot di Leonardo da Vinci. Obtenido de www.leonardo3.net.

Taglialagamba, S. (2010). Leonardo \& I'architettura. CB Edizioni: Poggio a Caiano.

Taglialagamba, S., \& Pedretti, C. (2010). Leonardo: La Arquitectura. CB Edizioni: Poggio a Caiano.

Tomasini, M. (2012). Las máquinas de Leonardo da Vinci. Ciencia y Tecnología, $\mathrm{n}^{\circ} 12$.

Torres, F. (2003). Leonardo da Vinci: Un modelo multidisciplinar abierto al mundo de hoy. Exposición: "Leonardo y las Ciencias".Madrid. Museo de la Ciudad.

Triado, J., \& García, L. (2001). Leonardo, pintores de siempre. Susaeta Ediciones: Madrid.

Truesdell, C. (1975). Ensayos de la Historia de la Mecánica. Editorial Tecnos: Madrid.

United Nations. (1972). Declaration of the United Nations Conference on the Human Environment. Stockholm. Obtenido el 01/04/2019 de https://digitallibrary.un.org/record/523249? In=es.

Vasari, G. (1550). Las vidas de los más excelentes arquitectos, pintores y escultores italianos desde Cimabue a nuestros tiempos, descritas por Giorgio Vasari, pintor natural de Arezzo. Con una útil y necesaria introducción a las artes de aquéllos. Obtenido de http://www.historia-del-arte-erotico.com/vasari/.

Vezzosi, A. (2011). Leonardo Da Vinci, ciencia y arte del universo. Ed. Blume: Barcelona.

White, M. (2003). Leonardo el primer científico. Ed. De Bolsillo: 
Barcelona.

www.aqua-zone.com, obtenido el 02/02/2018.

www.brunelleschi.imss.fi.it/automobile/html/digitale_00.htm

(imágenes de prototipos de vehículos), obtenido el 09/03/2018.

www.casasxavier.blogspot.com.es/2009, obtenido el 02/02/2018.

www.cmiberica.com/productos/elevacion/gatos-de-cremallera-y-

husillo, obtenido el 13/03/18.

www.cotransa.net, obtenido el 05/02/2018.

www.dailymail.co.uk, obtenido el 13/03/2018.

www.imss.fi-it, obtenido el 10/02/2018.

www.jincheng-scaffold.com, obtenido el 08/03/2018.

www.leonardo3.net, obtenido el 03/02/2018.

www.museoscienza.org, obtenido el 02/02/2018.

www.portalplanetasedna.com.ar/davinci, obtenido el 10/02/2018.

www.rinconesconencantofrancia.blogspot.com.es/2013/06/castillode-chambord.html, obtenido el 09/03/2018.

www.stuartking.co.uk/index.php/how-i-built-leonardo-da-vincis-lathe/, obtenido el 09/03/2018.

Nota: Las referencias " $v$ " $y$ " $r$ " junto a la denominación de los folios (f.) o en francés "carte" (c.) de los manuscritos o códices, se refieren a "verso" y "recto". 



\section{ANEXOS}

"La bondadosa naturaleza procede siempre de tal manera que en todo el universo siempre encontraras cosas dignas de imitar".

LEONARDO DA VINCI (Manuscrito $\mathrm{H}$, folio $3 \mathrm{v}$, de la Biblioteca del Instituto de Francia, París). 
ANEXO

\author{
ANEXO I. \\ TABLA RESUMEN DE LOS CÓDICES Y \\ MANUSCRITOS DE LEONARDO CON SU \\ UBICACIÓN, CONTENIDO Y DATACIÓN \\ APROXIMADA
}




\begin{tabular}{|c|c|c|c|}
\hline \multicolumn{4}{|c|}{ LOS CÓDICES Y MANUSCRITOS DE LEONARDO } \\
\hline CÓDICE & UBICACIÓN & \begin{tabular}{|c|} 
DATACIÓN \\
APROXIMADA
\end{tabular} & $\begin{array}{c}\text { PRINCIPALES TEMAS TRATADOS EN SU } \\
\text { CONTENIDO }\end{array}$ \\
\hline & ALIA & & \\
\hline $\begin{array}{l}\text { Códice } \\
\text { Atlántico }\end{array}$ & $\begin{array}{c}\text { Biblioteca } \\
\text { Ambrosiana de } \\
\text { Milán }\end{array}$ & $1478-1518$ & $\begin{array}{l}\text { Variado contenido: estudios de matemáticas, geometría, } \\
\text { mecánica, óptica, teoría de la luz y las sombras, } \\
\text { perspectiva, hidráulica, arquitectura, geografía y mapas, } \\
\text { astronomía, química, botánica, zoología, anatomía y arte } \\
\text { militar. }\end{array}$ \\
\hline $\begin{array}{l}\text { Códice del } \\
\text { Vuelo de los } \\
\text { Pájaros }\end{array}$ & $\begin{array}{l}\text { Biblioteca Real } \\
\text { de Turín, Italia }\end{array}$ & 1505 & $\begin{array}{l}\text { Estudios sobre el vuelo de los pájaros, analizado } \\
\text { mediante estudios mecánicos del funcionamiento del ala, } \\
\text { de la resistencia del aire, y de las corrientes de viento. }\end{array}$ \\
\hline $\begin{array}{c}\text { Códice } \\
\text { Trivulziano }\end{array}$ & \begin{tabular}{|c|} 
Biblioteca \\
Trivulziana de \\
Milán
\end{tabular} & $1487-1490$ & $\begin{array}{l}\text { Proyectos de arquitectura militar y religiosa, y estudios } \\
\text { autodidácticos del propio Leonardo para mejorar su } \\
\text { formación. }\end{array}$ \\
\hline & REINO UNIDO & & \\
\hline Códice Arundel & $\begin{array}{l}\text { Biblioteca } \\
\text { Británica, } \\
\text { Londres }\end{array}$ & $1478-1518$ & $\begin{array}{l}\text { Estudios de matemáticas, de física, de mecánica, de } \\
\text { geometría euclídea, de pesos, de hidráulica, de óptica, } \\
\text { de astronomía y de anatomía. Además de proyectos } \\
\text { arquitectónicos y urbanos, diseños de máquinas } \\
\text { voladoras, de armas y máquinas de guerra. }\end{array}$ \\
\hline
\end{tabular}




\begin{tabular}{|c|c|c|l|}
\hline $\begin{array}{c}\text { Códice Forster } \\
\text { I }\end{array}$ & $\begin{array}{c}\text { Victoria and } \\
\text { Albert Museum, } \\
\text { Londres }\end{array}$ & $\begin{array}{c}1487-1490 \text { y } \\
1505\end{array}$ & $\begin{array}{l}\text { Versa sobre ingeniería hidráulica, y el movimiento del } \\
\text { agua. }\end{array}$ \\
\hline $\begin{array}{c}\text { Códice Forster } \\
\text { II }\end{array}$ & $\begin{array}{c}\text { Victoria and } \\
\text { Albert Museum, } \\
\text { Londres, }\end{array}$ & $1495-1497$ & $\begin{array}{l}\text { Trata sobre la teoría de las proporciones, estudios sobre } \\
\text { los pesos y sobre la tracción, tensiones y equilibrios, así } \\
\text { como dibujos y proyectos de mecanismos para control y } \\
\text { paro de campanas, y de ballestas. }\end{array}$ \\
\hline $\begin{array}{c}\text { Códice Forster } \\
\text { III }\end{array}$ & $\begin{array}{c}\text { Victoria and } \\
\text { Albert Museum, } \\
\text { Londres }\end{array}$ & $1993-1496$ & $\begin{array}{l}\text { Trata sobre geometria, estudios de pesos, máquinas } \\
\text { hidráulicas y física. }\end{array}$ \\
\hline $\begin{array}{c}\text { Windsor } \\
\text { Castillo de }\end{array}$ & $\begin{array}{c}\text { Windsor, Royal } \\
\text { Library, } \\
\text { Windsor }\end{array}$ & $1478-1518$ & $\begin{array}{l}\text { Una primera sección está formada por Dibujos y Temas } \\
\text { varios de 452 folios; una segunda para los Dibujos } \\
\text { Anatómicos de 152 folios con alrededor de 200 dibujos } \\
\text { de gran calidad que grafían las reflexiones científicas de } \\
\text { Leonardo sobre el cuerpo humano, después de haber } \\
\text { diseccionado más de 30 cadáveres humanos y varios } \\
\text { animales. A esta sección le siguen los Paisajes y mapas. } \\
\text { Finalmente, hay "Hojas misceláneas" que contienen } \\
\text { material vario. }\end{array}$ \\
\hline $\begin{array}{c}\text { Manuscrito A } \\
\text { (incluye Códice } \\
\text { Ashburnham II } \\
\text { o 2038 (1) }\end{array}$ & $\begin{array}{c}\text { Biblioteca del } \\
\text { Instituto de } \\
\text { Francia, París }\end{array}$ & $1490-1492$ & $\begin{array}{l}\text { Contiene estudios de estática y de dinámica de arcos y } \\
\text { otros elementos arquitectónicos; estudios de perspectiva, } \\
\text { sobre la pintura, etc. } \\
\text { Yel Códice Ashburnham 2038 (II) trata de estudios } \\
\text { sobre la pintura, y matemático-científicos. }\end{array}$ \\
\hline
\end{tabular}




\begin{tabular}{|c|c|c|c|}
\hline $\begin{array}{l}\text { Manuscrito B } \\
\text { (incluye Códice } \\
\text { Ashburnham I } \\
\text { o } 2037^{(1)} \text { ) }\end{array}$ & $\begin{array}{l}\text { Biblioteca del } \\
\text { Instituto de } \\
\text { Francia, París }\end{array}$ & $1487-1489$ & $\begin{array}{l}\text { Trata de maquinas de guerra, muestra proyectos sobre } \\
\text { máquinas de volar y bocetos sobre un submarino, y un } \\
\text { "tornillo aéreo" } \\
\text { Y el Códice Ashburnham } 2037 \text { (I), estudios de } \\
\text { geometría, óptica, vuelo de los pájaros y arte militar. }\end{array}$ \\
\hline Manu & $\begin{array}{l}\text { Bibliotec } \\
\text { Institut } \\
\text { Francia, }\end{array}$ & 1 & $\begin{array}{l}\text { Trata de estudios de óptica, los problemas de la visión, } \\
\text { así como de los efectos de la luz y de las sombras. Más } \\
\text { otras cuestiones sobre pintura. }\end{array}$ \\
\hline Manı & $\begin{array}{l}\text { Biblioteca del } \\
\text { Instituto de } \\
\text { Francia, París }\end{array}$ & 150 & $\begin{array}{l}\text { Estudios de óptica; estudios del ojo humano y la } \\
\text { percepción visual y su relación con la pintura, con sus } \\
\text { diez atributos de la visión: oscuridad, claridad, materia, } \\
\text { color, forma, posición, alejamiento, proximidad, } \\
\text { movimiento y reposo. }\end{array}$ \\
\hline Manu & $\begin{array}{r}\text { Bibli } \\
\text { Ins } \\
\text { Fran }\end{array}$ & 1513 & geometría, de física, de mecánica \\
\hline Manu & $\begin{array}{r}\text { Biblic } \\
\text { Inst } \\
\text { Franc }\end{array}$ & 1508 & $\begin{array}{l}\text { Versa sobre estudios de hidráulica y bombeo del agua, } \\
\text { de geología, de astronomía, de óptica, de teoría de las } \\
\text { "sombras" y teoría sobre el "vuelo de los pájaros" }\end{array}$ \\
\hline Manuscrito G & $\begin{array}{l}\text { Biblioteca del } \\
\text { Instituto de } \\
\text { Francia, París }\end{array}$ & $\begin{array}{c}1510-1511 y \\
1515\end{array}$ & $\begin{array}{l}\text { Trata sobre su teoría de las "luces y de las sombras"; de } \\
\text { estudios de las plantas y su crecimiento. Y temas } \\
\text { variados de geometría, hidráulica, óptica y vuelo de los } \\
\text { pájaros }\end{array}$ \\
\hline
\end{tabular}




\begin{tabular}{|c|c|c|c|}
\hline Manuscrito $\mathrm{H}$ & \begin{tabular}{|c|} 
Biblioteca del \\
Instituto de \\
Francia, París
\end{tabular} & $1493-1494$ & $\begin{array}{l}\text { Estudio de hidráulica y en concreto de las corrientes de } \\
\text { agua. También incluye apuntes propios para el } \\
\text { autoaprendizaje del latín }\end{array}$ \\
\hline Manuscrito I & \begin{tabular}{|c|} 
Biblioteca del \\
Instituto de \\
Francia, París
\end{tabular} & $\begin{array}{r}1497-1 \\
15 \\
\end{array}$ & $\begin{array}{l}\text { Estudios y problemas vinculados con la mecánica y la } \\
\text { geometría. } Y \text { otros temas variados. }\end{array}$ \\
\hline $\begin{array}{c}\text { Manuscrito } \mathrm{K} \\
\text { (hoy dividido } \\
\text { en } \mathrm{K} 1, \mathrm{~K} 2 \mathrm{y} \\
\mathrm{K} 3 \text { ) }\end{array}$ & $\begin{array}{l}\text { Biblioteca del } \\
\text { Instituto de } \\
\text { Francia, París }\end{array}$ & $\begin{array}{r}1503 \\
150\end{array}$ & $\begin{array}{l}\text { Contiene proyectos de arquitectura y de canalizaciones } \\
\text { de agua, correspondientes a la época en que trabajó } \\
\text { para Charles d'Amboise, gobernador francés de Milán }\end{array}$ \\
\hline Manuscrito L & $\begin{array}{l}\text { Biblioteca del } \\
\text { Instituto de } \\
\text { Francia, París }\end{array}$ & $\begin{array}{c}1497-1502 \text { y } \\
1504\end{array}$ & $\begin{array}{l}\text { de la Pintura. Y existen algunos } \\
\text { a Cena }\end{array}$ \\
\hline Manuscrito M & $\begin{array}{c}\text { Biblioteca del } \\
\text { Instituto de } \\
\text { Francia, París }\end{array}$ & $1495-1500$ & $\begin{array}{l}\text { Observaciones de geometría, y estudios e indagaciones } \\
\text { sobre el texto de Euclides. También existen dibujos de } \\
\text { mecanismos de relojería, engranajes, transmisiones, } \\
\text { regulaciones, automatizaciones mediante contrapesos y } \\
\text { gravedad, etc. }\end{array}$ \\
\hline \multicolumn{4}{|c|}{ ESPAÑA } \\
\hline $\begin{array}{c}\text { Códice Madrid } \\
\text { I }\end{array}$ & $\begin{array}{c}\text { Biblioteca } \\
\text { Nacional de } \\
\text { España, Madrid }\end{array}$ & $\begin{array}{l}1490-1496 \\
1499 \text { y } 1508\end{array}$ & $\begin{array}{l}\text { Se trata de un "tratado técnico" en todas sus } \\
\text { consecuencias. Aborda principalmente estudios de } \\
\text { mecánica, de hecho, el título que se le puso en su tapa } \\
\text { interior en castellano es "Tratado de Estática y } \\
\text { Mechánica En Italiano, Escrito en el año 1493", y se }\end{array}$ \\
\hline
\end{tabular}




\begin{tabular}{|c|c|c|c|}
\hline & & & $\begin{array}{l}\text { puede afirmar que es el primer tratado monográfico de } \\
\text { estática y mecánica conocido sobre el tema. }\end{array}$ \\
\hline \multirow[t]{2}{*}{$\begin{array}{l}\text { Códice de } \\
\text { Madrid II }\end{array}$} & $\begin{array}{c}\text { Biblioteca } \\
\text { Nacional de } \\
\text { España, Madrid }\end{array}$ & $\begin{array}{c}1491-1493 \text { y } \\
1503-1505\end{array}$ & $\begin{array}{l}\text { Contiene apuntes de geometría y proyectos de } \\
\text { arquitectura e ingeniería militar, parte del proyecto de } \\
\text { canalización para desviar el río Arno a su paso por Pisa, } \\
\text { el proyecto de la fortificación de la ciudad de Piombino, y } \\
\text { diseños de instrumentos musicales. En su parte final } \\
\text { (últimos } 16 \text { folios) representa el proyecto de detalle de la } \\
\text { fundición del "Monumento ecuestre Sforza". }\end{array}$ \\
\hline & $\begin{array}{l}\text { ESTADOS } \\
\text { UNIDOS }\end{array}$ & & \\
\hline \multirow[t]{2}{*}{$\begin{array}{l}\text { Códice } \\
\text { Leicester (o } \\
\text { Hammer) }\end{array}$} & $\begin{array}{l}\text { Colección } \\
\text { privada de Bill } \\
\text { Gates. en } \\
\text { Seatle }\end{array}$ & $1506-1510$ & $\begin{array}{l}\text { Preferentemente estudios de hidráulica y movimiento del } \\
\text { agua. También proyectos de canales y embalses, } \\
\text { diseños de equipos para aprovechamiento del agua y } \\
\text { estudios de astronomía. }\end{array}$ \\
\hline & $\begin{array}{l}\text { CIUDAD DEL } \\
\text { VATICANO }\end{array}$ & & \\
\hline $\begin{array}{l}\text { Códice Ubinate } \\
1270 \text { o Tratado } \\
\text { de la Pintura, } \\
\text { redactado por } \\
\text { F. Melzi con } \\
\text { apuntes de } \\
\text { Leonardo }\end{array}$ & $\begin{array}{l}\text { Biblioteca } \\
\text { Apostólica } \\
\text { Vaticana, } \\
\text { Ciudad de } \\
\text { Vaticano }\end{array}$ & h. 1550 & $\begin{array}{l}\text { Caracteriza a la pintura como el supremo arte; establece } \\
\text { las reglas de carácter científico que debe usar el pintor: } \\
\text { la acción principal y las secundarias y el contraste entre } \\
\text { ambas, el decoro de las actitudes de los personajes, el } \\
\text { arreglo de los movimientos, la contraposición de tintas y } \\
\text { claro-oscuros, etc. Prima necesidad de la observación } \\
\text { del natural, para que "las obras parezcan como hijas } \\
\text { legitimas de la naturaleza". }\end{array}$ \\
\hline
\end{tabular}


(1) El historiador, bibliófilo y conde italiano Guglielmo Libri (1803, Florencia-1869, Fiesole) que ejerció de profesor de matemáticas y bibliotecario en Francia, sustrajo varios libros en diferentes bibliotecas e instituciones públicas, entre ellos, varias páginas de los Manuscritos A y B conservados en la biblioteca del Instituto de Francia (París). Al conocer su procesamiento por las autoridades francesas, huyo en 1948 a Inglaterra y con ello conformo tres nuevos Códices: el Ashburnham I, el Ashburnham II y el Códice del Vuelo de los Pájaros. De esos tres cuadernos, los dos primeros fueron vendidos al Conde de Ashburnham (de ahí su denominación), y luego recomprados por el gobierno francés, que los reincorporó de nuevo a los Manuscritos B y A de donde habían sido extraídos.

Con los folios sobrantes del manuscrito B que se referían a los estudios de Leonardo sobre el vuelo de las aves, Libri conformó el Códice del Vuelo de los Pájaros, y en 1867 fue vendido al conde Giacomo Manzoni di Lugo (Lugo, 1816-1889) político y bibliógrafo italiano. Más tarde, en 1892, fue adquirido por el príncipe y erudito ruso Teodoro Sabachnikoff (1869, Moscú-1927, Turín), quien finalmente lo regalo a su vez a la casa real de Saboya, depositándolo esta en la Biblioteca Real de Turín, donde se ubica actualmente.

\section{Elaboración propia, a partir de las siguientes Referencias:}

Códice sobre el Vuelo de los Pájaros, artículo de la web: Códice sobre el vuelo de los pájaros - Biblioteca Digital Mundial (wdl.org) , obtenido el 22/12/2020.

Ruiz E. y Martínez, J. (2012). El Imaginario de Leonardo. Los Códices de Madrid. Ed. Ministerio de Cultura.

Shaw Pooler, R. (2014). Leonardo da Vinci's Treatise of Painting. The Story of the World's Greatest Treatise on Painting Its Origins, History, Content and Influence. Vernon Press.

Web de la Biblioteca digital mundial de la Unesco, obtenida el 17/02/20, mediante: https://www.wdl.org/es/item/19477/view/1/3/

Webs de Wikipedia, obtenidas el 20/11/2020, mediante: Guglielmo Libri Carucci dalla Sommaja - Wikipedia, la enciclopedia libre; https://es.wikipdia.org/wiki/C\%C3\%B3dice_sobre_el_vuelo_de_los_p\%C3\%A1jaros 


\title{
ANEXO II.
}

\author{
TABLA RESUMEN DE LAS EDICIONES DEL \\ CONGRESO INTERNACIONAL EN DIRECCIÓN E \\ INGENIERÍA DE PROYECTOS EN LAS QUE SE HA \\ PRESENTADO LOS CAPÍTULOS 2 A 12 DE LA \\ PRESENTE TESIS DOCTORAL
}



El autor de la presente Tesis la ha desarrollado durante el período 2014-2021, habiendo publicado junto a sus dos directores de Tesis los avances y resultados parciales de la investigación. Él orden de los capítulos en el documento no se corresponde con el orden diacrónico de publicación en los correspondientes congresos, puesto que el criterio adoptado es el de coherencia expositiva según el planteamiento de tesis expuesto en la introducción de la misma.

\begin{tabular}{|l|l|l|}
\hline $\begin{array}{l}\text { Número de } \\
\text { Capítulo }\end{array}$ & Título & Referencia de la publicación (Congreso CIDIP) \\
\hline 2 & $\begin{array}{l}\text { Análisis taxonómico de la obra } \\
\text { escrita por Leonardo da Vinci. }\end{array}$ & $\begin{array}{l}\text { Cerveró, E., Ferrer, P., \& Capuz, S. (2020). Actas deI XXIV } \\
\text { Congreso Internacional de Dirección e Ingeniería de } \\
\text { Proyectos. Alcoi. AEIPRO. }\end{array}$ \\
\hline 3 & $\begin{array}{l}\text { Análisis de las investigaciones } \\
\text { realizadas sobre la obra de } \\
\text { Leonardo da Vinci. }\end{array}$ & $\begin{array}{l}\text { Cerveró, E., Ferrer, P., \& Capuz, S. (2020). Actas del XXIV } \\
\text { Congreso Internacional de Dirección e Ingeniería de } \\
\text { Proyectos. Alcoi. AEIPRO. }\end{array}$ \\
\hline 4 & $\begin{array}{l}\text { Teorías, métodos y técnicas para } \\
\text { el diseño de sistemas técnicos en } \\
\text { la obra de Leonardo da Vinci. }\end{array}$ & $\begin{array}{l}\text { Cerveró, E., Ferrer, P., \& Capuz, S. (2016). Actas del XX } \\
\text { Congreso Internacional de Dirección e Ingeniería de } \\
\text { Proyectos. Cartagena. AEIPRO. }\end{array}$ \\
\hline
\end{tabular}




\begin{tabular}{|l|l|l|}
\hline 5 & \multicolumn{1}{|c|}{$\begin{array}{l}\text { características del } \\
\text { Las densamiento de Leonardo da } \\
\text { Vinci, paradigma de la creatividad. }\end{array}$} & $\begin{array}{l}\text { Cerveró, E., Ferrer, P., \& Capuz, S. (2021). Actas del XXV } \\
\text { Congreso Internacional de Dirección e Ingeniería de } \\
\text { Proyectos. Alcoi. AEIPRO. }\end{array}$ \\
\hline 6 & $\begin{array}{l}\text { Análisis de la documentación } \\
\text { técnica de los diseños y proyectos } \\
\text { de Leonardo da Vinci. }\end{array}$ & $\begin{array}{l}\text { Cerveró, E., Ferrer, P., \& Capuz, S. (2019). Actas del XXIII } \\
\text { Congreso Internacional de Dirección e Ingeniería de } \\
\text { Proyectos. Málaga. AEIPRO. }\end{array}$ \\
\hline 7 & $\begin{array}{l}\text { Contribuciones de Leonardo da } \\
\text { Vinci a las Técnicas Gráficas para } \\
\text { el Diseño o Proyecto Técnico. }\end{array}$ & $\begin{array}{l}\text { Cerveró, E., Ferrer, P., \& Capuz, S. (2017). Actas del XXI } \\
\text { Pongreso Internacional de Dirección e Ingeniería de } \\
\text { Proyectos. Cádiz. AEIPRO. }\end{array}$ \\
\hline 8 & $\begin{array}{l}\text { Análisis de los instrumentos de } \\
\text { diseño aportados por Leonardo da } \\
\text { Vinci en su obra científica y } \\
\text { técnica. }\end{array}$ & $\begin{array}{l}\text { Cerveró, E., Ferrer, P., \& Capuz, S. (2017). Actas del XXI } \\
\text { Congreso Internacional de Dirección e Ingeniería de } \\
\text { Proyectos. Cádiz. AEIPRO. }\end{array}$ \\
\hline
\end{tabular}




\begin{tabular}{|l|l|l|}
\hline 9 & $\begin{array}{l}\text { El diseño basado en analogías en } \\
\text { la obra de Leonardo da Vinci. }\end{array}$ & $\begin{array}{l}\text { Cerveró, E., Ferrer, P., Capuz, S. (2018). Actas del XXII } \\
\text { Congreso Internacional de Dirección e Ingeniería de } \\
\text { Proyectos. Madrid. AEIPRO. }\end{array}$ \\
\hline 10 & $\begin{array}{l}\text { Leonardo da Vinci, pionero del } \\
\text { Ecodiseño. }\end{array}$ & $\begin{array}{l}\text { Cerveró, E., Ferrer, P., \& Capuz, S. (2019). Actas deI XXIII } \\
\text { Congreso Internacional de Dirección e Ingeniería de } \\
\text { Proyectos. Málaga. AEIPRO. }\end{array}$ \\
\hline 11 & $\begin{array}{l}\text { Revisión de la factibilidad } \\
\text { funcional de los sistemas técnicos } \\
\text { disenados por Leonardo da Vinci. }\end{array}$ & $\begin{array}{l}\text { Cerveró, E., Ferrer, P., \& Capuz, S. (2018). Actas del XXII } \\
\text { Congreso Internacional de Dirección e Ingeniería de } \\
\text { Proyectos. Madrid. AEIPRO. }\end{array}$ \\
\hline 12 & $\begin{array}{l}\text { El Caballo Sforza de Leonardo da da desde la } \\
\text { Vincilizado de } \\
\text { perspectiva de los proyectos de } \\
\text { ingeniería. }\end{array}$ & $\begin{array}{l}\text { Cerveró, E., Ferrer, P., \& Capuz, S. (2016). Actas del XX } \\
\text { Pongreso Internacional de Dirección e Ingeniería de } \\
\text { Proyectos. Cartagena. AEIPRO }\end{array}$ \\
\hline
\end{tabular}


ANEXOS

A la fecha de presentación de la tesis también se ha publicado un trabajo en revista indexada en Scopus, que no se ha reproducido en el documento, pero a la que se puede acceder sin necesidad de suscripción al tratarse de una revista de acceso abierto. La referencia al mismo es:

Cerveró-Meliá, E., Capuz-Rizo S.F., \& Ferrer-Gisbert P. (2020). Leonardo da Vinci's Contributions from a Design Perspective. Designs. Vol. 4 No. 3:38. 